\title{
Modeling of Groundwater Flow and Radionuclide Transport at the Climax Mine sub-CAU, Nevada Test Site
}

\author{
Prepared by \\ Karl Pohlmann, Ming Ye, Donald Reeves, Mavrik Zavarin, \\ Dave Decker, and Jenny Chapman
}

Submitted to

Nevada Site Office

National Nuclear Security Administration

U.S. Department of Energy

Las Vegas, Nevada

September 2007

Publication No. 45226 
Reference herein to any specific commercial product, process, or service by trade name, trademark, manufacturer, or otherwise, does not necessarily constitute or imply its endorsement, recommendation, or favoring by the United States Government or any agency thereof or its contractors or subcontractors.

Available for sale to the public from:

U.S. Department of Commerce
National Technical Information Service
5285 Port Royal Road S/D
Springfield, VA 22161-0002
Phone: 800.553.6847
Fax: 703.605.6900
Email: orders@ntis.gov
Online ordering: http://www.ntis.gov/ordering.htm

Available electronically at http://www.ntis.gov/bridge

Available for a processing fee to the U.S. Department of Energy and its contractors, in paper, from:

U.S. Department of Energy

Office of Scientific and Technical Information

P.O. Box 62

Oak Ridge, TN 37831-0062

Phone: 865.576.8401

Fax: 865.576.5728

Email: reports@adonis.osti.gov 


\title{
Modeling of Groundwater Flow and Radionuclide Transport at the Climax Mine sub-CAU, Nevada Test Site
}

\author{
Prepared by \\ Division of Hydrologic Sciences \\ Desert Research Institute \\ Nevada System of Higher Education \\ and \\ Mavrik Zavarin \\ Lawrence Livermore National Laboratory \\ Publication No. 45226 \\ Submitted to \\ Nevada Site Office \\ National Nuclear Security Administration \\ U.S. Department of Energy \\ Las Vegas, Nevada
}

Karl Pohlmann, Ming Ye, Donald Reeves, Dave Decker, and Jenny Chapman

September 2007

The work upon which this report is based was supported by the U.S. Department of Energy under Contract \#DE-AC52-06NA26383. Approved for public release; further dissemination unlimited. 
THIS PAGE INTENTIONALLY LEFT BLANK 


\section{EXECUTIVE SUMMARY}

\section{Introduction and Objectives}

The Yucca Flat-Climax Mine Corrective Action Unit (CAU) on the Nevada Test Site comprises 747 underground nuclear detonations, all but three of which were conducted in alluvial, volcanic, and carbonate rocks in Yucca Flat. The remaining three tests were conducted in the very different hydrogeologic setting of the Climax Mine granite stock located in Area 15 at the northern end of Yucca Flat. As part of the Corrective Action Investigation (CAI) for the Yucca Flat-Climax Mine CAU, models of groundwater flow and radionuclide transport will be developed for Yucca Flat. However, two aspects of these CAU-scale models require focused modeling at the northern end of Yucca Flat beyond the capability of these large models. First, boundary conditions and boundary flows along the northern reaches of the Yucca Flat-Climax Mine CAU require evaluation to a higher level of detail than the CAU-scale Yucca Flat model can efficiently provide. Second, radionuclide fluxes from the Climax tests require analysis of flow and transport in fractured granite, a unique hydrologic environment as compared to Yucca Flat proper. This report describes the Climax Mine sub-CAU modeling studies conducted to address these issues, with the results providing a direct feed into the CAI for the Yucca Flat-Climax Mine CAU.

Three underground nuclear detonations were conducted for weapons effects testing in the Climax stock between 1962 and 1966: Hard Hat, Pile Driver, and Tiny Tot. Though there is uncertainty regarding the position of the water table in the stock, it is likely that all three tests were conducted in the unsaturated zone. In the early 1980s, the Spent Fuel Test Climax (SFT-C) was constructed to evaluate the feasibility of retrievable, deep geologic storage of commercial nuclear reactor wastes. Detailed mapping of fractures and faults carried out for the SFT-C studies greatly expanded earlier data sets collected in association with the nuclear tests and provided invaluable information for subsequent modeling studies at Climax.

The objectives of the Climax Mine sub-CAU work are to (1) provide simulated heads and groundwater flows for the northern boundaries of the Yucca Flat-Climax Mine CAU model, while incorporating alternative conceptualizations of the hydrogeologic system with their associated uncertainty, and (2) provide radionuclide fluxes from the three tests in the Climax stock using modeling techniques that account for groundwater flow in fractured granite. Meeting these two objectives required two different model scales. The northern boundary groundwater fluxes were addressed using the Death Valley Regional Flow System (DVRFS) model (Belcher, 2004) developed by the U.S. Geological Survey as a modeling framework, with refined hydrostratigraphy in a zone north of Yucca Flat and including Climax stock. Radionuclide transport was simulated using a separate model confined to the granite stock itself, but linked to regional groundwater flow through boundary conditions and calibration targets.

\section{Incorporation of Uncertainty}

Particular effort is placed throughout this project on evaluating uncertainty with respect to both aspects of the conceptualization of the hydrogeologic system and the parameterization of the numerical models of flow and transport so that uncertainty may be carried through to the determination of compliance boundaries in the Yucca Flat-Climax 
Mine CAU. Conceptual model uncertainty arises from alternative interpretations of the hydrostratigraphy in the northern portion of Yucca Flat where, owing to sparse hydrogeologic data, the hydrogeologic system is not well understood. Uncertainty in groundwater recharge in the region is evidenced by the existence of several independent approaches for estimating this aspect of the hydrologic system. Both hydrostratigraphy and recharge are important factors controlling the amount of groundwater flow that passes Climax and enters Yucca Flat from the north, such that quantifying the uncertainty in these models is critical to understanding the overall inflow component of the Yucca Flat groundwater system.

The regional recharge model set includes five models that are based on three independent methodologies. A modification of the empirical Maxey-Eakin method estimates groundwater recharge as a function of precipitation estimates for selected zones of elevation, and is updated for this work using new datasets and an expanded area of coverage. The netinfiltration method employs a distributed-parameter watershed model for estimating temporal and spatial distribution of net infiltration and potential recharge. Two recharge models are based on this methodology, one that incorporates a surface water runon-runoff component and another that does not include the runon-runoff component. Estimates of chloride ion balances within hydrologic input and output components of individual hydrologic basins provide the basis for the third approach for estimating groundwater recharge. In the present study, this chloride mass-balance methodology accounts for the elevation of precipitation and the limited quantities of recharge that are thought to occur on low-elevation alluvial surfaces and leads to two models of recharge, one that eliminates recharge in areas covered by alluvium and another that eliminates recharge in areas below a threshold elevation and areas covered by alluvium.

Five alternatives of the hydrostratigraphic framework model of northern Yucca Flat were considered. One was developed by the U.S. Geological Survey and represents the configuration of hydrogeologic units in the entire DVRFS model. The other four were developed for the Yucca Flat-Climax Mine CAU as part of the Underground Test Area (UGTA) program. These include a base model and two alternatives that were developed to address uncertainty regarding particular features of the hydrostratigraphy that might be important to groundwater flow and contaminant transport in Yucca Flat. One alternative incorporates a different interpretation of the configuration of hydrostratigraphic units with respect to the $\mathrm{CP}$ thrust fault and the second alternative postulates a barrier to groundwater flow on the east side of the Climax stock. The fifth model merges the two UGTA alternative models to form a single alternative.

Uncertainty incorporated in the flow fields generated by the regional flow model is conveyed to the detailed model of flow in the Climax granite through boundary conditions and calibration targets. Building upon this foundation, the granite flow model generates three-dimensional networks of fracture zones according to probability distributions describing fracture placement, orientation, length, and density, and furthermore includes parametric uncertainty in hydraulic parameters. The resulting uncertain flow fields are carried through to the calculations of radionuclide transport in the granite, with additional parametric uncertainty contributed by porosity, sorption coefficients, and matrix diffusion. 


\section{Model Averaging for Prediction of Regional Groundwater Flow}

The composite prediction of groundwater flow in northern Yucca Flat is derived from a regional model that formally incorporates the uncertainty in multiple alternative input models of recharge and hydrostratigraphy using Maximum Likelihood Bayesian Model Averaging (MLBMA) methods. In addition, an assessment of the joint predictive uncertainty of the input models is produced. During this process, predictions of the alternative models are weighted by their probability, which is the degree of belief that the model is correct given site measurements and prior information. The MLBMA utilizes prior information and field measurements through both expert elicitation and parameter estimation inverse modeling to develop these probabilities. Prior probabilities for each of the alternative conceptual models were elicited from two panels of technical experts (one for the recharge models and one for the hydrostratigraphic models) based on the panelists' beliefs regarding the relative plausibility of each model considering their apparent consistency with available knowledge and data. Each elicitation panel evaluated the completeness of the sets of recharge and geologic models and ranked the models within each set.

The panelists' rankings of the five recharge models were aggregated to yield final prior probabilities. From highest probability to lowest probability, the models are net infiltration with runon-runoff (30\%), modified Maxey-Eakin (25\%), elevation-dependent chloride mass balance with zero recharge in alluvium and elevations below 1,237 $\mathrm{m}(20 \%)$, elevation-dependent chloride mass balance with zero recharge in alluvium (13\%), and net infiltration with no runon-runoff component (12\%). Because all model probabilities are close to the equally likely probability of 20 percent, there is no justification to select one model and discard others based on the available prior information and expert judgment. This reflects the inherent uncertainty in the recharge models, since they are developed independently based on solid physical principles and assumptions, calibrated with site measurements, and have been applied to Nevada water resource issues (especially the modified Maxey-Eakin method).

Aggregation of the prior probabilities of the hydrostratigraphic models resulted in the DVRFS model having the lowest probability (11\%) and the UGTA base model having the highest (28\%). The UGTA hydraulic barrier alternative had the second highest probability $(26 \%)$, while the UGTA CP thrust alternative and the UGTA hydraulic barrier-CP thrust combination alternative had similar probabilities of 17 percent and 18 percent, respectively. Since all five models have similar prior probabilities, though the prior probabilities given by each individual expert were significantly different, selection of one model while discarding the others was not justified considering the prior information and expert judgment. This reflects the inherent uncertainty in the hydrostratigraphic models, owing to sparse geologic data in the Climax area and the resulting inability to completely describe the local hydrostratigraphy.

The Climax regional flow model is based on the DVRFS model, but is extended through the incorporation of multiple conceptual models of regional groundwater recharge and local hydrostratigraphic framework. Though most aspects of the DVRFS model are preserved in the Climax regional flow model, the DVRFS model was modified by refining the 1,500-m mesh in northern Yucca Flat to accommodate the highly resolved models of hydrostratigraphy. Use of the regional DVRFS model as the modeling framework provided for simulation of groundwater flow rates in northern Yucca Flat where data are sparse while 
honoring more numerous regional measurements of hydraulic head and groundwater flow rate.

Numerical calibration of the Climax regional flow model was a critical component of this project since it provided the framework for quantification of the uncertainty originating from multiple alternative input model conceptualizations, differentiating between the alternative models, and assessing parameter estimation uncertainty. Of the 55 parameters calibrated in the DVRFS model, a maximum of 32 parameters most significant to flow and transport in the northern Yucca Flat area were selected for calibration. For example, hydraulic conductivity and drain (representing springs) parameters located far and down-hydraulic-gradient from the northern Yucca Flat (e.g., in the Amargosa Valley and Death Valley areas) were not calibrated. Examination of the sum of squared weighted residuals (SSWR) for each calibrated model showed that the overall model fit was improved compared to the DVRFS model. This is because calibration of the Climax regional flow model can be viewed as further calibration of the DVRFS model and that only the 32 parameters related to northern Yucca Flat were calibrated in the Climax model. For the same reason, when including only the observations in northern Yucca Flat, 22 of the 25 rechargehydrostratigraphic model combinations had lower SSWR than the DVRFS model. Taking the hydrostratigraphic models individually, the lowest residuals were associated with the UGTA base and CP thrust alternatives, indicating that these models are the most plausible based on flow model calibration. For the recharge models, the net infiltration runon-runoff model generally provided the lowest residuals and therefore the best fit, while the modified Maxey-Eakin model always provided the largest SSWR, indicating that it was the least plausible recharge model regardless of hydrostratigraphy. Residuals of the other three recharge models were of a similar magnitude. The fact that residuals of the various hydrostratigraphic models for each recharge model exhibited larger variation than the residuals of the various recharge models for each hydrostratigraphic model demonstrates that simulation of groundwater flow in northern Yucca Flat is more sensitive to hydrostratigraphic conceptualization, as compared to the recharge model.

Posterior model probabilities were calculated using Bayes' theorem from the prior model probabilities produced during the expert elicitations and the model likelihood functions calculated from the calibration results. Generalized Likelihood Uncertainty Estimation (GLUE) methods were utilized to calculate the likelihood functions from the inverse of the SSWR values for each model combination. The net infiltration runon-runoff model combined with the $\mathrm{CP}$ thrust hydrostratigraphic model produced the highest posterior probability of the 25 model combinations. This was followed by the net infiltration runon-runoff model combined with the UGTA base hydrostratigraphic model and the chloride mass-balance model with zero recharge in alluvium and low elevations with the CP thrust model. These posterior probabilities were then used to weight each model combination in the averaged flow model such that model combinations having the best calibration results carried the most weight in subsequent simulations.

Parametric uncertainty arising from parameter estimation was assessed for each model by generating random values using the uncertainty in parameter estimates described by the covariance matrix produced during model calibration. This form of parametric uncertainty results from the measurement error of the calibration data, not from variability of data values measured in the field as is commonly done in the assessment of parametric 
uncertainty. However, sparse field data in the Climax area, and in the larger Death Valley region, prevent adequate and consistent characterization of all parametric distributions from measurements. Two hundred realizations of each model were generated. The results show that posterior model variance is dominated by intermodel variance as opposed to intramodel variance, indicating that conceptual model uncertainty dominates total model uncertainty. Without consideration of conceptual model uncertainty, predictive uncertainty would be significantly underestimated.

The Climax regional flow model produced a set of realizations of simulated hydraulic heads and groundwater flow rates that incorporate both parametric and conceptual model uncertainty. The averaged flow into northern Yucca Flat is higher than previous estimates as a result of higher flow simulated in the original DVRFS model, as well as inclusion of alternative hydrstratigraphic framework models that provide a conduit for flow in the upper Lower Carbonate Aquifer in the area between the Climax stock and the northwest Halfpint Range. These results were used to provide both input for the flow model of the Climax stock as part of this project and to provide observation data for the northern boundary of the Yucca Flat-Climax Mine CAU currently under development.

\section{Fracture Continuum Groundwater Flow Model for the Climax Granite}

Predictions of radionuclide migration from the three nuclear tests in the Climax stock require representation of the groundwater flow and transport characteristics of the granite intrusive. These characteristics cannot be adequately represented at the scale of the DVRFS, even with the grid refinement in northern Yucca Flat. A groundwater flow model specific to the Climax stock was developed as the basis for the transport calculations. The groundwater flow fields and associated model uncertainty described above are carried forward into the Climax-specific model so that the radionuclide migration predictions include the effects of conceptual model and parametric uncertainty.

Local-scale simulations of groundwater flow in the Climax stock are based on the conceptualization that the majority of flow occurs through rock fractures within a lowpermeability rock mass. A fracture continuum method involving MODFLOW is used to model flow through the randomly generated fracture zone networks within the Climax stock. These three-dimensional networks are generated according to probability distributions describing fracture placement, orientation, length and hydraulic conductivity, and an algorithm used to control fracture density. Probability distributions are used within a Monte Carlo methodology to incorporate parametric uncertainty and spatial variability. The fractures are mapped onto the MODFLOW finite-difference grid using a stair-step pattern to preserve flow continuity.

Seven fracture sets are included in the model. Spatially, fractures are exponentially distributed, with lengths assigned using a Pareto model consistent with observed data (the range of modeled fracture lengths is 30 to $1,000 \mathrm{~m}$ ). Fractal geometry concepts were used to establish a three-dimensional fracture density guideline for the model grid based on the observed fracture spacing in one dimension. Two of the model parameters, fracture density and hydraulic conductivity, were determined during the calibration process where the geometric mean of hydraulic flux from individual realizations of the local-scale fracture continuum model (FCM) are calibrated to the target flux from the corresponding alternative of the Climax regional model. A lognormal distribution is used for hydraulic conductivity, with a mean $\log _{10}$ value of $10^{-8} \mathrm{~m} / \mathrm{s}$ for most fracture sets, and $10^{-7} \mathrm{~m} / \mathrm{s}$ for the fracture set 
oriented with the least amount of compressive stress normal to the fracture walls. A value of $10^{-10} \mathrm{~m} / \mathrm{s}$ is used to represent an upscaled matrix that has some degree of background fracturing, though the majority of fluid flow is restricted to the fractures. Permeability disks, a two-dimensional radial zone containing unique values of hydraulic conductivity (and porosity for the transport model), are incorporated into the fracture continuum permeability fields for the introduction of radionuclide particles in the transport model.

The spatial distribution of recharge, constant head conditions at model boundaries, and a flux calibration target for each local-scale granite model realization are based on one of the 25 alternatives of the Climax regional flow model. The water table simulated by the regional model is directly mapped onto the local-scale model forming the confined upper boundary. The bottom local-model boundary condition is no-flow, with the lateral boundaries treated as constant head as interpolated from the regional flow alternatives. A total of 200 Monte Carlo realizations are generated for each of the regional flow alternatives, resulting in 5,000 local-scale flow field realizations. The randomness of the simulated fracture networks leads to a high degree of variability in flux values. A GLUE technique is implemented to assign unique probability weights to each flow realization. Realizations that more closely match the target flux value for the given regional flow alternative receive more weight than those with a poor match. These weights, along with model weights assigned to each of the regional flow alternatives, are applied to the mass flux calculations during post-processing of the transport model results.

\section{Calculations of Radionuclide Transport in the Climax Granite}

The simulation of radionuclide transport in the Climax stock is based on a random walk particle code that tracks both conservative and nonconservative radionuclide particle trajectories through each of the 5,000 velocity field realizations produced from the localscale fracture continuum model. Advective velocity assigned to individual grid cells is computed from constant porosity values for rock matrix cells and variable porosity values for fracture cells. The porosity distribution for fracture cells is estimated from a tracer test conducted in granite at the Shoal site, where a power-law equation describes the relationship between fracture hydraulic conductivity and individual fracture cell porosity. Dispersive particle motion is simulated according to a Gaussian dispersion tensor.

Radionuclides simulated in the transport model were produced by the Hard Hat, Pile Driver, and Tiny Tot tests, and the daughters created by radioactive decay. All radionuclides are assumed to be located in the saturated zone, consistent with the UGTA approach for tests in the vadose zone, initially in a circular region proportional in diameter to each test cavity. Radionuclides are distributed according to their volatility as an aqueous-sorbed fraction and nuclear melt glass fraction. The aqueous-sorbed fraction is assumed to migrate (subject to retardation processes) immediately after each nuclear test, neglecting any time for vadosezone transport. Nuclides within the melt glass are released according to glass dissolution rates, calculated based on test-specific conditions. Over the course of the 1,000-year simulation timeframe, less than 5 percent of the particles assigned to melt glass are released into the flow field. With the exception of the temperature impact on glass dissolution, early time cavity conditions and near-field properties affected by the nuclear tests are not considered, because the projection of the radionuclides to the water table location renders inclusion of test effects problematic. 
Once released into the groundwater system, the radionuclides are subject to retardation processes. Many of the radionuclides are retarded by reactions with aquifer materials. Retardation factors, estimated from sorption experiments with Climax granite and other granites found worldwide, are used in algorithms that simulate radionuclide particle retardation along fracture walls and matrix blocks. Uncertainty in sorption coefficients is included, assuming a uniform distribution. The diffusion of radionuclides in a fractured medium is described by a transfer probability approach that controls the movement of radionuclides between rock fractures and matrix blocks.

Radionuclides are grouped according to general sorption behavior and to melt-glass proportion into eight unique transport classes. Particle tracking simulations are conducted for each transport class using specific values for sorption and the fraction of radionuclides in the melt glass state. Mass flux values for individual radionuclides leaving the Climax stock are computed by post-processing the results. The largest degree of transport is exhibited by the group of radionuclides experiencing no retardation and no portion in the nuclear melt glass. This group consists of ${ }^{3} \mathrm{H},{ }^{14} \mathrm{C},{ }^{39} \mathrm{Ar}$, and ${ }^{85} \mathrm{Kr}$. Approximately 36 percent of the particles for this group exit the model domain with the 1,000-year simulation period. Most of these particles exit through the southern boundary, where they may enter the regional carbonate aquifer beneath Yucca Flat. All three tests contribute to the breakthrough, with 41 percent from Tiny Tot (closest to the southern boundary), 33 percent from Pile Driver (larger than Hard Hat), and 26 percent from Hard Hat. Peak particle flux (ignoring radioactive decay), occurs about 300 years after the nuclear tests.

Radionuclide groups with significant sorption properties (e.g., $\log K_{d}$ values of 2 and above) showed no breakthrough at the granite model boundary, even at the 95 -percent confidence interval. These radionuclides, including isotopes of cesium, plutonium, and americium, can be expected to remain within the Climax stock for at least 1,000 years. Very limited breakthrough was calculated for groups with lower, but nonzero, $\log K_{d}$ values. This includes isotopes of strontium, uranium, and neptunium.

The seven radionuclides modeled without sorption reactions all exhibit breakthrough at the granite boundary. The mass flux depends on the source mass of the radionuclide, the amount present in the nuclear melt glass, and the radioactive decay rate. The peak mass flux is exhibited by tritium, followed by ${ }^{99} \mathrm{Tc}$. The peak mean mass flux of tritium is approximately $5 \times 10^{-5}$ moles/yr at about 25 years after the tests. The impact of uncertainty is evident in the peak of the upper 95-percent confidence interval at a value of about $2 \times 10^{-4}$ moles/yr. The upper bound also peaks later in time, between 50 and 75 years. At later times, the mass flux of other radionuclides overtakes short-lived tritium. Among these longer-lived radionuclides modeled as nonsorbing, ${ }^{14} \mathrm{C},{ }^{36} \mathrm{Cl}$, and ${ }^{99} \mathrm{Tc}$ exhibit breakthrough rates between 1 and $5 \times 10^{-5}$ moles/yr for much of the simulation period. For all radionuclide groups, even those exhibiting some breakthrough, the lower boundary of the 95-percent confidence interval is zero.

\section{Concluding Remarks}

The investigation reported here demonstrates that the Climax stock region is important for models of both groundwater flow and radionuclide transport in Yucca Flat. A significant portion of the groundwater flux though Yucca Flat may come through the northern Yucca Flat area, but hydrogeologic data are very sparse in this upgradient region. Evaluation of alternative conceptual models allows quantification of possible inflow into 
Yucca Flat that honors available data and includes parametric and conceptual uncertainty. These alternatives include the possibility of greater flow into northern Yucca Flat than previously suggested. The results of model averaging demonstrate that significant uncertainty results from including alternative conceptual models, larger than that exhibited within a single conceptual framework. Given the lack of data to support groundwater conditions north of Yucca Flat, including these sources of uncertainty will produce a more realistic and defendable depiction of groundwater flow.

The conceptual and parametric uncertainty quantified by the Climax regional flow model is also important for the predictions of radionuclide transport from the Hard Hat, Pile Driver, and Tiny Tot tests. That uncertainty is carried forward into a model honoring the fracture flow characteristics of the granite, by means of boundary conditions and calibration to simulated regional flux values. Additional processes and sources of uncertainty are included in the granite model, such as fracture network geometry and retardation properties. Evaluating transport from the Climax tests using a model consistent with the fracture flow environment of the granite stock, and including conceptual and parametric uncertainty, has demonstrated the possibility of radionuclide transport out of the granite and into the regional carbonate aquifer in Yucca Flat.

\section{ACKNOWLEDGEMENTS}

The authors wish to thank Sigmund Drellack of Bechtel Nevada for his assistance in correlating hydrostratigraphic units in northern Yucca Flat to regional units, Thomas Beard and Keely Brooks of Stoller-Navarro Joint Venture for supporting the transfer of hydrostratigraphic models to DRI, Claudia Faunt and Joan Blainey of the U.S. Geological Survey for consultations on the configuration and use of the Death Valley Regional Flow system model, and Greg Ruskauff of Stoller-Navarro Joint Venture for providing guidance on the transfer of DRI's results to the flow and transport models under development for the Yucca Flat-Climax Mine Corrective Action Unit. Greg Pohll is thanked for his development of code to selectively refine our numerical model mesh and for his other invaluable technical comments and contributions to the project. We also thank the members of our Underground Test Area preemptive review team for their comments during preemptive reviews and on the draft version of this report. These reviewers included Bruce Crowe, Jeff Daniels, Keith Halford, Gayle Pawloski, Dave Prudic, Paul Reimus, Bob Roback, Andy Tompson, Rick Waddell, and Andy Wolfsberg. We also greatly appreciate the data collection and interpretations provided by David Gillespie and Craig Shirley, the outstanding electronic publishing support provided by Debi Noack, and the technical editorial support of Marjory Jones. 


\section{CONTENTS}

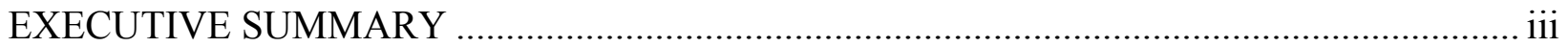

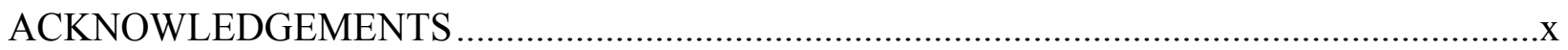

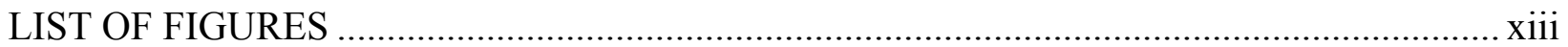

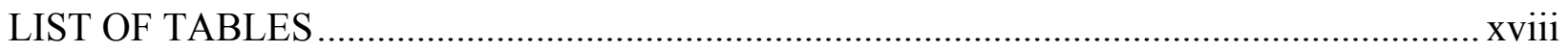

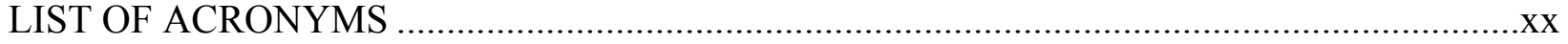

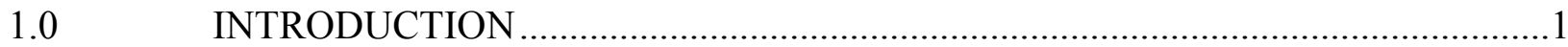

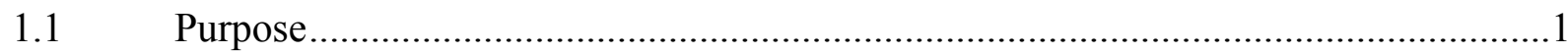

$1.2 \quad$ Description of the Climax Mine Study Area .....................................................

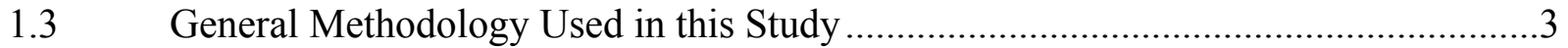

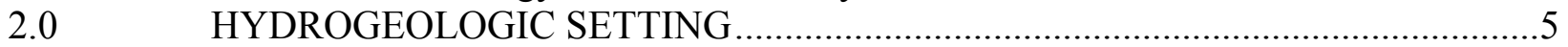

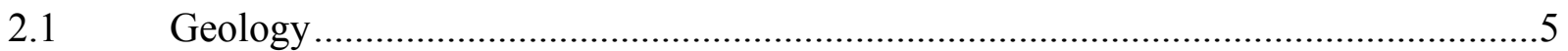

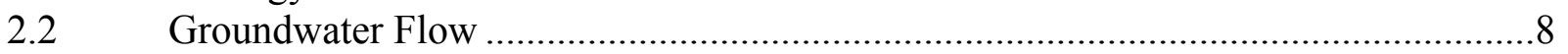

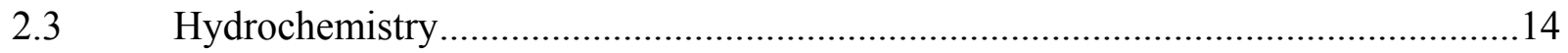

2.4. Nuclear Tests and Other Subsurface Studies at Climax ........................................15

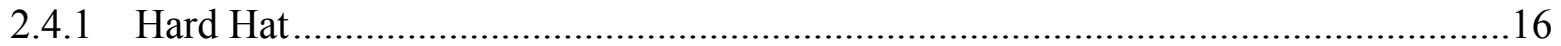

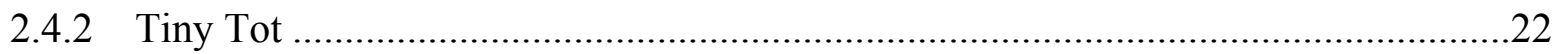

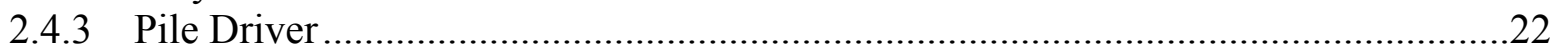

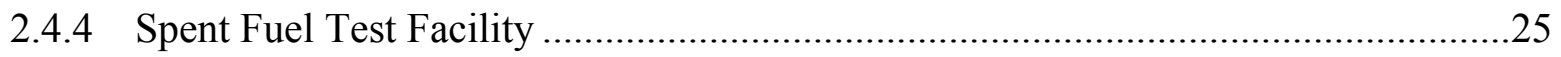

2.5 Overview of the Death Valley Regional Flow System Model................................25

3.0 GROUNDWATER FLOW MODEL FOR THE REGION SURROUNDING

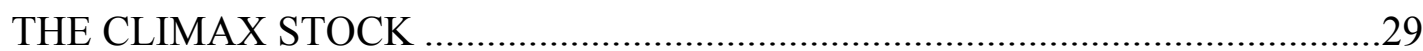

3.1 Bayesian Model Averaging to Assess Conceptual Model Uncertainty ...................29

3.2 Postulation of Alternative Conceptual Models ...................................................

3.2.1 Alternative Models of Groundwater Recharge ...................................................31

3.2.2 Alternative Models of the Hydrostratigraphic Framework .....................................40

3.3 Use of Expert Elicitation to Assess Alternative Model Uncertainty .......................49

3.3.1 Process of Expert Elicitation and Elicited Issues...............................................50

3.3.2 Elicitation Results for Alternative Models of Recharge ......................................51

3.3.3 Elicitation Results for Alternative Models of the Hydrostratigraphic Framework....55

3.3.4 Prior Probabilities of Recharge/Hydrostratigraphic Model Combinations................60

3.4 Use of Model Calibration to Assess Alternative Model Uncertainty .......................61

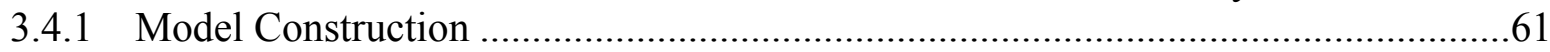

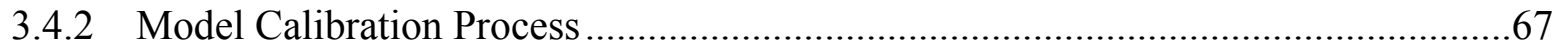

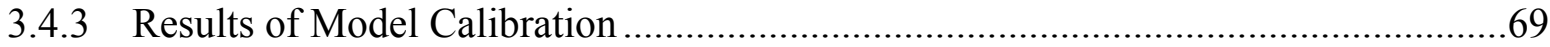

3.5 Assessment of Uncertainty for Parameters and Alternative Models ........................99

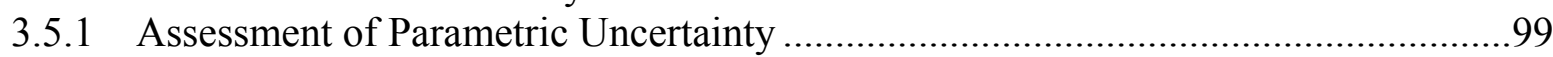

3.5.2 Model Averaging and Assessment of Model Uncertainty ...................................106

3.6 Incorporation of Climax Regional Model Results in the Yucca Flat-Climax Mine

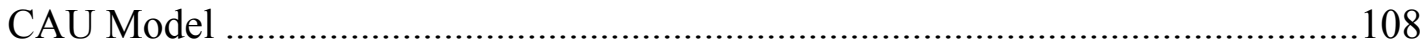

4.0 SIMULATION OF GROUNDWATER FLOW IN THE CLIMAX STOCK.........111

4.1 Conceptualization of Groundwater Flow ............................................................111

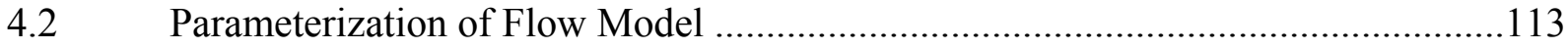

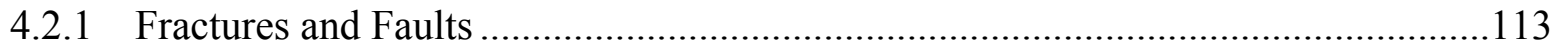

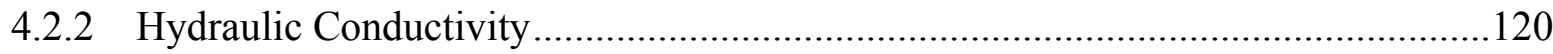




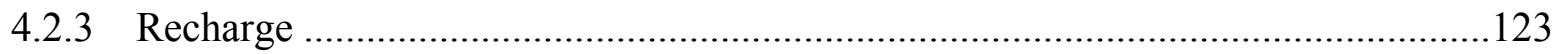

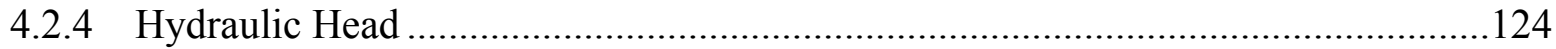

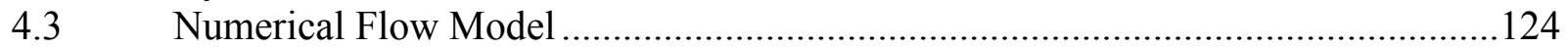

4.3.1 Generation of Fractures and Mapping to Finite-difference Grid ..............................124

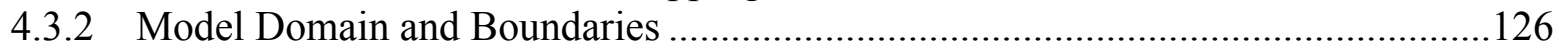

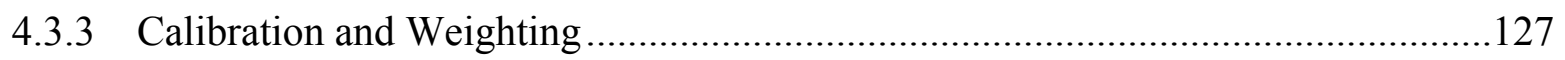

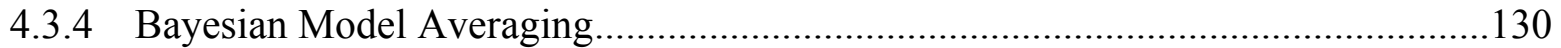

5.0 SIMULATION OF RADIONUCLIDE TRANSPORT IN THE CLIMAX

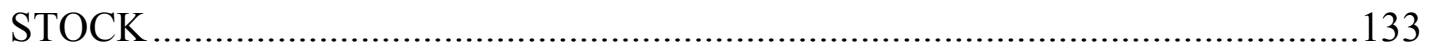

5.1 Parameterization of Transport Model ………...................................................134

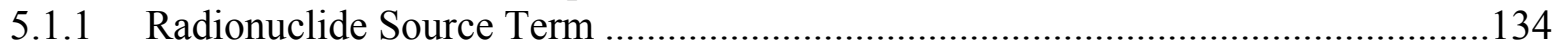

5.1.2 Radionuclide Release: Nuclear Melt Glass Dissolution Model..................................143

5.1.3 Retardation Behavior of Radionuclides in the Climax Stock ...................................160

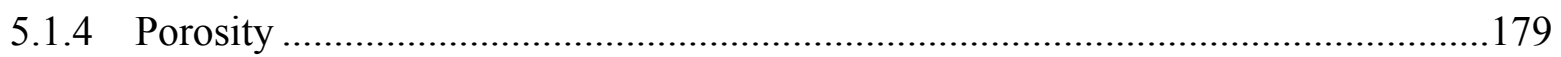

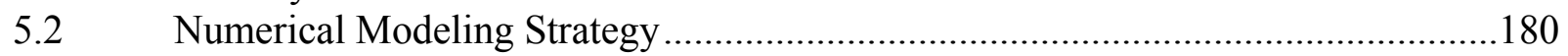

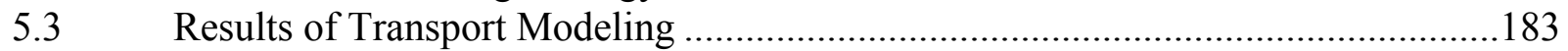

5.3.1 Conservative Particle Transport and Groundwater Velocity ...................................184

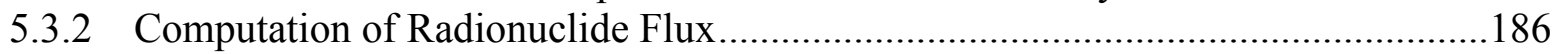

5.3.3 Radionuclide Flux of Individual Radionuclides .................................................191

5.3.4 Incorporation of Radionuclide Flux Estimates into Yucca Flat CAU Model.........202

6.0 SUMMARY, CONCLUSIONS AND RECOMMENDATIONS ...........................205

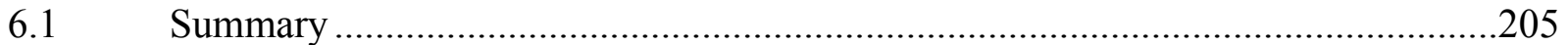

6.1.1 Alternative Conceptual Models .........................................................................20

6.1.2 Refinement of the DVRFS Model and Inclusion of Alternate Models....................205

6.1.3 Uncertainty Assessment and Model Averaging..................................................206

6.1.4 Groundwater Flow Model for the Climax Granite .............................................206

6.1.5 Parameterization of the Transport Model ...........................................................206

6.1.6 Radionuclide Transport Calculations.....................................................................20

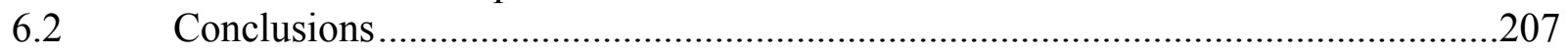

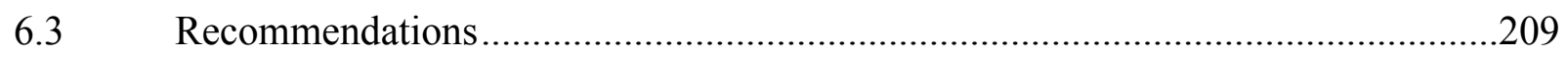

6.4 Integration of Climax Mine Sub-CAU Model Results in the Yucca Flat-Climax

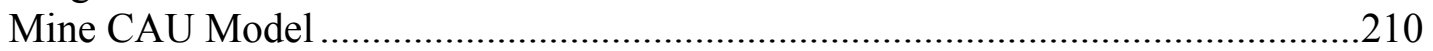

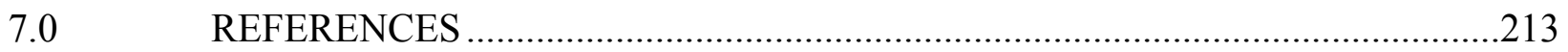

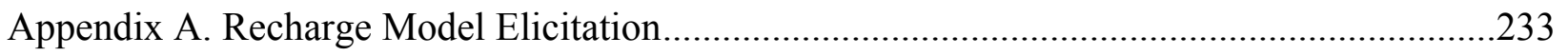

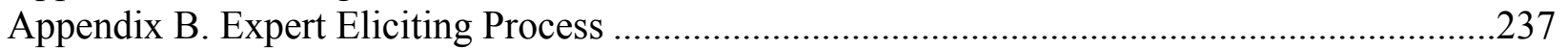

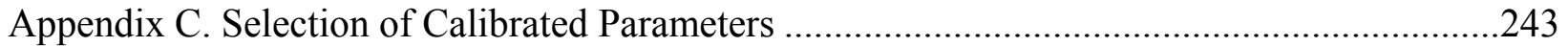

Appendix D. Calibrated Parameters and Simulated Results of Individual Models ......................249

Appendix F. Data Analysis of Fracture, Fault, and Joint Distribution and Orientation in Climax Stock (located on CD at back of report) …………...................................28

Appendix G. Examples of Matching Temperature History of Nuclear Test Glass Zones Using

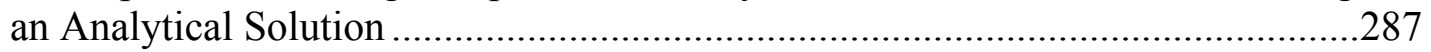

Appendix H. Predicting Radionuclide Sorption for the Climax Stock with Mechanistic Geochemical Models 


\section{LIST OF FIGURES}

1-1. Location of the Climax Mine underground nuclear tests and the hydrostratigraphic models of northern Yucca Flat with respect to the Yucca Flat-Climax Mine hydrostratigraphic framework model.............................................................................

2-1. Map of the major rock types outcropping in the region of Yucca Flat (Bechtel Nevada, 2006).

2-2. Map of the pre-Tertiary structures in the region of Yucca Flat (Bechtel Nevada, 2006).

2-3. Contour map of composite predevelopment water levels for the Yucca Flat-Climax Mine CAU investigation area. From DOE (2000b)

2-4. West-east hydrogeologic cross section through the Climax stock and the adjacent clastic confining units at the northern end of Yucca Flat. ..................................................13

2-5. Location of Tiny Tot and Pile Driver/Hard Hat shafts...................................................15

2-6. Diagram of Hard Hat near field and post-test drilling operations. ...................................17

2-7. $\quad$ Map view of Hard Hat and Pile Driver pretest drifts.......................................................18

2-8. Reentry drift at the Hard Hat chimney edge. ................................................................ 18

2-9. Figures from Boardman and Skrove (1966), which indicate the location and measured permeability or rocks in the vicinity of the Hard Hat test..................................................20

2-10. Summary of permeability measurements reported in Quong (1979), Boardman and Skrove (1966), Short (1964), Mehta et al. (1964), and Boardman (1965)........................22

2-11. Diagram of Pile Driver near field and post-test drilling operations....................................2

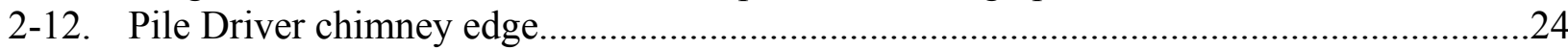

2-13. Map showing the location of the Death Valley Regional Flow System model in relation to regional geographic features and other major regional flow models. ..............26

2-14. East-west cross section across a portion of the DVRFS model domain showing general configuration of the model layers.

3-1. Recharge map for the DVRFS model domain developed using a modification of the Maxey-Eakin method (units are $\mathrm{m} / \mathrm{d}$ ). ..........................................................................3

3-2. Recharge maps for the DVRFS model domain developed using the net infiltration method (a) with the runon-runoff component, and (b) with no runon-runoff component (units are $\mathrm{m} / \mathrm{d}$ ).

3-3. Recharge maps for the DVRFS model domain developed using the elevationdependent chloride mass-balance method with (a) zero recharge in alluvium, and (b) zero recharge at elevations below 1,237 $\mathrm{m}$ and elevations above $1,237 \mathrm{~m}$ that are covered by alluvium (units are $\mathrm{m} / \mathrm{d}$ ).

3-4. Map of the region (bounded by the dashed line) depicted in the perspective views of the DVRFS HGUs shown in Figure 3-5

3-5. Perspective views of the Mesozoic Climax granite intrusion and the pre-Tertiary HGUs in the Climax area as represented in the DVRFS model.

3-6. North-south cross section approximately $2 \mathrm{~km}$ east of the Climax stock showing the potentiometric surface simulated by the DVRFS model, the thin volcanic units, and the continuity of the LCA across northern Yucca Flat.

3-7. Perspective views of the Mesozoic Climax granite intrusion and the pre-Tertiary HGUs as represented in the Yucca Flat-Climax Mine CAU hydrostratigraphic framework model. 
3-8. North-south cross section showing the Yucca Flat-Climax Mine CAU

hydrostratigraphy just west of the Climax stock outcrop. ……..........................................4

3-9. Cross sections showing east-west profiles through the CPT fault in the base model and the CPT alternative model.................................................................................. 48

3-10. Cross sections showing east-west profiles through the Climax stock in the base model and the hydrologic barrier alternative model...............................................................4

3-11. Column chart of the plausibility ranking of the five models. ...........................................52

3-12. Column chart of the prior probability of the five models.............................................52

3-13. Column chart of the prior probability of the three categories of the five models...............53

3-14. Iteratively aggregated prior probability with consideration of expert-to-expert

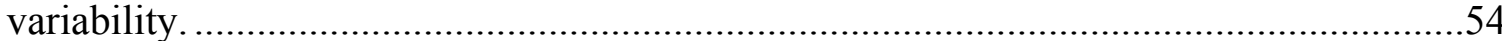

3-15. Simply aggregated prior probability by assigning equal weight to the experts..................54

3-16. Expert weight assigned by each expert ( $\mathrm{x}$ axis) to all experts. .........................................55

3-17. Column chart of the plausibility ranking of the five models. ...........................................56

3-18. Column chart of the prior probability of the five models.................................................57

3-19. Iteratively aggregated prior probability....................................................................5

3-20. Simply aggregated prior probability by assigning equal weight to the experts.................59

3-21. Expert weight assigned by each expert ( $\mathrm{x}$ axis) to all experts........................................60

3-22. Prior probabilities of combinations of recharge and geological models...........................60

3-23. Map of the model domain in plan view, showing areas where the mesh is refined. .........62

3-24. Comparison of the boundary flows from the refined mesh to the original mesh of the DVRFS model.

3-25. Configuration of the HSU transition zone used for physically joining Yucca Flat HSUs in the northern Yucca Flat with DVRFS in the remainder of the CRFM. ..............66

3-26. Residuals and simulations for (a-1) discharge and constant-head boundary flow, (a-2) head, and (a-3) head change of the DVRFS modeling of Belcher et al. (2004).......72

3-27. Residuals and simulations for (a-1) discharge and constant-head boundary flow, (a-2) head, and (a-3) head change of model G1R2. .73

3-28. Residuals and simulations for (a-1) discharge and constant-head boundary flow, (a-2) head, and (a-3) head change of model G2R2.

3-29. Residuals and simulations for (a-1) discharge and constant-head boundary flow, (a-2) head, and (a-3) head change of model G1R5.

3-30. Residuals and simulations for (a-1) discharge and constant-head boundary flow, (a-2) head, and (a-3) head change of model G2R5.

3-31. Residuals and simulations for (a-1) head and (a-2) head change of the DVRFS of

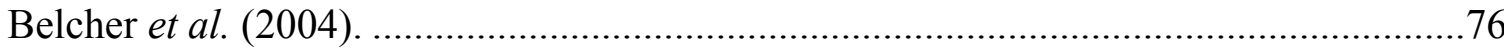

3-32. Residuals and simulations for (a-1) head and (a-2) head change of model G1R2 ............77

3-33. Residuals and simulations for (a-1) head and (a-2) head change of model G1R5 ............78

3-34. Residuals and simulations for (a-1) head and (a-2) head change of model G2R2 ............78

3-35. Residuals and simulations for (a-1) head and (a-2) head change of model G2R5 ............79

3-36. Weighted residuals of the 50 observations of head (index from 1 to 50) and nine observations of head change (index from 51 to 59) for all of the 25 models....................80

3-37. Weighted residuals of the 50 observations of head and nine observations of head change for all of the 25 models.

3-38. Calibrated model parameters of the five recharge models for geological model G1 (USGS model). 
3-39. Prior and posterior probabilities of the 25 models................................................. 85

3-40. Calibrated and uncalibrated recharge rate $\left(\mathrm{m}^{3} /\right.$ day) of the 25 alternative models in the DVRFS.

3-41. Calibrated and uncalibrated recharge rate $\left(\mathrm{m}^{3} /\right.$ day) of the 25 alternative models in the northern Yucca Flat area.

3-42. Relation between recharge percentage and posterior probability of all the models. .........88

3-43. Plot of posterior probability versus recharge percentage of all the models.....................88

3-44. Unweighted boundary-flow rate ( $\mathrm{m}^{3} /$ day) along constant-head boundary segments of the DVRFS.

3-45. Weighted boundary-flow rate along constant-head boundary segments of the DVRFS...90

3-46. Three-dimensional contours of hydraulic head simulated in the northern Yucca Flat area by the calibrated models: (a) G3R2, (b) G2R2, (c) G3R5, (d) G2R5, (e) G2R3, and (f) G2R1. G2 and G3 are the UGTA base model and its CP thrust alternative.

3-47. Cell-by-cell flow crossing the front face of MODFLOW cells (i.e., $\mathrm{Q}_{\mathrm{y}}, \mathrm{m}^{3} /$ day) predicted at the southern boundary (x-z cross section) of northern Yucca Flat by models (a) G3R2, (b) G2R2, (c) G3R5, (d) G2R5, (e) G2R3, and (f) G2R1.

3-48. Total flow rate into Yucca Flat through the cross section shown in Figure 3-47.

3-49. Scatterplot of residuals of heads and head-changes and contours of hydraulic head at the top layer of the northern Yucca Flat area simulated by models (a) G3R2, (b) G2R2, (c) G3R5, (d) G2R5, (e) G2R3, and (f) G2R1.

3-50. Observed and simulated groundwater discharge by subregion: (a) northern Death Valley, (b) central Death Valley, and (c) southern Death Valley..... 96

3-51. Observed and simulated groundwater discharge by subregion: (a) northern Death Valley, (b) central Death Valley, and (c) southern Death Valley.

3-52. Observed and simulated groundwater discharge by subregion: (a) northern Death Valley, (b) central Death Valley, and (c) southern Death Valley.... .98

3-53. Minimum, mean, and maximum of the 200 realizations of generalized parameters for models G3R2 and G2R2 (the two best models).

3-54. GLUE weights of the 200 realizations of models (a) G3R2, (b) G2R2, and (c) G3R5 (the top three best models).

3-55. Convergence of simulated head at two arbitrary points for models (a) G3R2, b) G2R2, and (c) G3R5 (the top three best models).

3-56. Simulated head over the 87 stress periods at two selected points within the northern Yucca Flat with node index (number of row and column) of (a) $(110,137)$ and (b) $(140,137)$ for model G3R2 (the best model, G3 being the CP thrust alternative geologic model, R2 being the NIW1 recharge model).

3-57. Mean head predictions of (a) model averaging and models (b) G3R2, (c) G2R2, (d) G3R5, (e) G2R5, and (f) G2R3.

3-58. Standard deviation of head predictions of (a) model averaging and models (b) G3R2, (c) G2R2, (d) G3R5, (e) G2R5, and (f) G2R3.

3-59. Mean cell-by-cell flow crossing front face of MODFLOW cells predicted by (a) model averaging and models (b) G3R2, (c) G2R2, (d) G3R5, (e) G2R5, and (f) G2R3. .105

3-60. Standard deviation of cell-by-cell flow crossing front face of MODFLOW cells predicted by (a) model averaging and models (b) G3R2, (c) G2R2, (d) G3R5, (e) G2R5, and (f) G2R3. 
3-61. Standard deviation of (a) posterior, (b) within-model, and (c) between-model variance of head predictions.

3-62. Standard deviation of (a) posterior, (b) within-model, and (c) between-model variance of flow crossing the front face (in the $y$-direction) of MODFLOW cells.........................108

4-1. Map of the Climax granite flow model domain.............................................................112

4-2. Lower hemisphere equal area projection of the poles to the mean orientation vectors for Sets 1 through 6 .

4-3. Mandelbrot plot of the all of the fracture lengths $(l)$ along with best fit Pareto powerlaw (PL), truncated Pareto power-law (TPL) and exponential (exp) models................. 116

4-4. Linear regression of the number of fracture-occupied cells $N$ at the reciprocal of cell length $r$ in log-log space for the original composite transect.........................................118

4-5. Linear regression of the number of fracture-occupied cells $N$ at the reciprocal of cell length $r$ in log-log space for 100 three-dimensional fracture network realizations.........119

4-6. A $\log _{10}$ probability plot of fracture aperture suggests that this quantity is lognormally

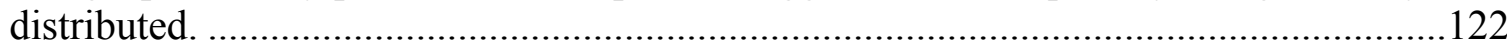

4-7. Two-dimensional slice of a three-dimensional fracture continuum zone network (red)

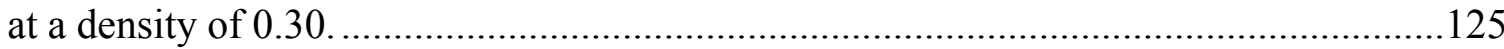

4-8. Fracture mapping on a continuum grid results in a stair-step pattern of both horizontal and vertical flow components and longer flowpaths. ..................................................126

4-9. Selection of the local-scale FCM domain (b) from the CRFM model (a).......................126

4-10. Northeast view of the local-scale fracture continuum model. ........................................127

4-11. Frequency histogram of $\log _{10}$ flux values for 200 individual FCM realizations corresponding to the G1R2 CRFM.........................................................................128

4-12. The distribution of model weights for FCM realizations based on the G1R2 boundary conditions and flux target before (black curve) and after (blue curve) the use of the GLUE methodology...

5-1. The two fractions of the radiologic source term: exchange volume (green) and glass volume (red).

5-2. Locations of the three underground tests (spheres) in relation to the DVRFMsimulated water table.

5-3. Map view of Climax local-scale fracture continuum domain showing permeability disks (red) within active cells of the model domain (blue).

5-4. Distribution of tritium (pCi/L) in waters located near the Hard Hat (left) and Pile Driver (right) tests (red).

5-5. Plan view of distribution of tritium (green diamonds) in waters located near the Hard Hat and Pile Driver tests (red).

5-6. Dissolution rates for synthetic volcanic glasses measured at $65^{\circ} \mathrm{C}$ by Mazer (1987).....144

5-7. Fit (thick black line) to $65^{\circ} \mathrm{C}$ dacite dissolution data of Mazer (1987) (thick red line)..147

5-8. Far-from-saturation, surface-area-normalized dissolution rates for granodiorite (solid) and quartz monzonite (dashed) glass as a function of temperature and $\mathrm{pH}$.

5-9. Evolution of solution $\mathrm{pH}$ as a function of temperature starting with $25^{\circ} \mathrm{C}$ groundwater chemistry reported in Table 5-6 for various modeling conditions.

Comparison of far-from-saturation Climax stock glass (granodiorite) dissolution rate as a function of temperature and $\mathrm{pH}$ (from Figure 5-8) to the simplified glass dissolution model used in the particle code (black line).

5-11. Parallelepiped used in analytical solution of the temperature history of the glass zone..154 
5-12. Predicted mean temperature history of the Hard Hat test based on the analytical solution with initial temperatures of $100^{\circ} \mathrm{C}$ (red), $180^{\circ} \mathrm{C}$ (blue), and $1,070^{\circ} \mathrm{C}$ (black) and measured data.

5-13. Predicted mean temperature history of the Pile Driver test based on the analytical solution with initial temperatures of $100{ }^{\circ} \mathrm{C}$ (red), $198^{\circ} \mathrm{C}$ (blue), $238^{\circ} \mathrm{C}$ (green), and $477^{\circ} \mathrm{C}$ (black) and measured data.

5-14. Predicted mean temperature history of the Tiny Tot test based on the analytical solution with initial temperatures of $100{ }^{\circ} \mathrm{C}$ (red) and $478^{\circ} \mathrm{C}$ (black).

5-15. Glass dissolution as a function of time for three underground nuclear tests conducted in the Climax stock.

5-16. Plan view of the Spent Fuel Test facility and adjacent workings with the subsurface water collection points reported in Isherwood et al. (1982)

5-17. Cross-sectional view of the Spent Fuel Test facility tunnel and access shaft with the water sampling locations reported in Isherwood et al. (1982).

5-18. Piper/stiff diagrams for the five sample locations reported in Isherwood et al. (1982). .162

5-19. Box plots for all $K_{d}$ values reported for granites worldwide: (a) Climax stock project reports, (b) all nuclear science agency, or 'gray literature' $K_{d}$ values for granites worldwide except the Climax stock, (c) open science literature for all granites except the Climax stock, and (d) all data combined.

5-20. Histogram for all $K_{d}$ values found for granite.

5-21. Comparison of $K_{d}$ values measured for uranium using Climax granite and values for neptunium using granites worldwide.

5-22. Comparison of $K_{d}$ measured for strontium using climax granite samples and calculated for calcium using CRUNCH.

5-23. Comparison of $K_{d}$ values measured for nickel, zirconium, and niobium using granites worldwide.

5-24. Comparison of $K_{d} \mathrm{~s}$ measured for Cs using Climax granite, and measured for Sn and Pd using other granites.

5-25. Comparison of $K_{d} \mathrm{~s}$ measured for $\mathrm{Am}, \mathrm{Pu}$, and Eu using Climax granite, and calculated for Sm using CRUNCH and Climax mineralogy.

5-26. A lognormal probability plot of fracture porosity based on the conversion of 10,000 random hydraulic conductivity values to porosity according to (5.1).

5-27. Location of eastern, western, and southern model boundaries along with percentage of radionuclide particles exiting each boundary.

5-28. Vertical exit locations (layers) of particles leaving the Southern boundary.....

5-29. Particle flux times for transport Class I to model domain boundaries for each source origin along with the ensemble trend.

5-30. Histogram of $\log _{10}$ velocity for all particles that exit the local-scale FCM model domain. Values of bin midpoints are given.

5-31. Empirical CDF of radionuclide flux for ${ }^{14} \mathrm{C}$ at a time of 307 years along with values corresponding to L95, median, and U95.

5-32. Radionuclide mass flux for $14 \mathrm{C}$ based on a straight Monte Carlo simulation where all realizations are weighted equally.

5-33. Incorporation of regional conceptual model uncertainty into radionuclide mass flux for ${ }^{14} \mathrm{C}$ 
5-34. Incorporation of parametric uncertainty, expressed as values of GLUE-weighted volumetric flux, in the local-scale Climax fracture continuum model for ${ }^{14} \mathrm{C}$ mass flux.

5-35. Final radionuclide mass flux values incorporate both alternative model and parametric uncertainty......

5-36. Mass flux curves for ${ }^{3} \mathrm{H}$.

5-37. Mass flux curves for ${ }^{14} \mathrm{C}$.

5-38. Mass flux curves for ${ }^{39} \mathrm{Ar}$.

5-39. Mass flux curves for ${ }^{85} \mathrm{Kr}$. 193

5-40. Ensemble particle flux times to model domain boundaries for Class III..........................194

5-41. Mass flux curves for ${ }^{41} \mathrm{Ca}$.

5-42. Mass flux curves for ${ }^{90} \mathrm{Sr}$.

5-43. Particle flux times for transport Class IV to model domain boundaries for each source

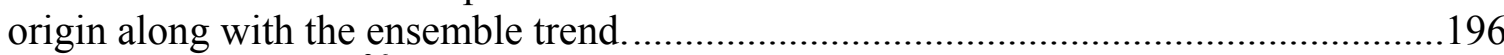

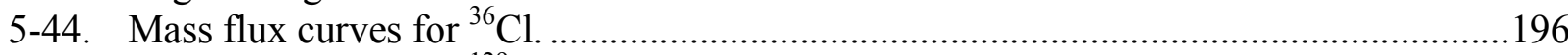

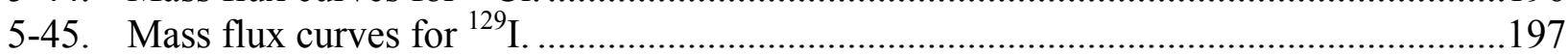

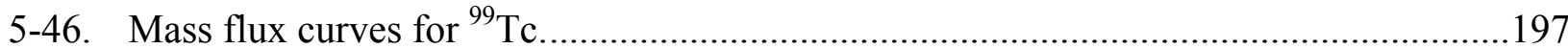

5-47. Ensemble particle flux times to model domain boundaries for Class VI. ........................198

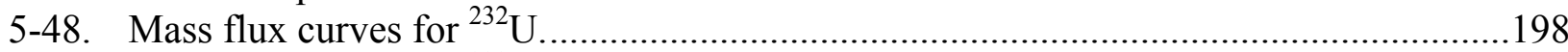

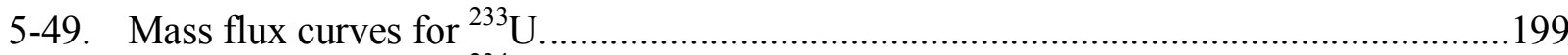

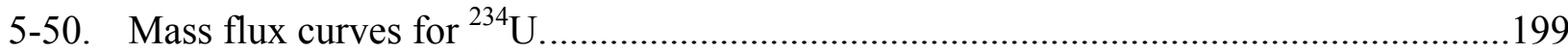

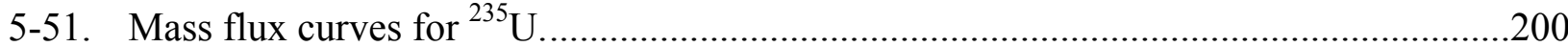

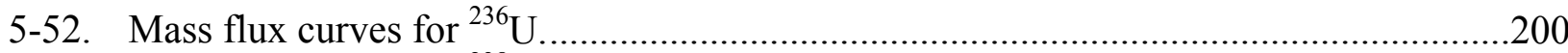

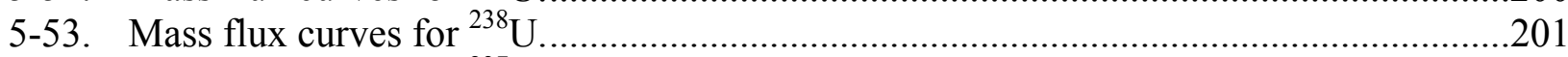

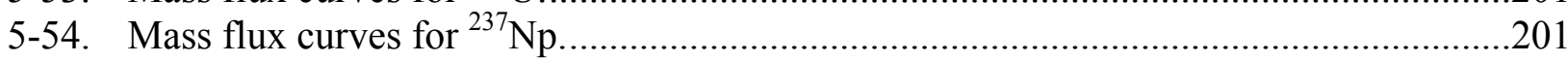

\section{LIST OF TABLES}

2-1. Hydrostratigraphic units of the Yucca Flat-Climax Mine Hydrostratigraphic Framework Model (Bechtel Nevada, 2006)....................................................................

2-2. Location and nuclear-test related data for Hard Hat, Tiny Tot, and Pile Driver. ...............16

3-1. Recharge estimates $\left(\mathrm{m}^{3} / \mathrm{d}\right)$ of the MME, CMB1, and CMB2 models and net infiltration estimates $\left(\mathrm{m}^{3} / \mathrm{d}\right)$ of the CMB1 and CMB2 models in the DVRFS and

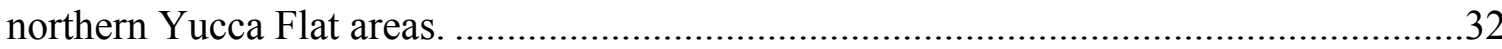

3-2. Recharge coefficients for the Maxey-Eakin recharge method...........................................32

3-3. Mean recharge coefficients for the Epstein (2004) recharge estimation method. ..............34

3-4. Correlations between DVRFS HGUs and UGTA HSUs present in the Yucca FlatClimax Mine CAU (after Bechtel Nevada, 2006).

3-5. Boundary coordinates of the Climax Regional Flow Model and the refined area in northern Yucca Flat.

3-6. Comparison of the sum of squared weighted residuals and fluid balance results from the refined mesh to the original mesh of the DVRFS model.

3-7. Sum of squared weighted residuals (SSWR) of alternative models for all the calibration data and each type of the calibration data throughout the DVRFS. 
3-8. Sum of squared weighted residuals (SSWR) of alternative models for all the calibration data and each type of the calibration data located in northern Yucca Flat. .....75

3-9. Prior and posterior model probabilities of the 25 alternative models...............................84

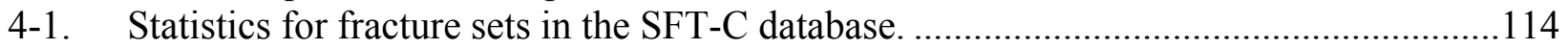

4-2. Values of target volumetric flux and corresponding fracture density for each of the 25 alternative CRFMs.

4-3. Values of recharge flux for each alternative conceptual model in the local-scale fracture continuum model.

5-1. Estimated radionuclide inventories, in moles, decay corrected to $t_{0}$ for three tests conducted in the Climax stock.

5-2. Partitioning of radionuclides between phases, as determined by the IAEA (1998)........138

5-3. Assignment of radionuclides to eight transport classes and the partitioning between glass and aqueous-sorbed phases.

5-4. Composition of granodiorite and quartz monzonite, from Maldonado 1977. ..................148

5-5. Climax stock melt glass dissolution rate constants at standard state $\left(25^{\circ} \mathrm{C}\right) \ldots \ldots \ldots \ldots \ldots \ldots . . .148$

5-6. Geochemical analysis for UG-02 from Isherwood et al. (1982).

5-7. Modal analysis of samples obtained from SFT canister emplacement boreholes, Appendix B2, Ryerson and Qualheim (1983).

5-8. Climax stock rock mineralogy, Maldonado (1977).

5-9. Chemical analysis of samples from the southwest part of the Climax intrusive, Borg (1970).

5-10. Average chemical composition in weight percent of granodiorite and quartz monzonite from the Climax stock, Maldonado (1977).

5-11. Rock properties and mineral volume percentages of altered quartz monzonite, Connolly (1981)

5-12. $\quad \log K_{d}$ values determined from laboratory batch experiments on samples collected from the Climax stock.

5-13. $\log K_{d}$ values determined from laboratory batch experiments on whole-rock granite samples from the available literature.

5-14. Summary of radionuclide $\log K_{d}$ s for the Climax stock and other granites worldwide. 169

5-15. Summary of radionuclide $\log K_{d}$ ranges reported for $\pm 1 \sigma$. 170

5-16. Radionuclides grouped into categories based on similar ranges in sorption coefficients.

5-17. Summary of diffusion parameters reported in the literature. 178

5-18. Comparison of fracture and matrix retardation coefficients used in the transport model, for $\log _{10} K_{d}$ values arbitrarily selected from modeled range.

5-19. Radionuclide transport groups and associated glass mass percentage, total particles used in the transport simulations, along with minimum and maximum $\log K_{d}$ values....183 


\section{LIST OF ACRONYMS}

$\begin{array}{ll}\text { ALRA } & \text { Apache Leap Research Site } \\ \text { amsl } & \text { above mean sea level } \\ \text { BAS } & \text { UGTA base model } \\ \text { BMA } & \text { Bayesian model averaging } \\ \text { BRA } & \text { Belted Range aquifer } \\ \text { CAI } & \text { Corrective Action Investigation } \\ \text { CAS } & \text { Corrective Action Site } \\ \text { CAU } & \text { Corrective Action Unit } \\ \text { CHD } & \text { constant head boundary (MODFLOW package) } \\ \text { CHOB } & \text { constant head flow observation (MODFLOW process) } \\ \text { CMB } & \text { chloride mass balance } \\ \text { CP } & \text { Control Point } \\ \text { CPT } & \text { CP Thrust } \\ \text { CRFM } & \text { Climax Regional Flow Model } \\ \text { DEM } & \text { digital elevation model } \\ \text { DFN } & \text { discrete fracture network } \\ \text { DOE } & \text { U.S. Department of Energy } \\ \text { DRI } & \text { Desert Research Institute } \\ \text { DRN } & \text { drain (MODFLOW package) } \\ \text { DROB } & \text { drain observation (MODFLOW process) } \\ \text { DVRFS } & \text { Death Valley Regional Flow System } \\ \text { EDCMB } & \text { elevation-dependent chloride mass balance } \\ \text { ET } & \text { evapotranspiration } \\ \text { FCM } & \text { fracture continuum model } \\ \text { FFACO } & \text { Federal Facility Agreement and Consent Order } \\ \text { GIS } & \text { geographic information system } \\ \text { GLUE } & \text { Generalized Likelihood Uncertainty Estimation } \\ \text { HB } & \text { hydrologic barrier } \\ \text { HFM } & \text { hydrostratigraphic framework model } \\ \text { HGU } & \text { hydrologic unit } \\ \text { HOB } & \text { head observation (MODFLOW process) } \\ \text { HSU } & \text { hydrostratigraphic unit } \\ \text { HUF } & \text { hydrogeologic unit flow (MODFLOW package) } \\ \text { ICU } & \text { intrusive-rock confining unit } \\ \text { KDEP } & \text { depth decay of hydraulic conductivity (MODFLOW package) } \\ \text { LCA } & \text { lower carbonate-rock aquifer } \\ \text { LCCU } & \text { lower clastic-rock confining unit } \\ \text { MC } & \text { Monte Carlo } \\ \text { ML } & \text { maximum likelihood } \\ \text { MLBMA } & \text { Maximum Likelihood Bayesian Model Averaging } \\ \text { MME } & \text { Maxey-Eakin Model } \\ \text { MT } & \text { magnetotelluric } \\ \text { NED } & \text { National Elevation Dataset } \\ \text { NIM } & \text { net infiltration model } \\ & \end{array}$




$\begin{array}{ll}\text { NNSA } & \text { National Nuclear Security Administration } \\ \text { NSO } & \text { Nevada Site Office } \\ \text { NTS } & \text { Nevada Test Site } \\ \text { OBS } & \text { observations (MODFLOW process) } \\ \text { PL } & \text { Pareto power-law } \\ \text { PRETBG } & \text { pre-Grouse Canyon Tuff lava-flow aquifer } \\ \text { PRISM } & \text { Precipitation Estimation on Independent Slopes Model } \\ \text { RCH } & \text { recharge (MODFLOW package) } \\ \text { SEN } & \text { sensitivity (MODFLOW process) } \\ \text { SFT-C } & \text { Spend Fuel Test-Climax } \\ \text { SNJV } & \text { Stoller-Navarro Joint Venture } \\ \text { SSWR } & \text { sum of squared weighted residuals } \\ \text { TPL } & \text { truncated Pareto power-law } \\ \text { TUBA } & \text { Tub Spring aquifer } \\ \text { UCA } & \text { upper carbonate-rock aquifer } \\ \text { UCCU } & \text { upper clastic-rock confining unit } \\ \text { UGTA } & \text { Underground Test Area } \\ \text { USGS } & \text { U.S. Geological Survey } \\ \text { UTM } & \text { Universal Transverse Mercator }\end{array}$


THIS PAGE INTENTIONALLY LEFT BLANK

xxii 


\subsection{INTRODUCTION}

\subsection{Purpose}

Three underground nuclear tests were conducted between 1962 and 1966 (DOE, 2000) in the Climax Mine granite stock located at the northern end of Yucca Flat in Area 15 of the Nevada Test Site (NTS) (Figure 1-1). For the purposes of DOE's Environmental Restoration Program, these tests were originally considered separate from the tests in Yucca Flat owing to distinct differences in hydrogeologic setting, the igneous intrusion at Climax as compared to the alluvial, volcanic, and carbonate rocks in Yucca Flat. However, groundwater pathline analysis conducted as part of regional flow modeling for the Underground Test Area (UGTA) program suggested the possibility for groundwater flow from the Climax stock to downgradient Yucca Flat (DOE, 1997). Thus for this reason, and to simplify administrative tasks associated with the sites, the Climax Corrective Action Sites (CASs) were combined with those in Yucca Flat to form Corrective Action Unit (CAU) 97, the Yucca Flat-Climax Mine CAU (DOE, 2000a).

Modeling of the Climax Mine nuclear testing areas follows the Corrective Action Strategy for underground nuclear tests as presented in Appendix VI of the Federal Facility Agreement and Consent Order (FFACO); however, the Climax modeling is essentially a feed into the Corrective Action Investigation (CAI) for the entire Yucca Flat-Climax Mine CAU. Discussions with the U.S. Department of Energy (DOE), National Nuclear Security Administration (NNSA) Nevada Site Office (NSO) environmental engineering services contractor identified two aspects of the Yucca Flat-Climax Mine CAU model that required more detailed modeling at the northern end of Yucca Flat. First, UGTA's value of information analysis for Yucca Flat (IT, 1999) concluded that groundwater flow into the northern reaches of the Yucca Flat-Climax Mine CAU is an important factor for predicting contaminant migration from Yucca Flat. Addressing this issue requires evaluation to a higher level of detail than the Yucca Flat model can provide. Second, radionuclide fluxes from the Climax granite tests occur in a unique hydrologic environment of the stock as compared to Yucca Flat proper. These two modeling needs can be restated as the two objectives of this project:

- Provide groundwater flow rates for the northern boundaries of the Yucca Flat-Climax Mine CAU model, incorporating alternative conceptualizations of the hydrogeologic system with their associated uncertainty, and

- Provide radionuclide flux rates from the three tests in the Climax stock using modeling techniques that account for groundwater flow in fractured granite.

These issues relate to specific components of the overall Yucca Flat-Climax Mine CAU model and therefore the modeling investigations undertaken to address them have been referred to programmatically as the Climax Mine sub-CAU model. To address the project objectives presented above, the Climax Mine sub-CAU model actually comprises two interrelated models developed at different scales. The eventual Yucca Flat-Climax Mine CAU model will encompass the area around the Climax stock to include groundwater flow through the area and the nuclear tests conducted there (Figure 1-1). The Climax Mine sub-CAU model incorporates feasible alternate hydrostratigraphic models in the northern 
portion of Yucca Flat (the area outlined by the red dashed box on Figure 1-1). This area is referred to as "northern Yucca Flat" in this report.

The UGTA process consists of the following steps: 1) evaluation of data, 2) development of flow and transport models, and 3) definition of the contaminant boundary. For the Climax model, these processes have been followed with the final step consisting of a determination of radionuclide flux rather than calculation of the contaminant boundary because the boundary will be defined for the Yucca Flat-Climax Mine CAU as a whole. In response to an UGTA peer review performed jointly by the Institute for Regulatory Science and the American Society of Mechanical Engineers (ASME, 2001), particular effort has been placed throughout these steps on evaluating uncertainty. In addition to uncertainty in conceptual models, parametric uncertainty is incorporated throughout the modeling process so that it may be carried through to the determination of compliance boundaries in the Yucca Flat-Climax Mine CAU.

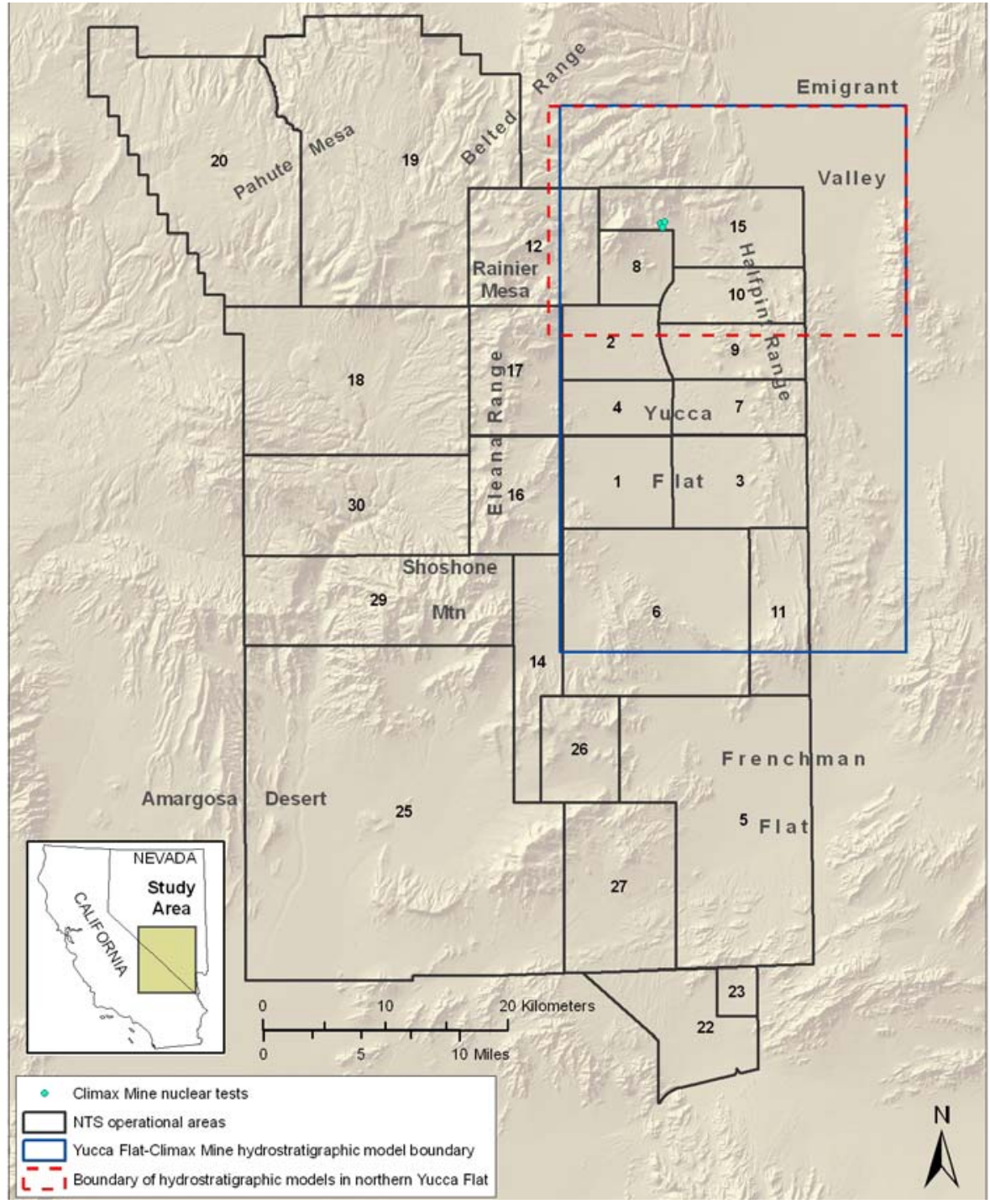

Figure 1-1. Location of the Climax Mine underground nuclear tests and the hydrostratigraphic models of northern Yucca Flat with respect to the Yucca Flat-Climax Mine hydrostratigraphic framework model. 


\subsection{Description of the Climax Mine Study Area}

The Cretaceous-age Climax Mine stock intrudes Paleozoic sedimentary rocks and is flanked by Tertiary volcanic rocks at the northern end of Yucca Flat, cropping out over an area of at least $5 \mathrm{~km}$ (Bath et al., 1983; Phelps et al., 2004). The stock is believed to be nearly circular at depth, covering an area of $200 \mathrm{~km}^{2}$ and extending to a depth of $7.5 \mathrm{~km}$ (Bath et al., 1983; Phelps et al., 2004). Recent drilling at ER-8-1 has extended the shallow subsurface distribution of this unit to the south of the Boundary Fault (Bechtel Nevada, 2006). The Cretaceous monzogranite and granodiorite of the stock are considered relatively impermeable, but locally they yield water from fracture zones. Major displacements have been identified along the eastern and southeastern edges of the Climax stock (Bath et al., 1983). The juxtaposition of the granite with the adjacent lower carbonate aquifer, which is the major regional aquifer in southern Nevada, provides a potential hydraulic connection between the two units.

The Climax stock is part of the uplands that form the northern border of Yucca Flat, including Rainier Mesa, Aqueduct Mesa, and the Eleana Range to the west and north and the Halfpint Range to the east. Elevations in the immediate area reach over 2,000 $\mathrm{m}$ above mean sea level (amsl) on Rainier Mesa and 1,900 m amsl in the Halfpint Range. Yucca Flat slopes downward to the south from a maximum elevation of approximately 1,342 $\mathrm{m}$ amsl near Climax.

Climax was the site of three underground nuclear detonations conducted for weapons effects testing between 1962 and 1966 (DOE, 2000). All three tests are within the Mesozoic granite confining hydrostratigraphic unit. The Hard Hat and Pile Driver tests were conducted in association with extensive underground workings constructed for weapons testing and data collection. Both tests were accessed from drifts extending from shaft U15.01. Tiny Tot was detonated in a drift within a much smaller set of underground workings located in another area of the Climax stock. In the early 1980s, additional workings were constructed from shaft U15.01 about $420 \mathrm{~m}$ below ground surface for the Spent Fuel Test - Climax (SFT-C) to evaluate the feasibility of retrievable, deep geologic storage of commercial nuclear reactor wastes (Patrick, 1986). Detailed mapping of fractures and faults as part of the SFT-C studies greatly expanded the earlier descriptions conducted in the tunnels and provided invaluable information for subsequent modeling studies at Climax.

\subsection{General Methodology Used in this Study}

The objectives of this work are addressed through two distinct but linked project stages. In Stage I, an assessment is made of the uncertainty that arises from alternative plausible conceptualizations of regional groundwater recharge and local hydrostratigraphic framework on groundwater flow in the vicinity of the Climax stock. This is accomplished through the development of a regional groundwater flow model that incorporates these multiple conceptual models while still honoring regional measurements of hydraulic head and groundwater flow for calibration. Uncertainty in the recharge and hydrostratigraphic models is formally incorporated into the deterministic model using Maximum Likelihood Bayesian Model Averaging (MLBMA) methods to evaluate prior information and field measurements, through both expert elicitation and parameter estimation inverse modeling. The regional flow model is based on the Death Valley Regional Flow System (DVRFS) model developed by the U.S. Geological Survey (USGS) (Belcher, 2004). This regional model is being adopted by the UGTA program to provide supporting hydrologic information 
for CAU-scale flow models where appropriate. Though the region covered by the DVRFS model is considerably more extensive than the area where groundwater flows are required in northern Yucca Flat, the limited availability of calibration data in the vicinity of the Climax stock required expanding the area of coverage to incorporate a reasonable amount of this information.

This approach differs from the general approach used in the UGTA CAU flow models for Frenchman Flat (CAU 98) (SNJV, 2006a) and Pahute Mesa (CAUs 101 and 102) (SNJV, 2006b). These CAU-scale models were constructed at a finer resolution and independent of the existing UGTA regional model (DOE, 1997), but rely on the regional model results for boundary conditions and calibration targets. Because edge boundaries of the CAU flow models generally do not correspond with hydrologic boundaries, heads on specified-head boundaries were interpolated onto boundary nodes from heads simulated by the regional model with some manual adjustments instituted during calibration. In addition, groundwater flows on edge boundaries of the CAU models were interpolated from the regional model and utilized as target values during the calibration process. The Climax sub-CAU model eliminates the need to construct arbitrary edge boundaries by adapting the DVRFS regional model and refining it in northern Yucca Flat where these groundwater flow investigations are focused. This approach allows simulated flow within northern Yucca Flat to be consistent with regional flow patterns and respond to changes in regional flow corresponding to alternative models of groundwater recharge and hydrostratigraphy.

The result of Stage I is a set of realizations of simulated hydraulic heads and groundwater flows that incorporate both parametric and conceptual model uncertainty. These results are used for two purposes. The first is to provide input for the groundwater flow model of the Climax granite stock developed in the second stage of this project, and the second is to provide observation data for the northern boundary of the Yucca Flat-Climax Mine CAU model. The latter information is delivered directly to Stoller-Navarro Joint Venture (SNJV; NSO's environmental engineering services contractor) for evaluation and incorporation in the model at the appropriate time.

Stage II of the project is the development of flow and transport models within the Climax stock to provide radionuclide flux rates from the Climax stock into the northern boundaries of the Yucca Flat-Climax Mine CAU model. These simulations are focused on the granite stock under the assumption that radionuclides calculated to travel beyond the granite will be entering fast pathways such as fault zones or the regional carbonate aquifer, major features that are likely to be directly incorporated in the Yucca Flat-Climax Mine model. The Climax granite flow model is distinct from the Climax regional flow model described above, but relies on that larger model for simulated values of groundwater flux, hydraulic head, groundwater recharge, and calibration weights. The uncertainty arising from model conceptualization in the regional model is carried through to the granite model as parametric uncertainty. The transport model formulation includes source term release functions for the underground tests, sorption, and matrix diffusion, all of which are treated as uncertain. 


\subsection{HYDROGEOLOGIC SETTING}

The hydrostratigraphic framework of the NTS was first described by Winograd and Thordarson (1975) and though considerable refinement of various aspects has occurred with the collection of new data over the intervening years, their model has remained the foundation for most interpretations relating to the geology around Climax. The following two sections briefly summarize the geology and groundwater flow in the vicinity of Yucca Flat and are based on their work, as well as subsequent studies focused more directly on Yucca Flat as part of UGTA hydrogeologic investigations, including Laczniak et al. (1996), IT (1996a, b, c) and Bechtel Nevada (2006). Results of these studies and numerous other investigations in the region are incorporated in a digital three-dimensional model of the hydrostratigraphic framework of Yucca Flat developed in support of the UGTA project (Bechtel Nevada, 2006).

An overview of the geologic framework of northern Yucca Flat is given in Section 2.1. Regional groundwater flow into northern Yucca Flat is discussed in Section 2.2. The hydrochemistry of regional groundwater is presented in Section 2.3, along with an introduction to the nature of groundwater samples collected in the Climax stock. Section 2.4 describes the three nuclear tests and other subsurface studies conducted in the Climax granite. Section 2.5 presents an overview of the Death Valley Regional Flow System model.

\subsection{Geology}

Yucca Flat is a Cenozoic-age basin formed in response to basin-and-range extensional tectonics. Figure 2-1 shows the major rock types exposed at ground surface. The oldest rocks in the basin are marine carbonate and siliciclastic sediments accumulated during a period of uniform sedimentation during the Precambrian and Paleozoic, attaining an overall thickness of over $11,000 \mathrm{~m}$. Generally uniform deposition during this long period has resulted in geologic formations that exhibit similar lithologic character and thickness over the greater southern Nevada region, far beyond the boundaries of Yucca Flat. Two major sequences of clastic and carbonate sedimentation are identified throughout the region during the Precambrian and Paleozoic (Winograd and Thordarson, 1975). The base of the section is predominantly quartzite and siltstone up to 3,000 m thick. Above this lies about 5,000 m of limestone and dolomite, then $2,400 \mathrm{~m}$ of quartzite, siltstone, argillite, and conglomerate. The top of the section is chiefly limestone, having thicknesses of up to $1,200 \mathrm{~m}$.

In Yucca Flat, thick siliciclastic rocks and the base of the carbonates are exposed in the Halfpint Range anticline, a structural uplift on the eastern portion of the basin. At this location, they gently dip to the southwest below Yucca Flat forming the southwest flank of the anticline. On the western margin of the basin, Paleozoic siliciclastic sediments overlie older Paleozoic carbonate rocks in the subsurface and in outcrops in the western part of Yucca Flat and in the Eleana Range. Younger Paleozoic sedimentary rocks outcrop along many of the basin margins.

During the Mesozoic Era, large-scale, contractional deformation consisting of uplift and erosion and subsequent folding, thrusting, and strike-slip faulting resulted in complicated deformation of Paleozoic and older rocks (Figure 2-2). East- and west-directed thrust faulting laterally displaced pre-Tertiary rocks up to several kilometers. The major east-directed Belted Range thrust fault resulted in vertical displacement of Precambrian and Cambrian siliciclastic rocks forming a structural high and truncating lower Paleozoic carbonates. The CP Thrust 
fault extends south from the Climax area into the western portion of Yucca Flat, having placed carbonate rocks over siliciclastic rocks. Though this fault appears to be relatively flat-lying at ground surface, magnetotelluric data (Asch et al., 2005) suggest that the fault plane steepens rapidly eastward forming a ramp structure beneath central Yucca Flat (Bechtel Nevada, 2006). Contractional deformation also caused extensive folding; for example, siliciclastic sediments on the western margin of the basin are contracted into several north-south-trending folds, possibly as a result of displacement along the Tippinip Thrust (Winograd and Thordarson, 1975). Mesozoic-age rocks are represented only by several small Late Cretaceous intrusive masses including the Climax Mine stock and the Gold Meadows stock. The Climax Mine stock is a composite granitic intrusive comprising a medium-grained granodiorite and a fine- to medium-grained, coarsely porphyritic quartz monzonite.

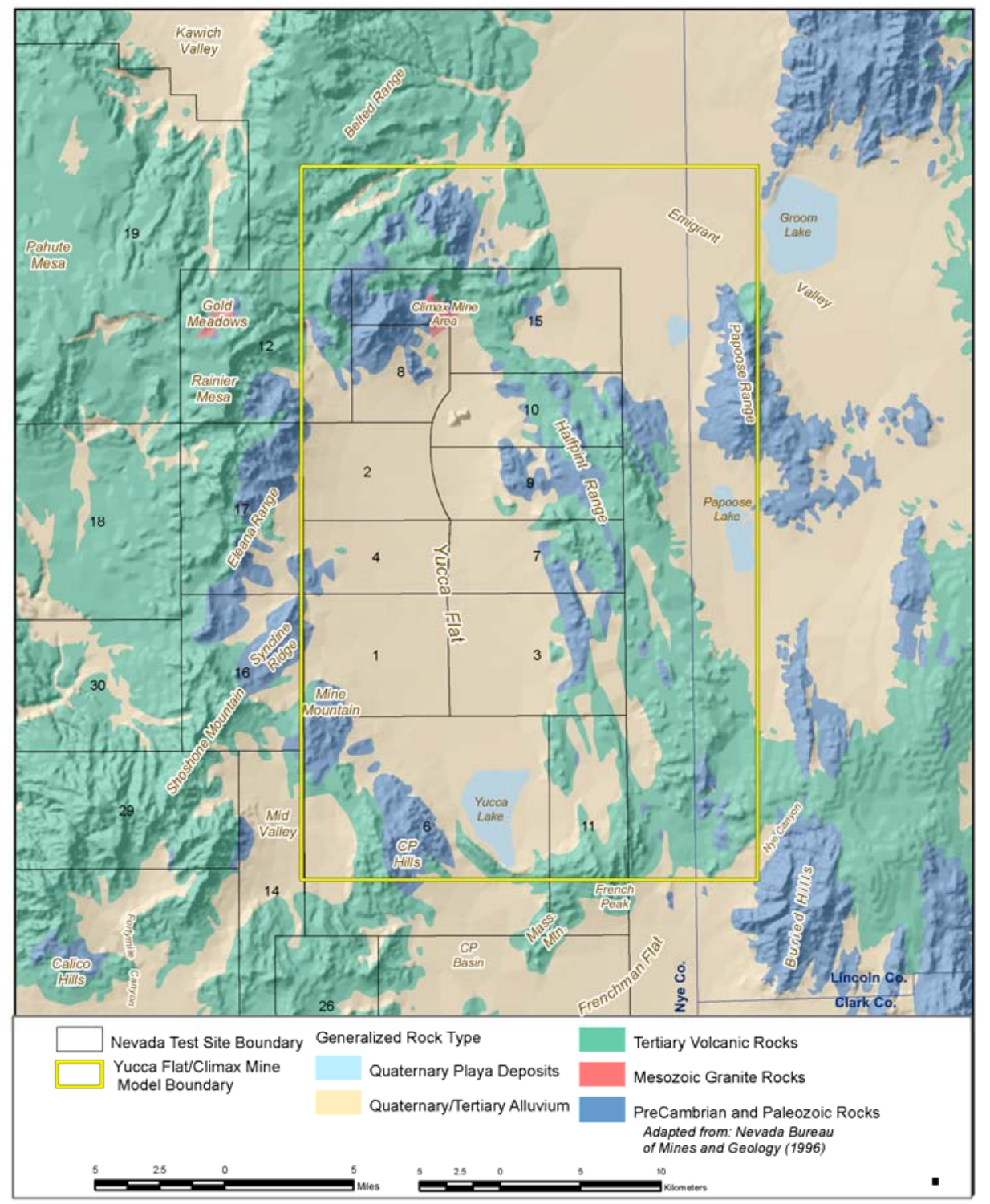

Figure 2-1. Map of the major rock types outcropping in the region of Yucca Flat. The Climax Mine granite intrusion is exposed in the extreme northern end of Yucca Flat. From Bechtel Nevada (2006). 


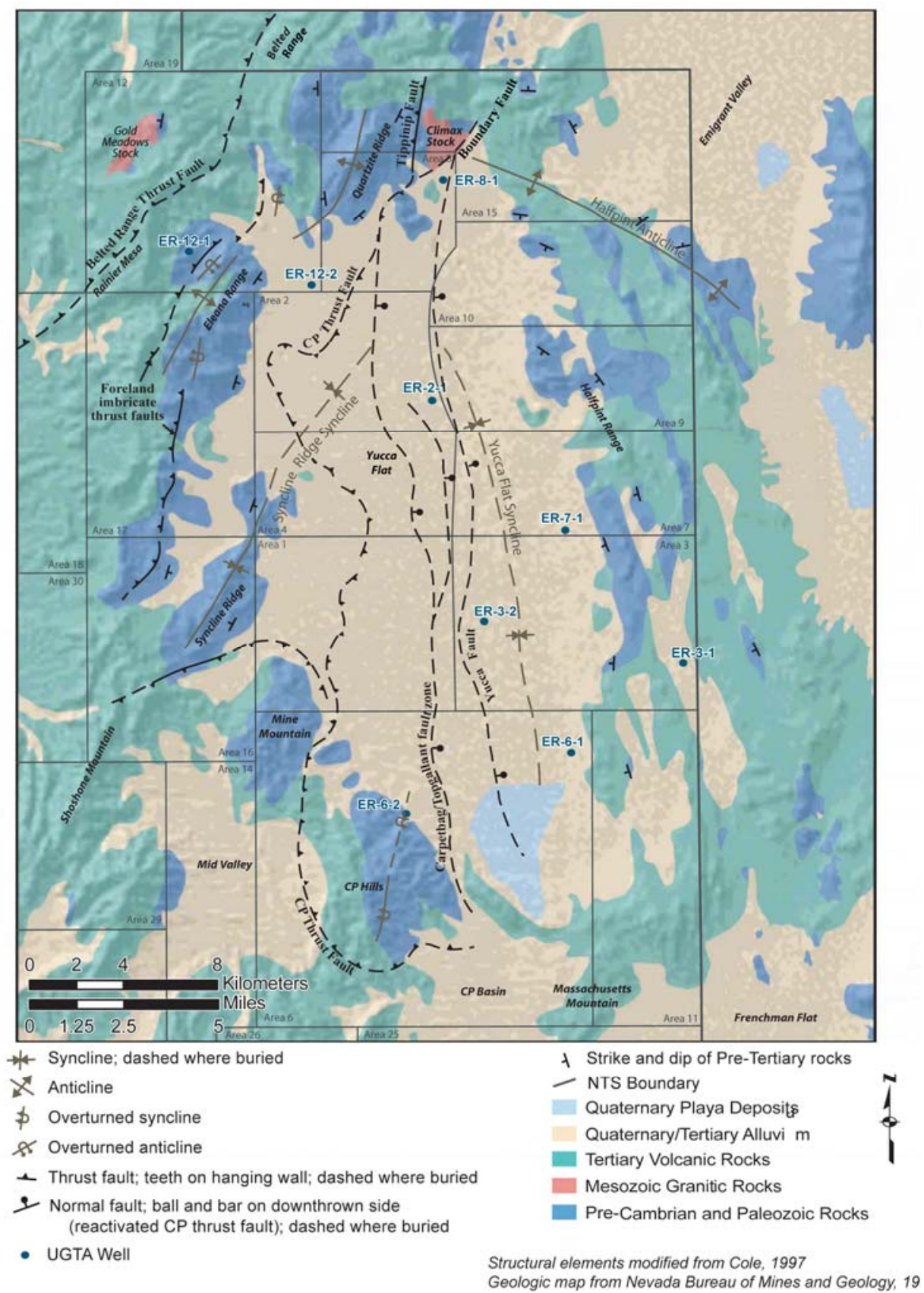

Figure 2-2. Map of the selected structural features in the Yucca Flat region. Modified from Bechtel Nevada (2006).

The Tertiary section is dominated by volcanic and associated sedimentary rocks that originate from calderas and vents associated with the southwestern Nevada Volcanic Field $30 \mathrm{~km}$ to the west. The volcanic rocks, which reach thicknesses of over 2,000 m, include ash-flow tuff, ash-fall tuff, and reworked tuff, and their exposures predominate in the uplands surrounding the basin and throughout the NTS. Unlike the Precambrian and Paleozoic rocks, the areal extent, thickness and physical properties of the volcanic Tertiary strata are widely variable over the region 
Regional Basin-and-Range extension began in mid-Tertiary time, resulting in large-scale normal block faulting that disrupted the Tertiary strata and the previously deformed Precambrian and Paleozoic rocks. The two adjacent north-south-trending structural basins that comprise Yucca Flat were created during this period as a result of dip-slip displacement along the north-striking and east-dipping Carpetbag-Topgallant and Yucca fault systems. The eastern basin lies east of the Yucca fault and is formed by the Yucca fault syncline. The western basin is formed by the northeast continuation of the Syncline Ridge syncline (Figure 2-2). Extensional normal faulting also formed important basins adjacent to Yucca Flat, including Emigrant Valley and Kawich Valley to the north and Frenchman Flat to the south. Tertiary-age and Quaternary-age surficial deposits consisting of alluvium, colluvium, eolian deposits, basalt lavas, and playa deposits cover older rocks in much of the basin.

Three major faults are present in the vicinity of the Climax stock. The north-northeast-trending strike-slip Tippinip fault is located west of the Climax granite outcrop. The west side is downthrown relative to the east, placing upper Paleozoic clastic rocks laterally adjacent to Paleozoic carbonate rocks. The Boundary fault is located along the southeast side of the stock and trends northeast, placing the Climax granite in fault contact with Paleozoic carbonates. The Tippinip and Boundary faults appear to merge at depth southeast of the stock. The Yucca fault is one of the principal basin-forming dip-slip faults in Yucca Flat, trending northward though the center of the valley. This fault extends across the entire length of Yucca Flat, possibly merging with the Boundary fault immediately southeast of the Climax stock.

\subsection{Groundwater Flow}

Bechtel Nevada (2006) developed a classification system that defines 25 hydrostratigraphic units (HSUs) in Yucca Flat, including 13 aquifers and 12 confining units (Table 2-1). The alluvial section is represented by three HSUs; two are aquifers and one is a confining unit. The Tertiary volcanic section is organized into 15 HSUs, nine of which are aquifers and six are confining units. The granite intrusive (e.g., the Climax Mine stock) is a single HSU and is defined as a confining unit. Finally, the pre-Tertiary section is represented by six HSUs, which include three aquifers and four confining units.

Table 2-1. Hydrostratigraphic units of the Yucca Flat-Climax Mine hydrostratigraphic framework model. From Bechtel Nevada (2006).

\begin{tabular}{|c|c|c|}
\hline Hydrostratigraphic Unit & Typical Lithologies & Hydrologic Significance \\
\hline $\begin{array}{l}\text { alluvial aquifer } \\
\text { (AA) }\end{array}$ & $\begin{array}{l}\text { Alluvium: Gravelly sand; also } \\
\text { includes one or more thin basalt } \\
\text { flows, playa deposits (differentiated } \\
\text { as separate HSUs), and eolian sands }\end{array}$ & Generally unsaturated except in deepest basins \\
\hline $\begin{array}{l}\text { playa confining unit } \\
\text { (PCUT) }\end{array}$ & Clayey silt and sandy silt & $\begin{array}{l}\text { Playa units occur well above local water table, but could impede } \\
\text { downward recharge, or could intermittently concentrate local } \\
\text { recharge through large surface cracks. Forms surface and near- } \\
\text { surface playas at Yucca Lake and Papoose Lake, and southern } \\
\text { West Emigrant Valley. }\end{array}$ \\
\hline $\begin{array}{c}\text { basalt lava-flow aquifer } \\
\text { (BFLA) }\end{array}$ & Basalt lava flows & $\begin{array}{l}\text { Several (possibly dissected) basalt flows recognized in the middle } \\
\text { of the alluvial section of southwestern Yucca Flat, at the surface } \\
\text { as dikes and sills in the Halfpint Range, and as a dike in the } \\
\text { subsurface of eastern Yucca Flat, at drill hole UE-7h. Generally } \\
\text { unsaturated, but deep-feeder dikes could possibly affect } \\
\text { groundwater flow. }\end{array}$ \\
\hline
\end{tabular}


Table 2-1. Hydrostratigraphic units of the Yucca Flat-Climax Mine hydrostratigraphic framework model. From Bechtel Nevada (2006) (continued).

\begin{tabular}{|c|c|c|}
\hline Hydrostratigraphic Unit & Typical Lithologies & Hydrologic Significance \\
\hline $\begin{array}{l}\text { Timber Mountain } \\
\text { upper vitric-tuff aquifer } \\
\text { (TM-UVTA) }\end{array}$ & $\begin{array}{l}\text { Includes vitric nonwelded to partially } \\
\text { welded ash-flow and bedded tuff }\end{array}$ & $\begin{array}{l}\text { Typically saturated only in the deepest structural basins. This } \\
\text { HSU comprises only the Ammonia Tanks Tuff, which } \\
\text { stratigraphically overlies the TM-WTA. }\end{array}$ \\
\hline $\begin{array}{l}\text { Timber Mountain } \\
\text { welded-tuff aquifer } \\
\text { (TM-WTA) }\end{array}$ & $\begin{array}{l}\text { Partially to densely welded ash-flow } \\
\text { tuff; vitric to devitrified }\end{array}$ & $\begin{array}{l}\text { Typically saturated only in deep structural basins. Strongly } \\
\text { welded zones typically sandwiched between less welded zones. }\end{array}$ \\
\hline $\begin{array}{l}\text { Timber Mountain lower vitric - } \\
\text { tuff aquifer } \\
\text { (TM-LVTA) }\end{array}$ & $\begin{array}{l}\text { Nonwelded ash-flow and bedded tuff; } \\
\text { vitric }\end{array}$ & $\begin{array}{l}\text { Typically includes the nonzeolitized, nonwelded lower portion of } \\
\text { the Rainier Mesa Tuff. However, this HSU can encompass all } \\
\text { nonzeolitized, nonwelded and bedded units below the welded } \\
\text { Rainier Mesa Tuff and above the level of pervasive zeolitization. } \\
\text { Unaltered nonwelded and ash-fall tuffs generally not found at } \\
\text { depths much below the static water level due to tendency to } \\
\text { become zeolitized (which drastically reduces permeability) under } \\
\text { saturated conditions. }\end{array}$ \\
\hline $\begin{array}{l}\text { upper tuff } \\
\text { confining unit } \\
\text { (UTCU) }\end{array}$ & Zeolitized bedded tuff & $\begin{array}{l}\text { Defined to encompass the zeolitized bedded tuffs that } \\
\text { stratigraphically overlie the Topopah Spring aquifer (TSA). } \\
\text { Although some geologic units of the UTCU are laterally } \\
\text { continuous with those of the LTCU, the UTCU is limited areally to } \\
\text { extreme southern Yucca Flat, where the welded Topopah Spring } \\
\text { Tuff is an important aquifer present between the two tuff confining } \\
\text { units (UTCU and LTCU). }\end{array}$ \\
\hline $\begin{array}{l}\text { Topopah Spring } \\
\text { aquifer } \\
\text { (TSA) }\end{array}$ & Welded ash-flow tuff & $\begin{array}{l}\text { Distribution in Yucca Flat is limited to the extreme southern } \\
\text { portion, south of the N } 828,000 \text { (NTS) grid line. Hydrogeologic } \\
\text { properties are similar to those of the TM-WTA. }\end{array}$ \\
\hline lower vitric tuff aquifer (LVTA) & $\begin{array}{l}\text { Nonwelded and bedded ash-flow tuff; } \\
\text { vitric }\end{array}$ & $\begin{array}{l}\text { Relatively thin VTA unit below the TSA. Grouped with the TM- } \\
\text { LVTA where TSA is not present. }\end{array}$ \\
\hline $\begin{array}{l}\text { Belted Range aquifer } \\
\text { (BRA) }\end{array}$ & Welded ash-flow tuff & $\begin{array}{l}\text { Typically saturated (perched water) only in the Rainier Mesa } \\
\text { area. This HSU includes only welded Grouse Canyon Tuff and is } \\
\text { limited to the northern portion of the Yucca Flat model area. }\end{array}$ \\
\hline $\begin{array}{l}\text { Belted Range } \\
\text { confining unit } \\
\quad(B R C U)\end{array}$ & Zeolitized bedded tuff & $\begin{array}{l}\text { Generally includes all zeolitized tuffs between the (welded) } \\
\text { Grouse Canyon tuff and the (welded) Tub Spring Tuff. Limited to } \\
\text { the northern Yucca Flat area. }\end{array}$ \\
\hline $\begin{array}{c}\text { pre-Grouse Canyon } \\
\text { Tuff lava-flow aquifer (PRETBG) }\end{array}$ & Lava flow & $\begin{array}{l}\text { Defined to include all the comendite lava flows emplaced before } \\
\text { the Grouse Canyon Tuff but after the Tub Spring Tuff. Limited to } \\
\text { the northern Yucca Flat area. }\end{array}$ \\
\hline $\begin{array}{l}\text { Tub Spring aquifer } \\
\text { (TUBA) }\end{array}$ & Welded ash-flow tuff & $\begin{array}{l}\text { Comprises only the welded Tub Spring Tuff and is thus limited to } \\
\text { the northern Yucca Flat area. }\end{array}$ \\
\hline $\begin{array}{l}\text { pre-Grouse Canyon } \\
\text { Tuff lava-flow } \\
\text { aquifer } 1 \\
\text { (PRETBG1) }\end{array}$ & Lava flow & $\begin{array}{l}\text { Defined to include all the comendite lava flows emplaced before } \\
\text { the Tub Spring Tuff but after the older Tunnel beds. Limited to the } \\
\text { northern Yucca Flat area. Hydrogeologically equivalent to the } \\
\text { PRETBG. }\end{array}$ \\
\hline $\begin{array}{l}\text { Lower } \\
\text { tuff confining unit } \\
\text { (LTCU) }\end{array}$ & $\begin{array}{l}\text { Zeolitized bedded tuff with } \\
\text { interbedded but less significant } \\
\text { zeolitized, nonwelded to partially } \\
\text { welded ash-flow tuff }\end{array}$ & $\begin{array}{l}\text { Generally includes all zeolitized tuff in the Yucca Flat area. } \\
\text { Stratigraphically the LTCU may include all units from the base of } \\
\text { the Rainier Mesa Tuff to the top of the Paleozoic rocks. The } \\
\text { strongly argillized older tuffs and paleocolluvium that immediately } \\
\text { overlie the pre-Tertiary rocks may also be included. The } \\
\text { uppermost zeolitized bedded tuffs overlying the TSA in the } \\
\text { southern Yucca Flat form a separate HSU (the UTCU). } \\
\text { Subdivided in the Yucca Flat basin (see below). }\end{array}$ \\
\hline $\begin{array}{l}\text { Oak Spring Butte } \\
\text { confining unit } \\
\text { (OSBCU) }\end{array}$ & $\begin{array}{l}\text { Devitrified to zeolitic non- to partially } \\
\text { welded tuffs and intervening bedded } \\
\text { tuffs }\end{array}$ & $\begin{array}{l}\text { Includes altered older ash-flow tuff units and Tunnel beds } 1 \text { and } \\
2 \text {. Welding in the older ash flow units may increase overall } \\
\text { hydraulic conductivity. Devitrification of the ash flow units may } \\
\text { have limited zeolitization. Differentiated in the Yucca Flat basin. }\end{array}$ \\
\hline $\begin{array}{l}\text { argilic tuff } \\
\text { confining unit } \\
\quad \text { (ATCU) }\end{array}$ & $\begin{array}{l}\text { Argillic bedded tuff, minor } \\
\text { paleocolluvium }\end{array}$ & $\begin{array}{l}\text { Includes the argillic, lowermost Tertiary volcanic units and } \\
\text { paleocolluvium that immediately overlie the pre-Tertiary rocks. } \\
\text { Differentiated in the Yucca Flat basin. }\end{array}$ \\
\hline $\begin{array}{l}\text { volcaniclastic confining unit } \\
\qquad \text { (VCU) }\end{array}$ & $\begin{array}{l}\text { Sandy gravel, siltstone, and } \\
\text { tuffaceous sandstone }\end{array}$ & $\begin{array}{l}\text { Older Tertiary-age sedimentary rocks of variable lithologies. } \\
\text { Present in the southeastern corner of the Yucca Flat model area, } \\
\text { but is a significant HSU in the Frenchman Flat model area } \\
\text { (Bechtel Nevada, 2005a). Similar to AA in the Yucca Flat model } \\
\text { in the area of overlap. }\end{array}$ \\
\hline
\end{tabular}


Table 2-1. Hydrostratigraphic units of the Yucca Flat-Climax Mine Hydrostratigraphic Framework Model. From Bechtel Nevada (2006) (continued).

\begin{tabular}{|c|c|c|}
\hline Hydrostratigraphic Unit & Typical Lithologies & Hydrologic Significance \\
\hline $\begin{array}{l}\text { Mesozoic granite confining unit } \\
\text { (MGCU) }\end{array}$ & Granodiorite and quartz monzonite & $\begin{array}{l}\text { Includes two intrusives: Climax and Gold Meadows. Based on } \\
\text { observations at the Climax site, the granite has very low } \\
\text { permeability, and is considered to be a confining unit. Locally may } \\
\text { have perched water contained within fractures. The two stocks } \\
\text { may be connected at depth and are the suspected cause of } \\
\text { and/or contributor to a hydrologic barrier at the north end of } \\
\text { Yucca Flat. }\end{array}$ \\
\hline $\begin{array}{l}\text { lower carbonate aquifer - Yucca } \\
\text { Flat upper plate } \\
\text { (LCA3) }\end{array}$ & Limestone and dolomite & $\begin{array}{l}\text { Typically includes the Cambrian through Devonian units that have } \\
\text { been thrust over the Eleana Formation and the Chainman Shale. }\end{array}$ \\
\hline $\begin{array}{l}\text { lower clastic confining unit- } \\
\text { Yucca Flat upper plate } \\
\text { (LCCA1/LCCU2) }\end{array}$ & Quartzite and siltstone & $\begin{array}{l}\text { Includes Proterzoic through lower Cambrian units that have been } \\
\text { thrust over younger units. }\end{array}$ \\
\hline $\begin{array}{l}\text { upper carbonate aquifer } \\
\text { (UCA) }\end{array}$ & Limestone & $\begin{array}{l}\text { Includes the Tippipah Limestone (correlative with the Bird Spring } \\
\text { Formation), which stratigraphically overlies the Chainman Shale } \\
\text { at Syncline Ridge and thus may contain perched water. }\end{array}$ \\
\hline $\begin{array}{l}\text { upper clastic confining unit } \\
\text { (UCCU) }\end{array}$ & Argillite and quartzite & $\begin{array}{l}\text { As much as } 2,745 \mathrm{~m} \text { thick. Typically forms foot walls of Mesozoic } \\
\text { thrust faults in NTS region. Limited areal extent (western Yucca } \\
\text { Flat and portions of CP Basin). }\end{array}$ \\
\hline lower carbonate aquifer (LCA) & Dolomite and limestone & $\begin{array}{l}\text { Important regional aquifer underlying most of southern Nevada. } \\
\text { Composite thickness up to } 4,430 \mathrm{~m} \text {. Transmissivity values differ } \\
\text { greatly and are directly dependent on fracture and fault } \\
\text { frequency. }\end{array}$ \\
\hline $\begin{array}{l}\text { lower clastic confining unit } \\
\text { (LCCU) }\end{array}$ & Quartzite and siltstone & $\begin{array}{l}\text { Significant regional confining unit. Composite thickness about } \\
2,870 \mathrm{~m} \text {. May present barrier to deep regional groundwater flow } \\
\text { where structurally high (e.g., northeastern Yucca Flat). }\end{array}$ \\
\hline
\end{tabular}

Of these 25 HSUs, interbasin groundwater movement is controlled for the most part by the distribution and thickness of the LCA, LCCU, and UCCU. The LCCU is comprised of Precambrian through early Cambrian quartzite, siltstone, shale, and sandstone. These rocks have very low matrix permeability and though generally brittle and fractured, secondary porosity is virtually eliminated by secondary mineralization and plastic deformation of the siltstone and shale layers (Winograd and Thordarson, 1975). The LCCU forms the hydrogeologic basement throughout Yucca Flat as a result of this low transmissivity combined with its low structural position. However, the LCCU also forms a barrier to lateral groundwater flow in areas where it is positioned structurally high, such as the Halfpint Range anticline east of the Climax stock. Deformation associated with the Belted Range and CP thrust faults has also placed LCCU on top of younger LCA and UCCU in local areas west of Yucca Flat. The LCCU components of these thrust plates are called LCCU1 and LCCU2, respectively (Bechtel Nevada, 2006).

Most groundwater flow through Yucca Flat occurs in the LCA, which represents lower Paleozoic limestones and dolomites. The LCA underlies saturated Tertiary volcanic aquifers and confining units below valleys and unsaturated units below ridges. Matrix permeability is very low in the LCA rocks, but they are highly fractured and locally brecciated as a result of structural deformation. On account of its high fracture transmissivity and regional distribution, the LCA forms the principal aquifer system in eastern and southern Nevada (Winograd and Thordarson, 1975). In western Yucca Flat, deformation associated with the CP thrust fault has placed LCA rocks on top of younger UCCU and LCA rocks. Though the subsurface distribution of this unit (LCA3) is limited and not well known, it may contribute to regional groundwater flow in the Climax area (Bechtel Nevada, 2006). 
Above the LCA in the western portion of Yucca Flat, the upper sequence of Paleozoic quartzite, siltstone, argillite, and conglomerate comprises the UCCU. Similar to the rocks of the LCCU, matrix permeability of the UCCU rocks is very low and open fractures tend not to occur at depth as a result of plastic deformation (Winograd and Thordarson, 1975).

Tertiary volcanic rocks form both aquifers and confining units in Yucca Flat (Table 2.1), however they tend to be fully saturated only in the central part of the valley and therefore are generally not related to interbasin groundwater flow.

Regional groundwater flow in the vicinity of the NTS is generally from north to south with a stronger southwest component directed toward Amargosa Valley in the southern portion (Figure 2.3) (IT, 1996b). Regional flow patterns are driven by groundwater recharge at higher elevations to the north and terminal discharge in low-elevation springs and evapotranspiration in Amargosa Valley and Death Valley. Most flow occurs in the regional LCA, with interbasin flow controlled by the arrangement of LCA with respect to LCCU and UCCU (Winograd and Thordarson, 1975).

Though some details of groundwater flow into the Yucca Flat basin remain uncertain, the work of Winograd and Thordarson (1975) and Laczniak et al. (1996) provides the most complete conceptualization of the hydrogeologic framework and the one upon which most subsequent interpretations have been based. In this model, the trough in the potentiometric surface that runs parallel with the longitudinal axis of the basin (Figure 2.3) is interpreted to reflect the large contrast in transmissivity between the LCA that underlies much of the basin and the LCCU and UCCU that predominate along its margins. The very low hydraulic gradient in the center of Yucca Flat is associated with the moderately transmissive LCA conducting the relatively small volume of groundwater that moves through the basin, 350 acre-ft/yr of inflow as calculated by Winograd and Thordarson (1975). Recharge within the basin is considered to be minimal.

High hydraulic gradients surrounding the trough along the margins of Yucca Flat, and the small amount of interbasin flow, are associated with barriers to inflow from adjacent basins. To the west, the Carpetbag/Topgallant fault zone and the CP thrust fault juxtapose thick UCCU on the west against LCA, restricting groundwater inflow from that direction. Though carbonate rocks are present at great depth below a portion of the UCCU west of Yucca Flat, flow through them is likely to be limited because they are bounded further west by low-permeability volcanic rocks. On the northeast, the LCA is above the water table and removed by erosion above the structurally high LCCU in the Halfpint Range anticline, thus flow from the east must pass through the very low-permeability LCCU.

The western and eastern barriers converge at the extreme northern end of Yucca Flat in the area of the Climax stock. The high hydraulic gradient through this area is thought to reflect another barrier to groundwater flow, namely the Climax stock granitic intrusion, but the LCA is also known to be present surrounding the intrusion. Regional flow from the north enters Yucca Flat via the LCA in the vicinity of the Climax stock, though this flowpath is constricted by the convergence of the thick clastic confining units. Figure 2.4 shows a west-east hydrogeologic cross section through northern Yucca Flat (Bechtel Nevada, 2006) and the configuration of the lateral boundaries to flow described above. Note that a thick section of LCA is shown west of the Climax granite outcrop; however, LCA thickness adjacent to the Climax stock appears to be highly variable depending on the nature of the faults in the area and the juxtaposition of units across them. In addition, unit thicknesses are 
uncertain in this area as a result of limited deep well control. The large change in hydraulic head evident between western Emigrant Valley, the next basin to the north, and northern Yucca Flat (an approximate 600-m decline) may be attributed to the higher elevation of the LCA in western Emigrant Valley and the barrier to flow created by the structurally high LCCU (Winograd and Thordarson, 1975). Thus, the high hydraulic gradients observed in the north-south direction across the Climax stock may originate from reduced cross-sectional area of the LCA, a change in aquifer elevation, barrier effects or, most likely, some combination of these factors.

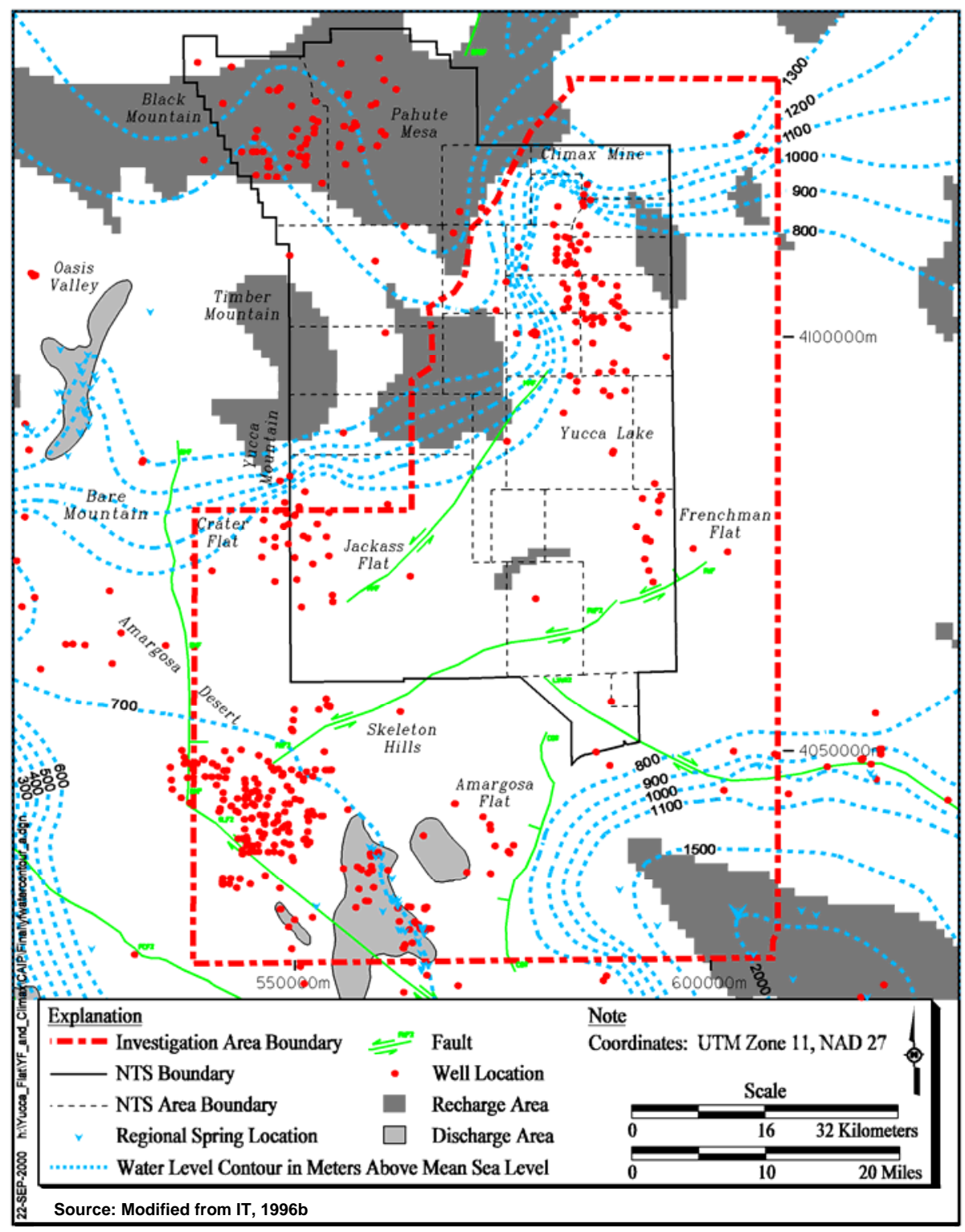

Figure 2-3. Contour map of composite predevelopment water levels for the Yucca Flat-Climax Mine CAU investigation area. From DOE (2000b). 

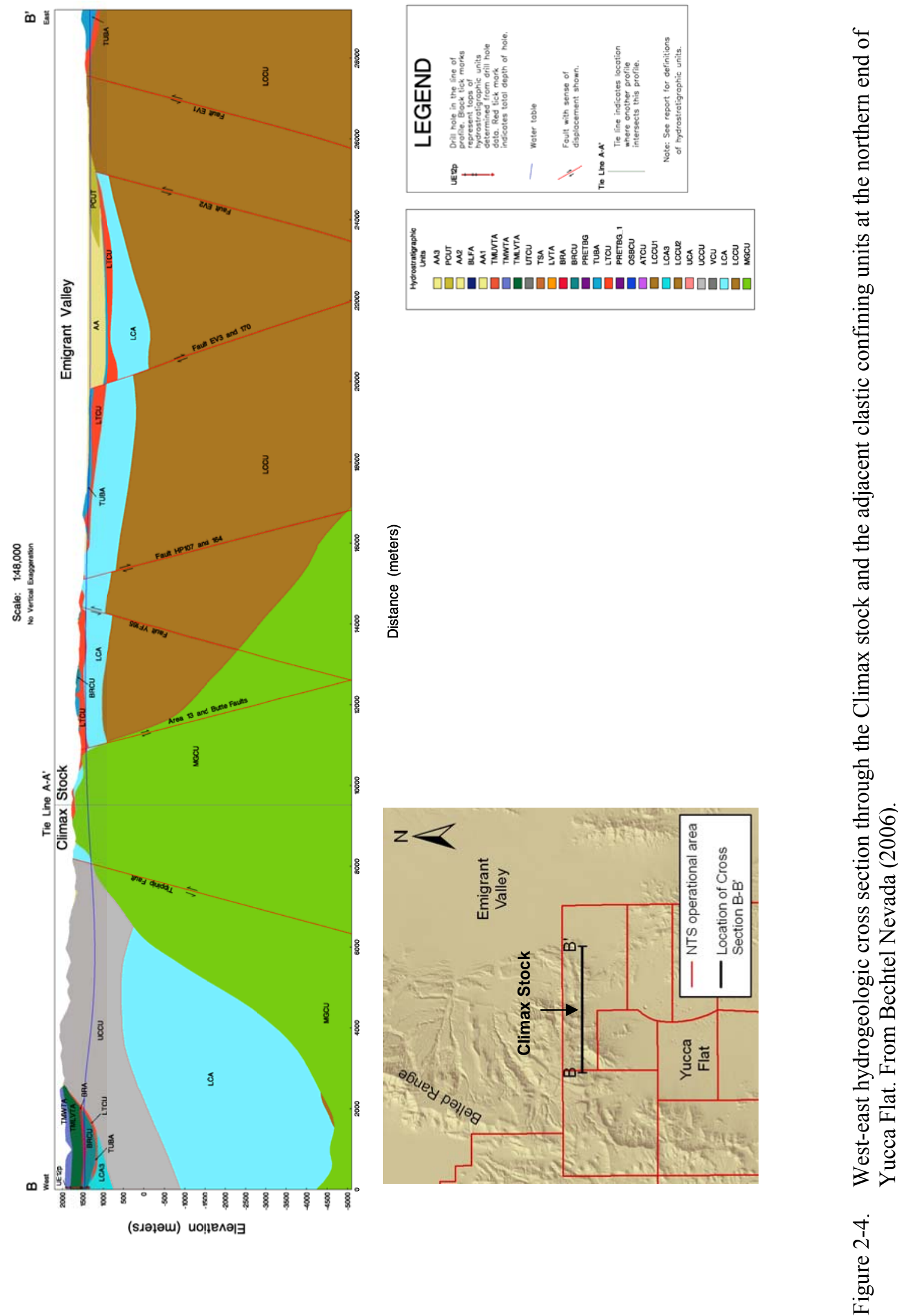


\subsection{Hydrochemistry}

The existing geochemical and isotopic data are too sparse to support conclusions regarding groundwater flow from the north into regional aquifers of Yucca Flat. General observations are presented below, whereas more detail regarding chemical analyses from samples of seeps in Climax granite is presented in Section 5.

The significant mineralogic differences between the regional aquifers in carbonate and volcanic rock lead to readily observed differences in groundwater chemistry. Typically, groundwater from regional carbonate aquifers in southern Nevada is characterized as belonging to the calcium-magnesium bicarbonate facies. Groundwater in volcanic aquifers, and alluvial aquifers comprised of volcanic rocks, is often of the sodium-potassium bicarbonate facies.

It has long been noted that groundwater in the LCA beneath the NTS and Ash Meadows differs significantly from water in the LCA elsewhere in the Death Valley Flow System (Winograd and Thordarson, 1975). The principal difference is in higher amounts of sodium plus potassium and sulfate plus chloride, in the NTS carbonate aquifer. Winograd and Thordarson (1975) primarily attribute the increase to downward leakage of sodium- and sulfate-rich water from the tuff confining unit. They also observe that oxidation of sulfide minerals such as pyrite from granitic stocks might serve as a source of sulfate. They point out that groundwater in Climax stock is high in sulfate, and pyrite is common along fractures in the rock, but note that the influence may be local.

Geochemical and isotopic evaluation of groundwater movement in the Yucca FlatClimax Mine CAU was recently conducted to identify potential flowpaths into and through Yucca Flat (Farnham et al., 2006). In regard to groundwater flow into northern Yucca Flat, the authors observe severe limitations in terms of data for upgradient wells and springs. In particular, the nearest LCA sampling location north of Yucca Flat is in Pahranagat Valley, more than $80 \mathrm{~km}$ away, and possibly on a different flowpath. Downgradient of Climax, the closest LCA well is UE-10j, which accesses the aquifer at three different depths (zone 1 being deepest, zone 3 the shallowest). Farnham et al. (2006) do not speculate regarding the origin of the water sampled at the deepest interval (UE-10j-1) due to the absence of upgradient data, though they are able to demonstrate that groundwater at the shallowest sampling horizon (UE-10j-3) can be derived by mixing of UE-10j-1 with local recharge.

Farnham et al. (2006) also evaluated the origin of the groundwater chemistry encountered at UE-15d water well. They suggested that the water observed at UE-15d was derived by mixing of various combinations of water from Emigrant Valley, local springs, UE-10j, ER-12-2, and seeps from Climax. They conclude that the high $\mathrm{Ca}$ and $\mathrm{SO}_{4}$ concentrations observed in Climax seeps preclude more than one or two percent of Climax water contributing to groundwater at UE-15d. The significance of this observation is unclear; UE-15d is completed within the LCCU, possibly in the Johnnie Formation, stratigraphically well below regionally important aquifers and thus the well is not completed to sample regional flow.

The nature of the few groundwater samples from Climax is also in question. As discussed in more detail in Section 5, no wells are completed within Climax stock that provide representative groundwater chemistry. Four seeps into underground tunnels and shafts, and one boring slant drilled into the floor of a drift, provide the Climax water samples. 
It is unclear if the slant borehole encounters the saturated zone, or is perched, but the other samples represent infiltration of recharge into the granite stock, rather than regional groundwater flowing laterally. Comparison of the slant-hole sample with the seeps indicates that conditions become more reducing with depth, such that the water chemistry in the regionally saturated zone may be radically different than that observed from the Climax tunnels and shafts. In the absence of chemical and isotopic data from regional groundwater within and upgradient of Climax stock, hydrochemistry places no constraints on possible flowpaths into the saturated zone of northern Yucca Flat.

\subsection{Nuclear Tests and Other Subsurface Studies at Climax}

Figure 2-5 is a plan view of the two shafts used to locate the Tiny Tot, Pile Driver, and Hard Hat tests (Pile Driver and Hard Hat were accessed from drifts off of the same vertical shafts). Details regarding the location, behavior, pre-test, and post-test conditions of each test are described below. Data regarding the tests are summarized in Table 2-2.

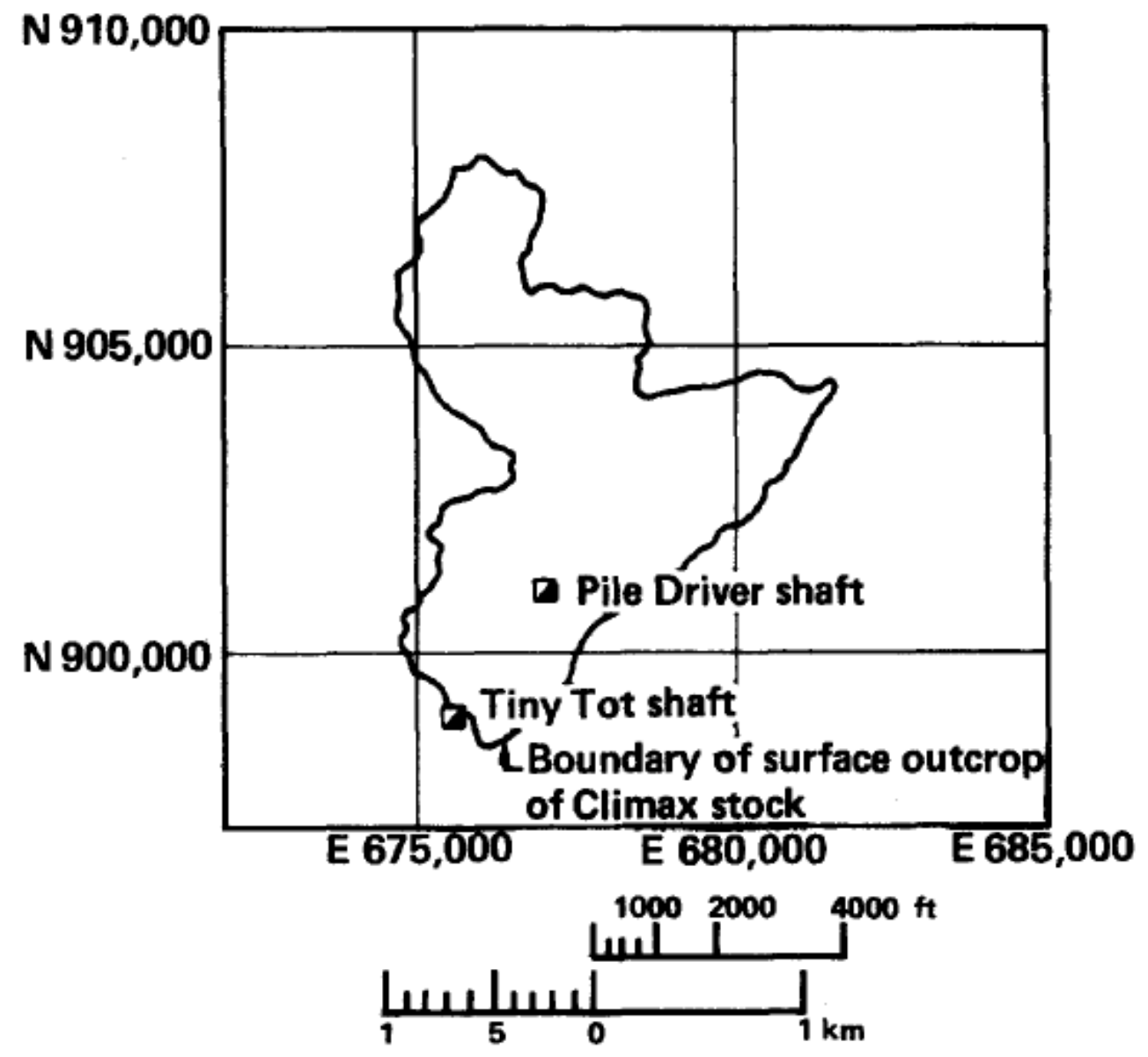

Figure 2-5. Location of Tiny Tot and Pile Driver/Hard Hat shafts. Coordinates are Nevada Coordinate System in feet. From Murray (1981). 
Table 2-2. Location and nuclear-test-related data for Hard Hat, Tiny Tot, and Pile Driver.

\begin{tabular}{|c|c|c|c|}
\hline & Hard Hat & Tiny Tot & Pile Driver \\
\hline Date $^{1}$ & February 15, 1962 & June 17,1965 & June 2, 1966 \\
\hline Emplacement hole & $\mathrm{U} 15 \mathrm{a}$ & $\mathrm{U} 15 \mathrm{e}$ & U15a-01 \\
\hline Latitude $^{1}$ & 37.226 & 37.223 & 37.227 \\
\hline Longtitude $^{1}$ & -116.06 & -116.058 & -116.056 \\
\hline Northing coordinate (m) & $4,120,153$ & $4,199,822$ & $4,120,268$ \\
\hline Easting coordinate (m) & 583,392 & 583,573 & 583,746 \\
\hline Land elevation $^{2}(\mathrm{~m})$ & 1,559 & 1,522 & 1,551 \\
\hline Depth of burial $^{2}(\mathrm{~m})$ & 287.4 & 111 & 463 \\
\hline Elevation of burial (m) & 1,272 & 1,411 & 1,088 \\
\hline \multicolumn{4}{|l|}{ Elevation of water table (m) } \\
\hline Pickus, 1997 & 1,337 & 1,294 & 1,366 \\
\hline DVRM & 1,050 & 955 & 1,114 \\
\hline Test yield $^{1}(\mathrm{kt})$ & 5.7 & $<20$ & 62 \\
\hline Cavity radius ${ }^{3}(\mathrm{~m})$ & 19.2 & $26.3^{*}$ & 44.5 \\
\hline $\begin{array}{l}\text { Shock fracturing distance }{ }^{4} \\
\text { (cavity radii) }\end{array}$ & $2.9 \pm 0.4$ & $2.8^{*}$ & $2.7 \pm 0.2$ \\
\hline
\end{tabular}

*estimate from Hard Hat and Pile Driver

Sources: ${ }^{1}$ (DOE, 2000); ${ }^{2}$ (Pickus, 1997): ${ }^{3}$ Hard Hat (McArthur, 1962), Pile Driver (Boardman, 1967); ${ }^{4}$ Borg (1971)

\subsubsection{Hard Hat}

The Hard Hat test was conducted on February 15, 1962, in U15a at a latitude of 37.226 degrees and longitude of 116.06 degrees and an announced yield of $5.7 \mathrm{kt}$ (DOE, 2000). The surface elevation at that location is $1,532 \mathrm{~m}$ (DOE, 2000). Pickus (1997) reports a surface elevation of $1,559 \mathrm{~m}$ and a device depth of burial of $287.4 \mathrm{~m}$. He also reports a water table depth of $222 \mathrm{~m}$ (1,337 m elevation). This is likely to be a perched water zone and not representative of the regional water table depth, which is reported to be at elevations of about 1,100 to $1,200 \mathrm{~m}$ to the northeast of the stock and 800 to $900 \mathrm{~m}$ to the southwest (Murray, 1981). Though the limited data indicate that Hard Hat was detonated in the unsaturated zone, according to convention in the UGTA project, it is considered a saturated-zone test because Hard Hat was conducted within $100 \mathrm{~m}$ of the water table (DOE, 2000a) and the Pickus (1997) water table was used for reference.

In addition to the emplacement hole (U15a), pretest underground workings included a vertical shaft and one main tunnel that reached to within 54.9 m horizontally and $27.1 \mathrm{~m}$ vertically of the working point. The underground workings also included a number of drifts normal to the main tunnel (Figures 2-6 through 2-8). 

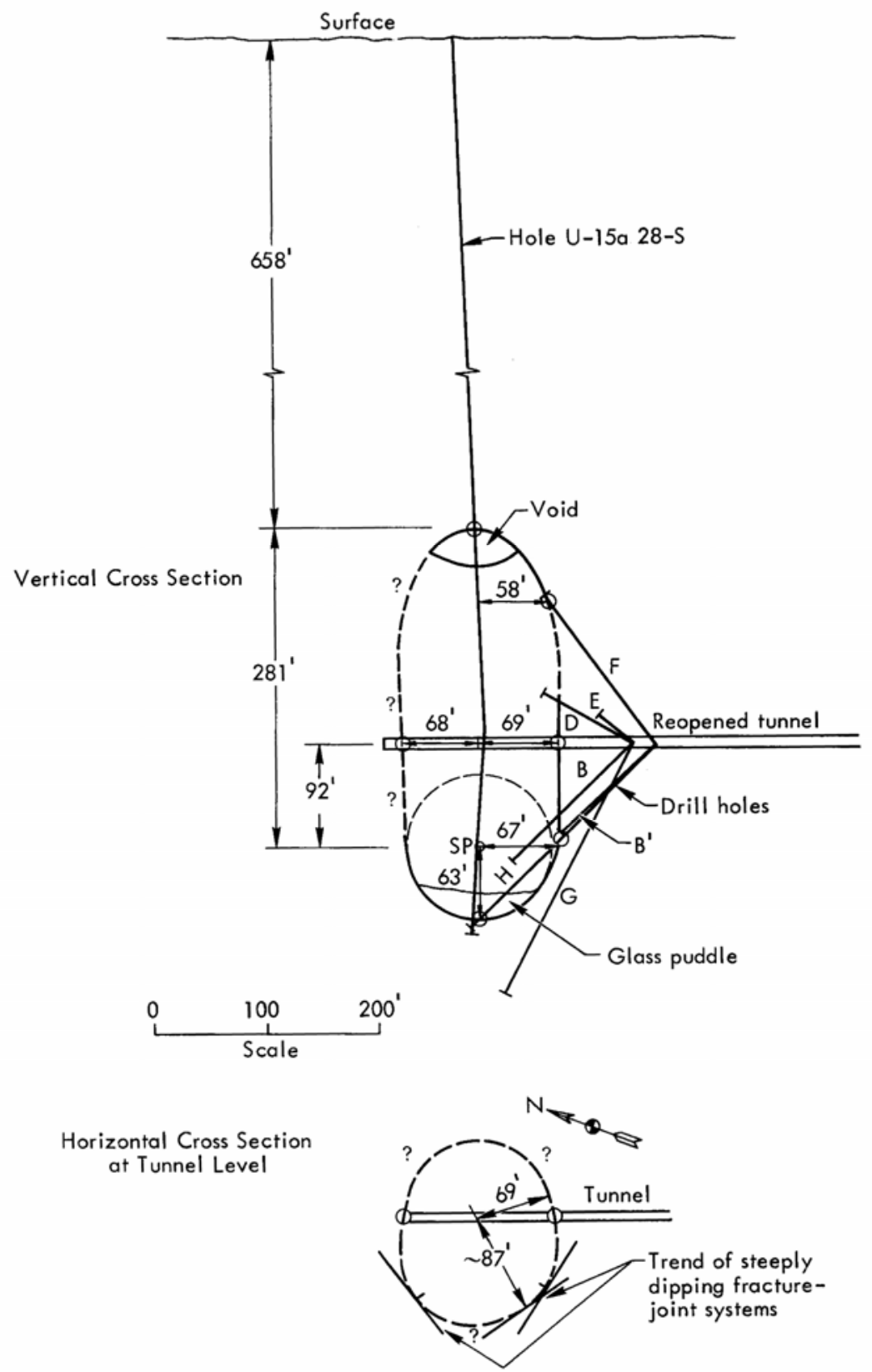

Figure 2-6. Diagram of Hard Hat near field and post-test drilling operations. From Borg (1970). 


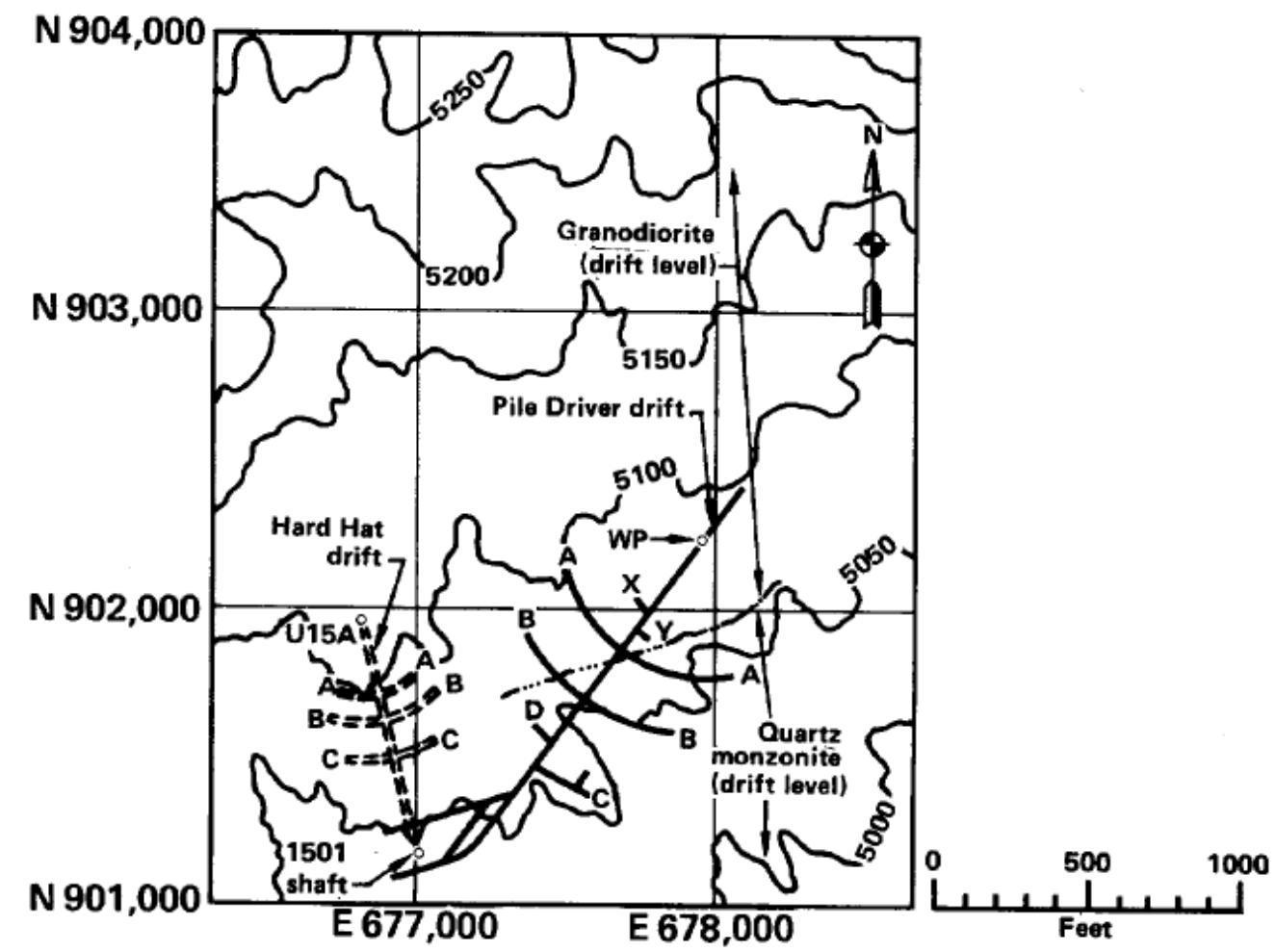

Figure 2-7. Map view of Hard Hat and Pile Driver pretest drifts. Coordinates are Nevada Coordinate System in feet. From Murray (1981).

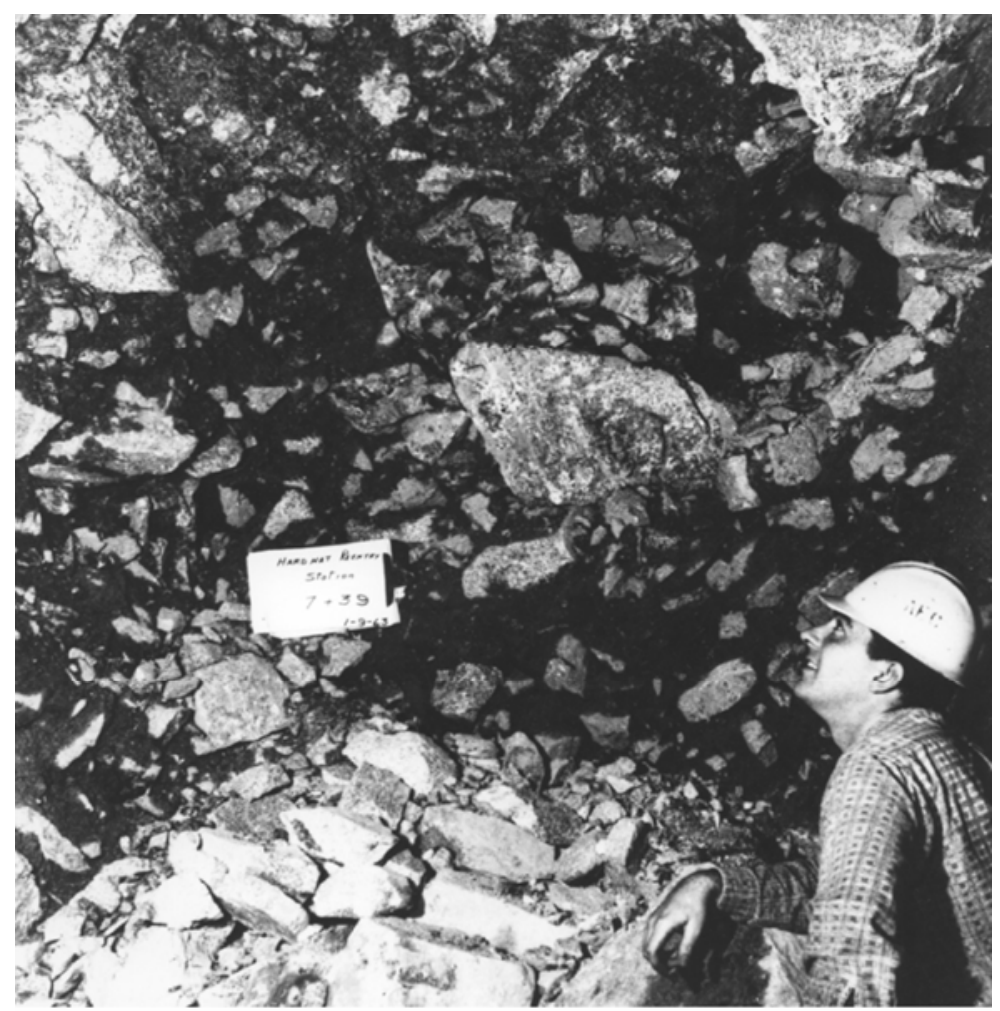

Figure 2-8. Reentry drift at the Hard Hat chimney edge. 


\subsubsection{Pretest Geology}

The Hard Hat test was emplaced in the Climax stock. The stock varies from a quartz monzonite to a granodiorite; the Hard Hat test took place within the granodiorite (McArthur, 1963). Prominent joint sets were reported to be of three orientations:

- A strong northwest-trending set, near vertical,

- A northeast-trending set, near vertical, and

- A northwest-trending set, which dips 20 to 35 degrees northeast.

The low angle set was typically well-cemented. Zones of near-vertical sheeting (jointing produced by pressure release) and shearing were common, with typical thicknesses of 1.5 to $3 \mathrm{~m}$ occurring every 15.2 to $30.5 \mathrm{~m}$.

\subsubsection{Post-test Observations}

Approximately one hour after the detonation, a low level of radioactivity was detected near ground zero. At approximately 11 hours, the test-induced underground cavity began to collapse. Following the cavity collapse, a strong sulfurous odor was detected and a surface fissure above the test point produced approximately $20 \mathrm{ppm} \mathrm{CO}$ gas. Gas and radiation levels at the surface dropped to background within two days (McArthur, 1963).

In the main access shaft, displacements as large as a few inches were observed. In the main tunnel, the floor had been lifted up to $1.8 \mathrm{~m}$. At $128 \mathrm{~m}$ (6.7 cavity radii) from the working point, complete tunnel blockage was observed. Shock fracturing was observed out to $158.5 \mathrm{~m}$ (8.25 cavity radii). At approximately 6 cavity radii, wall rock fracturing steadily increased with the approach toward the working point.

As part of post-test operations, the original tunnel was re-opened and extended into the chimney. A post-test drillback (U15a PS or U15a 28s) was also completed. Test fractures were evident in the extended tunnel and significant movement along a near-vertical shear zone was observed. At $6.4 \mathrm{~m}$ from the chimney edge, the intensity of shock fractures increased and vertical sheers parallel to the chimney occurred at 0.9- to 1.2-m intervals. Within the chimney, rock was severely damaged and was not competent (Figure 2-9).

The combined cavity-collapse chimney was $106 \mathrm{~m}$ high and 43 to $35.4 \mathrm{~m}$ in diameter. The cavity radius was estimated at $19.2 \mathrm{~m}$. A 10 -m void existed at the top of the chimney (McArthur, 1962). Based on volume calculations, it is estimated that 27 percent of the chimney is void space. If the void at the top of the chimney is excluded, the chimney void space is reduced to 22 percent (Boardman, 1966). Beyond the lower hemisphere of the cavity, a zone of extreme alteration $(>4.6 \mathrm{~m}$ ) was observed in which quartz and feldspar were minutely fractured so as to appear chalky. Bulk densities in this zone decreased from 2.67 to $2.36 \mathrm{~g} / \mathrm{cm}^{3}$, resulting in a porosity of 11 percent (Boardman, 1966).

A zone of puddle glass was found at the bottom of the cavity that was $7.6 \mathrm{~m}$ thick. Above the glass zone, the rubblized granite was composed of 10 percent 12- to 24-in rocks, 40 percent 6- to 12-in rocks, and 50 percent of rocks less than 6 in in diameter (McArthur, 1963). A significant fraction of the material appeared to be sand-sized. 

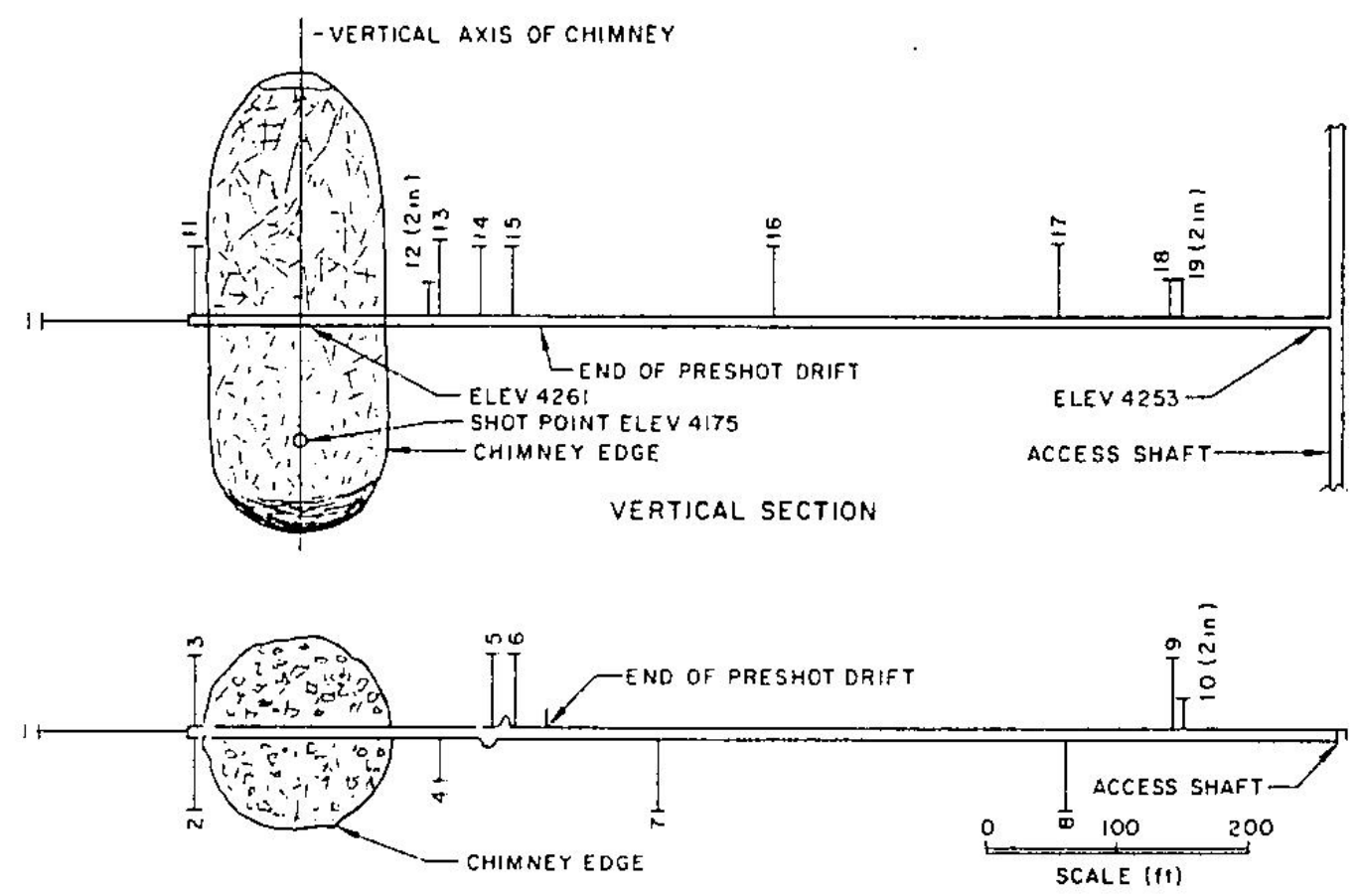

PLAN VIEW
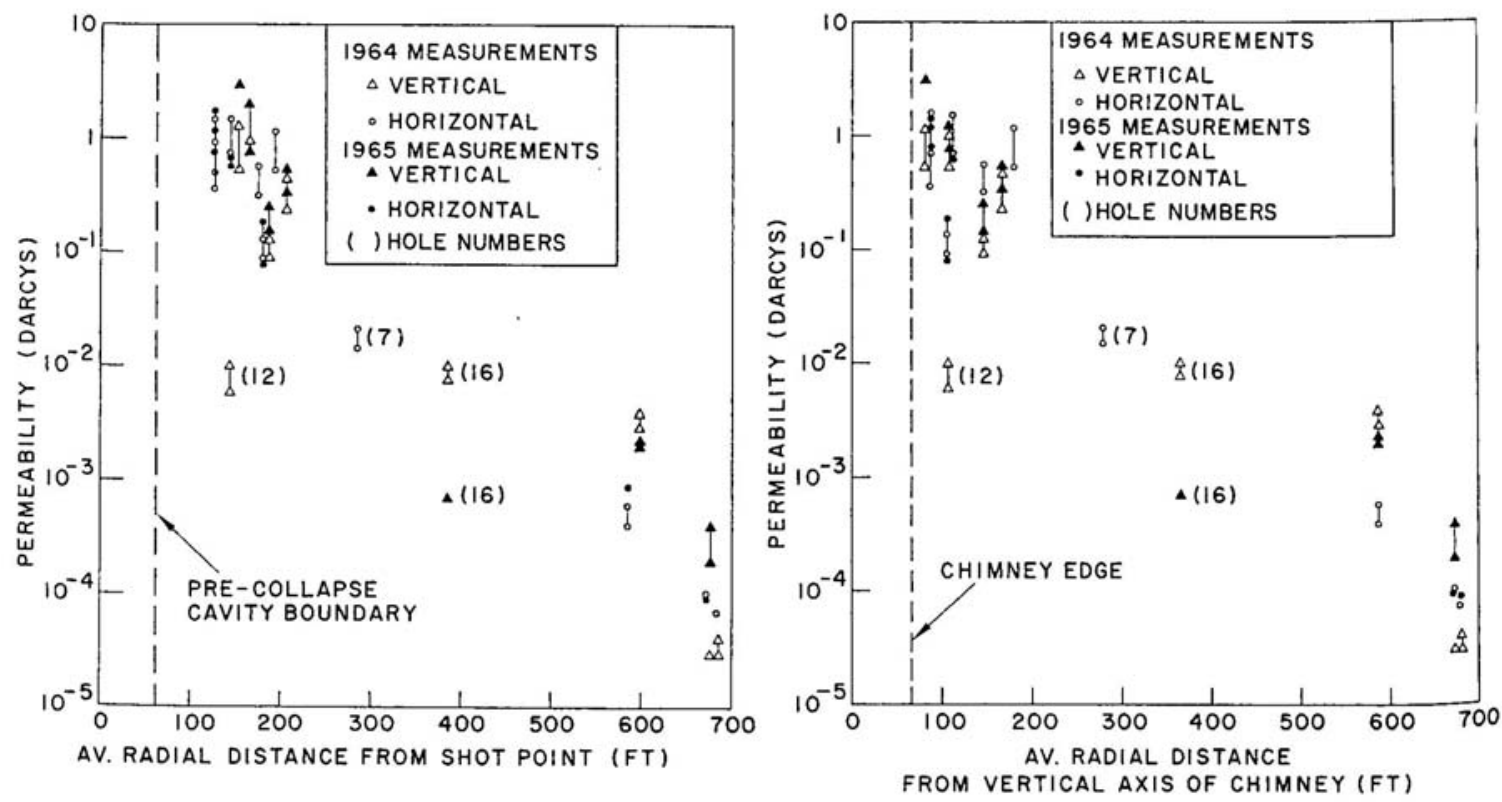

Figure 2-9. Figures from Boardman and Skrove (1966), which indicate the location and measured permeability or rocks in the vicinity of the Hard Hat test. 
Fluid losses during drilling occurred at $147 \mathrm{~m}$ above the detonation point. This is equivalent to 7.7 cavity radii and is consistent with observations of shock fractures out to $158 \mathrm{~m}, 8.25$ cavity radii (McArthur, 1963).

In summer 1964, nearly 1.5 years after the Hard Hat test, three holes were continuously cored from the original exploratory tunnel and into or close to the cavity/chimney (Boardman, 1966). For the two holes that entered the cavity/chimney, loss of drilling fluid circulation occurred only when drilling reached to within a few meters of the cavity/chimney. For the hole that was drilled through the cavity edge and past the glass zone, rock out to $4 \mathrm{~m}$ beyond the cavity had a chalky appearance and was friable. Similar chalky appearance was observed up to $7 \mathrm{~m}$ beyond the cavity edge in the third hole, which was meant to approach but not reach the cavity boundary. The "crush zone" porosity was estimated to be 11 percent based on bulk density measurements. The permeability of small core samples from this zone was measured to be 7 to 15 millidarcys (Boardman, 1966) $\left(5.8 \times 10^{-3}\right.$ to $\left.1.3 \times 10^{-2} \mathrm{~m} / \mathrm{d}\right)$. However, fracture permeability is said to be much higher. Permeability of native rock is on the order of 0.01 millidarcy (Mehta et al., 1964) $\left(8.4 \times 10^{-6} \mathrm{~m} / \mathrm{d}\right)$. Cavity/chimney pressurization measurements suggested that wall rock permeabilities are on the order of 1,200 to 1,400 millidarcys (Boardman, 1965) (approximately $1 \mathrm{~m} / \mathrm{d}$ ). More direct measurements of rock permeability near the cavity/chimney were reported to be 200 to 2,000 millidarcys $(0.2$ to $1.7 \mathrm{~m} / \mathrm{d})$ and decaying exponentially to below 1 millidarcy with distance from the working point (Figure 2-9) (Boardman and Skrove, 1966). Interestingly, experimentally shocked granite samples could produce permeabilities as high as 0.5 millidarcy $(4.2 \times 10 \mathrm{e}-4 \mathrm{~m} / \mathrm{d})($ compared to native rock permeabilities lower than $10^{-6}$ millidarcy). However, permeabilities as high as those measured in the field were never replicated in the laboratory (Quong, 1969). It is apparent that field-scale permeabilities are likely driven by large-scale fracture flow phenomena that cannot be captured with small laboratory measurements. A summary of various permeability measurements is presented in Figure 2-10.

Hard Hat cores were evaluated during investigations of the Pile Driver test (Borg, 1971). The limit of intense fracturing from Hard Hat was determined to be $1.3 \pm 0.2$ cavity radii, with detectable microfracturing observed to a distance of $2.9 \pm 0.4$ cavity radii.

Interestingly, melt glass was found as far as $23.8 \mathrm{~m}$ from the working point (1.2 cavity radii) and is likely the result of a prompt injection. Similar injection phenomena were observed in the Pile Driver test. Importantly, the Hard Hat cavity did not collapse until 11 hours after detonation. As a result, sufficient time was available for much of the nuclear melt glass to flow and pool at the bottom of the cavity and begin to solidify. This led to an unusually high fraction of glass in the glass puddle ( 73 percent by volume). Cavities that collapse quickly typically have glass fractions of 20 to 30 percent in the glass puddle due to the incorporation of infallen rock (Boardman, 1966). 


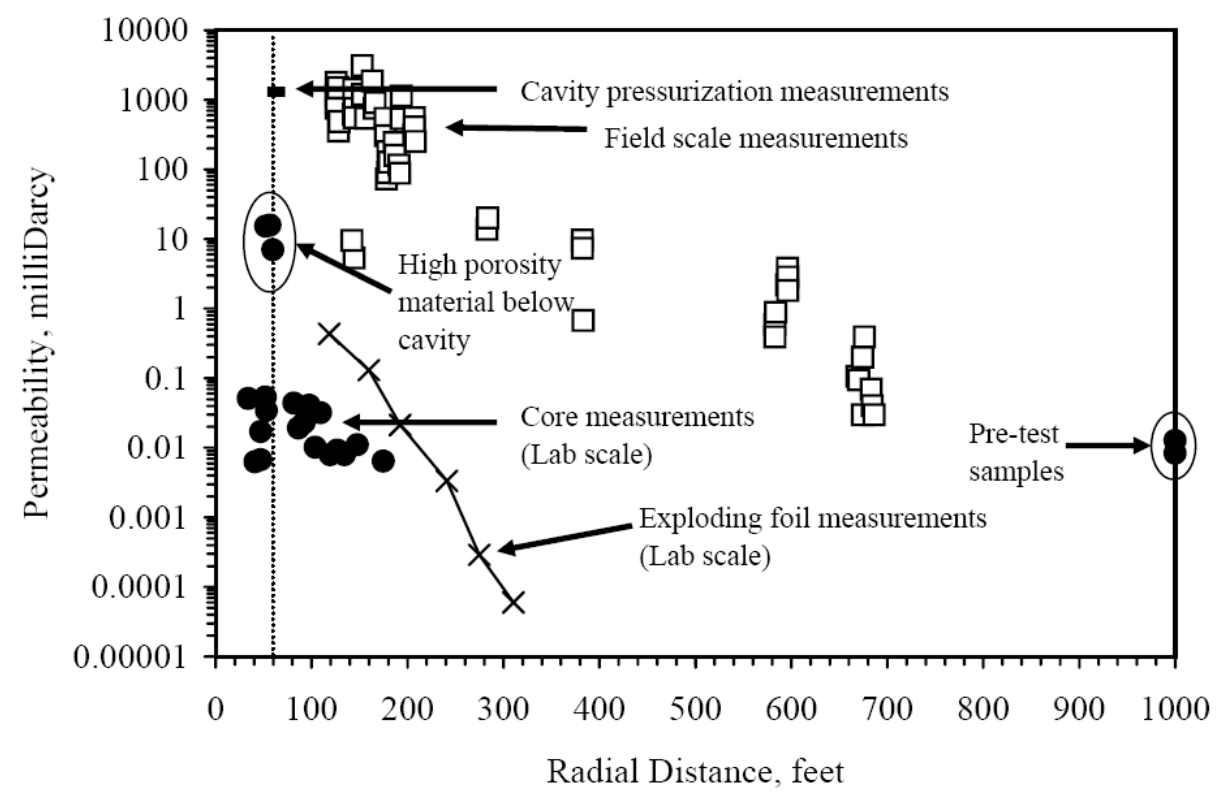

Figure 2-10. Summary of permeability measurements reported in Quong (1979), Boardman and Skrove (1966), Short (1964), Mehta et al. (1964), and Boardman (1965).

\section{$\underline{2.4 .2}$ Tiny Tot}

The Tiny Tot test was conducted on June 17, 1965, in U15e at a latitude of 37.223 degrees and longitude of 116.058 degrees and an announced yield of less than $20 \mathrm{kt}$ (DOE, 2000). Some radioactivity was released and detected on the NTS. The surface elevation at that location is not reported in DOE (2000a) but was reported in Pickus (1997) to be 1,522 m. Pickus (1997) reports a depth of burial of $111 \mathrm{~m}$. He also reports a water table depth of $228 \mathrm{~m}$ (1,294 $\mathrm{m}$ elevation). This is likely to be a perched water zone and not representative of the regional water table depth.

Tiny Tot is classified as a test conducted in the unsaturated zone, according to UGTA convention, because it was located more than $100 \mathrm{~m}$ above the water table (DOE, 2000a). Very little information is available regarding this test when compared to the Hard Hat and Pile Driver tests. As such, near-field distribution and transport behavior need to be extrapolated from the other two granite tests conducted at the NTS. In particular, the cavity radius is estimated here by fitting an exponential relationship to the announced yields and cavity sizes of Hard Hat and Pile Driver. Using the upper end of the Tiny Tot announced yield (less than $20 \mathrm{kt}$ ) leads to an estimated cavity radius of $26.3 \mathrm{~m}$. Similarly, the radial distance of shock fractures is estimated to be 2.8 cavity radii.

\section{$\underline{2.4 .3 \quad \text { Pile Driver }}$}

The Pile Driver test was conducted on June 2, 1966, in U15a.01 at a latitude of 37.227 degrees and longitude of 116.056 degrees and an announced yield of $62 \mathrm{kt}$ (DOE, 2000). Some radioactivity was released and detected on the NTS. The surface elevation at that location is reported in DOE (2000a) as 1,525 m; it is reported in Pickus (1997) to be $1,551 \mathrm{~m}$. Pickus (1997) reports a depth of burial of $463 \mathrm{~m}$ and a water table depth of $185 \mathrm{~m}$ (1,366 m elevation). However, this is likely to be perched water and not the regional water 
level. Pile Driver is considered a saturated-zone test according to UGTA convention, and is likely to be located below the water table.

A number of drillback operations were conducted in the years following the Pile Driver test. These are shown in Figure 2-11. From July 21 to August 2, 1966, a chimney exploration program was conducted (Boardman, 1967). Hole U15.01 PS\#1V was drilled into the top of the Pile Driver chimney (Figure 2-11). The top of the chimney was found to be at $277.3 \mathrm{~m}$ from the working point. Based on air pressurization experiments, it was found that the void volume in the chimney was $367,900 \pm 20,000 \mathrm{~m}^{3}$. This is equivalent to an open cavity radius of $44.5 \pm 1 \mathrm{~m}$ and a chimney void porosity of 19 percent. Permeability measurements above the chimney suggest that increased permeabilities extend out to $7.1 \pm 0.2$ cavity radii and approach 1 Darcy. The permeability of the chimney wall rock was found to be $1.5 \pm 0.3$ Darcys.

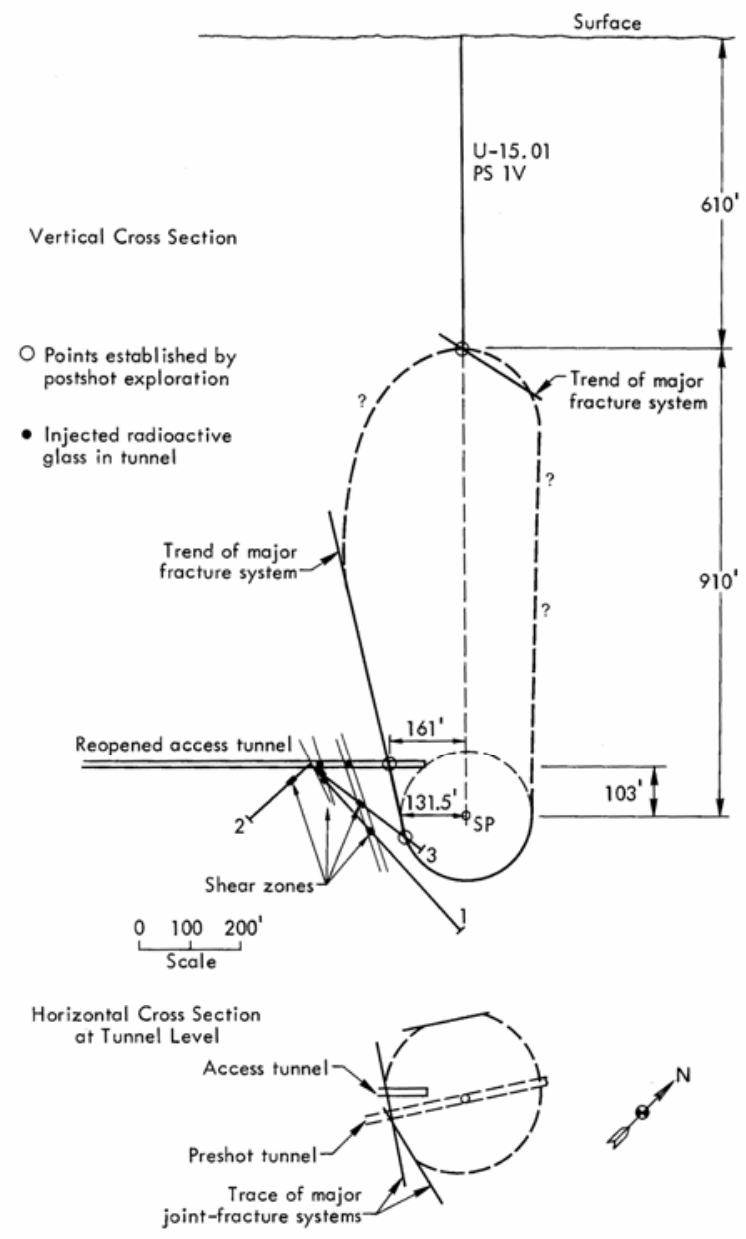

Figure 2-11. Diagram of Pile Driver near field and post-test drilling operations. From Borg (1970). 
In September/October 1967, a drift was extended into the chimney of the Pile Driver test from the emplacement drift (Raab, 1968). This drift extended 67 feet into the chimney. The chimney edge was clearly discernible (Figure 2-12) with relatively solid rock outside the chimney and highly rubblized material within it. Results of particle sieving indicated that about 40 percent of the chimney rubble is greater that 6 inches $(>0.15 \mathrm{~m})$ and 20 percent is less than 1 inch $(<0.025 \mathrm{~m})$. Interestingly, radioactivity measurements found that radioactivity correlated with particle surface area, with most of the radioactivity found in the smaller particle size fractions.

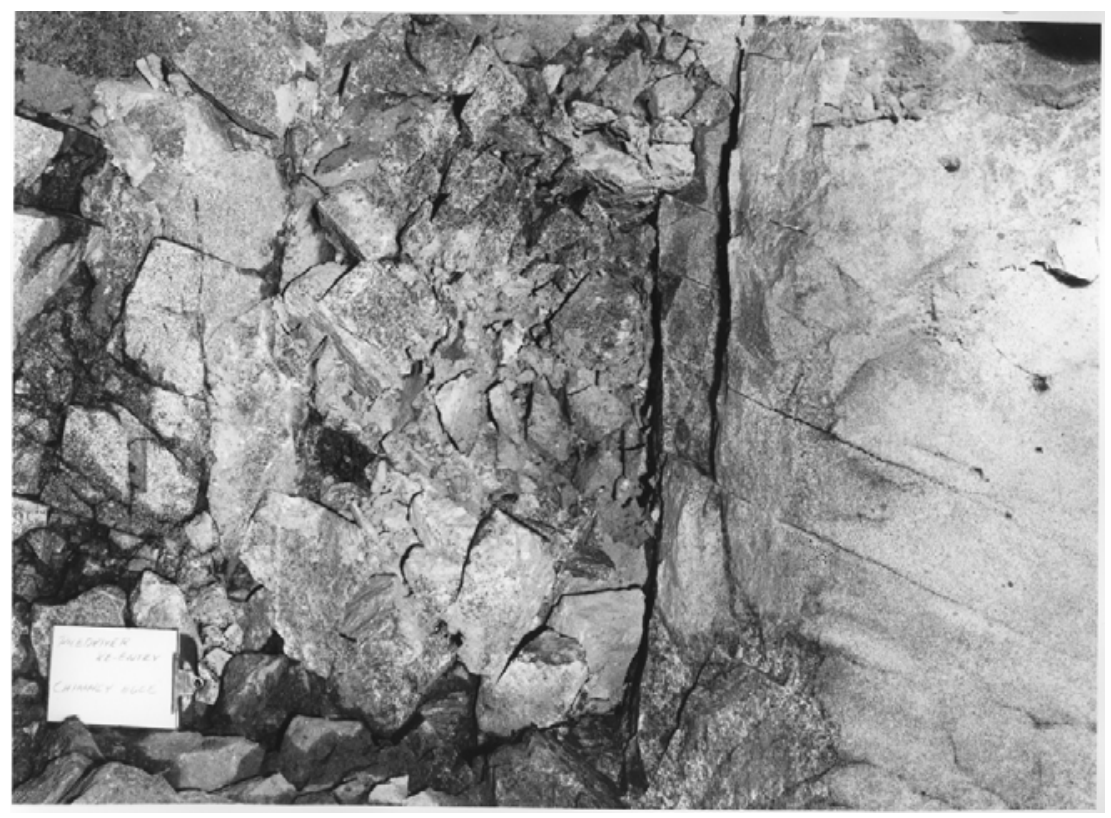

Figure 2-12. Pile Driver chimney edge.

In June to August 1969, three holes were drilled into the lower part of the Pile Driver cavity and below the access drift (Sterrett, 1969). Distribution of radioactive material was very heterogeneous near the cavity. In one drilling operation, drilling fluid circulation was lost at 1.5 cavity radii. In another drilling operation, fluid circulation was never lost even though drilling was as close as 1.2 cavity radii from the working point. Seams of glass were encountered outside the cavity sporadically during these drilling operations. Thin section examination of core samples from these hole identified radial distances of intense to low testinduced microfracturing (Borg, 1971). These results were compared with an analysis of Hard Hat core material. Pile Driver and Hard Hat limits of intense fracturing were $1.3 \pm 0.1$ and $1.3 \pm 0.2$ cavity radii, respectively. Detectable microfracturing was observed out to $2.7 \pm 0.2$ and $2.9 \pm 0.4$ cavity radii, respectively. Field-scale permeability measurement at Hard Hat indicated that test-induced high permeabilities ( $>0.1$ Darcy) were observed at these distances as well. Interestingly, the observed distance for intense and detectable fracturing in granite from French tests conducted in Algeria showed similar behavior (Borg, 1973). 


\subsubsection{Spent Fuel Test Facility}

In the late 1970s, the Climax stock was chosen as the site for experiments to demonstrate the feasibility of handling and short-term storage of spent nuclear reactor fuel assemblies in granite host rock at a depth representative of a permanent repository as part of a DOE program to evaluate the feasibility of retrievable, deep geologic storage of commercial nuclear reactor wastes (Patrick, 1986). The Spent Fuel Test-Climax facility was constructed in newly mined drifts extending northwest off the existing Pile Driver workings between 1978 and 1980 at a depth of $420 \mathrm{~m}$ below ground surface. Spent fuel canisters were emplaced in the facility in 1980 and removed in 1983, after which post-test data collection continued until 1985. Prior to emplacement in the facility, the spent-fuel assemblies were encapsulated in sealed stainless steel containers to prevent release of radioactive materials to the environment. No significant radiation exposure was reported during emplacement, testing, or retrieval operations (Patrick, 1986), and the SFT-C is not considered to be a source for radionuclide migration in the Climax stock.

The technical objectives of the SFT-C experiments involved extensive data collection and modeling of heat transfer, rock mechanical response, and radiation transport processes to address impacts of heat and radiation on canister materials and the near-field geologic environment (Patrick, 1986). Comprehensive site characterization and geologic investigations were undertaken to support these experiments, including mapping of locations and orientations of joints, faults, and shear zones; analysis of the hydrology of the granite stock; measurements of in situ state of stress; measurements of rock physical properties; and analysis of rock mineralogy and petrology. Some of these data are used in the current study and will be discussed in detail in the sections of this report describing the models of groundwater flow and radionuclide transport in the Climax stock.

\subsection{Overview of the Death Valley Regional Flow System Model}

The Death Valley Regional Flow System (DVRFS) model developed by the U.S. Geological Survey provides the framework for simulating groundwater flow in the region surrounding the Climax stock, evaluating conceptual model uncertainty, and providing groundwater heads and fluxes to the local-scale Climax stock granite flow model. The DVRFS model was developed for DOE to support investigations at the NTS and the proposed Yucca Mountain high-level nuclear waste repository (Belcher, 2004). This model is being adopted by the UGTA program to provide supporting regional hydrologic information to CAU-scale flow models though the CAU flow models for Frenchman Flat (SNJV, 2006a) and Pahute Mesa (SNJV, 2006b) utilize regional information from the earlier UGTA regional flow model (DOE, 1997) since their development began prior to the publication of the DVRFS model in September 2004. The DVRFS and UGTA regional models cover similar areas, but the DVRFS model extends further west and south so that it encompasses all of Death Valley and Pahrump Valley (Figure 2-13). Though the DVRFS model differs from the earlier UGTA regional model, it benefits from incorporation of the most recent conceptualizations of the regional hydrogeologic system and, as will be discussed in later sections of this report, the DVRFS model has been modified within the Climax sub-CAU area to include the UGTA program's alternative hydrostratigraphic models in northern Yucca Flat. 


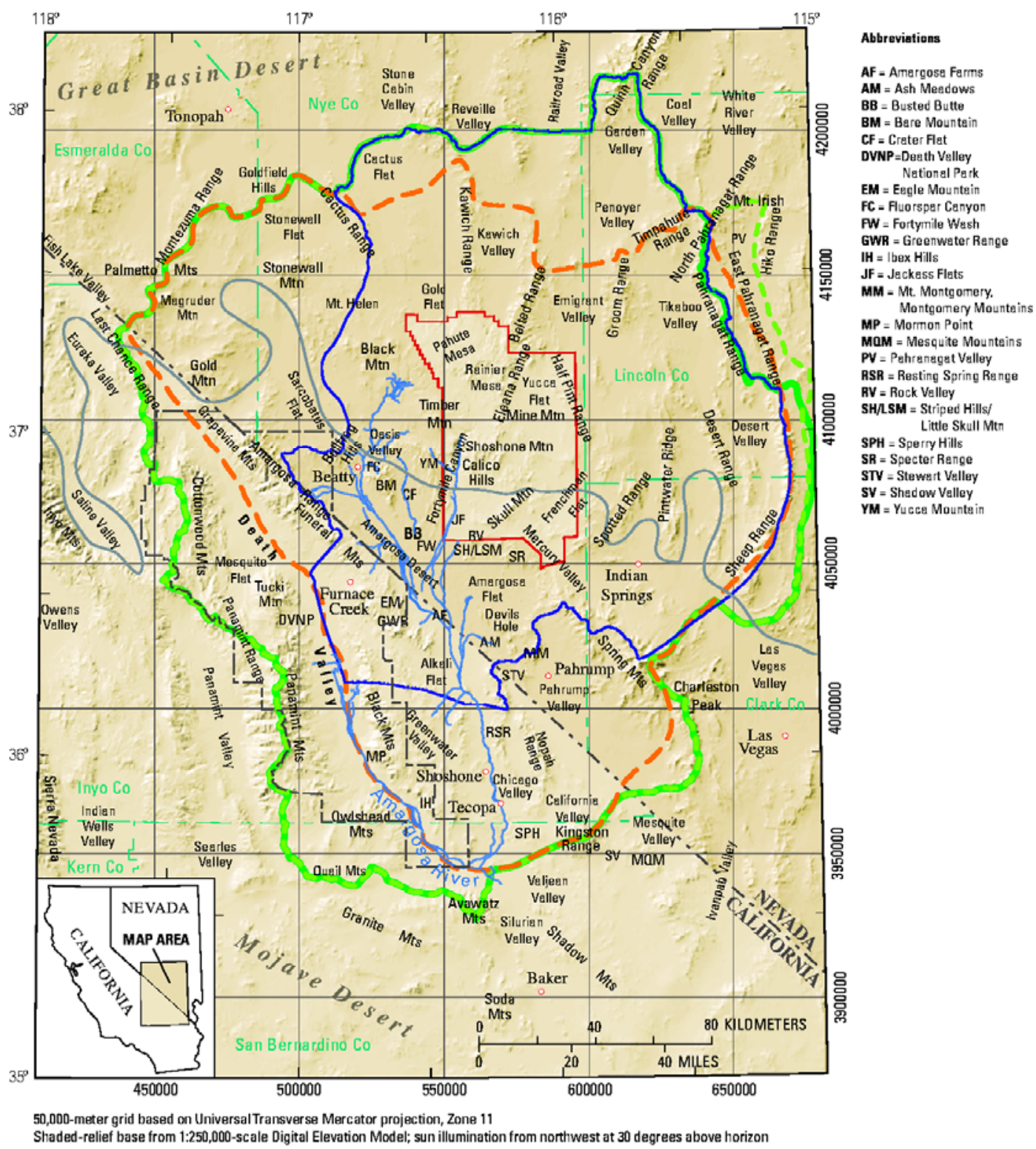

EXPLANATION

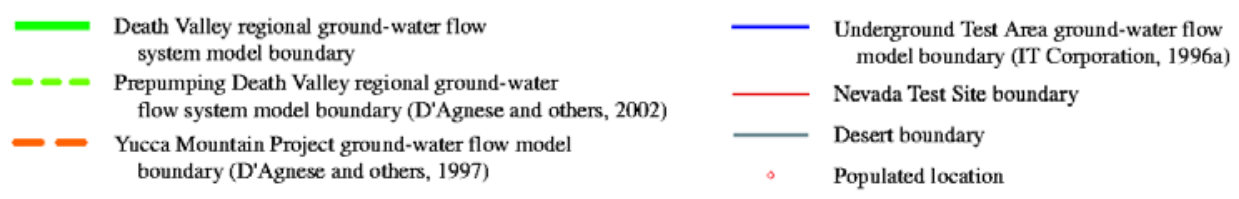

Figure 2-13. Map showing the location of the Death Valley Regional Flow System model in relation to regional geographic features and other major regional flow models. From Belcher et al. (2004).

The general characteristics of the DVRFS model as they pertain to this study are summarized below from Belcher et al. (2004). The DVRFS model utilizes the threedimensional groundwater flow code MODFLOW-2000 (version 1.13) (Harbaugh et al., 2000) and related modular flow packages to simulate flow in the greater Death Valley region, covering an area similar to previous regional models developed for Yucca Mountain 
(D’Agnese et al., 1997) and the NTS (IT, 1996d) (Figure 2-13). The MODFLOW-2000 code will hereafter be referred to in this report as MODFLOW.

The mesh is oriented north-south in alignment with the Universal Transverse Mercator (UTM) grid and is discretized in plan view into 160 columns and 194 rows. All cells outside the model boundary shown as the heavy green line on Figure 2-13 are inactive and all cells within the boundary are active. Sixteen model layers are used, with 15 of them ranging in thickness from 50 to about $300 \mathrm{~m}$ (Figure 2-14). Layer 1 forms the top of the model and its upper elevation is set to the simulated potentiometric surface. Attempts were made to run the model as unconfined, but stable solutions could not be obtained and therefore the model was configured as confined. Transient time steps specify yield for the top layer, thereby partially accounting for unconfined conditions. Layer 16 forms the base of the model and extends to 4,000 m below sea level. Model layer elevations do not conform to hydrologic units (HGUs) elevations owing to the irregular shapes of the geologic units that result from depositional and structural processes in the region (Belcher et al., 2004). Time is divided into one steady-state stress period that simulates conditions prior to the initiation of groundwater pumping in 1913, followed by 86 one-year transient stress periods that include groundwater pumping through the year 1998.
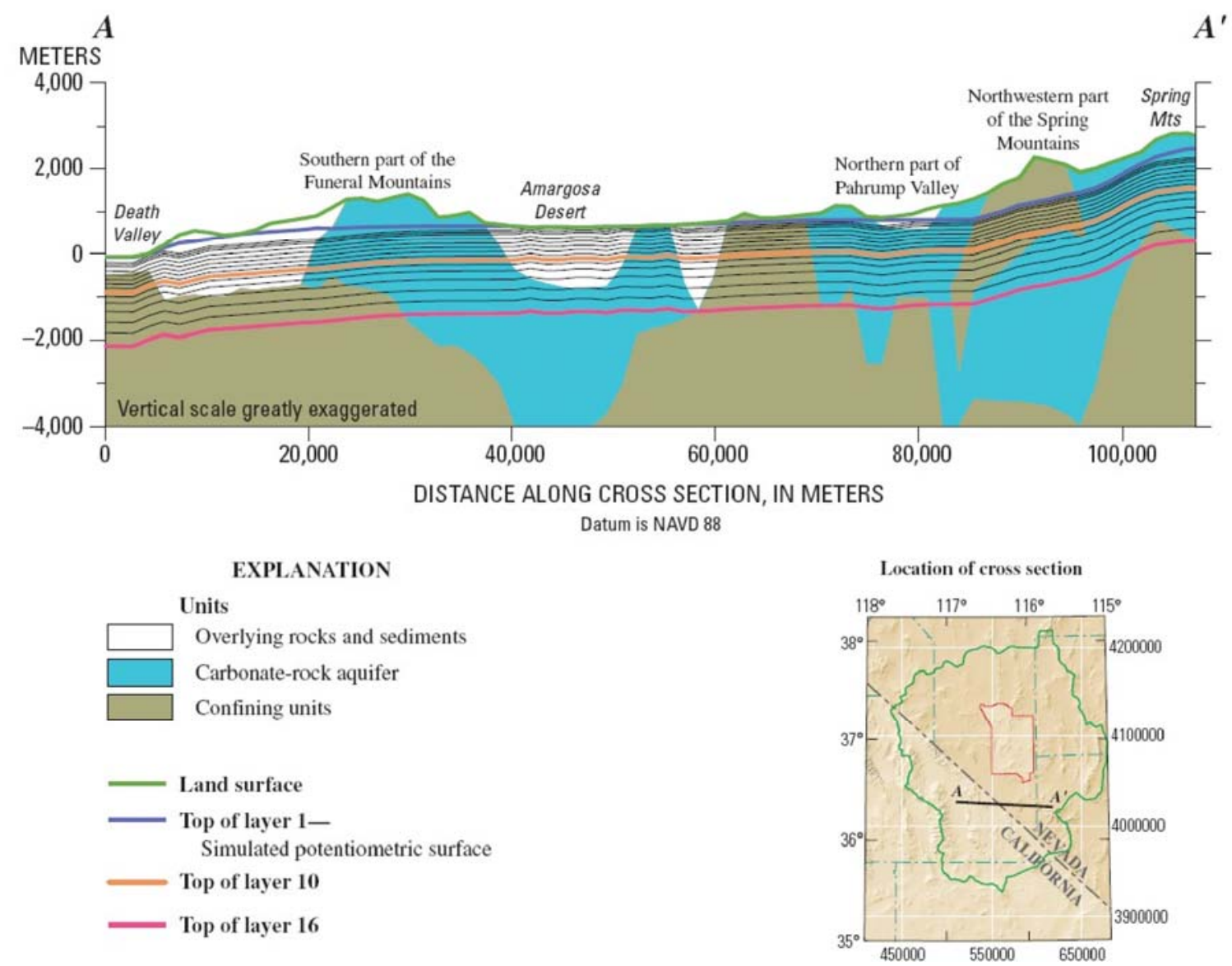

Figure 2-14. East-west cross section across a portion of the DVRFS model domain showing general configuration of the model layers. From Belcher et al. (2004). 
Lateral model boundaries are configured as constant head using the constant head (CHD) package, allowing flow into and out of the model. One segment is treated as no-flow where it coincides with the groundwater divide in the Spring Mountains and is parallel to the hydraulic gradient between the Spring Mountains and the Kingston Range to the south. Heads on all the boundaries were interpolated from a map of the regional potentiometric surface and flow rates across the boundary segments were estimated using water-budget and Darcy-calculations. The flow rates were used as observations during model calibration, though they were given less weight than the other, measured observations.

Hydraulic properties are assigned on the basis of HGUs using the HydrogeologicUnit Flow (HUF2) package (Anderman and Hill, 2000, 2003). The configuration of the HGUs in the model constitutes the DVRFS hydrostratigraphic framework model, which forms one of the alternative conceptualizations considered in the Climax regional model, and which will be discussed in detail in later sections of this report. Values of hydraulic conductivity, storage coefficient, vertical anisotropy, and depth decay of hydraulic conductivity (KDEP package) for the HGUs are based on Belcher et al. (2001) and vary spatially by zonation within HGUs based primarily on spatial distribution of geologic properties (Belcher et al., 2004).

The distribution and rates of groundwater recharge are based on a net infiltration model for the Death Valley region (Hevesi et al., 2003) and parameterized in the Recharge $(\mathrm{RCH})$ package. The net infiltration model is one of the alternative models of recharge in the Climax regional flow model and is discussed in detail in later sections of this report. Discharge is simulated as evapotranspiration (ET) and spring flow using the Drain (DRN) package, which simulates groundwater discharge through a head-dependent boundary.

Calibration of the model utilizes the parameter-estimation methods included in MODFLOW, i.e., finding values of model parameters that minimize the weighted least squares objective function through nonlinear regression of simulated values and the observations (Hill, 1998). The model was first calibrated to steady-state flow conditions (stress period 1) and the results used as the initial conditions for the transient flow stress periods. The model was then calibrated again to the transient conditions. During calibration, comparison of simulated values to observed values is coordinated in the Observation (OBS) package. The DVRFS model observations include hydraulic head as single values and head changes over time (HOB package), drains (i.e., ET and spring discharge) (DROB package), and flow estimates at constant-head boundaries (CHOB package). Sensitivities of observations and parameters are calculated for use in sensitivity analyses and for nonlinear regression during parameter estimation using the Sensitivity (SEN) process. 


\subsection{GROUNDWATER FLOW MODEL FOR THE REGION SURROUNDING THE CLIMAX STOCK}

The Climax Regional Flow Model (CRFM) uses the DVRFS model developed by the U.S. Geological Survey (Belcher et al., 2004) as the framework within which threedimensional, transient groundwater flow is simulated in the Climax stock area and the surrounding region. Most aspects of the DVRFS model are preserved in the CRFM, however, the CRFM differs in two important respects. First, the CRFM incorporates alternative models of groundwater recharge over the entire DVRFS model domain and hydrostratigraphic framework in northern Yucca Flat. Second, the horizontal mesh is highly refined from a spacing of 1,500 $\mathrm{m}$ in most of the DVRFS model domain to a spacing of $250 \mathrm{~m}$ in northern Yucca Flat to preserve the high level of detail inherent to Bechtel Nevada's hydrostratigraphic framework models.

An overview of the model averaging process used to incorporate alternate conceptual models in the CRFM is provided in Section 3.1. The alternative models of recharge and hydrostratigraphy are described in Section 3.2. Section 3.3 describes the methods used to assess uncertainty in the alternate models. The remainder of Section 3 describes the CRFM model and its construction and calibration, followed by an assessment of uncertain parameters and alternate models on groundwater flow through the Climax area of Yucca Flat.

\subsection{Bayesian Model Averaging to Assess Conceptual Model Uncertainty}

Hydrologic analyses have typically relied on a single conceptual model of a site, an approach that fails to recognize the potential for conceptual model uncertainty and the resulting statistical bias and underestimation of uncertainty. In the words of Hoeting et al. (1999), "standard statistical practice ignores model uncertainty ... leading to over-confident inferences and decisions that are more risky than one thinks they are." Bayesian model averaging (BMA) accounts for model uncertainty by providing an optimal way of combining the predictions of several alternative models and assessing their joint predictive uncertainty. Other philosophies of model building within an uncertainty framework are discussed by Beven and Binley (1992), Gauch (1993), Gaganis and Smith (2001), Burnham and Anderson (2002), and Christakos (2003).

Using the notation of Hoeting et al. (1999), if $\Delta$ is the predicted quantity (e.g., hydraulic head and flow rate), its posterior distribution given a set of data $\mathbf{D}$ is

$$
p(\Delta \mid \mathbf{D})=\sum_{k=1}^{K} p\left(\Delta \mid M_{k}, \mathbf{D}\right) p\left(M_{k} \mid \mathbf{D}\right)
$$

where $\mathbf{M}=\left(M_{1}, \ldots, M_{K}\right)$ is the set of all models considered. Neuman and Wierenga (2003) provided guidance on selecting a set of models that is small enough to be computationally feasible yet large enough to represent the breadth of significant possibilities. In Equation (3.1), $p(\Delta \mid \mathbf{D})$ is the average of the posterior distributions $p\left(\Delta \mid M_{k}, \mathbf{D}\right)$ under each model, weighted by their posterior model probabilities $p\left(M_{k} \mid \mathbf{D}\right)$. The posterior probability for model $M_{k}$ is given by Bayes' rule 


$$
p\left(M_{k} \mid \mathbf{D}\right)=\frac{p\left(\mathbf{D} \mid M_{k}\right) p\left(M_{k}\right)}{\sum_{l=1}^{K} p\left(\mathbf{D} \mid M_{l}\right) p\left(M_{l}\right)}
$$

where

$$
p\left(\mathbf{D} \mid M_{k}\right)=\int p\left(\mathbf{D} \mid \boldsymbol{\theta}_{k}, M_{k}\right) p\left(\boldsymbol{\theta}_{k} \mid M_{k}\right) d \boldsymbol{\theta}_{k}
$$

is the integrated likelihood of model $M_{k}, \boldsymbol{\theta}_{k}$ is the vector of parameters associated with model $M_{k}, p\left(\boldsymbol{\theta}_{k} \mid M_{k}\right)$ is the prior density of $\boldsymbol{\theta}_{k}$ under model $M_{k}, p\left(\mathbf{D} \mid \boldsymbol{\theta}_{k}, M_{k}\right)$ is the joint likelihood of model $M_{k}$ and its parameters $\boldsymbol{\theta}_{k}$, and $p\left(M_{k}\right)$ is the prior probability of $M_{k}$. All probabilities are implicitly conditional on $\mathbf{M}$. Computing the integral in Equation (3.3) requires exhaustive Monte Carlo simulations of the prior parameter space $\boldsymbol{\theta}_{k}$ for each model, which may be computationally demanding. In particular, it is infeasible when parameter measurements are too sparse to evaluate meaningful distributions of $\boldsymbol{\theta}_{k}$. To render BMA computationally feasible in a hydrologic context, Neuman (2003) proposed obviating the need for such simulations and prior parameter information by adopting a Maximum Likelihood (ML) version (MLBMA) of BMA. It consists of replacing $\boldsymbol{\theta}_{k}$ by its maximum likelihood estimate $\hat{\boldsymbol{\theta}}_{k}$ based on the likelihood $p\left(\mathbf{D} \mid \boldsymbol{\theta}_{k}, M_{k}\right)$. Neuman (2003) proposed further to evaluate the posterior model probability, $p\left(M_{k} \mid \mathbf{D}\right)$, based on a result due to Kashyap (1982).

The posterior mean and variance of $\Delta$ are (Draper, 1995)

$$
\begin{gathered}
E[\Delta \mid \mathbf{D}]=\sum_{k=1}^{K} E\left[\Delta \mid \mathbf{D}, M_{k}\right] p\left(M_{k} \mid \mathbf{D}\right) \\
\operatorname{Var}[\Delta \mid \mathbf{D}]=\sum_{k=1}^{K} \operatorname{Var}\left[\Delta \mid \mathbf{D}, M_{k}\right] p\left(M_{k} \mid \mathbf{D}\right)+\sum_{k=1}^{K}\left(E\left[\Delta \mid \mathbf{D}, M_{k}\right]-E[\Delta \mid \mathbf{D}]\right)^{2} p\left(M_{k} \mid \mathbf{D}\right)
\end{gathered}
$$

In Equation (3.5), the first term on the right-hand side represents within-model variance; the second term represents between-model variance.

Prior model probabilities are subjective values reflecting the analyst's belief about the relative plausibility of each model based on its apparent consistency with available knowledge and data. Posterior model probabilities are modifications of these subjective values based on an objective evaluation of each model's consistency with available data. Posterior probabilities are valid only in a comparative, not in an absolute, sense. They are conditional on the choice of models (in addition to being conditional on the data) and may be sensitive to the choice of prior model probabilities (Ye et al., 2005). This sensitivity is expected to diminish with increased level of conditioning on data.

To implement BMA, one would (1) postulate alternative conceptual-mathematical models for a site; (2) assign a prior probability to each model; (3) optionally assign prior probabilities to the parameters of each model; (4) obtain posterior ML parameter estimates, and estimation covariance, for each model by inversion (model calibration); (5) calculate a posterior probability for each model; (6) predict quantities of interest using each model; (7) assess prediction uncertainty (distribution, variance) for each model using Monte Carlo 
or, where applicable, geostatistical or stochastic moment methods; (8) weight predictions and uncertainties by the corresponding posterior model probabilities; and (9) sum the results over all models.

Ye et al. (2004) applied MLBMA to seven alternative geostatistical models of log air permeability data from single-hole pneumatic injection tests in six boreholes at the Apache Leap Research Site (ALRS) in central Arizona. Predictive performance of MLBMA was evaluated through cross-validation by eliminating from consideration all data from one borehole at a time and comparing the predictive capability of MLBMA with that of each individual model. Two criteria, predictive log score and coverage, were used to evaluate the predictive performance of MLBMA and that of individual models. The lower the predictive log score of a model, the smaller the amount of information lost upon eliminating a borehole's data from the original dataset (i.e., the higher the probability that the model based on the reduced dataset would reproduce the eliminated borehole's data). Predictive coverage was the percent of measurements from the eliminated borehole's data that fell within a given prediction interval generated by conducting Monte Carlo simulations of log air permeability conditioned on the data from the remaining boreholes. The predictive log score of MLBMA was lower than that of any individual model, indicating that MLBMA was a better predictor than any of the single model alternatives. The predictive coverage of MLBMA was larger than that of any individual model, attesting also to its superior performance.

\subsection{Postulation of Alternative Conceptual Models}

Alternative conceptual models were included in the modeling process to directly incorporate the uncertainty associated with the conceptualization of the hydrogeologic system. Two types of alternative conceptual models are addressed in this project: groundwater recharge and hydrostratigraphic framework. The five recharge models considered originate from independent methods of characterizing recharge and cover the entire Death Valley region. The five hydrostratigraphic models represent alternate interpretations of the hydrostratigraphic framework in northern Yucca Flat.

\section{$\underline{3.2 .1 \quad \text { Alternative Models of Groundwater Recharge }}$}

Five recharge models were chosen by an elicitation panel of technical experts for inclusion in the CRFM. They are a modification of the Maxey-Eakin model (MME), two variants of a net infiltration model, and two variants of an elevation-dependent chloride mass-balance model. The models were developed by independent researchers using different methodologies and are summarized below. As shown in Table 3-1, these models give significantly different estimates of recharge or net infiltration $\left(\mathrm{m}^{3} / \mathrm{d}\right)$ for the DVRFS and the northern Yucca Flat areas. At both areas, the recharge estimate of MME is the highest, while the chloride mass balance (CMB) models give higher estimates than the net infiltration models (NIM) models. As described in the model calibration section, actual recharge estimates of the NIM models are lower than the net infiltration estimates listed in Table 3.1, since some of the net infiltration estimates of the NIM models were multiplied by recharge coefficients less than 1.0. The actual recharges were discussed later in the section on calibration results. Note that recharge estimates of the CMB models at the northern Yucca Flat area are the same. 
Table 3-1. Recharge estimates $\left(\mathrm{m}^{3} / \mathrm{d}\right)$ of the MME, CMB1, and CMB2 models and net infiltration estimates $\left(\mathrm{m}^{3} / \mathrm{d}\right)$ of the CMB1 and CMB2 models in the DVRFS and northern Yucca Flat areas.

\begin{tabular}{ccc}
\hline Recharge Model & DVRFS $\left(\mathrm{m}^{3} / \mathrm{d}\right)$ & Northern Yucca Flat $\left(\mathrm{m}^{3} / \mathrm{d}\right)$ \\
\hline MME & $596,190.8$ & $9,242.9$ \\
NIM1 & $341,930.6$ & $3,317.3$ \\
NIM2 & $282,223.1$ & $2,362.5$ \\
CMB1 & $385,213.7$ & $5,738.7$ \\
CMB2 & $365,647.2$ & $5,738.7$ \\
\hline
\end{tabular}

\subsubsection{Modification of the Maxey-Eakin Method}

During the late 1940s, the USGS and Nevada's Office of the State Engineer conducted a series of cooperative groundwater investigations published as Nevada Water Resource Bulletins (Maxey and Jameson, 1945; Maxey and Robinson, 1947; Robinson et al., 1947; Phoenix et al., 1948; Loeltz et al., 1949; and Maxey and Eakin, 1949). In Water Resources Bulletin No. 8, Maxey and Eakin (1949) presented an empirical method for estimating groundwater recharge as a function of precipitation estimates for selected zones of elevation. This estimation technique has become known as the Maxey-Eakin method. Since its inception, the Maxey-Eakin method has become the predominant technique used for estimating annual recharge in Nevada.

Maxey and Eakin calculated groundwater recharge by predicting how annual precipitation varied with elevation and then adjusting the precipitation amounts by coefficients to estimate the fraction of precipitation that recharges the groundwater system. The coefficients were developed through a trial-and-error method to attain a general agreement between the volumes of modeled recharge and measured discharge for 13 basins in eastern and central Nevada (Maxey and Eakin, 1949). The coefficients determined by Maxey and Eakin increase in magnitude as the amount of precipitation increases (Table 3-2) while evapotranspiration and surface water runoff presumably decline. The basins used to develop the recharge estimation technique were not directly referenced in the original bulletin, but in a later examination of the Maxey-Eakin method and through personal communication with Maxey, Watson et al. (1976) identified 21 basins that appear to have been ultimately used to calculate the coefficients.

Table 3-2. Recharge coefficients for the Maxey-Eakin recharge method.

\begin{tabular}{cc}
\hline Precipitation Zone (in/yr) & Coefficient \\
\hline Less than 8 & 0.00 \\
8 to less than 12 & 0.03 \\
12 to less than 15 & 0.07 \\
15 to less than 20 & 0.15 \\
Greater than 20 & 0.25 \\
\hline
\end{tabular}

The Maxey-Eakin method assumes that the basins under investigation are in a state of hydrologic equilibrium such that the quantity of discharge from the basin is a reasonable 
approximation of the recharge into the basin. Thus the relationship between precipitation and recharge can be defined by the linear relation

$$
R=\sum_{i=1}^{N} C_{i} P_{i}
$$

where $R$ is the estimated recharge (acre-ft/yr), $C_{\mathrm{i}}$ is the percentage adjustment coefficients, $P_{\mathrm{i}}$ is the annual precipitation zones (acre-ft/yr), and $N$ is the number of precipitation zones.

Maxey and Eakin (1949) utilized the precipitation map for Nevada developed by Hardman (1936) that includes hand-drawn contours of equal precipitation based on weather station records and topography. Precipitation is distributed among 5-, 8-, 12-, 15- and 20-in isohyets, though Maxey and Eakin assumed that precipitation zones receiving less than 8 in of rainfall per year did not contribute to groundwater recharge. The Hardman (1936) precipitation map is limited to the state of Nevada; therefore the original Maxey-Eakin method could not be used in this study to estimate recharge in the portion of the DVRFS domain that extends into southeastern California.

Given the incomplete coverage of the DVRFS domain by the Hardman precipitation map, an alternative method that incorporates the basic Maxey-Eakin methodology was developed for producing a recharge map for the DVRFS model. Epstein (2004) developed a method for estimating groundwater recharge that is based on Maxey and Eakin's approach, but utilizes techniques not available to them and also broadens the region of application to beyond Nevada's borders. The primary differences between Epstein's method and the Maxey-Eakin method are:

1. The PRISM (Precipitation Estimation on Independent Slopes Model) map (Daly et $a l ., 1994)$ is used to predict annual precipitation. Use of the PRISM map allows estimation of groundwater recharge in a consistent way over both the Nevada and California portions of the DVRFS domain.

2. An automated calibration procedure is used to calculate the recharge coefficients rather than trial and error.

3. Uncertainty in the estimates of annual precipitation is calculated from precipitation observations and incorporated in the recharge coefficients.

4. Four precipitation zones are used ( 0 to 10,10 to 20,20 to 30 , and greater than 30 in/yr).

5. The coefficient for the lowermost precipitation zone is allowed to be nonzero.

6. A total of 91 basins with recharge estimates are used.

Epstein's (2004) modified Maxey-Eakin method was used here to generate a recharge map for the DVRFS model domain (Figure 3-1) using the mean recharge coefficient for each precipitation zone (Table 3-3). The mean coefficients for each of the four precipitation intervals were calculated first, then these values were multiplied by the PRISM-derived annual precipitation value appropriate for each active model grid cell to arrive at the array of estimated mean recharge values. Each recharge value is then converted from in/yr to $\mathrm{m} / \mathrm{day}$ for use in the DVRFS model. 
The PRISM precipitation estimates are calculated for each DVRFM grid cell based on an area-weighted average. The PRISM precipitation estimates are available at a contour resolution of $2 \mathrm{in} / \mathrm{yr}$ for both Nevada and California. The DVRFM grid is then overlayed onto the PRISM contours. The relative area is then calculated for each precipitation contour that intersects a grid cell and the area-weighted average is used to apply a precipitation value. Figure 3-1 clearly shows that unlike the Maxey-Eakin method, Epstein's method simulates groundwater recharge in every active cell of the model, reflecting the fact that recharge is simulated for all precipitation zones, including the lowest. This results from incorporating uncertainty in the estimates of annual precipitation through autocalibration, which leads to a nonzero value of the recharge coefficient in the lowest precipitation zone.

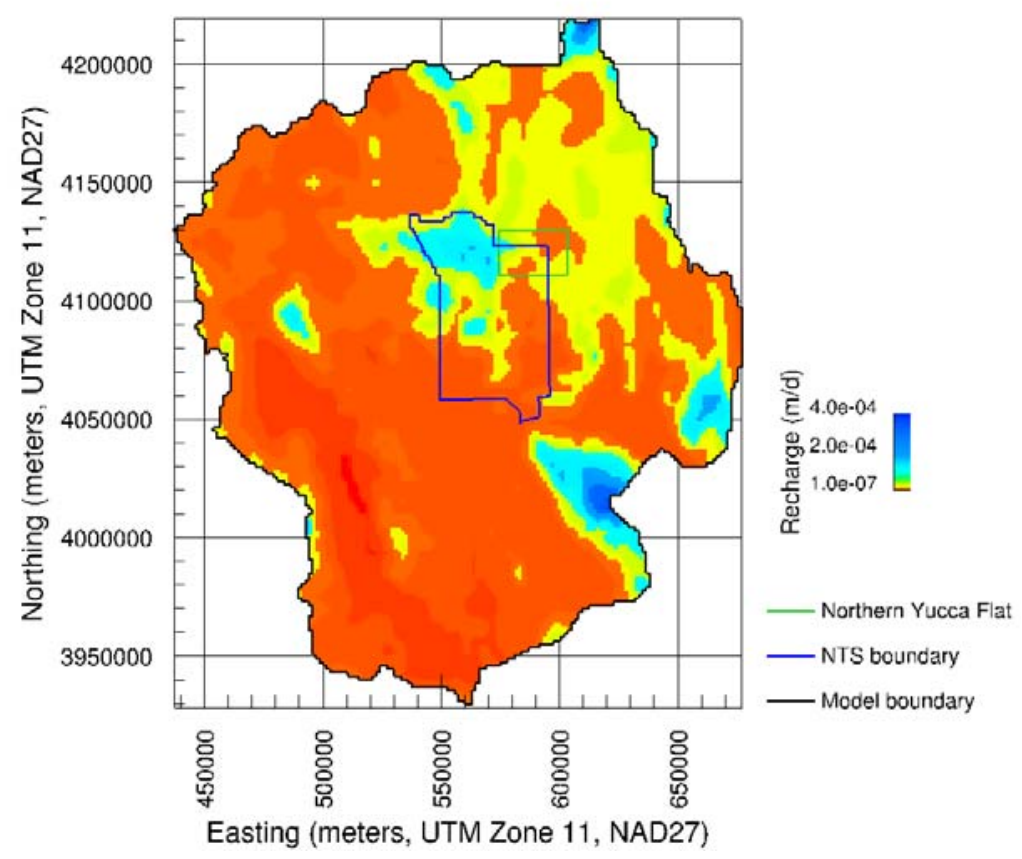

Figure 3-1. Recharge map for the DVRFS model domain developed using a modification of the Maxey-Eakin method (units are $\mathrm{m} / \mathrm{d}$ ).

Table 3-3. Mean recharge coefficients for the Epstein (2004) recharge estimation method.

\begin{tabular}{ccc}
\hline Coefficient (i) & Precipitation zone (inches per year) & Coefficient \\
\hline 1 & 0 to less than 10 & 0.019 \\
2 & 10 to less than 20 & 0.049 \\
3 & 20 to less than 30 & 0.195 \\
4 & Greater than 30 & 0.629 \\
\hline
\end{tabular}

Though Epstein's method utilizes the basic concept proposed by Maxey and Eakin (1949) relating groundwater recharge to precipitation through a set of recharge coefficients, several steps of the methodology differ from those used in the "revised" Maxey-Eakin method that was utilized to develop spatial distributions of recharge for the Frenchman Flat and Pahute Mesa CAU flow models. For example, to generate consistent estimates of 
precipitation across the Nevada and California portions of the DVRFS model domain, Epstein's method incorporates the PRISM model, rather than the updated Hardman (1936) precipitation map used in the CAU models. In addition, Epstein's recharge coefficients are calculated through model calibration rather than using Maxey-Eakin values and incorporate uncertainty in the precipitation estimates. Finally, recharge in the lowermost zone is allowed to be nonzero. The implication of these differences in methodology is that Epstein's distribution of recharge differs from the distribution developed using the revised MaxeyEakin method in the CAU models, an issue that was considered during the expert elicitation.

\subsubsection{Net Infiltration Models}

Hevesi et al. (2003) developed a distributed-parameter watershed model, INFILv3, for estimating temporal and spatial distribution of net infiltration and potential recharge in the Death Valley region, including the DVRFS. The estimates of net infiltration quantify downward drainage of water across the lower boundary of the root zone, and are used as an indication of potential recharge under current climate conditions. Description of the methodology is summarized below from Hevesi et al. (2003).

Based on the daily average water balance at the root zone, the distributed-parameter watershed model represented processes controlling net infiltration and potential recharge. The daily water balance included precipitation (as either rain or snow), snow accumulation, sublimation, snowmelt, infiltration into the root zone, evapotranspiration, drainage, water content change throughout the root-zone profile, runoff (defined as excess rainfall and snowmelt) and surface water run-on (defined as runoff that is routed downstream), and net infiltration (simulated as drainage from the bottom root-zone layer). To simulate potential evapotranspiration, an hourly solar radiation model was used to evaluate daily net radiation, and daily evapotranspiration was simulated as an empirical function of the root zone water content and potential evapotranspiration. In the model, daily climate input (precipitation and air temperature) and a spatially detailed representation of watershed characteristics were used to simulate daily net infiltration at all locations in the watershed, including active stream channels. A geographic information system (GIS) was used to define a set of spatially distributed input parameters over a modeling grid with more than 1 million nodes defined by a digital-elevation model (DEM). Daily precipitation and air temperature were estimated by using the elevation values from the DEM with monthly regression models developed from daily climate data from a regionally distributed network of 132 climate stations. The elevation values were also used to simulate atmospheric effects on potential evapotranspiration, develop topographic parameters to simulate the effects of shading on potential evapotranspiration, and develop parameters to simulate surface-water flow. Surface-water flow was modeled as a downstream redistribution of runoff generated by rain or snowmelt, and was routed across all the model grid cells as a daily surface-water run-on component of the water balance (for days when runoff was generated) using an eightdirectional (D-8), convergent-flow routing algorithm. A six-layer root-zone system - five soil layers and one bedrock layer - was used to simulate daily root-zone water balance, including evapotranspiration, infiltration, drainage, and redistribution of moisture in the root zone. Evapotranspiration from each root-zone layer was modeled as a function of potential evapotranspiration, the estimated root density for each layer, and the simulated water content for each layer. Downward drainage through each layer was modeled as a function of soil saturated hydraulic conductivity, soil texture, and the simulated water content. Snowfall, 
sublimation, and snowmelt were modeled as functions of the spatially distributed daily climate input and the simulated solar radiation component of the potential evapotranspiration model.

Model calibration consisted of qualitative and quantitative comparisons of simulated streamflow to historical streamflow records in the Death Valley region, in conjunction with comparisons of basin-wide average net infiltration to previous estimates of basin-wide recharge. In the calibration process, various model parameters were adjusted to establish the best set of model parameters based on a simultaneous fit to all available streamflow records. Parameters adjusted during calibration included bedrock saturated hydraulic conductivity, root density, storm duration, and parameters defining stream-channel characteristics (soil saturated hydraulic conductivity and wetted area). Results from the calibration process indicated that for many locations the spatial coverage of daily climate records in the Death Valley region is insufficient for representing local-scale, high-intensity summer storms that cause a significant portion of the recorded streamflows, especially for smaller-area, higherelevation watersheds. In addition, the calibration results indicated a high sensitivity in simulated streamflow because of uncertainty in the parameters defining stream channel characteristics. Comparison of simulated net infiltration to basin-wide estimates of recharge indicated model sensitivity to estimates of bedrock hydraulic conductivity and root density.

To evaluate model parameter sensitivity, three alternative models were used to develop 50-year simulations of net infiltration. The base model was referred to as model 1 . Model 2 is identical to model 1, except that it does not include a runon-runoff component. Model 3 includes a slight reduction in the sublimation rate parameter, a decrease in storm duration, a decrease in bedrock saturated hydraulic conductivity, a decrease in the streamchannel wetted area, and a decrease in stream-channel hydraulic conductivity for soils. Model 4 is identical to model 3, except that storm duration is restored, the sublimation coefficient is set back to 0.4 , and the solar radiation subroutine uses a 1-hour time step. Results indicated that simulated daily streamflow is sensitive to uncertainty in estimates of storm duration and stream channel characteristics, and to a lesser degree uncertainty in estimates of bedrock hydraulic conductivity. Model comparison indicated that infiltration from surface-water run-on accounts for only about 14 percent of the total net infiltration volume for the DVRFS. However, for some basins within the regional flow system, surface water flow may contribute as much as 40 percent to the total net infiltration volume. Net infiltration showed a high sensitivity to uncertainty in bedrock hydraulic conductivity and root density. Both streamflow and net infiltration are strongly sensitive to uncertainty in spatially distributed precipitation and estimated soil thickness.

Calibration results showed that the base model provided the best model fit, while model 2 without a runon-runoff component gave the poorest overall fit. While model 4 gave satisfactory calibration results, model 3 overestimated streamflow, but provided improved predictions of the frequency and occurrence of streamflow relative to models 1 and 4 . For the purpose of estimating net infiltration and potential recharge and for simulating basin-wide water balance, model performance based on predicting streamflow magnitude was considered more important than model performance based on streamflow frequency and occurrence. Therefore, among the four alternative models, the base model with a runonrunoff component and its direct alternative without runon-runoff component were selected for this project. Time-average, annual net infiltration estimated by the models provides an 
indication of spatial distribution of potential recharge to the DVRFS under current climate conditions.

In the DVRFS model of Belcher et al. (2004), groundwater recharge was estimated based on the net infiltration predicted by the base model of the distributed-parameter method described by Hevesi et al. (2003). The potential recharge estimated by their method was adjusted across the model domain to provide an improved balance with discharge. Since the net-infiltration distribution only accounted for surficial characteristics of the system and not the hydraulic conductivity of the rocks at the water table (Hevesi et al., 2003), a recharge zone multiplication array of nine recharge multipliers was defined to adjust the net infiltration (Belcher et al., 2004). During calibration, which will be discussed below, only two recharge parameters (the multipliers) were calibrated, and other parameters took the values of Belcher et al. (2004). Figure 3-2 shows the two alternative maps of recharge based on the net-infiltration method that were used in this study.
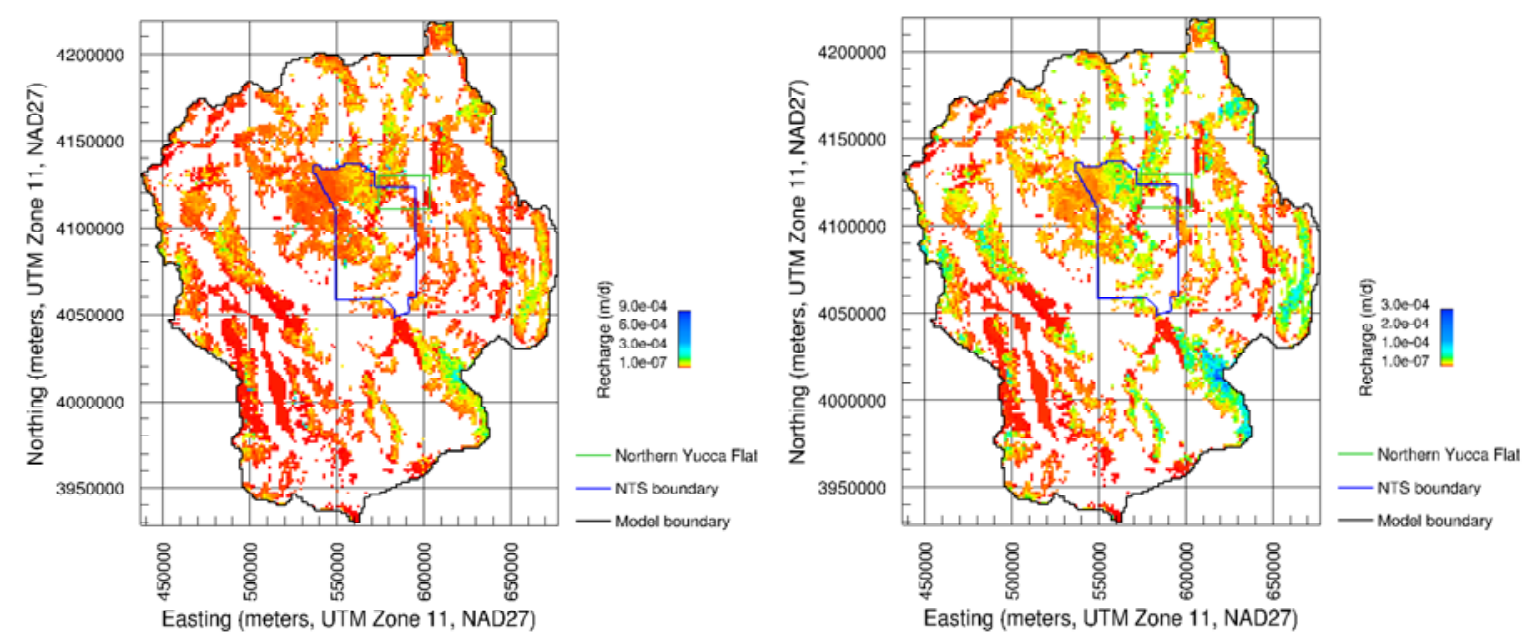

Figure 3-2. Recharge maps for the DVRFS model domain developed using the net infiltration method (a) with the runon-runoff component, and (b) with no runon-runoff component (units are $\mathrm{m} / \mathrm{d}$ ).

\subsubsection{Elevation-dependent Chloride Mass-balance Models}

Another method available for estimating recharge in basin and range hydrologic systems utilizes estimates of chloride ion balances within hydrologic input and output components of individual basins. The chloride mass-balance (CMB) method assumes that chloride in groundwater within these basins originates in mountain uplands from chloride in precipitation and dry fallout and is transported to adjacent valleys by groundwater flow (Dettinger, 1989). At its most fundamental level, the method requires only estimates of annual precipitation in the recharge areas, total chloride input (chloride concentrations in precipitation and recharge water), and total chloride output (chloride concentrations in adjacent basin groundwater). The rate of recharge, $R(\mathrm{~L} / \mathrm{yr})$, can be calculated as (Maurer et al., 1996)

$$
R=\frac{C_{p} P}{C_{r}}-\frac{C_{s w} S_{w}}{C_{r}}
$$


where $C_{p}$ is the combined wet-fall and dry-fall atmospheric chloride concentration normalized to precipitation $(\mathrm{mg} / \mathrm{L}), P$ is the mean annual precipitation rate $(\mathrm{L} / \mathrm{yr}), C_{r}$ is the chloride concentration in recharge water $(\mathrm{mg} / \mathrm{L})$, and $C_{s w}$ is the chloride concentration $(\mathrm{mg} / \mathrm{L})$ in surface water runoff $S_{w}(\mathrm{~L} / \mathrm{yr})$. For individual basins, recharge rate can be estimated from this information if the following assumptions are met (Dettinger, 1989): (1) there are no other major sources or sinks for chloride in the system; (2) surface runoff is small in comparison to groundwater flow; and (3) the recharge areas are correctly delineated.

Russell and Minor (2002) extended the chloride mass-balance approach to account for the elevation of precipitation, the limited quantities of recharge that are thought to occur on low-elevation alluvial surfaces, and the parametric uncertainty inherent in the data. This elevation-dependent chloride mass-balance (EDCMB) approach was applied by Russell and Minor (2002) to a 7,900- $\mathrm{km}^{2}$ region of the NTS and vicinity.

To quantify the impact of elevation on recharge, Russell and Minor (2002) collected groundwater chloride samples and measured discharge from 17 springs at various elevations in the basin uplands. These springs were carefully selected so that their provenance could safely be assumed to be groundwater recharge originating solely from recharge in the local watershed and that evapotranspiration did not occur at the spring orifice. The elevation of each spring's watershed was approximated (using digital elevation data) as the average of the elevation of the spring orifice and the highest ridge line bounding the watershed. An estimate of recharge for each watershed was then calculated from Equation (3.7) using a precipitation rate determined from the geographic area of the watershed and three independent isohyetal maps (Hardman, 1965; Rush, 1970; Daley et al., 1994) and a chloride input flux based on published cosmogenic ${ }^{36} \mathrm{Cl}$ production and ${ }^{36} \mathrm{Cl} / \mathrm{Cl}$ ratios in large regional springs. The correlation between recharge estimate and watershed elevation was modeled using nonlinear regression and then used to simulate recharge rates on a grid covering the study area.

Though this recharge/elevation relationship simulates recharge at all elevations, Russell and Minor (2002) cite several studies that suggest significant groundwater recharge does not occur in low-elevation alluvial sediments in southern Nevada and they utilize two approaches for defining this zone of zero net recharge. The first approach assumes that all land surface areas covered by alluvial sediments receive negligible recharge based on the results of previous studies and soil-water chloride profiles of 40 boreholes completed in unsaturated alluvium within the NTS (Russell and Minor, 2002). Maps of surface geology (Burchfiel et al., 1974; Guth, 1986; Wahl et al., 1997) were used to define alluvium coverage and these areas were assigned a groundwater recharge value of zero regardless of elevation (the highest alluvial cover occurs at an elevation of 2,134 $\mathrm{m}$ amsl). This approach is referred to as the chloride mass-balance model with alluvial mask to signify that recharge is simulated as zero in alluvium. The second approach assumes that the elevation of the lowest perennial spring that discharges from a perched groundwater system in the study area represents the lowest elevation at which significant recharge occurs. This spring is Cane Spring, which is located at an elevation of 1,237 $\mathrm{m}$ amsl. Coincidentally, this is approximately the same elevation (1,200 m) that Harrill (1976) and Dettinger (1989) consider to be the minimum at which precipitation makes a significant contribution to recharge in desert basins of central and southern Nevada. Using the concept of a recharge cutoff elevation, Russell and Minor (2002) define a zone of zero recharge that encompasses all elevations below 1,237 m plus elevations above $1,237 \mathrm{~m}$ that are covered by alluvium. This second approach is referred to 
as the chloride mass-balance model with both alluvium and elevation masks to signify that recharge is not simulated at elevations below $1,237 \mathrm{~m}$ nor in alluvium.

A significant degree of uncertainty is inherent to many of the parameters used in the development of any estimate of recharge. Russell and Minor (2002) appraised the total uncertainty contained in their recharge estimates by quantifying the uncertainty in each component of the process and then running Monte Carlo simulations to simulate recharge ranges. The parameters considered uncertain included the chloride concentration in spring waters (sampling and temporal variability), precipitation amount (variability arising from use of three independent isohyetal maps), effective chloride concentration in precipitation ( $\mathrm{Cl}$ flux to land surface, ${ }^{36} \mathrm{Cl} / \mathrm{Cl}$ ratio of Amargosa Springs, and mean precipitation rate in the study area), and watershed elevation and size.

Russell (2004) expanded the region investigated by Russell and Minor (2002) to include 14 additional hydrographic basins in their entirety. Owing to the larger geographic area covered by the later study, Russell (2004) utilized several data sets that differed from those used in the original EDCBM analysis. The expanded study used a smaller-scale geologic map (Stewart and Carlson, 1978) to delineate the area of alluvial cover, a newer higher-resolution PRISM data set (PRISM, version 2000) on a 4- $\mathrm{km}^{2}$ grid, hydrographic basin boundaries defined by the State of Nevada Water Resources Division (unpublished data, 1999), and newer seamless digital elevation data on a 30-m grid (USGS National Elevation Dataset [NED]). To develop recharge models for the DVRFS model domain, Russell's (2004) results required further geographic expansion in Nevada and particularly in the Death Valley region of California. Land surface elevations for the new areas in Nevada and California were obtained from the same NED used in Russell (2004), however, a newer $2-\mathrm{km}^{2}$ resolution PRISM precipitation data set was incorporated for the entire region. The California surficial geology was obtained from the California Department of Conservation, Division of Mines and Geology (2000). The datasets of chloride concentration input and output were unchanged from the original Russell and Minor (2002) study.

Monte Carlo methods were used to simulate multiple realizations of recharge for the DVRFS model domain using the uncertain nonlinear regression equation developed by Russell and Minor (2002) for chloride enrichment and precipitation, the updated datasets described above, and the DVRFS model mesh. The distributions of mean recharge calculated for the EDCMB-A0 and EDCMB-EA0 methods are shown in Figure 3-3. These maps display the mean values of recharge calculated for each cell from the 1,000 realizations of recharge for each method. The impact of eliminating recharge at lower elevations in the EDCMB-EA0 map is clearly shown in the Death Valley and Amargosa areas of the domain, but the two methods do not differ greatly in their estimation of recharge in the northern NTS area near Climax. 

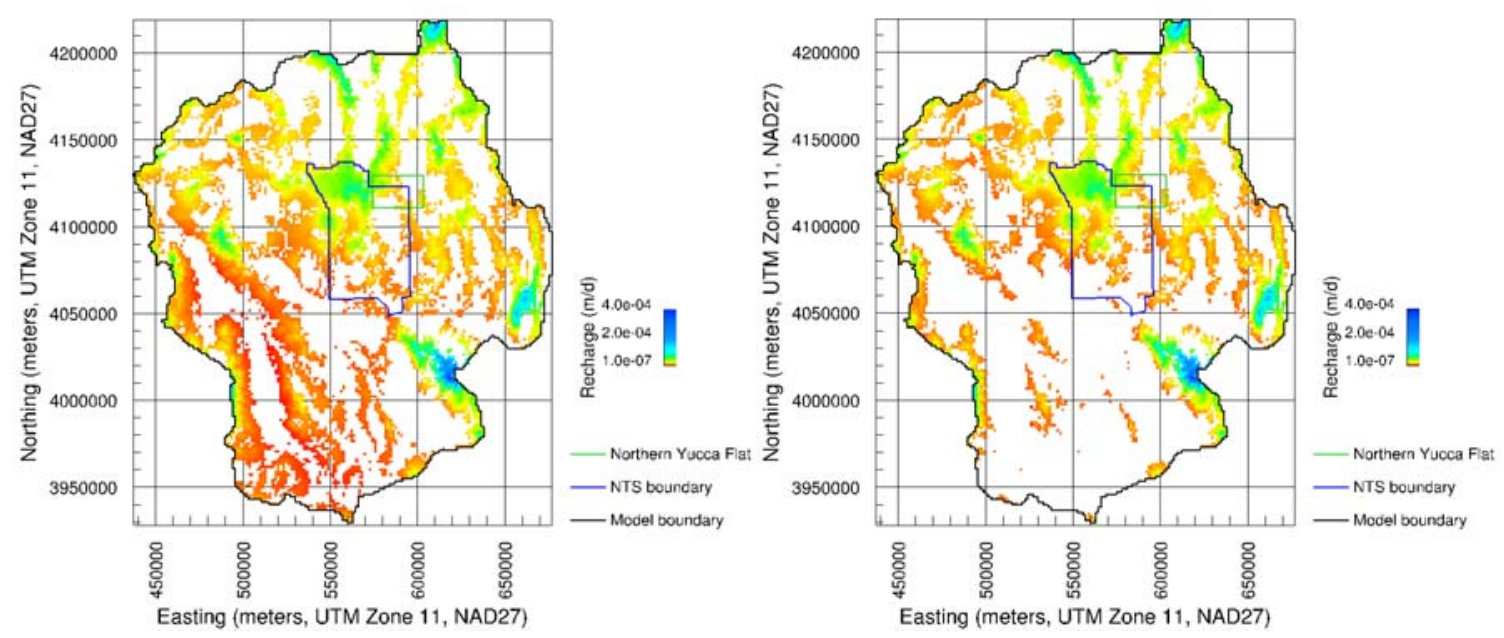

Figure 3-3. Recharge maps for the DVRFS model domain developed using the elevation-dependent chloride mass-balance method with (a) zero recharge in alluvium, and (b) zero recharge at elevations below $1,237 \mathrm{~m}$ and elevations above $1,237 \mathrm{~m}$ that are covered by alluvium (units are $\mathrm{m} / \mathrm{d}$ ).

\subsubsection{Alternative Models of the Hydrostratigraphic Framework}

Five hydrostratigraphic framework models (HFMs) of the northern Yucca Flat area were chosen by an elicitation panel for evaluation and inclusion in the CRFM. One model is the representation of hydrogeologic units throughout the Death Valley region developed by the USGS and included in the DVRFS model. Another is the UGTA model developed for the Yucca Flat-Climax Mine CAU. This model includes a base and several alternatives that were developed to address uncertainty regarding particular features of the flow system that might be important to groundwater flow and contaminant transport (Bechtel Nevada, 2006). Two of these alternatives were considered by the elicitation panel to have potential impacts on groundwater flow in northern Yucca Flat and so they also have been included in the CRFM model. The fifth model merges the two UGTA alternative models to form a single alternative. It should be noted that the USGS hydrogeologic framework model covers the entire CRFM domain. The other four models cover only the northern portion of the Yucca Flat-Climax Mine CAU hydrostratigraphic model. These four models are merged with the DVRFS framework model outside northern Yucca Flat in the CRFM.

\subsubsection{USGS Death Valley Regional Flow System Model}

The hydrogeologic framework model developed by the USGS (Belcher et al., 2004) for the DVRFS flow model integrates regional geologic interpretations from investigations conducted to support modeling of groundwater flow and contaminant transport on the NTS (IT Corporation, 1996) and for supporting studies for a proposed geologic repository for high-level radioactive waste and spent nuclear fuel at Yucca Mountain, Nevada (D'Agnese $e t$ al., 1997). Though both investigations were based on essentially the same information, differences occurred where different specific data sets were used or where data were sparse and interpretations were subject to a high degree of uncertainty. Resolutions of these differences generally emphasized regional consistency over local detail since the model was designed to simulate flow at the regional scale (Belcher et al., 2004) and does not have the 
necessary resolution to resolve many local features. To the extent possible, data collected subsequent to the development of these two models are also incorporated in the DVRFS hydrogeologic framework model (Belcher et al., 2004).

A detailed description of the regional DVRFS hydrogeologic framework is provided by Belcher et al. (2004). What follows here very briefly summarizes their approach and describes the spatial distribution and relationships of the HGUs that impact groundwater flow in the region around the Climax stock and specifically northern Yucca Flat. The DVRFS hydrogeologic framework comprises 25 HGUs, each of which "has considerable lateral extent and has reasonably distinct hydrologic properties because of its physical (geological and structural) characteristics" (Belcher et al., 2004).

Table 3-4 lists the HGUs in the DVRFS model and corresponding units of northern Yucca Flat in the UGTA base HFM. Note that several of the DVRFS HGUs are not present in Yucca Flat and several more are not present in northern Yucca Flat. Further discussion of the Yucca Flat-Climax Mine HSUs is included in the description of the UGTA Base Model (Section 3.2.2.2).

As a group, pre-Tertiary sedimentary rocks and the Mesozoic Climax granite intrusive form the primary flow features controlling the majority of groundwater flow into Yucca Flat through the Climax area and thus are the focus of this study. The sedimentary rocks use the same nomenclature and follow the same general distribution first established by Winograd and Thordarson (1975) and later refined by Laczniak et al. (1996). These units are listed on Table 3-4 (from oldest to youngest) as the lower clastic-rock confining unit (LCCU), the lower carbonate-rock aquifer (LCA), the upper clastic-rock confining unit (UCCU), and the upper carbonate-rock aquifer (UCA). The intrusive-rock confining unit (ICU) comprises all the intrusive rocks in the Death Valley region including the Climax granite. A series of three-dimensional perspective views of selected HGUs and twodimensional cross sections will be used here to illustrate the spatial relationships of the HGUs to each other and to the regional groundwater flow system. Note that the HGUs are presented as they are discretized on the 1,500-m flow model mesh to most clearly illustrate their geometry and their potential impact on simulated flow patterns. The location of these perspective views relative to northern Yucca Flat and regional topographic features is shown in Figure 3-4.

Figure 3-5 represents in stratigraphic sequence selected HGUs in the pre-Tertiary section as represented in the DVRFS. The ICU covers a portion of the base of the model in northern Yucca Flat and west of Yucca Flat. Within northern Yucca Flat, the ICU is represented by the Climax granite, which intrudes the pre-Tertiary sedimentary rocks in the west-central portion of the area. On its eastern edge, the ICU is bounded by the LCCU, which forms the principal barrier to north-south groundwater flow in the bulk of the preTertiary section of northern Yucca Flat. Above the ICU and to the west of the LCCU, the LCA is present as an 11-km-wide band, connecting larger extents of the carbonate aquifer in Penoyer Valley to the north with Yucca Flat to the south. Though minimal thicknesses are simulated just north of the northern Yucca Flat, this model clearly represents the LCA as an important conduit for groundwater flow across the northern Yucca Flat and into Yucca Flat. The LCA is overlain by the UCCU over much of its extent within northern Yucca Flat. 
Table 3-4. Correlations between DVRFS HGUs and UGTA HSUs present in the Yucca Flat-Climax Mine CAU (after Bechtel Nevada, 2006). For operational reasons, several of the HSU names in the CRFM differ from these, as is described in Section 3.4.1.2.

\begin{tabular}{|c|c|c|c|c|}
\hline \multirow{2}{*}{$\begin{array}{l}\text { Stacking } \\
\text { Order }\end{array}$} & \multicolumn{2}{|c|}{ Death Valley Regional Flow System Model } & \multicolumn{2}{|c|}{ Yucca Flat-Climax Mine Hydrostratigraphic Model } \\
\hline & Hydrogeologic Unit & ID & Hydrostratigraphic Unit & ID \\
\hline 27 & Younger alluvial aquifer & YAA & Alluvial aquifer & $\mathrm{AA} 2, \mathrm{AA} 1$ \\
\hline 26 & Younger alluvial confining unit & YACU & Playa confining unit & $\mathrm{PCU}$ \\
\hline 25 & Older alluvial aquifer & OAA & Alluvial aquifer & AA2, AA1 \\
\hline 24 & Older alluvial confining unit & $\mathrm{OACU}$ & $n p$ & - \\
\hline 23 & Limestone aquifer & LA & $n p$ & - \\
\hline 22 & Lava-flow unit & LFU & Basalt lava-flow aquifer & $B L F A$ \\
\hline 21 & Younger volcanic-rock unit & YVU & $n p$ & - \\
\hline 20 & Volcanic- and sedimentary-rock unit (upper) & $\begin{array}{l}\text { Upper } \\
\text { VSU }\end{array}$ & $n p$ & - \\
\hline \multirow[t]{3}{*}{19} & Timber Mtn. volcanic-rock aquifer & TMVA & Timber Mountain upper vitric-tuff aquifer & TM-UVTA \\
\hline & & & Timber Mountain welded-tuff aquifer & TM-WTA \\
\hline & & & Timber Mountain lower vitric-tuff aquifer & TM-LVTA \\
\hline 17 & Calico Hills volcanic-rock unit & CHVU & Lower vitric-tuff aquifer & LVTA \\
\hline 16 & Wahmonie volcanic-rock unit & WVU & $n p$ & - \\
\hline 15 & Crater Flat-Prow Pass aquifer & CFPPA & $n p$ & - \\
\hline 14 & Crater Flat-Bullfrog confining unit & CFBCU & $n p$ & - \\
\hline 13 & Crater Flat-Tram aquifer & CFTA & $n p$ & - \\
\hline \multirow[t]{3}{*}{12} & Belted Range unit & BRU & Belted Range aquifer & BRA \\
\hline & & & Belted Range confining unit & BRCU \\
\hline & & & Pre-Grouse Canyon Tuff lava-flow aquifer & PRETBG \\
\hline \multirow[t]{5}{*}{11} & Older volcanic-rock unit & OVU & Tub Spring aquifer & TUBA \\
\hline & & & Pre-Grouse Canyon Tuff lava-flow aquifer 1 & PRETBG1 \\
\hline & & & Lower tuff confining unit & LTCU \\
\hline & & & Oak Spring Butte confining unit & OSBCU \\
\hline & & & Argillic tuff confining unit & ATCU \\
\hline 10 & Volcanic- and sedimentary-rock unit (lower) & $\begin{array}{l}\text { Lower } \\
\text { VSU }\end{array}$ & $n p$ & - \\
\hline 9 & Sedimentary-rock confining unit & $\mathrm{SCU}$ & $n p$ & - \\
\hline 8 & Upper carbonate aquifer & UCA & Upper carbonate aquifer & $U C A$ \\
\hline 7 & Upper clastic-rock confining unit & UCCU & Upper clastic confining unit & UCCU \\
\hline 6 & Lower carbonate aquifer, thrust plate & LCA_T1 & Lower carbonate aquifer & LCA3 \\
\hline 5 & Lower carbonate aquifer & LCA & Lower carbonate aquifer & LCA \\
\hline 4 & Lower clastic-rock confining unit, thrust plate & LCCU_T1 & Lower clastic confining unit, thrust plate & LCCU1 \\
\hline 3 & Lower clastic-rock confining unit & $\mathrm{LCCU}$ & Lower clastic confining unit & LCCU \\
\hline 2 & Crystalline-rock confining unit & $\mathrm{XCU}$ & $n p$ & - \\
\hline 1 & Intrusive-rock confining unit & $\mathrm{ICU}$ & Mesozoic granite confining unit & MGCU \\
\hline
\end{tabular}

Notes: $n p=$ not present. Italicized HSUs are not present in northern Yucca Flat. 


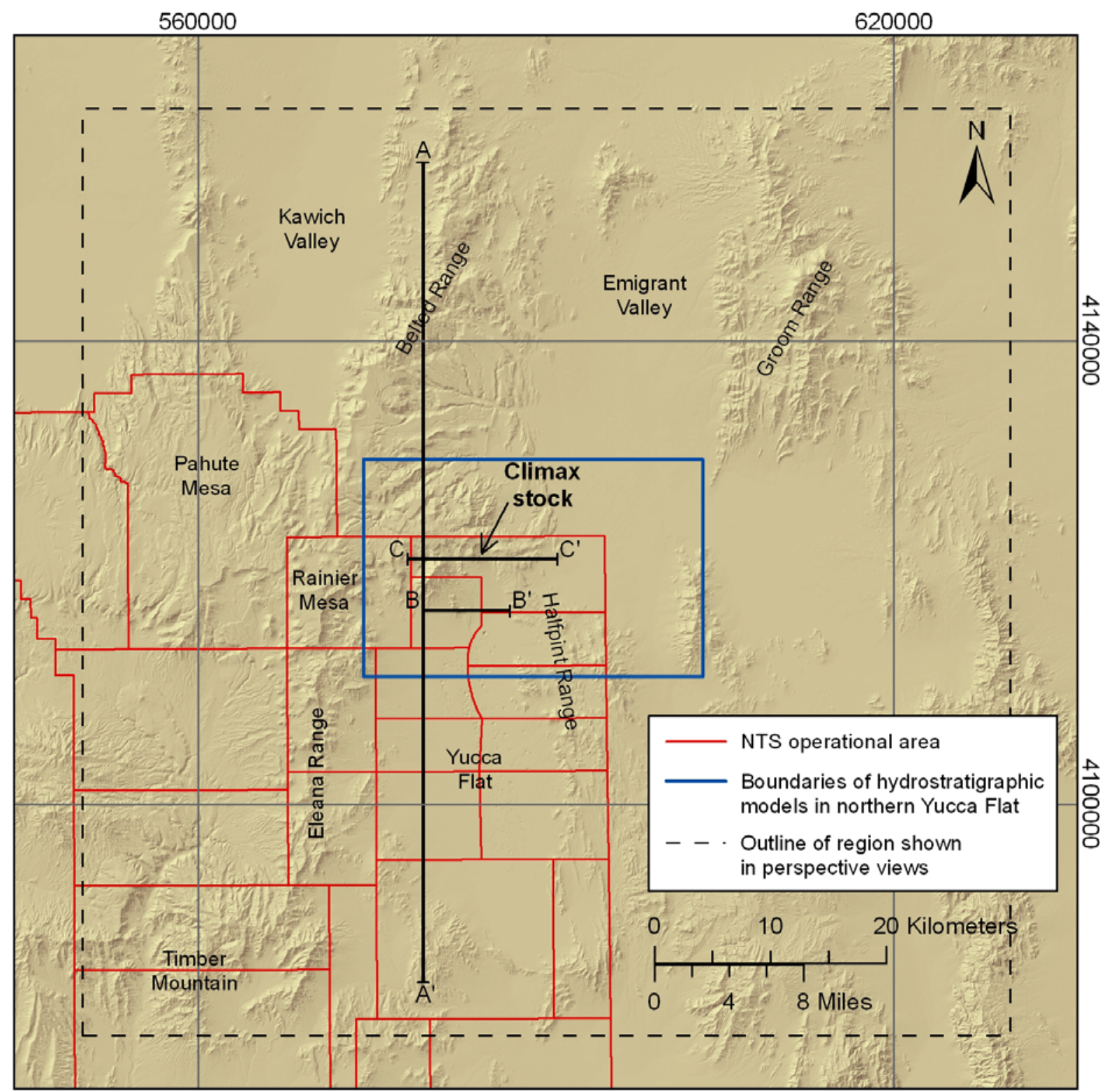

Figure 3-4. Map of the region (bounded by the dashed line) depicted in the perspective views of the DVRFS HGUs shown in Figure 3-5. Also shown are the locations of the cross sections shown on Figures 3-6, 3-8, 3-9, and 3-10. 

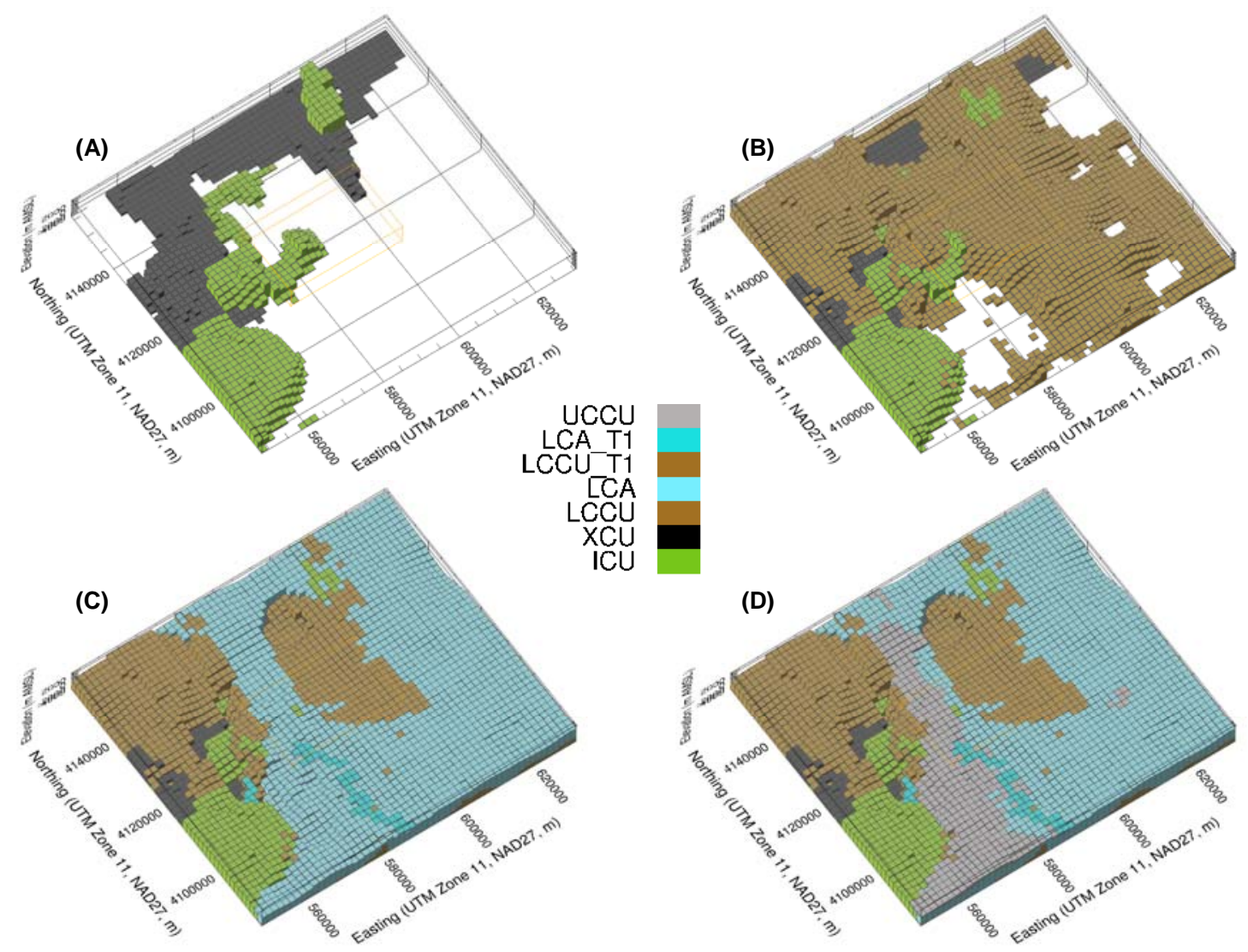

Figure 3-5. Perspective views of the Mesozoic Climax granite intrusion and the pre-Tertiary HGUs in the Climax area as represented in the DVRFS model. The northern Yucca Flat area is shown as an orange box. The area represented by these views is indicated on Figure 3-4.

The DVRFS model delineates fewer volcanic units than are present in the Yucca Flat HFM as a result of the more regional scale and an approach that groups stratigraphic units into hydrogeologic units (Laczniak et al., 1996; Belcher et al., 2004). As a result, the Cenozoic volcanic section is relatively less complex than it is in the UGTA models. In any case, in addition to having lower $K$ values, the Cenozoic volcanic units in northern Yucca Flat tend to be thin and above the regional water table, and thus also tend to provide less of a contribution to groundwater flow through the northern Yucca Flat (Figure 3-6). 


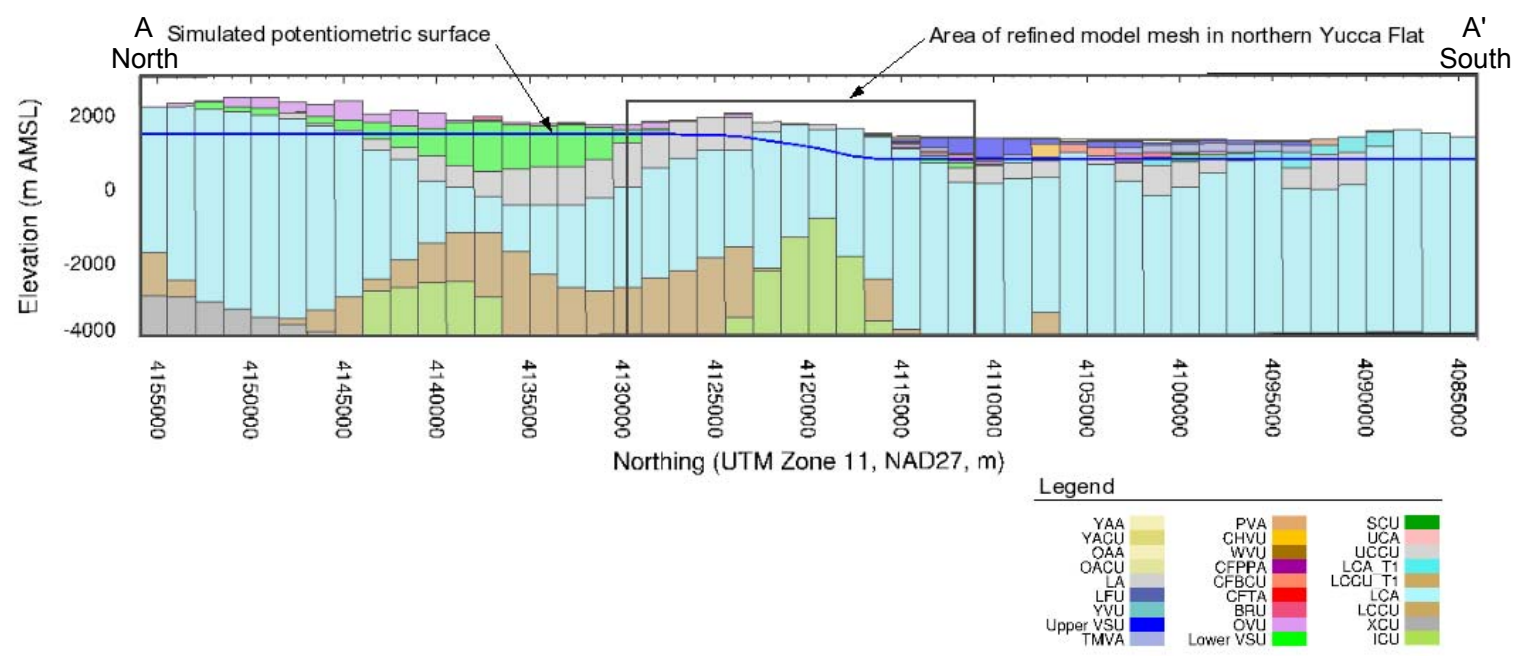

Figure 3-6. North-south cross section approximately $3 \mathrm{~km}$ west of the Climax stock outcrop showing the potentiometric surface simulated by the DVRFS model, the thin volcanic units, and the continuity of the LCA across northern Yucca Flat. The location of this cross section is indicated on Figure 3-4.

\subsubsection{UGTA Base Model}

The HFM developed for the Yucca Flat-Climax Mine CAU represents a detailed three-dimensional hydrostratigraphic model based upon successive geologic interpretative studies conducted over the years at the NTS and particularly within Yucca Flat (Winograd and Thordarson, 1975; IT Corporation, 1996; Laczniak et al., 1996; and Bechtel Nevada, 2006). This model provides the hydrogeologic context for UGTA groundwater flow and contaminant transport modeling in the Yucca Flat-Climax Mine CAU and is therefore used here as the base HFM for the CRFM. The model depicts the geometry of 25 HSUs, which are defined by Bechtel Nevada (2006) as "groupings of contiguous stratigraphic units that have a particular hydrogeologic character, such as an aquifer or confining unit." Twenty of these HSUs extend north from Yucca Flat proper into the Climax area.

In addition to hydrostratigraphic units, the HFM also depicts the major structural features (e.g., thrust faults and normal faults) in northern Yucca Flat. However, the DVRFS model does not explicitly include individual faults as hydraulic conduits at the regional scale (Belcher et al., 2004). Two faults in Yucca Flat, the Yucca Fault and the Carpetbag/Topgallant Fault Zone, were included in the DVRFS model as hydraulic barriers but were found to have little effect on the simulation of heads and discharges and were therefore not included in the calibrated model (Belcher et al., 2004). Because faults that may act as hydraulic conduits within Yucca Flat are not explicitly incorporated in the DVRFS model, they have not been incorporated as features in the CRFM; faults that may form hydraulic barriers to flow through stratigraphic juxtaposition are included.

Differences between the geometry of HSUs in the Yucca Flat base model and the DVRFS model are clearly evident in the pre-Tertiary sedimentary rock section as well as the Mesozoic Climax granite intrusion. Figure 3-7 presents three-dimensional perspective views 
of these HSUs in northern Yucca Flat. Note that these figures represent the units as discretized on a 250-m mesh and therefore the surfaces are smoother and more highly resolved than the same units that are discretized on the 1,500-m mesh of the DVRFS model. In contrast to the DVRFS model, the Yucca Flat-Climax Mine hydrostratigraphic model extends the Climax granite stock through the northwest of northern Yucca Flat where it ultimately joins with the Gold Meadow stock near Rainier Mesa. This configuration displaces a significant portion of the DVRFS LCCU, and more importantly, LCA, in the northwest corner of northern Yucca Flat. To the east of the Climax stock, however, the distribution of the LCCU is very similar to the DVRFS model. Unlike the DVRFS model, though, the LCA extends northeast over the LCCU, further linking it to the regional carbonate aquifer to the north. The distribution of UCCU overlying the LCA on the western portion of the northern Yucca Flat is similar to that of the DVRFS model.

Figure 3-8 is a north-south cross section showing the hydrostratigraphy just west of the Climax stock outcrop. Note that the LCA is represented as extending across the northern Yucca Flat with a configuration very similar to the DVRFS model. It should also be noted that the volcanic and alluvium HSUs are absent or very thin in the vicinity of Climax and therefore are unlikely to make a significant contribution to groundwater flow patterns here.
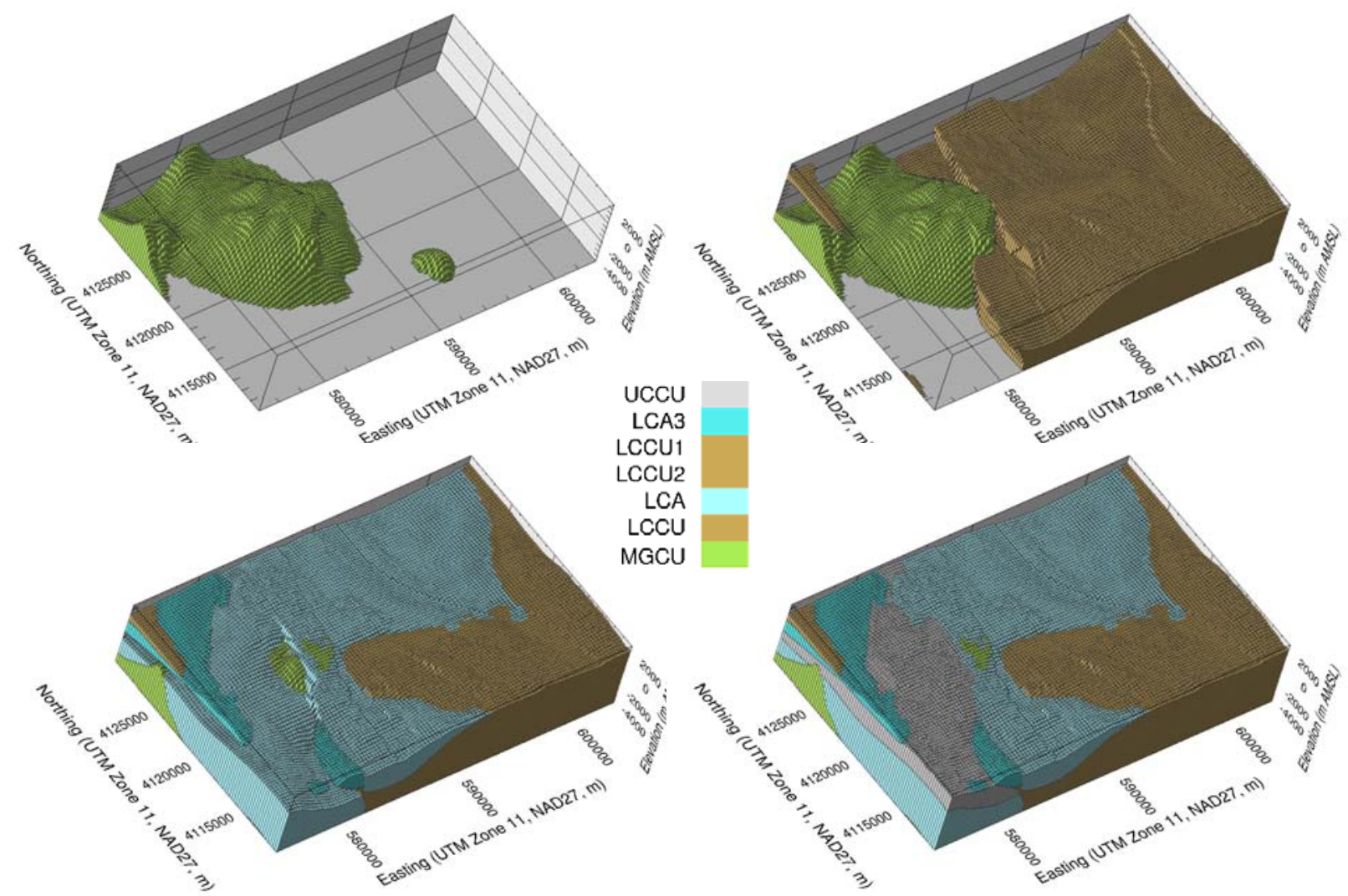

Figure 3-7. Perspective views of the Mesozoic Climax granite intrusion and the pre-Tertiary HSUs as represented in the northern Yucca Flat area of the Yucca Flat-Climax Mine CAU hydrostratigraphic framework model. 


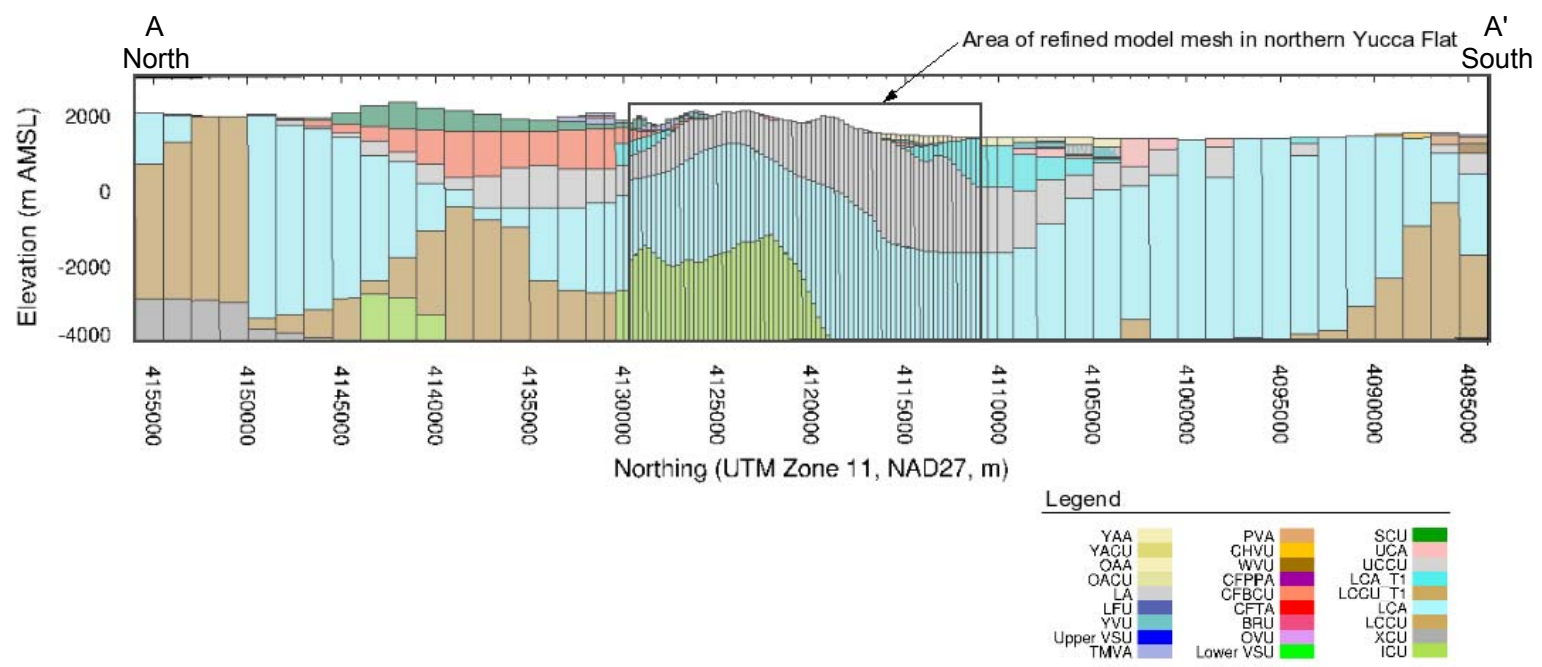

Figure 3-8. North-south cross section showing the Yucca Flat-Climax Mine CAU hydrostratigraphy just west of the Climax stock outcrop. The location of this cross section is indicated on Figure 3-4.

\subsubsection{CP Thrust Alternative Model}

The CP thrust (CPT) alternative addresses uncertainty about the geometry and spatial distribution of the UCCU and LCA. Bechtel Nevada (2006) used results of the magnetotelluric (MT) survey and regional structural analysis to conclude in the base model that the UCCU forms the footwall of the CPT fault (which coincides with the CarpetbagTopgallant fault system), thus limiting the UCCU to the western portion of northern Yucca Flat (i.e., west of the Carpetbag-Topgallant fault). However, operational constraints during the MT survey limited the amount of MT data collection east of the fault and therefore Bechtel Nevada (2006) developed a possible alternative configuration where these subsurface data are sparse.

In the base model, the CP thrust fault separates LCA, which lies directly below the UCCU in the footwall, from thick LCCU and overlying LCA on the east (Figure 3-9). The alternative model shifts the CPT fault from the Carpetbag-Topgallant fault east to the Yucca Fault in northern Yucca Flat, and in conjunction, extends the UCCU and LCA east to the Yucca fault. The UCCU replaces a relatively shallow portion of the LCA that lies between the Carpetbag-Topgallant fault and the Yucca fault in the base case, while the deeper LCA replaces a portion of the base-case LCCU. It is hypothesized that replacement of the shallower LCA with low-K UCCU may significantly impact flow patterns in the Climax area, and in particular, reduce groundwater flow into northern Yucca Flat (Bechtel Nevada, 2006). 


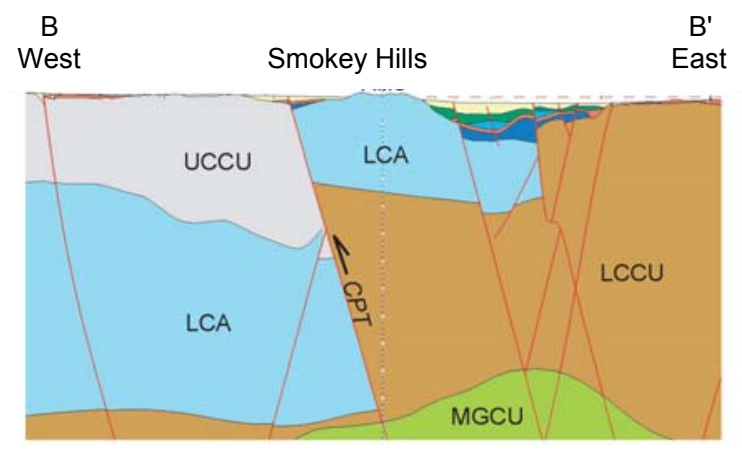

Profile through Northern Yucca Flat-Base Model

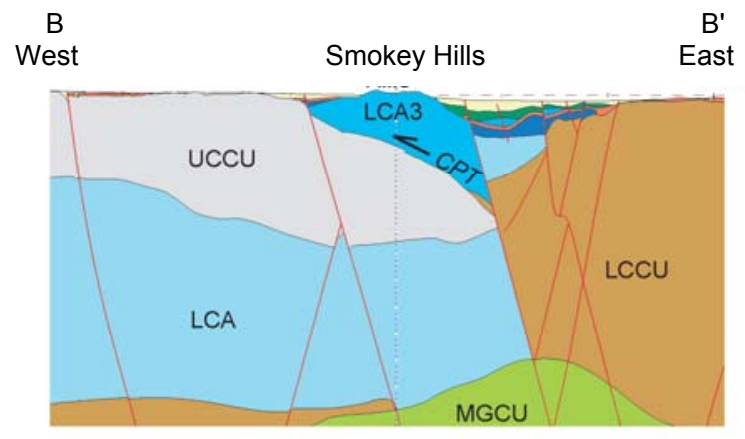

Profile through Northern Yucca Flat-CP Thrust Alternative

Figure 3-9. Cross sections showing east-west profiles through the CPT fault in the base model and the CPT alternative model. The location of these cross sections is shown on Figure 3-4. From Bechtel Nevada (2006).

\subsubsection{Hydrologic Barrier Model}

The hydrologic barrier (HB) alternative provides another possible scenario for reducing groundwater flow, as compared to the base-case model, into Yucca Flat from the north (Bechtel Nevada, 2006). The base-case model provides for groundwater flow within the LCA on both the east and west sides of the Climax stock. The LCA is significantly thicker on the west side, but is physically much deeper in the section below the UCCU, suggesting that depth decay of hydraulic conductivity might reduce the potential for significant groundwater flow. The LCA is considerably thinner on the east side of Climax, but is much higher in the section above the very thick LCCU, such that depth decay of hydraulic conductivity is unlikely to play an important role.

The HB alternative raises the LCCU up to the water table in a small area corresponding to the northwestern end of the Halfpint Range anticline, just east of the Climax stock, thus replacing the LCA there and effectively preventing groundwater flow past the east side of the stock (Bechtel Nevada, 2006). Figure 3-10 illustrates the configuration of the HB alternative in an east-west cross section.

\subsubsection{Combination of CP Thrust and Hydrologic Barrier Models}

Based on analysis of the alternative UGTA models during the elicitation, the expert panel concluded that the CPT and HB alternatives could be combined into a single independent alternative (CPT-HB). With the exception of the small area just east of the Climax stock where the HB alternative raises the LCCU up to the water table (Figure 3-10), the CPT-HB alternative is identical to the CPT alternative. Thus, the CPT-HB alternative represents the same substantial change to the UGTA base model that is represented by the CPT alternative, with the addition of the HB modification. 


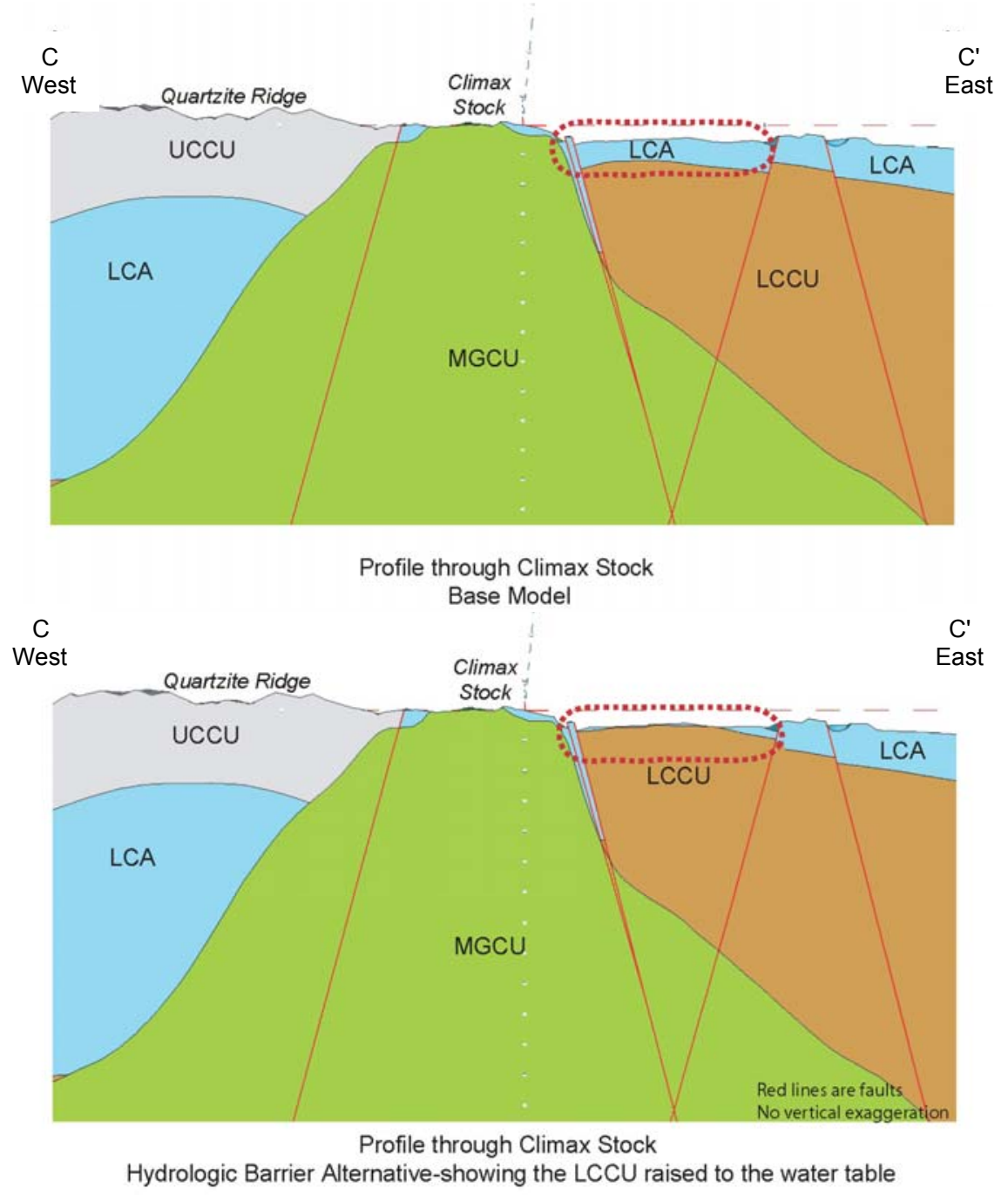

Figure 3-10. Cross sections showing east-west profiles through the Climax stock in the base model and the hydrologic barrier alternative model. The location of these cross sections is shown on Figure 3-4. From Bechtel Nevada (2006).

\subsection{Use of Expert Elicitation to Assess Alternative Model Uncertainty}

Expert elicitation was used to evaluate, based on expert judgment, all of the alternative regional models of groundwater recharge and the models of hydrostratigraphy in northern Yucca Flat. Since the recharge and geologic models are independent, two expert elicitations were conducted separately for the two types of models. Nevertheless, each elicitation followed the same process as described below. Each elicitation panel evaluated the completeness of the sets of recharge and geologic models and ranked them within model type. More importantly, the elicitations gave informative prior probabilities of the models, as opposed to noninformative prior probabilities that treat the models equally likely. The prior model probabilities were directly incorporated in the Bayesian model averaging process introduced previously. Using the informative prior probabilities is expected to yield more accurate predictions, as demonstrated by Ye et al. (2005) in another study. 


\subsubsection{Process of Expert Elicitation and Elicited Issues}

While several processes of expert elicitation have been suggested in the literature (e.g., Hora and Iman, 1989; Bonano et al., 1990), the process proposed by Keeney and von Winterfeldt (1991) was followed, since it is closely pertinent to eliciting probability from experts and has been successfully applied to model probability elicitation (Zio and Apostolakis, 1996). The formal process consists of the following steps (Kenney and von Winterfeldt, 1991):

(1) Identification and selection of issues

(2) Identification and selection of experts

(3) Discussion and refinement of issues

(4) Training for the elicitation

(5) Elicitation

(6) Analysis, aggregation, and resolution of disagreements

(7) Documentation and communication

Descriptions of the implementation of each of these steps are described in Appendix B. Three principal issues were selected for assessment of conceptual model uncertainty in the recharge and geological models, and the elicitations were each conducted in one day. The issues and the rationale for selecting them are as follows:

(1) Is the model set complete? If not, specify plausible recharge model(s).

Bayesian Model Averaging (BMA) requires that alternative models are mutually exclusive and comprehensively exhaustive. The exclusiveness can be satisfied in standard hydrologic practice, where one typically selects a single model at the exclusion of all other models. However, the exhaustiveness cannot be satisfied in an absolute sense, since a true model representing reality is unknown. It is thus required that a model set is complete if, for given objectives of an analysis, it includes all models consistent with prior knowledge and data. In other words, a complete model set is expected to provide a satisfactory representation of the system of interest and enclose all uncertain conceptual models.

(2) What are the plausibility ranks of these models?

While ranking of model plausibility is qualitative and the ranks are not used in BMA, evaluating the ranks helps experts evaluate relative plausibility of alternative models before they estimate prior model probability.

(3) What is the probability value that best represents the confidence you would place on each recharge model, given the objective of the analysis?

Model probabilities are the final goal of expert elicitation, and will be used directly in the BMA. Summation of the model probabilities is first. Setting prior probability of one more to 1 requires setting the prior probabilities of all other models equal to zero. This means that the joint probabilities of any two models in the model set are zero (i.e., they are mutually exclusive).

Since recharge and geological models are independent, the three issues above were elicited separately for the recharge and geological models in two elicitations. Prior probabilities of combination of any recharge and geological models can be easily estimated due to their independent nature. 


\subsubsection{Elicitation Results for Alternative Models of Recharge}

Elicitation results of alternative recharge models are summarized below.

\subsubsection{Model Set Completeness}

The five recharge models in the model set are:

- Model 1: modified Maxey-Eakin model (MME)

- Model 2: net infiltration model with runon-runoff component (NIM1)

- Model 3: net infiltration model without runon-runoff component (NIM2)

- Model 4: chloride mass-balance model with alluvial mask (CMB1)

- Model 5: chloride mass-balance model with alluvial and elevation masks (CMB2)

While four experts considered that the model set is complete, three experts suggested the deuterium-calibrated groundwater flow model used together with the Discrete-State Compartment (DSC) model (Feeney et al., 1987; Kirk and Campana, 1990; Sadler et al., 1991). This model is based on saturated-zone studies and, in this sense, is similar to the chloride mass-balance models included in the model set. It is a combination of a tracer technique and a numerical modeling method. The numerical modeling method (i.e., the discrete-state compartment model) divides a flow domain into various cells and estimates uniform recharge within each cell by calibrating tracer mass estimates against site measurements. For this project, the deuterium-calibrated groundwater flow model is considered unsuitable, mainly because it does not incorporate recharge spatial variability within each cell (always covering a large area), although recharge at different cells may be different. This renders the model less plausible than the distributed parameter watershed models and the chloride mass-balance models, which consider recharge variability over the simulation domain at high resolution. While Epstein's (2004) modification of the MaxeyEakin model considers recharge spatial variability at a relatively coarse resolution (by dividing precipitation into four zones), it still provides higher resolution of recharge variability than the deuterium-calibration groundwater model.

\subsubsection{Model Plausibility Ranking and Prior Model Probability}

Model rankings elicited from the experts are plotted in Figure 3-11. For each model, each column represents one expert's ranking of the model. Models 2 and 3 received the highest and lowest overall ranking, respectively. The ranking of model 5 is higher than that of model 4 , but lower than that of model 1 . The model plausibility ranking is consistent with elicited prior model probability plotted in Figure 3-12, in which the maximum and minimum prior probabilities are 45 percent and 5 percent, respectively. Models 1, 2, and 5 did not receive the minimum prior probability from any expert, and they are the three most plausible models, as shown below. Although the experts evaluated the models from various aspects (e.g., model assumptions, sensitivity of output to mode parameter, and calibration results), no experts placed more than 50 percent confidence on the models. This is reasonable since the models were developed independently for Nevada and belong to three different recharge technique categories (Scanlon, 2004): empirical (e.g., the Maxey-Eakin model), recharge techniques based on unsaturated-water studies (e.g., the net infiltration models), and recharge techniques based on saturated-water studies (e.g., the chloride mass-balance models). 
Figure 3-13 plots prior probability of the three model categories, in which the second category includes Models 2 and 3 and the third category, Models 4 and 5. Probability of the second category exceeds 50 percent, indicating the experts have more confidence in this type of model, since it considers recharge spatial variability and potentially can capture certain future phenomena. The third category has higher probability than the first one, since it can better represent recharge spatial variability than the first model category. Based on the prior

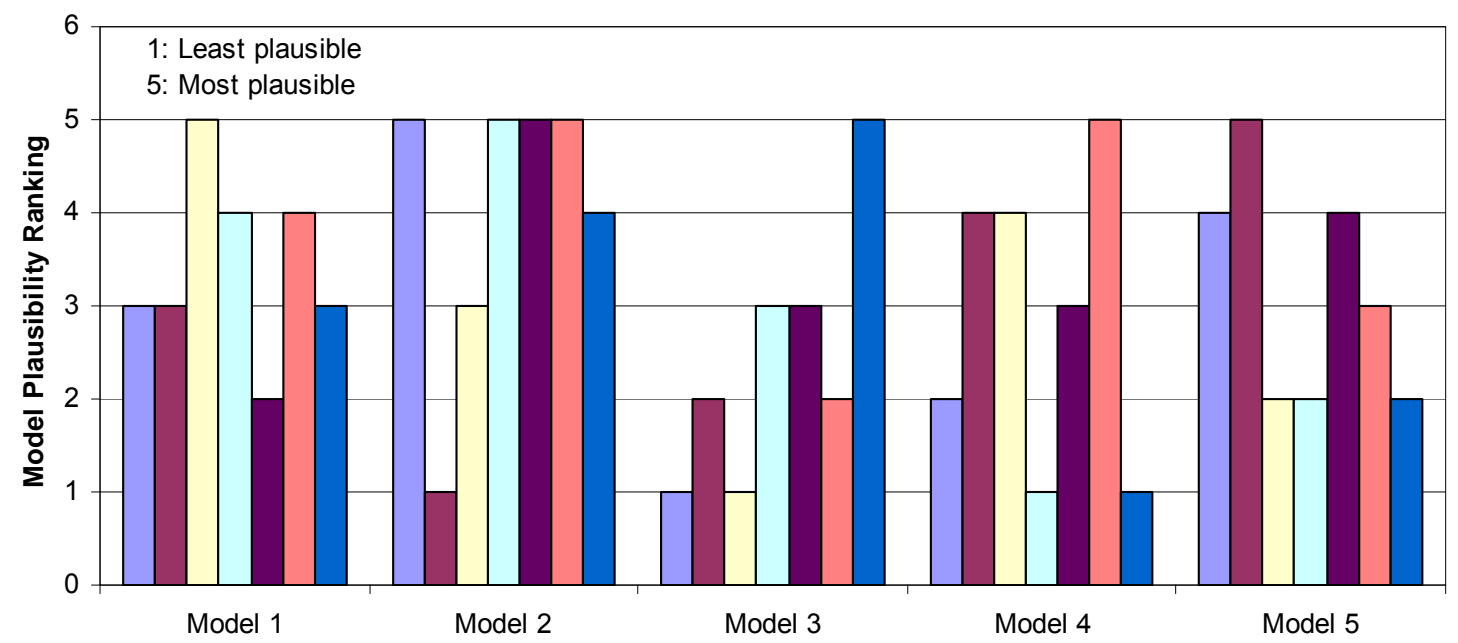

Figure 3-11. Column chart of the plausibility ranking of the five models. The columns of each model represent elicited model ranking from the experts. The most plausible model is ranked 5 and the least plausible model is ranked 1. (Model 1: Maxey-Eakin model; Model 2: distributed parameter watershed model with runon-runoff component; Model 3: distributed parameter watershed model without runon-runoff component; Model 4: chloride mass-balance model with only alluvial mask; Model 5: chloride mass-balance model with both alluvial and elevation masks.)

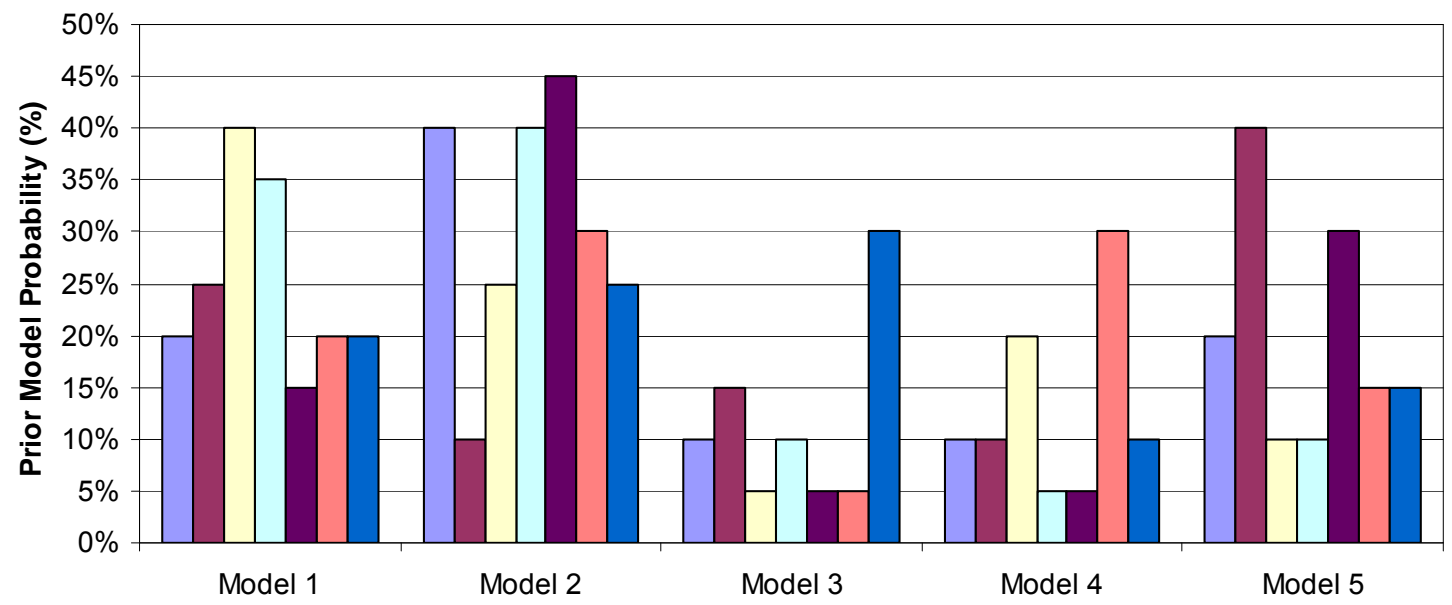

Figure 3-12. Column chart of the prior probability of the five models. The columns of each model represent elicited prior model probability from the experts. (Model 1: Maxey-Eakin model; Model 2: distributed parameter watershed model with runon-runoff component; Model 3: distributed parameter watershed model without runon-runoff component; Model 4: chloride mass-balance model with only alluvial mask; Model 5: chloride mass-balance model with both alluvial and elevation masks.) 


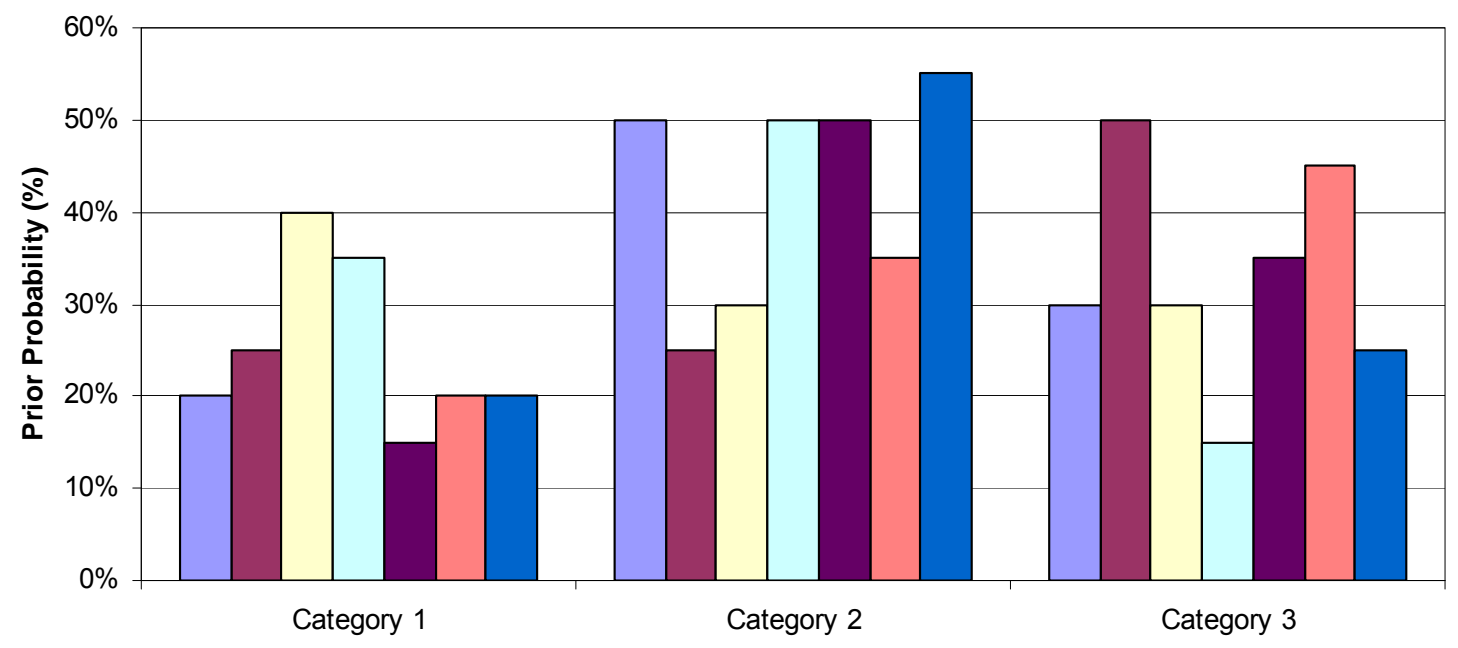

Figure 3-13. Column chart of the prior probability of the three categories of the five models. The columns of each model represent elicited prior model probability from the experts. (Category 1: Maxey-Eakin model; Category 2: distributed parameter watershed model with/without runon-runoff component; Category 3: chloride mass-balance model with only alluvial mask and with both alluvial and elevation masks.)

model probabilities, it appears that the bias of overconfidence did not occur during the elicitation. Although model developers were included in the elicitation panel, they did not exclude other models, and explicitly mentioned limitations of their models in the questionnaire. The bias of anchoring is also not seen, since each expert gave different prior probabilities to different recharge models. In addition, elicited prior probabilities are significantly different for the experts. It is unclear if the bias of availability was avoided, based on the experts' answers to the questionnaire.

\subsubsection{Aggregation of Prior Model Probability and Expert Weight}

The prior model probabilities of the five models elicited from each expert were aggregated to yield final prior probabilities using the method of De Groot (1974), which is discussed in Appendix B, following Cooke (1991). The aggregated prior model probabilities are plotted in Figure 3-14. Models 2 and 3 have the largest and smallest probability, respectively. Probability of Model 5 is larger than that of Model 4, but less than that of Model 1. This order of model plausibility is consistent with the model ranking depicted in Figure 3-12. Since none of the models has prior model probability larger than 50 percent, there is no justification to select one model and discard others based on prior information and expert judgment. Although prior probabilities given by each expert are significantly different (Figure 3-12), the aggregated probabilities are more or less uniform, considering that equally likely prior probability is 20 percent. The largest deviation from the equally likely prior probability is only 10 percent for Model 2 . This, however, does not imply the bias of anchoring that occurred in the elicitation, since each expert assigned significantly different prior probabilities to different models (Figure 3-12). Instead, this manifests the inherent uncertainty in the recharge models, since they are developed independently based on solid physical principles and assumptions, calibrated with site measurements, and have been applied to Nevada water issues (especially the Maxey-Eakin method). 


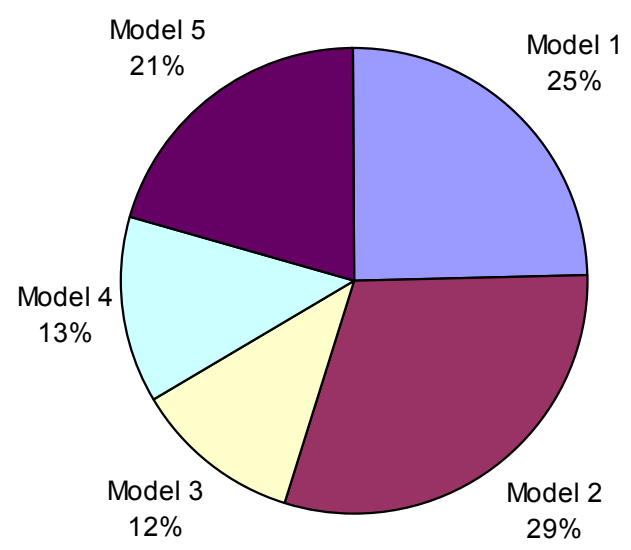

Figure 3-14. Iteratively aggregated prior probability with consideration of expert-to-expert variability. (Model 1: Maxey-Eakin model; Model 2: distributed parameter watershed model with runon-runoff component; Model 3: distributed parameter watershed model without runonrunoff component; Model 4: chloride mass-balance model with only alluvial mask; Model 5: chloride mass-balance model with both alluvial and elevation masks.)

Although the aggregation method above considers expert-to-expert variation, the aggregated prior probabilities are close to simple averaging results by assigning equal weights to all experts, i.e., $P_{j}=\frac{1}{N} \sum_{i=1}^{N} P_{i j}$, where $N$ is the number of experts and $P_{i j}$ is the prior probability expert $i$ assigns to alternative model $j$. Figure 3-15 plots the simply aggregated prior model probabilities, and it is almost identical to Figure 3-14 of the iteratively aggregated prior probabilities, except for the 1-percent difference in the prior probabilities of Models 2 and 3. The negligible difference results from the more-or-less uniform expert weights assigned by each expert. Figure 3-16 shows that four experts assigned the exact same or almost the same weights to all experts. Despite the small difference between the results of iterative and simple aggregation results, the iterative aggregation is still preferred, since it provides a formal way to reach consensus with consideration of expert-to-expert variability.

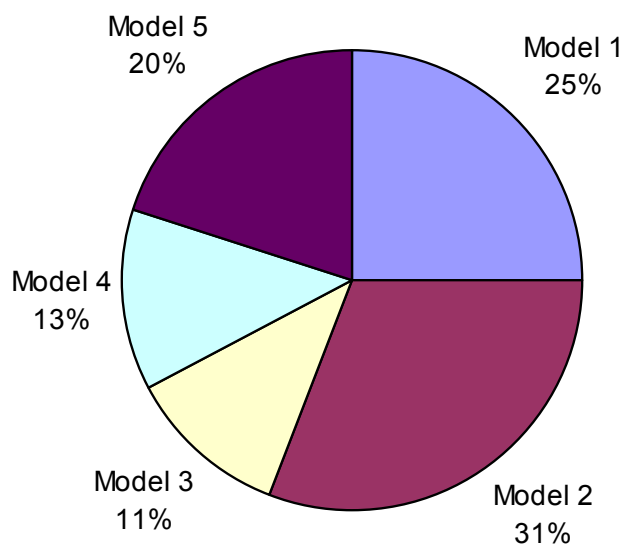

Figure 3-15. Simply aggregated prior probability by assigning equal weight to the experts. (Model 1: Maxey-Eakin model; Model 2: distributed parameter watershed model with runon-runoff component; Model 3: distributed parameter watershed model without runon-runoff component; Model 4: chloride mass-balance model with only alluvial mask; Model 5: chloride mass-balance model with both alluvial and elevation masks.) 


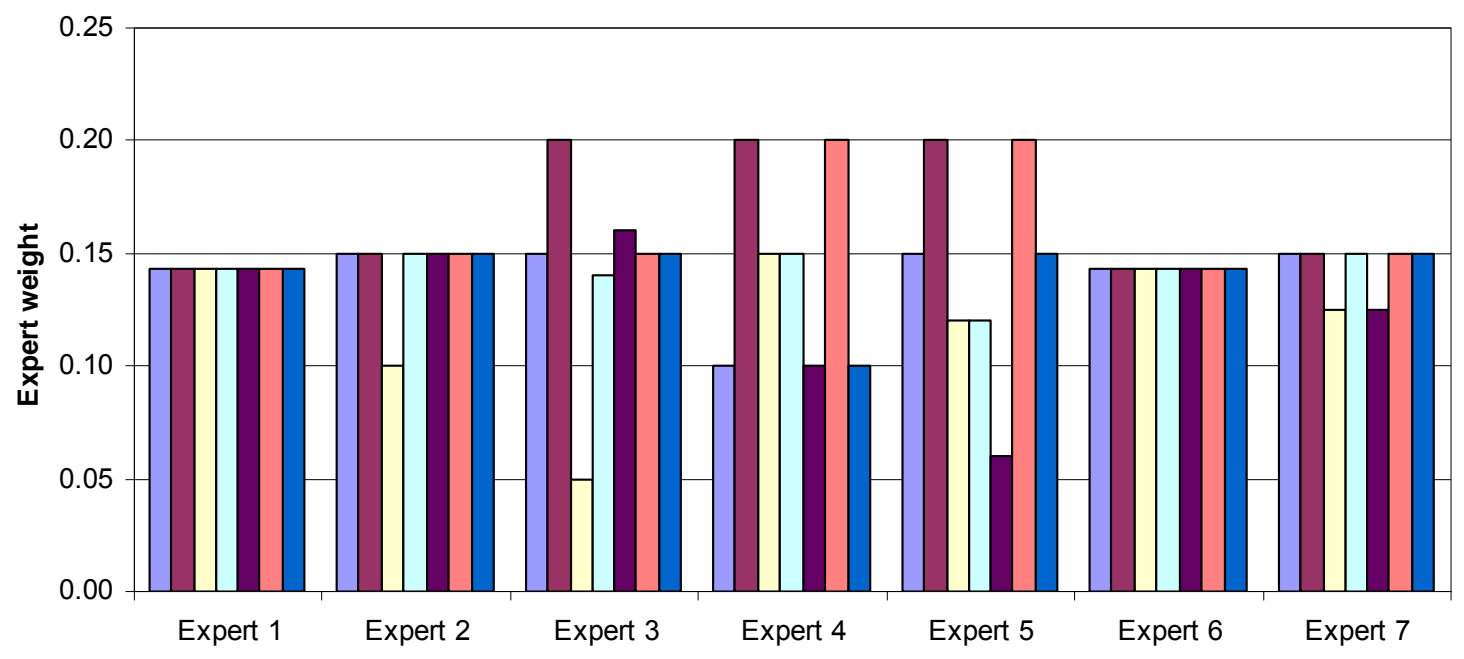

Figure 3-16. Expert weight assigned by each expert (x axis) to all experts. The columns of each expert represent the weight assigned to all experts.

\subsubsection{Elicitation Results for Alternative Models of the Hydrostratigraphic Framework}

Expert elicitation results of alternative geological models are summarized below.

\subsubsection{Model Set Completeness}

The alternative models considered in the Climax Mine modeling project include:

(1) Model 1: USGS Death Valley Regional Flow System Model (USGS)

(2) Model 2: UGTA base model (BAS)

(3) Model 3: CP thrust alternative of the base model (CPT)

(4) Model 4: Hydrologic barrier model (HB)

(5) Model 5: Combination of Model 3 and Model 4 (CPT+HB)

Among these models, Model 1 (USGS) was developed independently from other models; Models 3 through 5 are the alternatives proposed for Model 2 (BAS). These models are mutually exclusive since they are different enough to be distinguished from one another. These models are considered to provide a sufficiently complete representation of the geologic models of northern Yucca Flat and its vicinity and adequately incorporate uncertainty in geologic models. In other words, taking the project into consideration, there is no other plausible geologic model that is consistent with prior information and can potentially provide good calibration results against site measurements. Plausibility rank and probabilities of the above five models were elicited from the experts as qualitative and quantitative expressions of the experts' confidence in the models.

\subsubsection{Model Plausibility Ranking and Prior Model Probability}

Model rankings elicited from the experts are plotted in Figure 3-17, where each column of a model represents an expert's ranking for the model. For example, the plausibility ranking of the five models given by Expert 3 is 3, 5, 2, 4, and 1, as presented by the yellow columns. Qualitatively speaking, Models 1 and 2 receive the lowest and highest overall ranking, respectively. Models 2 and 4 have similar rankings, while models 3 and 5 have 
similar rankings. Three experts treat Models 2 through 5 (the base model and its alternatives) equally likely and two experts treat Models 3 through 5 (the three alternatives of the base model) equally likely. This indicates that the prior information is not enough for the experts to rank certain models. The model plausibility ranking is consistent with the elicited prior model probabilities plotted in Figure 3-18, which shows that the maximum and minimum prior probabilities are 45 percent and 5 percent, respectively. Although the experts evaluated the models from various aspects, no expert places more than 50 percent confidence on any single model. One of the reasons is that, while available data (e.g., drill-hole and geophysical) are sufficient to discriminate certain models (e.g., USGS model consistently receives low probability), the data are insufficient to significantly discriminate one model against another. In addition, the prior information (e.g., experts' knowledge and experience) is inadequate to encourage the experts to place considerably high confidence on certain models.

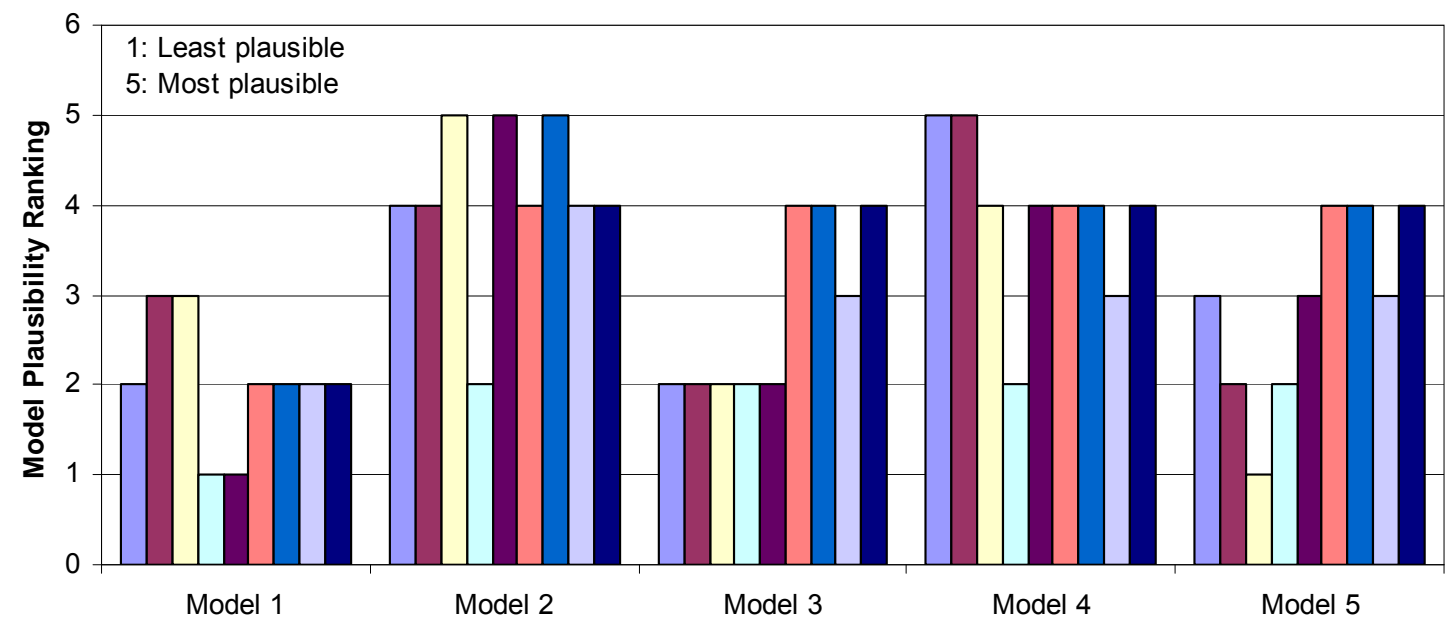

Figure 3-17. Column chart of the plausibility ranking of the five models. The columns of each model represent elicited model ranking from the experts. The most plausible model is ranked 5 and the least plausible model is ranked 1. (Model 1: USGS Death Valley model; Model 2: base model; Model 3: CP thrust alternative; Model 4: hydrologic barrier alternative; Model 5: combination of the $\mathrm{CP}$ thrust and hydrologic barrier alternatives.) 


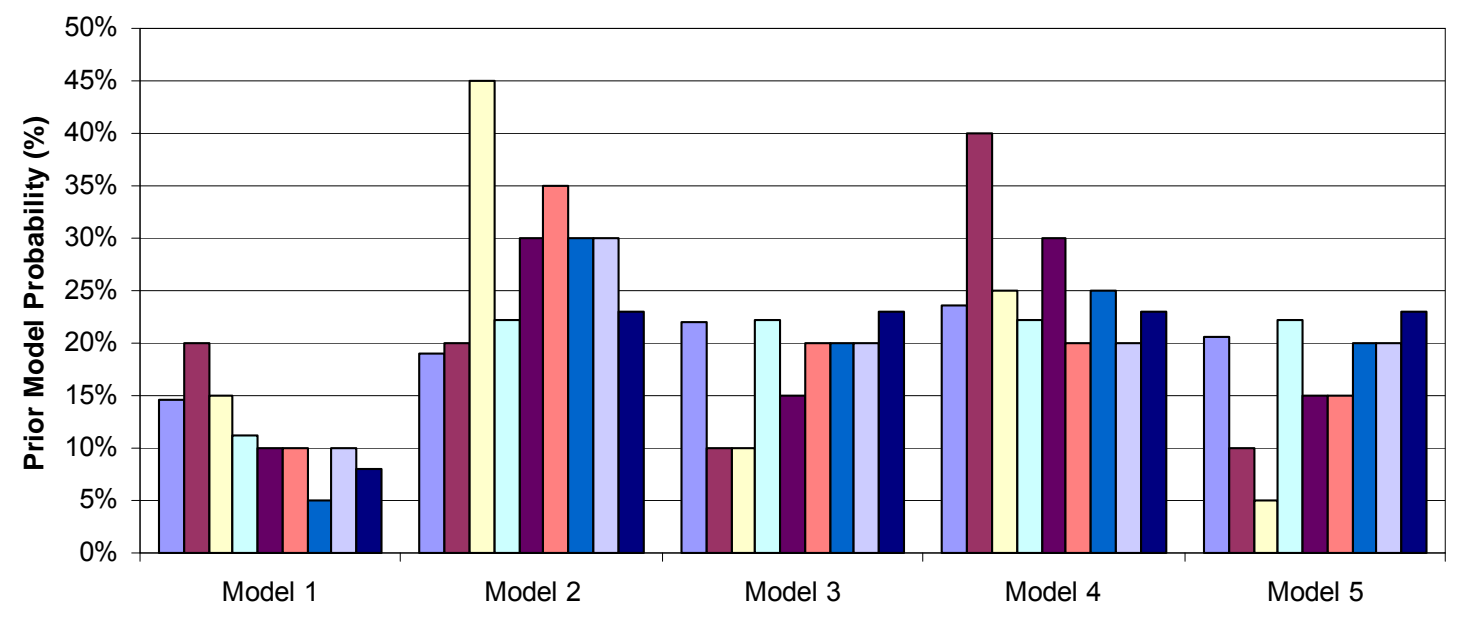

Figure 3-18. Column chart of the prior probability of the five models. The columns of each model represent elicited prior model probability from the experts. (Model 1: USGS Death Valley model; Model 2: base model; Model 3: CP thrust alternative; Model 4: hydrologic barrier alternative; Model 5: combination of the CP thrust and hydrologic barrier alternatives.)

Model 1 (USGS) receives the lowest probability from seven of the nine experts, and the reasons are summarized as follows:

(1) It is contrary to certain data.

(2) It does not honor certain data and the data used are not current.

(3) Interpretation of certain data is improper.

(4) It does not rely on geologic interpolation as much as other models.

(5) Its scale is too large and data interpretation may be too smooth. It thus cannot present the details and reflect local change.

(6) It disagrees with the experts' knowledge and experience at the site.

Although the USGS model presentation differed from that of the other models, the reasons given above of assigning low prior probability to the model are solid, indicating that the evaluation of this model is not biased.

Model 2 (BAS) receives the highest probability from seven experts, three of whom consider it as equally plausible as Model 4. The reasons are summarized as follows:

(1) It agrees with all available data.

(2) It incorporates the current data and properly interprets the data.

(3) It represents the best interpretation of the hydrogeology from a team of geologists who are familiar with the site.

Model 4 (HB) receives the highest probability from five experts, three of whom consider it as plausible as Model 2. The reasons are summarized as follows:

(1) Some sort of competent barrier exists between Yucca Flat and Groom Lake.

(2) Extending the LCCU to create a hydrologic barrier is consistent with, but not required by, the surface geology. 
(3) Elevating the core of the Halfpint anticline requires the smallest modification of the existing model and is most geologically reasonable because just the amplitude of the existing fold is being modified.

The probability of Model 3 (CPT) is larger than Model 1 (USGS), but smaller than Models 2 (BAS) and 4 (HB). The reasons are summarized as follows:

(1) Data supporting the CP thrust farther east (i.e., MT data) are weaker than data supporting other alternatives (drill-hole and surface geology).

(2) The model appears to violate MT data.

(3) The model is against the experience with drill hole ER 12-2 and with the surface geology near the Tippinip fault.

(4) The model leaves model outcrops of Wood Canyon near the Climax stock unexplained.

Six of nine experts consider Model 5 as plausible as Model 3, while three experts assign smaller probability to Model 5 than to Model 3, mainly because Model 5 is the combination of two uncertain alternatives and thus subjected to larger uncertainty.

Based on the values of prior model probability given by the experts, it appears that the bias of overconfidence did not occur in the elicitation, since the largest prior model probability is 45 percent. The bias of anchoring was slightly observed for Models 3 and 5, since their probabilities are around 20 percent, the default value of equal probability. The bias of availability was not apparently observed, since the experts used various sources, evidence, and reasoning to determine the prior probabilities.

\subsubsection{Aggregation of Prior Model Probability and Expert Weight}

The prior model probabilities of the five models elicited from each expert were aggregated to yield final prior probabilities using the method of De Groot (1974), which is described in Appendix B, following Cooke (1991). The aggregated prior model probabilities are plotted in Figure 3-19, in which Models 1 and 2 have the smallest (11\%) and largest (28\%) probability, respectively. Model 4 has the second largest probability (26\%), only 2 percent smaller than the largest one. Models 3 and 5 have similar probabilities $(17 \%$ and $18 \%$ ), which are slightly larger than the smallest one. Since the models have similar prior probabilities, there is no justification to select one model and discard others based on prior information and expert judgment. Although prior probabilities given by each expert are significantly different (Figure 3-18), the aggregated probabilities are more or less uniform, recalling that the equally likely prior probability is 20 percent. The largest deviation from the equally likely prior probability is only 9 percent for Model 1 . This manifests the inherent uncertainty in the geologic models, due to the lack of data and inability to completely describe the geologic conditions at the site. It is interesting that the base model does not receive significantly high prior probability (e.g., 80\%), since Models 3 through 5 are its alternatives and the four models do not differ drastically. Aggregated prior model probabilities using simple averaging are plotted in Figure 3-20. These probabilities are almost identical to those iteratively aggregated, and only a 1 percent difference of Models 1 and 4 is observed. The negligible difference between Figures 3-19 and 3-20 results from the more-or-less uniform expert weights assigned by each expert. Figure 3-21 shows that two experts assigned the exact same and four experts assigned almost the same weights to all 
experts. Despite the small difference between the iterative and simple aggregation results, the iterative aggregation is still preferred, since it provides a formal way to reach consensus with consideration of expert-to-expert variability.

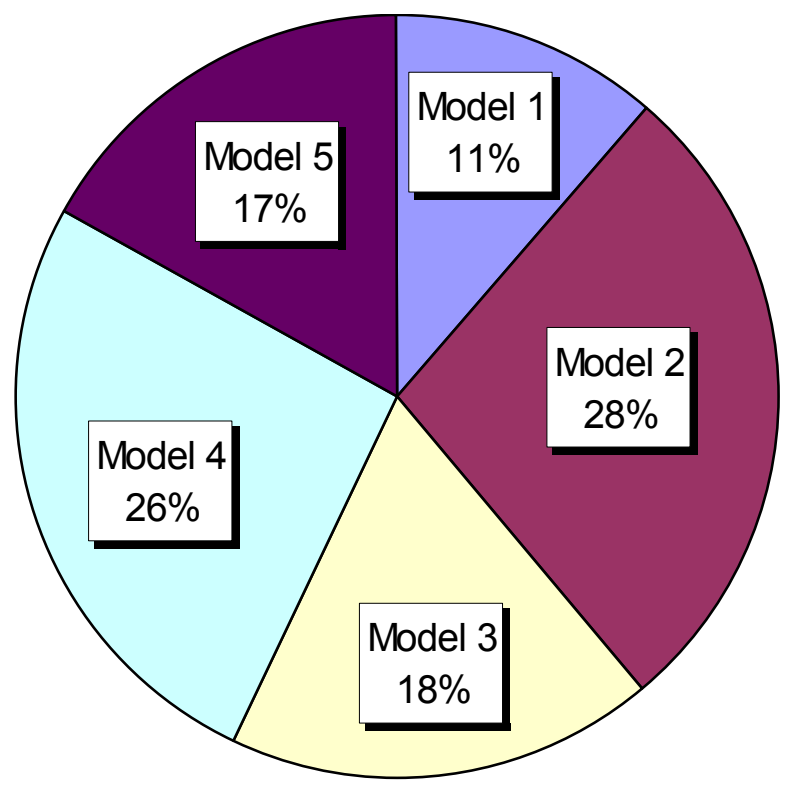

Figure 3-19. Iteratively aggregated prior probability. (Model 1: USGS Death Valley model; Model 2: base model; Model 3: CP thrust alternative; Model 4: hydrologic barrier alternative; Model 5: combination of the $\mathrm{CP}$ thrust and hydrologic barrier alternatives.)

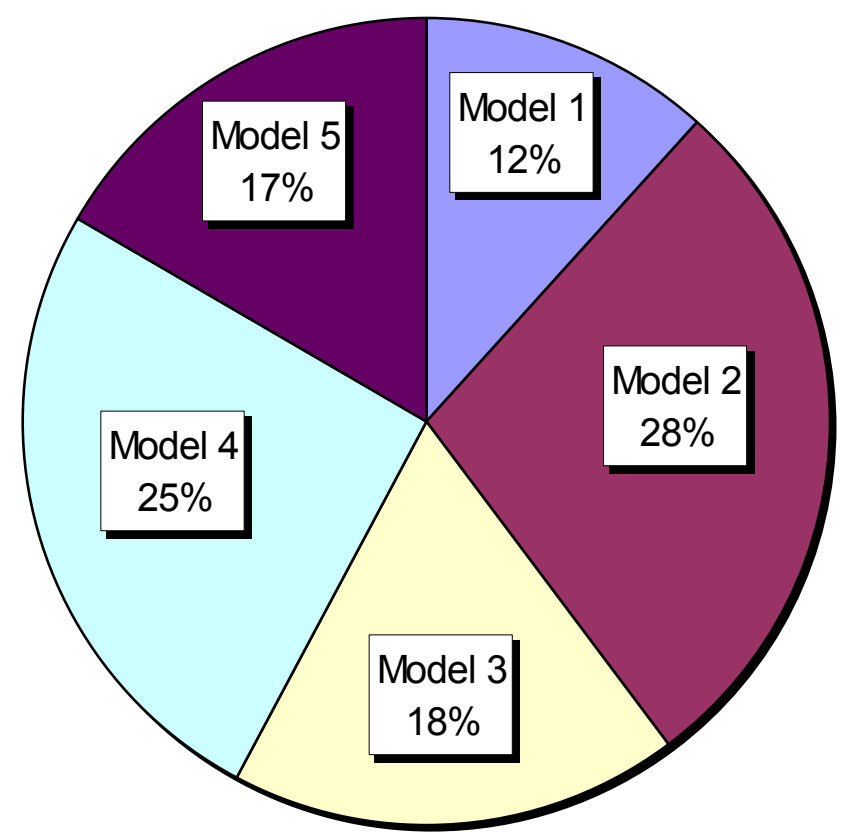

Figure 3-20. Simply aggregated prior probability by assigning equal weight to the experts. (Model 1: USGS Death Valley model; Model 2: base model; Model 3: CP thrust alternative; Model 4: hydrologic barrier alternative; Model 5: combination of the CP thrust and hydrologic barrier alternatives.) 


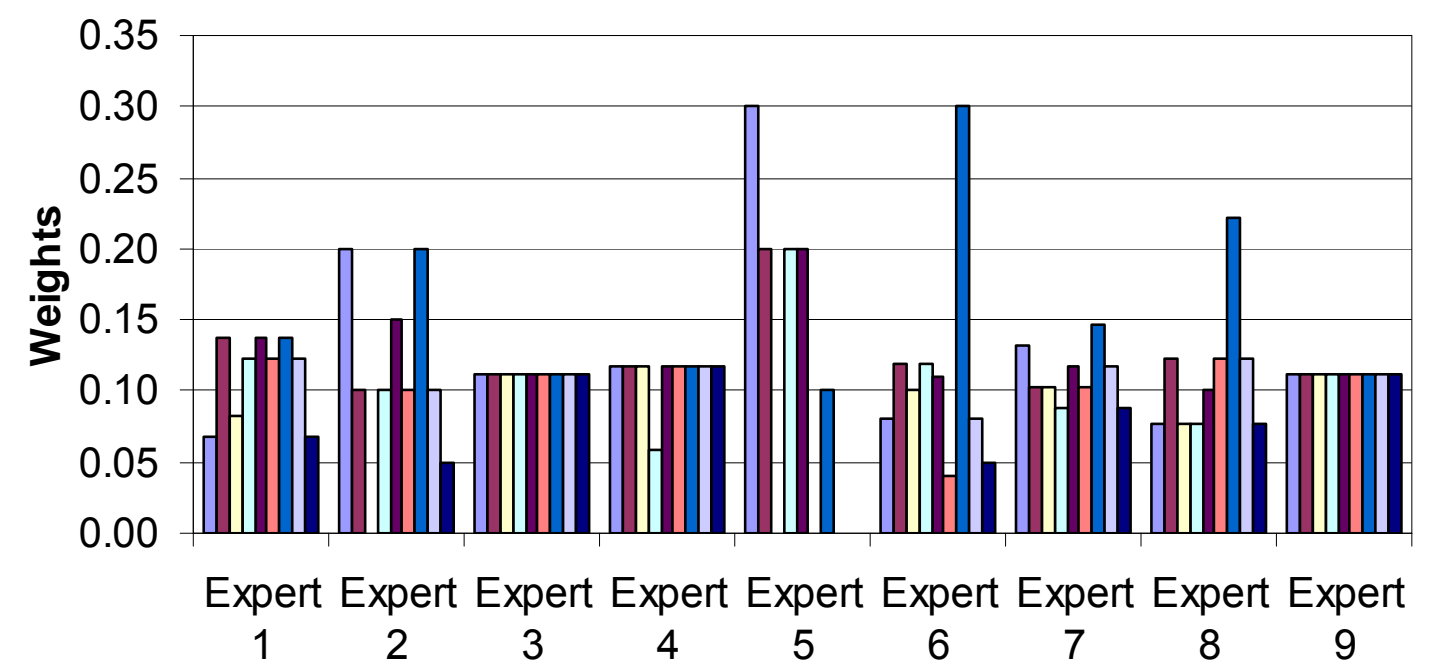

Figure 3-21. Expert weight assigned by each expert (x axis) to all experts. Each cluster represents the weights each expert assigned to all experts.

\subsubsection{Prior Probabilities of Recharge/Hydrostratigraphic Model Combinations}

Given that recharge and geological models are independent, prior probabilities of a combination of any recharge and geological models can be estimated based on their prior probabilities obtained from the two elicitations. Figure 3-22 plots prior probabilities of the 25 combined models, where $\mathrm{G}$ and $\mathrm{R}$ stand for geological and recharge models, respectively. Probabilities of 15 of the 25 models are less than 4 percent, if all the models are treated equally likely. Although no model receives more than 10 percent probability, variation of the prior probabilities is still relatively significant. For example, model G1R3 has only 1.32-percent probability, while model G2R2 has 8.4-percent probability. This is not surprising since geological model G1 (USGS model) and recharge model R3 (net infiltration model without runon-runoff component) have the smallest probabilities among the geological and recharge models. By the same token, G2R2 has the highest probability, since models G2 and R2 have the highest probabilities among the geological and recharge models.

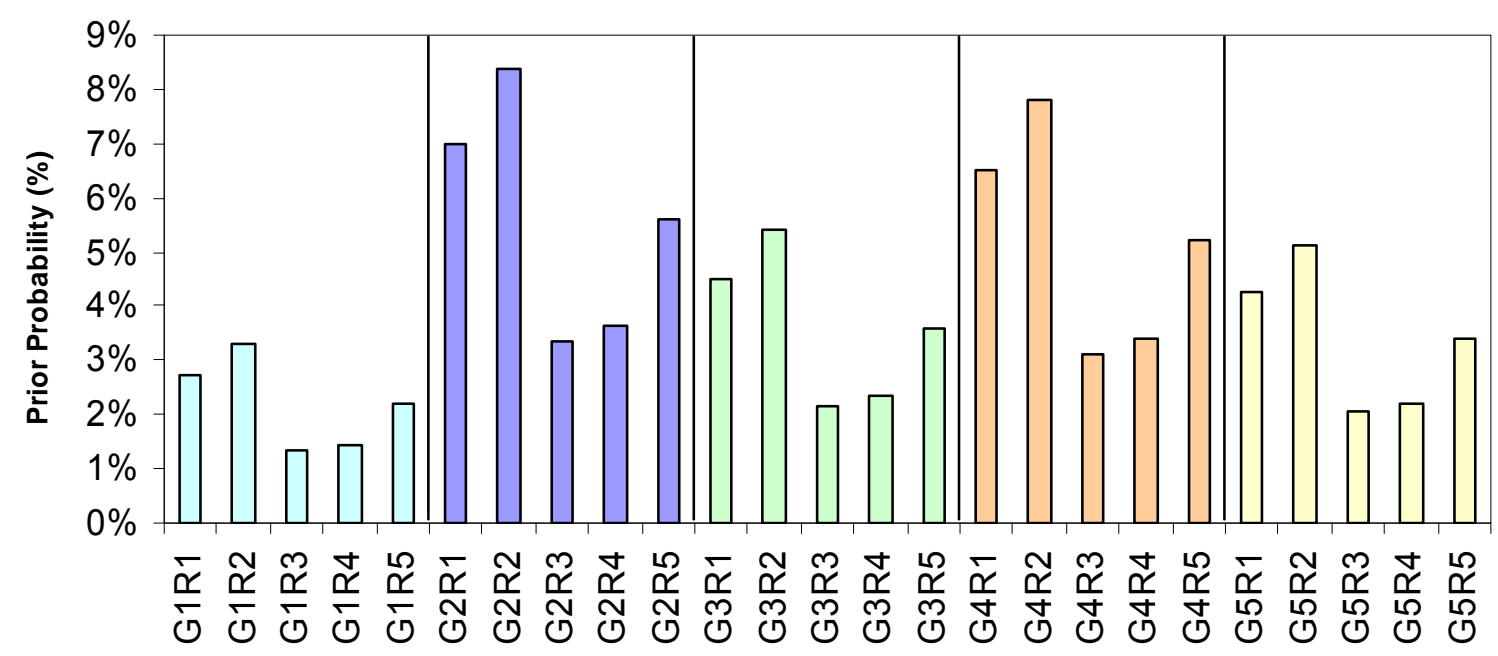

Figure 3-22. Prior probabilities of combinations of recharge and geological models. 


\subsection{Use of Model Calibration to Assess Alternative Model Uncertainty}

Uncertainty arising from the various alternative models of groundwater recharge and hydrostratigraphic framework is assessed through their incorporation in the Climax regional flow model. Calibration of this model provides the basis for differentiating between the alternative models and for assessing parametric uncertainty. The modeling framework developed for the DVRFS was adapted for calibration of the Climax model. In addition, modifications to the Death Valley model allowed for inclusion of the alternative models and for the higher resolution of the Yucca Flat hydrostratigraphic framework models.

\subsubsection{Model Construction}

The CRFM is based directly on the DVRFS model. The principal differences are (1) the model mesh is refined to incorporate the more highly resolved Yucca Flat HFMs, and (2) alternative models of groundwater recharge and HFM are integrated.

\subsubsection{Model Domain}

The flow model mesh is oriented north-south in alignment with the UTM grid and is discretized in plan view into 262 columns and 261 rows (Figure 3-23, Table 3-5). Though the numbers of rows and columns have been significantly increased from the DVRFS model, the vertical model layering structure has been preserved. Sixteen layers are used, with 15 of them ranging in thickness from 50 to about $300 \mathrm{~m}$. Layer 1 forms the top of the model and its upper elevation is set to the simulated potentiometric surface. Layer 16 forms the base of the model and extends to $4,000 \mathrm{~m}$ below sea level. Model layer elevations do not conform to HGU elevations owing to the irregular shapes of the geologic units that result from depositional and structural processes in the region (Belcher et al., 2004).

Bechtel Nevada's hydrostratigraphic framework models are built at a resolution much higher than the mesh spacing of the DVRFS model. To preserve this high level of detail in the CRFM, the horizontal mesh within northern Yucca Flat is refined to a 250-m spacing from the 1,500-m spacing in the DVRFS model, or 36 refined cells per one original cell. Model cells within northern Yucca Flat are centered on the HFM model mesh, while model cells outside a transition zone surrounding northern Yucca Flat (described below) coincide with the DVRFS model mesh. Refinement of the entire domain at the 250-m spacing was not justified because additional hydrostratigraphic detail was not available for the majority of the domain outside northern Yucca Flat and the concomitant computational demands of the model runs would have been exorbitant.

To minimize the truncation error that originates from the finite-difference formulation for irregular mesh spacing, a zone of variably sized cells surrounds northern Yucca Flat, providing a gradual transition between the $250-\mathrm{m}$ cells and the $1,500-\mathrm{m}$ cells of the original model mesh. Four rows and four columns of progressively increasing spacing (at a ratio of less than 1.6) separate the $250-\mathrm{m}$ cells from the $1,500-\mathrm{m}$ cells on the north and south sides and the east and west sides, respectively, of northern Yucca Flat. Detailed mapping of numerous parameters (including boundary heads, boundary fluxes, drains, observations, hydrogeologic units, etc.) was required from single cells in the original model to multiple cells in the refined model. A complete description of this process is included in Appendix E, however, it is important to point out here that elevations (e.g., HGU tops and bottoms, model layers, etc.) were mapped directly from original cells to refined cells with no interpolation. 
For example, if an HGU in a particular cell of the original model had an elevation of $800 \mathrm{~m}$, this HGU would be assigned an elevation of $800 \mathrm{~m}$ in all the refined cells in the area covered by the original cell. Distributed parameters (e.g., recharge) likewise were not interpolated in refined cells, but were assigned their original values at all refined cells within the area of the original cell.

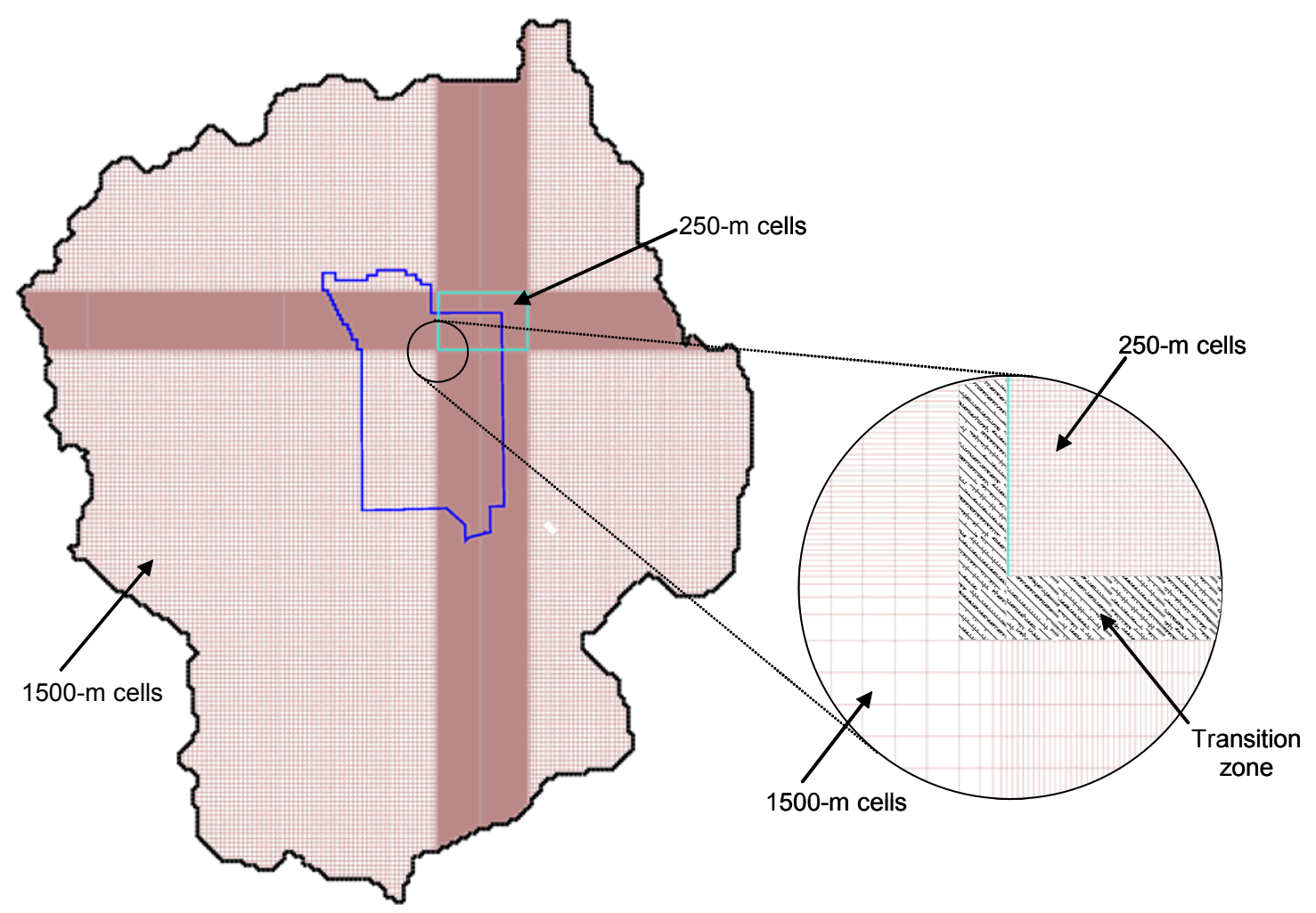

Figure 3-23. Map of the model domain in plan view, showing areas where the mesh is refined.

Table 3-5. Boundary coordinates of the Climax Regional Flow Model and the refined area in northern Yucca Flat. Locations given at outside edges of cells.

\begin{tabular}{ccccc}
\hline Corner & Mesh Row & Mesh Column & Easting (m) & Northing (m) \\
\hline Flow Model Domain & & & & \\
Upper left & 1 & 1 & 437,000 & $4,219,000$ \\
Upper right & 1 & 262 & 677,000 & $4,219,000$ \\
Lower left & 261 & 1 & 437,000 & $3,928,000$ \\
Lower right & 261 & 262 & 677,000 & $3,928,000$ \\
Northern Yucca Flat (area of 250-m mesh refinement) & & & \\
Upper left & 63 & 95 & 574,250 & $4,129,750$ \\
Upper right & 63 & 211 & 603,500 & $4,129,750$ \\
Lower left & 137 & 95 & 574,250 & $4,111,000$ \\
Lower right & 137 & 211 & 603,500 & $4,111,000$ \\
\hline
\end{tabular}


The mesh refinement process is not without consequence to the solution of the flow problem, however. To investigate the implications of these modifications to the DVRFS model on the simulation results, a comparison was made between the original and the refined versions. Other than the mesh refinement and associated changes, the input structure of the two models is essentially identical and both were run in forward mode. The results indicate that both groundwater fluxes and heads within the model were impacted by changes to the mesh (Table 3-6). In particular, mesh refinement led to the simulation of about five percent more groundwater moving through the system, with the great majority of this increased flux occurring at the constant head boundaries. The largest differences are seen in boundary segments 4, 7, and 8, where the refined mesh extends to the boundaries (Figure 3-24). However, these differences are small, especially in relation to the "errors" in simulated boundary fluxes in the DVRFS model as compared to the estimated boundary fluxes. Increases in simulated groundwater flow across numerical flow model boundaries with increasing grid resolution has been attributed to several factors, including geometric complexity, variability in material properties, boundary conditions, and the physics of the problem (Bower et al., 2005).

Table 3-6. Comparison of the sum of squared weighted residuals and mass balance results from the refined mesh to the original mesh of the DVRFS model at the end of time step 2 in stress period 87.

\begin{tabular}{lccr}
\hline Parameter & $1,500-\mathrm{m}$ Mesh & Refined Mesh & Percent Difference \\
\hline Sum of Squared Weighted Residuals $\left(\mathrm{m}^{2}\right)$ & & & \\
Heads (4,899 observations) & 36,431 & 39,271 & 7.8 \\
Heads in northern Yucca Flat (58 observations) & 540 & 438 & -18.9 \\
Drains (49 observations) & 637 & 647 & 1.6 \\
Constant-head boundary flows (15 observations) & 438 & 497 & 13.5 \\
All dependent variables (4,963 observations) & 37,507 & 40,414 & 7.8 \\
& & & \\
Mass Balance ( $\mathrm{m}^{3} /$ day) & & & \\
Rates into the model & & & 0.4 \\
Storage & 220,400 & 221,332 & 13.2 \\
Constant Head & 341,283 & 386,393 & 0.0 \\
Recharge & 303,415 & 303,537 & -1.1 \\
Wells & 46,106 & 45,606 & 5.0 \\
Total & 911,205 & 956,868 & \\
& & & \\
Rates out of the model & & & 0.9 \\
Storage & 8,893 & 8,969 & 13.8 \\
Constant Head & 282,299 & 321,297 & -0.2 \\
Drains & 344,658 & 351,379 & 5.0 \\
Wells & 275,934 & 275,434 & -63.6 \\
Total & 911,784 & 957,079 & - \\
IN - OUT ( $\left.\mathrm{m}^{3} / \mathrm{d}\right)$ & -579 & -211 & \\
Percent Difference & -0.06 & -0.02 & \\
\hline
\end{tabular}




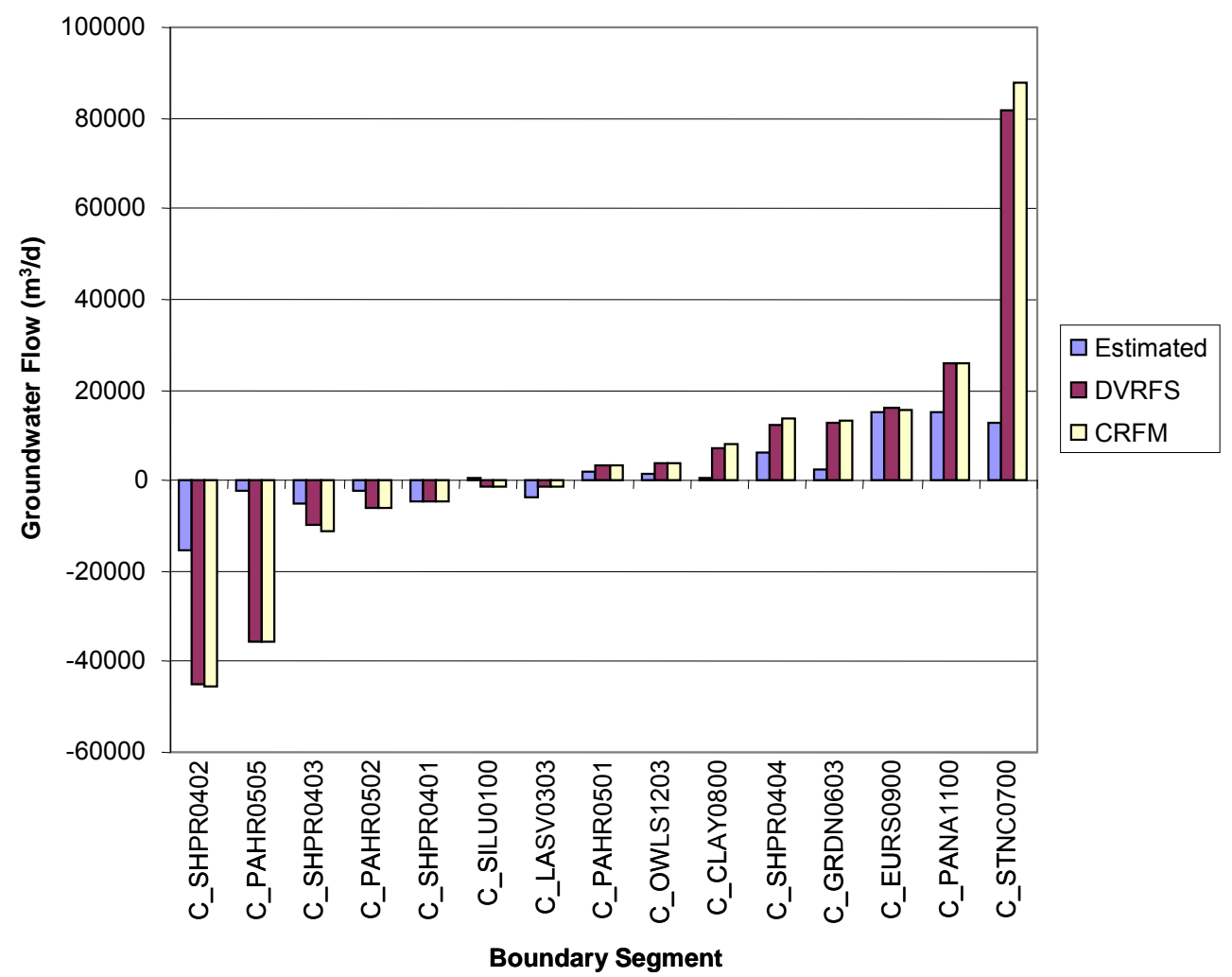

Figure 3-24. Comparison of the boundary flows from the refined mesh to the original mesh of the DVRFS model at the end of time step 2 in stress period 87.

Changes in the simulation of internal groundwater flow arise from slight differences in the horizontal distribution of cell-by-cell parameter values in the cells transitioning from $1,500 \mathrm{~m}$ to $250 \mathrm{~m}$ in the refined mesh as compared to the $1,500-\mathrm{m}$ mesh. Since these variably-sized cells do not have the same cell boundary locations as the uniform 1,500-m mesh, the locations of changes between parameter values in adjacent cells in the DVRFS model are slightly changed in the refined mesh resulting in small changes in the solution of the flow equation. Well pumping, and spring discharge rates all changed two percent or less with mesh refinement and that the overall mass balance was actually improved (Table 3-6). Simulated heads were impacted to a similar degree. The sum of squared weighted residuals (SSWR) for all 4,899 head observations increased about eight percent, but the simulation of heads in northern Yucca Flat actually improved - the SSWR for the 58 observations there was reduced by almost 19 percent.

\subsubsection{Incorporation of Alternative Models}

As in the DVRFS model, the CRFM represents groundwater recharge as spatially distributed average annual values that are constant over both the steady-state and transient stress periods. As described previously, five alternative recharge models were evaluated for incorporation into the CRFM.

Recharge in the DVRFS model is based on a deterministic model of net infiltration developed for the Death Valley region by Hevesi et al. (2003). As described in Section 3.2.1.2, the infiltration values are adjusted by a set of multipliers (spatially distributed in nine recharge zones) that were determined during model calibration and that represent the 
redistribution of recharge based on simulated infiltration rates and relative permeability of the surface materials (Belcher et al., 2004). These recharge multipliers and zones are preserved in the CRFM such that this recharge model is identical to the corresponding recharge model used in the DVRFS model. The net infiltration model without runon-runoff is handled in essentially the same manner.

The recharge models for the modified Maxey-Eakin method and the two chloride mass-balance methods were incorporated into the CRFM using a similar approach. Because all three of these models incorporate parametric uncertainty, they each required calculation of an average spatial distribution of recharge to be consistent with the two deterministic net infiltration models. For the MME model, this was accomplished by multiplying the mean value of the uncertain recharge coefficient (precipitation zone) appropriate for the geographic location of each active model cell by the PRISM-derived annual precipitation value for that location. For the EDCMB models, the mean recharge values for each model cell were obtained by calculating the mean of the 1,000 Monte Carlo realizations for that cell. In all three cases, resampling of the recharge maps was only necessary for the refined cells because the original maps were all developed on the DVRFS mesh. As with the other model parameters, this resampling assigned the same recharge values to all refined cells within an original-sized cell; interpolation was not used. Recharge multipliers, of the type used for the net infiltration-based recharge models in the DVRFS model, were not implemented in the CRFM for the Maxey-Eakin and chloride mass-balance methods. Thus, there is no redistribution at ground surface of recharge between areas of the model.

With the exception of subsampling to the refined flow model mesh, the DVRFS hydrogeologic framework was used unmodified in the CRFM. The distribution of each HGU and its parameterization were all preserved. The HGU top elevations and thicknesses were not interpolated to the refined mesh, but were maintained at their original values. As a result, the flow model mesh has a finer discretization than the hydrostratigraphic framework in northern Yucca Flat, which is in contrast to the Yucca Flat alternative hydrostratigraphic models that are all resolved to the 250-m mesh in the flow model.

Incorporation of the alternative HFMs required a substantial amount of processing to be consistent with the construction of the DVRFS model. The digital three-dimensional hydrostratigraphic framework models of Yucca Flat were developed by Bechtel Nevada and SNJV using EarthVision ${ }^{\circledR}$ geologic modeling software tools (Bechtel Nevada, 2006). For these models to be integrated in the CRFM, the relevant HSU information required (1) mapping to a mesh aligned with the DVRFS model mesh, (2) development of a consistent correlation between Yucca Flat hydrostratigraphic units and DVRFS hydrogeologic units, and (3) conversion of the HSU surface elevation meshes to a format appropriate for the MODFLOW HUF package. The process necessary to accomplish these objectives is briefly described below.

For each alternative, SNJV exported from the EarthVision ${ }^{\circledR}$-based model the elevations of the top of each HSU on a 125-m block-centered grid aligned with the UTM grid (Zone 11, NAD27). These surfaces were delivered to Desert Research Institute (DRI) and then directly subsampled to the 250-m mesh used in the CRFM by honoring the HSU top elevation at every other grid point. By using the $250-\mathrm{m}$ cell centered at $574,375 \mathrm{~m}$ east and $4,111,125 \mathrm{~m}$ north as the southwest corner, the HSU mesh is aligned with the DVRFS model mesh and no interpolation was necessary. 
Using the hydrostratigraphic correlations between Yucca Flat and DVRFS units established by Bechtel Nevada (2006) (Table 3-4), Yucca Flat HSUs were physically mapped across a transition zone surrounding northern Yucca Flat to their corresponding units in the DVRFS model. The transition zone is 4,500 m wide on the east and west sides of northern Yucca Flat and 7,500 $\mathrm{m}$ wide on the north and south sides. A narrower east-west transition was chosen to avoid the complicated structure near Rainier Mesa, while the increased width on the north and south provides a smoother transition in the direction of mean groundwater flow (Figure 3-25). Within northern Yucca Flat, the 250-m-scale Yucca Flat HSUs are used, while outside of the transition zone, the 1,500-m-scale DVRFS HGUs are used. Within the transition zone, the corresponding units were obtained from SNJV's draft version of the DVRFS model, within which the Yucca Flat, Pahute Mesa-Oasis Valley, and the Frenchman Flat HFMs are all embedded. In this model, the HSUs have been upscaled from their original highly resolved HFM scale to the 1,500-m scale of the DVRFS. However, this model provided the critical information needed to properly build the transition between the UGTA-derived stratigraphy in northern Yucca Flat and the USGS-derived stratigraphy in the remainder of the CRFM. The DVRFS HGUs were not considered within the transition zone, only those included in the UGTA version of the DVRFS model, even if they were not present in northern Yucca Flat. Once the units were physically joined across the transition zone they were mapped to the refined mesh and the appropriate files containing top elevation and thickness of each HGU were generated for the HUF package. An example of the configuration of HSUs across this transition zone is shown in Figure 3-8.

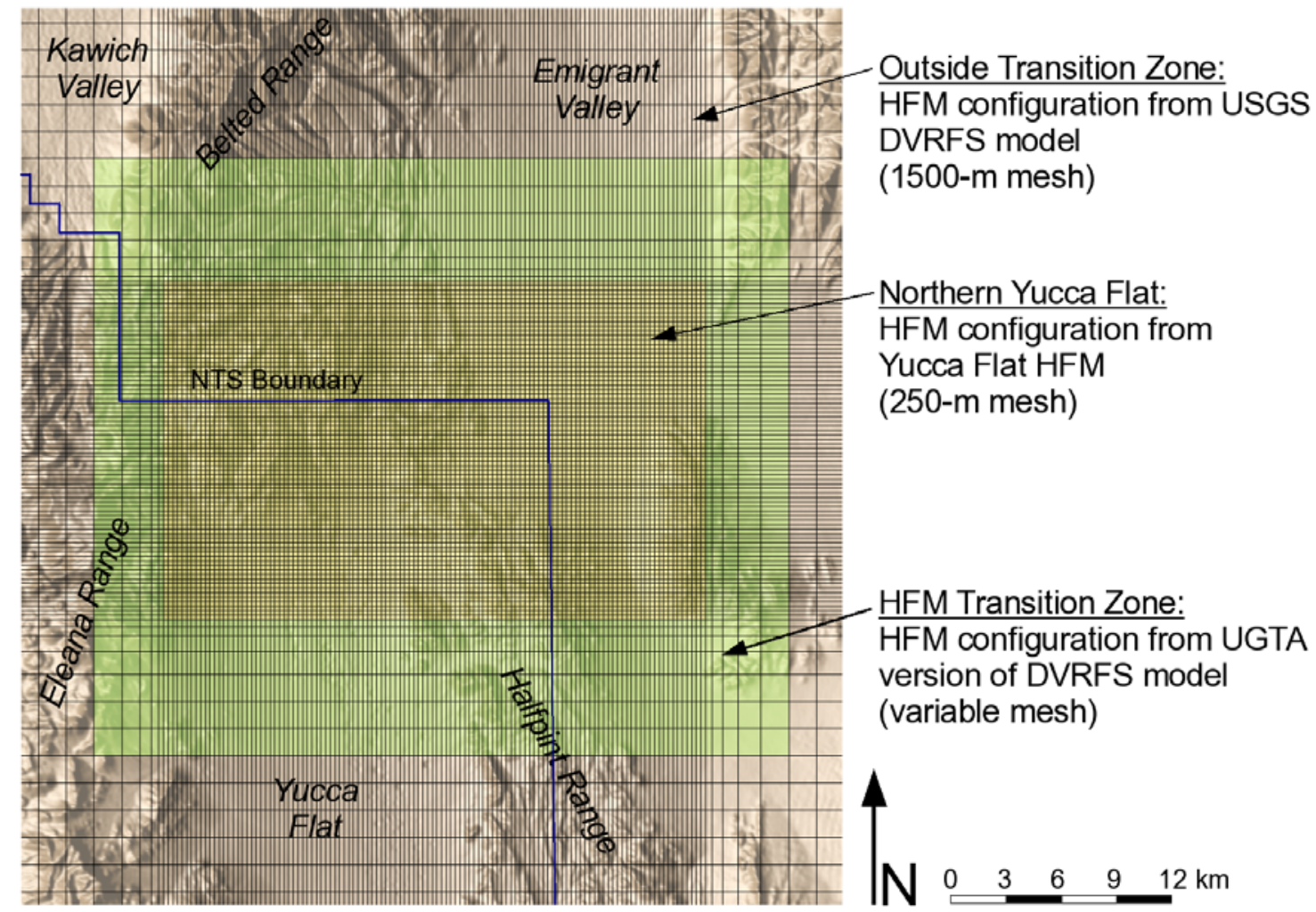

Figure 3-25. Configuration of the transition zone used for physically joining Yucca Flat HSUs in northern Yucca Flat with DVRFS HGUs in the remainder of the Climax regional flow model. The refinement of the model mesh in northern Yucca Flat is also shown. 
Several UGTA HSUs were merged to minimize increased model complexity that would accompany the creation of HGUs and HUF parameters not present in the DVRFS model. In two cases, HSUs of limited aerial extent in northern Yucca Flat were merged with larger units even though their lithologies differ. These units are physically connected to the larger units, they have relatively limited spatial extent, and most importantly, they share similar hydraulic properties (SNJV, 2006c). The pre-Grouse Canyon Tuff lava-flow aquifer (PRETBG) was combined with the Belted Range aquifer (BRA) and the pre-Grouse Canyon Tuff lava-flow aquifer 1 (PRETBG1) was combined with the Tub Spring aquifer (TUBA). Additionally, the two portions of the LCCU upper thrust plate (LCCU1 and LCCU2) that are physically separated in the Yucca Flat HFM were merged into a single unit (LCCU1) in the CRFM (though the physical separation is maintained).

Furthermore, there are several cases where HSUs overlie themselves in the Yucca Flat HFM (e.g., at locations where they are displaced by high-angle faults), creating situations where HSUs are vertically repeated. The HUF package is not designed to address vertically repeated units, so the corresponding HGUs were divided into two physically separate units with different names. The physical properties of the two parts of these HGUs are identical, but they are listed in the HUF input files as separate HGUs because their physical locations are distinct from each other. The newly created HGUs are BRU_LOWER, TUBA_LOWER, LCA_LOWER, and LCCU_LOWER. New HUF parameters were not needed in these cases; the new HGUs were simply included under existing parameters. However, the appropriate zone files were adjusted to account for the locations of any additional HUF units.

The results of the expert elicitation of hydrostratigraphic framework models included the combination of two alternative HFMs, the CP thrust, and the hydrologic barrier, as an independent model. This CPT-HB combination was developed using the CPT model as the basis because it represents a substantial change to the base model, while the HB model impacts only a small area east of the Climax stock. A cell-by-cell comparison of the two models in the area of the hydraulic barrier indicated where the two models differed and the appropriate cells in the CPT model were then modified to incorporate the hydraulic barrier. With the exception of subsampling to the refined flow model mesh, the DVRFS hydrogeologic framework was used unmodified in the CRFM. The distribution of each HGU and its parameterization were all preserved. The HGU top elevations and thicknesses were not interpolated to the refined mesh, but were maintained at their original values. As a result, the flow model mesh has a finer discretization than the hydrostratigraphic framework in northern Yucca Flat, which is in contrast to the Yucca Flat alternative hydrostratigraphic models that are all resolved to the 250-m mesh in the flow model.

\subsubsection{Model Calibration Process}

The alternative models corresponding to different conceptualizations of site geology and recharge were calibrated using the parameter estimation package of MODFLOW. The calibration is critical in this project, since it is the basis of differentiating alternative models and assessing parameter uncertainty, as discussed later on. The modeling framework developed for the DVRFS model (Belcher et al., 2004) was used for the calibration. The calibration process in this study was thus essentially the same as that of Belcher et al. (2004), except for the number of calibrated parameters and calibration steps. Among the 100 parameters of the DVRFS, 55 parameters were calibrated by Belcher et al. (2004) using a 
two-step process. In the first step, 23 parameters were calibrated to prepumped (steady-state) flow conditions, while 32 parameters were calibrated to transient flow conditions with the 23 parameters fixed. The 55 calibrated parameters are located over the entire DVRFS. In this project, since interest was only in flow in northern Yucca, only 32 (or 30 as explained below) parameters that may significantly affect flow in northern Yucca Flat and its vicinity were calibrated. The two-step process of calibration of Belcher et al. (2004) is related to the history of model development, where a steady-state model was first developed and then expanded to the transient state model. In this modeling, it is unnecessary to follow the twostep calibration process. Instead, all of the 32 (or 30) parameters using the transient state model of Belcher et al. (2004) were calibrated. These two variations from the process of DVRFS parameter calibration also saved calibration time, especially for the case in which 25 alternative models were calibrated.

The calibrated parameters in the CRFM were selected from the 55 parameters calibrated by Belcher et al. (2004). Parameters not calibrated by them were not selected in this project, since sensitivity analysis of Belcher et al. (2004, p341) showed that there is inadequate information to estimate these parameters. Among the 55 parameters, only parameters significant to flow and transport at the Climax mine area were selected for calibration. For example, hydraulic conductivity and drain parameters located far from and at downgradient of the Climax mine (e.g., Death Valley area) were not calibrated. Location of HGUs relative to the Climax mine were determined based on the surface maps plotted in Figures F-12 through F-34 in Belcher et al. (2004) and the HUF file of the DVRFS model. Depth-decay coefficients were considered as important variables for flow and transport, and thus were selected for calibration. Three parameters of hydraulic conductivity (K1221UCCU, K3PVA, and K4_VFVANVL) were not calibrated, due to numerical instability. Values of uncalibrated parameters were adopted from Belcher et al. (2004). Appendix C lists all of the calibrated parameters and rationale for selecting them in details.

Parameters listed in Appendix C are only for one of the alternative models, G1R2, with the USGS geological model and net infiltration model with runon-runoff component. Parameters of other alternative models are slightly different in the following two aspects:

(1) Geological models G2 through G5 (UGTA base model and its alternatives) have three more parameters (K3_ATCU, K3_TMLVTA, and K3_TMUVTA) than model G1 (USGS model), as explained before. However, hydraulic conductivity of the three parameters was not calibrated due to numerical instability. Instead, their values were adopted from the draft UGTA regional flow model that is based on the DVRFS model (Parviz Montazer, personal communication, 2005).

(2) For the recharge models of Maxey-Eakin (R1), chloride mass-balance with elevation mask (R4) and with elevation and alluvial masks (R5), recharge is estimated directly. Therefore, it is unnecessary to use recharge multipliers, $\mathrm{RCH}$, to transfer net infiltration into recharge, as it is for the net infiltration models (R2 and R3). However, for operational convenience, these parameters are still retained as model parameters for the models R1, R4, and R5, but their values are assigned 1 and not calibrated.

As a result, models associated with $\mathrm{R} 2$ and $\mathrm{R} 3$ have two more calibrated parameters ( $\mathrm{RCH}_{2} 2$ and $\left.\mathrm{RCH} 335\right)$ than models associated with R1, R4, and R5, regardless of the geological models. 
The alternative models were calibrated to the same observations of head and flux. This is to fulfill the requirement of the BMA method that model probability is conditioned on the same calibration data. Despite that the project is to simulate flow and transport at the Climax mine and its vicinity area, observations of all different models have a slightly different number of calibrated parameters, although the level of parsimony of the models is accounted for in the method through a penalty term, in that a model with a large number of calibrated parameters has a large penalty term. Convergence criteria and other variables used by MODFLOW for calibration are the same. This ensures that all models are calibrated to the same level so that the same basis is used for evaluation of model. Calibration was conducted using parallel MODFLOW with four processors on a Beowulf computing cluster at DRI.

\subsubsection{Results of Model Calibration}

Results of model calibration were evaluated quantitatively and qualitatively for two purposes. First, quantitative analysis was conducted to examine quality of the calibration in terms of goodness-of-fit between observations and simulations. For this purpose, residuals of the DVRFS were used to investigate whether the model calibration reached the same level of goodness-of-fit as that of Belcher et al. (2004). Table 3-7 shows that goodness-of-fit of all models was improved, except for those associated with the MME recharge model (the reason was given later on). Similar conclusions can be drawn for the northern Yucca Flat area based on residuals in this area. In addition to the quantitative analysis, qualitative analysis was conducted to help understand how the flow system behaves for different conceptualizations of recharge and site geology. For this purpose, a comparison was made of the calibrated recharge values, mass balance, boundary flow of the DVRFS, spatial distribution of residuals in northern Yucca Flat, and flow rate into northern Yucca Flat simulated by the calibrated model.

\subsubsection{Residuals of Alternative Models}

Residuals of each calibrated model were examined by calculating the SSWR (those being the difference between observations and corresponding model simulations). The SSWR measures the overall degree of model fit to observations. Detailed model fit to observations was examined by comparing observations with their corresponding simulations. As discussed in the last section, observations throughout the DVRFS were used to calibrate alternative models, since this can better constrain the flow system than just using sparse observations in northern Yucca Flat. As a result, residuals of alternative models were analyzed in two steps. Residuals of all the observations were examined in the first step to investigate overall quality of model fit. The effect of different recharge models on calibration was evaluated in this step, since the recharge models were applied to the whole DVRFS. In the second step, residuals of the observations in northern Yucca Flat were examined to investigate quality of fit in the domain of interest to the project. This analysis can reveal effects of different geological models on model calibration. Since flow and transport in northern Yucca Flat is of interest, the focus was on residuals of calibration data in northern Yucca Flat. Model probabilities used for model averaging were calculated based on residuals in northern Yucca Flat, as discussed later. 
Table 3-7. Sum of squared weighted residuals (SSWR) of alternative models for all the calibration data and each type of the calibration data throughout the DVRFS.

\begin{tabular}{|c|c|c|c|c|c|c|c|}
\hline \multirow[b]{2}{*}{$\begin{array}{c}\text { Type of } \\
\text { observation }\end{array}$} & \multirow[b]{2}{*}{$\begin{array}{l}\text { Number of } \\
\text { observations }\end{array}$} & \multirow[b]{2}{*}{$\begin{array}{l}\text { Belcher et } \\
\text { al. (2004) }\end{array}$} & \multicolumn{5}{|c|}{ Geological Model 1 (USGS) } \\
\hline & & & MME & NIM1 & NIM2 & CMB1 & CMB2 \\
\hline Hydraulic head & 2,227 & 23,083 & 26,246 & 19,220 & 20,420 & 20,419 & 19,839 \\
\hline $\begin{array}{l}\text { Hydraulic-head } \\
\text { changes (transient) }\end{array}$ & 2,672 & 13,348 & 11,767 & 12,968 & 13,064 & 12,529 & 12,116 \\
\hline Discharge & 49 & 638 & 1,974 & 690 & 633 & 861 & 1,049 \\
\hline \multicolumn{8}{|l|}{ Constant-head } \\
\hline boundary flow & 15 & 438 & 1,785 & 328 & 304 & 673 & 725 \\
\hline Total & 4,963 & 37,507 & 41,771 & 33,205 & 34,421 & 34,482 & 33,729 \\
\hline & & & \multicolumn{5}{|c|}{ Geological Model 2 (BAS) } \\
\hline $\begin{array}{c}\text { Type of } \\
\text { observation }\end{array}$ & $\begin{array}{c}\text { Number of } \\
\text { observations }\end{array}$ & $\begin{array}{l}\text { Belcher et } \\
\text { al. (2004) }\end{array}$ & MME & NIM1 & NIM2 & CMB1 & CMB2 \\
\hline Hydraulic head & 2,227 & 23,083 & 28,052 & 22,116 & 21,823 & 21,604 & 21,436 \\
\hline Hydraulic-head & & & & & & & \\
\hline changes (transient) & 2,672 & 13,348 & 12,201 & 13,002 & 12,742 & 12,391 & 12,111 \\
\hline Discharge & 49 & 638 & 3,246 & 763 & 652 & 1,320 & 1,175 \\
\hline \multicolumn{8}{|l|}{ Constant-head } \\
\hline boundary flow & 15 & 438 & 1,820 & 244 & 260 & 719 & 780 \\
\hline Total & 4,963 & 37,507 & 45,320 & 36,124 & 35,478 & 36,035 & 35,502 \\
\hline & & & \multicolumn{5}{|c|}{ Geological Model 3 (CPT) } \\
\hline $\begin{array}{c}\text { Type of } \\
\text { observation }\end{array}$ & $\begin{array}{c}\text { Number of } \\
\text { observations }\end{array}$ & $\begin{array}{l}\text { Belcher et } \\
\text { al. (2004) }\end{array}$ & MME & NIM1 & NIM2 & CMB1 & CMB2 \\
\hline $\begin{array}{l}\text { Hydraulic head } \\
\text { Hydraulic-head }\end{array}$ & 2,227 & 23,083 & 28,784 & 21,195 & 21,991 & 21,232 & 20,912 \\
\hline changes (transient) & 2,672 & 13,348 & 12,222 & 12,800 & 12,755 & 12,425 & 12,060 \\
\hline Discharge & 49 & 638 & 2,877 & 667 & 677 & 1,237 & 1,261 \\
\hline \multicolumn{8}{|l|}{ Constant-head } \\
\hline boundary flow & 15 & 438 & 1,615 & 230 & 245 & 715 & 577 \\
\hline Total & 4,963 & 37,507 & 498 & 34,891 & 35,668 & 35,609 & 34,810 \\
\hline & & & \multicolumn{5}{|c|}{ Geological Model 4 (HB) } \\
\hline $\begin{array}{c}\text { Type of } \\
\text { observation }\end{array}$ & $\begin{array}{c}\text { Number of } \\
\text { observations }\end{array}$ & $\begin{array}{l}\text { Belcher et } \\
\text { al. (2004) }\end{array}$ & MME & NIM1 & NIM2 & CMB1 & CMB2 \\
\hline Hydraulic head & 2,227 & 23,083 & 27,271 & 18,997 & 20,121 & 21,108 & 19,796 \\
\hline Hydraulic-head & & & & & & & \\
\hline changes (transient) & 2,672 & 13,348 & 11,830 & 12,804 & 13,022 & 12,556 & 12,144 \\
\hline Discharge & 49 & 638 & 2,513 & 692 & 682 & 1,006 & 1,165 \\
\hline \multicolumn{8}{|l|}{ Constant-head } \\
\hline boundary flow & 15 & 438 & 1,409 & 434 & 318 & 911 & 698 \\
\hline Total & 4,963 & 37,507 & 43,023 & 32,927 & 34,143 & 35,581 & 33,804 \\
\hline & & & \multicolumn{5}{|c|}{ Geological Model $5(\mathrm{CPT}+\mathrm{HB})$} \\
\hline $\begin{array}{c}\text { Type of } \\
\text { observation }\end{array}$ & $\begin{array}{l}\text { Number of } \\
\text { observations }\end{array}$ & $\begin{array}{l}\text { Belcher et } \\
\text { al. }(2004)\end{array}$ & MME & NIM1 & NIM2 & CMB1 & CMB2 \\
\hline $\begin{array}{l}\text { Hydraulic head } \\
\text { Hydraulic-head }\end{array}$ & 2,227 & 23,083 & 27,386 & 20,443 & 21,781 & 21,015 & 19,857 \\
\hline changes (transient) & 2,672 & 13,348 & 11,930 & 12,808 & 13,237 & 12,739 & 12,141 \\
\hline Discharge & 49 & 638 & 2,392 & 689 & 741 & 896 & 1,112 \\
\hline \multicolumn{8}{|l|}{ Constant-head } \\
\hline boundary flow & 15 & 438 & 1,525 & 354 & 348 & 579 & 828 \\
\hline Total & 4,963 & 37,507 & 43,233 & 34,294 & 36,108 & 35,229 & 33,939 \\
\hline
\end{tabular}




\subsection{Residuals of All Observations in the DVRFS}

A total of 4,963 observations were used to calibrate each of the 25 alternative models. The observations include 2,227 hydraulic heads, 2,672 hydraulic head-changes, 49 discharges, and 15 constant-head boundary flows. Belcher et al. (2004) discussed their quality and calibrated their weights, which were adopted in this calibration. Table 3-7 lists the SSWR of all the observations and each type of observation for alternative models. The table also lists the SSWR of Belcher et al. (2004) as a reference. In comparison with the SSWR of Belcher et al. (2004), all alternative models, except those associated with recharge model MME, have smaller SSWR, indicating better model fit. This is not surprising, since the calibration can be viewed as a further calibration based on that of Belcher et al. (2004), recalling that the 32 (or 30) parameters related to northern Yucca Flat were calibrated with other parameters adopted from Belcher et al. (2004). The significantly larger SSWR of models associated with the MME model indicates that the MME model is less plausible than other recharge models (regardless of geological models) because of the larger recharge that MME estimates. For other alternative models, the SSWR of heads and head changes was reduced, regardless of any combination of recharge and geological models. For the net infiltration models (NIM1 and NIM2) combined with any geological model, in comparison with the SSWR of Belcher et al. (2004), the SSWR of constant-head boundary flows is also reduced, while the SSWR of discharge remains essentially the same, indicating that this calibration improves the calibration of Belcher et al. (2004) by calibrating parameters significant to northern Yucca Flat with other parameters adopted from Belcher et al. (2004). However, for the chloride mass-balance models (CMB1 and CMB2) combined with any geological model, the SSWR of constant-head boundary flows and discharge increases. The increase in the SSWR of discharge is attributed to the fact that discharge parameters were not calibrated, but adopted from Belcher et al. (2004) and calibrated for the recharge model NIM1. The increase in the SSWR of constant-head boundary flow may be due to the larger recharge estimated by CMB models than NIM models. Nevertheless, the increase in the SSWR of the discharge and constant-head boundary flows is smaller than the decrease in the SSWR of the heads and head changes, and the latter SSWR dominates the total SSWR. Therefore, the calibration of the alternative models is considered satisfactory.

The model fit was further evaluated by examining the variation of residuals with simulations and plotting the observations with corresponding simulations. Ideally, residuals should have zero mean (indicating unbiased predictions) and small variation. In addition, no trend of residual variation with simulations should be observed, indicating that there is no systematic simulation error. Observations and simulations should fall on a 45 degree line. Figure 3-26 is such a plot for the four types of observations (discharge and constant-head boundary flow being combined) obtained from the DVRFS modeling in Belcher et al. (2004). This figure is similar to Figures F3-28 and F3-29 of Belcher et al. (2004). However, since weights were not applied to the residuals and simulations, bias is more obvious in Figure 3-26 a-1 and b-1 than in Figure F-3-28 (A) and F-3-29 (A) in Belcher et al. (2004), respectively. This does not affect the discussion below since Figure 3-26 is used only as a reference to compare residuals of alternative models with those of the DVRFS model of Belcher et al. (2004). Figure 3-27 and Figure 3-28 plot the same figures for models G1R2 (USGS geological model and NIM1 recharge model, equivalent to the DVRFS model of Belcher et al. [2004]) and G2R2 (UGTA base geological model and NIM1 recharge model). 
These three figures are visually nearly identical, except that, by comparing Figure 3-28 a-1 and b-1 of the three figures, bias of the G1R2 and G2R2 models is slightly less than that of the DVRFS model of Belcher et al. (2004), due to the improved calibration discussed above. Figure 3-29 and Figure 3-30 plot the residuals for models G1R5 (USGS geological model and CMB2 recharge model) and G2R5 (UGTA base geological model and CMB2 recharge model). As shown in Table 3-7, the SSWR of discharge and constant-head boundary flow is larger for these two models than that of the DVRFS model of Belcher et al. (2004). However, residuals of the two models are visually similar to those of the DVRFS model of Belcher et al. (2004), as shown in Figure 3-30 a-1 and b-1 of these three models.

\subsection{Residuals of Observations in Northern Yucca Flat}

While the above residual analysis for all the observations indicates that calibration was improved based on the calibration of Belcher et al. (2004), residuals of observations in northern Yucca Flat are the main areas of interest, since these residuals measure goodness of model fit at the domain of interest. Therefore, the residuals of observations in northern Yucca Flat will be used to evaluate relative model plausibility later. In northern Yucca Flat, only 50 head and 9 head-change observations are available, and observations of drains and constanthead flow are unavailable. Since northern Yucca Flat is a small area, the effect of different recharge models on simulation of local heads is not as significant as for the entire DVRFS. Similar to the residual analysis above, the SSWR was first calculated, and residuals of heads and head changes were then plotted.
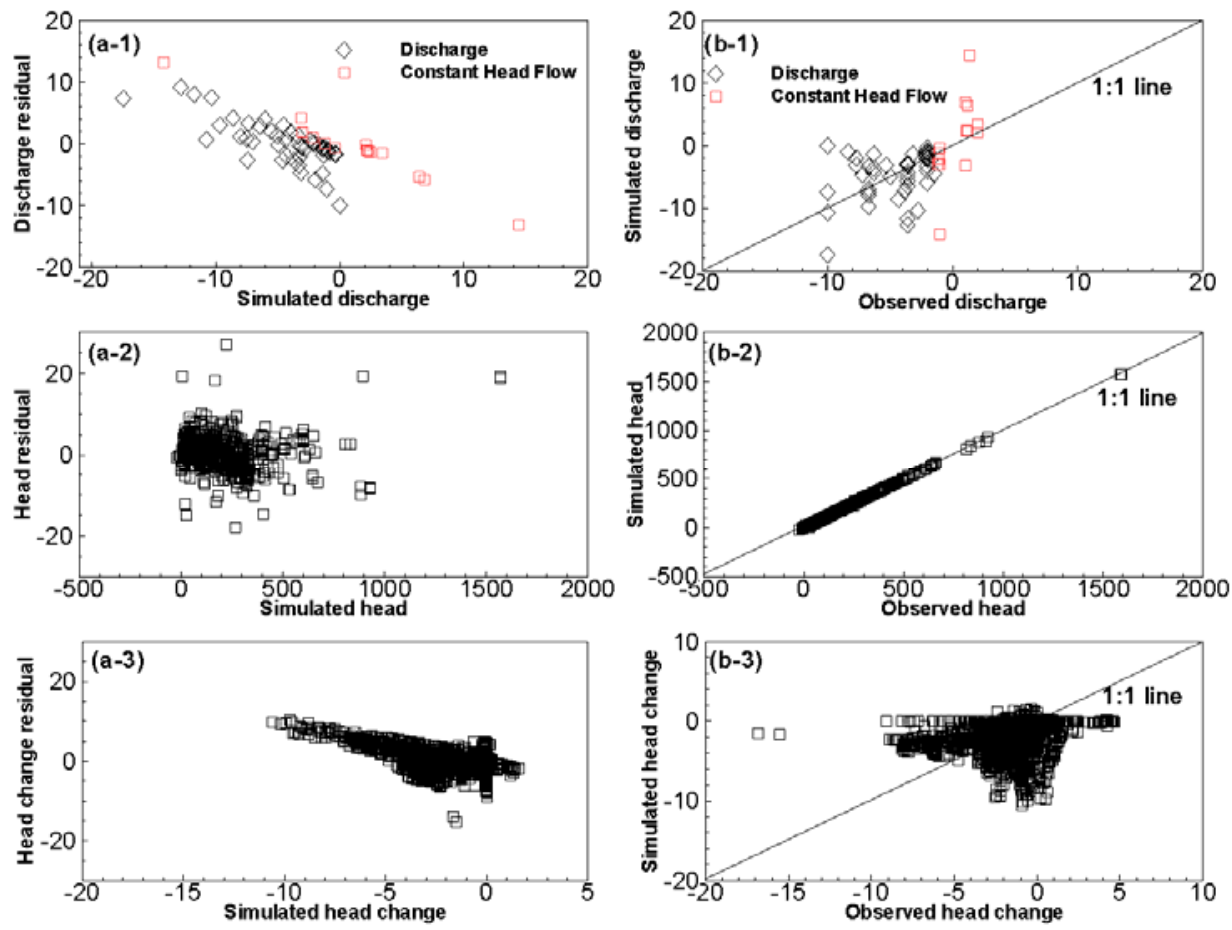

Figure 3-26. Residuals and simulations for (a-1) discharge and constant-head boundary flow, (a-2) head, and (a-3) head change of the DVRFS model of Belcher et al. (2004). Observations and simulations for (b-1) discharge and constant-head flow, (b-2) head, and (b-3) head changes of the DVRFS model of Belcher et al. (2004). 

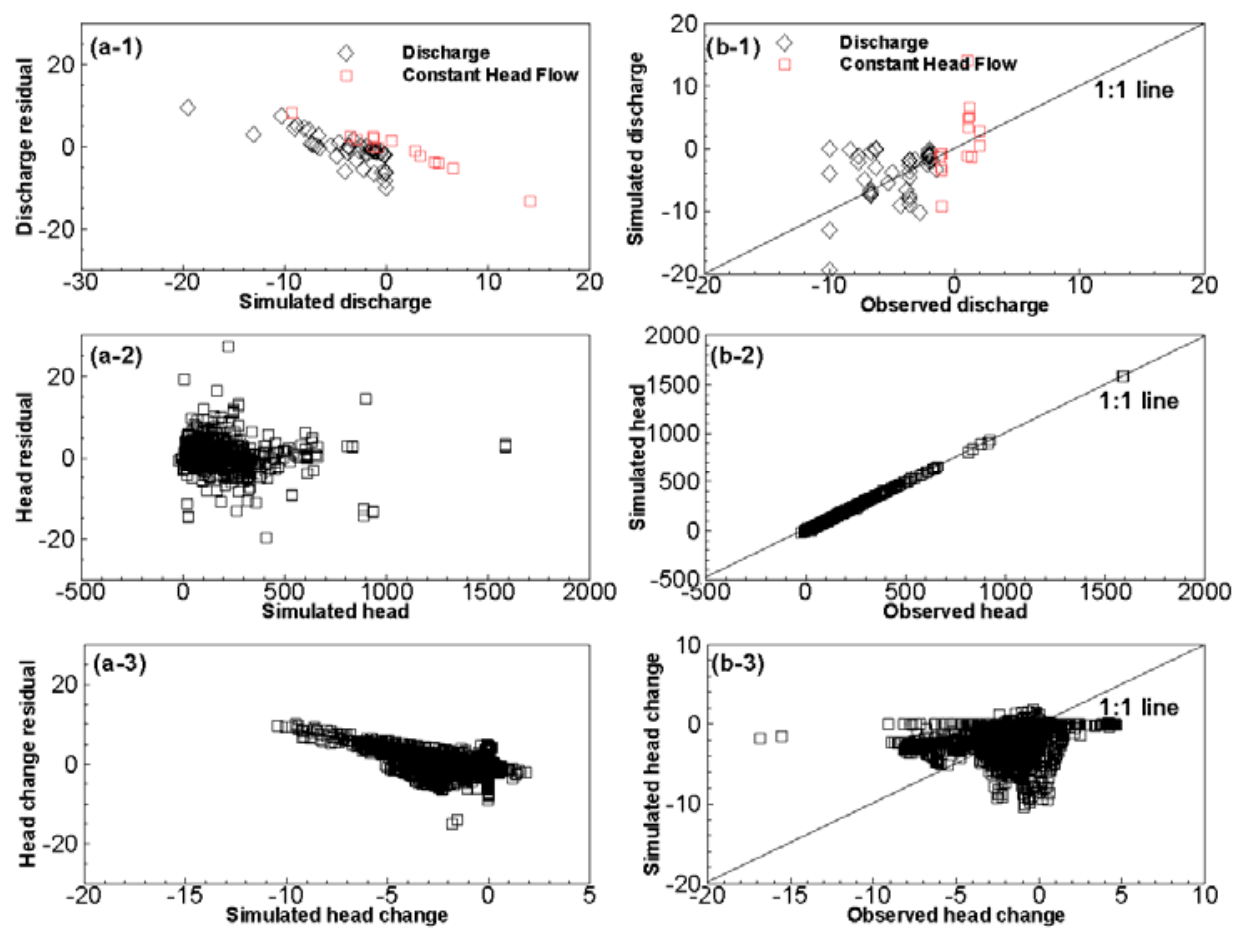

Figure 3-27. Residuals and simulations for (a-1) discharge and constant-head boundary flow, (a-2) head, and (a-3) head change of model G1R2. Observations and simulations for (b-1) discharge and constant-head flow, (b-2) head, and (b-3) head changes of model G1R2.
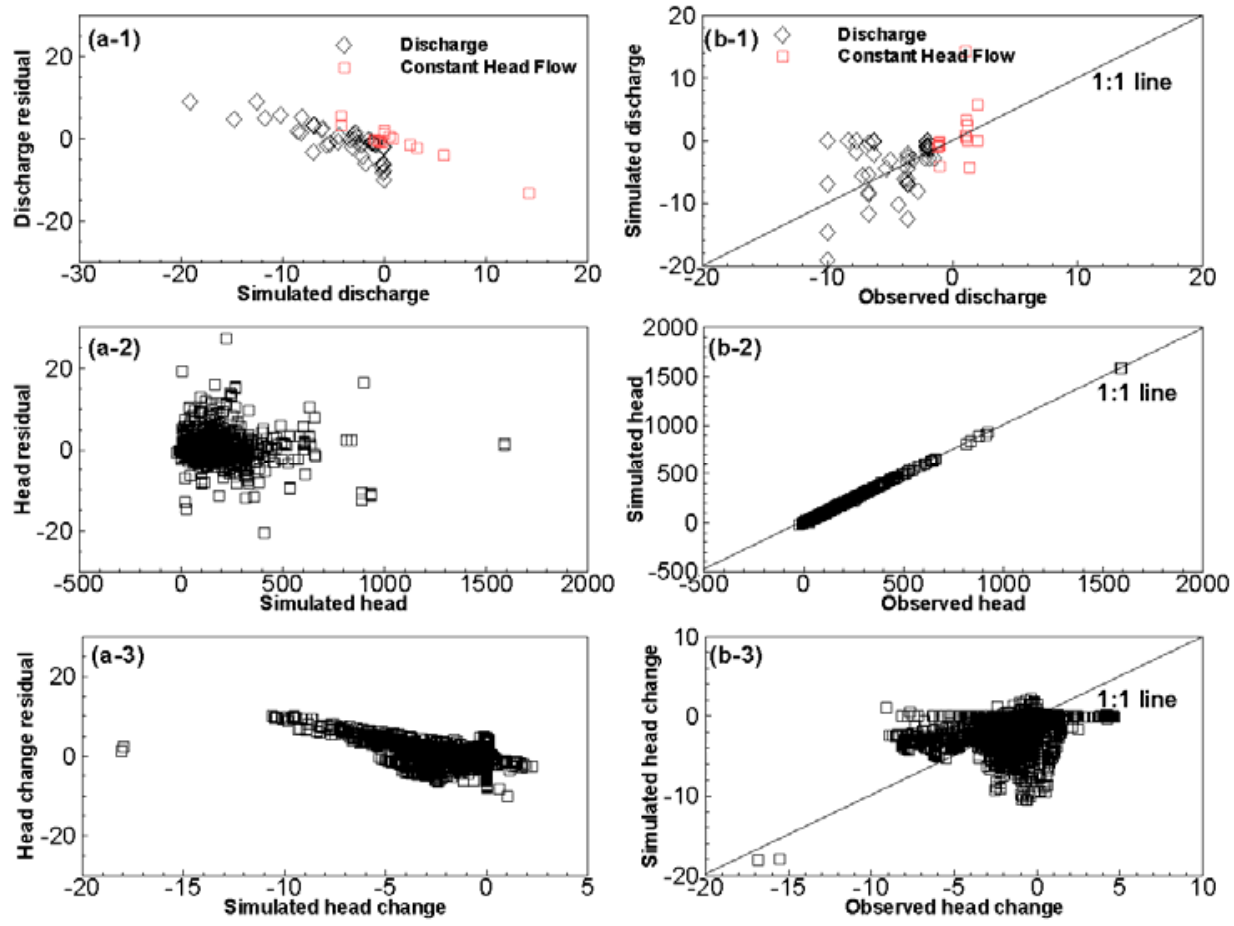

Figure 3-28. Residuals and simulations for (a-1) discharge and constant-head boundary flow, (a-2) head, and (a-3) head change of model G2R2. Observations and simulations for (b-1) discharge and constant-head flow, (b-2) head, and (b-3) head changes of model G2R2. 

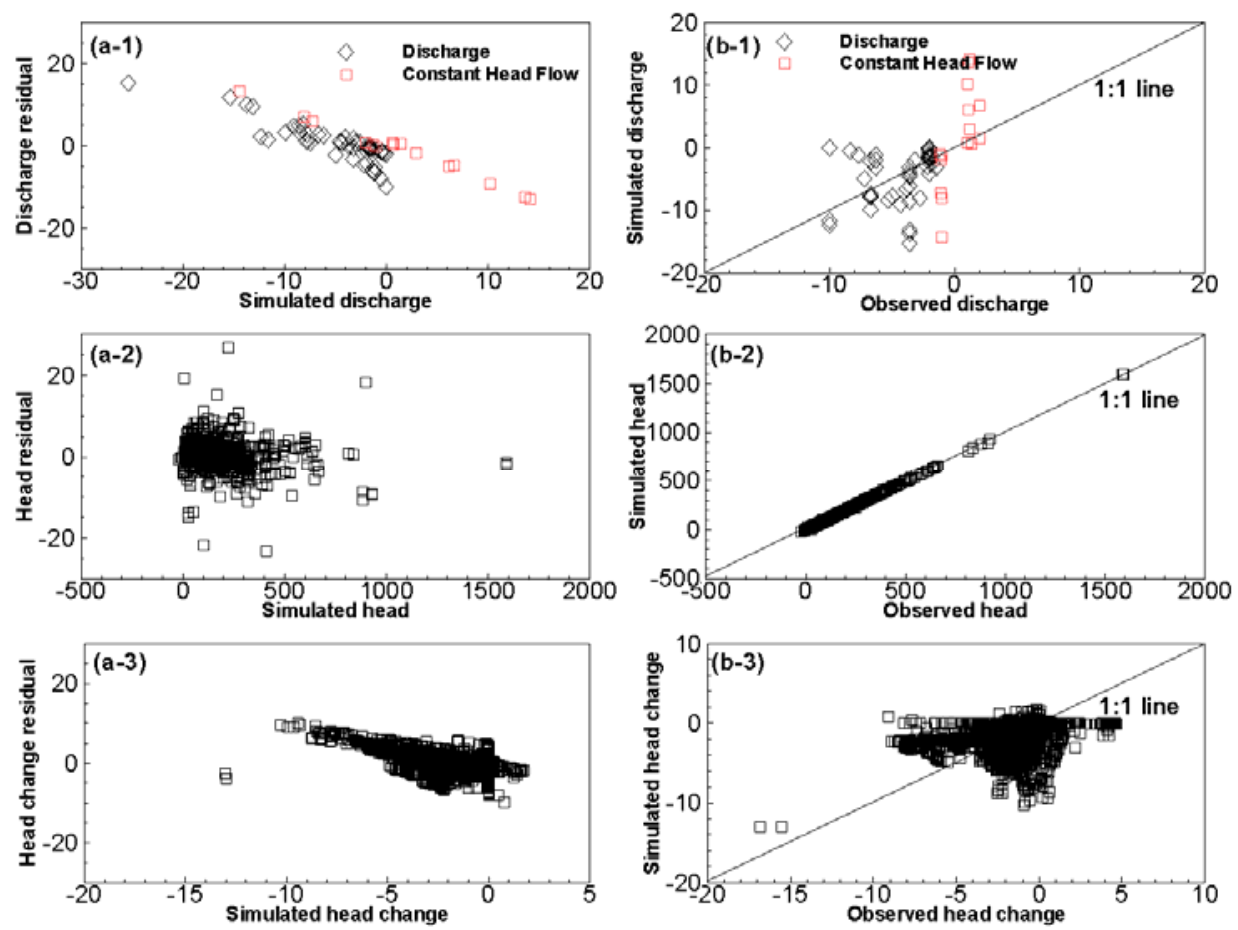

Figure 3-29. Residuals and simulations for (a-1) discharge and constant-head boundary flow, (a-2) head, and (a-3) head change of model G1R5. Observations and simulations for (b-1) discharge and constant-head flow, (b-2) head, and (b-3) head changes of model G1R5.
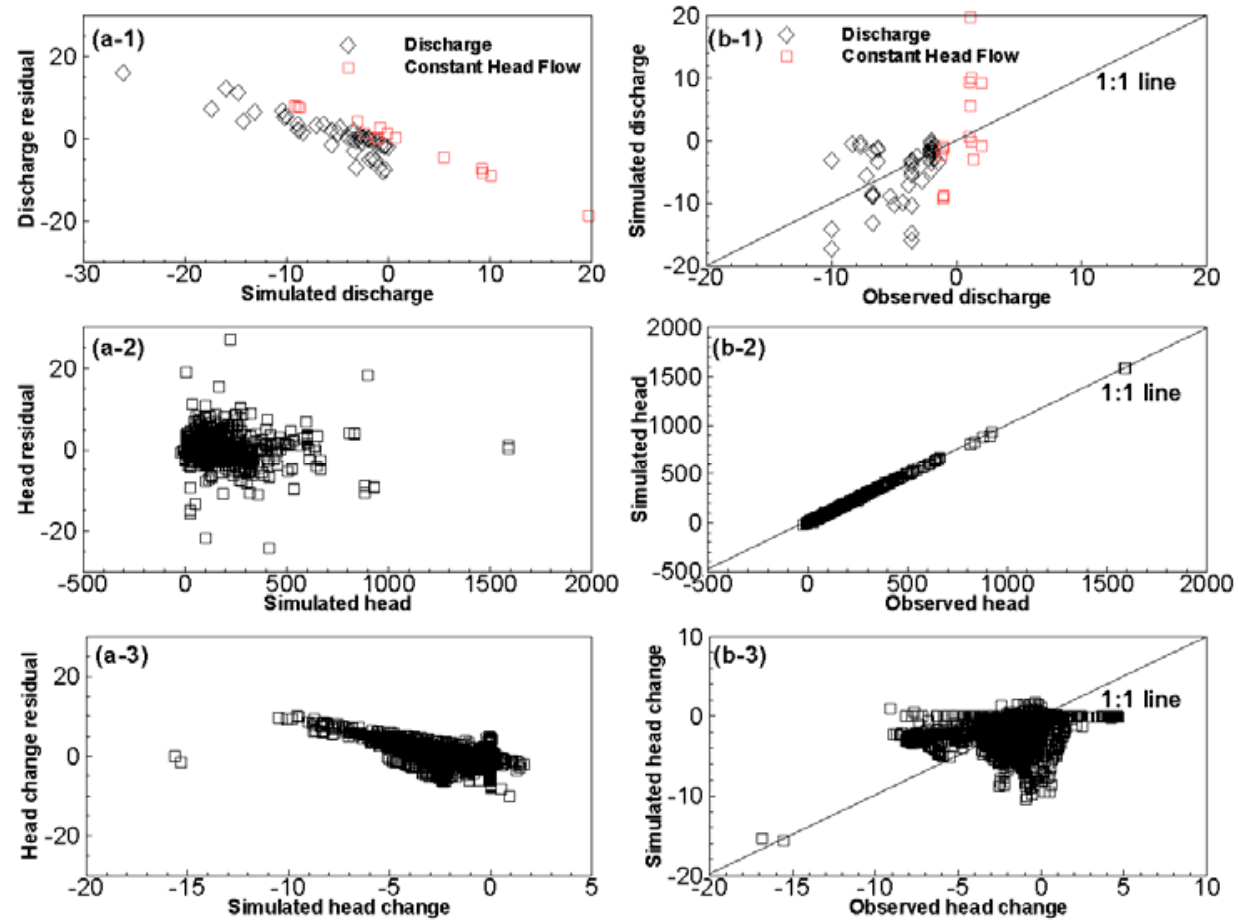

Figure 3-30. Residuals and simulations for (a-1) discharge and constant-head boundary flow, (a-2) head, and (a-3) head change of model G2R5. Observations and simulations for (b-1) discharge and constant-head flow, (b-2) head, and (b-3) head changes of model G2R5. 
Table 3-8 lists the number of observations of heads and head changes, SSWR of the DVRFS model of Belcher et al. (2004), and SSWR of all the 25 alternative models. In comparison with the DVRFS model of Belcher et al. (2004), all the alternative models have smaller SSWR, except for the combination of the G3 geological model (the alternative of the hydraulic barrier) and MME, and NIM1 recharge models and another combination of the G5 geological model (combination of CPT and hydraulic barrier alternatives) and MME recharge model. The reduction is mainly attributed to reduction of head observations. Reduction of the SSWR for head-change observations is small, and the SSWR of some models even increases. Reduction of the SSWR for the G2 geological model (UGTA base model) and G3 (its CPT alternative) is significantly larger than that of the other three models, indicating that the two geological models are more plausible than other models in terms of

Table 3-8. Sum of squared weighted residuals (SSWR) of alternative models for all the calibration data and each type of the calibration data located in northern Yucca Flat.

\begin{tabular}{|c|c|c|c|c|c|c|c|}
\hline \multirow[b]{2}{*}{$\begin{array}{c}\text { Type of } \\
\text { observation }\end{array}$} & \multirow[b]{2}{*}{$\begin{array}{c}\text { Number of } \\
\text { observations }\end{array}$} & \multirow[b]{2}{*}{$\begin{array}{l}\text { Belcher et } \\
\text { al. }(2004)\end{array}$} & \multicolumn{5}{|c|}{ Geological Model 1 (USGS) } \\
\hline & & & MME & NIM1 & NIM2 & CMB1 & CMB2 \\
\hline Hydraulic head & 50 & 528.0 & 372.3 & 296.1 & 211.5 & 213.6 & 227.3 \\
\hline $\begin{array}{c}\text { Hydraulic-head } \\
\text { changes (transient) }\end{array}$ & 9 & 12.3 & 12.1 & 29.6 & 46.8 & 12.1 & 12.1 \\
\hline Total & 59 & 540.3 & 384.4 & 325.7 & 258.3 & 225.7 & 239.4 \\
\hline & & & \multicolumn{5}{|c|}{ Geological Model 2 (BAS) } \\
\hline $\begin{array}{c}\text { Type of } \\
\text { observation }\end{array}$ & $\begin{array}{c}\text { Number of } \\
\text { observations }\end{array}$ & $\begin{array}{l}\text { Belcher et } \\
\text { al. (2004) }\end{array}$ & MME & NIM1 & NIM2 & CMB1 & CMB2 \\
\hline Hydraulic head & 50 & 528.0 & 234.3 & 127.6 & 102.5 & 122.3 & 155.7 \\
\hline $\begin{array}{l}\text { Hydraulic-head } \\
\text { changes (transient) }\end{array}$ & 9 & 12.3 & 12.1 & 11.8 & 11.9 & 12.0 & 12.0 \\
\hline \multirow[t]{2}{*}{ Total } & 59 & 540.3 & 246.4 & 139.4 & 114.5 & 134.3 & 167.7 \\
\hline & & & \multicolumn{5}{|c|}{ Geological Model 3 (CPT) } \\
\hline $\begin{array}{c}\text { Type of } \\
\text { observation }\end{array}$ & $\begin{array}{c}\text { Number of } \\
\text { observations }\end{array}$ & $\begin{array}{l}\text { Belcher et } \\
\text { al. }(2004)\end{array}$ & MME & NIM1 & NIM2 & CMB1 & CMB2 \\
\hline Hydraulic head & 50 & 528.0 & 181.6 & 79.2 & 56.4 & 107.6 & 78.3 \\
\hline Hydraulic-head & & & & & & & \\
\hline changes (transient) & 9 & 12.3 & 12.0 & 6.4 & 105.6 & 11.7 & 12.4 \\
\hline \multirow[t]{2}{*}{ Total } & 59 & 540.3 & 193.6 & 85.6 & 162.0 & 119.3 & 90.7 \\
\hline & & & \multicolumn{5}{|c|}{ Geological Model 4 (HB) } \\
\hline $\begin{array}{c}\text { Type of } \\
\text { observation }\end{array}$ & $\begin{array}{l}\text { Number of } \\
\text { observations }\end{array}$ & $\begin{array}{l}\text { Belcher et } \\
\text { al. (2004) }\end{array}$ & MME & NIM1 & NIM2 & CMB1 & CMB2 \\
\hline Hydraulic head & 50 & 528.0 & $1,184.8$ & 506.2 & 360.5 & 434.7 & 317.4 \\
\hline $\begin{array}{l}\text { Hydraulic-head } \\
\text { changes (transient) }\end{array}$ & 9 & 12.3 & 11.8 & 11.6 & 11.6 & 12.0 & 11.9 \\
\hline \multirow[t]{2}{*}{ Total } & 59 & 540.3 & $1,196.6$ & 517.8 & 372.1 & 446.7 & 329.3 \\
\hline & & & \multicolumn{5}{|c|}{ Geological Model 5 (CPT+HB) } \\
\hline $\begin{array}{c}\text { Type of } \\
\text { observation }\end{array}$ & $\begin{array}{l}\text { Number of } \\
\text { observations }\end{array}$ & $\begin{array}{l}\text { Belcher et } \\
\text { al. (2004) }\end{array}$ & MME & NIM1 & NIM2 & CMB1 & CMB2 \\
\hline Hydraulic head & 50 & 528.0 & 978.1 & 586.9 & 247.3 & 484.3 & 397.6 \\
\hline $\begin{array}{l}\text { Hydraulic-head } \\
\text { changes (transient) }\end{array}$ & 9 & 12.3 & 0.4 & 2.4 & 6.4 & 0.3 & 0.4 \\
\hline Total & 59 & 540.3 & 978.6 & 589.3 & 253.7 & 484.5 & 397.9 \\
\hline
\end{tabular}


residuals. Nevertheless, the other two alternatives (HB and CPT $+\mathrm{HB}$ ) of the UGTA base model are less favored by the calibration data. For any geological model, the MME recharge model gave the largest SSWR, indicating that it is the least plausible recharge model, regardless of geological models.

Similar to Figure 3-26, Figure 3-31 plots variation of residual with simulated heads and head changes, and observed heads and head changes with their corresponding simulations. Figure 3-26 and Figure 3-31 have the same scale and can be compared, as can other figures below. Figure 3-31 (a-1) shows that, while most of the 50 residuals of heads are around 0 , residuals of two observations are large and heads are overestimated. These two observations are denoted as 063104604354 and 060106554395 in the DVRFS model of Belcher et al. (2004), and are named wells "stewart1" and "stewart2" by the USGS (Thordarson et al., 1967). The two wells are shallow with depths of $102.4 \mathrm{~m}$ and $67.4 \mathrm{~m}$, respectively. Static heads at the two wells were 1,332.2 $2 \mathrm{~m}$ and 1,331.39 m, measured on $8 / 8 / 1960$ and $7 / 13 / 1955$, respectively. Standard deviations of the two observations are 8.25 and 5.27, respectively, indicating that the two observations are reliable. Weighted observed head (observed head divided by standard deviation) at the two points are $161.5 \mathrm{~m}$ and $252.6 \mathrm{~m}$, but their simulated values are $173.2 \mathrm{~m}$ and $270.5 \mathrm{~m}$. These two points are of particular interests, since simulated heads at the two points are different in different models, resulting in different SSWR, as shown later. For the nine observations of head changes, there are two points where observations and simulations do not fall on the 45-degree line. The two observations were denoted as 068099804221 and 068099834222 in the DVRFS model of Belcher et al. (2004). However, residuals at these two points are close to zero (Figure 3-31 [a-20]) in the DVRFS model of Belcher et al. (2004) and most of the other models.
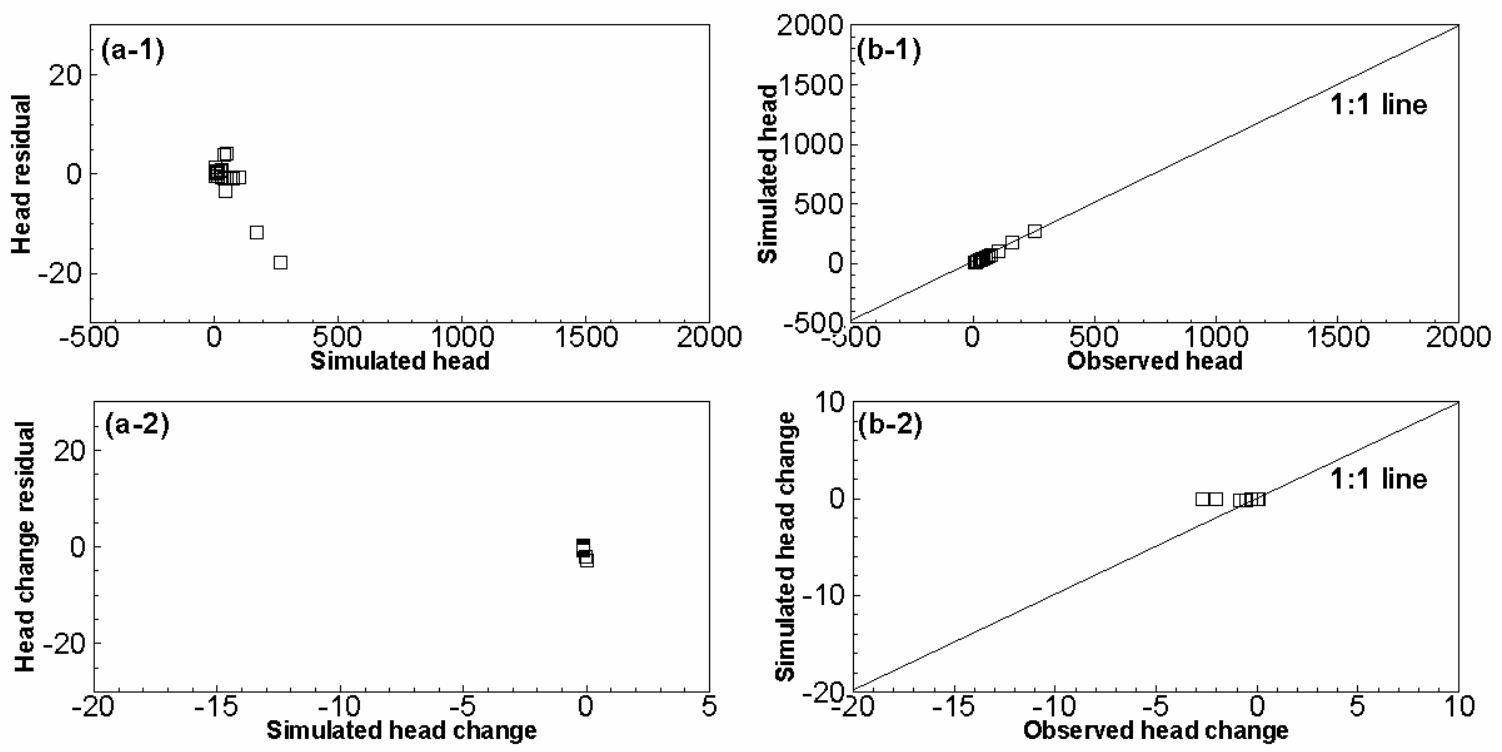

Figure 3-31. Residuals and simulations for (a-1) head and (a-2) head change of the DVRFS of Belcher et al. (2004). Observations and simulations for (b-1) head and (b-2) head changes of the DVRFS of Belcher et al. (2004). 
Residuals of the 25 alternative models were plotted in the same manner as that of Figure 3-31 to evaluate goodness of model fit. However, it is unnecessary to present all of them in the report. Figure 3-32 plots the residual figures for model G1R2 (USGS geological model and NIM1 recharge model), equivalent to the DVRFS model of Belcher et al. (2004). However, due to different calibration processes discussed before, residuals of the two models are different. Comparing (a-1) of Figure 3-31 and Figure 3-32 shows that residuals of head observations were reduced for model G1R2, while residuals of observations of head changes were increased. Nevertheless, the total residuals were reduced as shown in Table 3-8.

Figure 3-33 plots the residual figures for model G1R5 (USGS geological model and CMB1 recharge model). Comparing (a-1) of Figure 3-31 and Figure 3-33 shows that, while residuals of observations of head changes remained nearly the same, residuals of head observations were reduced for model G1R5. The reduction is mainly due to the new calibration process. Figure 3-34 and Figure 3-35 plot the residuals for models G2R2 and G2R5, respectively. The two models have the same geological model (UGTA base model), but different recharge models (NIM1 and CMB2). Residuals of the nine observations of head changes are almost the same for the two models, as shown in (a-2) of Figure 3-34 and Figure 3-35. However, the SSWR of heads for G2R2 is less than that of G2R5, as shown in (a-1) of the two figures. The difference is mainly caused by the two head observations denoted by 063104604354 and 060106554395 in the DVRFS model of Belcher et al. (2004). At the two points, heads were all underestimated, but only slightly for model G2R2.
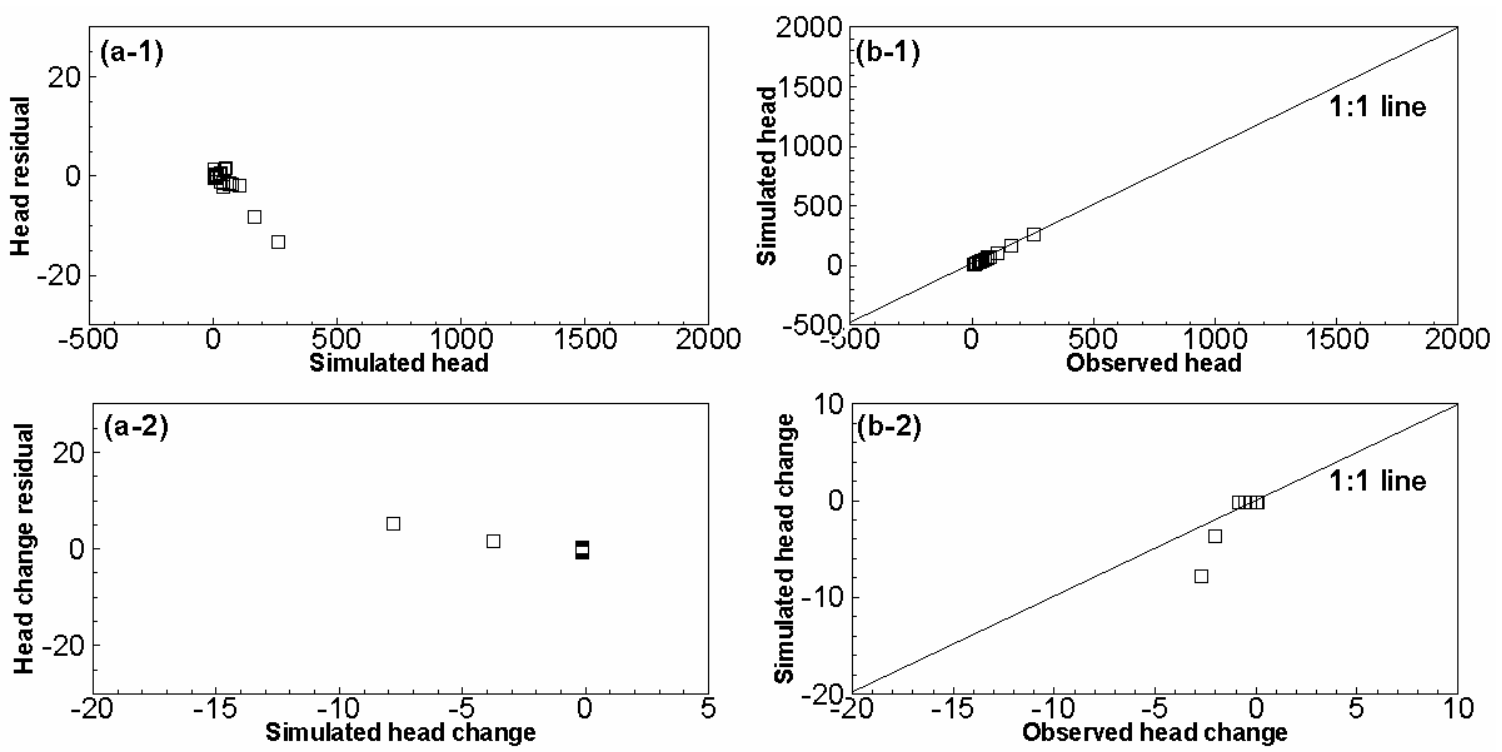

Figure 3-32. Residuals and simulations for (a-1) head and (a-2) head change of model G1R2. Observations and simulations for (b-1) head and (b-2) head changes of model G1R2. 

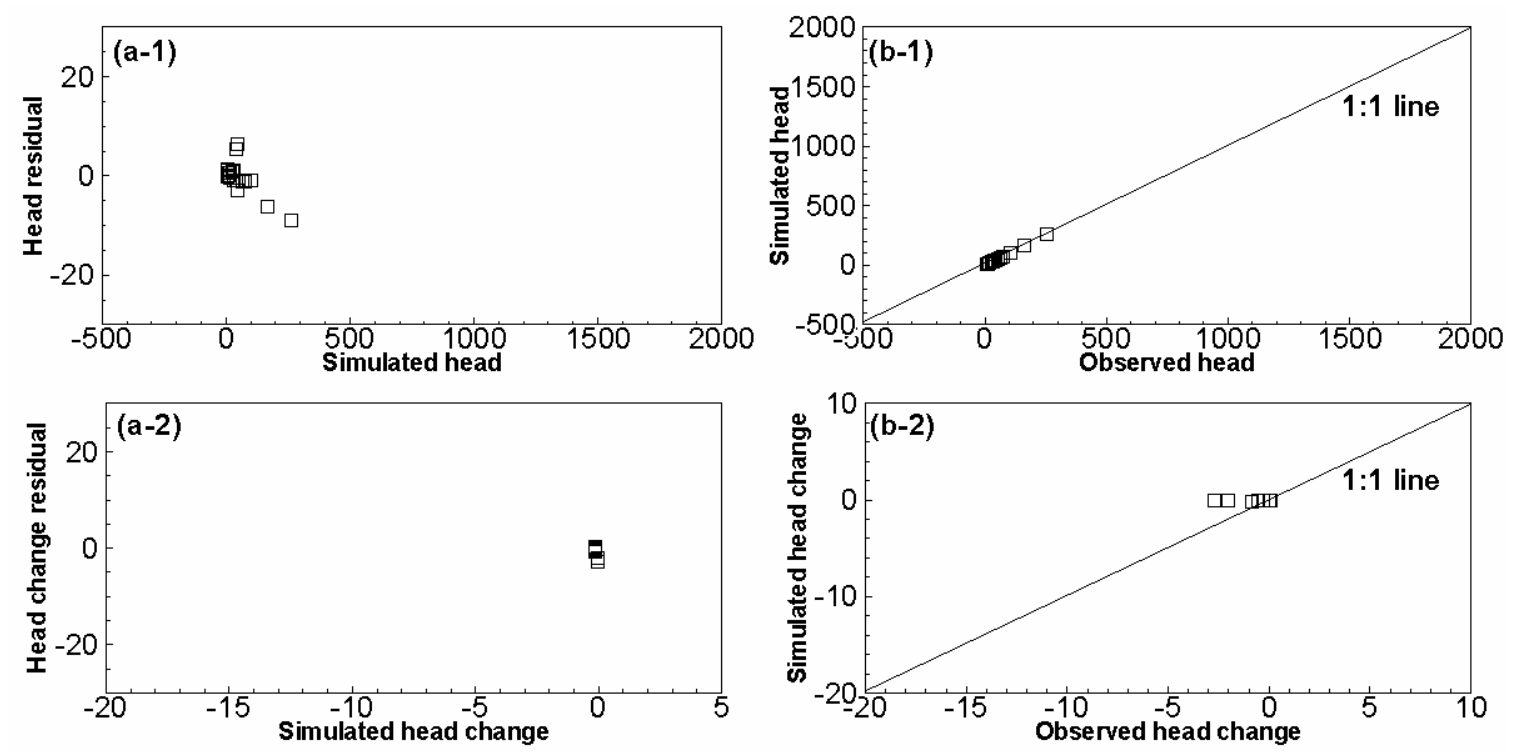

Figure 3-33. Residuals and simulations for (a-1) head and (a-2) head change of model G1R5. Observations and simulations for (b-1) head and (b-2) head changes of model G1R5.
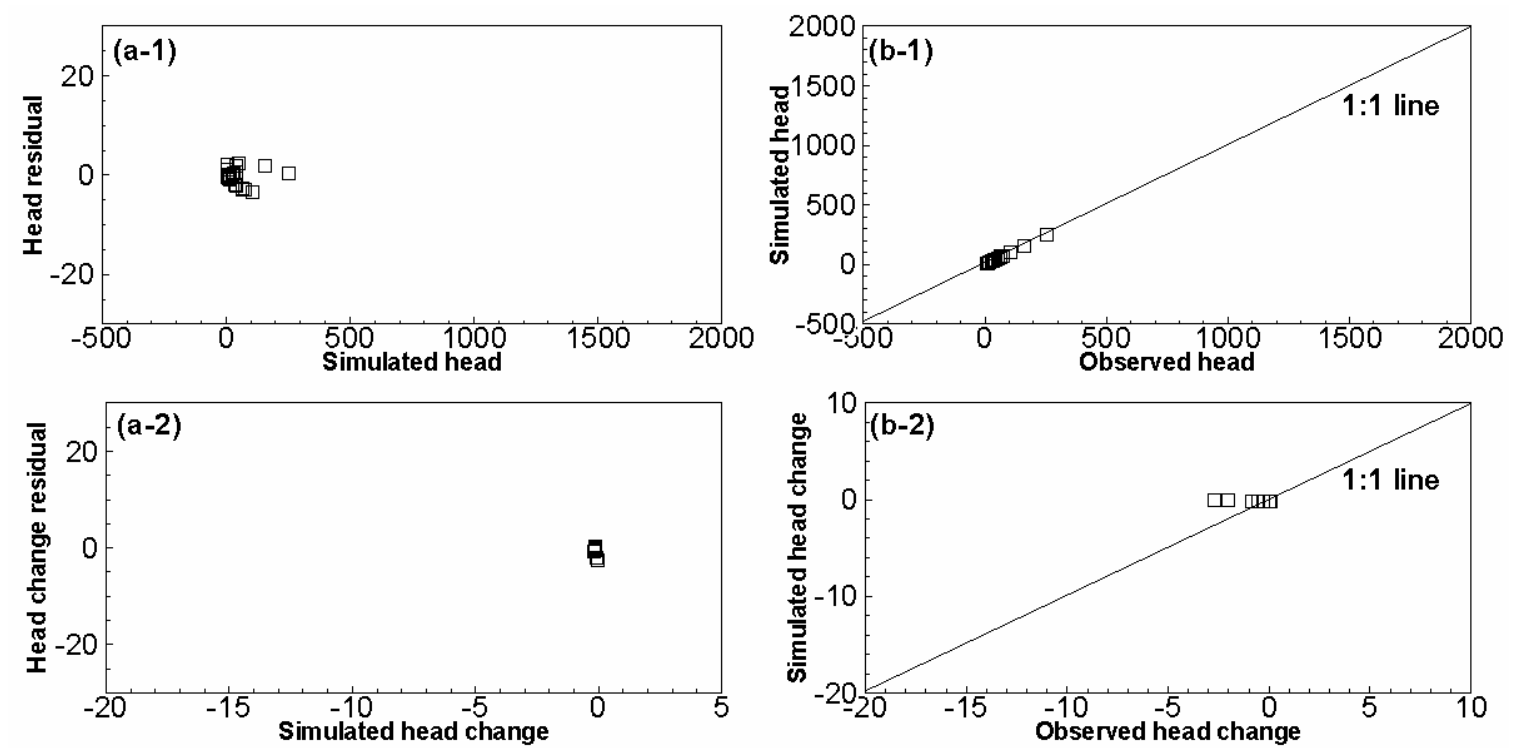

Figure 3-34. Residuals and simulations for (a-1) head and (a-2) head change of model G2R2. Observations and simulations for (b-1) head and (b-2) head changes of model G2R2. 

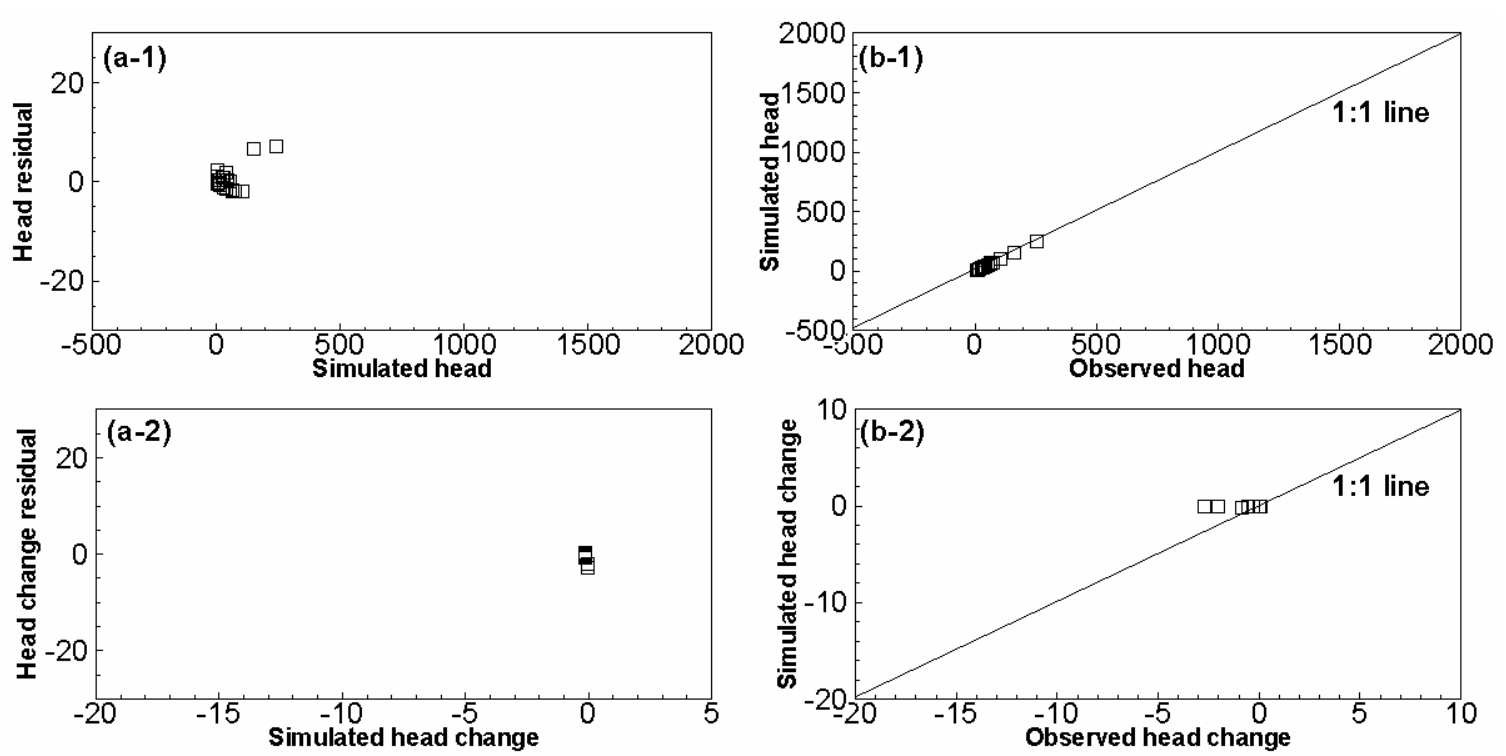

Figure 3-35. Residuals and simulations for (a-1) head and (a-2) head change of model G2R5. Observations and simulations for (b-1) head and (b-2) head changes of model G2R5.

To further investigate residuals of the 25 models, all residuals of the 50 head observations and nine head-change observations are plotted together in Figure 3-36. Residuals of the five recharge models under one geological model are plotted together. Weights were applied to the two types of observations to render them dimensionless for comparison. The figure shows that most of the residuals are nearly the same for all the alternative models, except the four points identified before. For the two head-change observations (068099804221 and 068099834222 with indices 58 and 59 in Figure 3-36), their residuals for most of the 25 models are nearly the same, except for recharge model R3 (NIM2) under geological model G3 (the CPT alternative) and recharge models R2 and R3 under geological model G1 (the USGS model). However, for the two observations of heads (063104604354 and 060106554395), their residuals are different for all of the 25 models. Qualitatively speaking, for the two observations, geological model G3 gives the smallest residuals regardless of recharge models; models G4 and G5 give the largest residuals.

Figure 3-37 and Figure 3-36 are similar, except that residuals of the five geological models are plotted together for a recharge model, and for each recharge model, most of the residuals of different geological models are similar, except for the four observations identified before. However, residuals of different geological models for a recharge model have larger variation than residuals of different recharge models for a geological model. This indicates that, qualitatively speaking, in northern Yucca Flat, the effect of recharge models on flow is smaller that that of geological models. As shown in Table 3-8, recharge model R2 (NIM1) in general gives the smallest residuals. The second best recharge model appears to be the CMB2. The worst model in terms of residuals is the MME. 

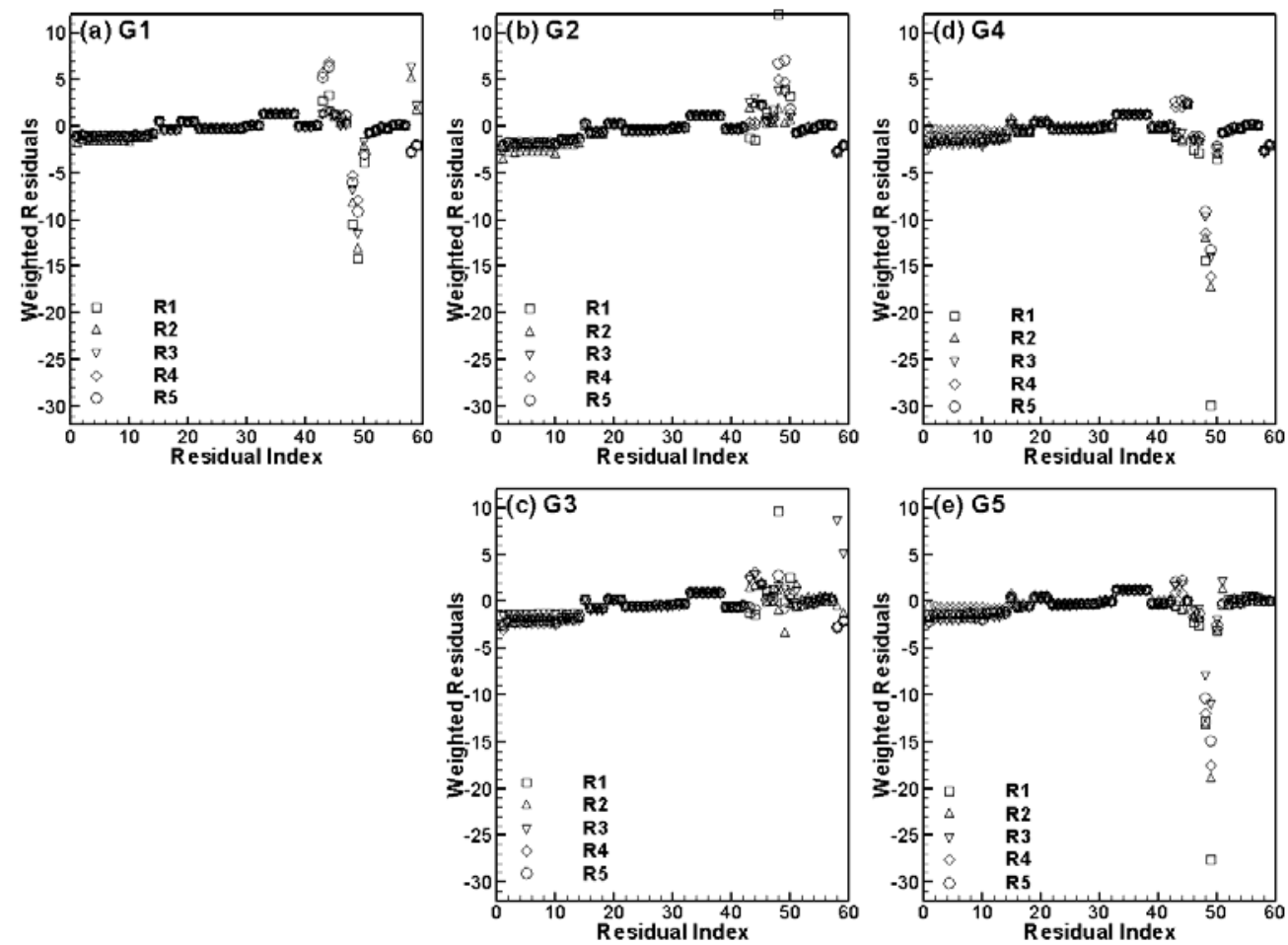

Figure 3-36. Weighted residuals of the 50 observations of head (index from 1 to 50 ) and nine observations of head change (index from 51 to 59) for all of the 25 models. The residuals of different recharge models under one geological model are plotted.
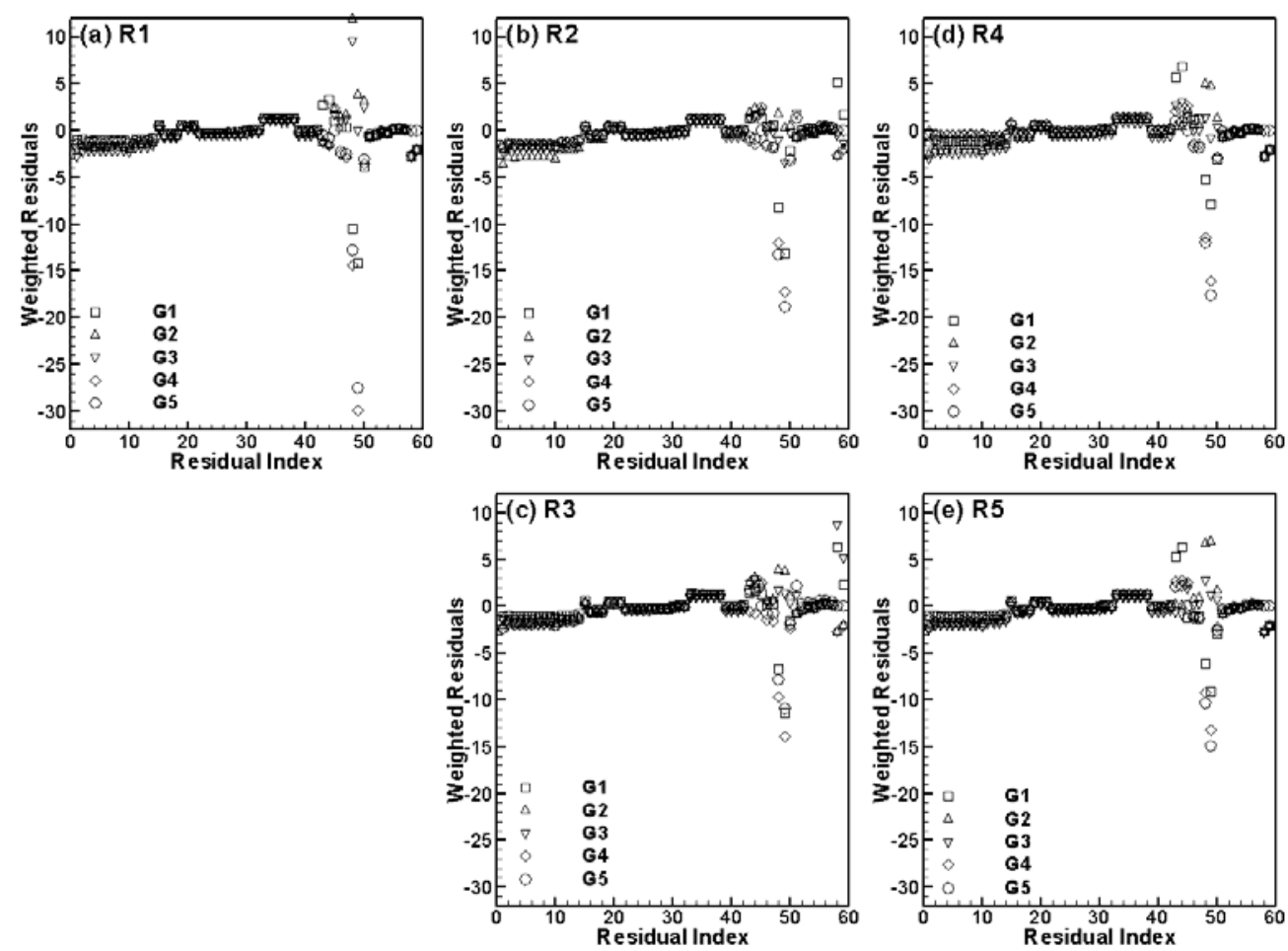

Figure 3-37. Weighted residuals of the 50 observations of head and nine observations of head change for all of the 25 models. The residuals of different geological models under one recharge model are plotted. 


\subsubsection{Calibrated Parameters of Alternative Models}

When calibration of each model is completed, MODFLOW gives optimum parameters, the covariance matrix of parameter estimation uncertainty, and the 95-percent confidence intervals of the parameters. While model calibration does not require normal distribution of model parameters, calculation of the 95-percent confidence intervals requires that calibrated parameters follow a normal distribution with the mean given by the calibrated parameter values and the variance given by the covariance matrix. The confidence interval essentially measures accuracy of parameter estimates, i.e., unknown true parameters are with the interval with 95-percent probability. As the confidence interval is a byproduct of calibrated parameters and their covariance matrix, focus in this section is on the calibrated parameters of alternative models and their covariance matrix. The covariance matrix is used later on to generate realizations of model parameters, and thus will be discussed then.

Figure 3-38 plots calibrated parameters of the five recharge models for geological model G1 (the USGS model). All 32 parameters are plotted on a log scale so that they can be plotted together. For better comparison, the 32 parameters are separated into two parts, and plotted in Figures 3-38(a) and (b). The recharge multiplier $\mathrm{RCH}_{-} 2$ and $\mathrm{RCH}_{-} 35$ of recharge models MME, CMB1, and CMB2 are also plotted, although their values were not calibrated
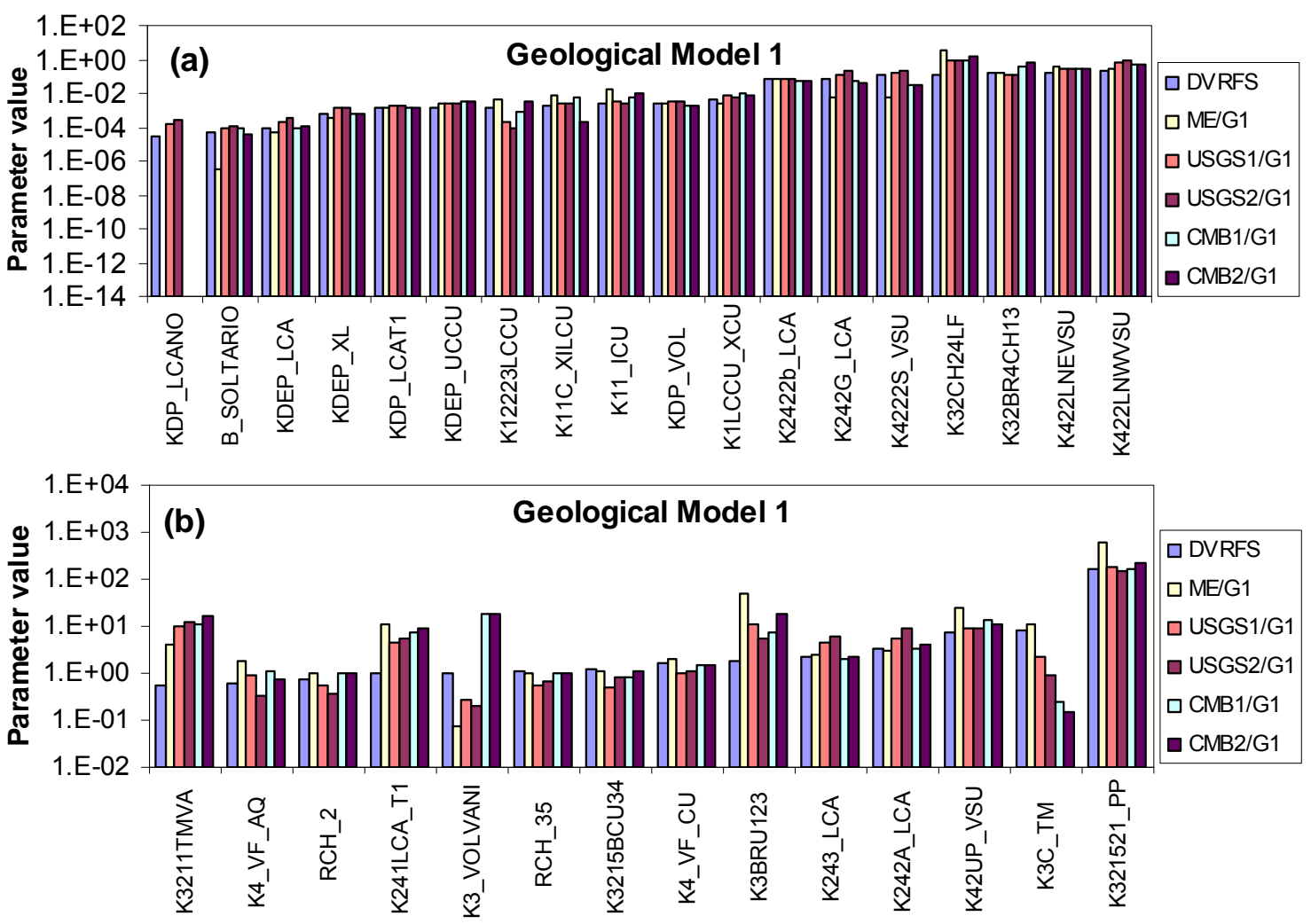

Figure 3-38. Calibrated model parameters of the five recharge models for geological model G1 (USGS model). Calibrated parameters of Belcher et al. (2004) were also plotted for reference. 
(fixed as 1) for the three models. During model calibration, the depth decay coefficient KDP_LCANO became 10E-14 for recharge models MME, CMB1, and CMB2, and MODFLOW terminated calibration due to numerical instability. The small value of KDP_LCANO implies that depth decay is not desirable for hydrogeologic unit LCANO. Using the depth-decay coefficient, $\lambda$ (e.g., KDP_LCANO value), hydraulic conductivity at depth $d, K_{\text {Dep }}$, can be calculated as $K_{\text {Dep }}=K_{\text {surface }} 10^{-\lambda d}$, where $K_{\text {surface }}$ is hydraulic conductivity at a reference surface (land surface in this case) (Anderman and Hill, 2003). The KDP_LCANO value of 10E-14 renders that $K_{\text {Dep }}=K_{\text {surface }}$ regardless of the value of depth $d$. The parameter KDP_LCANO is associated with LCA units of K2_DV_LCA, K243GV_LCA, K241SM_LCA, and K243PP_LCA, and their hydraulic conductivities $\left(K_{\text {surface }}\right)$ are $3.0 \mathrm{~m} / \mathrm{d}, 2.4 \mathrm{E}-3 \mathrm{~m} / \mathrm{d}, 1.5 \mathrm{E}-3 \mathrm{~m} / \mathrm{d}$, and $1.0 \mathrm{~m} / \mathrm{d}$ (none of the parameters being calibrated in this project for the reasons discussed before). Average depths of these parameters are $981 \mathrm{~m}, 1,367 \mathrm{~m}, 2,670 \mathrm{~m}$, and $836 \mathrm{~m}$, respectively (Belcher et al., 2004, Table F-9). Given these hydraulic conductivities and the depth decay formula, theMODFLOW termination for KDP LCANO is not considered abnormal. Thus, the value of KDP_LCANO is fixed at 10E-14, and calibration for the three recharge models continued. Values of the calibrated parameters were also plotted for other models in the manner of Figure 51, but not shown in the report. Instead, values of calibrated parameters of all models are listed in Appendix D.

The calibrated parameters of Belcher et al. (2004) are plotted in Figure 3-38 as reference. Physical reasonableness of these parameters has been comprehensively examined by Belcher et al. (2004). If calibrated parameters of the 25 alternative models are close to those of Belcher et al. (2004), they are regarded reasonable. If they differ significantly, the values of calibrated hydraulic conductivity of the alternative models are compared to the ranges of hydraulic conductivity given in Tables F8 through F11 of Belcher et al. (2004). The values of the calibration parameters for the 25 models and ranges of these parameters for the DVRFS model are listed in Appendix D. However, the parameter ranges are available only for certain parameters in the DVRFS. In addition, due to limited reliability of the ranges, they should be used only as a reference, not absolute criterion, for judging reasonableness of calibrated parameters. For example, range of hydraulic conductivity of hydraulic parameter K3PVA is $7 \times 10^{-7} \mathrm{~m} / \mathrm{d}$ to $17 \mathrm{~m} / \mathrm{d}$; the calibrated parameter value of Belcher et al. (2004) is 288.5. This is not unreasonable when examining model fit. Note that ranges do not exist for parameters other than hydraulic conductivity.

Figure 3-38a shows that, under geological model G1 (USGS model), parameter variation for different recharge models is small. In addition, except that the depth decay coefficient, KDP_LCANO, is $1 \times 10^{-14}$ for recharge models MME, CMB1, and CMB2, other parameter values of the five recharge models are close to those of Belcher et al. (2004). The calibrated parameters shown in Figure 3-38(b) vary significantly for the recharge models. A similar pattern of parameter variation is also observed for other models. As shown in Appendix D, all calibrated parameters are within the parameter ranges, except the parameter K321521_PP, the hydraulic conductivity of Crater Flat-Prow Pass Aquifer, whose range is from $0.001 \mathrm{~m} / \mathrm{d}$ to $180 \mathrm{~m} / \mathrm{d}$. The maximum value of the calibrated parameter is $1,010 \mathrm{~m} / \mathrm{d}$ for the combination of CMB1 recharge (R4) and UGTA base geological (G2) models. The second and third largest values are $834 \mathrm{~m} / \mathrm{d}$ and $683 \mathrm{~m} / \mathrm{d}$ for the combination of CMB2 recharge model (R5) with USGS base model (G2) and CP thrust alternative model (G3). In 
general, recharge models MME, CMB1, and CMB2 give larger calibrated values of hydraulic conductivity of K321521_PP than recharge models NIM1 and NIM2, regardless of geological models. This is caused by larger recharge estimated by the former three models at locations where the parameter K321521_PP is defined. Despite that some calibrated values of K321521_PP exceed the parameter range, the calibrated values are still considered reasonable for the aquifer, given that the calibrated values are one order of magnitude larger than its maximum range of $180 \mathrm{~m} / \mathrm{d}$. As a summary, given the available parameter information and residual analysis, all of the calibrated parameters for the 25 models are considered reasonable.

\subsubsection{Probabilities of Alternative Models}

While model probabilities were estimated using the expert elicitation, they are subjective perceptions of the experts of relative model plausibility, and they need to be updated based on calibration results. Calibration measures plausibility of alterative models by comparing optimum model prediction (after calibration) with site observations. If one model fits the observations better than other models, its prior probability should be adjusted to yield higher posterior probability, using Bayes' theorem

$$
p\left(M_{k} \mid \mathbf{D}\right)=\frac{p\left(\mathbf{D} \mid M_{k}\right) p\left(M_{k}\right)}{\sum_{l=1}^{K} p\left(\mathbf{D} \mid M_{l}\right) p\left(M_{l}\right)}
$$

where $M_{k}$ is the $k$-th of total $K$ alternative models, $p\left(M_{k}\right)$ is prior probability of model $M_{k}$ obtained from expert elicitation and satisfying $\sum_{k=1}^{K} p\left(M_{k}\right)=1, p\left(M_{k} \mid \mathbf{D}\right)$ is posterior probability of model $M_{k}$ conditioned on calibration data $\mathbf{D}$, and $p\left(\mathbf{D} \mid M_{k}\right)$ is model likelihood.

The most important step of estimating posterior model probability is to evaluate the model probability $p\left(\mathbf{D} \mid M_{k}\right)$, using a variety of proposed methods. $p\left(\mathbf{D} \mid M_{k}\right)$ can be calculated using likelihood functions (Beven [2006] and its reference for his method of Generalized Likelihood Uncertainty Estimation, GLUE) in chi-squared sense, the information criterion of AIC (Akaike, 1974) or AICc (Hurvich and Tsai, 1989) in KullbackLeibler sense (Poeter and Anderson, 2005), or the information criterion of BIC (Schwartz, 1978) or KIC (Kashyap, 1982) in Bayesian sense (Hoeting et al., 1999; Neuman, 2003; Ye et al., 2004). There is no consensus as to which method is superior. Using the information criteria (AIC, AICc, BIC, and KIC) may be more appropriate than the likelihood method of GLUE, since the criteria agree with the principal of parsimony. However, this case is more complicated than general cases of uncertainty analysis. First, although the interest is in flow and transport in northern Yucca Flat, the DVRFS regional models were calibrated using all observations throughout the DVRFS, since this will constrain the flow system better than just using observations in northern Yucca Flat. The advantage of doing so has been explained earlier in the residual analysis. Second, calibrated parameters are not distributed throughout the DVRFS, but close to northern Yucca Flat. Lack of correspondence between the domain of interest, modeling domain, calibration data, and calibrated parameters renders application of the information criteria to calculate model likelihood questionable. Instead, the likelihood 
method of GLUE does not consider the principal of parsimony, and only uses model fit to evaluate model probability. Thus, the GLUE method is used to evaluate model probability.

Following Beven and Binley (1992), the likelihood function can be calculated as inverse of the SSWR, listed earlier for all of the 25 models. This indicates that the better a model fit, the more plausible the model. Typical GLUE application is to assess parametric uncertainty for multiple parameter realizations. It is extended here to assess the uncertainty of alternative models. Also included is prior model probability in the GLUE process to evaluate model probability using Equation (3.8). Table 3-9 lists posterior model probabilities for two sets of prior model probabilities. In the first set, all models are treated equally likely, and each model has a prior probability of 4 percent. In this case, posterior probability is solely determined by the quality of model fit measured by the SSWR. In the second set, the prior model probabilities obtained from expert elicitation are used together with the SSWR to calculate the posterior model probabilities using Equation (3.8). The difference between the two sets of posterior probabilities will be discussed below. From the Bayesian point of view, including expert judgment is a strength rather than a weakness. Thus, the second set of posterior probabilities is used for the flow and transport simulation. Corresponding prior and posterior model probabilities are plotted in Figure 3-39.

Table 3-9. Prior and posterior model probabilities of the 25 alternative models. Two sets of posterior probabilities are calculated for equal priors and unequal priors obtained from expert elicitation.

\begin{tabular}{ccccc}
\hline Models & Prior $(\%)$ & Posterior $(\%)$ & Prior $(\%)$ & Posterior (\%) \\
\hline G1R1 & 4.0 & 2.24 & 2.75 & 1.55 \\
G1R2 & 4.0 & 2.65 & 3.30 & 2.19 \\
G1R3 & 4.0 & 3.34 & 1.32 & 1.11 \\
G1R4 & 4.0 & 3.82 & 1.43 & 1.37 \\
G1R5 & 4.0 & 3.60 & 2.20 & 1.99 \\
G2R1 & 4.0 & 3.50 & 7.00 & 6.15 \\
G2R2 & 4.0 & 6.19 & 8.40 & 13.05 \\
G2R3 & 4.0 & 7.54 & 3.36 & 6.36 \\
G2R4 & 4.0 & 6.43 & 3.64 & 5.87 \\
G2R5 & 4.0 & 5.14 & 5.60 & 7.23 \\
G3R1 & 4.0 & 4.46 & 4.50 & 5.03 \\
G3R2 & 4.0 & 10.07 & 5.40 & 13.66 \\
G3R3 & 4.0 & 5.33 & 2.16 & 2.89 \\
G3R4 & 4.0 & 7.23 & 2.34 & 4.25 \\
G3R5 & 4.0 & 9.51 & 3.60 & 8.60 \\
G4R1 & 4.0 & 0.72 & 6.50 & 1.18 \\
G4R2 & 4.0 & 1.67 & 7.80 & 3.26 \\
G4R3 & 4.0 & 2.32 & 3.12 & 1.82 \\
G4R4 & 4.0 & 1.93 & 3.38 & 1.64 \\
G4R5 & 4.0 & 2.62 & 5.20 & 3.42 \\
G5R1 & 4.0 & 0.88 & 4.25 & 0.94 \\
G5R2 & 4.0 & 1.46 & 5.10 & 1.87 \\
G5R3 & 4.0 & 3.40 & 2.04 & 1.74 \\
G5R4 & 4.0 & 1.78 & 2.21 & 0.99 \\
G5R5 & 4.0 & 2.17 & 3.40 & 1.85 \\
Sum & 100.00 & 100.00 & 100.00 & 100.00 \\
\hline
\end{tabular}


The best model shown in the table and figure is G3R2 (CPT geologic model and NIM1 recharge model), no matter which set of prior probabilities is used to calculate the posterior probability. The second best model is G2R2 (UGTA base geologic model and NIM1 recharge model), if its posterior probability is calculated using the prior probability obtained from expert elicitation. However, the result is different if the equal prior is used. The reason is that this model has the largest prior probability, since the UGTA base geologic model (G2) and NIM1 recharge model (R2) were evaluated as the best models in the two elicitations. The third best model is G3R5 (CP thrust geologic model and CMB2 recharge model). It is the second best model if the equal prior is used to calculate posterior model probability. The effect of prior on posterior model probabilities is not negligible. The posterior model probability of a model calculated solely by SSWR is increased if the model has a high prior probability (e.g., for G2R2), but decreased otherwise (e.g., G3R5). However, the SSWR is the critical variable determining posterior model probabilities. For example, model G4R2 (hydrologic barrier alterative geologic model and NIM1 recharge model) has the second largest prior probability, but its posterior is only 3.26 percent, as calculated by using the high prior. The reason is that a poor model fit was yielded for this model. By the same token, even though model G4 is favored by the experts, model combinations that included this geologic model received low probabilities, since this geologic model gave poor model fit, as discussed before.

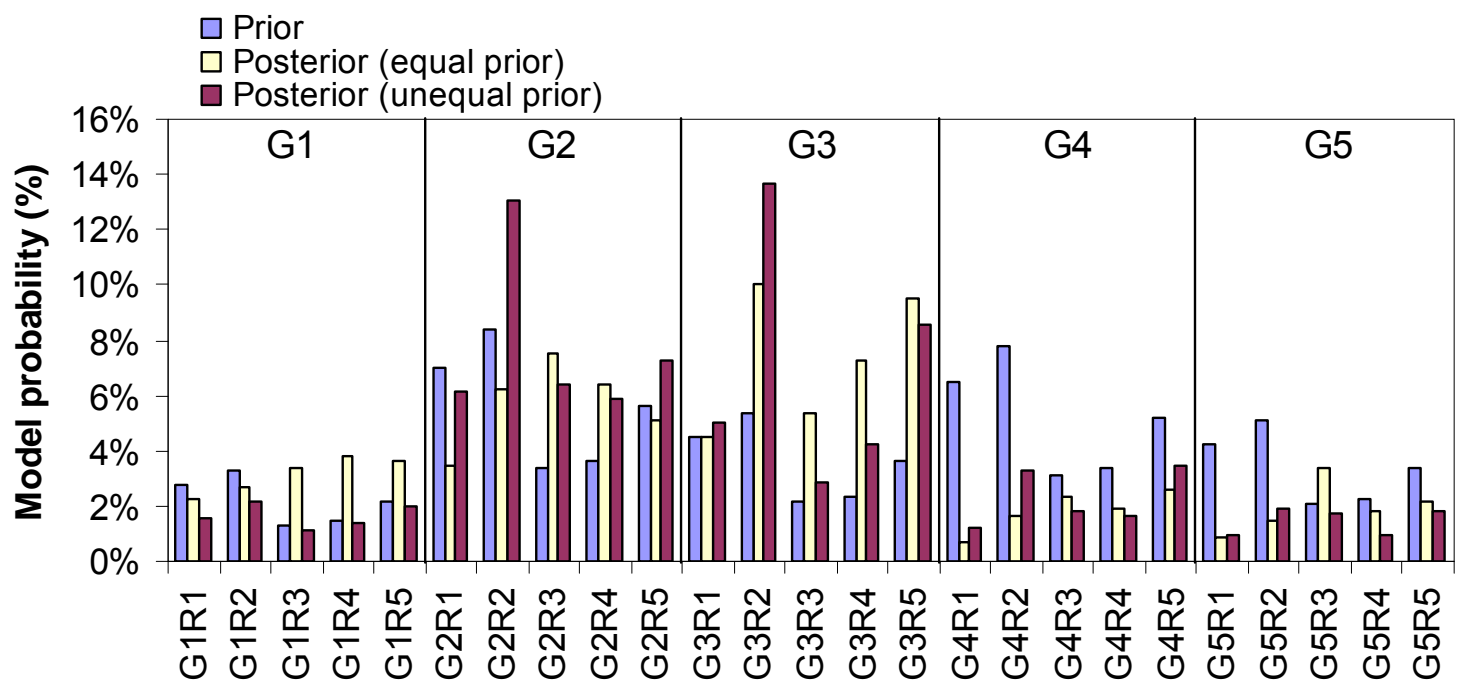

Figure 3-39. Prior and posterior probabilities of the 25 models. The posterior model probabilities correspond to equal and unequal prior model probabilities.

\subsubsection{Recharge, Mass Balance, Hydraulic Head, and Flow Rate of the Calibrated Models}

This section examines recharge, mass balance, hydraulic head, and flow rate in northern Yucca Flat, and spatial distribution of residuals in the northern Yucca Flat area. These results were simulated by calibrated models. The effect of these simulated hydraulic variables on the posterior model probabilities is discussed. 


\subsection{Simulated Recharge}

As discussed before, of the five recharge models, NIM1 and NIM2 estimated net infiltration that needs to be transferred into recharge, while MME, CMB1, and CMB2 estimated recharge directly. Table 3-1 lists the estimates $\left(\mathrm{m}^{3} / \mathrm{d}\right)$ of net infiltration and recharge. For NIM1 and NIM2, recharge was estimated by multiplying the net infiltration by five recharge coefficients, two of which $\left(\mathrm{RCH}_{-} 2\right.$ and $\left.\mathrm{RCH} \_35\right)$ were calibrated for the models associated with the two recharge models. Values of the calibrated coefficients were listed in Appendix D. Table 3-10 lists the actual recharge in the DVRFS and northern Yucca Flat areas for the models associated with the net infiltration models. The values for NIM1 and NIM2 were separated. The table shows that the recharge estimates varied significantly among different models. For example, for model NIM1, the smallest recharge estimate of model G3R2 is only 57 percent of the largest estimate of model G5R2. The variation becomes smaller in northern Yucca Flat, and the ratio of recharge estimates of model NIM1 between G3R2 and R5R2 increases to 72 percent. For better comparison, Figure 3-40 plots recharge of all 25 models. Note that recharge of models associated with MME, CMB1, and CMB2 is constant and independent of HFMs (Table 3-1), while that of models associated with NIM1 and NIM2 varies. Therefore, the recharge estimate of the models associated with R2 and R3 was different among the 25 models. Figure 3-41 plots the recharge estimated in the northern Yucca Flat area in the same manner as Figure 3-40. The two figures show that for the five recharge models, after model calibration, recharge varies significantly. For each geological model, the recharge estimate of MME is higher than that of the CMB1 and CMB2 models. CMB1 gives slightly higher recharge than CMB2 in the DVRFS, whereas the two models have the same recharge in the northern Yucca Flat area. The NIM1 and NIM2 models give the smallest recharge estimate relative to the other three models, while NIM1 gives a larger estimate than NIM2. However, as discussed below, there is no correlation between recharge and model plausibility measured by posterior model probability.

Table 3-10. Calibrated recharge $\left(\mathrm{m}^{3} / \mathrm{d}\right)$ of NIM1 (R2) and NIM2 (R3) for different geological models in the DVRFS and northern Yucca Flat areas. G1 through G5 stands for the DVRFS model, UGTA base model, its CPT alternative, hydrologic barrier alternative, and the CPT and hydrologic barrier alternative.

\begin{tabular}{|c|c|c|}
\hline Recharge Model & DVRFS $\left(\mathrm{m}^{3} / \mathrm{d}\right)$ & Northern Yucca Flat $\left(\mathrm{m}^{3} / \mathrm{d}\right)$ \\
\hline \multicolumn{3}{|c|}{ Net infiltration model with runon-runoff (NIM1) } \\
\hline G1R2 & $180,220.1$ & $1,980.7$ \\
\hline G2R2 & $156,416.9$ & $2,273.9$ \\
\hline G3R2 & $128,621.9$ & $1,723.4$ \\
\hline G4R2 & $178,465.3$ & $1,646.0$ \\
\hline G5R2 & $225,793.6$ & $2,285.0$ \\
\hline \multicolumn{3}{|c|}{ Net infiltration model without runon-runoff (NIM2) } \\
\hline G1R3 & $143,009.1$ & $1,515.2$ \\
\hline G2R3 & $112,848.1$ & $1,352.4$ \\
\hline G3R3 & $83,857.9$ & 877.9 \\
\hline G4R3 & $167,186.9$ & $1,706.8$ \\
\hline G5R3 & $110,276.9$ & $1,214.8$ \\
\hline
\end{tabular}




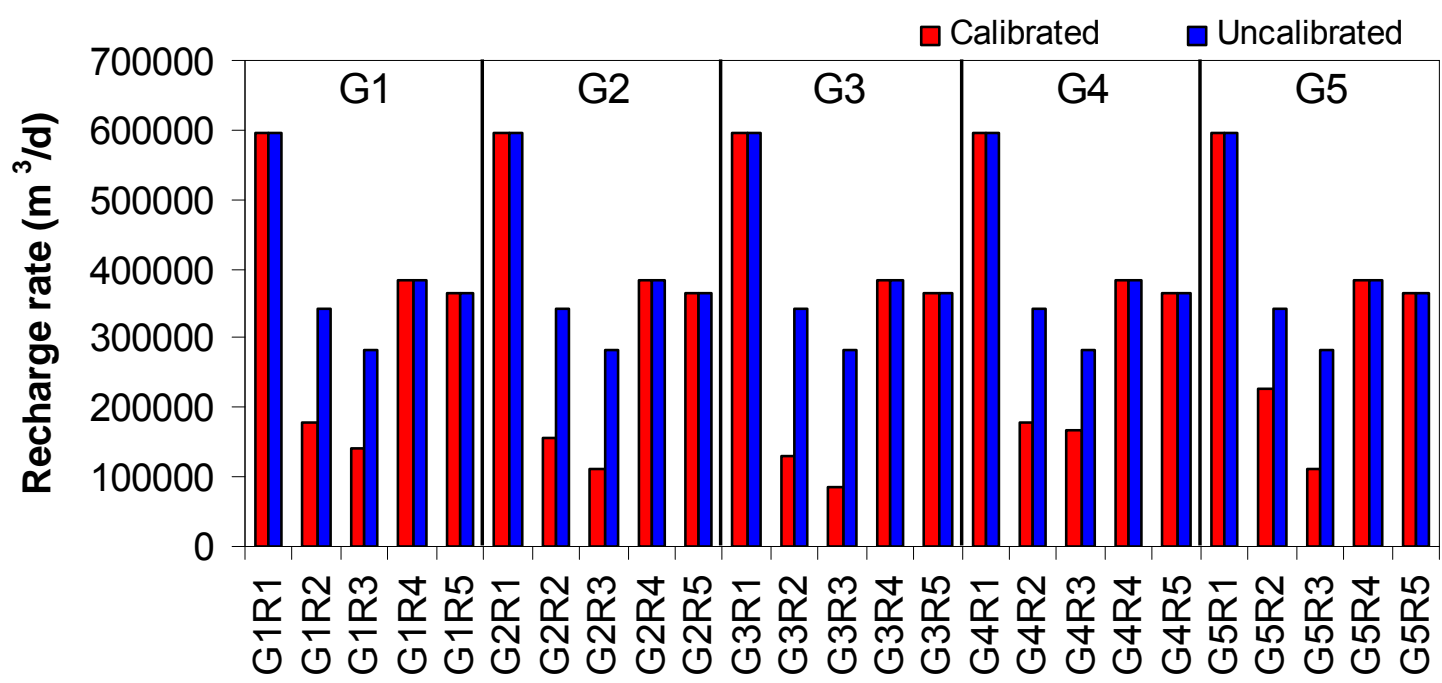

Figure 3-40. Calibrated and uncalibrated recharge rate $\left(\mathrm{m}^{3} /\right.$ day) of the 25 alternative models in the DVRFS. For the models associated with NIM1 (R2) and NIM2 (R3), recharge coefficients are calibrated and used to transfer net infiltration into recharge. For the models associated with the other three models, recharge is not calibrated and is the same before and after the calibration. G1 through G5 stands for the DVRFS model, UGTA base model, its CPT alternative, hydrologic barrier alternative, and the CPT and hydrologic barrier alternative. R1 through R5 stands for the MME, NIM1, NIM2, $\mathrm{CMB} 1$, and CMB2 recharge models.

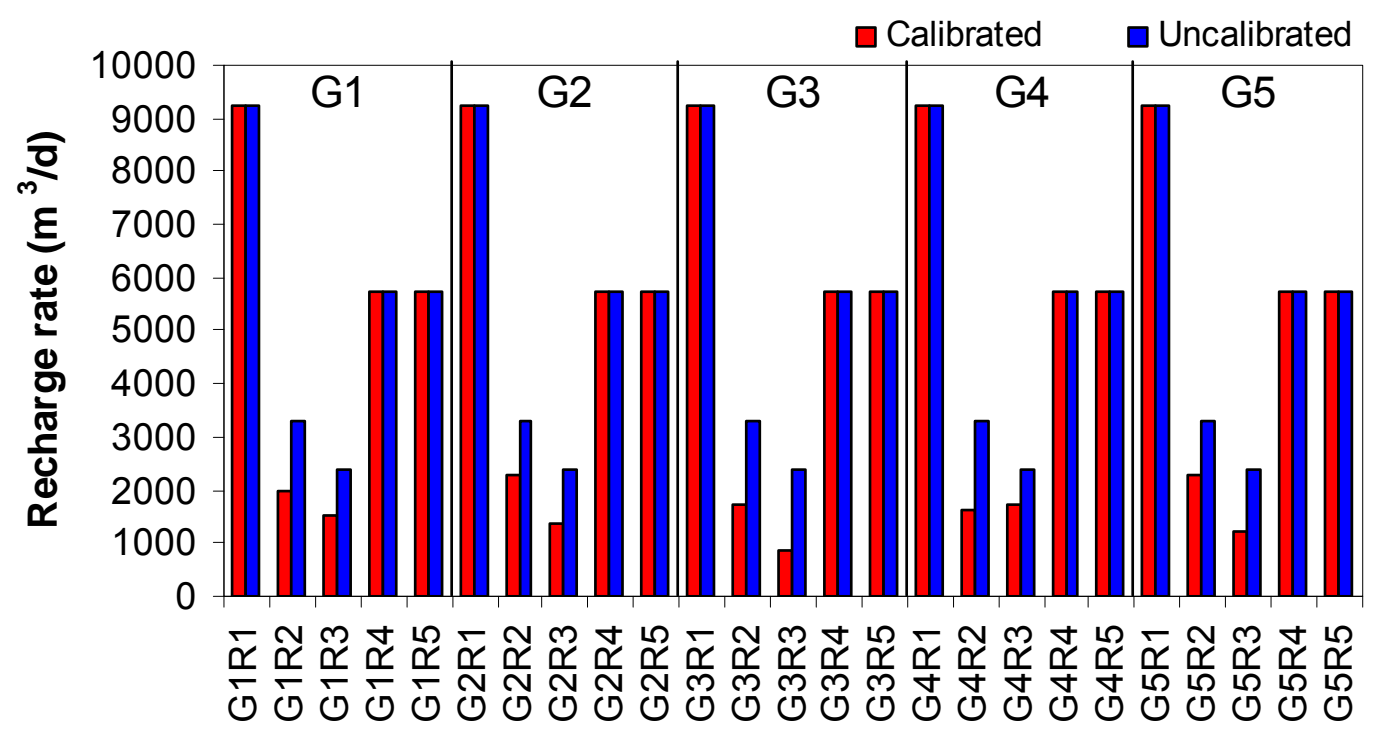

Figure 3-41. Calibrated and uncalibrated recharge rate $\left(\mathrm{m}^{3} /\right.$ day) of the 25 alternative models in the northern Yucca Flat area. For the models associated with NIM1 (R2) and NIM2 (R3), recharge coefficients are calibrated and used to transfer net infiltration into recharge. For the models associated with the other three models, recharge is not calibrated and is the same before and after the calibration. G1 through G5 stands for the DVRFS model, UGTA base model, its CPT alternative, hydrologic barrier alternative, and the CPT and hydrologic barrier alternative. R1 through R5 stands for the MME, NIM1, NIM2, CMB1, and CMB2 recharge models. 
The relationships between the recharge estimates and posterior model probabilities of all the models were further examined by plotting them in Figure 3-42. In addition to the recharge estimates of models NIM1 and NIM2 listed in Table 3-10, recharge estimates of the other models as listed in Table 3-1 are included. Recall that recharge of the later three models does not change among different geological models. For the purpose of plotting, Figure 3-42 plots the recharge percentage, which is the ratio between recharge of a single model and the total recharge of all the models. No pattern of correlation between recharge and model probability was found. This is also confirmed by Figure 3-43, which plots the posterior probability versus recharge percentage of all the models.

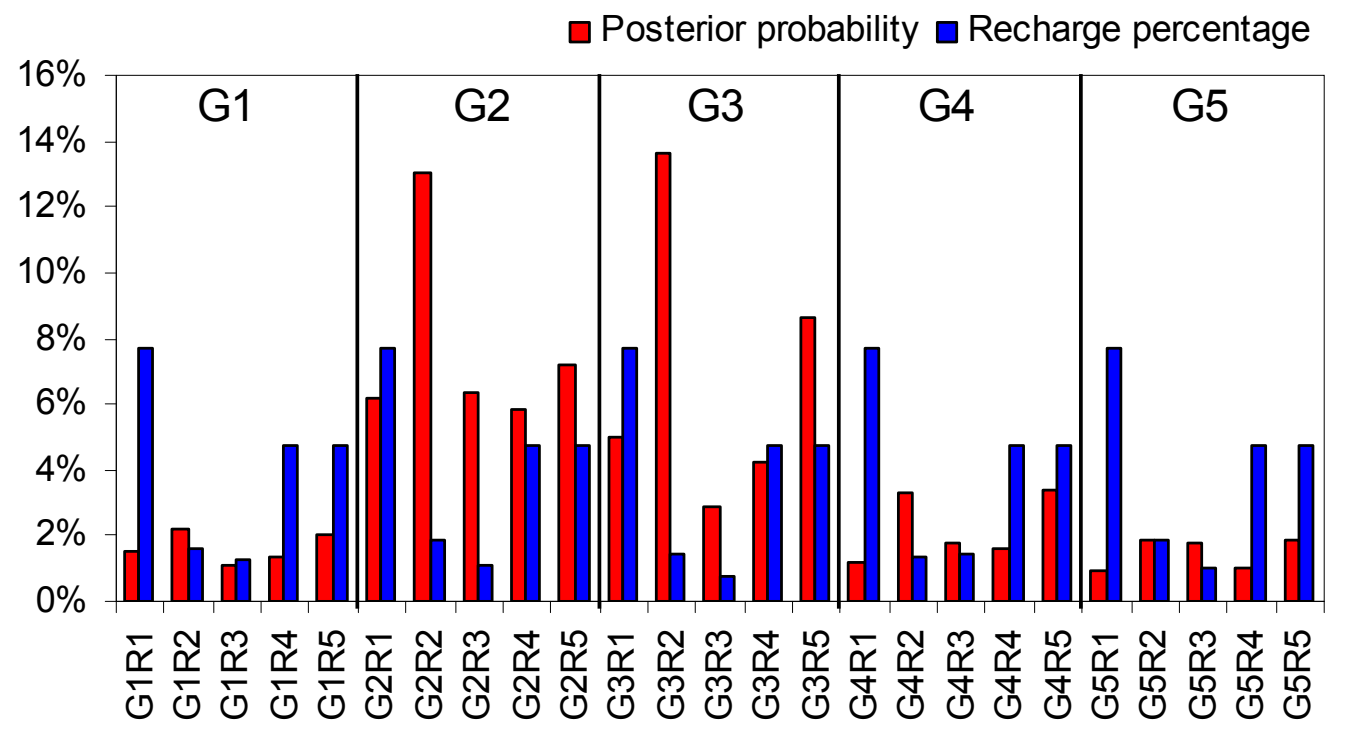

Figure 3-42. Relationship between recharge percentage and posterior probability of all the models. G1 through G5 stands for the DVRFS model, UGTA base model, its CPT alternative, hydrologic barrier alternative, and the CPT and hydrologic barrier alternative. R1 through R5 stands for the MME, NIM1, NIM2, CMB1, and CMB2 recharge models.

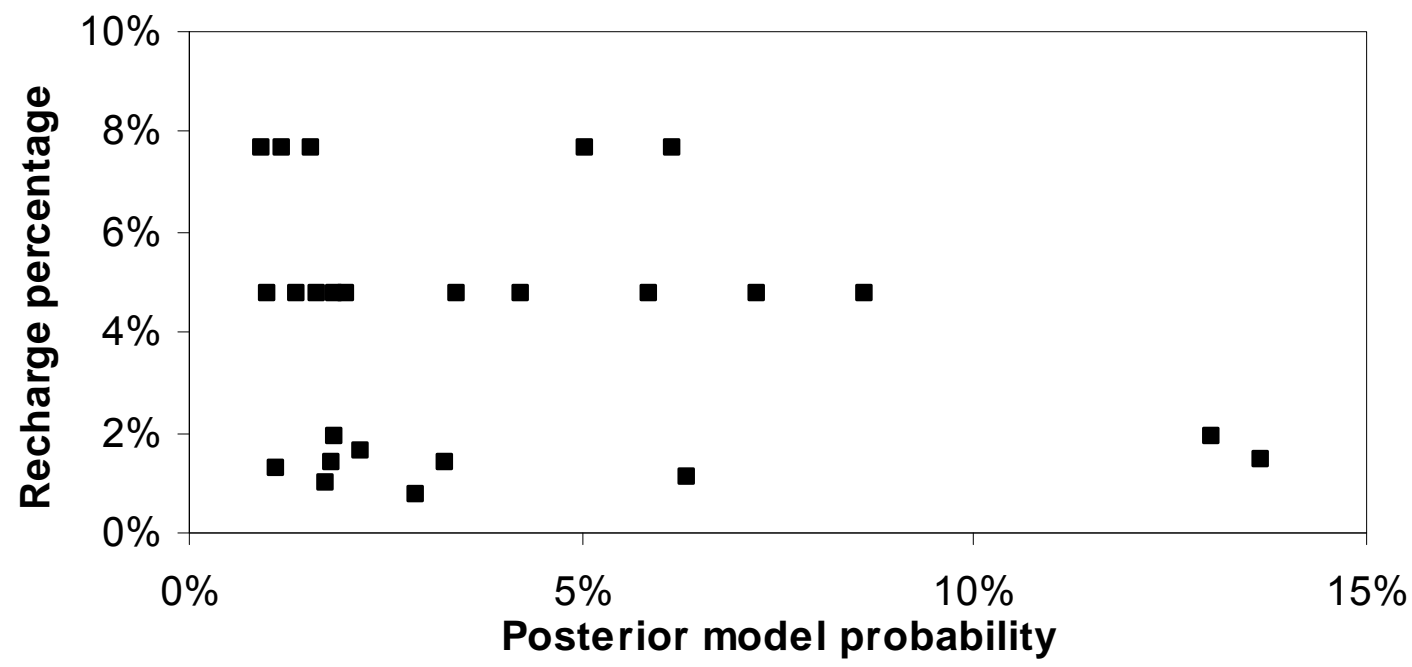

Figure 3-43. Plot of posterior probability versus recharge percentage of all the models. 


\subsection{Simulated Mass Balance and Boundary Flow of the DVRFS}

Mass balance results for the 25 calibrated models are listed for the reader's reference in Tables D6 through D10 of Appendix D. The percentage difference of mass balance is small, indicating that the simulation results are accurate in terms of mass balance. Among the in- and out-flow terms, the boundary flows of the constant-head boundary segments are of concern, however. As pointed out by Belcher et al. (2004), uncertainty in the flow rate $\left(\mathrm{m}^{3} /\right.$ day) estimates is high, and thus low weights were assigned to these estimates. This implies that these data should be used with low confidence in calibrating the models and analyzing calibration results. Due to the low weights, weighted and unweighted boundary flows are dramatically different. The unweighted boundary flow estimates and the simulated values for all 25 models are plotted in Figures D-1 through D-5 in Appendix D, while the weighted values are shown in Figures D6 through D10. Figures 3-44 and 3-45 plot the unweighted and weighted boundary flows, respectively, for the models associated with the USGS geological model 1 (model G1). Results of DVRFS modeling by Belcher et al. (2004) are also plotted for reference. These figures show that while the simulated boundary-flow agrees reasonably well with the corresponding estimate for both the unweighted and weighted cases, there is significant mismatch at the segments of Stone Cabin-Railroad, Sheep Range, and Pahranagat. This was also observed by Belcher et al. (2004), who attributed the mismatch to inaccuracy in the USGS geological model and the boundary-flow estimates. The causes of mismatch were believed the same in the present modeling. The reason is that in addition to adopting the boundary-flow estimates of Belcher et al. (2004), their geological model over the entire Death Valley region was also adopted. Only in the northern Yucca Flat area was the geological model reconceptualized.

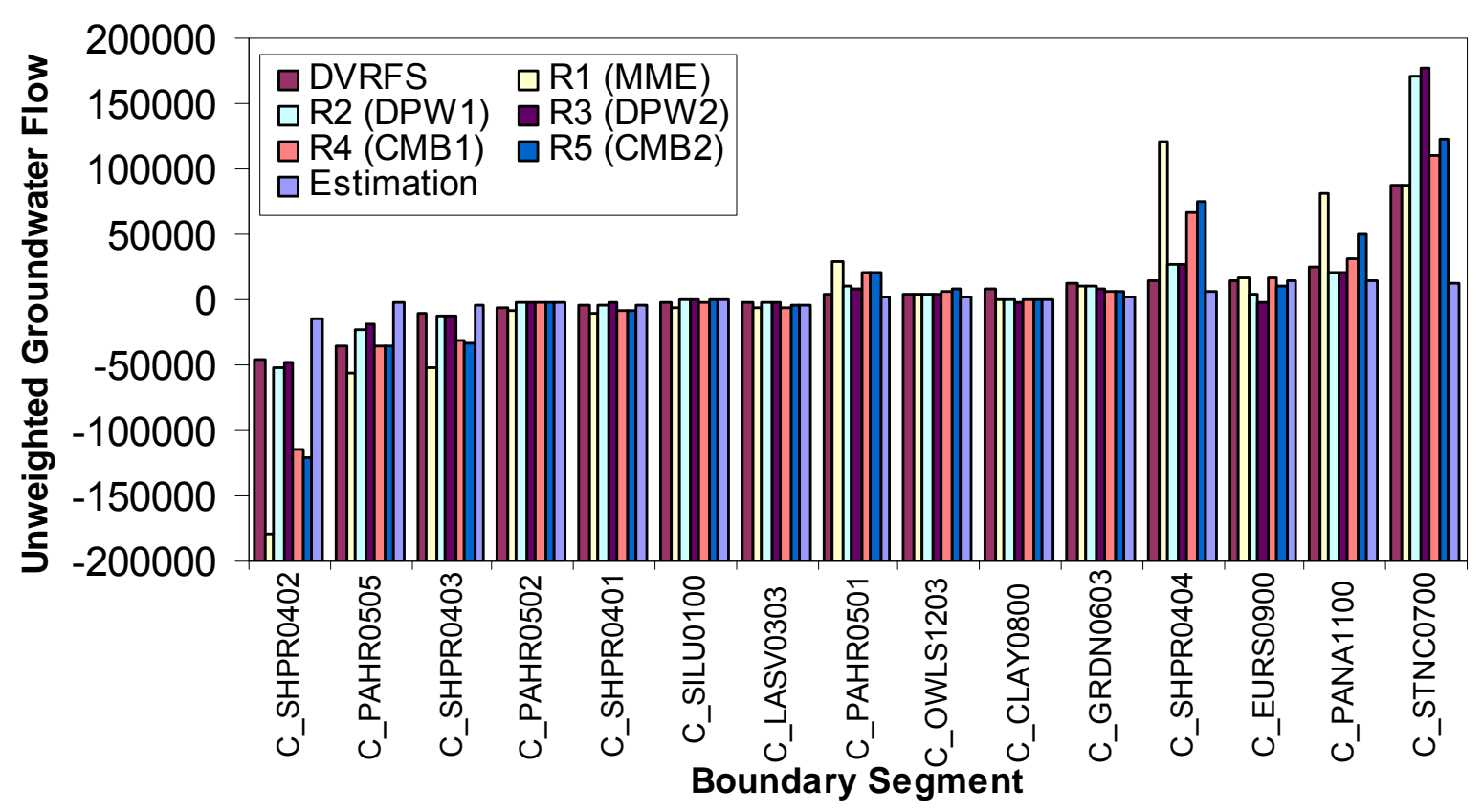

Figure 3-44. Unweighted boundary-flow rate $\left(\mathrm{m}^{3} /\right.$ day) along constant-head boundary segments of the DVRFS. The simulated flow rate is for the USGS geological model. 


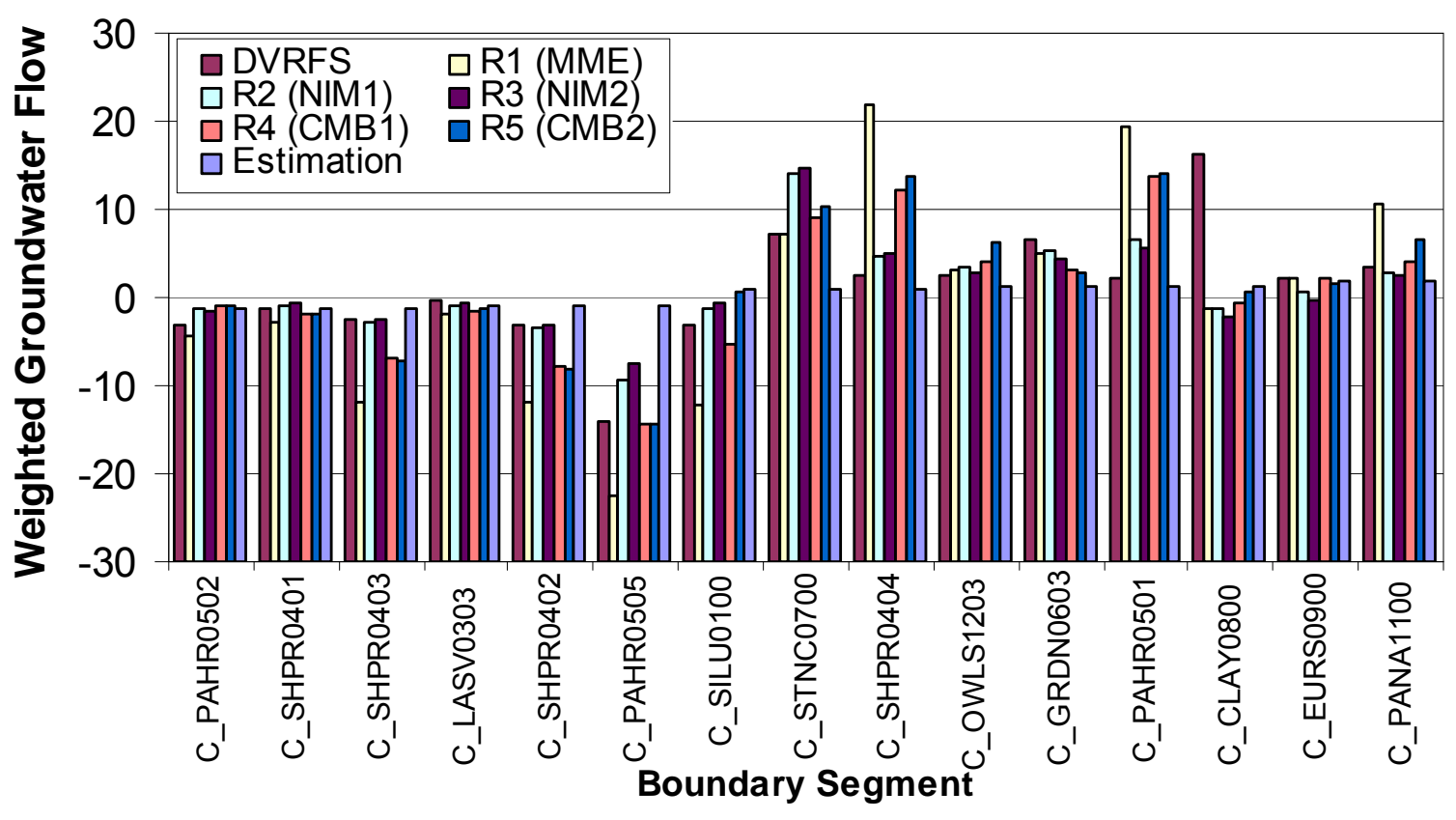

Figure 3-45. Weighted boundary-flow rate along constant-head boundary segments of the DVRFS. The simulated flow rate is for the USGS geological model.

\subsection{Simulated Hydraulic Head}

Figure 3-46 plots three-dimensional contours of hydraulic head simulated in the northern Yucca Flat area by the six most plausible models (shown in Figure 3-39). The head contour of each model is shown in Figures D-11 through D-15 in Appendix D. These figures show that the simulated head has similar patterns of spatial distribution. For example, low hydraulic head (blue area) is located to the south and has similar spatial distribution; and hydraulic head increases from south to north gradually. However, the figures exhibit significant variation in the hydraulic head values among the alternative models. The effect of different recharge models on the hydraulic head distribution can be observed at the top of the domain. For example, model CMB2 (R5) simulates more recharge than model NIM1 (R2), and the hydraulic gradient of the models (e.g., G3R5) associated with R5 is larger than that of models (e.g., G3R2) associated with R2. The effect of different geological models on the head distribution can also be investigated by comparing models associated with the same recharge but different geological models. Comparing Figure 3-46 (c) and (d) shows that the head gradient of G3R5 is larger than that of G2R5. The effect of geological models is more apparent by examining simulated flow rate into Yucca Flat from the north, as discussed in the next section. 

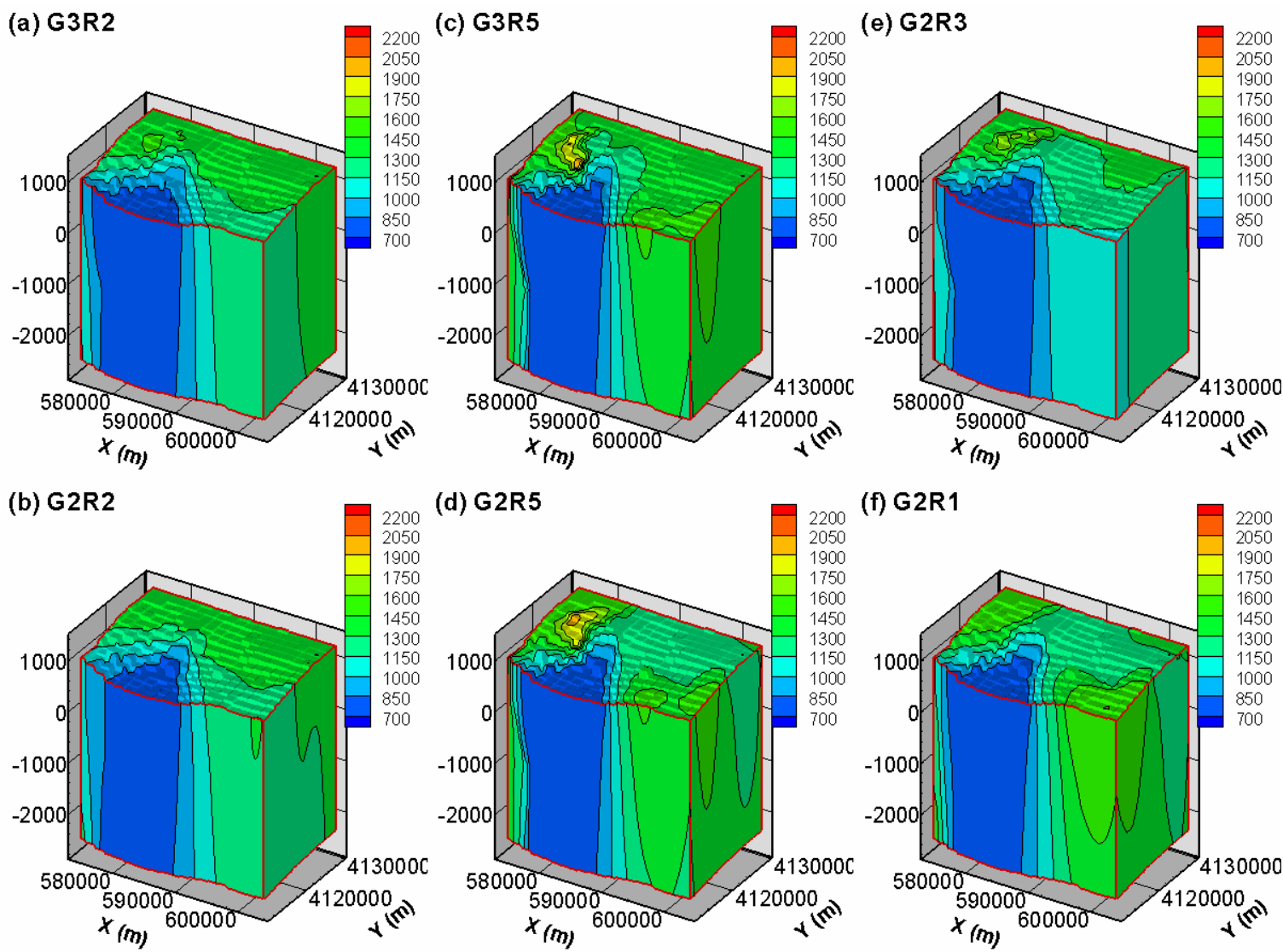

Figure 3-46. Three-dimensional contours of hydraulic head simulated in the northern Yucca Flat area by the calibrated models: (a) G3R2, (b) G2R2, (c) G3R5, (d) G2R5, (e) G2R3, and (f) G2R1. G2 and G3 are the UGTA base model and its CPT alternative. R1, R2, R3, and $\mathrm{R} 5$ are MME, NIM1, NIM2, and CMB2 recharge models, respectively. The $\mathrm{x}$ - and $\mathrm{Z}$-coordinates are in meters. Z-coordinate is exaggerated eight times for better presentation.

\subsection{Simulated Flow Rate into Northern Yucca Flat}

Figure 3-47 plots the contours of cell-by-cell flow crossing the front face of MODFLOW cells (i.e., $\mathrm{Q}_{\mathrm{y}}, \mathrm{m}^{3} / \mathrm{day}$ ) at the southern boundary ( $\mathrm{x}-\mathrm{z}$ cross section) of northern Yucca Flat. These contours were for the six most plausible models (shown in Figure 3-39), and similar contours of each model are shown in Figures D-15 through D-20 in Appendix D. An area of high flow rate appears at the area of low hydraulic head (blue area of Figure 346). The effect of geological models on the simulated flow rate is apparent. Taking models G2 (UGTA base model) and G3 (its CPT alternative model) as an example, in model G3 the LCA moves eastward and replaces the LCCU (as shown in Figure 3-9). Similarly, the UCCU moves eastward and replaces the LCA. As a result, in this transition zone where the CPT alternative model is developed, conductivity is higher at the upper area of the domain but lower at the bottom area of the domain in model G2. However, it is opposite in model G3 owing to the different conceptualization of the CP Thrust. This is reflected in the simulated flow rate into Yucca Flat. For example, Figure 3-47 (a) and (c) shows that, for the models associated with model G3 (regardless of the recharge models), the flow rate is higher at the 
bottom of the cross section, but lower at the upper area of the cross section. The opposite pattern was observed in Figure 3-47 (b), (d), (e), and (f) for models associated with model G2. The figure also demonstrates that the effect of recharge models on the flow rate into Yucca Flat is not as significant as that of geological models. For example, comparing models G2R1, G2R2, G2R3, and G2R5 shows that recharge affects values of the flow, whereas flow pattern is determined by geological models.

(a) G3R2

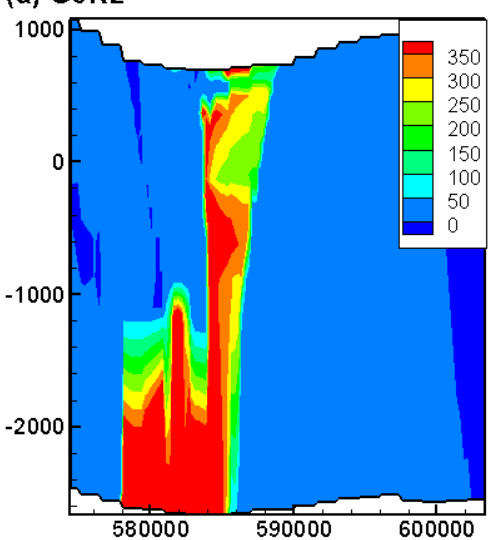

(b) G2R2

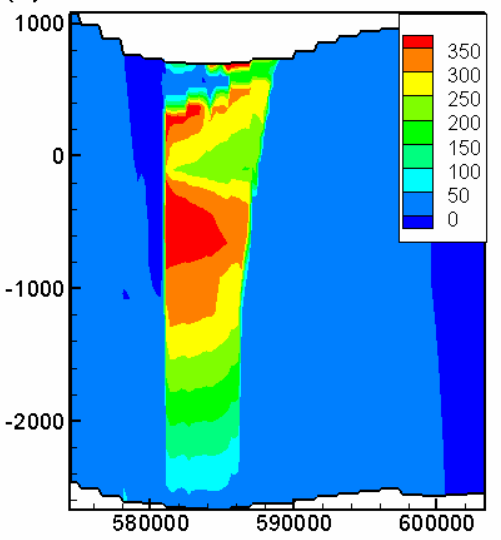

(c) G3R 5

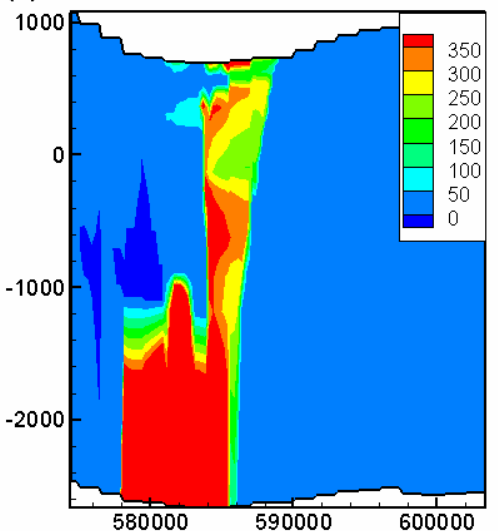

(d) G2R5

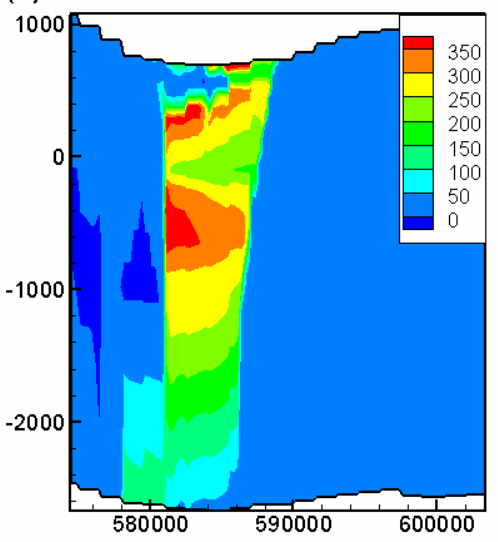

(e) G2R3

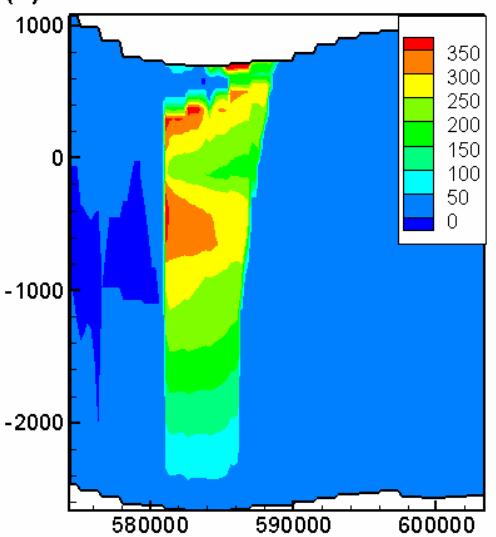

(f) G2R1

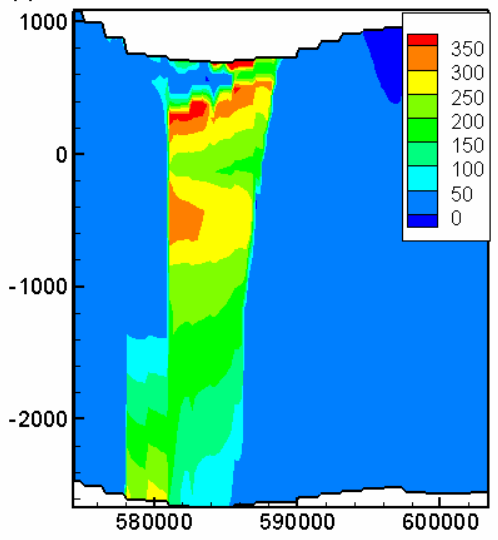

Figure 3-47. Cell-by-cell flow crossing the front face of MODFLOW cells (i.e., $\mathrm{Q}_{\mathrm{y}}, \mathrm{m}^{3} / \mathrm{day}$ ) predicted at the southern boundary ( $\mathrm{x}-\mathrm{z}$ cross section) of northern Yucca Flat by models (a) G3R2, (b) G2R2, (c) G3R5, (d) G2R5, (e) G2R3, and (f) G2R1. G2 and G3 are the UGTA base model and its CPT alternative. R1, R2, R3, and R5 are MME, NIM1, NIM2, and CMB2 recharge models, respectively. The $\mathrm{x}$ - and z-coordinates are in meters.

The flow rates into Yucca Flat through the cross section shown in Figure 3-47 were calculated for the 25 alternative models. These data are organized by recharge model and plotted in Figure 3-48. The figure shows significant variation of the flow rate, demonstrating the effect of the recharge and geological models on the flow simulation. As shown in Figure 3-47 for six models, Figure 3-48 shows for all of the models that geological models are a stronger control on flow rate than recharge models. Variation of the flow rate of the same recharge model but different geological models is larger than that for the same geological model but different recharge models. The USGS geological model (Belcher et al., 2004) 
simulates the lowest flow rate for all the recharge models except R2 (NIM1). The alternative geological models with the hydrologic barrier alternative (HFM4 and HFM5) simulate lower flow rates than the UGTA base model and its CPT alternative. As can be see here, although the regional DVRFS model of Belcher et al. (2004) was used as the framework for model calibration and simulation, using the regional model did not conceal variation of flow in northern Yucca Flat. The reason is that the local flow rate is largely controlled by the geological model in northern Yucca Flat.

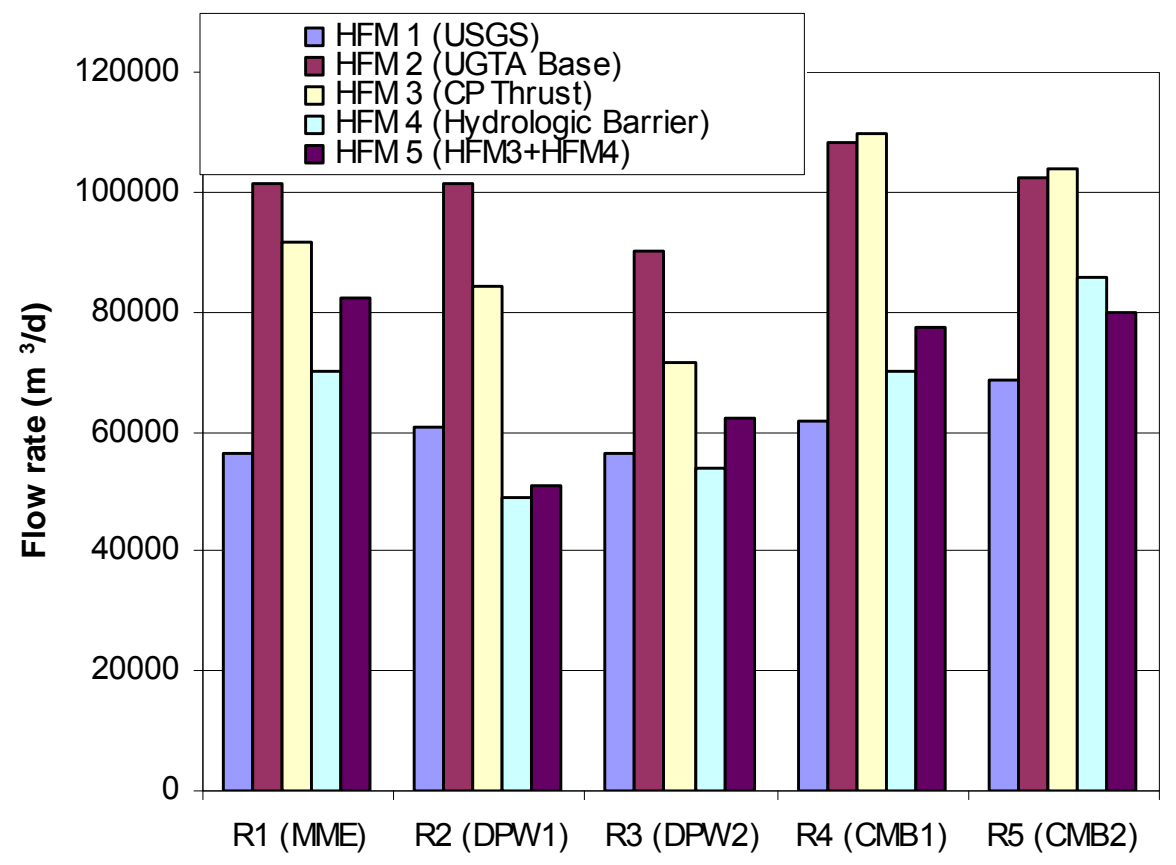

Figure 3-48. Total flow rate into Yucca Flat through the cross section shown in Figure 3-47. Each cluster represents the flow rate of the five geological models for a recharge model.

\subsection{Spatial Distribution of Residuals of Heads and Head-changes}

Figure 3-49 is a scatterplot of residuals of hydraulic heads and head-changes in the northern Yucca Flat area simulated by the six most plausible models (shown in Figure 3-39). Scatter symbol size is proportional to the magnitude of the residuals. Head contours at the top layer of the domain are also plotted. Similar scatterplots and contours of each model are shown in Figures D-21 through D-25 in Appendix D. Figure 3-49 shows that magnitude of the residuals is similar in the area (in blue) where hydraulic head is low, which is consistent with Figures 3-36 and 3-37 shown before. These observations are not critical to discriminate the alternative models. In contrast, observations in the area north of the low-head area are critical, since their values change significantly for the different models. Taking the sample highlighted by the blue circle in Figure 3-49 (a) as an example, the residual at this location increases from Figure 3-49 (a) to (f). Correspondingly, probabilities of the models from Figure 3-49 (a) to (f) decrease. Thus, the magnitude of the residuals appears determined by both the recharge and geological models. If more information and data are needed to further discriminate the models, this type of figure can be used to guide where to collect them. 

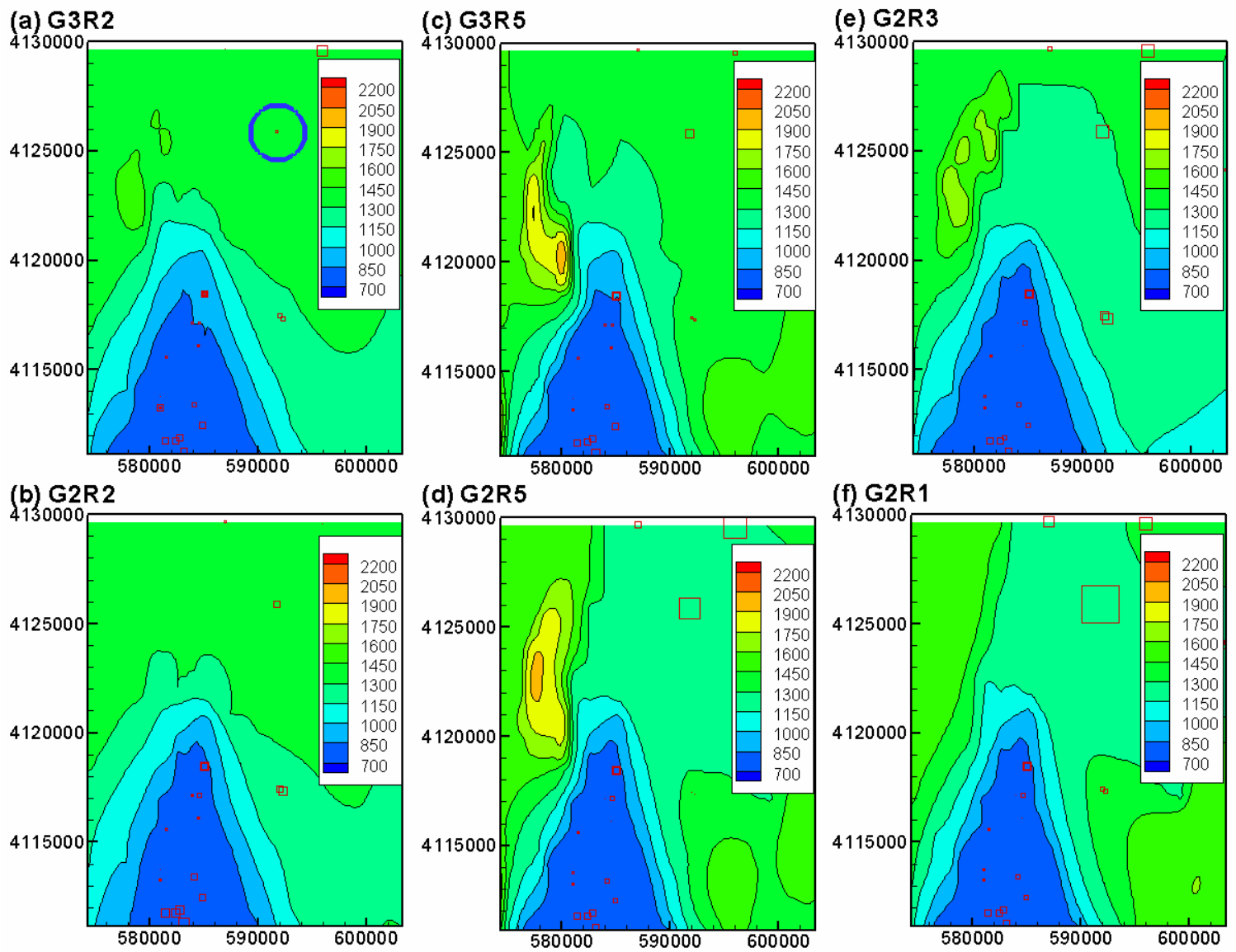

Figure 3-49. Scatterplot of residuals of heads and head-changes and contours of hydraulic head at the top layer in the northern Yucca Flat area simulated by models (a) G3R2, (b) G2R2, (c) G3R5, (d) G2R5, (e) G2R3, and (f) G2R1. G2 and G3 are the UGTA base model and its CPT alternative. R1, R2, R3, and R5 are MME, NIM1, NIM2, and CMB2 recharge models, respectively. The $\mathrm{X}$ - and z-coordinates are in meters. Size of the scatter symbols is scaled to the magnitude of the residuals.

\subsection{Effect of Uncalibrated Parameters on Model Simulation Results}

While Belcher et al. (2004) calibrated 55 parameters for the DVRFS, 32 parameters (30 for models not associated with the NIM recharge models) were selected for calibration, since hydraulic head and flow in northern Yucca Flat were of interest to this project. Reasons for selecting these parameters were given in Section 3.4.2 and Appendix C. The values of the uncalibrated parameters were adopted from Belcher et al. (2004). This section investigates the effect of the uncalibrated parameters on model simulation results by examining observed and simulated natural groundwater discharge. Observations of discharge were selected since they are located downgradient from northern Yucca Flat, as shown in Figure F-7 of Belcher et al. (2004). In the DVRFS model, the discharge was simulated using the MODFLOW drain package, which calculates discharge by multiplying the drain conductance and difference of hydraulic heads in MODFLOW cells and drain head. The drain conductance is defined using the hydraulic properties of materials through which water flows from groundwater to the drains. Belcher et al. (2004) calibrated five out of seven drain conductances, while none of 
them were calibrated in this project. If the calibrated values of the drain conductance of Belcher et al. (2004) had been incorrect under different recharge and geological models, the problem of simulated discharge would have been observed. On the other hand, if other calibrated parameter values (e.g., hydraulic conductivity) downgradient of northern Yucca Flat given by Belcher et al. (2004) had been incorrect under different recharge and geological models, discrepancy between the discharge simulated by Belcher et al. (2004) and in this project would also have been observed. However, as shown below, the discrepancy was not observed.

Similar to Figure F-44 of Belcher et al. (2004), Figure 3-50 plots the unweighted observed and simulated groundwater discharge by subregion: (a) northern Death Valley, (b) central Death Valley, and (c) southern Death Valley. The error bar for the observed discharge was calculated by \pm one standard deviation of the observation error estimated in Belcher et al. (2004). In addition to the simulated discharge (DVRFS) of Belcher et al. (2004) shown as a reference value, the figure plots discharge simulated by all the recharge models (R1 through R5) associated with the USGS geological model (G1). As shown in Figure 3-50, different recharge models simulated significantly different discharge values. Except for the MME model (R1) which over-simulates discharge, all models simulated comparable discharge values relative to that of the DVRFS. In particular, model G1R2 simulated better discharge values (closer to the observation) than the DVRFS in some areas (e.g., SARCO-NE and DV-MESQU). However, at most locations where simulated discharge of the DVRFS was out of the range of observation of \pm one standard deviation, the alternative models (G1R1 through G1R5) behaved about the same as the DVRFS model. Similar trends are evident as well for models associated with other geological models. For example, Figure 3-51 plots the observed and simulated discharge for the UGTA base model (G2R1 through G2R5). Comparing Figures 3-50 and 3-51 shows that although the two geological models are different in the northern Yucca Flat area, their simulated discharge values at downgradient areas are similar for a given recharge model. This became more apparent when investigating the simulated discharge of different geological models given the same recharge model. Figure 3-52 plots the observed and simulated discharge of the CMB2 recharge model associated with all five geological models and shows that at many observation locations, simulated discharge of the geological models is similar. In other words, although the alternative geological models in northern Yucca Flat have significant impacts on the flow simulated in northern Yucca Flat as shown before, their impact on simulated discharge in downgradient areas is small. Based on this analysis, it is concluded that it is acceptable to adopt the calibrated parameter values of Belcher et al. (2004) for the uncalibrated parameters in the Climax regional flow model. 

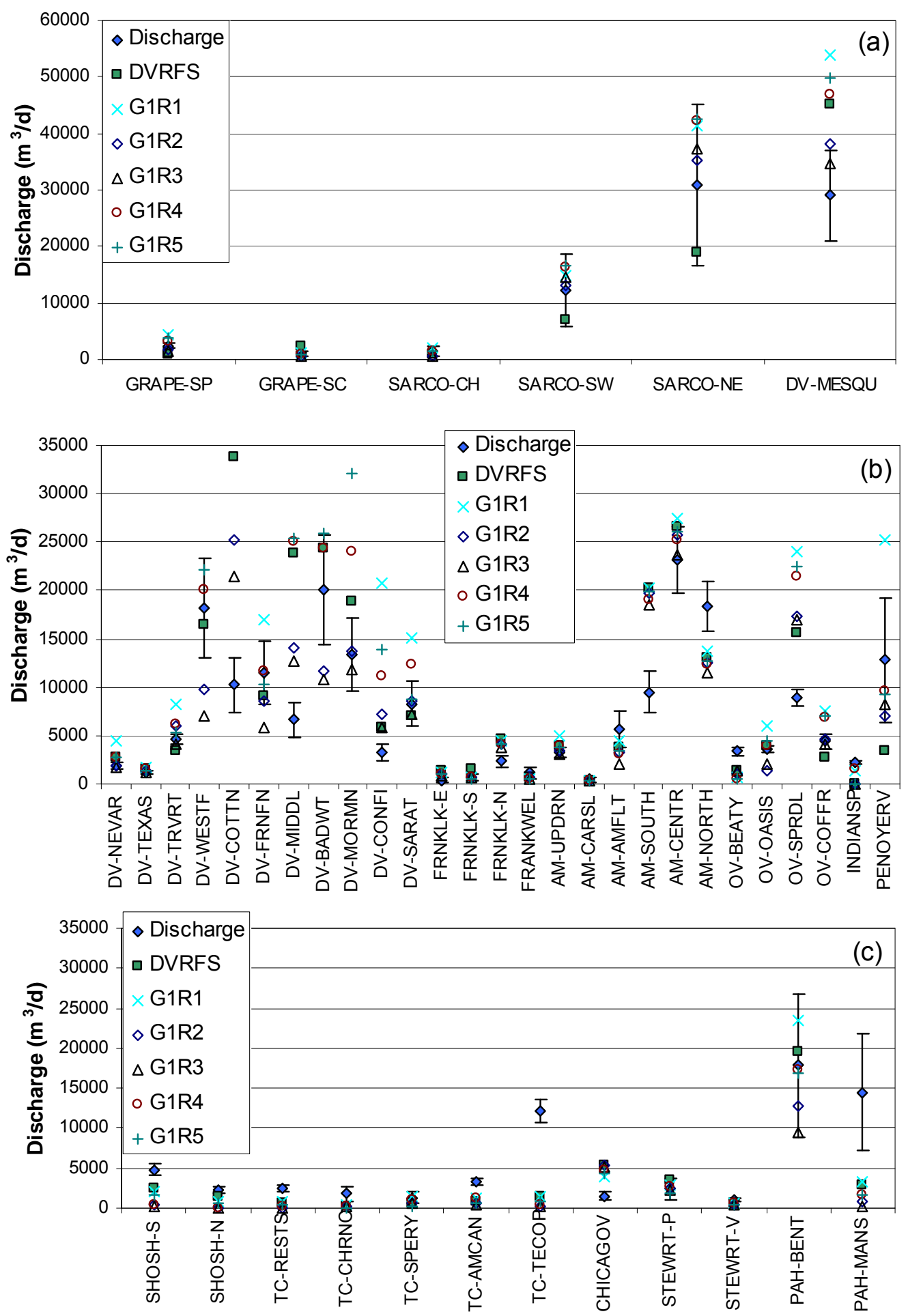

Figure 3-50. Observed and simulated groundwater discharge by subregion: (a) northern Death Valley, (b) central Death Valley, and (c) southern Death Valley. The error bar of the observed discharge was calculated by \pm one standard deviation of observation error estimated in Belcher et al. (2004). G1 is the DVRFS geological model. R1, R2, R3, and R5 are MME, NIM1, NIM2, and CMB2 recharge models, respectively. 

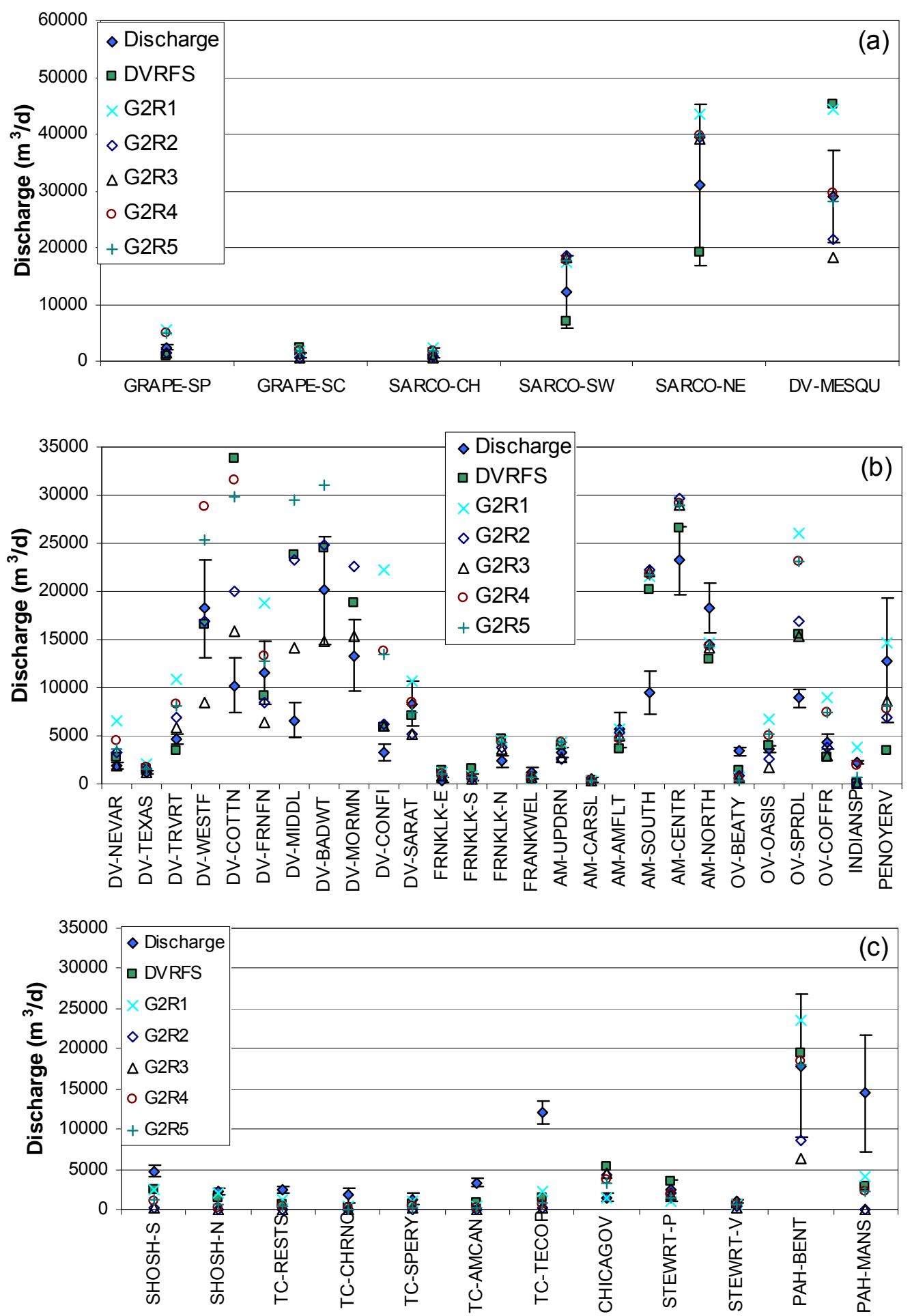

Figure 3-51. Observed and simulated groundwater discharge by subregion: (a) northern Death Valley, (b) central Death Valley, and (c) southern Death Valley. The error bar of the observed discharge was calculated by \pm one standard deviation of observation error estimated in Belcher et al. (2004). G2 is the USGS base model. R1, R2, R3, and R5 are MME, NIM1, NIM2, and CMB2 recharge models, respectively. 

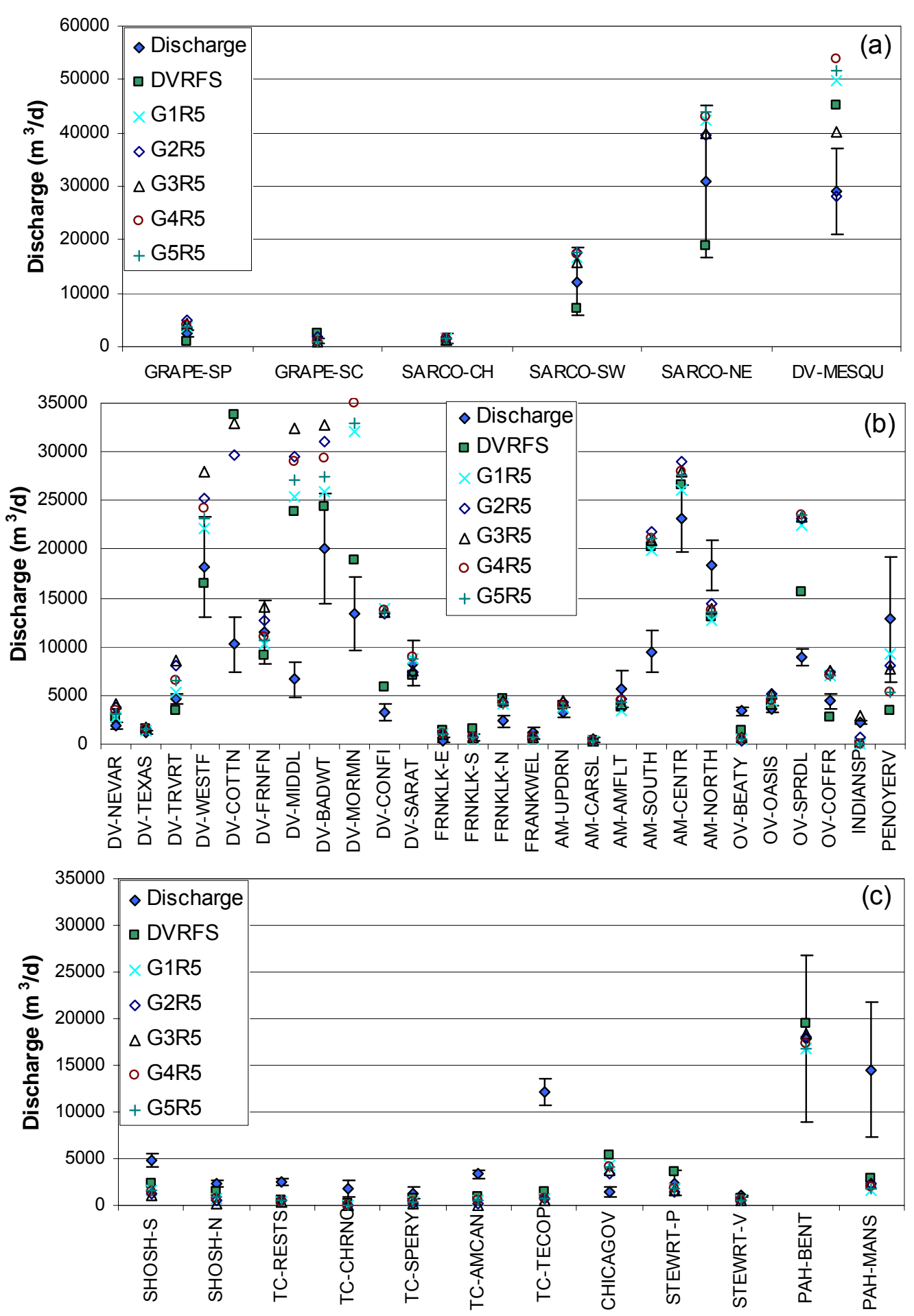

Figure 3-52. Observed and simulated groundwater discharge by subregion: (a) northern Death Valley, (b) central Death Valley, and (c) southern Death Valley. The error bar of the observed discharge was calculated by \pm one standard deviation of observation error estimated in Belcher et al. (2004). R5 is the CMB2 recharge model. G1 is the USGS geological model, G2 is the UGTA base model, G3 is the CPT alternative model, G4 is the hydrologic barrier alternative model, and G5 is the CPT and hydrologic barrier alternative model. 


\subsection{Assessment of Uncertainty for Parameters and Alternative Models}

\subsubsection{Assessment of Parametric Uncertainty}

\subsubsection{Generation of Random Parameters for Alternative Models}

Parameter estimates obtained from the least-square inverse modeling are subject to uncertainty. The uncertainty is caused by insufficient data and their corruption by noise (e.g., measurement error). According to the maximum likelihood theory, the parameters are unknown deterministic quantities. The least-square method is a special case of the maximum likelihood method (Hill, 1998). This differs from the Bayesian philosophy of viewing parameters as random variables in which parameter distributions are inferred from parameter measurements. It also differs from a geostatistics-based inverse method, which views hydraulic variables and model parameters as two correlated random variables. Neither the Bayesian nor the geostatistical inverse methods are feasible in this project, since parameter measurements are too sparse in the DVRFS to infer meaningful parameter distributions.

The parameter estimation uncertainty is measured by the parameter estimation covariance matrix (Hill, 1998)

$$
\mathbf{V}(\hat{\boldsymbol{\theta}})=s^{2}\left(\mathbf{X}^{T} \boldsymbol{\omega} \mathbf{X}\right)^{-1}
$$

where $\hat{\boldsymbol{\theta}}$ is parameter estimate, $\boldsymbol{\omega}$ is matrix of measurement errors, $\mathbf{X}$ is sensitivity of matrix evaluated at $\hat{\boldsymbol{\theta}}$, and $s^{2}$ is calculated error variance given by

$$
s^{2}=\frac{\mathbf{e}^{T} \boldsymbol{\omega e}}{N-N_{k}}
$$

with $N$ being the number of calibration data, $N_{k}$ being the number of calibrated parameters, and $\mathbf{e}$ being the residuals between observations and corresponding predictions. The covariance matrix is given as a byproduct of model calibration in the MODFLOW2000 output GLOBAL file. In this case, for models associated with recharge models of MME, CMB1, and CMB2, model calibration was terminated by MODFLOW2000 due to small values of KDP_LCANO. After restarting calibration with KDP_LCANO fixed, the resulting covariance matrix did not include elements associated with this parameter. In this case, a sensitivity simulation was calculated for all calibrated parameters (including KDP_LCANO) to obtain the sensitivity matrix $\mathbf{X}$, and then evaluate the covariance matrix $\mathbf{V}$ using equation (3.9).

According to the maximum likelihood theory (Berger, 1985), parameter estimates follow a multivariate normal distribution with mean of the calibrated parameters and covariance matrix of equation (3.9) (parameter correlation is incorporated in the matrix). This allows generating random parameters to assess the parametric estimation uncertainty of each single model. However, it is worth mentioning that equation (3.9) is derived based on an assumption that a model is nearly linear in the vicinity of $\hat{\boldsymbol{\theta}}$, which may not be easily justified in real-world applications.

Multiple realizations of random parameters were generated using the subroutine RNMVN of the International Mathematics and Statistical Library (IMSL) (http://www.vni.com/products/imsl/). The subroutine first generated parameter realizations following a multivariate normal distribution with zero mean and covariance $\mathbf{V}$. The calibrated parameters were then added to each realization. A total of 200 parameter 
realizations were generated for each model. Sample statistics (i.e., mean and variance) of the generated realizations are almost identical to input statistics, indicating that the generated parameter realizations represent probabilistic distributions of the calibrated model parameters. Figure 3-53 below plots the minimum, mean, and maximum values of the parameter realizations for models G3R2 and G2R2, the two best models. All the parameters are plotted together for better comparison between the different models. Mean parameters of the two models are different, since different models have different calibrated parameters corresponding to different geologic and recharge models. In addition, parameter ranges (between the minimum and maximum) of the two models are different, since sensitivity to model parameters varies in different models. This variation was also observed in parameter realizations of the other 23 models, whose plots (not shown) are similar to Figure 3-53.
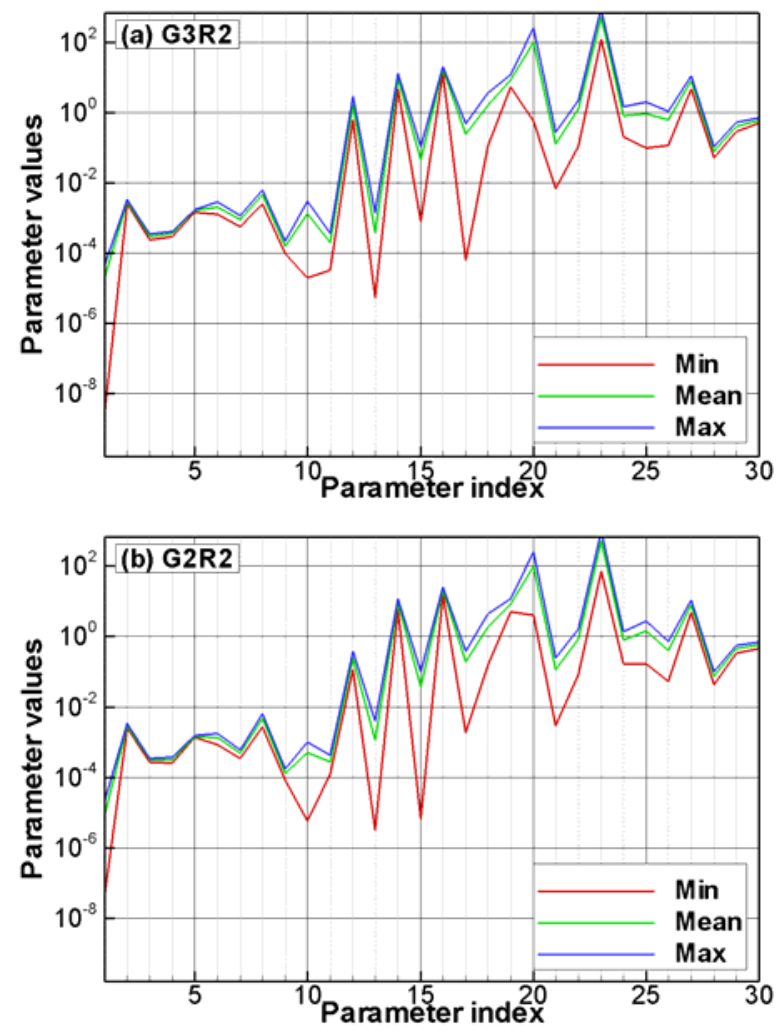

Figure 3-53. Minimum, mean, and maximum of the 200 realizations of generalized parameters for models G3R2 and G2R2 (the two best models). G2 is the UGTA base geologic model, and G3 is its CPT alternative; R2 is the NIM1 recharge model.

\subsubsection{Assessment of Parametric Uncertainty for Alternative Models}

Based on the parameter realizations generated in the previous section, Monte Carlo (MC) simulation was conducted for each single model. Mean and variance of head and flux in northern Yucca Flat simulated by the DVRFS regional model were calculated to assess parametric uncertainty. This mean and variance will be aggregated in the next section using a model averaging method to assess both parametric and conceptual model uncertainty. When calculating the statistics for a single model, each realization was not considered equally likely. Instead, the SSWR of each realization was calculated based on the 59 observations of head and head changes in northern Yucca Flat. The inverse of the SSWR of each realization 
was then normalized by the sum of the inverse of the SSWR over all the realizations. This normalization gave GLUE weights for each realization, which are then used to calculate mean and variance of head and flux for each single model. During the MC simulation, several realizations diverged for each model, and these realizations were excluded from the GLUE process of estimating weights. In addition, for certain realizations that gave large SSWR (indicating bad model fit), they received essentially zero weights, in comparison to other realizations that gave small SSWR. The GLUE weights of models G3R2, G2R2, and G3R5 (the top three best models) are illustrated in Figure 3-54. It shows that some realizations received zero GLUE weights for models G3R2 and G2R2, while no realization of model G3R5 received zero weight. Weights of other models are similar (not shown).
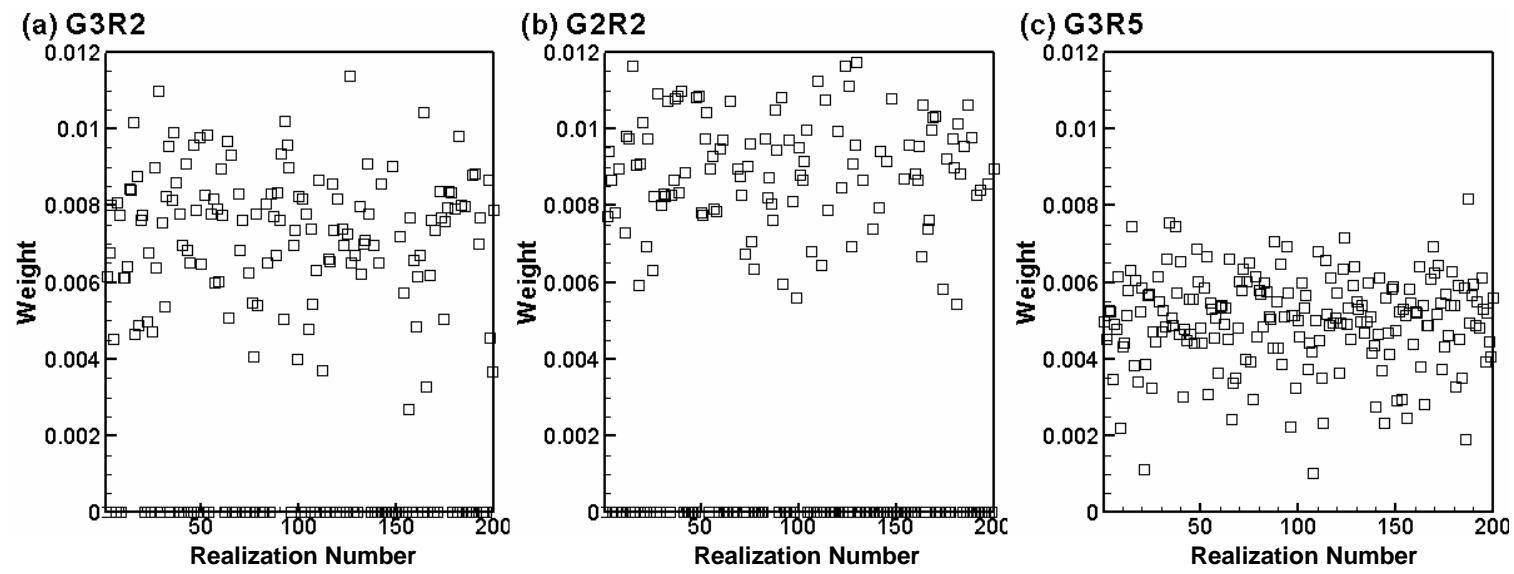

Figure 3-54. GLUE weights of the 200 realizations of models (a) G3R2, (b) G2R2, and (c) G3R5 (the top three best models). G2 is the UGTA base model, and G3 is its CPT alternative. $\mathrm{R} 2$ and $\mathrm{R} 5$ are the NIM1 and CMB2 recharge models.

Before sample statistics of mean and variance were calculated, convergence of the MC simulation of each model was examined to ensure that the sample statistics converge to ensemble moments. Figure 3-55 plots mean and standard deviation of head at two arbitrary locations within northern Yucca Flat for the top three best models (G3R2, G2R2, and G3R5). Note that the realizations of zero GLUE weights were not used to calculate the mean and standard deviation. The figure shows that for each model, the mean and standard deviation stabilized at each of the two locations. Convergence of mean head required fewer realizations than that of the standard deviation. A similar convergence pattern was also observed for the other models (not shown). 
(a) G3R2

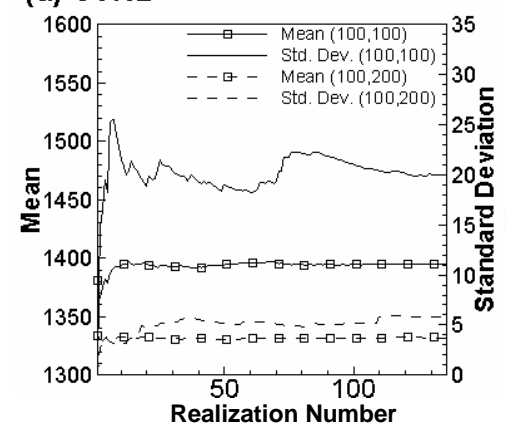

(b) G2R2

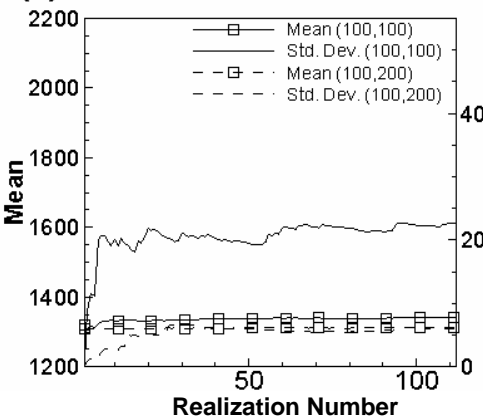

(c) G3R5

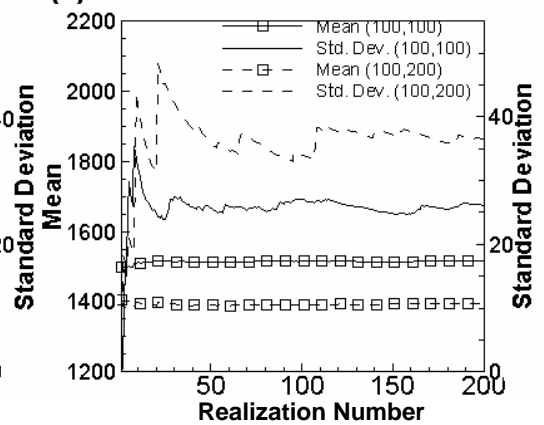

Figure 3-55. Convergence of simulated head at two arbitrary points for models (a) G3R2, (b) G2R2, and (c) G3R5 (the top three best models). G2 is the UGTA base model and G3 is its CP thrust alternative. R2 and R5 are the NIM1 and CMB2 recharge models.

Mean and variance of head and flux were calculated at each cell in northern Yucca Flat over the simulation period. For convenience of presentation, only mean and variance at the top model layer and last simulation time step are shown (Figures 3-57 through 3-59). Investigation of the temporal variation of head near Climax demonstrates that the model is essentially at steady state in this area and therefore consistent with the undeveloped Yucca Flat-Climax Mine CAU flow model, which is likely to be constructed as steady state. Two locations were selected that represent the two main blocks of LCA in northern Yucca Flat in all five HFMs. The first is near the western boundary of northern Yucca Flat at 578,125 m east and 4,111,125 m north (UTM Zone 11, NAD27) and the second is roughly directly south of the Climax stock outcrop at 585,625 m east and 4,111,125 m north. Figure 3-56 shows that, for model G3R2 (the best model), at the two selected points, simulated head is the same over the 87 stress periods. This is not surprising due to the quasi-steady state of the regional flow system in this area. Similar patterns of heads over time were also observed for the other models (not shown).

Figure 3-57 shows the mean head for the top five best models (G3R2, G2R2, G3R5, G2R5, and G2R3); summation of these posterior model probabilities is 48.9 percent. Mean head obtained from model averaging is also shown in Figure 3-57 and will be discussed in the next section. General patterns of head variation are similar for these models. Heads are high in the north and low in the south. A large gradient is predicted at the lower-left part of northern Yucca Flat (between the green and blue colors). On the other hand, different spatial distributions of head were predicted for each combination of geologic and recharge models. Models G3R5 and G2R5 predicted relatively high heads at the northwest and southeast corners of the domain. This is partly attributed to high recharge predicted by R5 in these areas. Model G2R3 gave the lowest head predictions at the lower-left corner of northern Yucca Flat. Figure 3-58 plots standard deviation of head in the same manner as Figure 3-57. In the figure, areas of high standard deviation appear at the northwest and southeast corners of the extension. In addition, the areas of high standard deviation are associated with areas of high head predictions shown in Figure 3-57. 

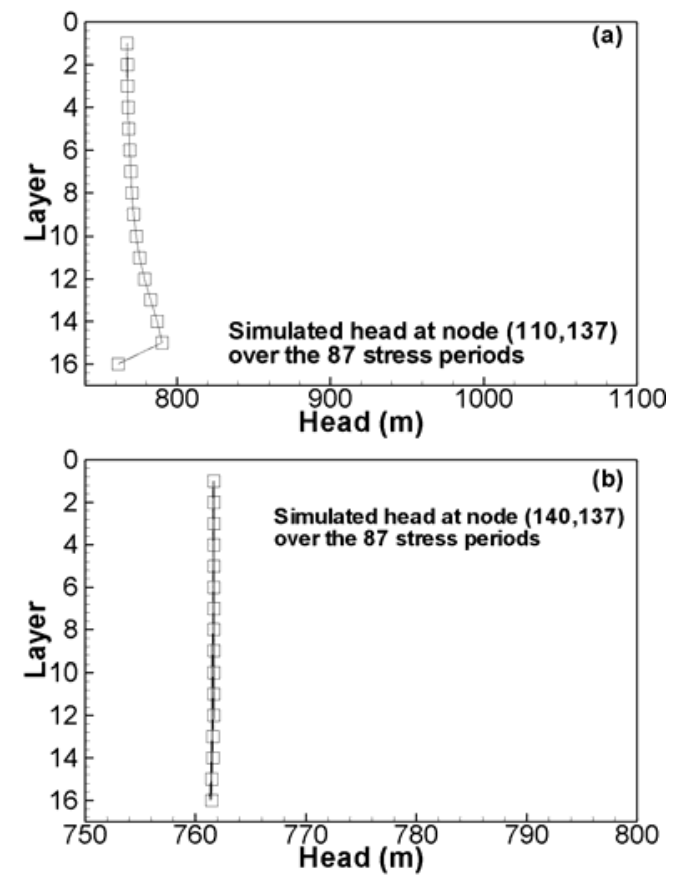

Figure 3-56. Simulated head over the 87 stress periods at two selected points within northern Yucca Flat with node index (number of row and column) of (a) $(110,137)$ and (b) $(140,137)$ for model G3R2 (the best model, G3 being the CPT alternative geologic model, R2 being the NIM1 recharge model).
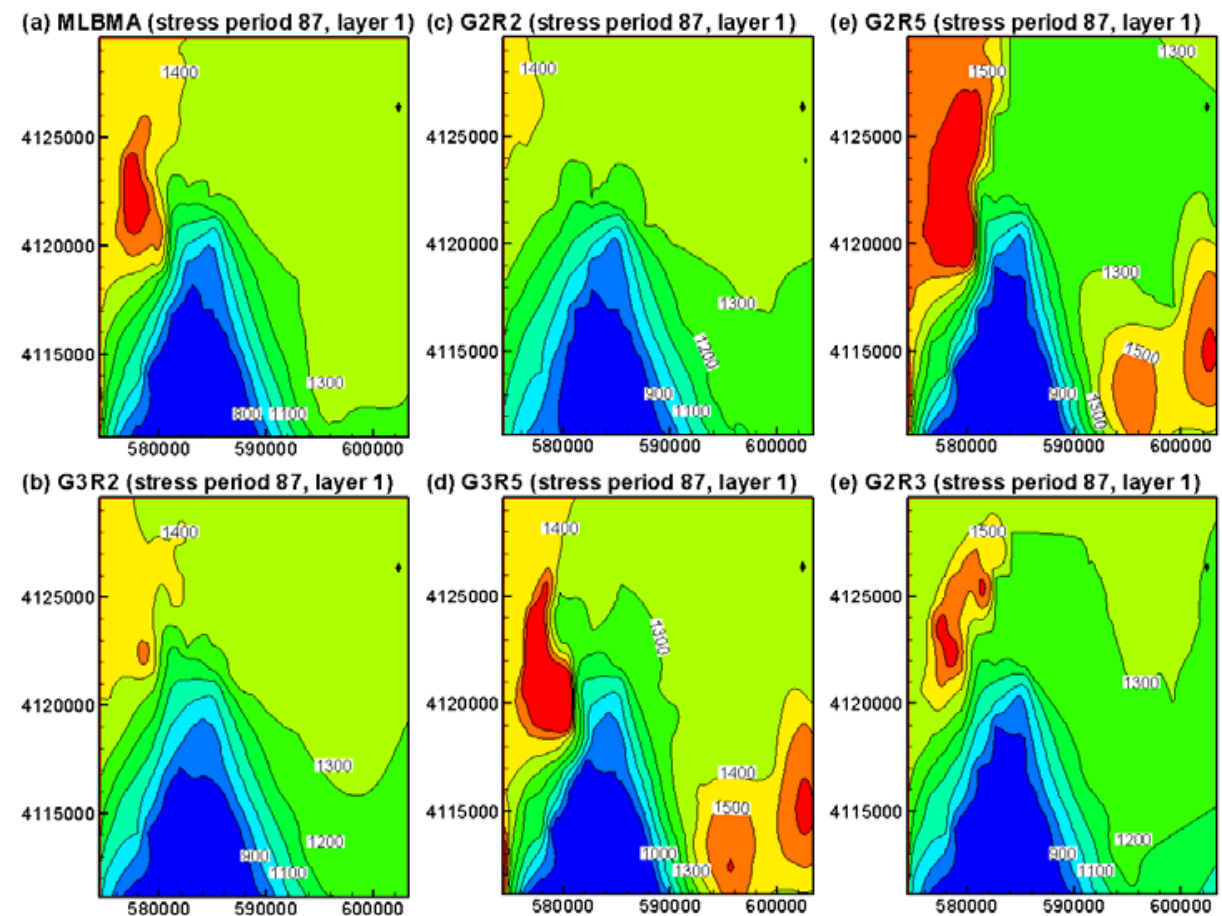

Figure 3-57. Mean head predictions of (a) model averaging and models (b) G3R2, (c) G2R2, (d) G3R5, (e) G2R5, and (f) G2R3. G2 and G3 are the UGTA base model and its CPT alternative. R2, R3, and R5 are NIM1, NIM2, and CMB2 recharge models, respectively. 

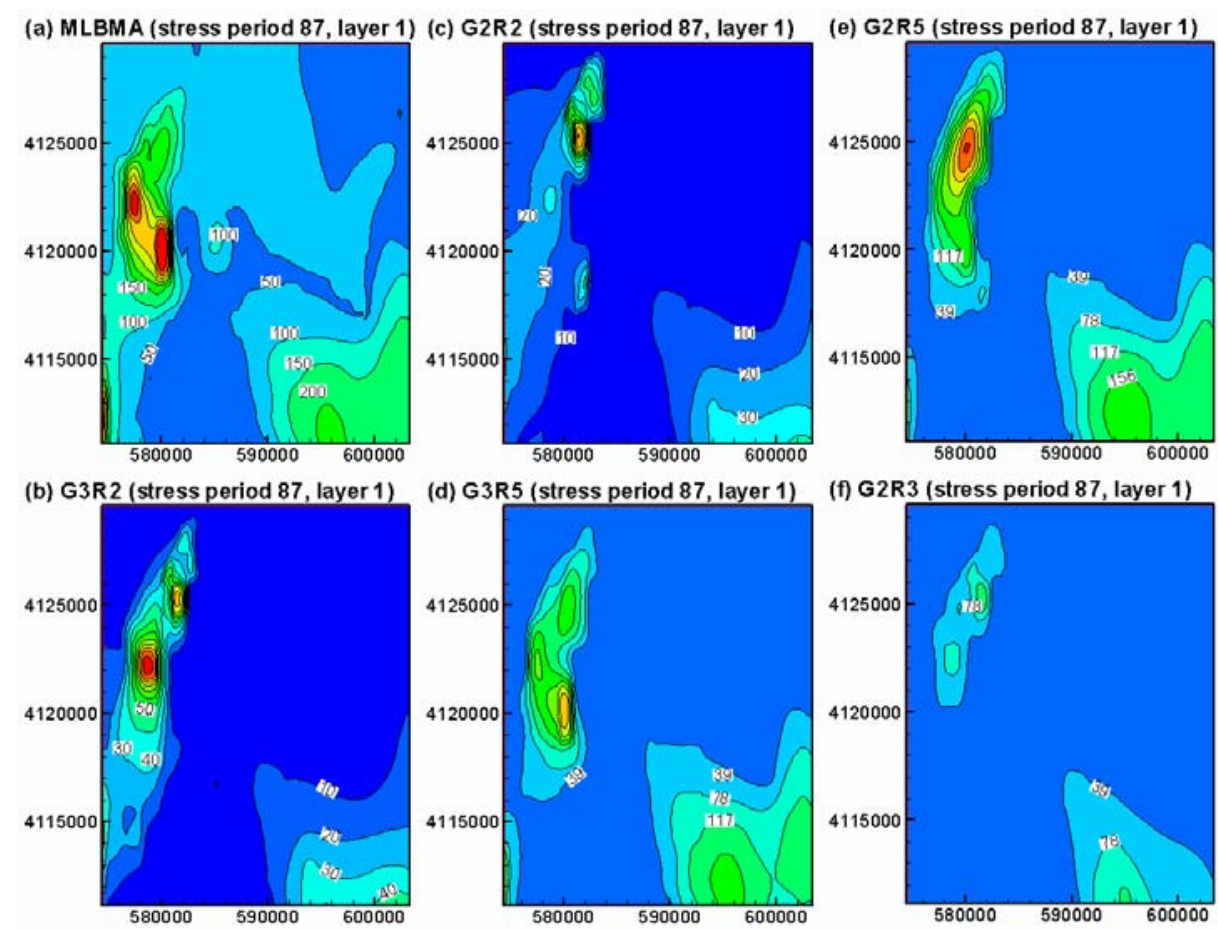

Figure 3-58. Standard deviation of head predictions of (a) model averaging and models (b) G3R2, (c) G2R2, (d) G3R5, (e) G2R5, and (f) G2R3. G2 and G3 are the UGTA base model and its CPT alternative. R2, R3, and R5 are NIM1, NIM2, and CMB2 recharge models, respectively.

Figure 3-59 plots mean cell-by-cell flow crossing the front cell faces (toward south) for the top five best models (G3R2, G2R2, G3R5, G2R5, and G2R3); the summation of these posterior model probabilities is 48.9 percent. It also plots mean flow obtained from model averaging, which will be discussed in the next section. The flow is positive, indicating that water moves southward in the direction of increasing row number. This flow is of interest to the project, since it determines flow from northern Yucca Flat to Yucca Flat. All of the flow is plotted at the same scale for convenience of comparison. General patterns of the flow are similar for these models. The narrow bands of large flow correspond to the area of the large head gradient shown in Figure 3-57. Once water moves through this narrow area, it tends to diverge over a larger area. The extent of spreading is slightly different for the different models. Figure 3-60 plots standard deviation of the flow in the same manner as Figure 3-57. Similar to the head variance, the areas of high standard deviation are associated with areas of high flow predictions shown in Figure 3-59. 
(a) MLBMA (stress period 87, layer 1) (c) G2R2 (stress period 87, layer 1)

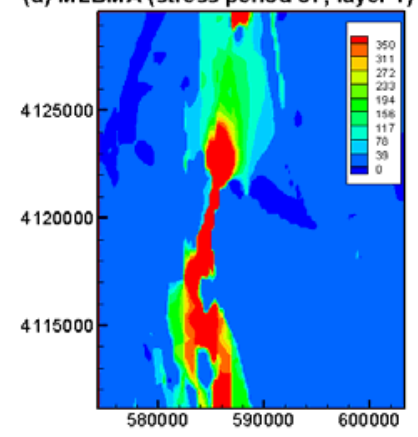

(b) G3R2 (stress period 87, layer 1)

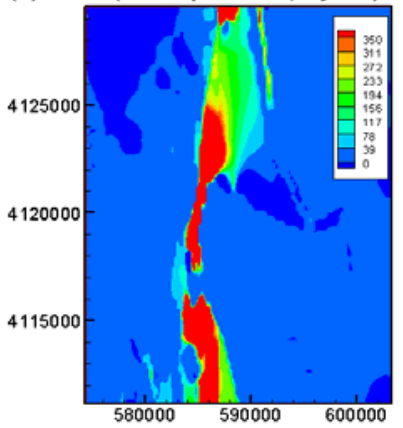

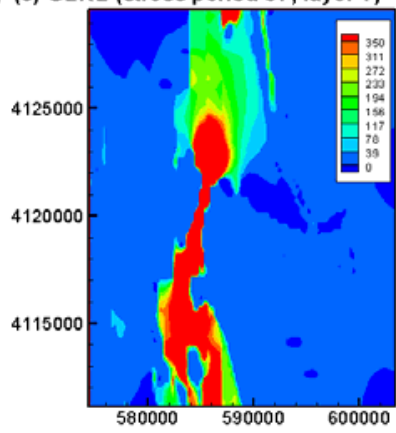

(d) G3R5 (stress period 87, layer 1)

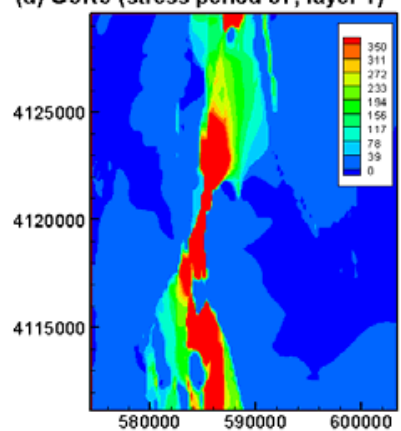

(e) G2R5 (stress period 87, layer 1)

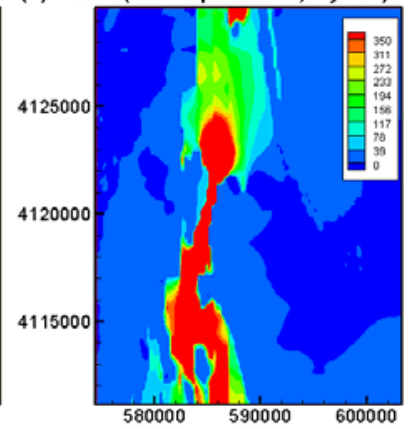

(f) G2R3 (stress period 87 , layer 1)

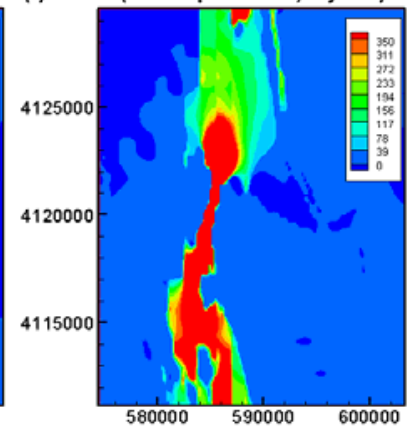

Figure 3-59. Mean cell-by-cell flow crossing front face of MODFLOW cells predicted by (a) model averaging and models (b) G3R2, (c) G2R2, (d) G3R5, (e) G2R5, and (f) G2R3. G2 and G3 are the UGTA base model and its CPT alternative. R2, R3, and R5 are NIM1, NIM2, and CMB2 recharge models, respectively.

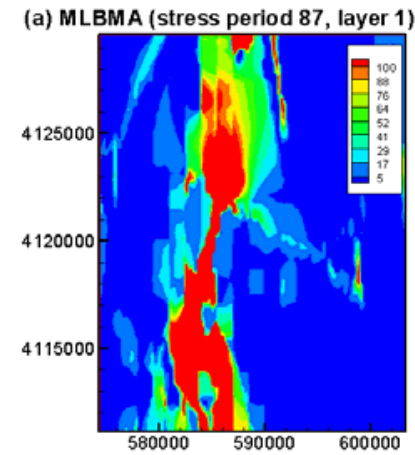

(b) G3R2 (stress period 87, layer 1)

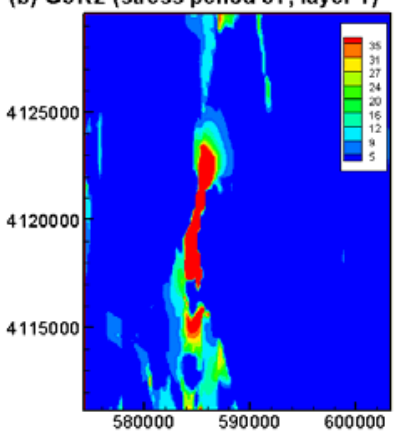

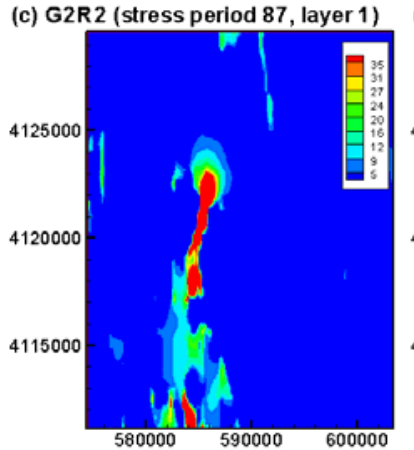

(d) G3R5 (stress period 87, layer 1 )

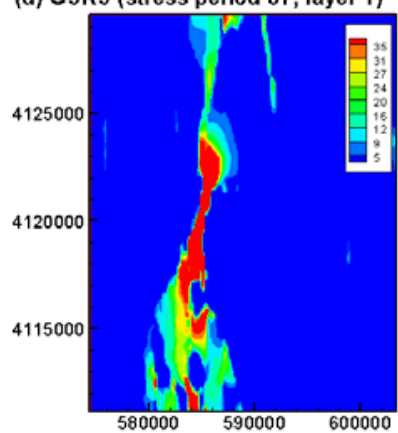

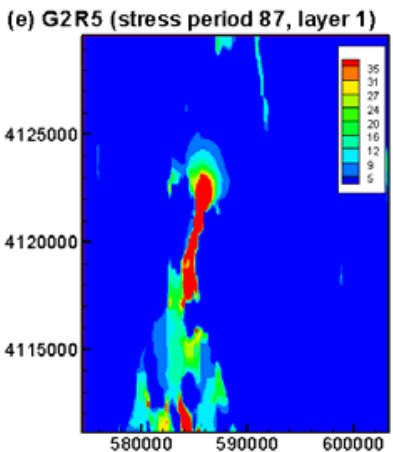

(f) G2R3 (stress period 87 , layer 1 )

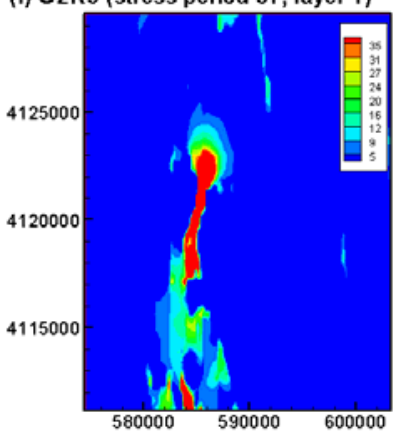

Figure 3-60. Standard deviation of cell-by-cell flow crossing front face of MODFLOW cells predicted by (a) model averaging and models (b) G3R2, (c) G2R2, (d) G3R5, (e) G2R5, and (f) G2R3. G2 and G3 are the UGTA base model and its CPT alternative. R2, R3, and $\mathrm{R} 5$ are NIM1, NIM2, and CMB2 recharge models, respectively. 


\subsubsection{Model Averaging and Assessment of Model Uncertainty}

It has been shown in previous sections of this report that different models give different predictions of head and flow. Variance of the predictions also varies for different models, indicating that parametric uncertainty of different models is different. Using a single model for a final prediction may cause Type I or Type II model error. Type I model error arises when one rejects (by omission) valid alternative models, which may result in an underestimation of predictive uncertainty and lead to overconfidence of model predictions. Type II model error arises when one adopts (fails to reject) an invalid model, which may introduce bias into predictions and damage modelers' credibility. To avoid these two types of model error, a concept of model averaging has been recently suggested (Apostolakis, 1990; Neuman, 2003; Ye et al., 2004, 2005; Poeter and Anderson, 2005; Refsgaard et al., 2006; Beven, 2006 and its references). Given a set of alternative models, $\left(M_{1}, \ldots, M_{K}\right)$, following Ye et al. (2004) and denoting a quantity one wants to predict as $\Delta$, its posterior distribution given a discrete set of data $\mathbf{D}$ is

$$
p(\Delta \mid \mathbf{D})=\sum_{k=1}^{K} p\left(\Delta \mid M_{k}, \mathbf{D}\right) p\left(M_{k} \mid \mathbf{D}\right)
$$

where $p\left(\Delta \mid M_{k}, \mathbf{D}\right)$ is prediction of the quantity under each model and $p\left(M_{k} \mid \mathbf{D}\right)$ is posterior probability of each model. The posterior mean and variance of $\Delta$ are (Draper, 1995)

$$
\begin{gathered}
E[\Delta \mid \mathbf{D}]=\sum_{k=1}^{K} E\left[\Delta \mid \mathbf{D}, M_{k}\right] p\left(M_{k} \mid \mathbf{D}\right) \text { and } \\
\operatorname{Var}[\Delta \mid \mathbf{D}]=\sum_{k=1}^{K} \operatorname{Var}\left[\Delta \mid \mathbf{D}, M_{k}\right] p\left(M_{k} \mid \mathbf{D}\right)+\sum_{k=1}^{K}\left(E\left[\Delta \mid \mathbf{D}, M_{k}\right]-E[\Delta \mid \mathbf{D}]\right)^{2} p\left(M_{k} \mid \mathbf{D}\right)
\end{gathered}
$$

where $E\left[\Delta \mid \mathbf{D}, M_{k}\right]$ and $\operatorname{Var}\left[\Delta \mid \mathbf{D}, M_{k}\right]$ are mean and variance of each model. In Equation (3.13), the first term on the right-hand side represents within-model variance and the second term represents between-model variance. Note that the predictive probabilities and leading moments are weighted by the posterior probabilities of the individual models.

Model averaging was implemented in this project to estimate posterior mean and variance of head and flow in northern Yucca Flat. Model probabilities of the 25 models were estimated in Section 3.3, and mean and variance of head and flux under each model were evaluated in the previous section. Posterior mean and variance of head were presented in Figure 3-57a and Figure 3-58a, respectively, and posterior mean and variance of flow were presented in Figure 3-59a and Figure 3-60a, respectively. Comparing posterior mean of head Figure-3-56a and flow Figure 3-59a with mean of head and flow of a single model shows that the posterior mean is the average of the means of the alternative models. For example, all alternative models predicted an area of low mean head at the southwest corner of northern Yucca Flat, and this area also appeared in posterior mean head (Figure 3-57a). In addition, the high head area at the upper-left corner of northern Yucca Flat also remained.

Nevertheless, the area of high mean head at the southeast corner of northern Yucca Flat predicted in models G3R5 (Figure 3-57d) and G2R5 (Figure 3-57e) is not shown in the contour of posterior mean head (Figure 3-57a). The reason is that these two alternative 
models have relatively lower averaging weights (posterior model probabilities) than models G3R2 and G2R2, which did not predict high mean head at the southeast corner. However, in this area, posterior mean head still increased due to the averaging effect. The similar effect of model averaging is also observed for posterior mean flow in the $y$-direction. The posterior mean flow (Figure 3-59a) is similar to the mean flow predicted by a single model.

Contrary to mean head, the posterior variance of head and flow is significantly different from the variance of head and flux predicted by a single alternative model. Figure 358 and Figure 3-60 show that the posterior variance is larger than the variance of any single model in terms of their magnitude and spatial distribution. This is obvious by comparing Figure 3-58 and Figure 3-60(a) showing posterior variance with other figures of variance for the single models. To further investigate the posterior variance, within-model and betweenmodel variance were calculated for head and flow according to Equation (3.13). Figure 3-61 plots the standard deviation of posterior variance, within-model variance, and between-model variance of head predictions. Figure 3-62 does the same for predictions of flow crossing the front face (in the $y$-direction) of MODFLOW cells. These two figures show that posterior variance is dominated by between-model variance. For example, the magnitude of betweenmodel variance is significantly larger than that of within-model variance, and that the spatial distribution of posterior variance is similar to that of between-model variance. This indicates that, without considering conceptual model uncertainty, underestimation of uncertainty is highly likely in terms of magnitude and spatial (also temporal) distribution of the predictive uncertainty.
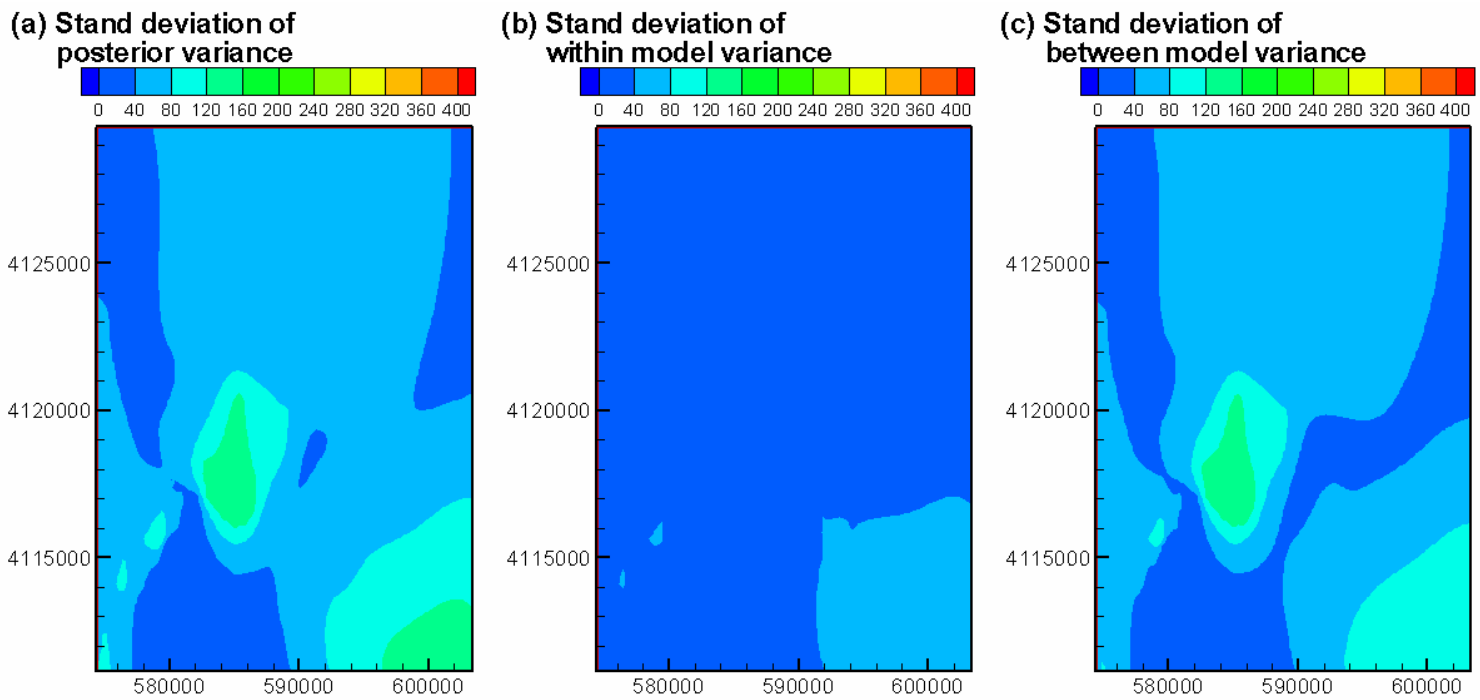

Figure 3-61. Standard deviation of (a) posterior, (b) within-model, and (c) between-model variance of head predictions. 
(a) Standard deviation of posterior variance

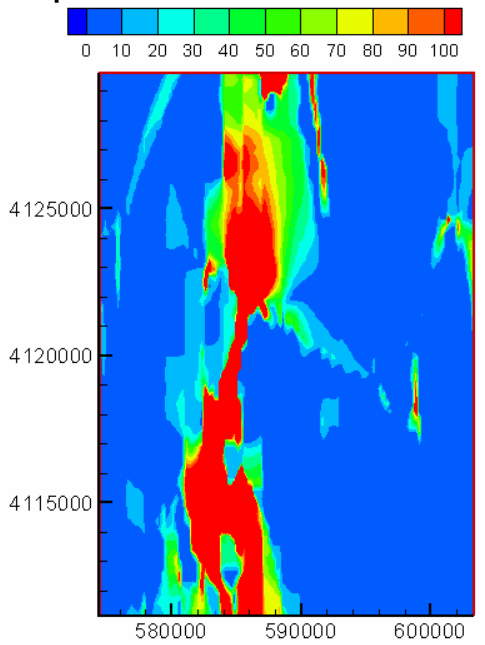

(b) Standard deviation of within model variance

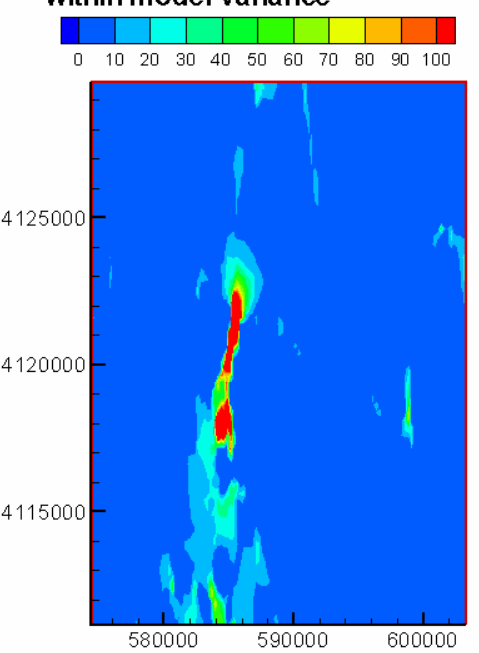

(c) Standard deviation of

between model variance

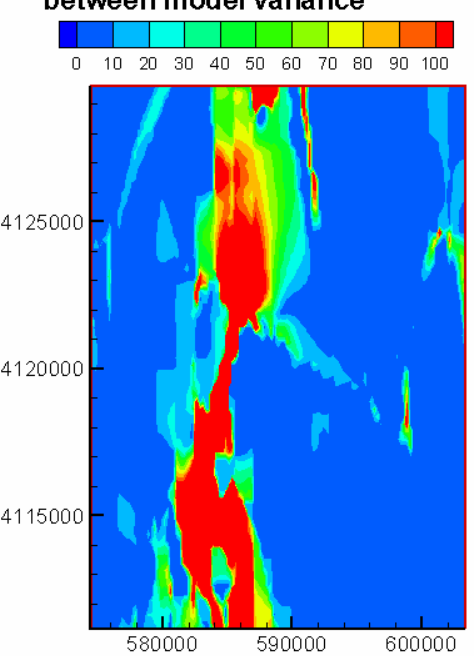

Figure 3-62. Standard deviation of (a) posterior, (b) within-model, and (c) between-model variance of flow crossing the front face (in the $y$-direction) of MODFLOW cells.

\subsection{Incorporation of Climax Regional Model Results in the Yucca Flat-Climax Mine CAU Model}

Composite predictions of hydraulic head and groundwater flow are produced from the Climax regional flow model by including parametric uncertainty and conceptual model uncertainty associated with multiple alternative models of regional groundwater recharge and hydrostratigraphy in northern Yucca Flat. Through Bayesian model averaging, the mean and variance of head and flow for each of the 25 conceptual model combinations generated through Monte Carlo simulation are weighted by their associated posterior probabilities. The results are provided as a mean and variance of hydraulic head (expressed as m amsl) and groundwater flow (expressed as $\mathrm{m}^{3} /$ day) for each active cell in the regional model domain. These values are reported on the highly resolved 250-m mesh within northern Yucca Flat and on the 1,500-m mesh throughout the remainder of the DVRFS domain. Note that groundwater flow into northern Yucca Flat is greater in the Climax regional flow model than what was simulated in the original UGTA regional model. This results from the greater flow in the DVFFS model upon which the Climax regional flow model is based.

Conceptually, the head and flow information provided by the averaged Climax Mine sub-CAU flow model can be utilized in the Yucca Flat-Climax Mine CAU flow model in at least two ways, though construction of the CAU flow model was underway at the time of this writing and the configuration of boundaries and simulation mesh had not been finalized. One approach is to use the Climax regional flow model to provide heads and flows for boundary conditions on the northern end of the Yucca Flat-Climax Mine CAU model, thereby eliminating the need for the CAU model to extend as far north as the Climax stock. Because the area of what has been termed "northern Yucca Flat" in this report extends east-west completely across the Yucca Flat-Climax Mine hydrostratigraphic model, the detailed hydrostratigraphy within the Climax model conforms seamlessly with the hydrostratigraphy that will provide the framework for the CAU model further south in Yucca Flat proper. Therefore, northern boundaries could be chosen at virtually any convenient location within 
northern Yucca Flat and the simulated heads and flows from the Climax model would incorporate the appropriate hydrostratigraphy on the boundary. Furthermore, boundary heads and flows developed in this way fully incorporate the uncertainty in conceptual models of flow into northern Yucca Flat, which will be a critical component of the Yucca Flat- Climax Mine CAU flow model.

A second approach is to use values of mean and variance of hydraulic head and groundwater flow at selected locations as observations in the northern portion of the CAU model. If the construction of the two models are in sufficient agreement, mean values can be used as calibration targets within the CAU model. If the CAU model is configured in a way that results in mean heads and/or flows being different from the Climax model, then the variation in these parameters can be used as the basis for calculating weights for internal heads or flows in the northern Yucca Flat area. Thus, even if the Climax flow model doesn't provide the same mean heads or flows simulated in the CAU model, the ranges in these values will be an important contribution to calibration of the Yucca Flat-Climax Mine CAU model. As with the first approach outlined above, including this variation explicitly accounts for the uncertainty associated with the conceptualization associated with groundwater flow into northern Yucca Flat. However, it should be noted that in order to include geologic conditions most consistent with those in the Yucca Flat-Climax mine hydrostratigraphic model, the second approach requires that the CAU model extend far enough north to include a significant number of observation points in the northern Yucca Flat area of the Climax regional flow model.

Estimates of groundwater flow from the north into Yucca Flat are uncertain owing to uncertain recharge rates, lack of good geologic control, few measurements of head, and virtually no hydraulic parameter data in the Climax stock region (particularly to the north of the NTS). Using water balance methods and the areal and inferred subsurface configuration of major geologic structures, Winograd and Thordarson (1975) estimated the total flow through the LCA below Yucca Flat to be less than approximately $1,180 \mathrm{~m}^{3} / \mathrm{d}$. Following the integration of subsequently-collected geologic and hydrologic data, UGTA's numerical flow model encompassing the NTS and surrounding region (DOE, 1997) predicted approximately $25,600 \mathrm{~m}^{3} / \mathrm{d}$ entering Yucca Flat from the north. This value is calculated at the southern boundary of northern Yucca Flat (the east-west transect at 4,111,000 m north, between 574,250 $\mathrm{m}$ and 603,500 m east; UTM Zone 11, NAD27). The DVRFS model simulates flow of $47,093 \mathrm{~m}^{3} / \mathrm{d}$ into Yucca Flat through this same transect $\left(54,459 \mathrm{~m}^{3} / \mathrm{d}\right.$ for the DVRFS model using the refined mesh). It should be noted that though the calibrated DVRFS model provides acceptable matches of observed discharge values at most regional springs and ET areas, the discharge simulated at Death Valley area springs and ET overpredicts observed discharge by $62,356 \mathrm{~m}^{3} / \mathrm{d}$ (Belcher, 2004). This implies that flow rates through areas contributing to discharge at Death Valley, including the Ash Meadows groundwater basin of which Yucca Flat is a component (Winograd and Thordarson, 1975; Laczniak et al. 1996), are potentially overpredicted in the DVRFS model.

The averaged Climax regional model simulates flow of $88,474 \mathrm{~m}^{3} / \mathrm{d}$ into northern Yucca Flat. This higher value as compared to the DVRFS model results from a flowpath established by the UGTA base-case and CPT alternative hydrostratigraphic framework models in the upper portion of the LCA at the northwest end of the Halfpint Range, immediately east of the Climax stock (illustrated in Figure 3-10). The position of this 
segment of LCA high in the section essentially eliminates the effect of depth decay on $K$ at this location and thus allows substantial flow through the Climax stock region. Recall that the USGS, UGTA HB, and UGTA CPT-HB hydrostratigraphic models do not include this LCA configuration, resulting in the simulation of less flow through northern Yucca Flat for their corresponding flow models (Figure 3-48). As discussed in Section 3.4.3.3, the most likely flow models incorporate the UGTA base-case or CPT hydrostratigraphic models, based on their better fit to the available observation data and the calibration methods incorporated in the DVRFS model. The higher Yucca Flat flow rates simulated in these models, combined with their higher probabilities, cause the averaged results to be higher than the Yucca Flat flows simulated in the original DVRFS model. The configuration of the upper LCA east of the Climax stock is thus critical in terms of estimating flow into Yucca Flat. 


\subsection{SIMULATION OF GROUNDWATER FLOW IN THE CLIMAX STOCK}

Local-scale simulations of groundwater flow in the Climax stock are based on the conceptualization that the majority of flow occurs through rock fractures within a lowpermeability granite rock mass. Numerical modeling of fluid flow in fracture-dominated subsurface flow regimes requires statistical analysis of fracture data for the determination of fracture properties, such as the number of fracture sets and their mean orientation, fracture length, fracture spacing and distribution of fractures, fracture density, fracture aperture, and permeability of individual fractures or zones (e.g., Andersson et al., 2002a,b; Munier, 2004). Properties of natural fracture networks are spatially variable. Consequently, probability distributions are commonly used to incorporate parametric uncertainty. Monte Carlo methodology can then be used to explore the influence of parameter variability on flow and transport characteristics of a fractured medium.

A fracture continuum method involving MODFLOW is used to model flow through randomly generated fracture zone networks within the Climax stock. These threedimensional networks are generated according to probability distributions describing fracture placement, orientation, length and hydraulic conductivity, and an algorithm used to control fracture density. The "coupling" of the regional-scale CRFM with the local-scale fracture continuum model (FCM) was necessary for several reasons. First, there is only one waterlevel measurement for the Climax stock (UG-02), and there is no evidence to support whether this single measurement is representative of a large perched water body or the regional flow system. Due to the lack of water level data for the Climax stock, the elevation of the water table for the local-scale FCM was inferred from the DVRFS model (Belcher $e t$ al., 2004). Heads from each of the CRFM were assigned to all boundary cells of the FCM. Second, the CRFM provides a volumetric flux target value for calibration. The calibration process, which involved matching the geometric mean of volumetric flux from individual realizations of the local-scale FCM to the target flux from the corresponding alternative CRFM, allowed for the determination of two essential parameter values that would not have been defined otherwise: mean fracture hydraulic conductivity and fracture zone density.

Permeability disks, a two-dimensional radial zone containing unique values of hydraulic conductivity (and porosity for the transport model), are incorporated into the fracture continuum permeability fields for the introduction of radionuclide particles in the transport model. Specific details of the permeability disks are included in section 5.1.1.2. The spatial distribution of recharge, constant head conditions at model boundaries, and flux calibration target for the local-scale FCM are based on one of the 25 CRFMs. A total of 200 Monte Carlo realizations are generated for each of the CRFMs, resulting in a 5,000 FCM flow field realizations. A GLUE technique is implemented to assign unique probability weights to each flow realization. These weights, along with model weights assigned to each of the CRFMs, are applied to the mass flux calculations during post-processing of the transport model results. A map of the FCM model domain in relation to the Climax area is shown in Figure 4-1.

\subsection{Conceptualization of Groundwater Flow}

Rock fractures, herein defined as joints, faults, and shear zones, govern fluid flow and solute transport in low-permeability rock masses (National Research Council, 1996; Neuman, 2005). The contrast in hydraulic conductivity values measured in the Climax stock for the 
rock matrix (on the order of $10^{-12}$ to $10^{-15} \mathrm{~m} / \mathrm{s}$ ) and a small sample of rock fractures (on the order of $10^{-7}$ to $10^{-10} \mathrm{~m} / \mathrm{s}$ ) (Murray, 1980, 1981) support this observation, indicating that potential radionuclide migration from the Hard Hat, Pile Driver, and Tiny Tot underground tests is controlled by the physical and hydraulic properties of fractures within a lowpermeability rock mass. Based on the conceptualization that rock fractures provide primary fluid flow pathways and the rock matrix contributes very little to the overall fluid flux, the flow model simulates three-dimensional, steady-state groundwater flow through fracture zone networks within the Climax stock. Application of this conceptual model to a numerical flow model is based on site-specific characterization of natural rock fractures in the Climax stock granite.

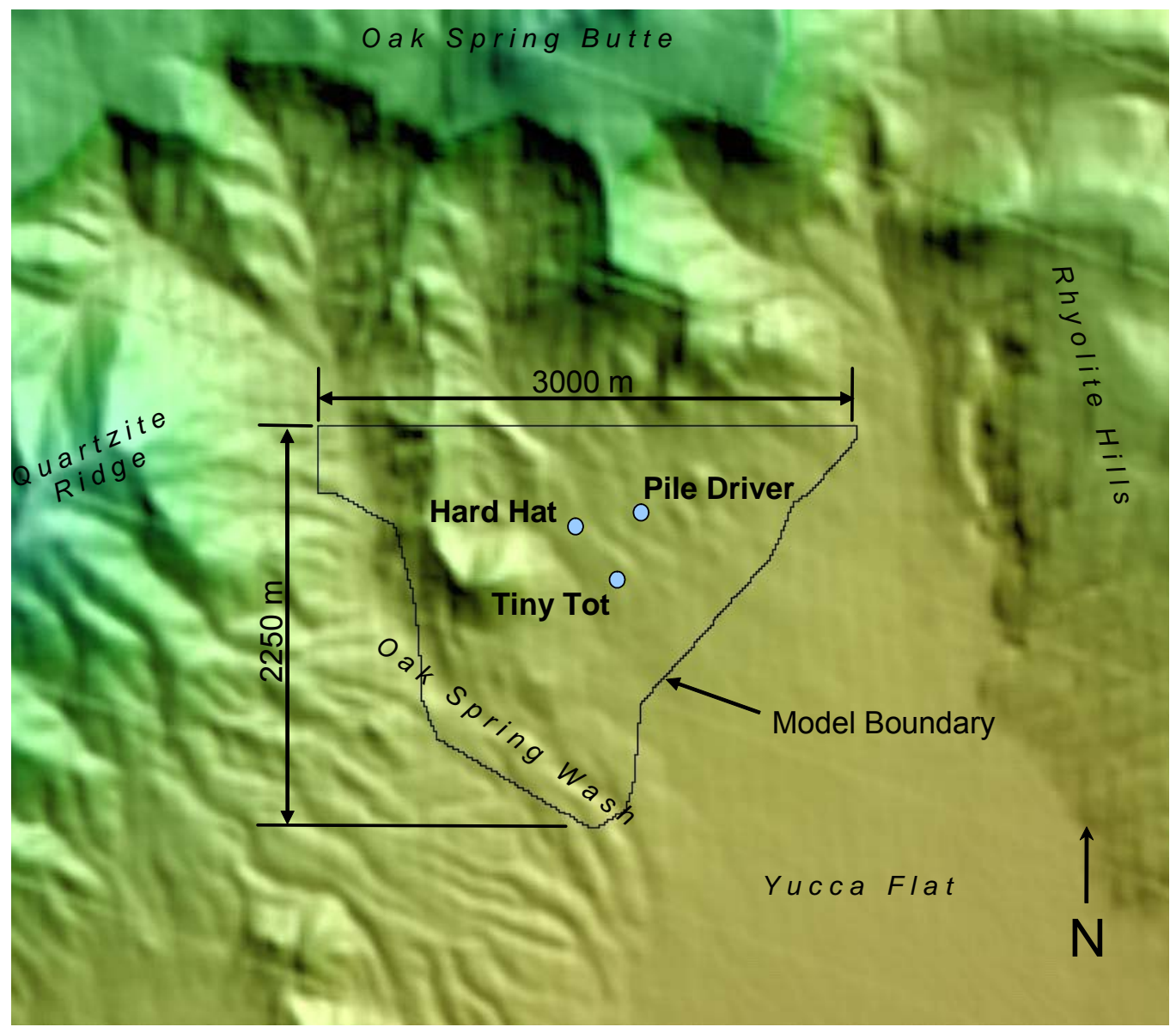

Figure 4-1. Map of the Climax granite flow model domain. The regional model predicts groundwater flow from the northeast to the southwest across the granite model domain.

A continuum approach (e.g., Svensson, 2001a,b; Ando et al., 2003; Reeves, 2006) is used to model groundwater flow through the Climax stock. This continuum model is based on a novel algorithm that directly maps fracture zones of any strike and dip orientation, represented as discrete fracture planes, as grid cell conductivities on a three-dimensional, finite-difference grid. The mapping of fracture zones as discrete features preserves the degree 
of anisotropy that fractures impart on a groundwater flow system. By maintaining a several order-of-magnitude permeability contrast between grid cells representing the rock matrix and grid cells representing rock fractures, this methodology closely follows the discrete fracture network approach (e.g., Dershowitz et al., 1991; Cvetkovic et al., 2004), where the majority of fluid flow occurs through fractures of a network. The use of a regularly spaced continuum grid provides the computational efficiency necessary for the simulation of kilometer-scale fracture flow, while preserving measured fracture attributes. For these reasons, it has been demonstrated in the literature that fracture continuum approaches perform well in simulating flow channeling and other extreme behavior characteristic of anisotropic fractured media.

\subsection{Parameterization of Flow Model}

Permeability fields of the FCM are created by mapping three-dimensional, randomly generated fracture zone networks onto a three-dimensional, regularly spaced, finitedifference grid. These fracture zone networks are generated according to probability distributions describing fracture spatial location, orientation, length, and hydraulic conductivity, while an algorithm is used to control fracture density. Values of both the mean fracture hydraulic conductivity and fracture density were determined concurrently during the calibration process. The mean and standard deviation of the fracture hydraulic conductivity distribution is constant for all CRFM, while a unique density value is assigned to each alternative CRFM based on calibration to volumetric flux.

\subsubsection{Fractures and Faults}

Fracture characterization is based on the Spent Fuel Test - Climax (SFT-C) Geologic Structure Database (Yow, 1984). The SFT-C database consists of data on joints, faults, and shear zones $(n=2,591)$ that were collected during fracture mapping efforts at four drifts (North Heater, Canister, South Heater, and Tail), an alcove, and an area referred to as a receiving room (Wilder and Yow, 1981). The orientation $\left(\mathrm{N} 61^{\circ} \mathrm{W}\right)$ of the Canister and two Heater drifts is based on joint data collected from tunnels of the Pile Driver test that indicate two dominant fracture strike directions: $\mathrm{N} 60^{\circ}-75^{\circ} \mathrm{W}$ and $\mathrm{N} 30^{\circ}-45^{\circ} \mathrm{E}$ (Maldonado, 1977; Carlson et al., 1980). At an orientation of $\mathrm{N} 61^{\circ} \mathrm{W}$, the Heater and Canister drifts are roughly parallel to the fracture set oriented at $\mathrm{N} 60-75^{\circ} \mathrm{W}$ and roughly perpendicular to the fracture set oriented at $\mathrm{N} 30-45^{\circ} \mathrm{E}$ (Carlson et al., 1980). The tail drift is oriented at $\mathrm{S} 76^{\circ} \mathrm{W}$; a rationale for its orientation is not listed. In addition to the correlation between drift and fracture set orientations, in-situ stress measurements indicate that directions of maximum and minimum principal stress are roughly parallel and perpendicular to the heater and canister drifts, respectively (Carlson et al., 1980). This suggests that fractures oriented parallel to the tunnel drifts are potentially more open and have higher permeabilities than fractures with other orientations to the stress field. Dimensions of the drifts are $4.6 \mathrm{~m}$ by $6 \mathrm{~m}$ for the canister drift, $3.4 \mathrm{~m}$ by $3.4 \mathrm{~m}$ for the heater drifts, and $3.7 \mathrm{~m}$ by $3.7 \mathrm{~m}$ for the tail drift. All four drifts are approximately $61 \mathrm{~m}$ long.

\subsubsection{Spatial Distribution}

Wilder and Yow (1984) report that fracture spacing at the Climax stock is approximately exponentially distributed. This supports other studies where fracture spacing is thought to be an exponentially distributed random variable (Rives et al., 1992; Brooks et al., 1996; Wines and Lilly, 2002). A Poisson process is used to assign fracture centers within 
the FCM domain, where joint uniform distributions in three dimensions lead to exponentially distributed spacing between fracture centers (Ross, 1985).

\subsubsection{Orientation}

All fracture orientation statistics are based on analysis of SFT-C fractures $(n=2,291)$ (see Table 18 on page 22 of Appendix F). Fracture orientation data were also collected for the Pile Driver and Tiny Tot underground tests; however, these data were not included in the statistical analysis of rock fractures because three-dimensional orientation was measured at these locations for only a small subset of the total fracture population. Appendix E applies the use of standard spherical statistical methods (e.g., Mardia and Jupp, 2000) to separate fracture orientation data into seven fracture sets, where fracture set orientation fits into three groups: high angle (69\%), low angle (16\%) and random (15\%) (Table 4-1; Figure 4-2). Of the seven fracture sets, Sets 1 through 6 fit a Fisher Distribution (Fisher, 1953)

$$
f(x)=\frac{\kappa \cdot \sin (x) \cdot e^{\kappa \cdot \cos (x)}}{e^{\kappa}-e^{-\kappa}}
$$

where the angle of divergence, $x$, from a mean orientation vector is symmetrically distributed according to a constant dispersion parameter, $\kappa$. The Fisher distribution is a special case of the Von Mises distribution for spherical data in Table 4-1, and is similar to a normal distribution for spherical data (Mardia and Jupp, 2000). The extent to which individual fractures cluster around a mean orientation is proportional to values of $\kappa$ (i.e., higher values of $\kappa$ describe higher degrees of clustering). The simulation of Fisher random deviates is based on a method described by Wood (1994). Separate Fisher random deviates are applied to both strike and dip of the mean orientation vector. For the fracture set with a random orientation, strike and dip are based on $U(0,2 \pi)$ random deviates. Corrections are applied to fracture orientations when dip values are outside the range $0 \leq \theta \leq \pi / 2$.

Table 4-1. Statistics for fracture sets in the SFT-C database.

\begin{tabular}{|c|c|c|c|c|c|c|c|}
\hline & Set 1 & Set 2 & Set 3 & Set 4 & Set 5 & Set 6 & Set 7 \\
\hline Prior Probability & 0.03 & 0.13 & 0.10 & 0.14 & 0.13 & 0.32 & 0.15 \\
\hline Mean Strike & 125 & 317 & 360 & 321 & 289 & 48 & N/A \\
\hline Mean Dip & 19 & 25 & 85 & 83 & 82 & 80 & $\mathrm{~N} / \mathrm{A}$ \\
\hline Dispersion $(\kappa)$ & 65 & 37 & 33 & 24 & 23 & 18 & N/A \\
\hline
\end{tabular}




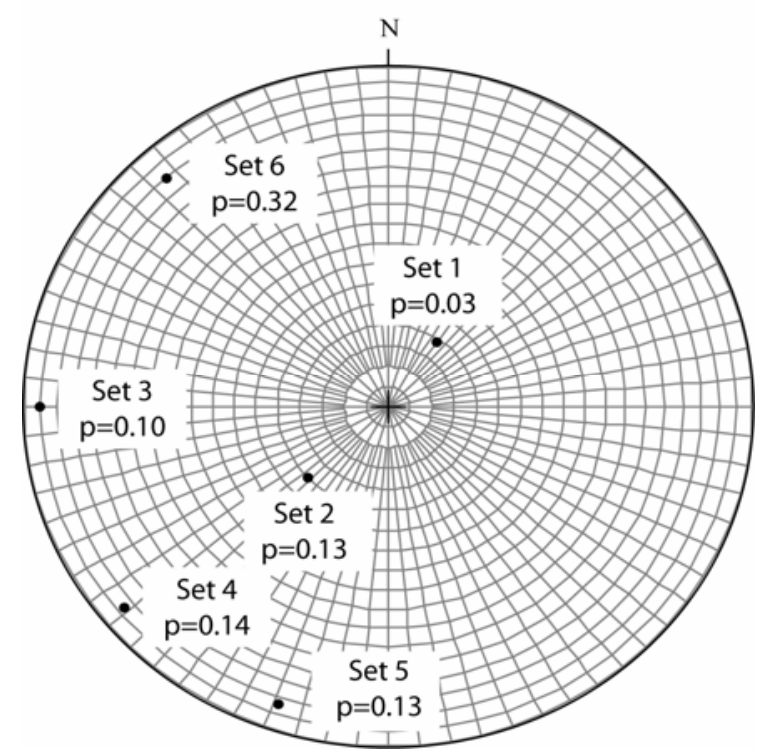

Figure 4-2. Lower hemisphere equal area projection of the poles to the mean orientation vectors for Sets 1 through 6 . The probability of each fracture set is given. Note that 85 percent of fracture orientations fit into Sets 1 through 6 . The remaining 15 percent of fractures are randomly oriented.

\subsubsection{Length}

All data used in the analysis of fracture lengths are contained in the SFT-C database, where fracture length $(n=2,460)$ is recorded for approximately 95 percent of the fractures mapped in the SFT-C drifts. The database lists fracture length as "apparent" length, as the recorded length of fractures is based on hand sketches scaled to the original maps (Yow, 1984). Fracture lengths range from $0.006 \mathrm{~m}$ to $40 \mathrm{~m}$. Note that fracture length is restricted by drift length $(\sim 61 \mathrm{~m})$ and orientation (i.e., the longest fractures are parallel to the drifts).

The distribution of fracture length was compared to uniform, exponential, normal, lognormal, Pareto, and type II extreme value probability distributions. Based on a maximum likelihood estimation method (Aban et al., 2005; Reeves, 2006), the data were found to best fit a Pareto power-law distribution that is truncated for the largest values of fracture length (denoted as "TPL") (Figure 4-3). The truncation in fracture length is artificial, and is a result of the drift orientation and length; the largest fracture is 67 percent of the drift length. However, there is no indication (besides the kilometer-scale faults that bound the Climax stock) that a classic Pareto power-law distribution (denoted as "PL"), is an appropriate choice for fracture length (Figure 4-3). A Pareto distribution is an extreme value distribution that, depending on the value of $\alpha$, can randomly generate very long fractures that could potentially span the entire domain of the local-scale FCM. 


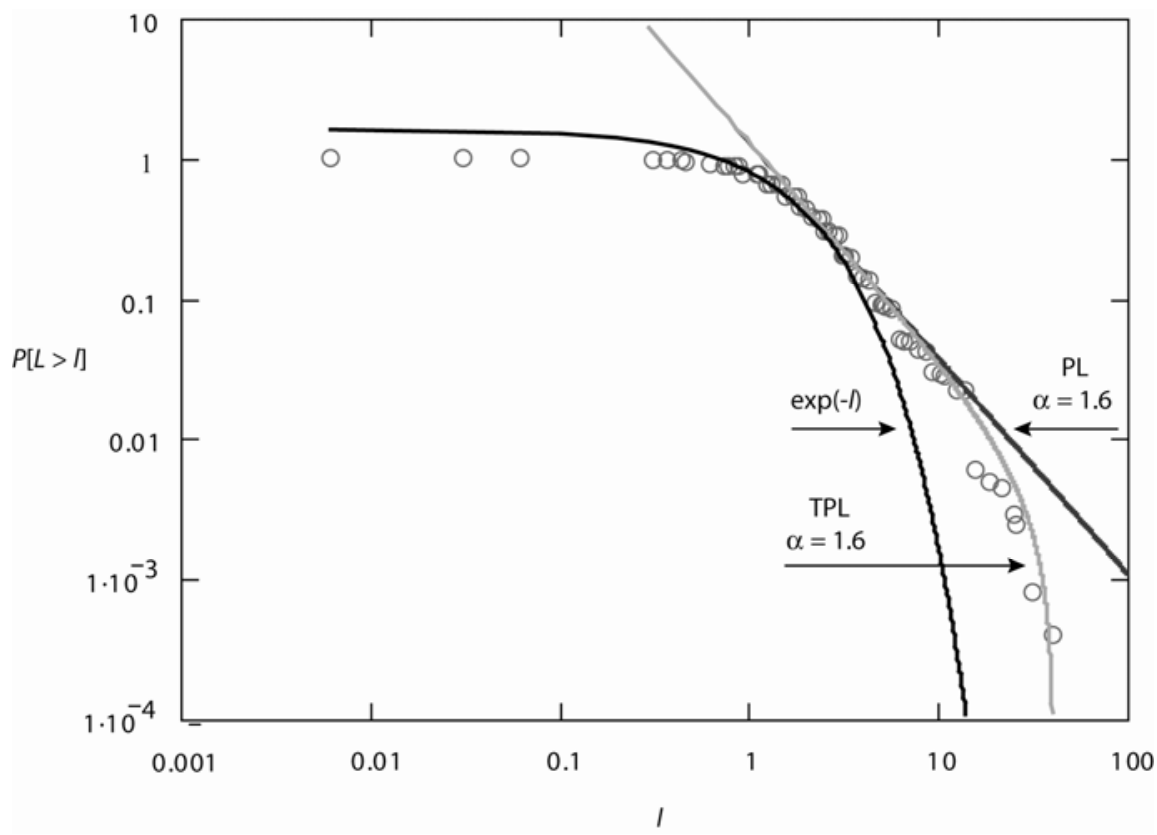

Figure 4-3. Mandelbrot plot of the all of the fracture lengths $(l)$ along with best fit Pareto powerlaw (PL), truncated Pareto power-law (TPL) and exponential (exp) models. Note that the decay of the largest fracture lengths (i.e., distributional tail) follows a strong powerlaw trend (linear in log-log space) with an abrupt truncation. The truncation is artificial and results from the length and orientation of the Canister drifts. All fracture lengths are in meters.

To honor the power-law trend observed for the fracture length data set (linear trend on Figure 4-3), a truncated Pareto model is used to randomly assign fracture lengths

$$
P(L>l)=\frac{\gamma^{\alpha}\left(l^{-\alpha}-v^{-\alpha}\right)}{1-\left(\frac{\gamma}{v}\right)^{\alpha}}
$$

where $L_{(1)}, L_{(2)}, \ldots, L_{(n)}$ are fracture lengths ranked in descending order, $\gamma$ and $v$ are the minimum and maximum values of $L$, and $\alpha$ describes the power-law tail of the distribution. Values of $\gamma$ and $v$ are arbitrary and selected at 30 and $1,000 \mathrm{~m}$, respectively. The lower cutoff of $30 \mathrm{~m}$ is equal to two times the edge of a cell in the continuum grid $(15 \mathrm{~m})$ and the upper cutoff of $1,000 \mathrm{~m}$ is equal to one-third of the length of the FCM domain in the x-direction $(3,000 \mathrm{~m})$. The presence of a power-law decay trend where $\alpha$ is less than 2 indicates that fracture lengths are scale invariant and that a "characteristic" length scale is undefined for fractures at the Climax stock. This observation is consistent with other studies of natural fracture networks where power-law distributions are commonly assigned to fracture length and $\alpha$ is thought to range between 1 and 3 (e.g., Bour and Davy, 1997; Renshaw, 1999; Bonnet et al., 2001).

\subsubsection{Density}

It is not possible to directly measure the three-dimensional fracture density of a rock mass. Instead, three-dimensional density for discrete fracture networks is estimated from 
density measures of lower dimensions (i.e., one-dimensional fracture frequency from boreholes and drifts or two-dimensional fracture density from outcrops and fracture trace maps). The most common measure of fracture density is one-dimensional fracture frequency (or intensity), which is defined as the total number of fractures per transect length. Fracture frequency in the SFT-C database, based on fracture mapping along the drift walls, is relatively high $(2.0 / \mathrm{m}$ to $5.5 / \mathrm{m})$ (Wilder and Yow, 1984). For discrete fracture network (DFN) modeling, a relation of proportionality is commonly used to convert a onedimensional fracture frequency to a three-dimensional spatial density (e.g., Holmén and Otters, 2002; Munier, 2004). However, these upscaled values $\left[\mathrm{m}^{2} / \mathrm{m}^{3}\right]$ can only be applied using DFN modeling approaches. The domain size of the model in the present study far exceeds computational constraints of DFN methods, which are usually limited to cubes of $100 \mathrm{~m}$ a side (e.g., Cvetkovic et al., 2004).

The grid size ( $15 \mathrm{~m}$ on a side) in relation to the average fracture spacing ( 2.0 to 5.5 fractures per meter) dictates that mapped fractures on the continuum grid represent fracture zones, defined as densely fractured regions containing multiple fractures. This conceptualization is supported by field observations that rock volumes are often intersected by only a few dominant fractures and only approximately 10 percent (or less) of the total fracture population contributes to flow. At Climax, this conceptualization is supported by observations from Ballou (1979) and Isherwood et al. (1982). In a tunnel drift for the SFT-C experiments, Ballou (1979) drilled a series of five boreholes used for permeability tests that extend from 9 to $12 \mathrm{~m}$ below the tunnel floor. After extensive air permeability testing over a period of 83 days, the permeabilities computed for all the boreholes yielded permeability values typical of unfractured granite cores at Climax. This indicates that the borehole array, which is on the scale of a grid cell, only intersected either solid rock or rock with "healed" fractures. "Healed" fractures (i.e., veins) refer to fractures that contain mineral precipitates (e.g., calcite) and are, therefore, not open to flow. Several instances of healed fractures were documented in the SFT-C fracture database (Yow, 1984). In the permeability test conducted by Isherwood et al. (1982), only two fractures out of $10(20 \%)$ in a densely fractured zone were open and had permeabilities higher than the background matrix.

The fracture continuum approach, incorporates a cell hierarchy where model cells are assigned either properties of fracture zones (i.e., densely fractured regions containing multiple fractures with a mean $K$ of $10^{-7}$ or $10^{-8} \mathrm{~m} / \mathrm{s}$ depending on fracture set orientation) or upscaled matrix cells (i.e., low permeability matrix with a small degree of background fracturing). The small degree of background fracturing is due to the cell size in which an upscaled $K$ value $\left(10^{-10} \mathrm{~m} / \mathrm{s}\right)$ captures the influence of both smaller, less-permeable fractures of lower hierarchy and the low-permeability granite matrix (on the order of $10^{-12}$ to $10^{-15} \mathrm{~m} / \mathrm{s}$ ). More information on fracture and matrix $K$ values is presented in Section 4.2.2.

To describe the fracture density of fracture zones in a continuum model, a novel method based on fractal geometry concepts (Mandelbrot, 1982) is used to determine an upper fracture zone density threshold for the FCM. First, a one-dimensional fractal dimension is computed from a composite transect of all non-zero fracture spacing values $(\mathrm{n}=1,140)$ in the SFT-C database according to the Cantor's dust box counting method (Velde et al., 1990; Barton, 1995) 


$$
D=\frac{\log (N)}{\log (1 / r)}
$$

where $N$ is the number of cells in which at least one fracture is present for a given cell length $r$. Note that $N$ is computed for a variety of cell lengths $r$ (i.e., $0.61,0.30,0.15,0.08,0.04$ ). The smallest cell size was arbitrarily selected as one-eighth of the resolution of the fracture spacing measurements in the SFT-C database $(0.3 \mathrm{~m})$. The number of fracture-occupied cells is then plotted against the reciprocal of cell length in a log-log plot (Figure 4-4). The slope of this plot is equal to the one-dimensional fractal dimension, $D=0.59$.

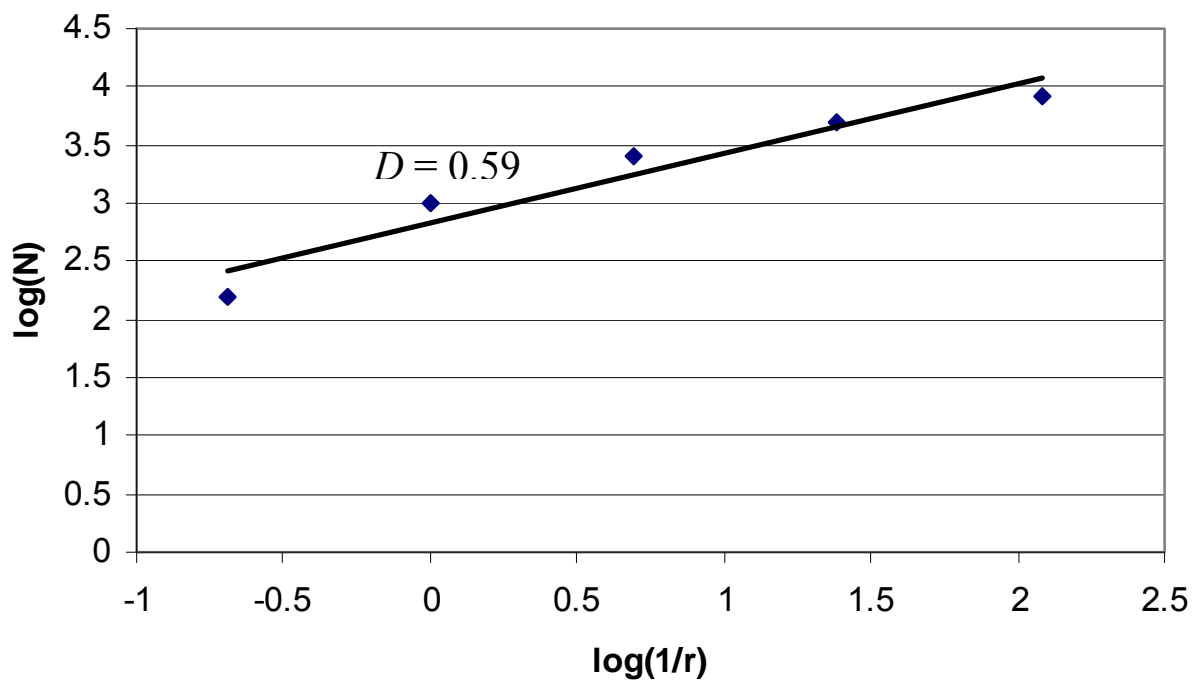

Figure 4-4. Linear regression of the number of fracture-occupied cells $N$ at the reciprocal of cell length $r$ in log-log space for the original composite transect. The slope of this plot is equal to the one-dimensional fractal dimension, $D=0.59$. The value of $D$ is sensitive to the order of the spacings and changes to 0.66 after re-sampling the composite transect via bootstrapping.

Values of $D$ are sensitive to the order of fracture spacings along a transect. Bootstrapping with replacement (Efron and Tibshirani, 1993) is used to resample fracture spacings along the original composite transect. After re-sampling of the original composite transect array 1,000 times, the mean fractal dimension stabilizes at 0.66 , with a mean linear regression coefficient, $\mathrm{R}^{2}=0.96$. The high value of $D$ is consistent with the observation that fractures in the Climax stock have a high frequency and are approximately exponentially distributed (Wilder and Yow, 1984; Gillespie et al., 1993). This value is also in agreement, especially with the upper limit, with other studies that report a range $0.40<D<0.70$ (e.g., Gillespie et al., 1993; Barton, 1995; Ehlen, 2000).

In addition to the scale-invariant property of fractals, estimates of $D$ can be extrapolated to other dimensions by applying the difference between the current dimension and the dimension of interest (i.e., a one-dimensional estimate of 0.5 is equal to 2.5 in three dimensions) (Barton, 1995; Marrett et al., 1999; Ehlen, 2000). Using this assumption, the three-dimensional fractal dimension for the Climax stock is 2.66. The application of a threedimensional fractal dimension of 2.66 to the fracture continuum model requires the 
generation of three-dimensional random fracture network based on Climax fracture statistics. A domain size of 3,000 $\mathrm{m}$ in the $x$-direction, $2,250 \mathrm{~m}$ in the $y$-direction, and $1,500 \mathrm{~m}$ in the $z$-direction was selected to approximate the domain of the local-scale Climax model, while having grid dimensions that are easily divisible by multiple cell sizes. The fracture networks are then mapped onto six different grids with cubic cell sizes of 15, 25, 30, 50, 75, and 125 $\mathrm{m}$. The mean fractal dimension is then computed for 100 fracture network realizations using Equation (4.3). Using a trial-and-error process, the above procedure is repeated until the mean (or ensemble) fractal dimension is equal to 2.66 (Figure 4-5). The upper fracture density threshold, defined as the average ratio of fracture occupied cells to total active cells in the model domain for the grid with the same cell size as the FCM $(15 \mathrm{~m})$, is 0.52 . This value suggests that fracture-occupied cells should not occupy more than 52 percent of the FCM grid.

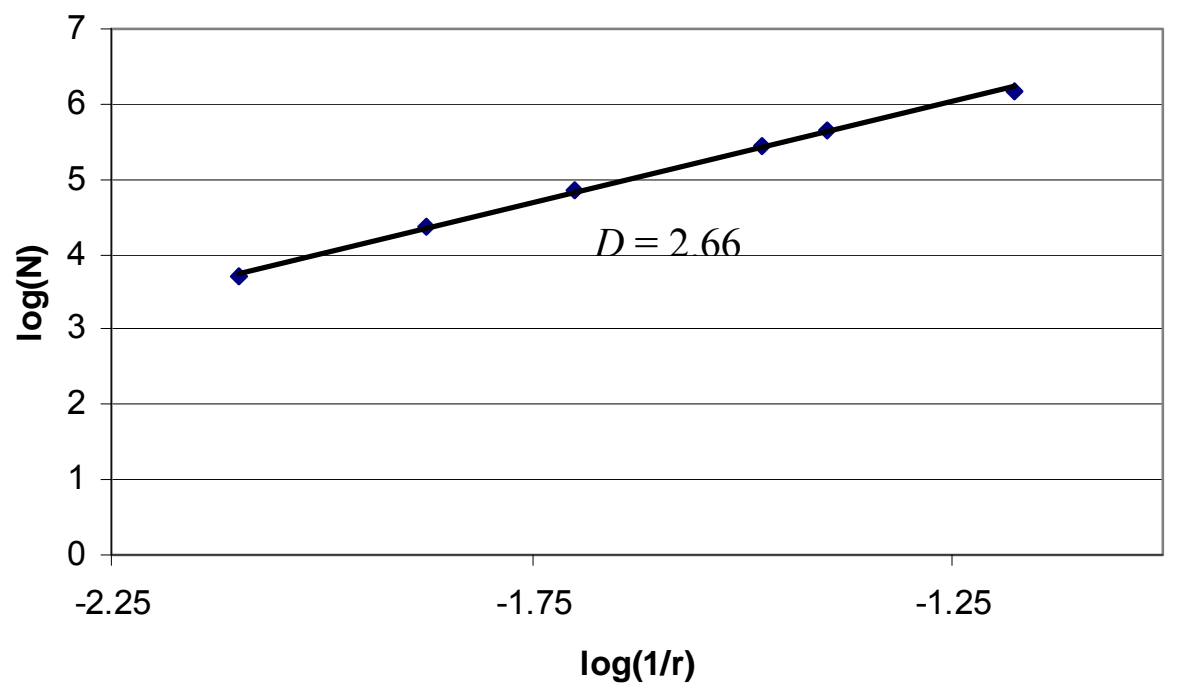

Figure 4-5. Linear regression of the number of fracture-occupied cells $N$ at the reciprocal of cell length $r$ in log-log space for 100 three-dimensional fracture network realizations. The slope of this plot is equal to the "up-dimensioned" three-dimensional fractal dimension of 2.66 .

The determination of fracture density for each FCM realization representing one of 25 CRFMs is a complex interplay between fracture hydraulic conductivity, boundary conditions and target volumetric flux from each CRFM, the upper fracture density threshold (0.52), and local-scale FCM-volumetric flux values. By restricting the mean and standard deviation of the fracture hydraulic conductivity distributions to constant values (refer to Section 4.2.2. for more detail), a constant fracture density is determined by calibrating volumetric flux from FCM realizations to the target volumetric flux for each corresponding CRFM (i.e., total volumetric flux from the FCM varies according to values of spatial density) (Table 4-2). The partial calibration of volumetric flux estimates incorporated a methodology that allowed enough flow through the Climax stock according to the lognormal distribution of $K$, while maintaining a density low enough to represent complex flow and transport characteristics of an anisotropic fractured medium. The density values for G2R1, G4R1, and G5R1 are greater than the recommended upper density threshold of 0.52 . This is deemed 
acceptable since these models are on the upper end of the CRFM volumetric flux distribution and calibrated poorly to the head measurements in the regional model. Thus, these models are assigned low weights and have little influence on the estimated radionuclide fluxes provided in Chapter 5 (Table 4-2).

Table 4-2. Values of target volumetric flux and corresponding fracture density for each of the 25 alternative CRFMs.

\begin{tabular}{ccc}
\hline $\begin{array}{c}\text { Alternative CRFM } \\
\text { (geologic framework/recharge) }\end{array}$ & $\begin{array}{c}\text { Target Volumetric Flux } \\
\left(\mathrm{m}^{3} / \mathrm{yr}\right)\end{array}$ & $\begin{array}{c}\text { Fracture Density } \\
\text { (fracture cells/total cells) }\end{array}$ \\
\hline G1R1 & $3,672,402$ & 0.210 \\
G1R2 & $2,271,897$ & 0.175 \\
G1R3 & $2,345,040$ & 0.180 \\
G1R4 & $2,252,813$ & 0.175 \\
G1R5 & $3,329,428$ & 0.220 \\
G2R1 & $6,002,826$ & 0.600 \\
G2R2 & $1,363,970$ & 0.225 \\
G2R3 & $1,220,893$ & 0.200 \\
G2R4 & $3,472,896$ & 0.425 \\
G2R5 & $3,483,820$ & 0.425 \\
G3R1 & $3,601,819$ & 0.475 \\
G3R2 & 757,169 & 0.138 \\
G3R3 & 706,644 & 0.138 \\
G3R4 & $1,798,069$ & 0.275 \\
G3R5 & $2,291,447$ & 0.325 \\
G4R1 & $7,025,040$ & 0.625 \\
G4R2 & $1,351,006$ & 0.185 \\
G4R3 & $1,409,483$ & 0.200 \\
G4R4 & $1,792,410$ & 0.250 \\
G4R5 & $3,751,154$ & 0.450 \\
G5R1 & $4,039,050$ & 0.575 \\
G5R2 & $1,031,675$ & 0.225 \\
G5R3 & $1,677,226$ & 0.325 \\
G5R4 & $1,280,366$ & 0.263 \\
G5R5 & $2,633,991$ & 0.450 \\
\hline & & \\
\hline
\end{tabular}

\subsubsection{Hydraulic Conductivity}

Only a handful of fracture permeability estimates are available for the Climax stock, and direct measurements of fracture $K$ come from only two sources: Isherwood et al. (1982) and Murray (1980). Isherwood et al. (1982) used packers to individually test a population of 10 vertical fractures intersected by two horizontal boreholes within a section of the Pile 
Driver tunnel complex. Only two of these fractures were hydraulically active (20\%) with measured permeabilities of 33 and 75 Darcies. Murray (1980) conducted infiltration experiments into a shear zone and computed permeability values of 3 to 60 Darcies.

Other values of permeability describe the "effective" permeability of the fractured rock, since these estimates are based on testing large well intervals where properties of multiple fractures and the relatively impermeable matrix are averaged. One such example is from USGS tests conducted between 1959 and 1961, where values of "effective" permeability were found to range between $2.5 \times 10^{-3}$ and $1.5 \times 10^{-2}$ Darcies by averaging two well tests over an interpreted high permeability zone thought to have a thickness of 12 meters (Price, 1959). Additional non-disturbed (i.e., no shock fracturing) permeability values come from Boardman and Skrove (1966), Izett (1960), and Murray (1981), which report values of $10^{-4}$ to $10^{-2}, 10^{-7}$, and $10^{-5}$ Darcies, respectively. Note that these values are based on only a couple of measurements (e.g., Boardman and Skrove, 1966) or a single measurement (e.g., the value of $10^{-5}$ Darcies is based on the infilling rate of borehole UG02 after dewatering by bailers).

Given the sparse data set of permeability values above, Murray (1980) assigned moderately to highly fractured zones at Climax a range of $10^{-4}$ to $10^{-1}$ Darcies (hydraulic conductivity is on the order of $10^{-10}$ to $10^{-7} \mathrm{~m} / \mathrm{s}$ ) and healed fractures and intact rock a permeability of less than $10^{-9}$ Darcies (hydraulic conductivity is on the order of $10^{-15} \mathrm{~m} / \mathrm{s}$ ). While the guidelines provided by Murray are helpful, the sparseness of his data set is reflected by the small range in the values of fracture permeability ( 3 orders of magnitude). This narrow range for fracture is inconsistent with other studies for highly characterized fractured granite rock masses where values of fracture permeability may encompasses 5 to 8 orders of magnitude (Paillet, 1998; Guimerá and Carrera, 2000; Andersson et al., 2002a,b; Gustafson and Fransson, 2005). The small range of fracture permeability is attributed to: 1) an under-sampling of conductive fractures and 2) the majority of permeability values represent an average value of conductive fractures and the rock matrix, thereby artificially restricting the range of fracture permeability values.

Values of hydraulic conductivity, $K$, can be determined from permeability using standard fluid properties of water (i.e., density and viscosity at $20^{\circ} \mathrm{C}$ ). The distribution of $K$ is thought to be lognormal for individual fractures or fracture zones (Stigsson et al., 2001; Andersson et al., 2002a,b). This is based on the observation that values of $K$ encompass several orders of magnitude and that the distribution of $K$ is positively skewed in the direction of the largest values. Instead of solely relying on a handful of permeability measurements and literature values to parameterize a probability distribution for fracture $K$, the distribution of mechanical fracture apertures in the SFT-C database (recorded as fracture width) is analyzed. All apertures less than $0.3 \mathrm{~m}(\mathrm{n}=2,280)$ are included in the analysis. Values larger than $0.3 \mathrm{~m}$ are attributed to either shear zones, which can be on the order of meters, or translation error during conversion from the original microfiche. Aperture values within this range encompass five orders of magnitude and fit a lognormal distribution with a best-fit $\log _{10}$ mean of -3.1 and standard deviation of 1.05 (Figure 4-6). Interestingly, this value is identical to the standard deviation of the transmissivity distribution used by Stigsson et al. (2001) at the Äspö Hard Rock Laboratory. 


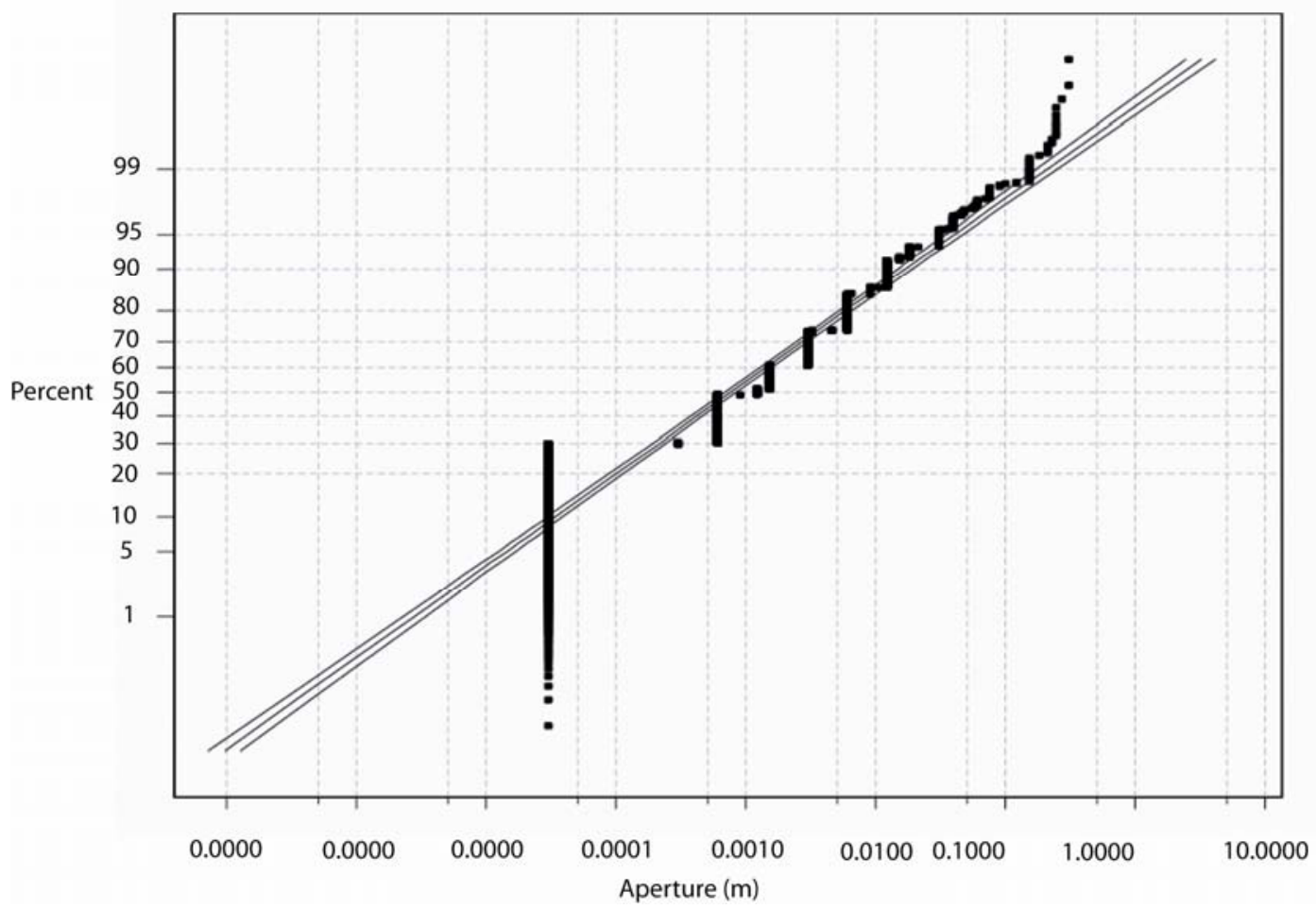

Figure 4-6. A $\log _{10}$ probability plot of fracture aperture suggests that this quantity is lognormally distributed. Deviations from the probability plot for the smallest apertures are caused by the lack of resolution in aperture measurements, where the smallest apertures are all assigned a value of $3.0 \times 10^{-5} \mathrm{~m}$. The deviation from the theoretical distribution for the largest values may be caused by the artificial truncation of fracture aperture at $0.3 \mathrm{~m}$.

The cubic law, a solution to the Navier-Stokes equation for laminar, incompressible flow between two parallel plates, describes a general relationship between fluid flow and fracture aperture assuming (Snow, 1965; Witherspoon et al., 1980)

$$
Q=\frac{\rho g}{12 \mu} b^{3} \nabla h
$$

where fluid discharge, $Q$, is proportional to the cube of the hydraulic aperture, $b$. The relationship between hydraulic aperture and hydraulic conductivity is described by $K=\frac{\rho g}{12 \mu} b^{2}$. However, the relationship between mechanical aperture, the physical distance between fracture walls, and hydraulic aperture, the equivalent aperture for a given flow rate, is unclear. As a general rule, hydraulic aperture is typically smaller than mechanical aperture when aperture is small (i.e., < $1 \mathrm{~cm}$ ) (e.g., Cook et al., 1990; Renshaw, 1995; Zimmerman and Bodvarsson, 1996; Chen et al., 2000). Discrepancies between mechanical aperture and hydraulic aperture are attributed to surface roughness, flowpath tortuosity, and stress normal to the fracture. Though empirical correction factors have been used in an attempt to correlate mechanical and hydraulic apertures (Bandis et al., 1985; Cook et al., 1990; Renshaw, 1995), no method is reliable for a wide range of fracture aperture. Thus, Climax aperture data is 
used only to demonstrate the appropriateness of a lognormal distribution for fracture $K$ and a rough estimate of standard deviation. The standard deviation of fracture $K$ based on aperture data is used only because this value is consistent with literature values (Stigsson et al., 2001); literature values are deemed more reliable since they are based on actual hydraulic tests using packers to isolate individual fractures.

In the fracture continuum approach, a cell hierarchy where model cells are assigned either properties of fracture zones (i.e., densely fractured regions containing multiple fractures) and upscaled matrix cells (i.e., low-permeability matrix with a small degree of background fracturing) is incorporated. The small degree of background fracturing is due to the cell size in which an upscaled $\mathrm{K}$ value of $10^{-10} \mathrm{~m} / \mathrm{s}$ captures the influence of both smaller, less permeable fractures and the low-permeability rock matrix. Based on both previous studies of fractured rock (Sigsson et al., 2001; Andersson et al., 2002a,b) and the distribution of fracture apertures (Figure 4-6), a lognormal distribution is used to assign $K$ values to the fracture zones. Instead of using Equation (4.4) to compute a mean $\log _{10} K$ value from fracture apertures, two different mean $\log _{10} K$ values of -7.0 and $-8.0 \mathrm{~m} / \mathrm{s}$ were selected during the calibration process, both of which are within the narrow range defined by Murray (1980, 1981). The higher mean of $-7.0 \mathrm{~m} / \mathrm{s}$ is assigned to fractures that belong to fracture set $6(32 \%$ of the fractures) (Table 4-1). Fractures in this set experience the least amount of compressive stress normal to the fracture walls, suggesting that these fractures are potentially more open and permeable than fractures oriented at other directions to the stress field. The remaining fracture sets (68\% of the fractures) are assigned $K$ values according to a lower mean of $-8.0 \mathrm{~m} / \mathrm{s}$. A $\log _{10}$ standard deviation value of 1.05 , based on the distribution of fracture aperture and literature values, is used for all fracture sets. A lognormal distribution with the above mean and standard deviation honors data trends observed at well-characterized fractured sites, while encompassing the suggested range by Murray (1980).

\subsubsection{Recharge}

One of five alternative conceptual models of spatially distributed recharge is used in each CRFM as described in Section 3.2.1. Each FCM incorporates the spatial distribution of recharge within the local-scale domain for a corresponding recharge model. A bilinear interpolation algorithm is used to interpolate recharge values from the CRFM grid, which has a $250 \mathrm{~m}$ cell size in the vicinity of the FCM, to the local-scale FCM grid with a $15 \mathrm{~m}$ cell size. The total flux applied for each recharge model is listed in Table 4-3. Annual recharge flux estimates in the area of the local-scale FCM domain range between 2.0 and $9.9 \mathrm{~mm} / \mathrm{yr}$. Though each chloride mass-balance model applies a different recharge rate to the regionalscale CRFM (refer to Section 3.2.1.3), the applied recharge in the area of the local-scale FCM domain (approximately 40 cells of the CRFM model) is identical ( $4.8 \mathrm{~mm} / \mathrm{yr}$ ). In general, recharge applied to the local-scale FCM accounts for only 1 percent of the total volumetric flux through the granite rock mass. 
Table 4-3. Values of recharge flux for each alternative conceptual model in the local-scale fracture continuum model.

\begin{tabular}{ccc}
\hline Recharge Model & Recharge Flux $(\mathrm{mm} / \mathrm{yr})$ & Recharge Flux $\left(\mathrm{m}^{3} / \mathrm{yr}\right)$ \\
\hline Modified Maxey-Eakin & 6.8 & 24,655 \\
Net Infiltration I & 9.9 & 36,262 \\
Net Infiltration II & 2.0 & 7,173 \\
Chloride Mass-balance I & 4.8 & 17,679 \\
Chloride Mass-balance II & 4.8 & 17,679 \\
\hline
\end{tabular}

\subsubsection{Hydraulic Head}

Hydraulic head values for each of the 25 CRFMs are used to provide boundary conditions to corresponding local-scale FCM realizations. Using a bilinear interpolation method similar to that used for recharge, head values from the CRFM grid are interpolated onto the local-scale fracture continuum grid. These head values are used as constant head boundaries and preserve the horizontal and vertical flow gradients modeled through the Climax stock in each regional-scale CRFM. As described in Section 3.5, the mean horizontal flow direction through the Climax stock for all regional models is southwest towards Yucca Flat (Figure 4-1).

\subsection{Numerical Flow Model}

A local-scale fracture continuum model is used to simulate steady-state, threedimensional groundwater flow through randomly generated fracture zone networks in the Climax stock. The selection of the model domain is based on the location of the three underground tests, the simulated water table from the DVRFM, and an isopach map of the Climax granite stock. The simulated water table from the DVRFM is directly mapped onto the local-scale FCM, forming the top surface of layer 1. With the exception of no-flow boundaries on the top and bottom of the model, FCM boundaries are constant head. Values for the constant head boundaries are interpolated from the alternative CRFMs. A finitedifference groundwater flow code, MODFLOW (Harbaugh et al., 2000), solves the steadystate groundwater flow equation for both fracture networks and rock matrix. Monte Carlo methodology is used to address parametric uncertainty for the random fracture zone networks. A subset of 200 fracture network zone realizations is generated for each of the 25 CRFM, resulting in a total of 5,000 individual flow realizations. The calibration of each 200 FCM realization subset to a corresponding CRFM is based on volumetric flux values. Weights, based on the GLUE technique, are assigned to each of the 200 individual realizations based on the match between volumetric flux values of the realizations and target volumetric flux computed from the corresponding CRFM. The weights for individual realizations reflect the variability in flux values modeled by the FCM. Model weights for each of the CRFM are then combined with the flow weights for the individual realization subsets using a Bayesian weighting procedure.

\subsubsection{Generation of Fractures and Mapping to Finite-difference Grid}

Fracture zone networks are randomly generated for seven fracture sets according to a compound Poisson process for fracture location, a Fisher distribution for variability about a mean fracture set orientation, a truncated Pareto distribution for fracture length, a lognormal distribution for fracture hydraulic conductivity, and an algorithm, based on the ratio between 
fracture-occupied cells and total active cells in the model domain, to control fracture density. These random fracture zone networks are then mapped to a continuum grid with a constant cell size of $15 \mathrm{~m}$ by $15 \mathrm{~m}$ by $15 \mathrm{~m}$ (Figure 4-7).

The mapping of discrete fractures onto a regularly spaced finite-difference grid requires a stair-step pattern to preserve flow continuity in both horizontal and vertical directions (Figure 4-8). A novel mapping algorithm, based on the equation of a plane, is used to accurately map discrete fractures (as fracture zones) of any strike and dip orientation as two-dimensional planar features within a three-dimensional model domain. Fractures mapped onto the grid are randomly assigned values of hydraulic conductivity according to one of the two lognormal distributions described in Section 4.2.2. Cells unoccupied by fractures represent an upscaled matrix and are assigned a $\log _{10}$ hydraulic conductivity value of $-10 \mathrm{~m} / \mathrm{s}$.

The use of a finite-difference grid to simulate discharge in a fracture that is not aligned with the grid requires an adjustment for longer flowpaths in the horizontal direction. Though head values in the model domain are unaffected by the configuration of the fracture continuum equivalents, longer horizontal flowpaths reduce the hydraulic gradient from cell to cell along the stair-step pattern (Figure 4-8). To correct for the gradient so that proper fracture discharge values can be obtained for each fracture, a correction factor

$$
K_{\text {MODFLOW }}=K_{\text {fracture }} \cdot[\sin |\theta|+\cos |\theta|]
$$

where $\theta$ is fracture orientation from the horizontal gradient (Figure 4-9).

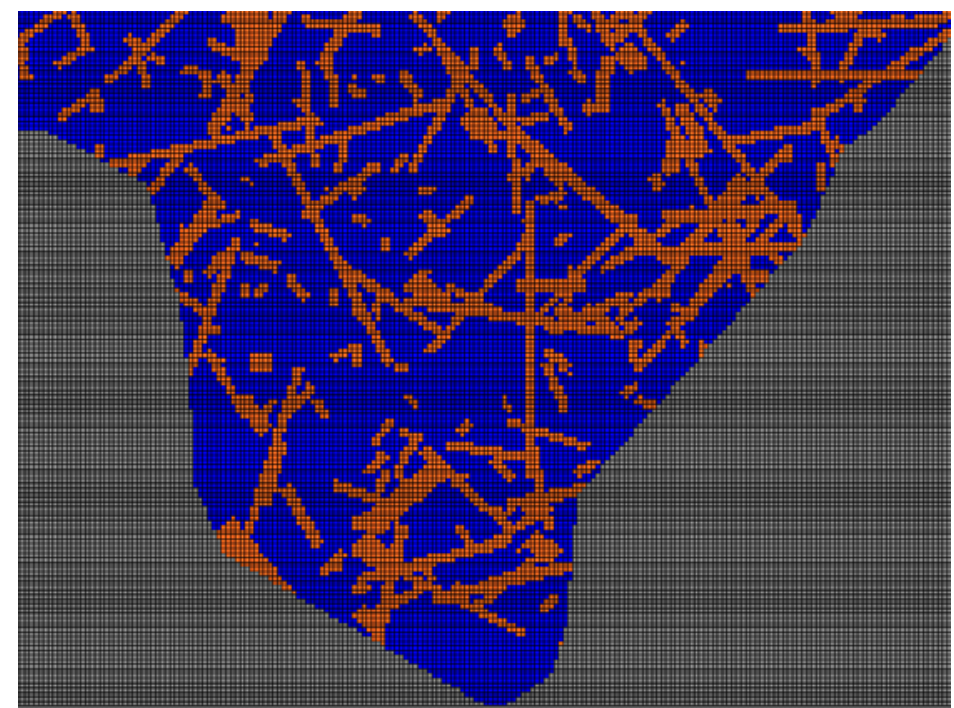

Figure 4-7. Two-dimensional slice of a three-dimensional fracture continuum zone network (red) at a density of 0.30 . Fracture zone thickness is a function of dip (i.e., gently dipping zones appear thicker than steeply dipping zones). Fracture zones that appear unconnected in the figure may be connected in three-dimensions. The model is $3 \mathrm{~km}$ in the $x$-direction and $2.25 \mathrm{~km}$ in the $y$-direction, with $15 \mathrm{~m}$ by $15 \mathrm{~m}$ cells. 


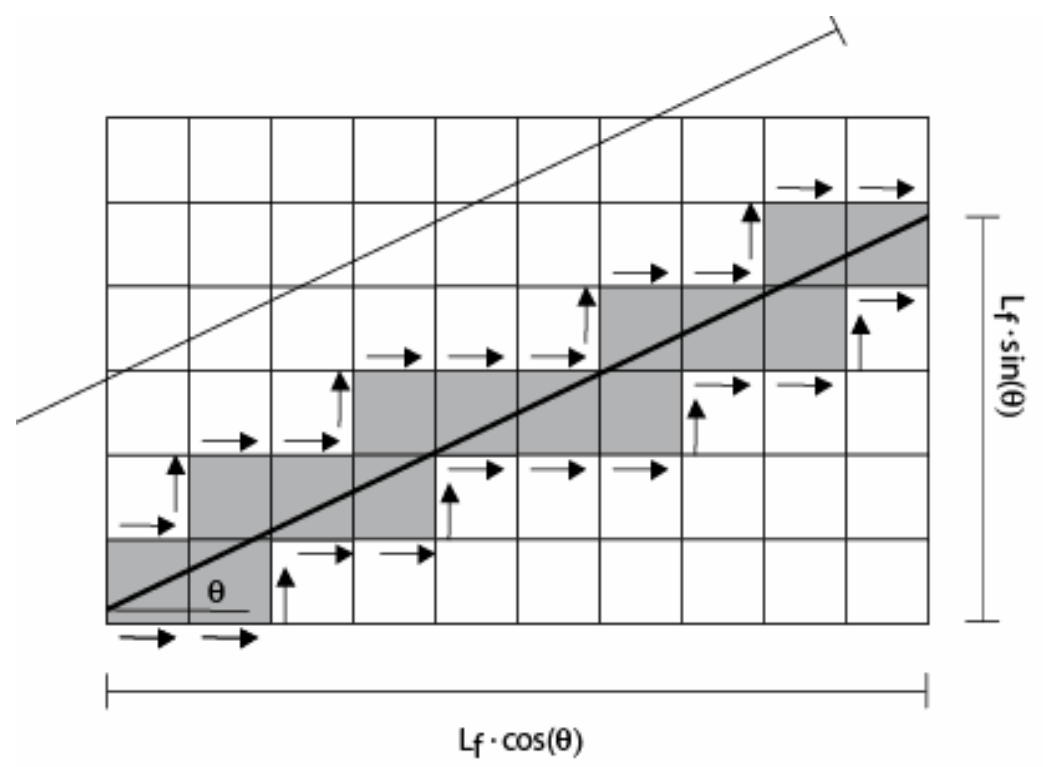

Figure 4-8. Fracture mapping on a continuum grid results in a stair-step pattern of both horizontal and vertical flow components and longer flowpaths.

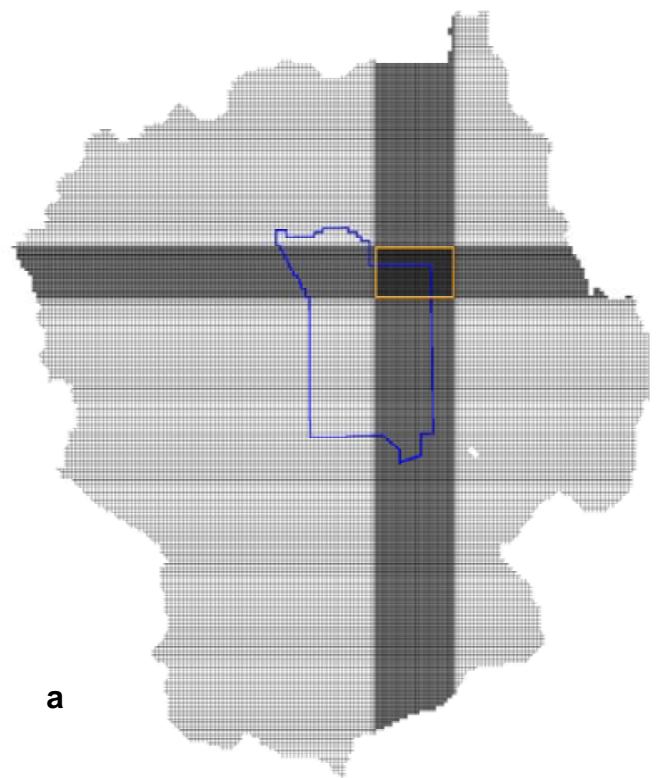

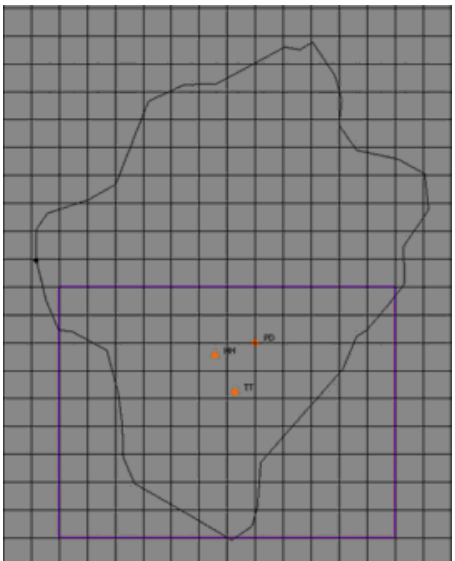

b

Figure 4-9. Selection of the local-scale FCM domain (b) from the CRFM model (a). The black line in (b) represents the extent of the saturated granite of the Climax stock. The purple box in (b) represents the horizontal extent of the local-scale FCM domain in relation to the subsurface tests (triangles).

\subsubsection{Model Domain and Boundaries}

The local-scale FCM is a continuum representation of fracture zone networks within the Climax stock. The location of the three underground tests, the simulated water table from the DVRFM, and an isopach map of the Climax granite were taken into account during the selection of the local-scale model domain. A contour of the saturated granite is computed by subtracting values from a digitized isopach map of the Climax stock from values of the 
DVRFM simulated water table (Figure 4-9). The location of the subsurface tests relative to the contour of the saturated granite indicates that the local-scale FCM does not need to include the entire extent of the saturated granite. Instead, the local-scale model only includes the southern half of the saturated granite (purple box in Figure 4-9b) and extends from $3,000 \mathrm{~m}$ in the $x$-direction and 2,250 $\mathrm{m}$ in the $y$-direction; the extent of the northern boundary was arbitrarily selected as approximately $250 \mathrm{~m}$ upgradient from the Pile Driver test. In the vertical direction, the model extends from 1,155 $\mathrm{m}$ (the highest elevation of DVRFM water table within the local-scale model domain) to sea level $(0 \mathrm{~m})$. The water table from the DVRFM is directly mapped onto the local-scale model grid (Figure 4-10); cells below the DVRFM water table are active, while cells above the water table are inactive.

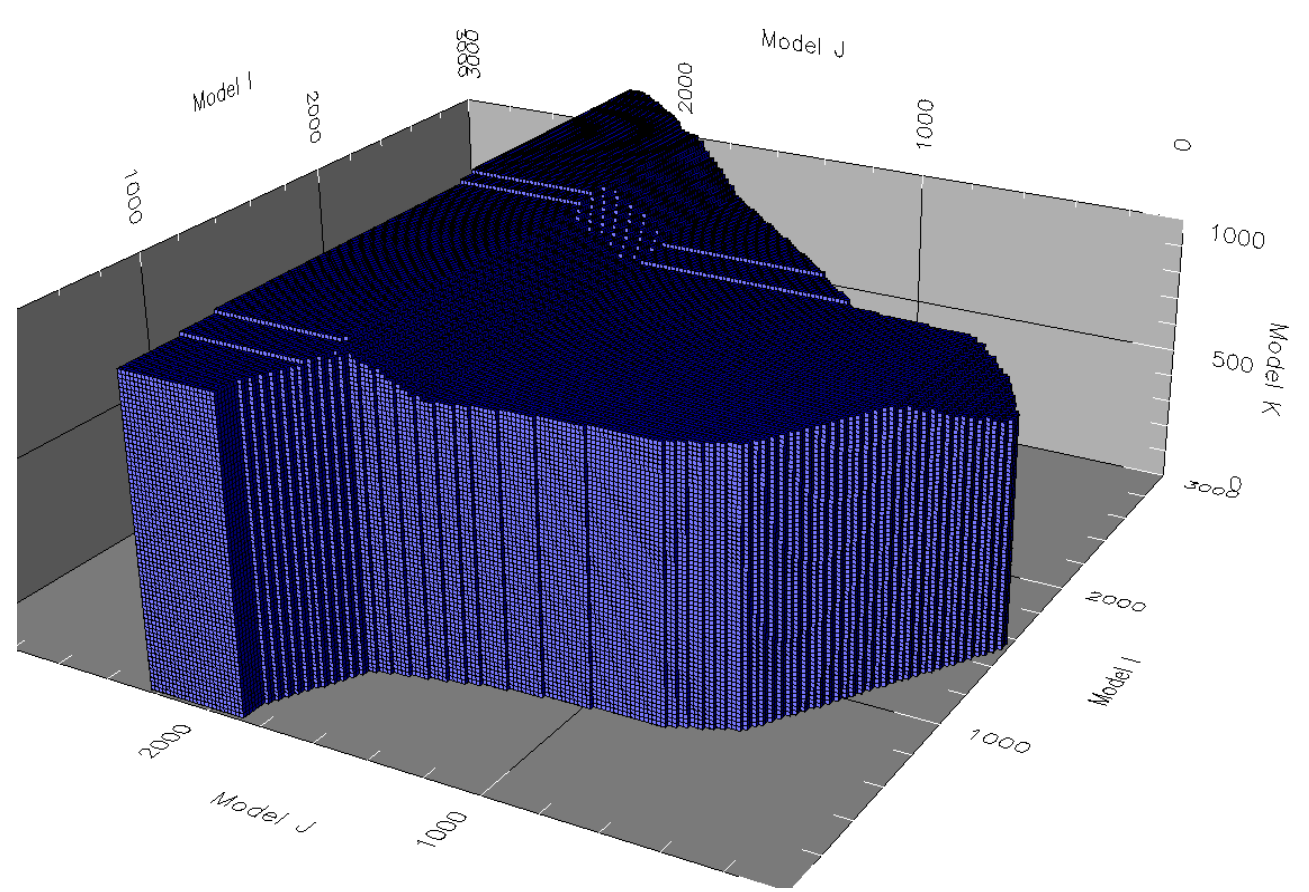

Figure 4-10. Northeast view of the local-scale fracture continuum model.

Cell size was selected to make the grid as fine as possible given the size of the model domain and computational constraints. A cell size of $15 \mathrm{~m}$ by $15 \mathrm{~m}$ by $15 \mathrm{~m}$ leads to a grid with a total of $2.31 \times 10^{6}$ cells, approximately 60 percent of which are active. All lateral model boundaries are constant head, with head values interpolated from each CRFM. The lower model boundary is no-flow. Spatially-distributed recharge is applied to cells in the upper layer representing the regional water table. MODFLOW (Harbaugh et al., 2000) is used to solve the steady-state groundwater flow equation for a confined aquifer within the FCM. Monte Carlo methodology is used to incorporate uncertainty in fracture network parameters. A total of 200 flow realizations are used for each of the 25 alternative CRFM, resulting in a total of 5,000 realizations.

\subsubsection{Calibration and Weighting}

There are no reliable head measurements for the Climax stock; therefore, head could not be used as a calibration target. Each of the 25 CRFM is used to provide both boundary 
conditions and target volumetric flux values for 200 of the 5,000 total FCM flow realizations. Calibration of the 200 fracture continuum realizations to each CRFM was further complicated by the approximate order-of-magnitude difference in volumetric flux values $\left(706,644 \mathrm{~m}^{3} / \mathrm{yr}\right.$ to $7,025,040 \mathrm{~m}^{3} / \mathrm{yr}$ ) for the CRFM (Figure 4-11). Through a trial and error process, it was determined that a mean $\log _{10}$ hydraulic conductivity value of $-7.0 \mathrm{~m} / \mathrm{s}$ for fracture set 6 and $-8.0 \mathrm{~m} / \mathrm{s}$ for the other fracture sets were sufficient to model the range in volumetric flux values for the CRFM, while honoring the upper density threshold defined in Section 4.2.1.4.

Calibration using inverse solution methods (e.g., Doherty, 2000) was unsuccessful due to objective functions with several local minima and the observation that volumetric flux values through individual network realizations with the same density can vary several orders of magnitude (Figure 4-11). The variability in flux values for randomly generated networks with identical density values is attributed to the degree of network connectivity and the hydraulic conductivity values assigned to individual fracture segments. Instead of using inverse methods, calibration was achieved by matching the target flux provided by a CRFM to the geometric mean of flux values for each of the 200 corresponding FCMs. Density values were changed until the geometric mean of all 200 realizations matched the target flux value within \pm 5 percent.

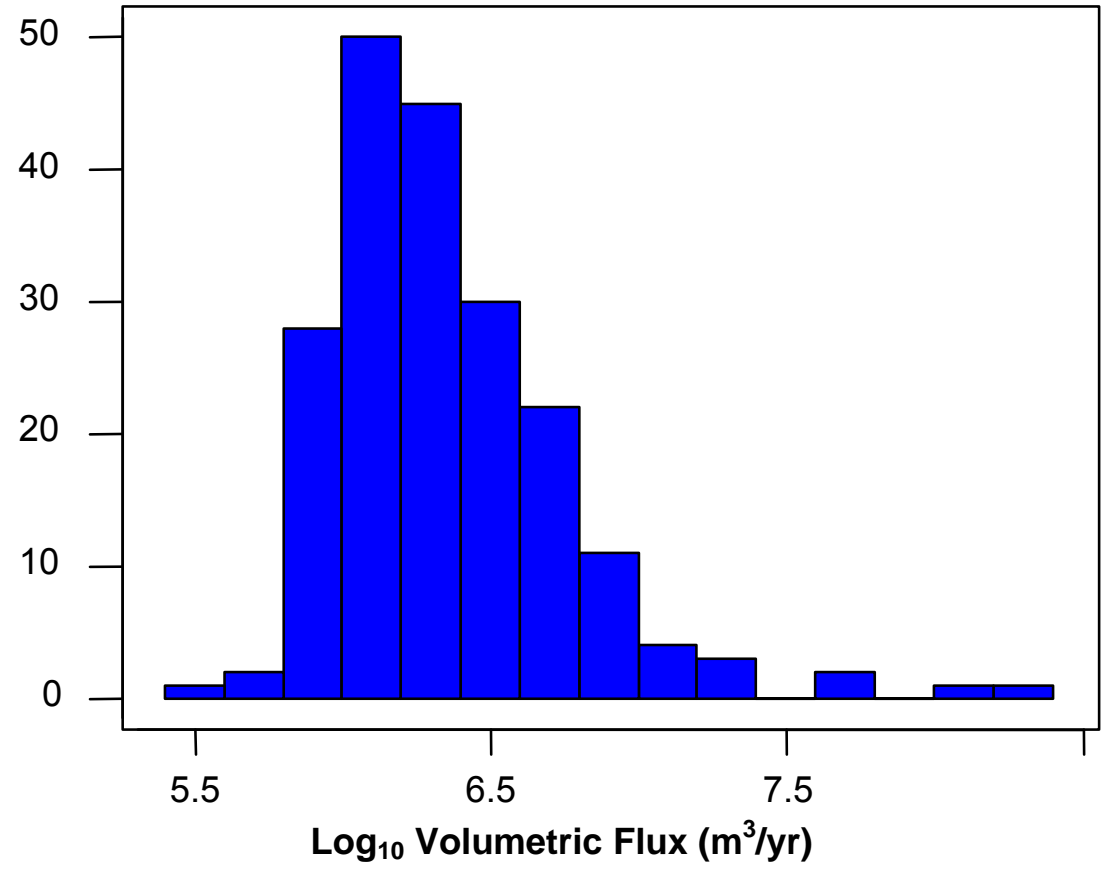

Figure 4-11. Frequency histogram of $\log _{10}$ flux values for 200 individual FCM realizations corresponding to the G1R2 CRFM. The distribution of flux for the other 24 200-realization subsets is similar (i.e., lognormally distributional).

In a standard Monte Carlo simulation, all of these realizations, regardless of flux values, would have equal weight. However, given the extreme variability in flux for individual realizations, it is reasonable to assume that flow realizations that more closely match the target flux value for a CRFM should receive more weight than flow realizations that show a poor match to the given target flux. 
Weights, based on a GLUE technique (Beven and Binley, 1992; Freer et al., 1996; Morse et al., 2003) are assigned to each of the 200 individual flow realization subsets for a given CRFM according to

$$
L\left(\vec{F} \mid \vec{\theta}_{i}\right)=\left[\frac{1}{E_{i}}\right]^{N}
$$

where $L\left(\vec{F} \mid \vec{\theta}_{i}\right)$ is the likelihood of the vector of simulated flux values for the local-scale fracture continuum realizations, $\vec{F}$, given the parameter set, $\vec{\theta} \cdot E_{i}$ is an objective function and $N$ is a likelihood shape factor that typically ranges between zero and one. By assuming a weak correlation between flux in each CRFM and the corresponding FCM realizations, the objective function can be defined as: $E_{i}=\left(F l u x_{i}-F l u x_{t}\right)^{2}$, where $F l u x_{i}$ are flux values for FCM realizations with index $i$ and $F_{l u x_{t}}$ is the target flux value for the corresponding CRFM. The selection of $N$ is central to the GLUE weighting method. A value of zero describes a standard Monte Carlo simulation where all realizations have equal weight. As $N$ increases from zero towards infinity, probability weight is shifted towards the realizations with the best match to the objective function. A value of 1.0 for $N$ describes realization weights that follow a normal distribution.

Flux values in the fracture zone networks are constrained only by the range and distribution of the network parameters and the constant head boundary conditions from the corresponding CRFM, which can simulate any amount of flow. As a consequence, the degree of variability in values of flux for these networks is much greater than would be expected if regional constraints were placed on the local-scale FCM. To address variability of volumetric flux through the Climax stock while adhering to regional flow constraints, 200 regional-scale flow realizations were generated for each CRFM (refer to Section 3.5). The distribution of flux values from the regional-scale realizations, where parametric uncertainty is addressed by using a covariance matrix for each of the 25 calibrated regional models (i.e., for a given parameter, its calibrated value is the mean and the deviation about the mean is described by its covariance), are thought to better reflect the variability in flow that is possible for the Climax stock. These regional-scale CRFM flux values are used in conjunction with flux values from the local-scale FCM to define $N$.

Values of flux for the regional-scale realizations were sorted and ranked to compute an empirical cumulative distribution function (CDF). Next, given an arbitrary value of $N$, an empirical CDF for the local-scale FCM flow weights, $L\left(\vec{F} \mid \vec{\theta}_{i}\right)$, is computed according to Equation (4.6). Flux values corresponding to the 95 -percent confidence intervals, 0.025 and 0.975 , are compared for both the regional-scale and local-scale models. The value of $N$ (which controls the distribution of weights for the local-scale model) is then changed until the difference in flux values corresponding to the lower and upper 95-percent confidence intervals is minimized. By following this procedure for all 25 CRFM, $N$ was found to range between 0.44 and 1.0. The mean (and median) of the distribution of $N$ is 0.69 . The use of this value for $N$ restricts the majority of probability weight to the realizations that best match the target flux value (Figure 4-12). 


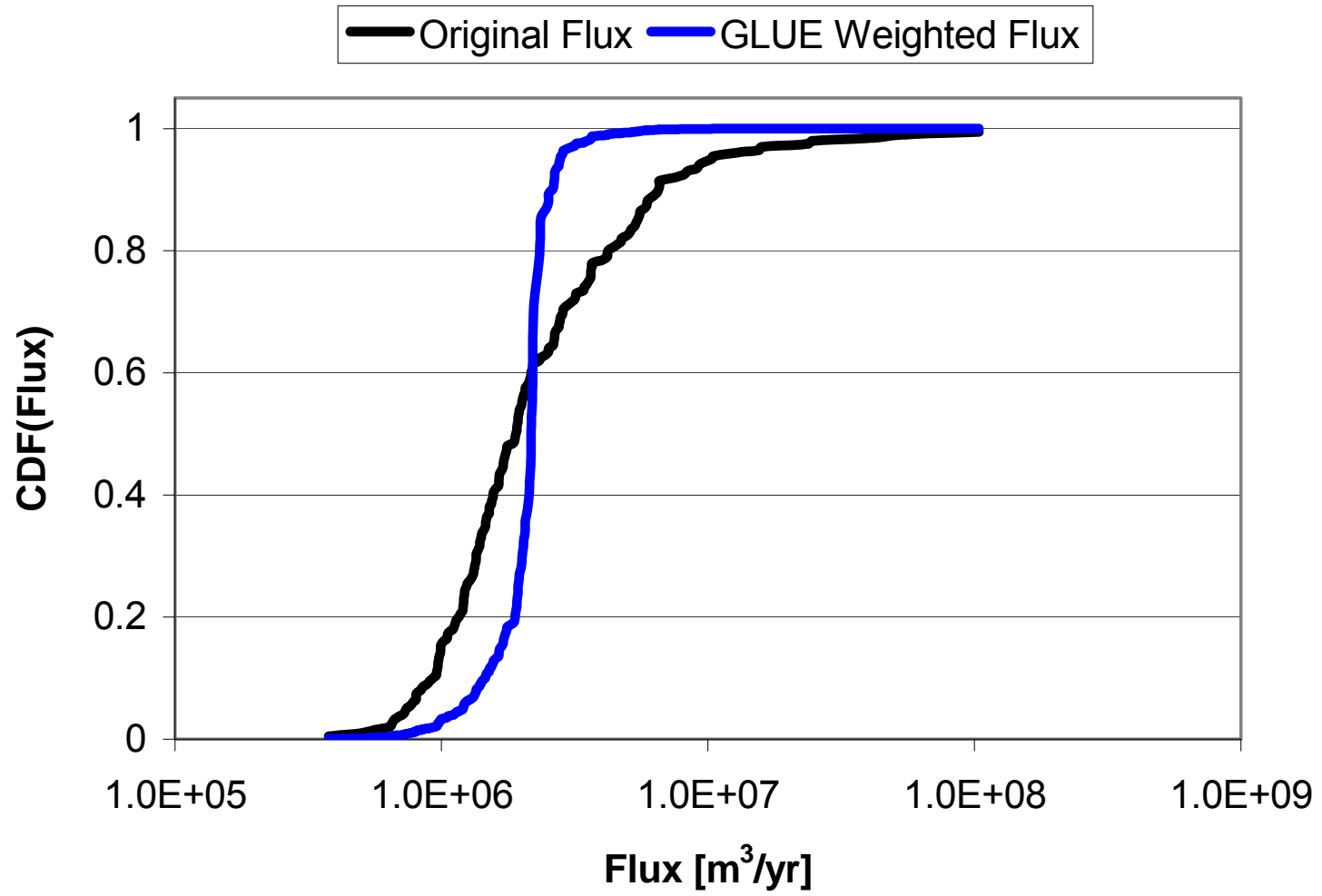

Figure 4-12. The distribution of model weights for FCM realizations based on the G1R2 boundary conditions and flux target before (black curve) and after (blue curve) the use of the GLUE methodology. A similar trend in GLUE weights was observed for all of the other realization subsets. Note that the GLUE weighting procedure preferentially weights realizations that more closely match the target flux value $(2.2 \mathrm{E}+06)$ based on $N$.

\subsubsection{Bayesian Model Averaging}

Final weights for each FCM flow realization are a combination of the flow weights assigned to each 200 realization FCM subset (refer to Section 4.3.6.1) and the model weight assigned to the CRFM (refer to Section 3.4.3.3) that provides the boundary conditions and target flux for the local-scale FCM. The final weights are then used to scale the simulated radionuclide flux estimates according to each flow realization and the CRFM model it represents. A maximum likelihood Bayesian model averaging method (BMA) is used to compute the final weights (Hoeting et al., 1999; Ye et al., 2004)

$$
E[\Delta \mid \boldsymbol{D}]=\sum_{k=1}^{25} E\left[\Delta \mid \boldsymbol{D}, \mu_{k}\right] p\left(\mu_{k} \boldsymbol{D}\right)
$$

where $\Delta$ is radionuclide mass flux, $\boldsymbol{D}$ is a discrete data set, $\mu$ is the geologic model with index $k$ and

$$
E\left[\Delta \mid \boldsymbol{D}, \mu_{k}\right]=\frac{1}{N} \sum_{i=1}^{200}\left[\Delta \mid \boldsymbol{D}, \theta_{i}\right] p\left(\theta_{i} \mid \boldsymbol{D}\right)
$$

where $\theta$ is a FCM realization with index $i$. By combining Equations (4.8) and (4.9), the final weights are described 


$$
E[\Delta \mid \boldsymbol{D}]=\frac{1}{N} \sum_{k=1}^{25} \sum_{i=1}^{200}\left[\Delta \mid \boldsymbol{D}, \mu_{k}, \theta_{i}\right] p\left(\mu_{k} \mid \boldsymbol{D}\right) p\left(\theta_{i} \mid \boldsymbol{D}\right)
$$

where the final weights $E[\Delta \mid \boldsymbol{D}]$ are a linear combination of the probability assigned to the CRFM models $p\left(\mu_{k} \mid \boldsymbol{D}\right)$ and the flow weights assigned to each FCM subset $p\left(\theta_{i} \mid \boldsymbol{D}\right)$. The application of the final weights to the radionuclide mass flux calculations is discussed in Section 5.3.2. 
THIS PAGE INTENTIONALLY LEFT BLANK 


\subsection{SIMULATION OF RADIONUCLIDE TRANSPORT IN THE CLIMAX STOCK}

The simulation of radionuclide transport in the Climax stock is based on a random walk particle code that tracks both conservative and nonconservative radionuclide particle trajectories through each of the 5,000 velocity field realizations produced from the localscale fracture continuum model. Advective velocity assigned to individual grid cells is computed from constant porosity values for rock matrix cells and variable porosity values for fracture cells. The porosity distribution for fracture cells is estimated from a tracer test conducted in granite at the Shoal site, where an empirical power-law relationship describes a correlation between fracture transmissivity and fracture cell porosity. Macrodispersion is caused by particle sampling of multiple fracture segments with varying length, orientation and velocity. The random walk allows for in-fracture local dispersion according to an anisotropic dispersion tensor. This allows particles to sample different streamlines and velocities present in individual fractures.

Radionuclides simulated in the transport model were produced by the Hard Hat, Pile Driver, and Tiny Tot tests, and the daughters created by radioactive decay. All radionuclides are assumed to be located in the saturated zone, consistent with the UGTA approach for tests in the vadose zone, initially in a circular region proportional in diameter to each test cavity. Radionuclides are distributed according to their volatility between an aqueous-sorbed fraction and nuclear melt glass fraction. The aqueous-sorbed fraction is assumed to migrate immediately after each nuclear test (subject to retardation processes), neglecting any time for vadose-zone transport. Nuclides within the melt glass are released according to glass dissolution rates, calculated based on test-specific conditions. With the exception of the temperature impact on glass dissolution, early-time cavity conditions and near-field properties affected by the nuclear tests are not considered in this analysis, because the projection of the radionuclides to the water table location renders inclusion of test effects problematic.

Once released into the groundwater system, the radionuclides are subject to retardation processes. Many of the radionuclides are retarded by reactions with aquifer materials. Retardation factors, estimated from sorption experiments with Climax granite and other granites found worldwide, are used in algorithms that simulate radionuclide particle retardation along fracture walls and matrix blocks. The diffusion of radionuclides in a fractured medium is described by a transition probability approach that simulates the movement of radionuclides between rock fractures and matrix blocks.

Radionuclides are grouped according to general sorption behavior and to melt-glass proportion into eight unique transport classes. Particle tracking simulations are conducted for each transport class using a specific range of values for sorption and the fraction of radionuclides in the melt glass state. Mass flux values for individual radionuclides leaving the Climax stock are computed during post-processing. The post-processing method used for Climax computes radionuclide mass flux estimates based on both weights assigned to each alternative regional model in Chapter 3 and GLUE weights assigned to individual realizations in Chapter 4. 


\subsection{Parameterization of Transport Model}

The migration of radionuclides from the three nuclear tests in Climax stock involves a complex system of physical and chemical processes, in addition to the groundwater flow aspects described previously. The abstraction of these processes into the numerical transport model is described in the following sections. The discussion is arranged according to four broad topics. First, the radionuclide source term is described. The contaminants under consideration are the radionuclides produced by the Hard Hat, Pile Driver and Tiny Tot tests, and the daughters created by radioactive decay. Different approaches for estimating the initial source mass values are explored, the apportioning of the mass into different phases (nuclear melt glass and the aqueous-sorbed portion) according to volatility is presented, and tritium data from Climax are discussed.

Second, the release of radionuclides into the groundwater flow system is quantified. Most, if not all, the nuclear tests in Climax occur above the water table. Consistency with the UGTA program requires projection of the tests to the saturated zone to avoid the complexity of radionuclide migration in the vadose zone. The method used to project the tests to the water table is presented. Radionuclides in the aqueous-sorbed fraction immediately begin transport in the saturated zone, but those present in the glass phase are only introduced as the nuclear glass dissolves. Development of the glass dissolution functions requires extensive explanation, beginning with calculating the rate, describing the implementation, and addressing the impact of temperature.

Once released, the radionuclides are subject to retardation processes. The selection of these parameters is discussed third. It begins with a description of the groundwater chemistry and mineralogy of the Climax stock, followed by presentation of sorption data from experiments with Climax rocks, and from data gathered from experiments with granites worldwide. Categories of sorption behavior are identified, followed by a discussion regarding matrix diffusion.

The fourth and final section regarding transport parameters describes the estimation of porosity, used to calculate particle velocity from the Darcy flux values.

\subsubsection{Radionuclide Source Term}

The unclassified radionuclide source term for the three Climax stock tests are derived wholly from Bowen et al. (2001). They report the total radionuclide inventory for five geographic testing locations at the NTS: Frenchman Flat, Pahute Mesa Area 19, Pahute Mesa Area 20, Rainier Mesa/Shoshone Mountain, and Yucca Flat. Tests conducted in the Climax stock are included in the Yucca Flat inventory. In the Yucca Flat case, Bowen et al. (2001) differentiate between tests conducted above and below the water table. The location of the water table relative to each test is determined based on the designation reported in Pickus (1997), where all tests with work points within $100 \mathrm{~m}$ of the water table or deeper were considered "below the water table."

The source term for unclassified Climax stock calculations can be determined either by simple averaging, or by scaling, the Bowen et al. (2001) values. An average source inventory is determined by dividing the total source term at the particular testing location by the total number of tests conducted in that particular testing location. Hard Hat and Pile Driver tests were included in the Yucca Flat, below the water table, source term (170 total 
tests, including any unsaturated zone tests within $100 \mathrm{~m}$ of the water tables, such as Hard Hat). Tiny Tot was included in the Yucca Flat, above the water table, source term (577 total tests). A scaled inventory considers the total unclassified, announced yield of all Yucca Flat inventory tests, then apportions the inventory based on the percentage of total yield represented by the announced yield of an individual test. Some tests only have announced yield ranges or qualifiers (e.g., a yield announced as less than a value), introducing imprecision to the approach, but scaling results in a logical larger inventory being assigned to larger tests that is missing from a simple average. Both Hard Hat and Pile Driver have announced yields (Table 2-4). The upper end of the Tiny Tot announced yield $(<20 \mathrm{kt}$, Table 2-4) is used here for scaling.

The data in Bowen et al. (2001) are decay corrected to September 23, 1992. To arrive at a mass balance as a function of time, the unclassified source term for each test must be decay corrected to the time zero of the particular test. The resulting radiologic source term (RST) inventory for the three tests is given in Table 5-1, with both the averaged inventory and yield-scaled inventory presented. Bowen et al. (2001) report the inventory of 43 radionuclides. For ${ }^{40} \mathrm{~K},{ }^{232} \mathrm{Th},{ }^{234} \mathrm{U},{ }^{235} \mathrm{U}$, and ${ }^{238} \mathrm{U}$, a significant fraction of the inventory is natural background radioactivity. Calculations regarding the contribution of natural radioactivity to the source term were based on a glass production rate of 700 metric tons $/ \mathrm{kt}$ yield and $\mathrm{K}$, Th, and $\mathrm{U}$ concentrations of 4 percent, $22 \mathrm{ppm}$, and $3.7 \mathrm{ppm}$ by weight, respectively (Bowen et al., 2001). For transport modeling, ${ }^{40} \mathrm{~K}$ and ${ }^{232} \mathrm{Th}$ can be ignored because their inventory is either wholly or overwhelmingly of a natural background nature. All $U$ isotopes were included because natural versus test-derived fractions could not be separated.

Table 5-1. Estimated radionuclide inventories, in moles, decay corrected to $t_{0}$ for three tests conducted in the Climax stock. Two approaches are presented: values derived by averaging the source term presented in Bowen et al. (2001), and values scaled by relative yield.

\begin{tabular}{|c|c|c|c|c|c|c|c|}
\hline \multirow[t]{2}{*}{ Radionuclide } & \multirow{2}{*}{$\begin{array}{l}\text { Half Life } \\
\quad(y r)\end{array}$} & \multicolumn{2}{|c|}{ Tiny Tot $6 / 17 / 1965$} & \multicolumn{2}{|c|}{ Hard Hat 2/15/1962 } & \multicolumn{2}{|c|}{ Pile Driver 6/2/1966 } \\
\hline & & $\begin{array}{l}\text { averaged } \\
\text { (mole) }\end{array}$ & $\begin{array}{l}\text { yield-scaled } \\
\text { (mole) }\end{array}$ & $\begin{array}{l}\text { averaged } \\
\text { (mole) }\end{array}$ & $\begin{array}{l}\text { yield-scaled } \\
\text { (mole) }\end{array}$ & $\begin{array}{c}\text { averaged } \\
\text { (mole) }\end{array}$ & $\begin{array}{c}\text { yield-scaled } \\
\text { (mole) }\end{array}$ \\
\hline${ }^{3} \mathrm{H}$ & $1.23 \mathrm{E}+01$ & 4.08 & 2.98 & 37.6 & 1.57 & 29.5 & 13.4 \\
\hline${ }^{14} \mathrm{C}$ & $5.72 \mathrm{E}+03$ & 0.0316 & 0.0230 & 0.0792 & 0.0033 & 0.0791 & 0.0358 \\
\hline${ }^{26} \mathrm{Al}^{1}$ & $7.10 \mathrm{E}+05$ & 0.000192 & 0.000140 & 0.00042 & 0.00002 & 0.00042 & 0.00019 \\
\hline${ }^{36} \mathrm{Cl}$ & $3.01 \mathrm{E}+05$ & 0.17 & 0.12 & 1.14 & 0.05 & 1.14 & 0.52 \\
\hline${ }^{39} \mathrm{Ar}^{3}$ & $2.69 \mathrm{E}+02$ & 0.000448 & 0.000327 & 0.00457 & 0.00019 & 0.00452 & 0.00205 \\
\hline${ }^{40} \mathrm{~K}^{2}$ & $1.27 \mathrm{E}+09$ & 506 & 369 & 5060 & 211 & 5060 & 2292 \\
\hline${ }^{41} \mathrm{Ca}$ & $1.03 \mathrm{E}+05$ & 0.427 & 0.311 & 2.82 & 0.12 & 2.82 & 1.28 \\
\hline${ }^{59} \mathrm{Ni}$ & $7.60 \mathrm{E}+04$ & 0.00788 & 0.00575 & 0.0533 & 0.0022 & 0.0533 & 0.0242 \\
\hline${ }^{63} \mathrm{Ni}$ & $1.00 \mathrm{E}+02$ & 0.00137 & 0.00100 & 0.0106 & 0.0004 & 0.0103 & 0.0047 \\
\hline${ }^{85} \mathrm{Kr}$ & $1.08 \mathrm{E}+01$ & 0.00343 & 0.00249 & 0.0738 & 0.0031 & 0.056 & 0.025 \\
\hline${ }^{90} \mathrm{Sr}$ & $2.88 \mathrm{E}+01$ & 0.0403 & 0.0294 & 0.74 & 0.03 & 0.667 & 0.302 \\
\hline${ }^{93} \mathrm{Zr}$ & $1.50 \mathrm{E}+06$ & 0.0498 & 0.0363 & 0.643 & 0.027 & 0.643 & 0.291 \\
\hline${ }^{93 \mathrm{~m}} \mathrm{Nb}$ & $1.61 \mathrm{E}+01$ & 0.000158 & 0.000115 & 0.00666 & 0.00028 & 0.00553 & 0.00251 \\
\hline${ }^{94} \mathrm{Nb}^{3}$ & $2.00 \mathrm{E}+04$ & 0.00223 & 0.00162 & 0.065 & 0.003 & 0.065 & 0.029 \\
\hline${ }^{99} \mathrm{Tc}$ & $2.13 \mathrm{E}+05$ & 0.0635 & 0.0463387 & 0.657 & 0.027 & 0.657 & 0.298 \\
\hline${ }^{107} \mathrm{Pd}$ & $6.50 \mathrm{E}+06$ & 0.0241 & 0.0175 & 0.0987 & 0.0041 & 0.0987 & 0.0447 \\
\hline${ }^{113} \mathrm{Cd}^{1}$ & $1.41 \mathrm{E}+01$ & 0.0000409 & 0.0000298 & 0.000522 & 0.000022 & 0.000422 & 0.000191 \\
\hline${ }^{121} \mathrm{Sn}$ & $5.50 \mathrm{E}+01$ & 0.000253 & 0.000185 & 0.00255 & 0.00011 & 0.00242 & 0.00110 \\
\hline${ }^{126} \mathrm{Sn}$ & $2.50 \mathrm{E}+05$ & 0.00412 & 0.00301 & 0.0377 & 0.0016 & 0.0377 & 0.0171 \\
\hline${ }^{129} \mathrm{I}$ & $1.57 \mathrm{E}+07$ & 0.0158 & 0.0115 & 0.14 & 0.01 & 0.14 & 0.06 \\
\hline${ }^{135} \mathrm{Cs}$ & $2.30 \mathrm{E}+06$ & 0.0772 & 0.0563 & 0.746 & 0.031 & 0.746 & 0.338 \\
\hline${ }^{137} \mathrm{Cs}$ & $3.01 \mathrm{E}+01$ & 0.0798 & 0.0581 & 0.932 & 0.039 & 0.844 & 0.382 \\
\hline
\end{tabular}


Table 5-1. Estimated radionuclide inventories, in moles, decay corrected to $t_{0}$ for three tests conducted in the Climax stock. Two approaches are presented: values derived by averaging the source term presented in Bowen et al. (2001), and values scaled by relative yield.

\begin{tabular}{|c|c|c|c|c|c|c|c|}
\hline \multirow[t]{2}{*}{ Radionuclide } & \multirow{2}{*}{$\begin{array}{l}\text { Half Life } \\
\quad(y r)\end{array}$} & \multicolumn{2}{|c|}{ Tiny Tot 6/17/1965 } & \multicolumn{2}{|c|}{ Hard Hat 2/15/1962 } & \multicolumn{2}{|c|}{ Pile Driver 6/2/1966 } \\
\hline & & $\begin{array}{l}\text { averaged } \\
\text { (mole) }\end{array}$ & $\begin{array}{c}\text { yield-scaled } \\
\text { (mole) }\end{array}$ & $\begin{array}{l}\text { averaged } \\
\text { (mole) }\end{array}$ & $\begin{array}{c}\text { yield-scaled } \\
(\text { mole })\end{array}$ & $\begin{array}{c}\text { averaged } \\
\text { (mole) }\end{array}$ & $\begin{array}{c}\text { yield-scaled } \\
\text { (mole) }\end{array}$ \\
\hline${ }^{151} \mathrm{Sm}$ & $9.00 \mathrm{E}+01$ & 0.00747 & 0.00545 & 0.0598 & 0.0025 & 0.0578 & 0.0262 \\
\hline${ }^{150} \mathrm{Eu}^{3}$ & $3.60 \mathrm{E}+01$ & 0.00399 & 0.00291 & 0.000117 & 0.000005 & 0.000108 & 0.000049 \\
\hline${ }^{152} \mathrm{Eu}$ & $1.35 \mathrm{E}+01$ & 0.00963 & 0.00705 & 0.0756 & 0.0032 & 0.0607 & 0.0276 \\
\hline${ }^{154} \mathrm{Eu}$ & $8.59 \mathrm{E}+00$ & 0.0112 & 0.0081 & 0.0915 & 0.0038 & 0.0647 & 0.0293 \\
\hline${ }^{166} \mathrm{Ho}^{3}$ & $1.20 \mathrm{E}+03$ & 0.000157 & 0.000115 & 0.00111 & 0.00005 & 0.00111 & 0.00050 \\
\hline${ }^{232} \mathrm{Th}^{2}$ & $1.40 \mathrm{E}+10$ & 405 & 295 & 4,040 & 168 & 4,040 & 1,828 \\
\hline${ }^{232} \mathrm{U}^{3}$ & $6.98 \mathrm{E}+01$ & 0.00004 & 0.00003 & 0.000574 & 0.000024 & 0.00055 & 0.00025 \\
\hline${ }^{233} \mathrm{U}$ & $1.59 \mathrm{E}+05$ & 0.0928 & 0.0676 & 0.4 & 0.02 & 0.4 & 0.2 \\
\hline${ }^{234} \mathrm{U}^{3}$ & $2.46 \mathrm{E}+05$ & 0.197 & 0.143 & 1.14 & 0.05 & 1.14 & 0.52 \\
\hline${ }^{235} \mathrm{U}^{3}$ & $7.04 \mathrm{E}+08$ & 8.73 & 6.36 & 37.3 & 1.6 & 37.3 & 16.9 \\
\hline${ }^{236} \mathrm{U}$ & $2.34 \mathrm{E}+07$ & 0.104 & 0.076 & 1.33 & 0.06 & 1.33 & 0.60 \\
\hline${ }^{238} \mathrm{U}^{3}$ & $4.47 \mathrm{E}+09$ & 188 & 137 & 1,160 & 48 & 1,160 & 523 \\
\hline${ }^{237} \mathrm{~Np}$ & $2.14 \mathrm{E}+06$ & 0.0108 & 0.0074 & 0.377 & 0.016 & 0.377 & 0.170 \\
\hline${ }^{238} \mathrm{Pu}$ & $8.77 \mathrm{E}+01$ & 0.00936 & 0.00682 & 0.0205 & 0.0009 & 0.0198 & 0.0090 \\
\hline${ }^{239} \mathrm{Pu}$ & $2.41 \mathrm{E}+04$ & 11.7 & 8.5 & 10.9 & 0.5 & 10.9 & 4.9 \\
\hline${ }^{240} \mathrm{Pu}$ & $6.56 \mathrm{E}+03$ & 0.808 & 0.589 & 0.763 & 0.032 & 0.763 & 0.345 \\
\hline${ }^{241} \mathrm{Pu}$ & $1.44 \mathrm{E}+01$ & 0.0886 & 0.0646 & 0.107 & 0.004 & 0.0869 & 0.0394 \\
\hline${ }^{242} \mathrm{Pu}$ & $3.75 E+05$ & 0.0136 & 0.0099 & 0.0285 & 0.0012 & 0.0285 & 0.0129 \\
\hline${ }^{241} \mathrm{Am}$ & $4.33 \mathrm{E}+02$ & $-0.01533^{*}$ & $-0.01114^{*}$ & $-0.03843^{*}$ & $-0.00160^{*}$ & $-0.01833^{*}$ & $-0.00828^{*}$ \\
\hline${ }^{243} \mathrm{Am}^{1}$ & $7.37 \mathrm{E}+03$ & 0.0000961 & 0.0000701 & 0.000415 & 0.000017 & 0.000415 & 0.000188 \\
\hline${ }^{244} \mathrm{Cm}^{3}$ & $1.81 \mathrm{E}+01$ & 0.000395 & 0.000288 & 0.00241 & 0.00010 & 0.00204 & 0.00093 \\
\hline
\end{tabular}

${ }^{1}$ Ignored in transport model because it is less than 0.1 percent of the inventory both in terms of moles and curies within the group of radionuclides that decay in a similar fashion $(\alpha, \beta$, or ec/it).

${ }^{2}$ Ignored because it is dominated by natural background radioactivity from melted rock (included in value).

${ }^{3}$ Partitioning behavior not reported in IAEA (1998) but estimated from partitioning of analog radionuclides.

${ }^{*}$ Ingrowth from ${ }^{241} \mathrm{Pu}$ is greater than the source term at September 23, 1992, resulting in a decay-corrected negative source term at $t_{0}$. For modeling purposes, an initial source term of $0 \mathrm{~mol}$ is used.

For all three tests, the initial inventory of ${ }^{241} \mathrm{Am}$ at $\mathrm{t}_{0}$ is less than zero. This occurs because ${ }^{241} \mathrm{Am}$ is part of the following decay and ingrowth chain

$$
{ }^{241} \mathrm{Pu} \stackrel{\mathrm{T}_{1 / 2}=14.4 \mathrm{yr}}{\longrightarrow}{ }^{241} \mathrm{Am} \stackrel{\mathrm{T}_{1 / 2}=433 \mathrm{yr}}{\longrightarrow}{ }^{237} \mathrm{~Np} \stackrel{T_{1 / 2}=2140000 \mathrm{yr}}{\longrightarrow} \cdots
$$

and ${ }^{241} \mathrm{Pu}$ is sufficiently abundant that its decay from $\mathrm{t}_{0}$ to September 23,1992 , yields more ${ }^{241} \mathrm{Am}$ than is present in the average inventory. The effect indicates that average inventories for each testing location described in Bowen et al. (2001) may be a good estimate of the total radiologic inventory at that location but are not comparable to classified inventories of individual tests. For modeling purposes, any test with a negative ${ }^{241} \mathrm{Am}$ source term will be modeled with an initial ${ }^{241} \mathrm{Am}$ source term of 0 mol.

The radiologic source term is typically separated into two fractions: the exchange volume and the nuclear melt glass volume (Tompson et al., 1999, 2004, 2005; Pawloski et al., 2001; SNJV, 2004, 2005a). Spatially, the exchange volume is typically visualized as a spherical volume centered about the working point. The glass volume includes the volume of solid glass that is pooled at the bottom of the nuclear test cavity (Figure 5-1). While this conceptual model does not accurately represent the complex and heterogeneous initial distribution of radionuclides, other processes and features, such as prompt injection, melt glass seams, preferential migration up the chimney, etc., are assumed here to be of second order importance from a transport modeling perspective. 


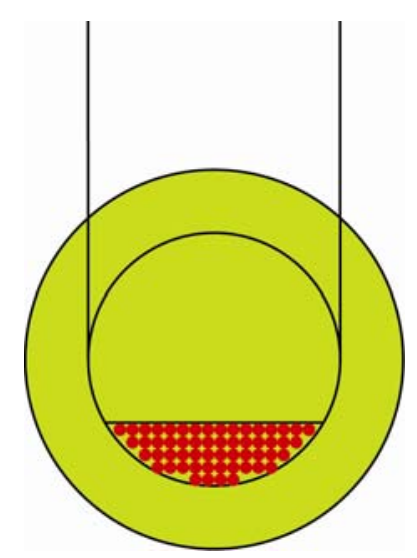

Figure 5-1. The two fractions of the radiologic source term: exchange volume (green) and glass volume (red).

Radionuclides associated with nuclear melt glass are initially isolated from groundwater, even within the saturated zone. They may be released into groundwater only as a result of nuclear melt glass dissolution. Radionuclides associated with the exchange portion represent the aqueous-sorbed fraction of the radiologic source term, which is not associated with nuclear melt glass. These radionuclides are accessible to groundwater but may be subject to retardation as a result of surface complexation, ion exchange, or precipitation reactions. The initial distribution of radionuclides in both the nuclear melt glass and the aqueous-sorbed portion for all three tests conducted in the Climax stock is discussed in the following sections.

\subsubsection{Radionuclide Distribution between the Melt Glass and Aqueous-sorbed Portion}

The radionuclide inventory is not uniformly distributed in the nuclear cavity and chimney. Rather, radionuclides are present as gases, liquids, and in two solid forms as part of the nuclear melt glass or mixed with rubble. The partitioning ratios between these phases for each radionuclide, established by the International Atomic Energy Agency (IAEA) (1998), are presented in Table 5-2. The IAEA (1998) recommend a partitioning into glass of 98 percent for $\mathrm{Pu}$ and $\mathrm{Am}$ in Volume 3 of their report, though 95 percent is used in the calculations presented in Volume 4. The more conservative value of 95 percent is used here. Partitioning of ${ }^{26} \mathrm{Al},{ }^{39} \mathrm{Ar},{ }^{40} \mathrm{~K},{ }^{94} \mathrm{Nb},{ }^{150} \mathrm{Eu},{ }^{166} \mathrm{Ho},{ }^{232} \mathrm{Th},{ }^{232} \mathrm{U},{ }^{234} \mathrm{U},{ }^{235} \mathrm{U},{ }^{238} \mathrm{U},{ }^{243} \mathrm{Am}$, and ${ }^{244} \mathrm{Cm}$ was not listed in the IAEA (1998). Potassium-40 and ${ }^{232} \mathrm{Th}$ partitioning is not relevant since the source of these two radionuclides is predominantly natural background, and can be ignored in the transport model. The partitioning of ${ }^{26} \mathrm{Al}$ can be ignored because its inventory is very small both in terms of moles and curies $(<0.1 \%$ of the total produced by the tests). ${ }^{243} \mathrm{Am}$ and ${ }^{113} \mathrm{Cd}$ can be ignored in transport modeling for the same reason. Argon-39 is assumed to partition similar to ${ }^{85} \mathrm{Kr},{ }^{94} \mathrm{Nb}$ is assumed to partition similar to ${ }^{93 \mathrm{~m}} \mathrm{Nb},{ }^{150} \mathrm{Eu}$ and ${ }^{166} \mathrm{Ho}$ are assumed to partition similar to ${ }^{152} \mathrm{Eu}$, all $\mathrm{U}$ isotopes are assumed to partition similar to ${ }^{233} \mathrm{U}$ and ${ }^{236} \mathrm{U}$, and ${ }^{244} \mathrm{Cm}$ is assumed to partition similar to ${ }^{241} \mathrm{Am}$.

There are data specific to Pile Driver for partitioning Cs and $\mathrm{Sr}$ in the nuclear melt glass. Borg (1975) reports that "a large fraction $(>60 \%)$ of the long-lived radionuclides inventoried reside in the glasses studied," including ${ }^{137} \mathrm{Cs}$ and ${ }^{90} \mathrm{Sr}$ (in this context, long-lived is thatwith a half-life more than a few months). Borg explains that deeply buried contained tests in competent rock will tend to have higher proportions of volatiles in glass, and 
substantiates this with data from the French Sahara tests in granite. The French reported 40 to 80 percent of ${ }^{90} \mathrm{Sr}$ in glass and 20 percent of ${ }^{137} \mathrm{Cs}$ in glass. Though the IAEA report 20 percent for ${ }^{134,135} \mathrm{Cs}$ in glass, for ${ }^{137} \mathrm{Cs}$ they assign 25 percent for one island and 40 percent for the other. Despite the Climax-specific information supporting larger portions in the melt glass, the lower (and more conservative values) of 20 percent for Cs and 40 percent for Sr are used here to be consistent with other UGTA transport models.

Borg (1975) reports $1.53 \mathrm{~g}$ of tritium is in the form of bound water (HTO) dissolved in the Pile Driver melt. This amounts to about $14,800 \mathrm{Ci}$, so is either 1.7 or 3.8 percent of the total initial tritium (depending whether the averaged or scaled source term is considered). Again, to be consistent with other UGTA models, the tritium observed in the melt glass is neglected here and all tritium is assumed present in the exchange volume.

In the interest of computational efficiency, radionuclides can be grouped into classes representing unique combinations of glass partitioning and retardation behavior (retardation processes and parameters are discussed in later sections). Transport modeling is performed for the class as a whole using a unit mass. Post-processing scales the results to the mass of the individual radionuclides within the class, and accounts for radioactive decay. To limit the number of classes, five radionuclides are assigned different glass partitioning than suggested by the IAEA. In all cases, the glass partitioning used for the Climax model is less than that of the IAEA, thus assigning a larger portion to the readily released rubble fraction. Specifically, ${ }^{41} \mathrm{Ca}$ is placed in a group of 40 percent glass rather than 70 percent, ${ }^{107} \mathrm{Pd},{ }^{121} \mathrm{Sn}$, and ${ }^{126} \mathrm{Sn}$ are placed in the 20 percent glass rather than 60 and 70 percent groups, and ${ }^{237} \mathrm{~Np}$ is modeled as 90 percent rather than 95 percent glass (Table 5-2). The radionuclide classes and modeled partitioning are summarized in Table 5-3.

Table 5-2. Partitioning of radionuclides between phases, as determined by the IAEA (1998). For the Climax nuclear tests, the portions in rubble, gas, and water are combined into the aqueous-sorbed portion readily accessible to groundwater.

\begin{tabular}{cccccc}
\hline Radionuclide & glass & glass* & $\begin{array}{c}\text { Partitioning, percent } \\
\text { rubble }\end{array}$ & gas & water \\
\hline${ }^{3} \mathrm{H}$ & 0 & & 0 & 2 & 98 \\
${ }^{14} \mathrm{C}$ & 0 & 10 & 80 & 10 \\
${ }^{26} \mathrm{Al}$ & & & & \\
${ }^{36} \mathrm{Cl}$ & 50 & 40 & 0 & 10 \\
${ }^{39}{ }^{39}$ & 0 & 10 & 80 & 10 \\
${ }^{40} \mathrm{~K}$ & & & & \\
${ }^{41} \mathrm{Ca}$ & 70 & 40 & 30 & 0 & 0 \\
${ }^{59} \mathrm{Ni}$ & 95 & & 5 & 0 & 0 \\
${ }^{63} \mathrm{Ni}$ & 95 & 5 & 0 & 0 \\
${ }^{85} \mathrm{Kr}$ & 0 & & 10 & 80 & 10 \\
${ }^{90} \mathrm{Sr}$ & 40 & & 60 & 0 & 0 \\
${ }^{93} \mathrm{Zr}$ & 95 & 5 & 0 & 0 \\
${ }^{93 \mathrm{~m}} \mathrm{Nb}$ & 95 & & 5 & 0 & 0 \\
${ }^{94} \mathrm{Nb}$ & 95 & & 0 & 0 \\
${ }^{99} \mathrm{Tc}$ & 80 & & 30 & 0 & 0 \\
${ }^{107} \mathrm{Pd}$ & 70 & 20 & 30 & 0 & 0 \\
${ }^{113} \mathrm{Cd}$ & 70 & & 40 & 0 & 0 \\
${ }^{121} \mathrm{Sn}$ & 60 & 20 & & 0 & 0 \\
\hline
\end{tabular}


Table 5-2. Partitioning of radionuclides between phases, as determined by the IAEA (1998). For the Climax nuclear tests, the portions in rubble, gas, and water are combined into the aqueous-sorbed portion readily accessible to groundwater (continued).

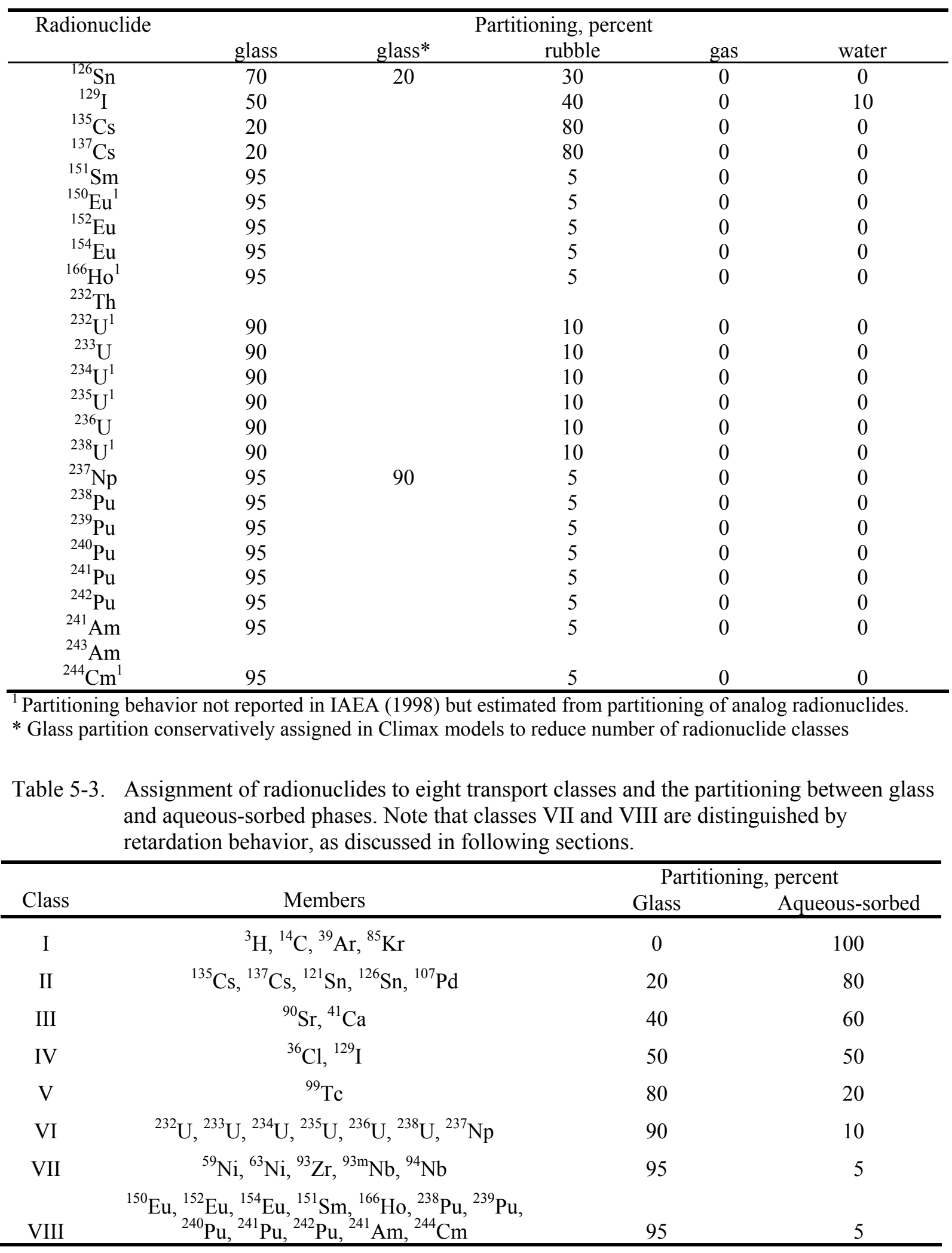




\subsubsection{Spatial Distribution of Radionuclides}

Presently, transport modeling of underground nuclear tests located in the vadose zone at the NTS is conducted using a conservative, though not physically based, modeling protocol. As a conservative measure (with respect to downstream migration of radionuclides), it has been assumed that the radiologic source term from unsaturated underground nuclear tests would be projected to the regional water table. There is little to no information on the regional water table located within the Climax stock. However, two of the three subsurface tests, Hard Hat and Tiny Tot, are above the simulated water table of the DVRFM (Figure 5-2, Table 2-4). The underground drifts constructed for Hard Hat were observed to be almost devoid of groundwater with the exception of isolated seeps (Walker, 1962). Though the same has been noted for Pile Driver (Murray, 1981), others report that the water table was encountered at an elevation of $1372 \mathrm{~m}$ in the Pile Driver shaft and the underground workings encountered a saturated shear zone that gave rise to substantial flow (Borg, 1970).

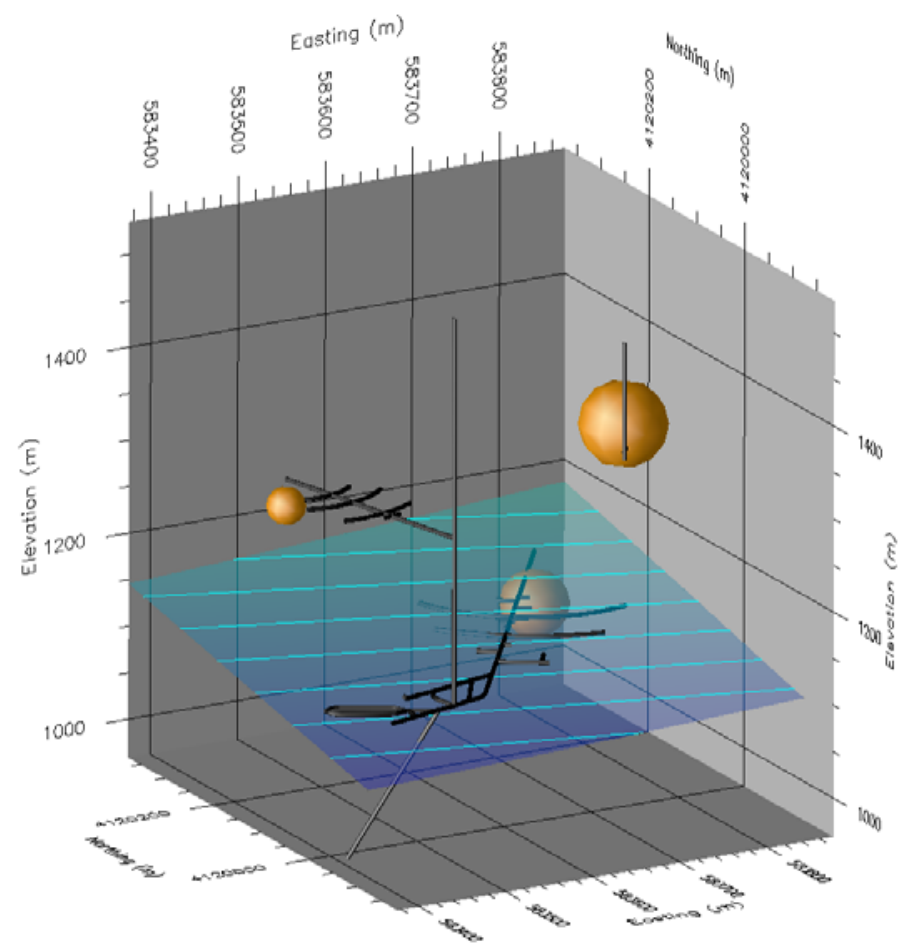

Figure 5-2. Locations of the three underground tests (spheres) in relation to the DVRFM-simulated water table. The tests from top to bottom are Tiny Tot, Hard Hat, and Pile Driver.

With the large degree of uncertainty regarding the elevation of the water table relative to the three underground tests, spherical damage zones are not incorporated into the flow model. Instead, permeability disks, defined as two-dimensional radial features with unique values of hydraulic conductivity, are incorporated into the fracture continuum permeability fields (Figure 5-3). The permeability disks function as a location of higher hydraulic conductivity $\left(10^{-8} \mathrm{~m} / \mathrm{s}\right)$ for the introduction of radionuclide source terms into the resultant velocity fields. The porosity of the permeability disks $(0.20)$ is representative of high-porosity rubble material. 
The radius of each permeability disk is a function of the extent of the shock fracturing, measured as cavity radii (Table 2-4). Typically, exchange volume radii of underground tests below the water table are larger than the cavity radius. At the Pile Driver test, radioactivity was observed $91.4 \mathrm{~m}$ from the working point, while the cavity radius was $40.2 \mathrm{~m}$ (Raab, 1969). Some of this was likely associated with thin glass seams injected into fractures (Borg, 1975). Nevertheless, this suggests an exchange volume radius as large as 2.3 cavity radii. At the Hard Hat test, post-test drilling into the chimney and cavity indicated that radiation levels $20.4 \mathrm{~m}$ above the working point and in the chimney were below detection 11 months after the test. However, some radioactivity was observed as much as 1.2 cavity radii from the test in a drill hole slant-drilled from the access tunnel. The limited data from Pile Driver and Hard Hat suggests that the exchange volume radius can vary widely. SNJV (2004) suggest a range of exchange volume from 1.3 to 2 cavity radii with a mean radius of 1.5. Based on the estimate of shock fracturing (including intense fracturing and microfracturing), the permeability disk radii are 55.7, 73.6, and $120.1 \mathrm{~m}$ for Hard Hat, Tiny Tot, and Pile Driver, respectively.

The elevation of the permeability disks for the Hard Hat and Tiny Tot tests is based on a downward projection to the water table of the local-scale FCM. The water table for the FCM model is based on the simulated water table from the DVRFM. The Pile Driver test is located below the DVRFM simulated water table. The elevation of this test $(1,088 \mathrm{~m})$ is used as the elevation of the permeability disk.

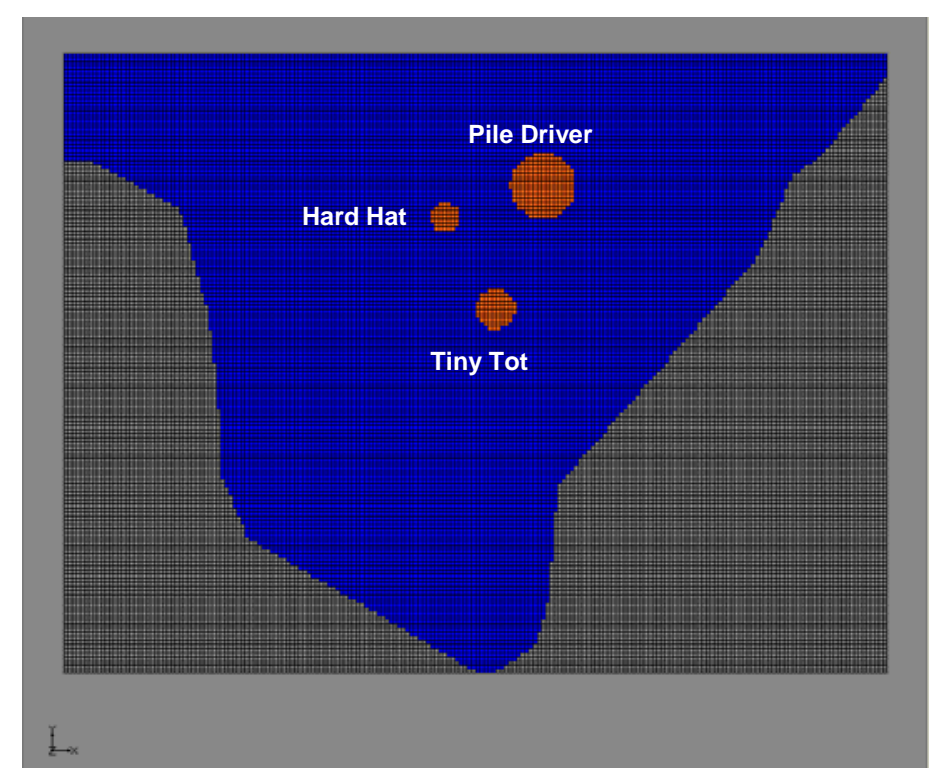

Figure 5-3. Map view of Climax local-scale fracture continuum domain showing permeability disks (red) within active cells of the model domain (blue). Cell size is $15 \mathrm{~m}$ by $15 \mathrm{~m}$.

\subsubsection{Tritium Observations}

Observations of tritium distribution in the Climax stock provide important information with regard to tracer transport in the near field. Figure 5-4 is a plot of the measured tritium concentrations relative to the locations of the Hard Hat and Pile Driver tests. The location of the pre-test tunnel complex and SFT drift is also included. Samples in 
the tunnel complex were analyzed for tritium in 1981 and 1982 (Isherwood et al., 1982). The tritium concentration in the Pile Driver cavity was estimated from tritium concentrations in water trapped in nuclear melt glass measured by Borg (1975). Importantly, these data suggest that (1) a significant quantity of tritium escaped well beyond the exchange volume of the two tests, (2) the observed concentrations outside the exchange volume are significantly lower than those observed in the cavity glass pore water, and (3) tritium has migrated down to the regional groundwater and contaminated it well above the drinking water standards $(20,000$ $\mathrm{pCi} / \mathrm{L})$. It indicates that tests conducted above the water table may still provide a significant radiologic source term below the regional groundwater table.

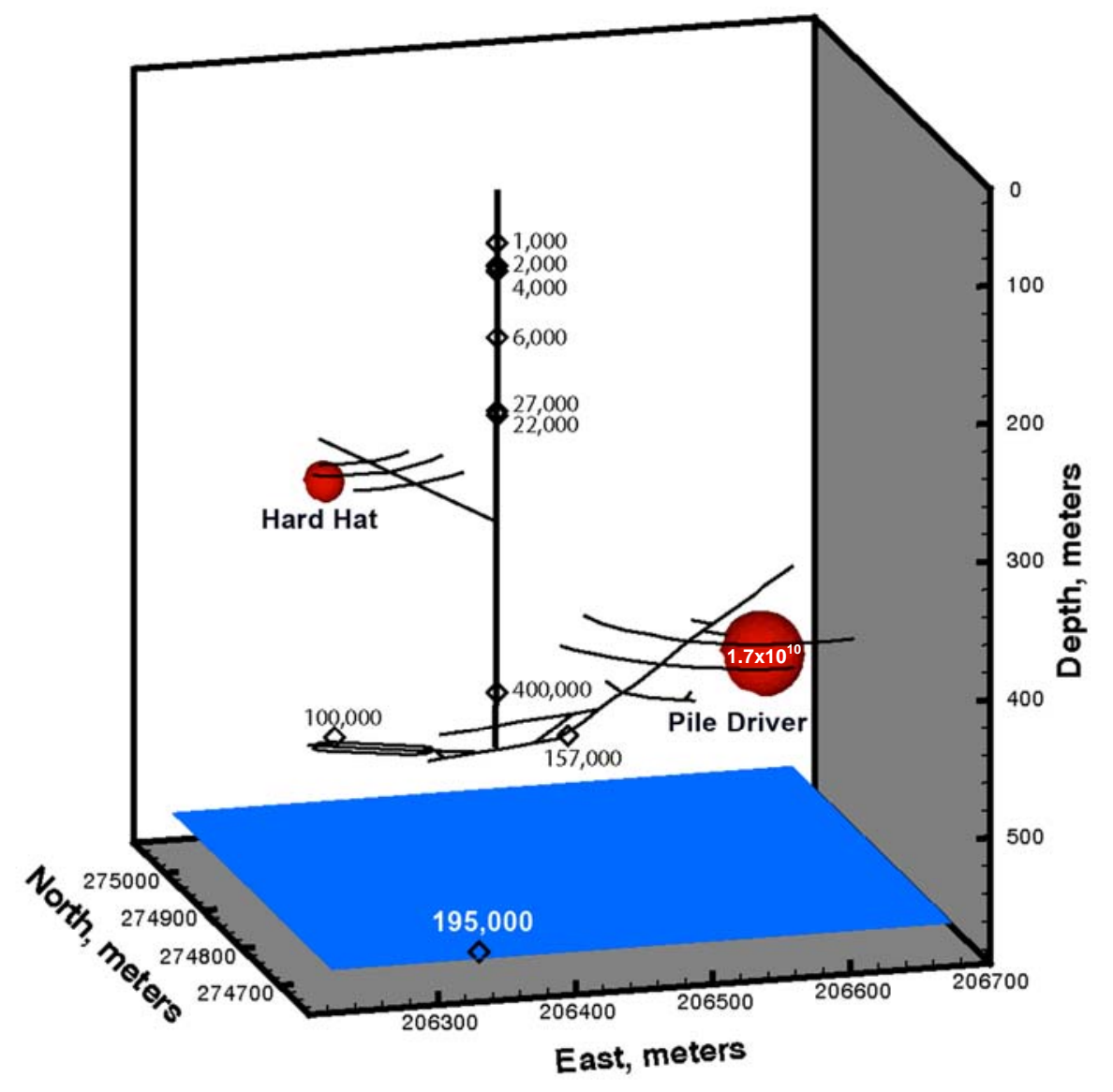

Figure 5-4. Distribution of tritium (pCi/L) in waters located near the Hard Hat (left) and Pile Driver (right) tests (red). Regional water table identified in blue. Pre-test shafts and tunnels are identified along with the Spent Fuel Test drifts.

In their original evaluation of tritium data, Isherwood et al. (1982) suggested that tritium observed in the shafts and tunnels were likely deposited as a result of the Pile Driver test and soon after the detonation. They did not elaborate on how they reached this conclusion. While it may be true that observed tritium concentrations were the result of the Pile Driver test, the potential role of the Hard Hat test should not be ignored. Since all samples but one were derived from seeps located in the shafts and tunnels, and the highest tritium concentrations were found in vertical fractures, it should be expected that the 
migration of the tritium should have a significant vertical component. In Figure 5-5, tritium sampling locations are plotted in plan view. In addition, major fractures located near each of the two tests and at the two SFT tunnel sampling locations are identified. The Hard Hat test is laterally closer to the locations of measured tritium. It is also at a higher elevation than the areas where high tritium concentrations were measured. The Pile Driver test is at an elevation well below all tritium measurement locations except the sample located at the water table. Importantly, Wilder (1987) indicated that significant seepage appears to occur only near fault and shear zones, but not in joints. Based on the location of the seepage points and direction of prominent shear and fault zones, it is not altogether clear whether Pile Driver is the source of the tritium found in the Climax stock tunnels. The Hard Hat test seems to be as likely a source. The existence of tritium well away from the cavities may also be related to the unsaturated conditions, allowing the potential for gas phase transport of tritium.

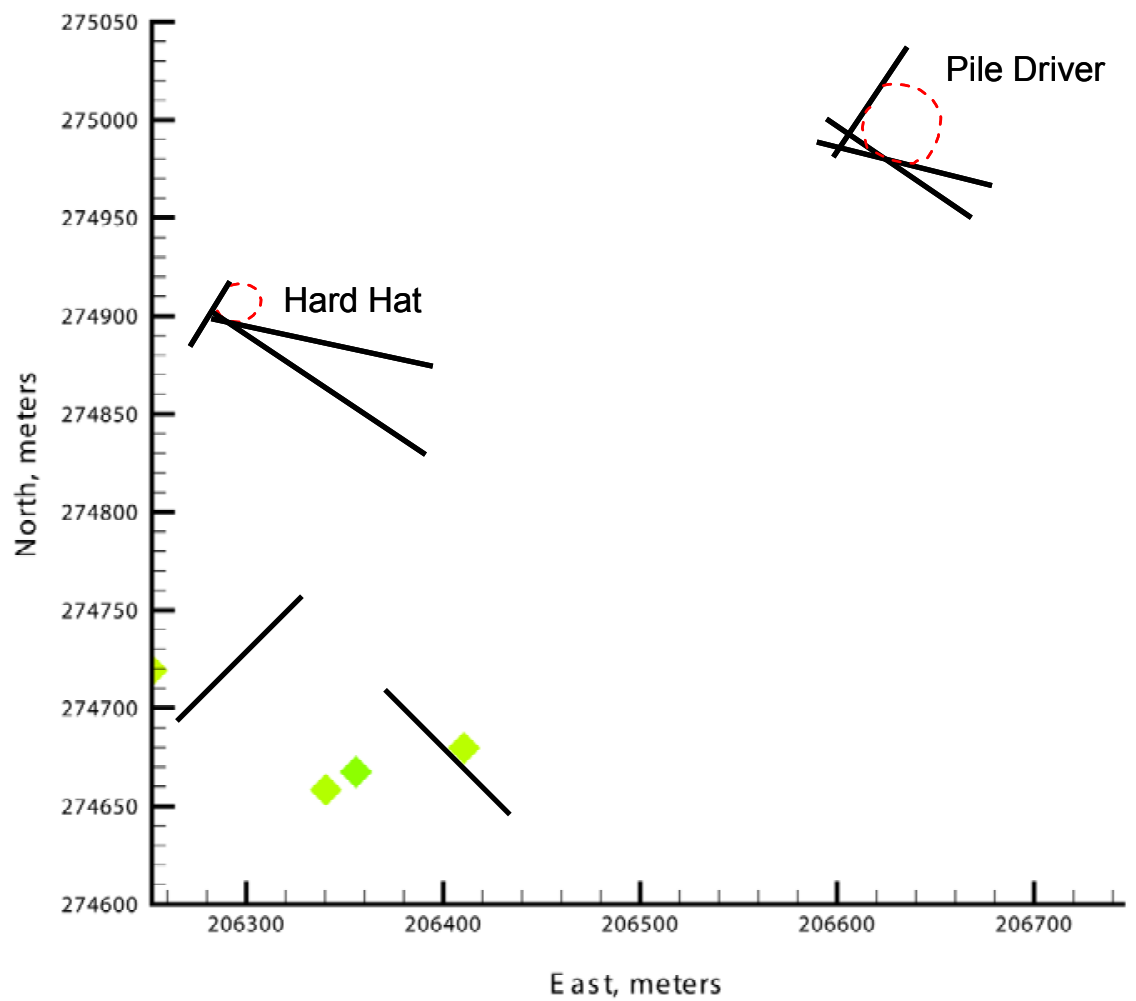

Figure 5-5. Plan view of distribution of tritium (green diamonds) in waters located near the Hard Hat and Pile Driver tests (red). Predominant fractures near the two tests and the strike of sheer and fault zones located near tunnel seeps are identified.

\subsubsection{Radionuclide Release: Nuclear Melt Glass Dissolution Model}

Radionuclides apportioned into the aqueous-sorbed fraction are considered immediately available for transport after each nuclear test. The remainder of radionuclides are only considered available for transport as they are released from the nuclear melt glass. Glasses are amorphous, thermodynamically unstable materials that tend to transform with time into more stable crystalline phases. The rate of this transformation provides a limit to the release rates of radioactive elements contained within the melt glass. 
When water first contacts an alkali aluminosilicate glass such as that formed in the Climax stock, an ion exchange process takes place at the glass-water interface that quickly depletes alkalis from the outermost few nanometers of the glass surface. With time, this outer alkali-depleted hydrous surface layer thickens, slowing the release rates of radionuclides from the glass by insulating the fresh glass from reactions. In fractured environments, the ion exchange reaction also results in hydration swelling, which decreases fracture permeability and further reduces release rates.

Elements released from the melt glass may be either incorporated into alteration mineral phases or remain in solution (and carried away by groundwater). Incorporation into the alteration mineral phases may occur through ion exchange, surface complexation, precipitation, or coprecipitation reactions. For a high-silicate glass, clay and zeolite alteration minerals are likely to form. However, zeolite precipitation is generally restricted to temperatures above ambient. The nature of the alteration minerals that form will dictate changes in solution composition. The changes in solution composition will, in turn, affect radionuclide release rates from the melt glass.

Alkali aluminosilicate glasses typically show a V-shaped $\mathrm{pH}$ dependence to their dissolution rates with a minimum at near-neutral pHs. Figure 5-6 presents far-from-saturation dissolution rate data where the dissolution rates are not reduced by saturation effects (Mazer, 1987). These rates are therefore the maximum values at which the glass will dissolve at the given $\mathrm{pH}$ (excepting any catalytic effects such as might occur in the presence of strong complexing agents). The rate data show a progressive increase in durability (decrease in dissolution rate) as the silica content of the glass increases. For example, dacitic (high-silica content) glass dissolves more slowly than basaltic (low-silica content) glass.

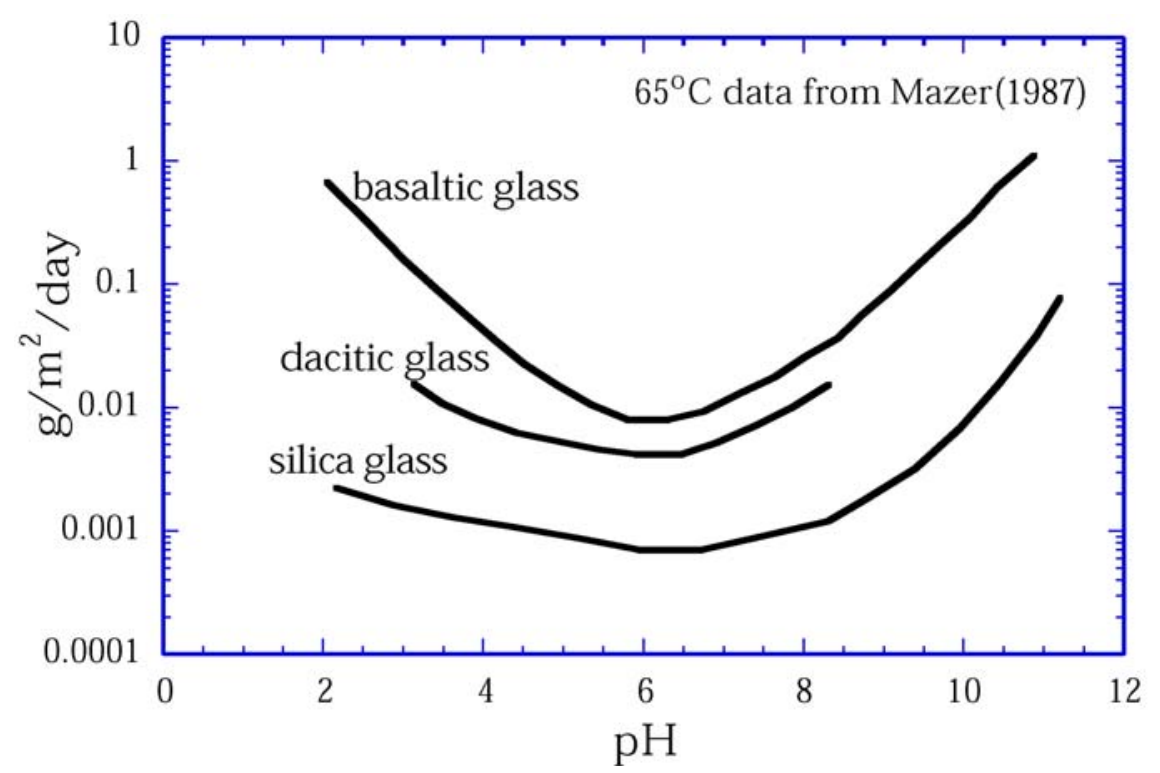

Figure 5-6. Dissolution rates for synthetic volcanic glasses measured at $65^{\circ} \mathrm{C}$ by Mazer (1987).

These rates are for test conditions far from saturation with respect to the glass.

Glasses exhibit a saturation effect similar to that of crystalline solids. In closed-system experiments, the dissolution rate slows as the concentration of dissolved species increases. The dissolution rate under near-saturation conditions can be several orders of magnitude slower than the rate measured far from saturation. For silicate glasses, the 
saturation effect is due mainly to dissolved silica. Most other aqueous species have less of an effect, particularly in neutral to alkaline $\mathrm{pH}$ solutions. The saturation effect, which slows the reaction rate, is likely to be important for slowly flowing groundwater interacting with the melt glass. Slow groundwater flow rates relative to glass-water reaction rates favor a build-up of silica in solution. Furthermore, since the ambient groundwater at NTS has a relatively high silica concentration due to the dissolution of native volcanic rocks containing glass and cristobalite, initial glass dissolution rates in contact with native waters will also be affected by saturation effects.

\subsubsection{Rate Equation}

The processes controlling the rate of glass dissolution described above are accounted for in a rate equation as follows:

$$
r=k_{0} \times e^{\frac{E_{a}}{R}\left(\frac{T-T_{0}}{T_{0} T}\right)} \times A_{s} \times \prod_{i} a_{i}^{n_{i}} \times\left(1-\left(\frac{Q}{K}\right)^{1 / \sigma}\right)^{v}+A_{s} k_{f}
$$

where $r$ is the rate of glass dissolution (mol-glass/g-glass/sec) at a specified temperature $T, A_{s}$ is the reactive surface area of the glass $\left(\mathrm{m}^{2} / \mathrm{g}\right), k_{0}$ is the rate coefficient $\left(\mathrm{mol} / \mathrm{m}^{2} / \mathrm{s}\right)$ for glass dissolution at a specified temperature $T_{0}$ (typically $25^{\circ} \mathrm{C}$ ), $E_{a}$ is the activation energy, $R$ is the gas constant, $\Pi \mathrm{a}_{\mathrm{i}}^{\mathrm{n}_{i}}$ is the product function of catalytic or inhibitive species $\left(\mathrm{H}^{+}\right.$and $\mathrm{OH}^{-}$in our model), $Q$ and $K$ are the activity product and solubility product for the glass dissolution reaction (Aagaard and Helgeson, 1982), $\sigma$ and $v$ are coefficients commonly used to fit the saturation effect, and $k_{f}$ is a term sometimes used to account for the relatively slow rate of glass dissolution close to saturation where the saturation term $(1-Q / K)$ alone is inadequate. The following sections report on the values used for each of these parameters.

\subsection{Glass Surface Area $A_{s}$}

One of the most critical parameters necessary for predicting radionuclide release rates from melt glass is the reactive surface area of melt glass. This term is important because the reaction rate of the glass is proportional to the reactive surface area. Note that the reactive surface area of glass refers to the surface area of glass alone, and not the surface areas of secondary precipitates on the glass (e.g., clays). Surface areas of crushed glass measured using BET may include the contributions of these alteration minerals that have much higher surface areas. Estimating the reactive surface area for melt glass is complicated by the high degree of heterogeneity of the melt glass zone. Photos taken of exploratory post-test drifts show that the melt glass zone is a breccia that is variably cracked and vesiculated (full of gas bubbles and having a texture similar to pumice). The relative proportions of massive to fractured and vesicular glass are unknown, and their distributions in space are probably chaotic.

The reactive surface area of glass is initially formed from several processes. Groundwater and other volatiles present in the subsurface at the time of the test and incorporated in the melt will tend to exsolve as the melt solidifies. This will result in vesicular zones of high porosity and comparatively high effective surface areas. However, it is not known whether these vesicular zones also have high permeability and allow flowing groundwater to contact most of its surface area. Also, when glasses cool from the outside, 
thermal gradients normal to the cooling surface produce differential thermal contraction that causes cracking. Even slowly cooled meter-sized glass masses end up as composites of fistsized glass pieces along with finer material in a three-dimensional mosaic of cracks (Baxter, 1983). A similar cracking process probably affects massive melt glass as it cools.

In the long term, reactions between the melt glass and water will give rise to hydrous alteration products. These reactions generally have a positive molar volume change and will therefore have a tendency to decrease the permeability in the zones that contain the hydrous phases. This results in an overall decrease in the fluid-accessible reactive surface area of glass. This effect has been observed in leaching studies of glasses from in situ vitrification sites (Timmons and Thompson, 1996). The above issues are difficult to address without detailed field examination and laboratory studies of melt glasses.

To provide an estimate for reactive surface area, measurements of reactive surface areas of intact natural analog rhyolite glass cores were made (Bourcier et al., 2000). Analog samples of pumice, breccias, massive glass, and mixtures of all three textures were collected. These samples were then cored in the laboratory, and these cores used in flow-through dissolution tests. The reactive surface area was determined by measuring the amounts of species dissolved by the fluid during passage through and reaction with the glass. Because surface area-normalized glass dissolution rate constants are known from previous work under these conditions, the integrated reactive surface area for the sample was computed from the amounts of dissolved glass constituents in the outlet fluid. BET surface area measurements of these samples were also made and compared to the flow-through dissolution test results. Based on their measurements, Bourcier et al. (2000) recommended using nuclear melt glass reactive surface areas of 0.001 to $0.01 \mathrm{~m}^{2} / \mathrm{g}$.

Based on observations of melt glass samples, it is believed that the natural analog samples represent the high-porosity vesiculated zones of the nuclear melt glasses. However, the nuclear melt glasses are heterogeneous and also contain zones of massive glass. The reactive surface area of the massive glass is likely to be very low; it could not be measured in laboratory experiments because flow could not be established (massive glass was not permeable). Water will contact only the fractured surfaces of the massive glass. The reactive surface areas of fractured man-made glass cylinders reported by Baxter (1983) are on the order of $0.00005 \mathrm{~m}^{2} / \mathrm{g}$, which is much lower than our measured reactive surface areas for vesicular and brecciated natural glass samples. Baxter's measurements were made on glass $\operatorname{logs} 0.6 \mathrm{~m}$ wide and $3.0 \mathrm{~m}$ long. The logs fracture during cooling due to thermal gradients and dissolution along these fractures dominated the reactive surface area test.

A bulk value for reactive surface area of $0.001 \mathrm{~m}^{2} / \mathrm{g}$ appears to be a good estimate of reactive surface area. It was chosen for the Phase II Cambric HST model (Carle et al., 2007) to account for the contribution of massive glass zones to reactive surface area. This value is identical to that used in the Cheshire HST (Pawloski et al., 2001) simulations. The 0.001$\mathrm{m}^{2} / \mathrm{g}$ value lies on the low end of the range of reported data for the analog samples. However, given the vessiculated nature of the analog glasses, this value is considered a fairly conservative estimate of the reactive surface area of the entire melt glass zone (that is, it does not underestimate surface area). In the model, the surface area of glass is allowed to decrease linearly with the amount of glass dissolved. 


\subsection{Rate coefficient $k_{0}$, product terms $a_{i}$ and $n_{i}$, and activation energy $E_{a}$}

Because the melt glass composition is similar to that for natural rhyolitic glasses, results of previous dissolution studies of natural silicate glasses (i.e., Mazer, 1987) were used to estimate the glass dissolution rate of the Climax stock melt glasses. The effects of small amounts of contaminants, including radioactive ones with their associated radiation fields, have been shown to have negligible effects on glass dissolution rates (Bibler and Jantzen, 1987).

For the Climax stock glasses, the dacite $\left(63.24 \% \mathrm{SiO}_{2}\right)$ dissolution data in Figure 5-7 were used to regress the value of the rate coefficient for glass dissolution. First, the $65^{\circ} \mathrm{C}$ data for dacite glass were fit to a polynomial. Three rate constants, in combination with the product function (where $a_{i}$ is the activity of $\mathrm{H}^{+}$or $\mathrm{OH}^{-}$and $n_{i}$ is the fitted exponent), were fit to this polynomial (Figure 5-7). Specifically, the V-shaped polynomial fit to the glass dissolution rate was modeled by using the sum of three linear rates: a pOH-dependent rate at low $\mathrm{pH}$, a $\mathrm{pH}$-independent rate at intermediate $\mathrm{pH}$, and a $\mathrm{pH}$-dependent rate at high $\mathrm{pH}$ (see fit in Figure 5-7). The combination of these linear rates accounts for the effect of $\mathrm{pH}$ on the dissolution rate.

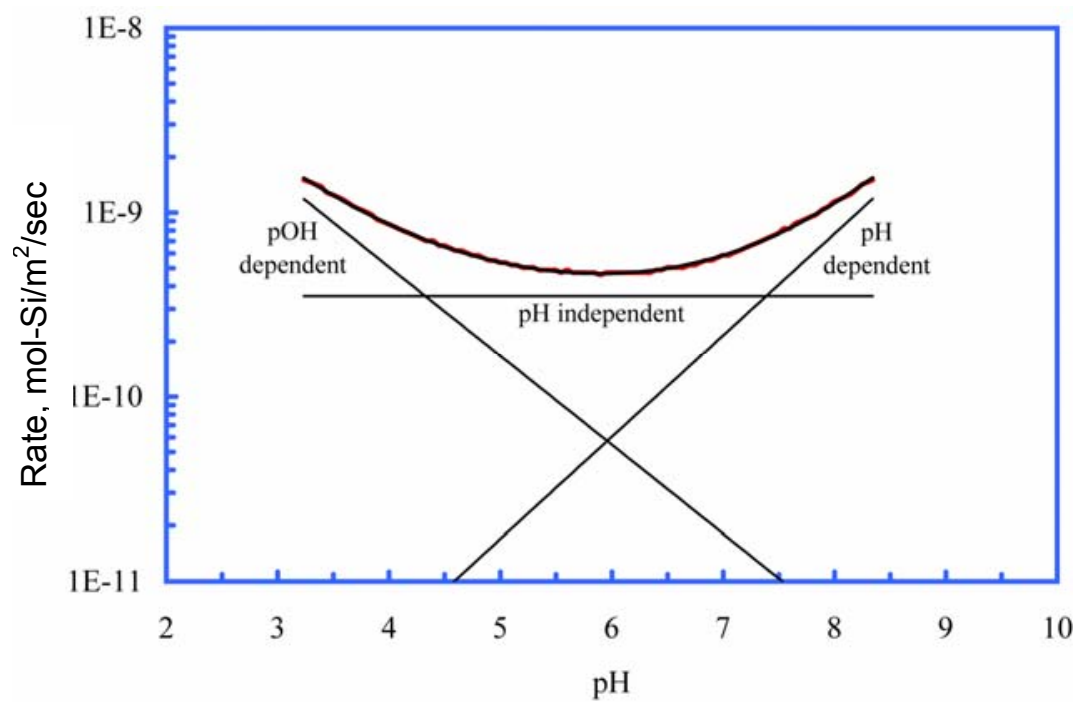

Figure 5-7. Fit (thick black line) to $65^{\circ} \mathrm{C}$ dacite dissolution data of Mazer (1987) (thick red line). The $\mathrm{pH}$-dependent rate is fit using a product of three rates: a $\mathrm{pOH}$-dependent rate, a $\mathrm{pH}$-independent rate, and a $\mathrm{pH}$-dependent rate (thin black lines). One mol of glass is defined as 100 grams.

As suggested earlier, the durability (or the rate that glass will dissolve) is greatly affected by the silica content of the glass (Figure 5-7). To account for the effect of glass composition on dissolution rate, it was estimated, based on the data shown in Figure 5-7, the dissolution rate (in $\mathrm{mol} \mathrm{Si} / \mathrm{m}^{2} / \mathrm{sec}$ ) decreases by $0.03 \log$ units for each one percent increase in $\mathrm{SiO}_{2}$ content. The rock in the Climax stock can be subdivided into granodiorite and quartz monzonite (Table 5-4). Hard Hat and Pile Driver glasses are predominantly formed from granodiorite rock, while Tiny Tot glass is formed from quartz monzonite. To arrive at a dissolution rate constant and $\mathrm{pH}$-dependence of glass dissolution for glasses with 67.6 percent or 69.1 percent $\mathrm{SiO}_{2}$, rate constants were adjusted by -0.131 and -0.176 log units (in $\mathrm{mol} \mathrm{Si} / \mathrm{m}^{2} / \mathrm{sec}$ ), respectively. 
Table 5-4. Composition of granodiorite and quartz monzonite, from Maldonado (1977).

\begin{tabular}{ccc}
\hline & Granodiorite weight \% & Quartz monzonite weight \% \\
\hline $\mathrm{SiO}_{2}$ & 67.6 & 69.1 \\
$\mathrm{Al}_{2} \mathrm{O}_{3}$ & 15.8 & 15.8 \\
$\mathrm{Fe}_{2} \mathrm{O}_{3}$ & 1.8 & 1.5 \\
$\mathrm{FeO}$ & 1.6 & 1.3 \\
$\mathrm{MgO}$ & 0.82 & 0.6 \\
$\mathrm{CaO}$ & 3.7 & 3.2 \\
$\mathrm{Na} 2$ & 3.1 & 3 \\
$\mathrm{~K}_{2} \mathrm{O}$ & 3.5 & 3.9 \\
$\mathrm{H}_{2} \mathrm{O}$ & 1 & 0.89 \\
$\mathrm{TiO}_{2}$ & 0.39 & 0.4 \\
$\mathrm{P}_{2} \mathrm{O}_{5}$ & 0.18 & 0.21 \\
$\mathrm{MnO}$ & 0.07 & 0.04 \\
$\mathrm{CO}_{2}$ & 0.2 & 0.1 \\
\hline
\end{tabular}

The rate of glass dissolution is strongly dependent on temperature. The temperature dependence is controlled by the activation energy $E_{a}$. In the unclassified Cheshire HST model (Pawloski et al., 2001), it was conservatively assumed that the activation energy for glass (and several secondary minerals) was $20 \mathrm{kcal} / \mathrm{mol}$. Recent glass dissolution experiments suggest that the activation energy is closer to 12 to $15 \mathrm{kcal} / \mathrm{mol}$ (Zavarin et al., $2004 \mathrm{a}, \mathrm{b})$. An activation energy of $15 \mathrm{kcal} / \mathrm{mol}$ provides a conservative estimate of glass dissolution at temperature. A reduction in activation energy from 20 to $5 \mathrm{kcal} / \mathrm{mol}$ dramatically reduced the glass dissolution rate at high temperatures $(\mathrm{a}>2$-order-ofmagnitude decrease in dissolution rate at $150{ }^{\circ} \mathrm{C}$ ).

In general, the standard state for reactions is reported at $25^{\circ} \mathrm{C}$. Thus, rate constants for glass dissolution should be determined at $25^{\circ} \mathrm{C}$. To determine the melt glass dissolution rate constants in their standard state, the rate constants determined at $65{ }^{\circ} \mathrm{C}$ were adjusted by the temperature-dependent term. The melt glass dissolution standard state $\left(25^{\circ} \mathrm{C}\right)$ rate constants for the Climax stock glasses (based on $15 \mathrm{kcal} / \mathrm{mol}$ activation energy) are listed in Table 5-5. Adjustment of parameters from $60{ }^{\circ} \mathrm{C}$ to $25^{\circ} \mathrm{C}$ was accomplished here (1) using an activation energy of $15 \mathrm{kcal} / \mathrm{mol}$, (2) accounting for the changing water dissociation constant $\left(\mathrm{K}_{\mathrm{w}}\right)$ as a function of temperature, and (3) using an $\mathrm{SiO}_{2}$ concentration consistent with X-ray fluorescence measurements for granodiorite and quartz monzonite.

Table 5-5. Climax stock melt glass dissolution rate constants at standard state $\left(25^{\circ} \mathrm{C}\right)$.

\begin{tabular}{ccc}
\hline Species & Exponent & Rate (mol-glass $\left./ \mathrm{m}^{2}-\mathrm{sec}\right)$ \\
\hline & & Granodiorite \\
$\mathrm{H}^{+}$ & 0.483 & $1.42 \mathrm{E}-09$ \\
$\mathrm{OH}^{-}$ & 0.552 & $1.30 \mathrm{E}-08$ \\
$\mathrm{pH}-$-independent & & $1.16 \mathrm{E}-11$ \\
& & Quartz monzonite \\
$\mathrm{H}^{+}$ & 0.482 & $1.25 \mathrm{E}-09$ \\
$\mathrm{OH}^{-}$ & 0.552 & $1.14 \mathrm{E}-08$ \\
$\mathrm{pH}-$-independent & & $1.03 \mathrm{E}-11$ \\
\hline
\end{tabular}

* 1 mol glass is defined as 100 grams of glass.

Figure 5-8 illustrates the effect of both $\mathrm{pH}$ and temperature on the far-from-saturation dissolution rates of the granodiorite and quartz monzonite melt glasses. The rates are 
calculated using an activation energy of $15 \mathrm{kcal} / \mathrm{mol}$. Note that the $\mathrm{V}$-shaped curves shift to the left with increasing temperature. This shift results from the change in the water dissociation as a function of temperature. For example, at $25{ }^{\circ} \mathrm{C}$, the $\mathrm{K}_{\mathrm{w}}$ of water is known to be $10^{-14}$. However, it is approximately $10^{-15}$ at $0^{\circ} \mathrm{C}$ and approximately $10^{-13}$ at $60^{\circ} \mathrm{C}$. This forces the curve to shift to the left with increasing temperature. This was observed in borosilicate glass dissolution experiments of Knauss et al. (1990) and is likely to occur in the case of nuclear melt glass dissolution as well.

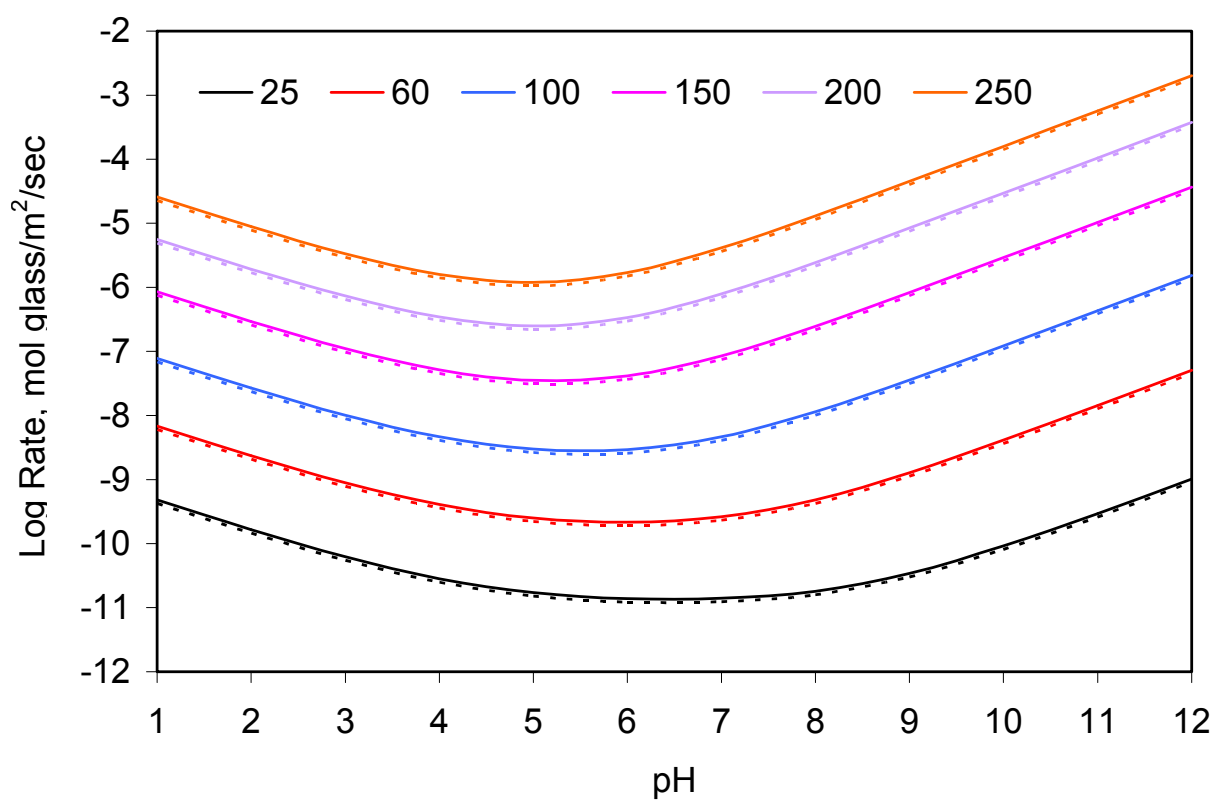

Figure 5-8. Far-from-saturation, surface-area-normalized dissolution rates for granodiorite (solid) and quartz monzonite (dashed) glass as a function of temperature and $\mathrm{pH}$.

\subsection{The saturation term $\left(1-(Q / K)^{1 / \sigma}\right)^{v}$}

As mentioned earlier, the rate of glass dissolution slows as the solution approaches saturation with respect to glass. Previous studies have shown that the primary cause of the rate decrease is the increasing concentration of dissolved silica (Grambow, 1987). Although other species may have some effect, our glass dissolution model is limited to the effect of silica because of the lack of more detailed information. This implies that for the saturation term $(1-\mathrm{Q} / \mathrm{K})$ in the rate equation, the value of $\mathrm{Q}$ is simply the concentration of dissolved $\mathrm{SiO}_{2}(\mathrm{aq})$ and $\mathrm{K}$ is the silica concentration in solution at glass "saturation" for a particular glass composition.

The equilibrium constant $(K)$ for glasses is usually determined experimentally by measuring the silica concentration in solution under conditions when the dissolution rate of the glass slows to near zero in static (closed-system) glass dissolution experiments. For silica-rich glasses, values of $K$ usually lie between the values of $\mathrm{K}$ for the silica polymorphs cristobalite and amorphous silica (Grambow, 1987). The larger the value of K, the larger the value of the saturation term and the higher the calculated dissolution rate. Because of the lack of available experimental data on saturation effects for melt glasses, the conservative assumption is made that $\mathrm{K}$ is defined by amorphous silica. 
The terms $v$ or $\sigma$ are often used to empirically fit observed dissolution or precipitation data. Recent glass dissolution experiments close to saturation (Zavarin et al., $2004 a, b)$ suggested that the $\sigma$ coefficient may be more suitable for glass dissolution. Values as high as 100 were reported and led to greatly reduced glass dissolution rates. However, the results were inconclusive; dissolution inhibition by $\mathrm{Al}^{3+}$ could provide similar reductions in glass dissolution rates. Because the mechanism of the glass dissolution rate reduction could not be identified, the effect of $\sigma$ on glass dissolution rate reduction was conservatively ignored.

\subsection{The close-to-saturation rate $k^{f}$}

Glasses exhibit a saturation effect similar to that of crystalline solids where the dissolution rate slows as species build up in solution. However, due to the unstable nature of glasses, dissolution is expected to continue even when solutions are at saturation with amorphous silica. The close-to-saturation rate accounts for this slow rate. Typically, this rate is several orders of magnitude slower than the dissolution rate far from saturation.

In the Climax stock glass model, silica concentrations in solution are not allowed to build up to levels high enough to make the close-to-saturation rate significant. Instead, the $\mathrm{SiO}_{2}$ (aq) concentration in solution is forced to be in equilibrium with $\beta$-cristobalite. This is done for two reasons: (1) silica aqueous concentrations in Climax stock waters are found close to equilibrium with $\beta$-cristobalite (below saturation with respect to amorphous silica), and (2) high silica build-up in the glass zone has not been observed in the field. Thus, the close-to-saturation rate of glass dissolution can be ignored in our model.

\subsubsection{Implementation of Glass Dissolution Model in a Particle Code}

A simplified version of the glass dissolution model described in the previous section is being incorporated into a particle model for the Climax stock radionuclide transport calculations. The particle code used in these simulations does not explicitly provide for the complex chemical interactions such as $\mathrm{pH}$ and secondary mineral precipitation that control glass dissolution rates. Thus, these effects must be prescribed in the model a priori.

The model must bound the expected limits of glass dissolution rates given potential variability in chemical and physical conditions. A moderate glass dissolution rate was developed for the Climax stock glass assuming that:

- $\quad \mathrm{The}^{\mathrm{SiO}}$ (aq) activity in solution is controlled by the solubility of $\beta$-cristobalite at all temperatures. This controls the saturation state of the solution with respect to glass. The saturation term coefficients $\sigma$ and $v$ are assumed to be equal to 1 .

- The $\mathrm{pH}$ of the solution is not affected by secondary mineral precipitates but is affected by temperature.

- The $\mathrm{pH}$-dependent glass dissolution rate constants are identical to those developed for the "complex" glass dissolution model described in the previous section.

- An activation energy of $15 \mathrm{kcal} / \mathrm{mol}$ controls the temperature dependence of the glass dissolution rate. 
To determine the glass dissolution rate for the particle model, the following procedure was taken. First, the rate coefficient $k$ and product terms $a_{j}^{i}$ were based on the parameters in Table 5-5. For simplicity, the granodiorite model was used in all cases. Differences between granodiorite and quartz monzonite are relatively small. The $\mathrm{pH}$ as a function of temperature in Climax stock groundwater was predicted using the groundwater composition at $25^{\circ} \mathrm{C}$ from Isherwood et al. (1982) (Table 5-6) and the Geochemist's Workbench code (Bethke, 1996). Results are plotted in Figure 5-9. Based on these simulations, water disproportionation and the solubility and speciation of elements associated with calcite were found to have the greatest influence over predicted $\mathrm{pH}$. Except in the absence of carbonate, the $\mathrm{pH}$ does not vary by more than $1 \mathrm{pH}$ unit between 25 and $275^{\circ} \mathrm{C}$. For glass dissolution modeling purposes, a polynomial fitted to the predicted $\mathrm{pH}$ under conditions of calcite and $\beta$ cristobalite saturation was used. This is a realistic representation of groundwater chemistry evolution. However, it is uncertain because the nature and rates of glass dissolution and secondary mineral precipitation may alter the water chemistry, including $\mathrm{pH}$. Nevertheless, very large changes in the groundwater $\mathrm{pH}$ near nuclear test cavities at the NTS have not been observed. The polynomial predicting $\mathrm{pH}$ as a function of temperature is the following:

$$
\begin{aligned}
p H(T)= & -2.14 \times 10^{-15} T^{6}+5.023 \times 10^{-12} T^{5}-3.020 \times 10^{-9} T^{4}+6.618 \times 10^{-7} T^{3} \\
& -2.619 \times 10^{-6} T^{2}-1.333 \times 10^{-2} T+7.825
\end{aligned}
$$

where $\mathrm{T}$ is in ${ }^{\circ} \mathrm{C}$.

Table 5-6. Geochemical analysis for UG-02 from Isherwood et al. (1982).

\begin{tabular}{cccc}
\hline Cations & $\mathrm{mg} / \mathrm{L}$ & Anions & $\mathrm{mg} / \mathrm{L}$ \\
\hline $\mathrm{Na}$ & 214 & $\mathrm{PO}_{4}$ & $<0.3$ \\
$\mathrm{Ca}$ & 114 & $\mathrm{Cl}$ & 70 \\
$\mathrm{~K}$ & 4.7 & $\mathrm{SO}_{4}$ & 480 \\
$\mathrm{Mg}$ & 1.5 & $\mathrm{HCO}_{3}$ & 165 \\
$\mathrm{Sr}$ & 4.2 & $\mathrm{NO}_{3}$ & $\mathrm{ND}$ \\
$\mathrm{Cs}$ & $\mathrm{ND}$ & $\mathrm{F}$ & 1.4 \\
$\mathrm{Al}$ & 0.02 & $\mathrm{pH}$ & \\
$\mathrm{U}$ & $<0.1$ & $\mathrm{Eh}, \mathrm{mV}$ & 7.5 \\
$\mathrm{Fe}$ & 0.8 & ${ }^{3} \mathrm{H}, \mathrm{pCi} / \mathrm{mL}$ & 86 \\
$\mathrm{Zn}$ & 0.03 & $\mathrm{TDS}, \mathrm{mg} / \mathrm{L}$ & 195 \\
$\mathrm{Mn}$ & 0.05 & $\mathrm{Conductivity,} \mu \mathrm{S}$ & 1,110 \\
$\mathrm{Li}$ & 0.17 & $\mathrm{O}_{2(\mathrm{~g})} \mathrm{mg} / \mathrm{L}$ & $<340$ \\
$\mathrm{Mo}$ & 0.09 & $\mathrm{SiO}_{2}, \mathrm{mg} / \mathrm{L}$ & $<0.15$ \\
& & & 23.9 \\
\hline
\end{tabular}




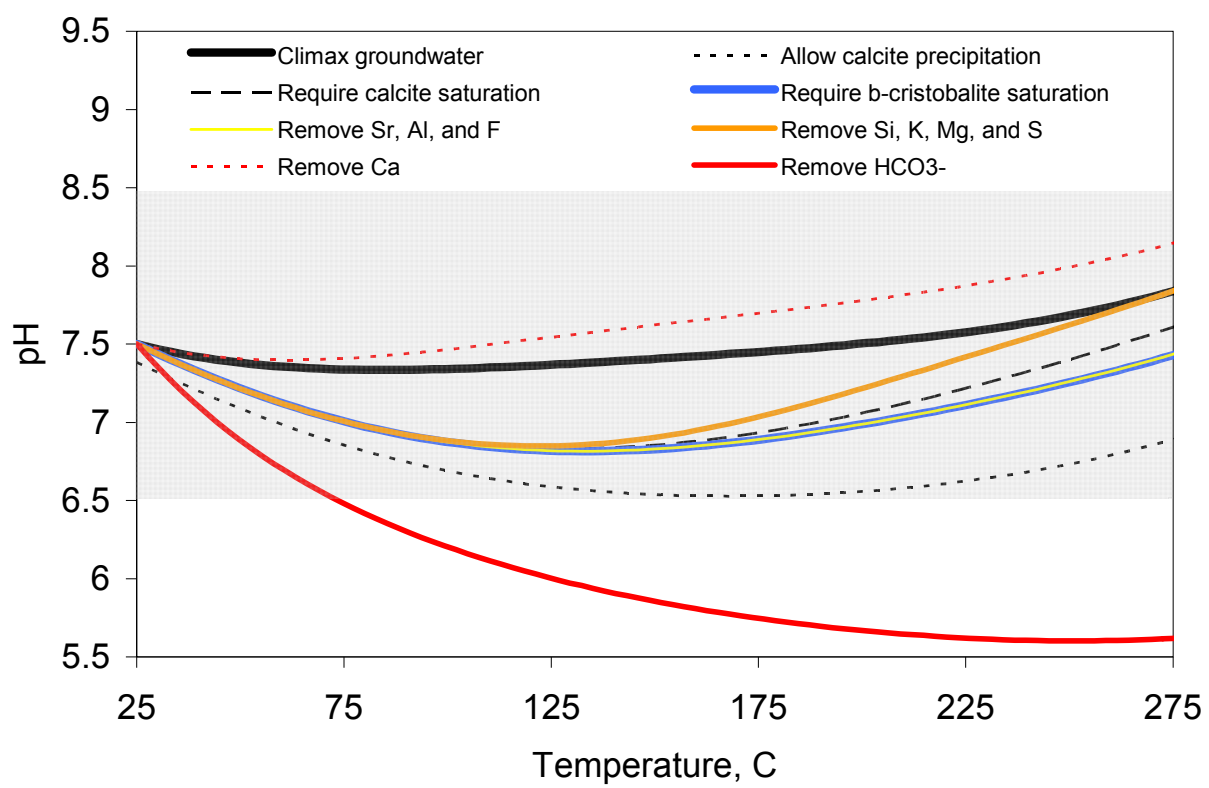

Figure 5-9. Evolution of solution $\mathrm{pH}$ as a function of temperature starting with $25^{\circ} \mathrm{C}$ groundwater chemistry reported in Table 5-6 for various modeling conditions. Model conditions were added consecutively: "Climax groundwater" did not include any mineral precipitation, "Allow calcite precipitation" allowed precipitation of calcite but no other minerals, "Require calcite saturation" forced initial solution conditions to saturation with calcite and allowed for calcite precipitation, "Require $\beta$-cristobalite saturation" forced conditions to saturation with $\beta$-cristobalite and calcite; "Remove $\mathrm{Sr}, \mathrm{Al}, \mathrm{F}$ " excluded these elements, "Remove $\mathrm{Si}, \mathrm{K}, \mathrm{Mg}, \mathrm{S}$ " excluded these elements, "Remove $\mathrm{Ca}$ " excluded $\mathrm{Ca}$, "Remove " $\mathrm{HCO}_{3}$ " excluded carbonate, leaving only $\mathrm{Na}^{+}$and $\mathrm{Cl}^{-}$ species in solution.

The $\mathrm{pOH}$ of water was calculated using the $\mathrm{pH}$ and the $\log \left(\mathrm{K}_{\mathrm{w}}\right)$ of water as a function of temperature. A polynomial was fit to the $\mathrm{K}_{\mathrm{w}}$ data from the EQ3/6 database (Johnson and Lundeen, 1997):

$$
\begin{aligned}
-\log (K w(T))= & 6.1485 \times 10^{-10} T^{4}-4.9425 \times 10^{-7} T^{3} \\
& +1.9154 \times 10^{-4} T^{2}-4.1691 \times 10^{-2} T+14.935
\end{aligned}
$$

where $\mathrm{T}$ is in ${ }^{\circ} \mathrm{C}$.

Using this function for $\mathrm{Kw}$ and the predicted $\mathrm{pH}$ change as a function of temperature resulted in the following equation of $\mathrm{pOH}$ as a function of temperature:

$$
p O H(T)=-\log \left(K_{w}(T)\right)-p H(T)
$$

These values can be combined with the information of Table 5-5 to determine the glass dissolution rate far from saturation at a particular temperature. To determine the saturation term as a function of temperature, the solubility of $\beta$-cristobalite and amorphous silica as a function of temperature was incorporated into the $1-Q / K$ term. By fitting the 
solubility of these two minerals to a polynomial, the saturation term as a function of temperature is predicted by the following:

$$
\begin{aligned}
\frac{Q(T)}{K(T)}= & -4.1559 \times 10^{-11} T^{4}+5.8913 \times 10^{-8} T^{3}-2.1665 \times 10^{-5} T^{2} \\
& +4.1143 \times 10^{-3} T+0.41544
\end{aligned}
$$

where $\mathrm{T}$ is in ${ }^{\circ} \mathrm{C}$. Finally, to complete the glass dissolution equation, an activation energy in the temperature-dependent term is assigned. A conservative estimate of $15 \mathrm{kcal} / \mathrm{mol}$ is suggested; values as low as $12 \mathrm{kcal} / \mathrm{mol}$ were observed in our experiments (Zavarin et al., 2004a,b). By combining the above equations and the rate constant data in Table 5-5, we arrive at the equation that controls glass dissolution rates in the particle code can be calculated. Note that the reactive surface area of glass is $0.001 \mathrm{~m}^{2} / \mathrm{g}$. The resulting rate of glass dissolution as a function of temperature is compared with the far-from-saturation rates in Figure 5-10.

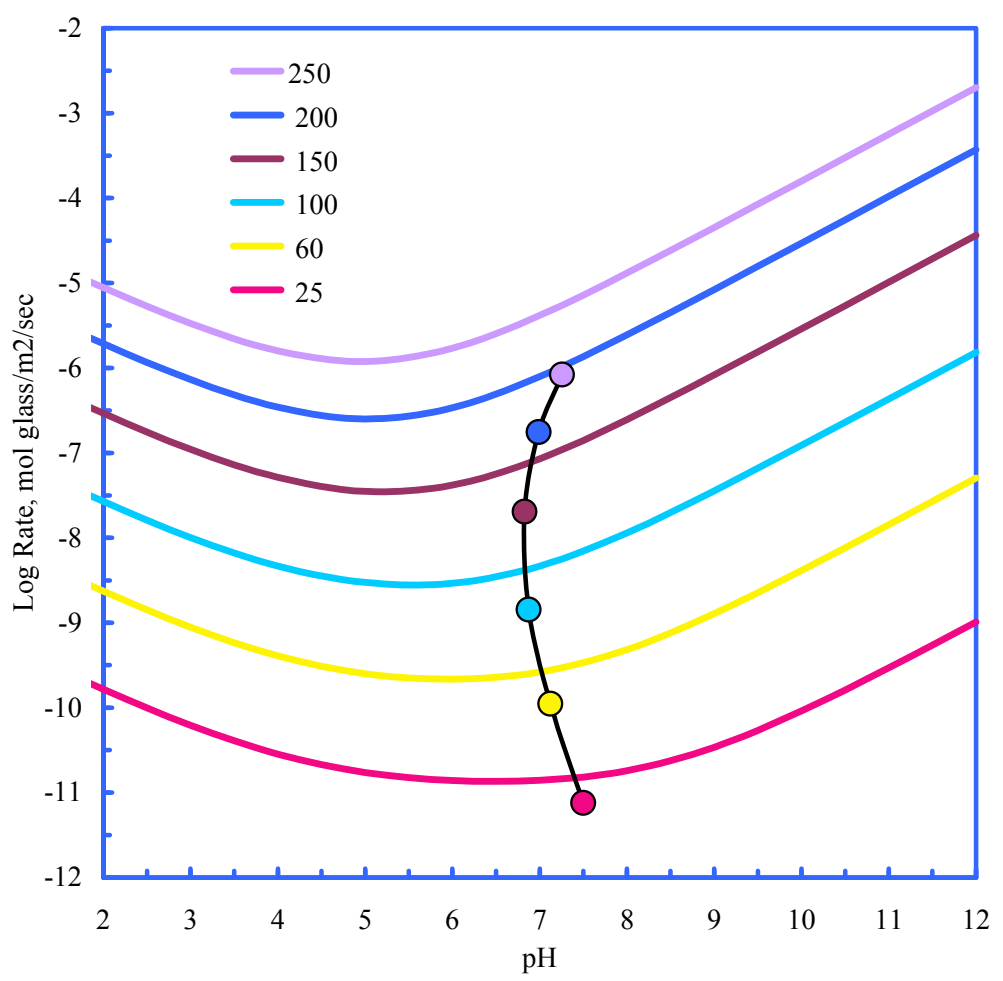

Figure 5-10. Comparison of far-from-saturation Climax stock glass (granodiorite) dissolution rate as a function of temperature and $\mathrm{pH}$ (from Figure 5-8) to the simplified glass dissolution model used in the particle code (black line). Rates identified by circles can be compared to far-from-saturation rates identified by lines of the same color. Differences reflect the effect of the model saturation term. 


\subsubsection{Temperature History of the Glass Zones in the Climax Stock}

Sufficient data are not available to determine the exact temperature history of glass produced by the three tests conducted in the Climax stock. Therefore, an analytical approach is taken here. It is based on the assumption that loss of heat from the glass zone as a result of conduction (and no convection) should represent the slowest (and, thus, the most conservative) loss of heat from the glass zone. This is illustrated by examples from other testing locations, presented in Appendix G.

Carslaw and Jaeger (1986) provide an analytical solution for the temperature of a parallelepiped $(|x|<a,|y|<b,|z|<c)$ initially at a single temperature, $T_{0}$, and an infinite volume outside the parallelepiped initially at 0 :

$$
T(x, y, z, t)=\frac{1}{8} T_{0}\left(\operatorname{erf} \frac{a-x}{2(k t)^{1 / 2}}+\operatorname{erf} \frac{a+x}{2(k t)^{1 / 2}}\right)\left(\operatorname{erf} \frac{b-y}{2(k t)^{1 / 2}}+\operatorname{erf} \frac{b+y}{2(k t)^{1 / 2}}\right)\left(\operatorname{erf} \frac{c-z}{2(k t)^{1 / 2}}+\operatorname{erf} \frac{c+z}{2(k t)^{1 / 2}}\right)
$$

where $x, y, z, a, b$, and $c$ are in meters, $k$ is the thermal diffusivity $\left(\mathrm{m}^{2} / \mathrm{s}\right)$, and $t$ is time (s). The glass zone can be approximated as being a parallelepiped that is $2 a$ by $2 b$ wide and $2 c$ high. The thermal diffusivity of the glass zone is also approximated to be equivalent to the surrounding granite and that the initial temperature of the glass zone is uniform, as is the surrounding granite (Figure 5-11). With these assumptions in place, the temperature history of a hypothetical glass zone can be predicted. Several examples are provided below, along with calculations for the three tests conducted in the Climax stock.

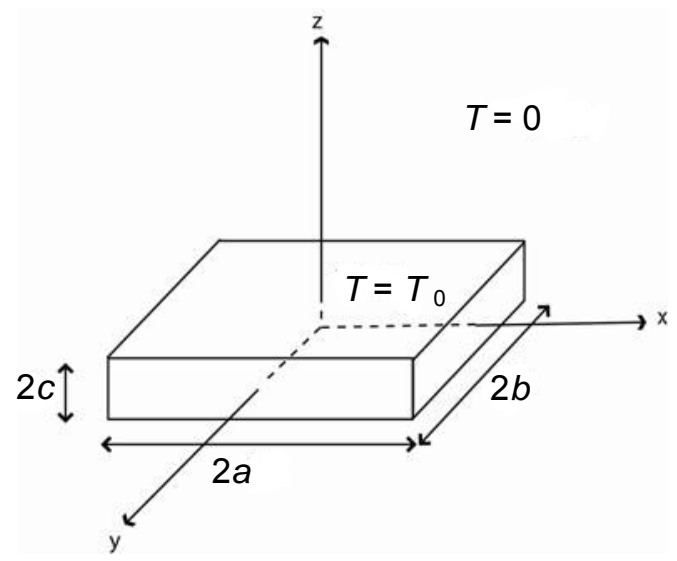

Figure 5-11. Parallelepiped used in analytical solution of the temperature history of the glass zone.

\subsection{Initial Temperature for the Climax Tests}

In the examples in Appendix $G$, the initial temperature for each test was based on the boiling point of water at the hydrostatic pressure at the bottom of the glass zone. This appears to provide a conservative estimate of temperature cooling histories for saturated tests, but has not been tested for unsaturated tests. In general, the water levels at Climax stock tests are based on very few actual measurements of water levels, resulting in significant uncertainty. 
One source of water level data is the Pickus (1997) report, which was also used to categorize radiologic source terms as tests conducted above or below the water table at Yucca Flat (i.e., Bowen et al., 2003). Climax stock tests were included in the Yucca Flat inventory in Bowen et al. (2003). Another source of water level information is the regional groundwater model developed recently by the USGS (Belcher, W.R., ed., 2004). Yet another source of water level data is individual reports that contain measured water levels (e.g., Murray, 1981). Differences between the various water level sources and their relationship to initial glass zone temperatures are discussed below.

The Tiny Tot test was conducted $111 \mathrm{~m}$ below ground surface (Pickus, 1997). Based on the data from Pickus (1997), the water level is $228 \mathrm{~m}$ below ground surface. The USGS regional model predicted a water level of $553 \mathrm{~m}$ below ground surface. There were no references suggesting that Tiny Tot was located in the saturated environment. Thus, significant interaction with water at this test before temperatures have cooled to below $100{ }^{\circ} \mathrm{C}$ is not expected. Importantly, unlike the three Pahute Mesa saturated tests discussed earlier, cavity cooling as a result of groundwater convection and boiling of infiltrated water should be largely absent in this unsaturated test. Thus, the estimate of cavity cooling by conduction is likely a good estimate of glass zone temperature history. However, an appropriate initial temperature for an unsaturated test is difficult to determine.

The Hard Hat test was conducted $287.4 \mathrm{~m}$ below ground surface (Pickus, 1997). Based on the data from Pickus (1997), the water level is $221.9 \mathrm{~m}$ below ground surface, which results in a working point $65.5 \mathrm{~m}$ below the water table. Based on a cavity radius of $19.2 \mathrm{~m}$ (Boardman, 1966), the bottom of the glass zone is $84.7 \mathrm{~m}$ below the water table. At this hydrostatic pressure, the boiling point of water is $180^{\circ} \mathrm{C}$. The USGS regional model predicted a water level of $370 \mathrm{~m}$ below ground surface, nearly $150 \mathrm{~m}$ lower than Pickus (1997). This suggests that the Hard Hat cavity is located in an unsaturated environment. This is consistent with drillback water level measurement approximately four months after the Hard Hat test, which determined that water levels were below $297 \mathrm{~m}$. It is also consistent with observations reported by Murray (1981) that the Climax stock SFT underground working point (440-m depth) was almost devoid of groundwater and most certainly above the regional water table. Thus, it appears that the Hard Hat test is essentially unsaturated and glass dissolution will likely occur only after temperatures have cooled to below $100{ }^{\circ} \mathrm{C}$.

The Pile Driver test was conducted $463 \mathrm{~m}$ below ground surface (Pickus, 1997). Based on the data from Pickus (1997), the water level is $185 \mathrm{~m}$ below ground surface. With a cavity radius of $40.1 \mathrm{~m}$ (Borg, 1970), the bottom of the glass zone is $317 \mathrm{~m}$ below the water table and the resulting boiling point is $238{ }^{\circ} \mathrm{C}$. The USGS regional model predicts a water level of $362 \mathrm{~m}$ below ground surface, nearly $200 \mathrm{~m}$ lower than Pickus (1997). This suggests that the bottom of the cavity is $140 \mathrm{~m}$ below the water table and the resulting boiling point is $198^{\circ} \mathrm{C}$. Murray (1981) stated that the underground working point of the Climax stock SFT (440-m depth) was essentially dry. Furthermore, the water level in well UG-02 that was drilled into the floor of the Climax stock SFT is at $974 \mathrm{~m}$ mean sea level ( 577-m depth). This direct measurement suggests that the Pile Driver test is also unsaturated, with the bottom of the cavity located $75 \mathrm{~m}$ above the regional water table. Based on this direct water level measurement, glass dissolution is unlikely to occur until the glass has cooled to below $100{ }^{\circ} \mathrm{C}$. 
Based on the data presented above, it appears that all three tests conducted in the Climax stock have glass zones located above the regional water table. While some perched groundwater may access the test cavities and provide a cooling mechanism for the glass, it is expected that most of the cooling will result from conduction. The glass zone may be initially cooled from mixing of cavity wall rock or collapsing chimney material, but the role of water will be much less pronounced than for the saturated tests. Glass dissolution is not likely to occur until temperatures have decreased to around $100{ }^{\circ} \mathrm{C}$.

\subsection{Models of Temperature History for the Climax Tests}

To estimate the temperature history of each test, the initial temperature of the glass zone and the dimensions of the glass zone must be provided along with the thermal properties of the rock. For saturated tests, the initial temperature for each test can be based on the boiling point at the bottom of the glass zone under hydrostatic conditions; this appears to provide a conservative estimate of glass zone cooling histories. For unsaturated tests, this may not be appropriate. Instead, energy balance calculations such as those presented in Peterson et al. (1991) were used to estimate initial glass zone temperatures, as described below.

For the Hard Hat test, the cavity radius is reported to be $19.2 \mathrm{~m}$ (Boardman, 1966). The top of the glass puddle was measured at $7.6 \mathrm{~m}$ above the bottom of the Hard Hat cavity (McArthur, 1963). Thus, the total volume of the glass zone is $3,000 \mathrm{~m}^{3}$. The volume of glass if estimated from the yield $(5.7 \mathrm{kt})$, a glass production rate of $700 \mathrm{t} / \mathrm{kt}$ yield, a glass density of $2.5 \mathrm{~g} / \mathrm{cm}^{3}$, and a porosity of 0.2 , is $2,000 \mathrm{~m}^{3}$, suggesting that the glass zone is composed of 35 percent infallen rubble material. Boardman (1966) suggested that this is a relatively high fraction of glass due to the slow collapse (11 hours) of the cavity, which allowed for the glass to puddle at the bottom of the cavity. Based on a puddle depth of $7.6 \mathrm{~m}$ and a total glass volume of $3000 \mathrm{~m}^{3}$, one can calculate the conduction-only analytical solution to heat dissipation from the glass zone using three initial temperatures: $100{ }^{\circ} \mathrm{C}$ (boiling point at hydrostatic pressure from USGS water levels, $180^{\circ} \mathrm{C}$ (boiling point at hydrostatic pressure from Pickus [1993] water levels), and $1,070{ }^{\circ} \mathrm{C}$ (initial temperature based on heat capacity and 30 percent total test energy deposited in the glass zone, as suggested in Peterson [1991]). All analytical solutions assume an ambient temperature of $25^{\circ} \mathrm{C}$. Results are presented in Figure 5-12.

Few data exist regarding the temperature history of the Hard Hat glass zone; the available reported measurements are plotted in Figure 5-21. In May 1962, three months after the test, a temperature log from the post-test drillback (U15a 28S) found that the glass zone temperature was $60{ }^{\circ} \mathrm{C}$ (McArthur, 1962). This value is significantly lower than the predicted temperature using a starting temperature of $1,070{ }^{\circ} \mathrm{C}$. In the temperature $\log$, the temperature below the glass zone appeared to be higher than the glass zone temperature, suggesting that the glass zone cooled more rapidly than the underlying rock. This may have occurred as drilling muds cooled the glass zone in the vicinity of the drillback. It, nevertheless, suggests that the Hard Hat glass zone may have cooled very rapidly. Interestingly, on June 21, 1962, the water level in the cavity was measured in the post-test drillback (Denton, 1962). The water level was found to be at a depth greater than $297 \mathrm{~m}$, which is substantially lower than the hydrostatic $222 \mathrm{~m}$ reported by Pickus (1997). 


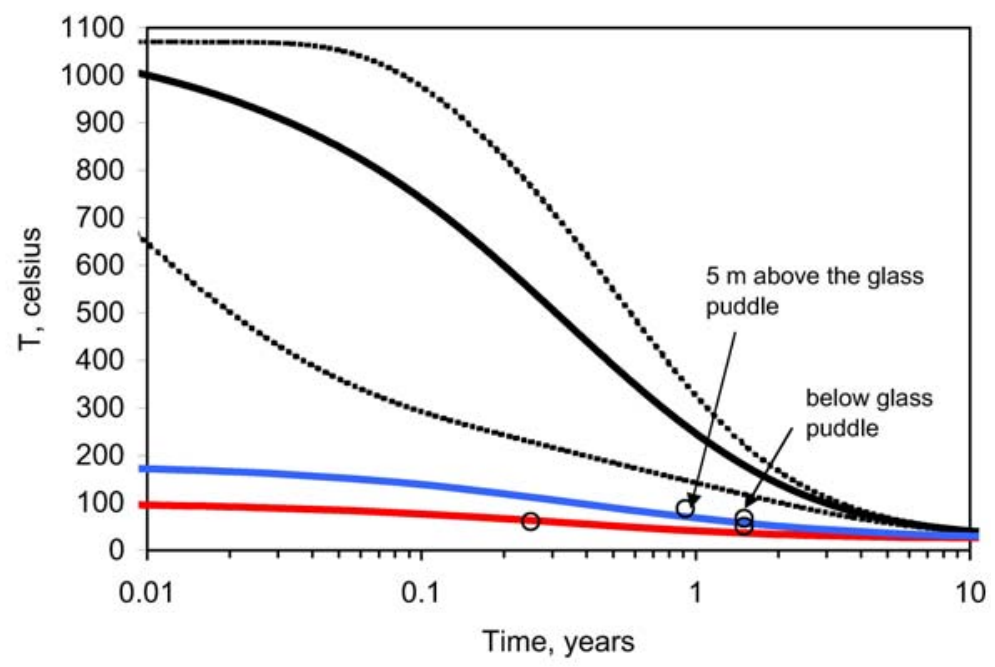

Figure 5-12. Predicted mean temperature history of the Hard Hat test based on the analytical solution with initial temperatures of $100^{\circ} \mathrm{C}$ (red), $180{ }^{\circ} \mathrm{C}$ (blue), and $1,070^{\circ} \mathrm{C}$ (black) and measured data. Dashed lines represent minimum and maximum glass zone temperatures in the $1,070{ }^{\circ} \mathrm{C}$ analytical solution.

On January 20, 1963, nearly one year after the test, an attempt was made to measure the glass zone temperature. The glass zone could not be reached but the temperature just $5 \mathrm{~m}$ above the glass zone was measured at $87^{\circ} \mathrm{C}$ (McArthur, 1963). This is likely to be the most reliable measurement since drilling-related artifacts were unlikely to affect this measurement. This value is also in good agreement with minimum temperature predicted for the glass zone with the $1,070{ }^{\circ} \mathrm{C}$ initial temperature. The minimum temperature in the glass is found at the edge of the glass zone and in proximity of the temperature measurement location.

In summer 1964, the glass zone temperature was measured from hole $\mathrm{H}$ drilled from the exploratory tunnel into the glass zone. The temperature of the glass zone was found to be $50{ }^{\circ} \mathrm{C}$ (Boardman, 1966). Interestingly, the temperature below the glass zone was $67^{\circ} \mathrm{C}$ and was believed to be higher do to the circulation of muds in the high permeability glass and cavity zones. This hypothesis is consistent with the $1,070{ }^{\circ} \mathrm{C}$ analytical solution, which predicts somewhat higher temperatures in the glass zone at that time.

Based on the comparison of measured temperatures and the conduction-only analytical solution, it appears that the analytical solution with a starting temperature of $1,070{ }^{\circ} \mathrm{C}$ is not inconsistent with the few measured data points. The Hard Hat test appears to be located above the regional water table. As a result, it is expected that heat dissipation from the glass zone will be driven primarily by conduction and not convection. Importantly, the mean glass temperature will reach $100^{\circ} \mathrm{C}$ only after 2.9 years. Thus, glass dissolution and groundwater radionuclide transport is not likely to occur before that time.

For the Pile Driver test, the cavity radius is reported to be $44.5 \mathrm{~m}$ (Boardman, 1967). The depth of the glass puddle was not determined from drillback holes. However, hole 3 drilled from the exploratory drift intersected the cavity at $11 \mathrm{~m}$ above the bottom of the cavity and encountered glass. Thus, the glass zone puddle height is greater than $11 \mathrm{~m}$. Unlike the Hard Hat test, the Pile Driver cavity collapsed in less the 14 seconds, suggesting that a 
large fraction of the glass puddle will be composed of infallen rubble. Boardman (1966) reported that the Gnome cavity collapsed very early and the percent melt glass in the puddle was found to be between 23 and 31 percent. If the volume of glass is estimated from the yield $(62 \mathrm{kt})$, a glass production rate of $700 \mathrm{t} / \mathrm{kt}$ yield, a glass density of $2.5 \mathrm{~g} / \mathrm{cm}^{3}$, and 23 percent glass in the glass puddle, the glass puddle volume is $75,500 \mathrm{~m}^{3}$. At this volume, it is estimated that the puddle height is $28 \mathrm{~m}$ and puddle diameter is $76 \mathrm{~m}$. Based on a puddle depth of $28 \mathrm{~m}$ and a total glass volume of $75,500 \mathrm{~m}^{3}$, the conduction-only analytical solution to heat dissipation can be calculated from the glass zone using four initial temperatures, $100{ }^{\circ} \mathrm{C}$ (boiling point at hydrostatic pressure from Murray [1981] water level data), $198{ }^{\circ} \mathrm{C}$ (boiling point at hydrostatic pressure from USGS water levels, $238^{\circ} \mathrm{C}$ (boiling point at hydrostatic pressure from Pickus [1993] water levels), and $477^{\circ} \mathrm{C}$ (initial temperature based on heat capacity and 30 percent total test energy deposited in glass zone, as suggested in Peterson et al. [1991]). All analytical solutions assume an ambient temperature of $25^{\circ} \mathrm{C}$. Results are presented in Figure 5-13.

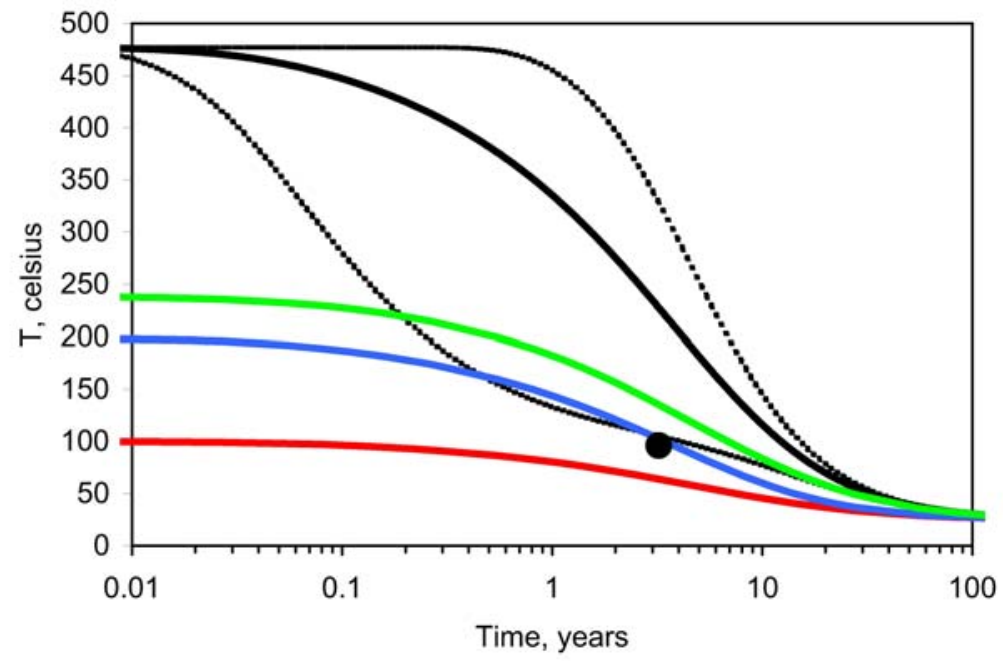

Figure 5-13. Predicted mean temperature history of the Pile Driver test based on the analytical solution with initial temperatures of $100{ }^{\circ} \mathrm{C}$ (red), $198^{\circ} \mathrm{C}$ (blue), $238^{\circ} \mathrm{C}$ (green), and $477{ }^{\circ} \mathrm{C}$ (black) and measured data. Dashed lines represent minimum and maximum glass zone temperatures in the $477^{\circ} \mathrm{C}$ analytical solution.

Only one data point was found for the temperature of the Pile Driver glass zone (Figure 5-13). In August 1969, 3.2 years after the test, a temperature log from hole 3 drilled from the horizontal drift measured a glass zone temperature of $96{ }^{\circ} \mathrm{C}$ at the cavity edge but within the glass zone (Sterrett, 1969). Figure 11 in Sterrett (1969) was compared to the original temperature log collected in August 1969. It was found that the figure in Sterrett incorrectly labeled the $\mathrm{x}$-axis as Temperature in degrees Celsius. The data reported in Figure 11 are actually in degrees Fahrenheit. The $205^{\circ} \mathrm{C}$ peak temperature reported in Figure 11 is, in fact, $96^{\circ} \mathrm{C}$. This value is at the lower limit of predicted glass temperatures using the $477^{\circ} \mathrm{C}$ initial condition. Based on the description of drilling conditions (all hole logs marked as "dry holes"), it appears that water had not returned to the glass zone 3.2 years after the test, which supports the data suggesting that Pile Driver was detonated above the regional 
water table. During drilling of post-test holes, no water was detected to a depth tens of feet below the cavity. Note that, using the $477^{\circ} \mathrm{C}$ initial condition, the mean temperature in the glass zone will drop below $100{ }^{\circ} \mathrm{C}$ only 12 years after the detonation.

For the Tiny Tot test, the yield was not announced and little information is available regarding the condition of the nuclear test cavity. Based on the announced yield range of less than 20kt (DOE, 2000), the maximum size of the cavity is assigned to this test. The cavity radius can be calculated for a 20-kt-yield test, 111-m depth of burial, and 2.66 overburden density to be $70.2 * 20^{1 / 3} /\left(2.66^{*} 111\right)^{1 / 4}=46 \mathrm{~m}$ (though this calculation follows a standard method [Pawloski, 1999], note that it results in a cavity radius that appears illogically large [e.g., compare to Pile Driver, which was a larger announced yield but smaller cavity radius] as a result of the shallow depth of burial and reported yield range. For this reason, the Tiny Tot cavity radius used in the transport model was extrapolated from Hard Hat and Pile Driver, giving a value of $26.3 \mathrm{~m}$ ). The amount of glass produced is calculated to be $5,600 \mathrm{~m}^{3}$. The depth of the glass puddle was not determined from drillbacks. It is estimated that the cavity collapsed early and that the glass zone is composed of 23 percent glass; the glass puddle volume is then $24,300 \mathrm{~m}^{3}$. At this volume, it is estimated that the puddle height is $13.5 \mathrm{~m}$ and the puddle diameter is $65 \mathrm{~m}$. Based on a puddle depth of $13.5 \mathrm{~m}$ and a total glass volume of $24,300 \mathrm{~m}^{3}$, the conduction-only analytical solution to heat dissipation from the glass zone can be calculated using two initial temperatures, $100{ }^{\circ} \mathrm{C}$ (boiling point at hydrostatic pressure) and $478^{\circ} \mathrm{C}$ (initial temperature based on heat capacity and 30 percent total test energy deposited in the glass zone, as suggested in Peterson [1991]). All analytical solutions assume an ambient temperature of $25^{\circ} \mathrm{C}$. Results are presented in Figure 5-14. No temperature data are available for the Tiny Tot test to compare with the analytical solution. Note, that using the $478^{\circ} \mathrm{C}$ initial condition, the mean temperature in the glass zone will drop below $100{ }^{\circ} \mathrm{C}$ only five years after the detonation.

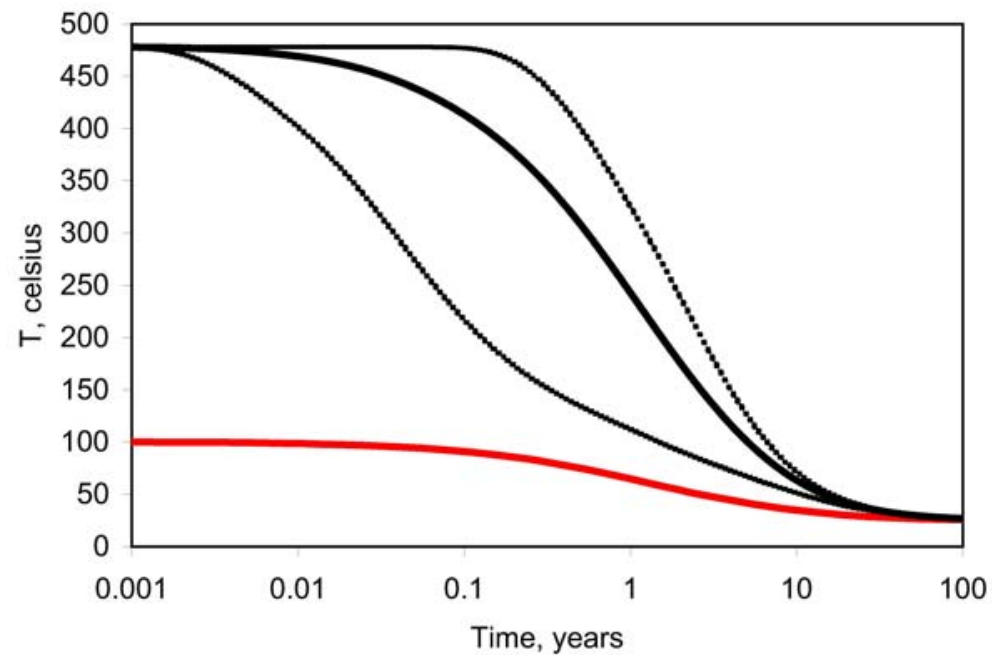

Figure 5-14. Predicted mean temperature history of the Tiny Tot test based on the analytical solution with initial temperatures of $100{ }^{\circ} \mathrm{C}$ (red) and $478^{\circ} \mathrm{C}$ (black). Dashed lines represent minimum and maximum glass zone temperatures in the $478{ }^{\circ} \mathrm{C}$ analytical solution. 


\subsubsection{Radionuclide Release Functions for Melt Glass}

Based on the mean temperature profiles and the glass dissolution model developed in earlier sections of this report, the rate of glass dissolution can be estimated as a function of time. All glass dissolution rates were developed using an initial glass zone temperature based on the energy balance calculation and conduction-only analytical solutions. It was also assumed that glass will begin to dissolve only as water condenses on glass surfaces $\left(\sim 100^{\circ} \mathrm{C}\right.$ in an unsaturated environment). The glass dissolution rates shown in Figure 5-15 are used to develop release rates for each radionuclide class (Table 5-3) from the glass zones of the three tests.

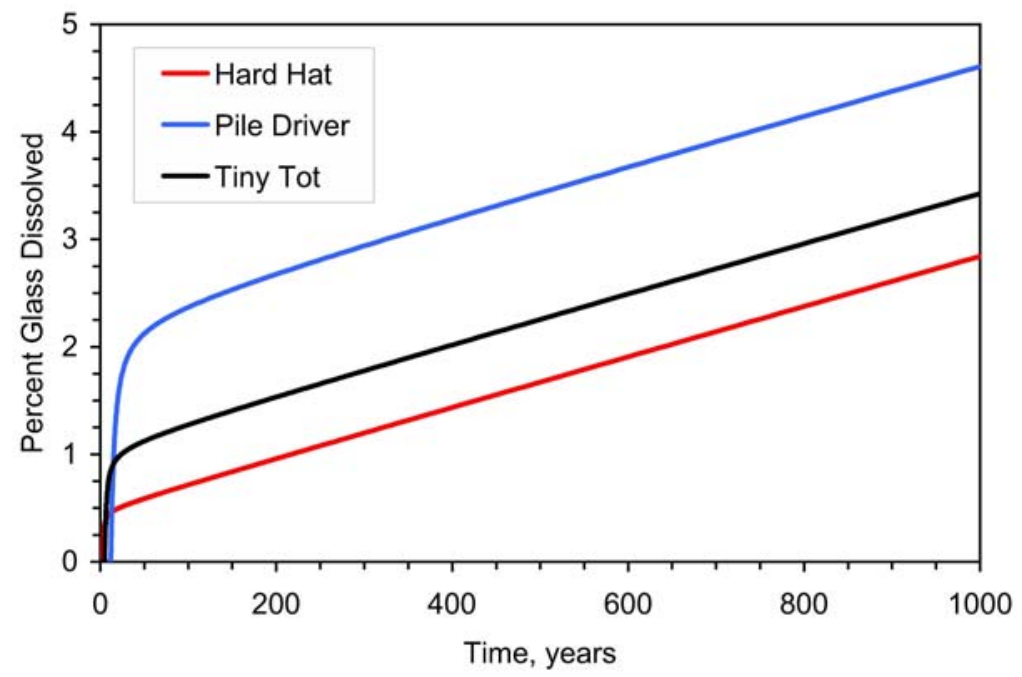

Figure 5-15. Glass dissolution as a function of time for three underground nuclear tests conducted in the Climax stock.

\subsubsection{Retardation Behavior of Radionuclides in the Climax Stock}

Radionuclide sorption occurs as a consequence of chemical reactions at the waterrock interface. The degree of sorption of individual radionuclides is a function of the speciation of the sorbing radionuclide, the water/rock ratio, and mineralogy. Radionuclide sorption will be primarily controlled by the rock mineralogy. Understanding the occurrence and distribution of minerals is a key component to successfully providing an estimate of radionuclide sorption behavior for individual radionuclides.

\subsubsection{Climax Stock Groundwater Chemistry}

A thorough search of the UGTA Geochemical Database (SNJV, 2005b) for the NTS did not reveal any completed wells within the Climax stock from which representative groundwater chemistry could be determined. However, a study associated with the Climax SFT collected and performed water quality analyses on water samples obtained from the Pile Driver and SFT drift complex. A total of five sample locations were established that were repeatedly sampled over a period of several months (Isherwood et al., 1982) (Figures 5-16 and 5-17). Sample locations C-30 and C-36 were established at water seep points in the Pile Driver access shaft at depths of 64 and $73 \mathrm{~m}$, respectively, and are probably representative of 
vertical recharge water. Sample locations NH-01 and CGW-1 were established at water seep points in the drift ceiling at a depth of $420 \mathrm{~m}$ and the water chemistry from these locations can also be interpreted as recharge water (Figure 5-18). Sample location UG-02 was established in an exploratory borehole slant drilled into the floor of the Pile Driver drift with a total hole vertical depth of $165 \mathrm{~m}$ below the floor and $585 \mathrm{~m}$ below land surface. Long-term monitoring of the water level in this borehole established a stabilized depth to water of $565 \mathrm{~m}$ below the land surface (145 m below the drift floor with $20 \mathrm{~m}$ of standing water in the borehole). The fact that a stabilized free-water surface was established in this borehole generally supports the conclusion that UG-02 provides a representation of a groundwater sampling location, though it is possible that UG-02 is actually a perched water table and is not hydraulically connected to the regional Climax stock groundwater system.

The samples collected from UG-02 were obtained with a Bennett pump. The borehole was repeatedly pumped over a period of several months to remove water for chemical analysis. During these pumping events, the borehole was also pumped dry to promote formation water transport into the borehole. When the repeated chemical analysis of these samples demonstrated a stable water chemistry, three samples were then obtained approximately a month apart, and the analyses from these samples were averaged and reported in Isherwood et al. (1982) (Table 5-6). The geochemistry reported in UG-02 is used in the mechanistic model simulations of radionuclide transport to estimate the sorption parameters for the radionuclide inventory, and to estimate glass dissolution rates. Isherwood et al. (1982) noted that relatively high levels of tritium were detected in the pumped water from UG-02 as well as the seeps located in the Climax SFT tunnel complex. They suggested that this tritium was derived from the Pile Driver test.

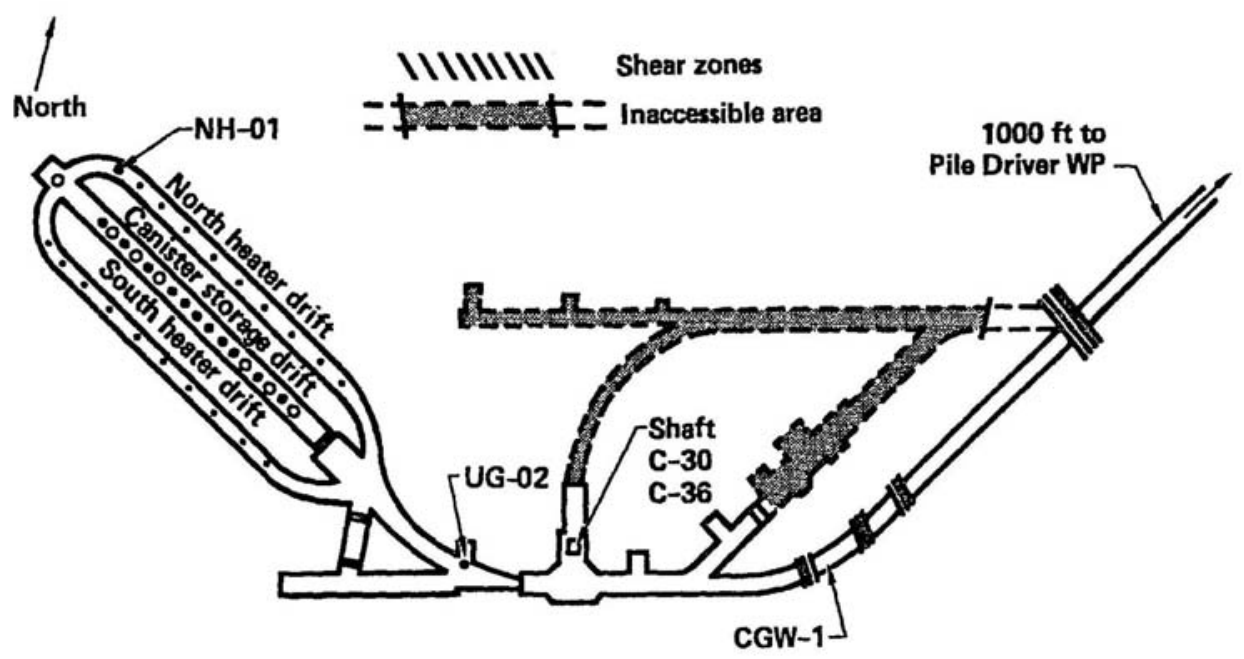

Figure 5-16. Plan view of the Spent Fuel Test facility and adjacent workings with the subsurface water collection points reported in Isherwood et al. (1982). 


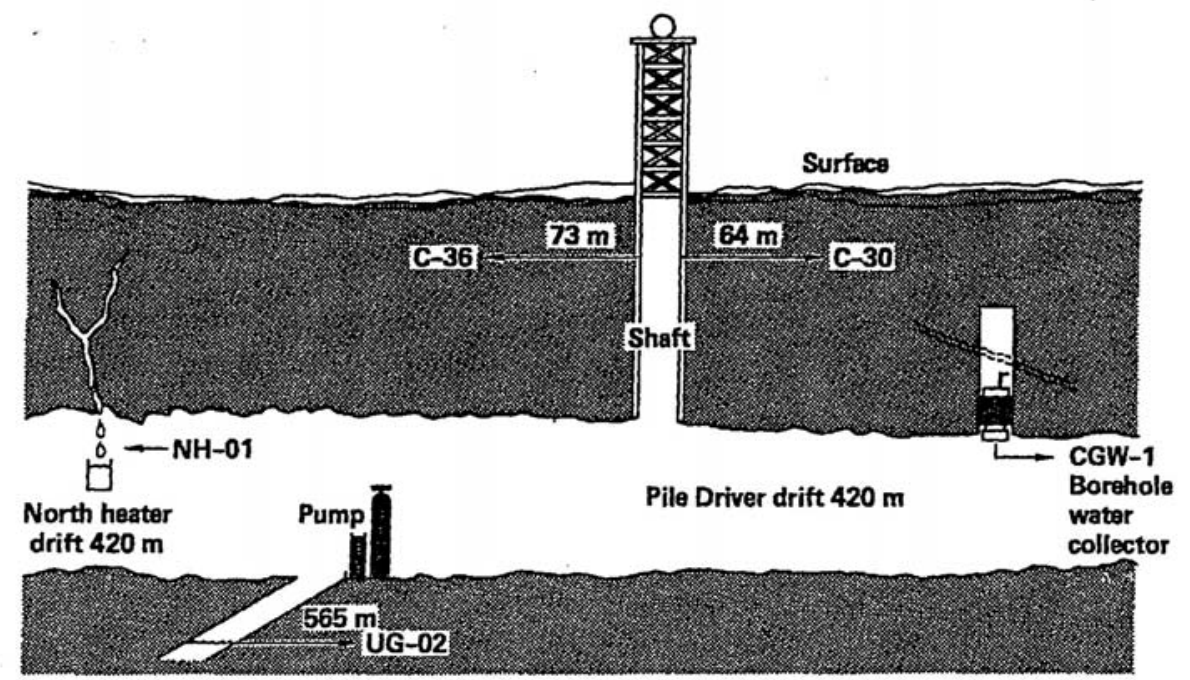

Figure 5-17. Cross-sectional view of the Spent Fuel Test facility tunnel and access shaft with the water sampling locations reported in Isherwood et al. (1982). These represent mean values calculated from 10 samples of CGW-1, three samples of UG-02, and two samples each of C-30 and C-36. NH-01 is a single sample.
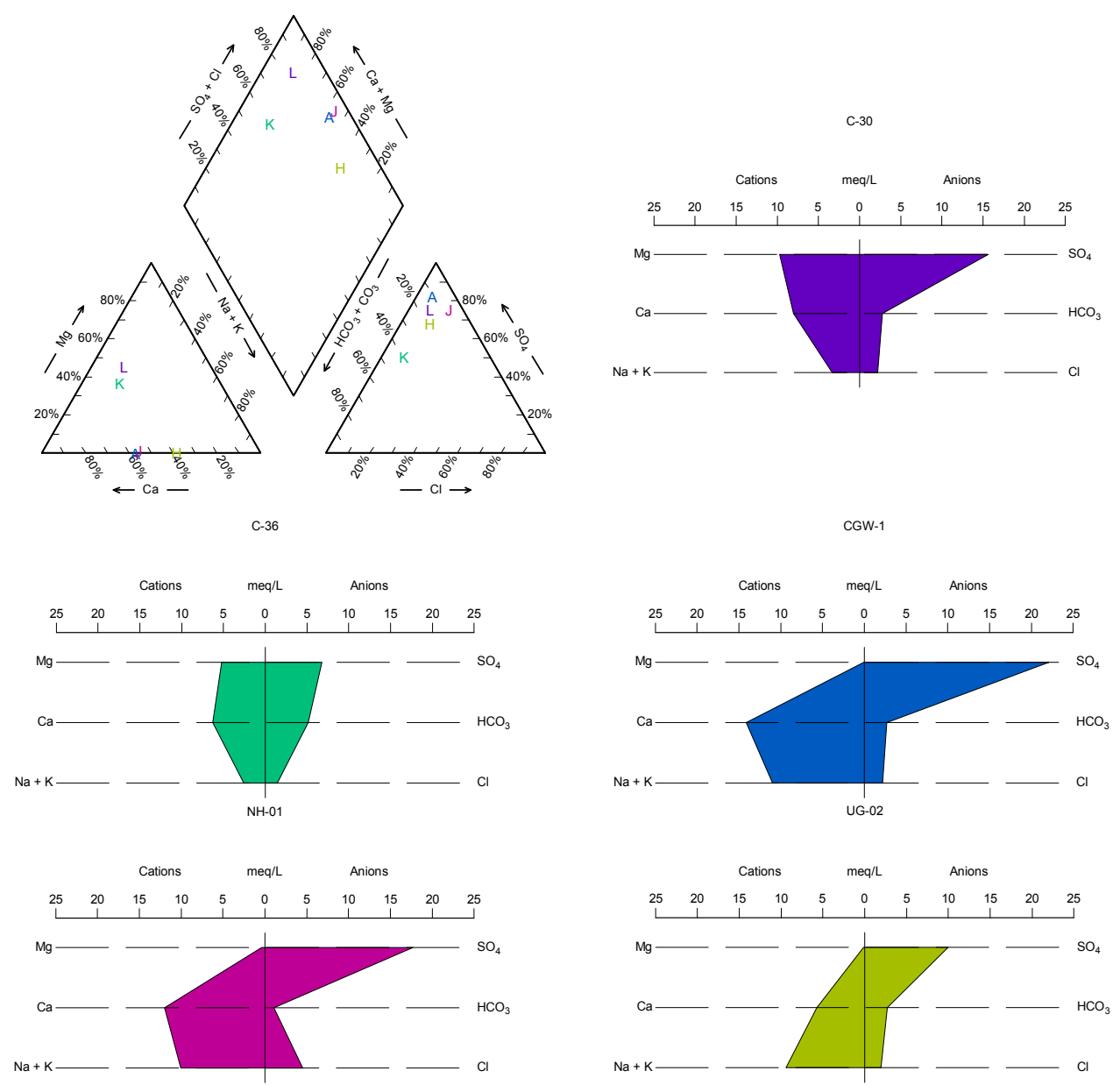

Figure 5-18. Piper/stiff diagrams for the five sample locations reported in Isherwood et al. (1982). 


\subsubsection{Climax Stock Mineralogy}

The Climax stock mineralogy has been examined and reported on by several research teams in the past several decades in work associated with the three tests in the stock, and in the later work on the SFT-C. Tables 5-7 through 5-11 report Climax stock mineralogy from several sources, and are presented as a compilation of the available mineralogical information for the Climax stock.

Table 5-7. Modal analysis of samples obtained from SFT canister emplacement boreholes, Appendix B2, Ryerson and Qualheim (1983). Selection of samples of core taken from canister emplacement holes was based on the criteria that the sample represented as closely as possible "fresh" unaltered rock free of fractures (Qualheim [1983] pp. 6). Data reported as mineral volume percent.

\begin{tabular}{lccccccccccccccccccc}
\hline Mineral Hole & 1 & 2 & 3 & 4 & 5 & 6 & 7 & 8 & 9 & 10 & 11 & 12 & 13 & 14 & 15 & 16 & 17 & Avg & S.D. \\
\hline Plagioclase & 38.2 & 40.9 & 37.5 & 30.5 & 51.8 & 37.9 & 45.8 & 45.0 & 47.5 & 43.3 & 49.9 & 36.9 & 41.3 & 39.2 & 44.8 & 36.7 & 49.8 & 42.2 & 5.8 \\
K-Feldspar & 28.5 & 22.7 & 27.8 & 37.5 & 23.9 & 33.4 & 20.3 & 32.3 & 21.0 & 23.8 & 24.1 & 21.5 & 27.2 & 31.5 & 19.6 & 30.6 & 25.4 & 26.5 & 5.2 \\
Quartz & 20.2 & 22.2 & 17.9 & 23.2 & 16.3 & 18.9 & 22.9 & 15.7 & 21.6 & 22.6 & 17.1 & 29.0 & 23.0 & 21.3 & 27.0 & 18.0 & 16.5 & 20.8 & 3.8 \\
Biotite & 7.4 & 9.4 & 2.6 & 5.6 & 4.0 & 5.1 & 5.8 & 4.8 & 3.7 & 6.2 & 5.7 & 6.6 & 4.3 & 3.4 & 5.2 & 8.0 & 5.4 & 5.5 & 1.7 \\
Muscovite & 1.8 & 0.2 & 6.1 & 0.4 & 1.2 & 0.8 & 1.0 & 0.5 & 0.8 & 1.0 & 0.3 & 0.6 & 0.7 & 0.4 & 1.0 & 0.3 & 0.3 & 1.0 & 1.4 \\
Chlorite & 0.5 & 0.3 & 0.2 & 0.2 & 0.5 & 1.1 & 0.5 & 0.1 & 0.4 & 0.6 & 0.2 & 0.4 & 0.8 & 0.3 & 0.2 & 1.1 & 0.2 & 0.4 & 0.3 \\
Calcite & 1.7 & 0.7 & 2.4 & 0.6 & 0.6 & 0.4 & 0.4 & 0.3 & 0.4 & 0.5 & 0.6 & 0.6 & 0.6 & 0.6 & 0.3 & 1.0 & 0.1 & 0.7 & 0.6 \\
Clinozoisite & 0.0 & 0.0 & 2.1 & 0.1 & 0.2 & 0.2 & 0.0 & 0.0 & 0.2 & 0.0 & 0.0 & 0.4 & 0.2 & 0.2 & 0.0 & 0.1 & 0.0 & 0.2 & 0.5 \\
Epidote & 0.3 & 0.2 & 0.2 & 0.3 & 0.2 & 0.4 & 0.5 & 0.1 & 0.1 & 0.8 & 0.2 & 0.7 & 0.2 & 0.2 & 0.4 & 0.4 & 0.2 & 0.3 & 0.2 \\
Kaolinite & 0.0 & 0.0 & 0.0 & 0.0 & 0.0 & 0.0 & 0.0 & 0.0 & 0.0 & 0.0 & 0.0 & 0.0 & 0.0 & 0.0 & 0.0 & 0.0 & 0.0 & 0.0 & 0.0 \\
Titanite & 0.4 & 1.4 & 0.8 & 0.4 & 0.6 & 0.4 & 1.2 & 0.3 & 0.2 & 0.5 & 0.8 & 1.0 & 0.5 & 1.0 & 0.3 & 1.8 & 0.6 & 0.7 & 0.4 \\
Rutile & 0.0 & 0.2 & 0.0 & 0.1 & 0.0 & 0.1 & 0.0 & 0.0 & 0.9 & 0.0 & 0.1 & 0.0 & 0.0 & 0.0 & 0.0 & 0.0 & 0.0 & 0.1 & 0.2 \\
Magnetite & 0.0 & 0.0 & 0.0 & 0.0 & 0.0 & 0.0 & 0.0 & 0.0 & 0.0 & 0.0 & 0.0 & 0.0 & 0.0 & 0.0 & 0.0 & 0.0 & 0.0 & 0.0 & 0.0 \\
Hematite & 0.0 & 0.0 & 0.0 & 0.0 & 0.0 & 0.0 & 0.0 & 0.0 & 0.0 & 0.0 & 0.0 & 0.0 & 0.0 & 0.0 & 0.0 & 0.0 & 0.0 & 0.0 & 0.0 \\
Pyrite & 0.9 & 1.9 & 2.3 & 1.2 & 1.8 & 1.4 & 1.7 & 1.0 & 2.6 & 0.8 & 0.0 & 2.1 & 1.3 & 1.9 & 1.3 & 1.8 & 1.5 & 1.5 & 0.6 \\
\hline
\end{tabular}

Table 5-8. Climax stock rock mineralogy, Maldonado (1977).

\begin{tabular}{|c|c|c|c|c|c|c|c|c|c|c|c|}
\hline & \multicolumn{5}{|c|}{ Granodiorite, weight \% } & \multicolumn{6}{|c|}{ Quartz Monzonite, weight \% } \\
\hline & HG-7 & FP-65 & FP-62 & HT-8 & average & G-70 & G-800-0 & FP-63 & HG-10 & G-277-0 & average \\
\hline Orthoclase & 19.5 & 21.3 & 20.1 & 16 & 19.2 & 20.1 & 23.1 & 30.1 & 23.6 & 33.1 & 26.0 \\
\hline Albite & 26.2 & 28.7 & 27 & 33 & 28.7 & 28.7 & 25.4 & 25.3 & 25.4 & 22.8 & 25.5 \\
\hline Anorthite & 16.7 & 14.8 & 18.2 & 20.5 & 17.6 & 17.4 & 16.2 & 8.1 & 13.5 & 13.6 & 13.8 \\
\hline Ilmenite & 0.7 & 0.6 & 0.9 & 0.9 & 0.8 & 0.7 & 0.7 & 0.4 & 0.6 & 0.7 & 0.6 \\
\hline Magnetite & 2.5 & 2.3 & 2.8 & 2.5 & 2.5 & 1.9 & 2.5 & 0.5 & 2.2 & 1.6 & 1.7 \\
\hline Hematite & 0.0 & 0.0 & 0.0 & 0.0 & 0.0 & 0.0 & 0.0 & 0.3 & 0 & 0 & 0.1 \\
\hline Quartz & 29.3 & 28.6 & 26.6 & 20.7 & 26.3 & 25.6 & 27.2 & 30.2 & 31 & 22.7 & 27.3 \\
\hline Corundum & 0.8 & 0.6 & 0.6 & 0.2 & 0.6 & 0.4 & 1 & 2.5 & 0.7 & 1 & 1.1 \\
\hline Hypersthene & 2.7 & 2.1 & 2.5 & 4.4 & 2.9 & 3.6 & 2.9 & 0.4 & 2.1 & 2.6 & 2.3 \\
\hline Apatite & 0.2 & 0.2 & 0.2 & 0.3 & 0.2 & 0.2 & 0.2 & 0.2 & 0.2 & 0.3 & 0.2 \\
\hline
\end{tabular}


Table 5-9. Chemical analysis of samples from the southwest part of the Climax intrusive, Borg (1970).

HG-7 $\quad$ HG-8 $\quad$ FP-62 $\quad$ FP-63

Granodiorite, weight \% Granodiorite, weight \% Granodiorite, weight \% Quartz Monzonite, weight \%

\begin{tabular}{lcccc}
\hline $\mathrm{SiO}_{2}$ & 68.6 & 68.2 & 67.5 & 70.8 \\
$\mathrm{Al}_{2} \mathrm{O}_{3}$ & 15.6 & 16.1 & 16.2 & 15.9 \\
$\mathrm{Fe}_{2} \mathrm{O}_{3}$ & 1.7 & 1.7 & 1.9 & 0.6 \\
$\mathrm{FeO}$ & 1.7 & 1.5 & 1.7 & 0.34 \\
$\mathrm{MgO}$ & 0.64 & 0.52 & 0.7 & 0.16 \\
$\mathrm{CaO}$ & 3.6 & 3.3 & 3.9 & 1.8 \\
$\mathrm{Na} 2 \mathrm{O}$ & 3.1 & 3.1 & 3.2 & 3 \\
$\mathrm{~K}_{2} \mathrm{O}$ & 3.3 & 3.5 & 3.4 & 5.1 \\
$\mathrm{H}_{2} \mathrm{O}$ & 0.7 & 0.8 & 0.83 & 1.1 \\
$\mathrm{TiO}_{2}$ & 0.38 & 0.4 & 0.46 & 0.22 \\
$\mathrm{P}_{2} \mathrm{O}_{5}$ & 0.18 & 0.18 & 0.18 & 0.13 \\
$\mathrm{MnO}$ & 0.06 & 0.04 & 0.07 & 0.02 \\
$\mathrm{CO}_{2}$ & 0.08 & 0.06 & 0.08 & 0.04 \\
\hline
\end{tabular}

Table 5-10. Average chemical composition in weight percent of granodiorite and quartz monzonite from the Climax stock, Maldonado (1977).

\begin{tabular}{lcc}
\hline & Granodiorite, (avg. of 24 samples) & Quartz Monzonite, (avg. of 24 samples) \\
\hline $\mathrm{SiO}_{2}$ & 67.6 & 69.1 \\
$\mathrm{Al}_{2} \mathrm{O}_{3}$ & 15.8 & 15.8 \\
$\mathrm{Fe}_{2} \mathrm{O}_{3}$ & 1.8 & 1.5 \\
$\mathrm{FeO}$ & 1.6 & 1.3 \\
$\mathrm{MgO}$ & 0.82 & 0.6 \\
$\mathrm{CaO}$ & 3.7 & 3.2 \\
$\mathrm{Na}_{2} \mathrm{O}$ & 3.1 & 3.0 \\
$\mathrm{~K}_{2} \mathrm{O}$ & 3.5 & 3.9 \\
$\mathrm{H}_{2} \mathrm{O}$ & 1.0 & 0.89 \\
$\mathrm{TiO}_{2}$ & 0.39 & 0.40 \\
$\mathrm{P}_{2} \mathrm{O}_{5}$ & 0.18 & 0.21 \\
$\mathrm{MnO}$ & 0.07 & 0.04 \\
$\mathrm{CO}_{2}$ & 0.20 & 0.10 \\
\hline
\end{tabular}


Table 5-11. Rock properties and mineral volume percentages of altered quartz monzonite, Connolly (1981).

\begin{tabular}{cccccc}
\hline & \multicolumn{5}{c}{ Alteration Type } \\
& Deuteric & Propylitic & Argillic & Phyllic & Potassic \\
\cline { 2 - 6 } Dry Bulk Density, g/cm & $2.65 \pm 0.01$ & $2.65 \pm 0.01$ & $2.57 \pm 0.01$ & & $2.51 \pm 0.06$ \\
Grain Density, $\mathrm{g} / \mathrm{cm}^{3}$ & $2.69 \pm 0.01$ & $2.70 \pm 0.01$ & $2.65 \pm 0.01$ & $2.67 \pm 0.01$ & $2.62 \pm 0.01$ \\
Calculated Porosity, \% & $1.49 \pm 0.37$ & $1.85 \pm 0.56$ & $3.02 \pm 0.74$ & & $4.20 \pm 0.93$ \\
Mineral & \multicolumn{5}{c}{ Volume Percent } \\
Plagioclase & $42.85 \pm 1.08$ & $39.16 \pm 2.38$ & $9.39 \pm 2.49$ & $20.45 \pm 0.01$ & $11.85 \pm 2.46$ \\
K-feldspar & $17.97 \pm 0.82$ & $17.97 \pm 0.82$ & $17.97 \pm 0.82$ & $17.97 \pm 082$ & $56.88 \pm 3.89$ \\
Quartz & $27.17 \pm 1.23$ & $27.17 \pm 1.23$ & $27.17 \pm 1.23$ & $27.17 \pm 1.23$ & $4.83 \pm 2.57$ \\
Biotite & $5.38 \pm 0.53$ & $4.44 \pm 0.80$ & $3.26 \pm 0.97$ & -- & -- \\
Muscovite & $1.48 \pm 0.28$ & $3.27 \pm 0.74$ & $6.27 \pm 3.29$ & $24.59 \pm 6.73$ & $12.89 \pm 2.55$ \\
Chlorite & $0.99 \pm 0.18$ & $1.28 \pm 0.34$ & $0.02 \pm 0.04$ & -- & $0.04 \pm 0.08$ \\
Calcite & $0.30 \pm 0.08$ & $1.34 \pm 0.35$ & $8.13 \pm 1.94$ & $4.83 \pm 1.69$ & $5.20 \pm 0.93$ \\
Clinozoisite & $0.55 \pm 0.05$ & $0.55 \pm 0.05$ & -- & -- & - \\
Epidote & $0.18 \pm 0.02$ & $0.18 \pm 0.02$ & -- & -- & - \\
Kaolinite & -- & $0.57 \pm 0.85$ & $22.64 \pm 5.42$ & $0.52 \pm 0.97$ & -- \\
Smectite & $0.07 \pm 0.05$ & $0.46 \pm 0.37$ & $0.50 \pm 0.39$ & $0.22 \pm 0.45$ & - \\
Titanite & $0.44 \pm 0.10$ & $0.27 \pm 0.10$ & -- & $0.05 \pm 0.13$ & - \\
Rutile & -- & $0.17 \pm 0.12$ & $0.74 \pm 0.16$ & $0.54 \pm 0.65$ & $0.53 \pm 0.16$ \\
Magnetite & $0.78 \pm 0.17$ & $0.31 \pm 0.12$ & -- & -- & -- \\
Hematite & -- & $0.13 \pm 0.05$ & $0.43 \pm 0.17$ & -- & -- \\
Pyrite & $0.03 \pm 0.03$ & $0.16 \pm 0.06$ & $0.15 \pm 0.13$ & $1.33 \pm 1.04$ & $0.46 \pm 0.20$ \\
\hline
\end{tabular}

The most comprehensive study of the Climax stock mineralogy is provided by Connolly (1981). This study is referred to by several later project reports associated with the SFT work. Connolly collected rock samples from the SFT study tunnel complex, including the SFT north- and south-heater drifts, and the canister drift. Connolly performed a detailed mineralogical analysis of the Climax stock quartz monzonite with an emphasis on hydrothermal alteration. Connolly categorized the quartz monzonite into five major alteration types, and performed an optical petrographic mineral analysis using point-counting methods on samples from each alteration type (Table 5-11). Deuteric alteration is described as a high-temperature process, wherein primary rock minerals are replaced with secondary mineralogy. Deuteric alteration temperatures can occur within a wide range from near rock melt temperatures to a few hundred degrees centigrade. Connolly classified deuteric alteration in the Climax quartz monzonite as plagioclase altering to muscovite, clinozoisite, calcite, potassium feldspar and smectite, and biotite altering to epidote, chlorite, and muscovite (Connolly, 1981, pp. 35). In turn, the deuteric rock alters to each of the remaining alteration types through exposure with hydrothermal fluids. Propylitic alteration is associated with high modal abundances of chlorite and epidote. In the Climax quartz monzonite, modal abundances of chlorite and epidote are quite similar for both propylitic and deuteric rock. The principal distinguishing characteristic of the propylitic alteration is the occurrence of rutile, hematite, and kaolinite, which are not present in deuteric alteration. Argillic alteration is characterized by high modal abundances of clay minerals such as kaolinite, smectite, and illite. Phyllic alteration is associated with high modal abundances of pyrite and calcite. 
Potassic alteration is associated with high modal abundances of biotite, plagioclase, and $\mathrm{k}$-feldspar and low modal abundances of quartz. Connolly concluded that following deuteric alteration, additional fracture-controlled hydrothermal alteration occurred, which resulted in the formation of the remaining alteration types. This secondary alteration sequence occurred as a consequence of a single hydrothermal fluid intrusion episode, and that alteration effects extend less than a meter beyond fracture apertures into the primary rock matrix. The alteration sequence, from the fracture wall extending into the rock matrix, occurs in the general order of potassic, phyllic, argillic, propylitic, and deuteric.

Radionuclide sorption occurs on granite matrix mineral surfaces that are exposed in rock fractures. While the presence of fracture coating minerals has been observed in Climax stock fractures, detailed mineralogy and spatial distribution information is not available in sufficient detail to assemble a defensible model of radionuclide sorption onto these minerals.

\subsubsection{Sorption Information for the Climax Stock and Analogous Environments}

Sorption parameter information has been collected from a combination of scientific literature, U.S. Department of Energy project reports, and foreign agency reports. There are a number of radionuclide transport laboratory studies that have been conducted on the Climax stock granite that contain useful sorption parameter information. In addition, other nuclear-capable countries have considered granitic formations for nuclear waste repositories and have reported on the sorption characteristics of radionuclides in these target formations.

\subsection{Climax-stock-specific Studies}

The Climax stock was the subject of an intensive period of research associated with the SFT in the mid-1980s. This research included laboratory studies to estimate radionuclide transport characteristics in crushed granite and granodiorite collected from test boreholes and Pile Driver drift tailings in the Climax stock. Sorption data are reported for experiments that were conducted in the $\mathrm{pH}$ range of 7 to 8.5 and with synthetic groundwater chemistries in Table 5-12. Synthetic groundwater for these studies was prepared based on an average 'granite-type' synthetic water chemistry using the water quality analyses of spring and seeps in granite in the Sierra Nevada Mountains of California and Nevada reported in Feth et al. (1964) (Maclean et al., 1978; Erdal et al., 1979; Treyer and Raybold, 1982), by choosing a 'representative' chemistry (Coles et al.,1980), or by reacting the Feth et al. (1964) water with rock collected from the Pile Driver drift tailings dump prior to initiating a batch experiment (Treyer and Raybold, 1982). Erdal et al. (1979) contains an analysis of the synthetic water used in these experiments. 
Table 5-12. Log $K_{d}$ values determined from laboratory batch experiments on samples collected from the Climax stock.

\begin{tabular}{|c|c|c|c|c|c|c|c|c|}
\hline \multirow[b]{2}{*}{ Radionuclide } & \multicolumn{5}{|c|}{ Observed Values, $\mathrm{ml} / \mathrm{g}$} & \multicolumn{2}{|c|}{$\begin{array}{l}\text { Computed } \\
\text { Values, } \mathrm{ml} / \mathrm{g}\end{array}$} & \multirow{2}{*}{ References } \\
\hline & Average & S.D. & Min & Max & $\begin{array}{l}\text { No. of } \\
\text { Obs. }\end{array}$ & $-\sigma$ & $+\sigma$ & \\
\hline $\mathrm{Ca}$ & $\mathrm{NA}^{1}$ & & & & & & & \\
\hline $\mathrm{Ni}$ & NA & & & & & & & \\
\hline $\mathrm{Sr}$ & 1.74 & 0.77 & 0.81 & 2.78 & 17 & 0.97 & 2.51 & $\begin{array}{l}\text { Maclean et al. (1978); Erdal et al. (1979); } \\
\text { Treyer and Raybold, } 1982\end{array}$ \\
\hline $\mathrm{Zr}$ & NA & & & & & & & \\
\hline $\mathrm{Nb}$ & NA & & & & & & & \\
\hline $\mathrm{Pd}$ & NA & & & & & & & \\
\hline $\mathrm{Sn}$ & NA & & & & & & & \\
\hline Cs & 2.96 & 0.44 & 2.33 & 4.11 & 17 & 2.52 & 3.40 & $\begin{array}{l}\text { Maclean et al. (1978); Erdal et al. (1979); } \\
\text { Treyer and Raybold, } 1982\end{array}$ \\
\hline $\mathrm{Sm}$ & NA & & & & & & & \\
\hline $\mathrm{Eu}$ & 3.16 & 0.49 & 2.56 & 3.98 & 7 & 2.67 & 3.64 & $\begin{array}{l}\text { Erdal et al. (1979); Treyer and Raybold, } \\
1982\end{array}$ \\
\hline $\mathrm{U}$ & 0.54 & 0.45 & 0.11 & 1.02 & 3 & 0.09 & 0.99 & Erdal et al. (1979) \\
\hline $\mathrm{Np}$ & NA & & & & & & & \\
\hline $\mathrm{Pu}$ & 3.51 & 0.51 & 2.92 & 4.30 & 12 & 3.00 & 4.03 & Erdal et al. (1979); Coles et al. (1980) \\
\hline $\mathrm{Am}$ & 3.58 & 0.15 & 3.38 & 3.83 & 6 & 3.43 & 3.74 & Erdal et al. (1979) \\
\hline
\end{tabular}

${ }^{1}$ There were no studies that examined and reported sorption $\mathrm{K}_{\mathrm{d}}$ for $\mathrm{Ca}, \mathrm{Ni}, \mathrm{Zr}, \mathrm{Nb}, \mathrm{Pd}, \mathrm{Sn}, \mathrm{Sm}$ and $\mathrm{Np}$ on Climax stock granites.

\subsection{Sorption Studies on Other Granitic Formations}

Taiwan, Japan, Sweden, and Norway have conducted extensive research on the efficacy of using granitic rock formations for the purposes of nuclear waste repository placement. A large body of literature has been published that reports the results of geochemical and hydrogeologic research on these formations. This work is useful to the Climax stock modeling effort because of the similarities in geology and mineralogy among these granitic formations. The studies included in Table 5-13 report batch sorption data for either formation water collected from the study site or a synthetically prepared water. Studies and data are excluded from this table that fall outside of the $\mathrm{pH}$ range of 7 to 8.5, or used distilled and deionized water or saline/seawater as part of the batch sorption experiments. Where time-series data are reported, only the $K_{d}$ s for the longest reaction times are included in the dataset. Several of the studies reported here were found through the Japan Nuclear Cycle Development Institute radionuclide sorption database (Shibutani et al., 1999; Suyama and Sasamoto, 2004; Saito et al., 2007). 
Table 5-13. $\log K_{d}$ values determined from laboratory batch experiments on whole-rock granite samples from the available literature.

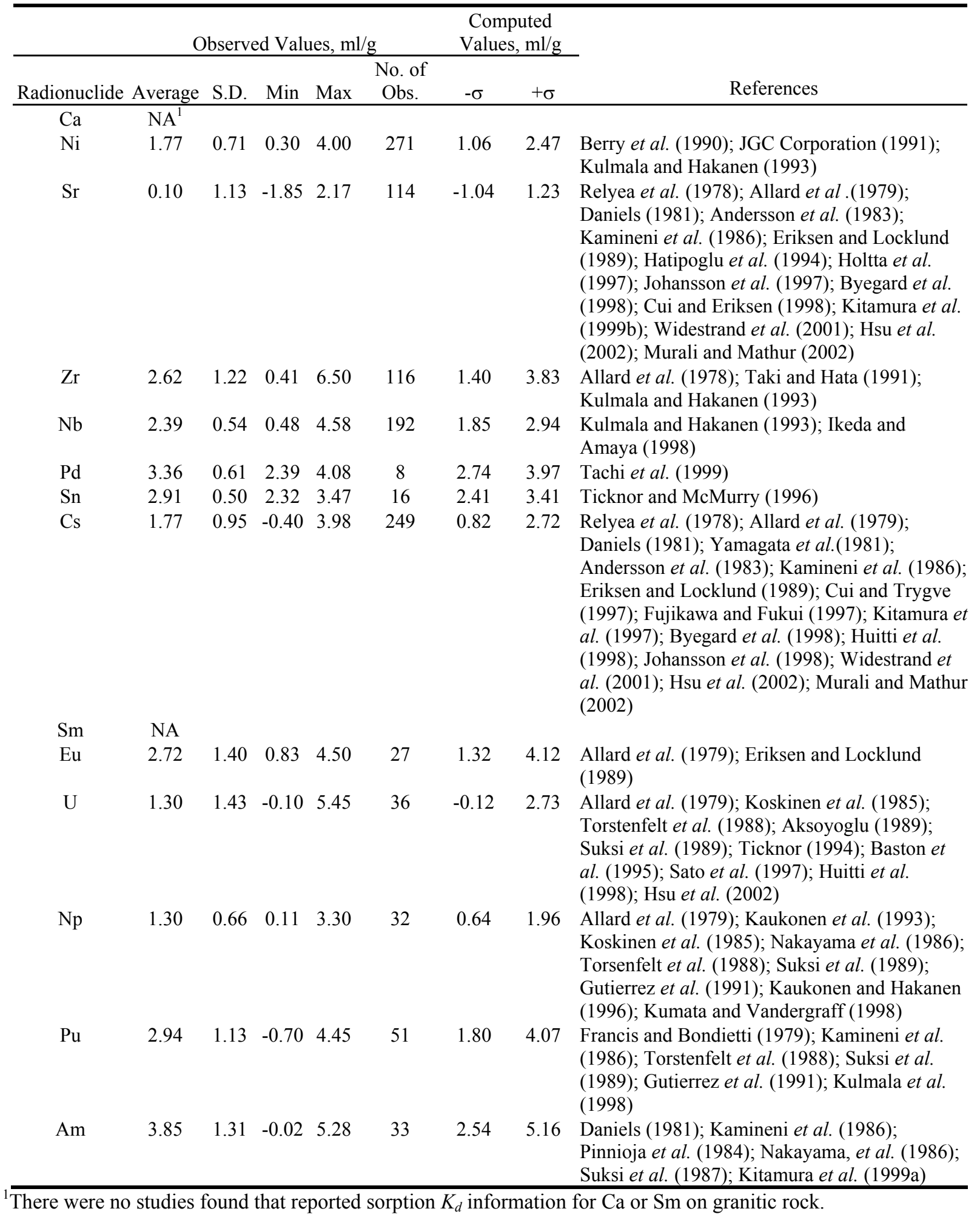


The studies that report radionuclide sorption data on granites other than the Climax stock can be sorted into two types. First, many of the references given in Table 5-13 are nuclear agency reports with an unknown and likely varying review process. A second type of literature also is reported in Table 5-13 and includes studies presented in the scientific openliterature in peer-reviewed journals. In consideration of the possibility of differences in data quality between the two types of literature that produced sorption information, the data in Table 5-13 have been split into these two groups, and are shown in comparison with all available sorption data specific to the Climax stock in Table 5-14 and computed $K_{d}$ ranges are presented in Table 5-15 for one-sigma. A graphical representation of the statistical properties of the data is possible with a box plot. Box plots for the available literature on radionuclide sorption on granites are given in Figure 5-19 as four separate box plots:

(a) Climax stock literature, (b) agency reports or 'gray literature' for all worldwide granites (except the Climax stock), (c) the open-science literature, and (d) all available data combined.

Table 5-14. Summary of radionuclide $\log K_{d}$ s for the Climax stock and other granites worldwide.

\begin{tabular}{ccccccc}
\hline & \multicolumn{2}{c}{$\begin{array}{c}\text { Open science literature, } \\
\text { worldwide granites }\end{array}$} & $\begin{array}{c}\text { Non-DOE nuclear power } \\
\text { agency reports, worldwide } \\
\text { granites }\end{array}$ & \multicolumn{2}{c}{$\begin{array}{c}\text { Climax stock project } \\
\text { reports }\end{array}$} \\
Component & Avg, ml/g & $\sigma(\mathrm{n}){ }^{1}$ & Avg, ml/g & $\sigma(\mathrm{n})$ & Avg, ml/g & $\sigma(\mathrm{n})$ \\
\hline $\mathrm{Ca}$ & $\mathrm{NA}$ & $\mathrm{NA}$ & $\mathrm{NA}$ & $\mathrm{NA}$ & $\mathrm{NA}$ & $\mathrm{NA}$ \\
$\mathrm{Ni}$ & $\mathrm{NA}$ & $\mathrm{NA}$ & 1.77 & $0.71(271)$ & $\mathrm{NA}$ & $\mathrm{NA}$ \\
$\mathrm{Sr}$ & 0.69 & $0.90(25)$ & -0.07 & $1.14(89)$ & 1.74 & $0.77(17)$ \\
$\mathrm{Zr}$ & 3.42 & $0.26(12)$ & 2.52 & $1.25(104)$ & $\mathrm{NA}$ & $\mathrm{NA}$ \\
$\mathrm{Nb}$ & $\mathrm{NA}$ & $\mathrm{NA}$ & 2.39 & $0.54(192)$ & $\mathrm{NA}$ & $\mathrm{NA}$ \\
$\mathrm{Pd}$ & $\mathrm{NA}$ & $\mathrm{NA}$ & 3.36 & $0.61(8)$ & $\mathrm{NA}$ & $\mathrm{NA}$ \\
$\mathrm{Sn}$ & 2.91 & $0.50(16)$ & $\mathrm{NA}$ & $\mathrm{NA}$ & $\mathrm{NA}$ & $\mathrm{NA}$ \\
$\mathrm{Cs}$ & 1.58 & $0.63(18)$ & 1.79 & $0.97(229)$ & 2.96 & $0.44(17)$ \\
$\mathrm{Sm}$ & $\mathrm{NA}$ & $\mathrm{NA}$ & $\mathrm{NA}$ & $\mathrm{NA}$ & $\mathrm{NA}$ & $\mathrm{NA}$ \\
$\mathrm{Eu}$ & 4.19 & $0.19(12)$ & 1.54 & $0.52(15)$ & 3.16 & $0.49(7)$ \\
$\mathrm{U}$ & 1.45 & $1.58(28)$ & 0.80 & $0.40(8)$ & 0.54 & $0.45(3)$ \\
$\mathrm{Np}$ & 1.54 & $0.45(16)$ & 1.05 & $0.75(16)$ & $\mathrm{NA}$ & $\mathrm{NA}$ \\
$\mathrm{Pu}$ & 2.22 & $0.45(10)$ & 3.00 & $1.18(45)$ & 3.51 & $0.51(12)$ \\
$\mathrm{Am}$ & 3.59 & $1.10(10)$ & 3.96 & $1.39(23)$ & 3.58 & $0.15(6)$ \\
\hline
\end{tabular}

${ }^{1}$ The average and standard deviation $(\sigma)$ are calculated from the sorption data found (number of data points, $n$ ) for each radionuclide.

Box plots graph data as a box representing statistical values. The boundary of the box closest to zero indicates the 25 th percentile, the black line within the box marks the median, the red line within the box represents the mean, and the boundary of the box farthest from zero indicates the 75 th percentile. The whiskers above and below the box indicate the $90^{\text {th }}$ and $10^{\text {th }}$ percentiles. Outlying points beyond the $10^{\text {th }}$ and $90^{\text {th }}$ percentiles are represented by black dots. 
Table 5-15. Summary of radionuclide $\log K_{d}$ ranges reported for $\pm 1 \sigma$.

\begin{tabular}{ccccccc}
\hline & \multicolumn{2}{c}{$\begin{array}{c}\text { Open science literature, } \\
\text { worldwide granites }\end{array}$} & $\begin{array}{c}\text { Non-DOE nuclear power } \\
\text { agency reports, worldwide } \\
\text { granites }\end{array}$ & \multicolumn{2}{c}{$\begin{array}{c}\text { Climax stock project } \\
\text { reports }\end{array}$} \\
Component & Low, ml/g & High, ml/g & Low, ml/g & High, ml/g & Low, ml/g & High, ml/g \\
\hline $\mathrm{Ca}$ & $\mathrm{NA}$ & $\mathrm{NA}$ & $\mathrm{NA}$ & $\mathrm{NA}$ & $\mathrm{NA}$ & $\mathrm{NA}$ \\
$\mathrm{Ni}$ & $\mathrm{NA}$ & $\mathrm{NA}$ & 1.06 & 2.47 & $\mathrm{NA}$ & $\mathrm{NA}$ \\
$\mathrm{Sr}$ & -0.09 & 1.59 & -1.21 & 1.07 & 0.97 & 2.51 \\
$\mathrm{Zr}$ & 3.16 & 3.67 & 1.27 & 3.77 & $\mathrm{NA}$ & $\mathrm{NA}$ \\
$\mathrm{Nb}$ & $\mathrm{NA}$ & $\mathrm{NA}$ & 1.85 & 2.94 & $\mathrm{NA}$ & $\mathrm{NA}$ \\
$\mathrm{Pd}$ & $\mathrm{NA}$ & $\mathrm{NA}$ & 2.74 & 3.97 & $\mathrm{NA}$ & $\mathrm{NA}$ \\
$\mathrm{Sn}$ & 2.41 & 3.41 & $\mathrm{NA}$ & $\mathrm{NA}$ & $\mathrm{NA}$ & $\mathrm{NA}$ \\
$\mathrm{Cs}$ & 1.02 & 2.17 & 0.81 & 2.76 & 2.52 & 3.40 \\
$\mathrm{Sm}$ & $\mathrm{NA}$ & $\mathrm{NA}$ & $\mathrm{NA}$ & $\mathrm{NA}$ & $\mathrm{NA}$ & $\mathrm{NA}$ \\
$\mathrm{Eu}$ & 4.00 & 4.38 & 1.03 & 2.06 & 2.67 & 3.64 \\
$\mathrm{U}$ & -0.12 & 2.82 & 0.39 & 1.20 & 0.09 & 0.99 \\
$\mathrm{~Np}$ & 1.09 & 1.99 & 0.30 & 1.80 & $\mathrm{NA}$ & $\mathrm{NA}$ \\
$\mathrm{Pu}$ & 1.77 & 2.67 & 1.83 & 4.18 & 3.00 & 4.03 \\
$\mathrm{Am}$ & 2.58 & 4.68 & 2.57 & 5.36 & 3.43 & 3.74 \\
\hline
\end{tabular}

The data for the Climax stock are limited in both radionuclides studied, and in the number of studies reporting sorption information (Figure 5-19a). In comparison, the gray literature for all other studies on granite is characterized by a broad distribution in reported $K_{d}$ for a given radionuclide (Figure 5-19b). Uranium is an exception to this observation because very few gray literature references examined uranium as a sorbent (a total of eight reported values (Table 5-15). The open science literature has fewer outlier points, but a correspondingly smaller number of total reported $K_{d}$ values overall (Figure 5-19c, Table 5-15). Uranium sorption on granites is reported in substantially more references in the open science literature.

There are no obvious characteristics in the sorption data reported in the gray literature versus the open-science literature that could point to definitive conclusions about data quality, and therefore no differences in data weighting between these two source types are assumed in this study. There are some differences between the reported $K_{d}$ values for the Climax stock and other granites. The average $K_{d}$ values reported for $\mathrm{Sr}, \mathrm{Cs}$, and $\mathrm{Pu}$ for the Climax stock are consistently higher than those reported for other granites. The Climax-stock specific $K_{d}$ data for $\mathrm{Sr}, \mathrm{Cs}$, and $\mathrm{Pu}$ plot as outliers when combined with all other granite $K_{d}$ data (Figure 5-19d). The average $K_{d}$ values reported for Eu, U, and Am for the Climax stock are generally consistent with other studies. The higher $K_{d}$ values for $\mathrm{Sr}, \mathrm{Cs}$, and $\mathrm{Pu}$ for the Climax stock are likely due to differences in sorbent mineralogy between the Climax and other granitic formations.

The distribution of all of the available sorption data for the Climax stock and other worldwide granites is presented for each radionuclide in the transport inventory (except ${ }^{41} \mathrm{Ca}$ and $\mathrm{Sm}$ ) in a series of histograms (Figure 5-20). These histograms were constructed using a bin width of $0.1 \log K_{d} \mathrm{~mL} / \mathrm{g}$. Predictions of Ca and Sm sorption, as well as reconciliation of 
observed differences between sorption reported for Climax granite relative to granites worldwide, were accomplished using mechanistic geochemical models. The details of these models are presented in Appendix $\mathrm{H}$, with results included in the selection of sorption classes presented in the following section.

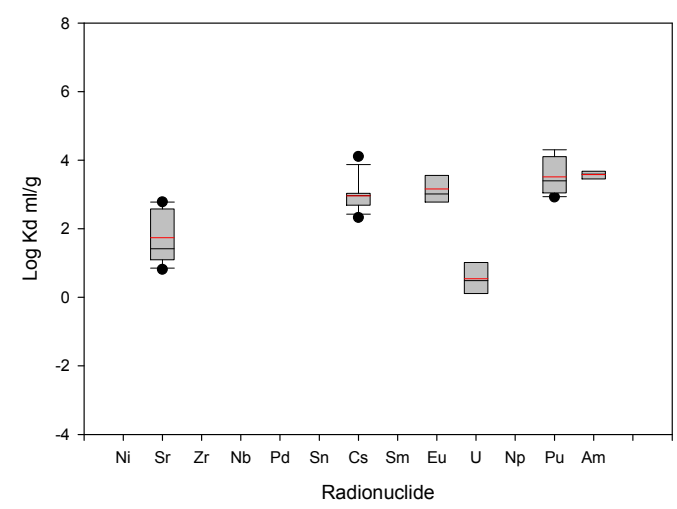

(a) Climax stock

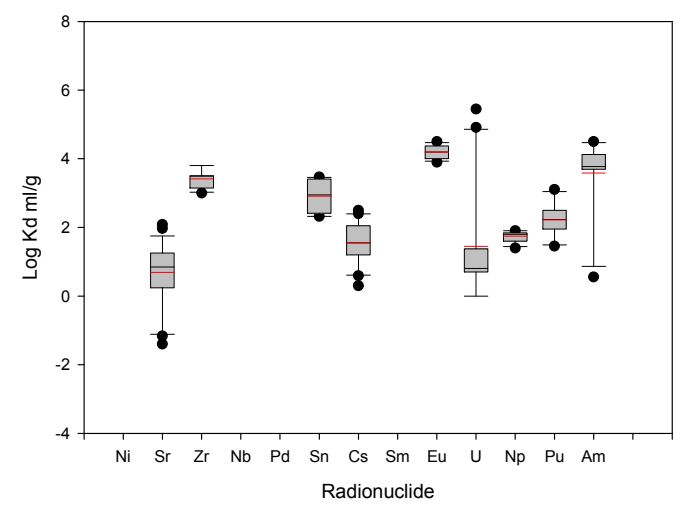

(c) Open literature

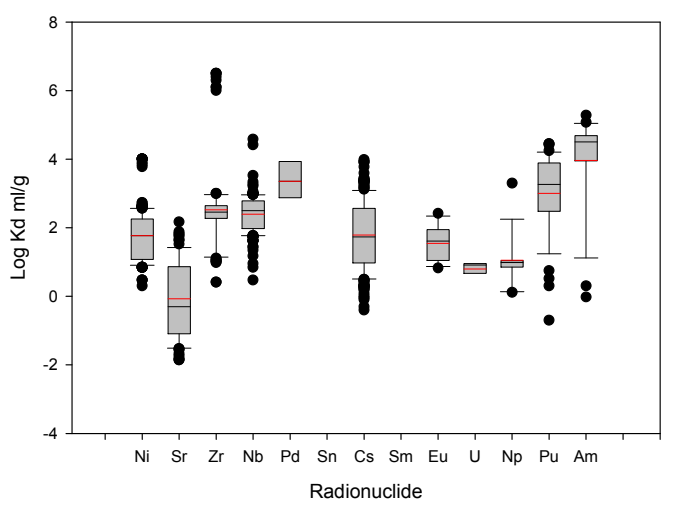

(b) Gray literature

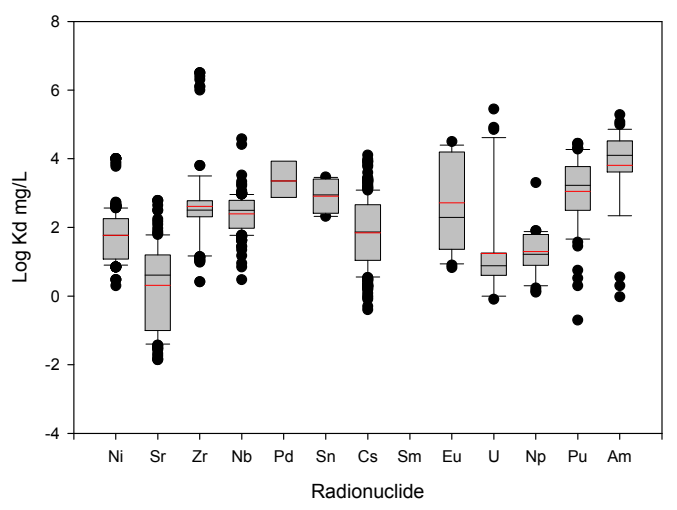

(d) All data combined

Figure 5-19. Box plots for all $K_{d}$ values reported for granites worldwide: (a) Climax stock project reports, (b) all nuclear science agency, or 'gray literature' $K_{d}$ values for granites worldwide except the Climax stock, (c) open science literature for all granites except the Climax stock, and (d) all data combined. 

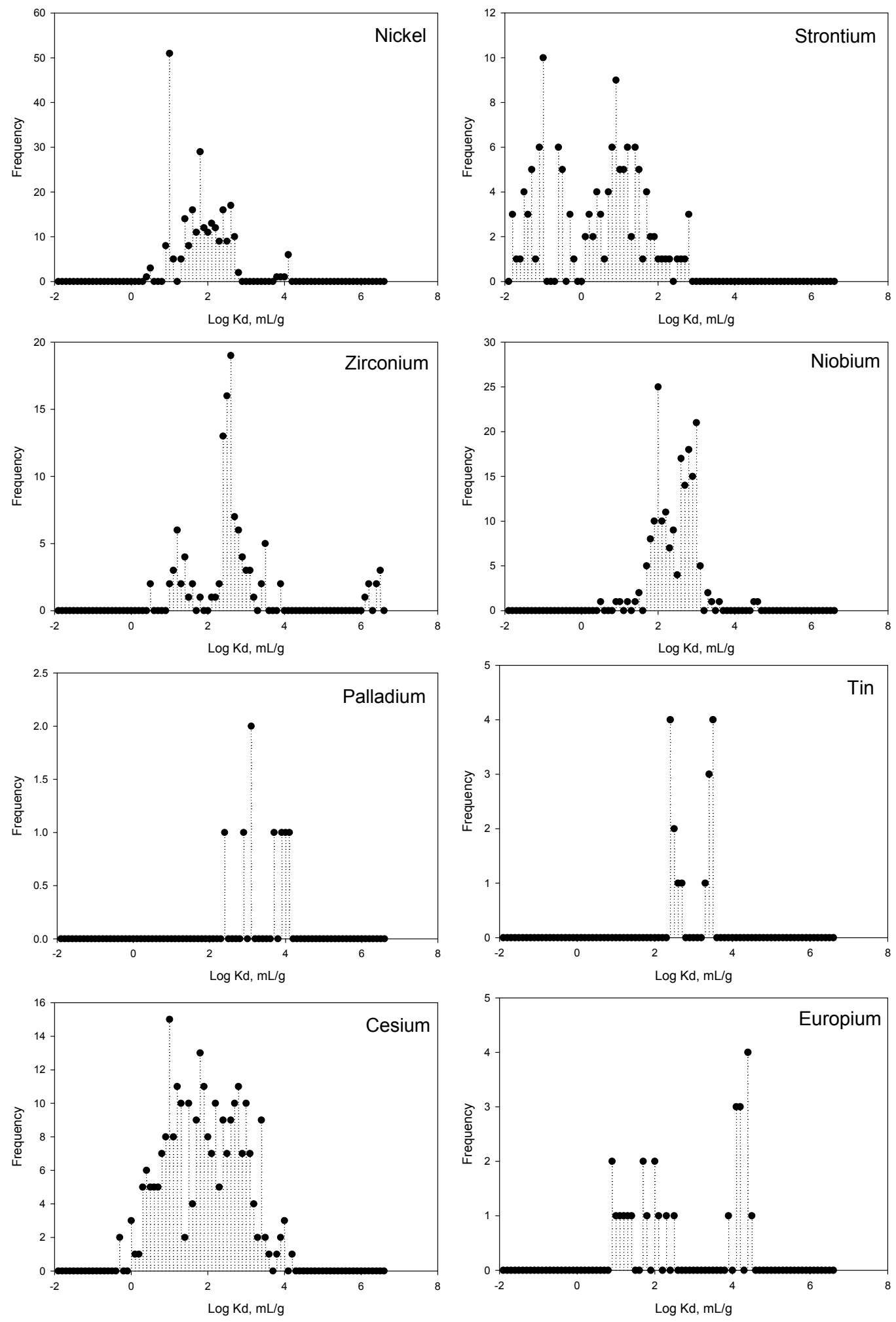

Figure 5-20. Histogram for all $K_{d}$ values found for granite. 

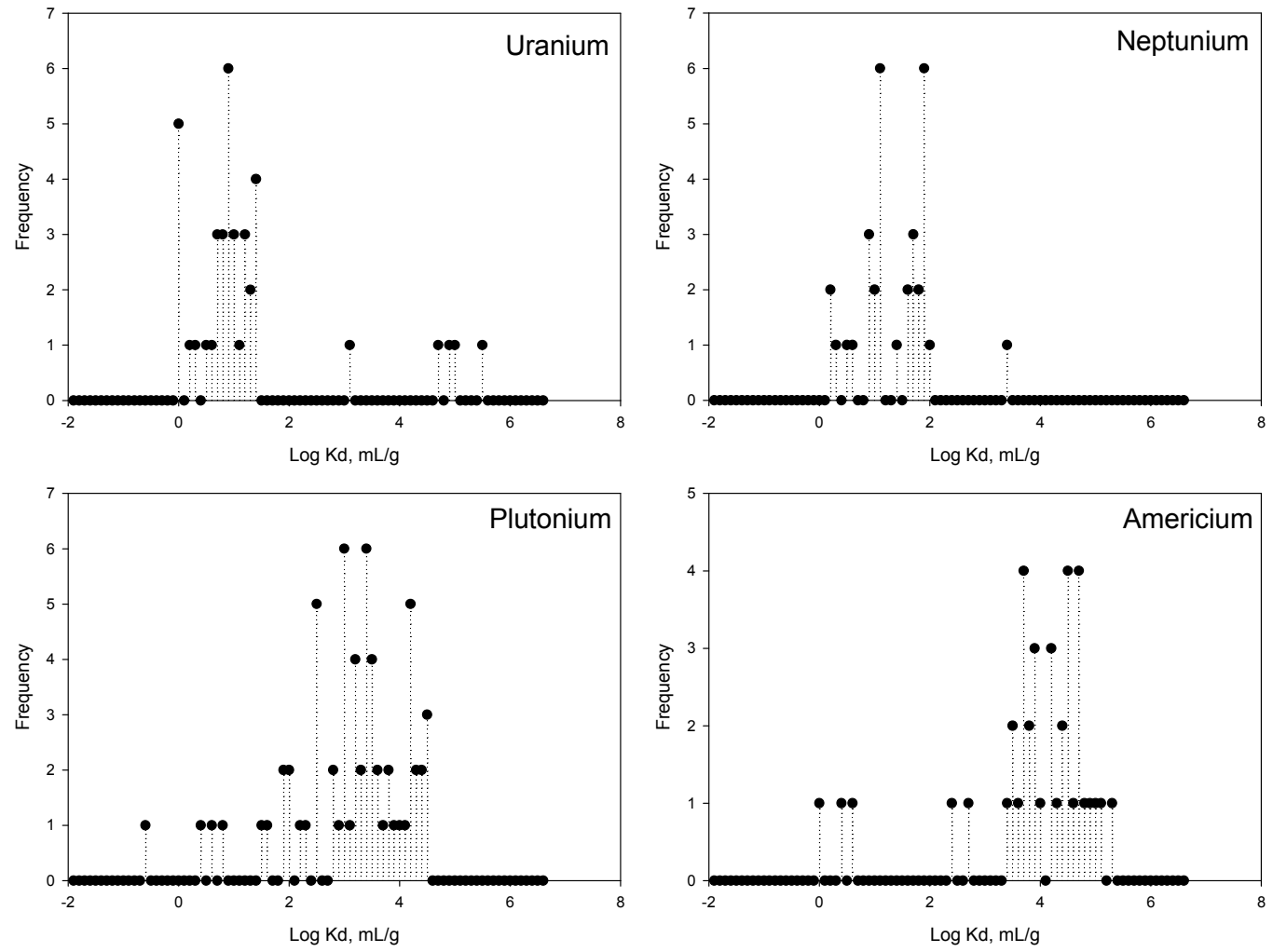

Figure 5-20. Histogram for all $K_{d}$ values found for granite (continued).

\subsubsection{Sorption Classes}

Significant overlap in ranges of $K_{d}$ values for different radionuclides is evident from the information discussed in the previous sections and in Appendix H. Just as classes were identified to group radionuclides according to similarities in apportioning in nuclear melt glass, classes can be established based on sorption behavior. Grouping reduces the computational requirements of the transport model.

The Climax source radionuclides are gathered into six sorption classes (Table 5-16) and are discussed here in order of increasing sorption affinity. One class assumes no sorption and includes ${ }^{3} \mathrm{H},{ }^{14} \mathrm{C},{ }^{39} \mathrm{Ar},{ }^{85} \mathrm{Kr},{ }^{36} \mathrm{Cl},{ }^{129} \mathrm{I}$, and ${ }^{99} \mathrm{Tc}$.

The uranium isotopes constitute the next sorption class. Experiments using Climax granite indicate somewhat lower uranium sorption relative to other studies worldwide (Table 5-14). Neptunium-237 is included in the uranium group. No Climax-specific data are available for ${ }^{237} \mathrm{~Np}$, but the lower end of the $\mathrm{Np}$ sorption range reported in the literature corresponds to the range of sorption values observed for uranium on Climax granite (Figure 5-21). Neptunium and $U$ sorption $K_{d} s$ reported in the literature are quite similar (Table 5-15). The CRUNCH calculations indicate that values in the lower end of the Np literature range are most appropriate for the Climax mineralogy (Table H-5 in Appendix H). 
Table 5-16. Radionuclides grouped into categories based on similar ranges in sorption coefficients. A notation of "Climax" in the source indicates data from experiments using that element in contact with Climax granite. A notation of "literature" reflects data reported in the literature using other granite samples.

\begin{tabular}{ccc}
\hline Mean $\log K_{d}(\mathrm{mg} / \mathrm{l})$ & $K_{d}$ source & Radionuclides \\
\hline- & $\mathrm{NA}$ & ${ }^{3} \mathrm{H},{ }^{14} \mathrm{C},{ }^{39} \mathrm{Ar},{ }^{85} \mathrm{Kr},{ }^{36} \mathrm{Cl},{ }^{129} \mathrm{I},{ }^{99} \mathrm{Tc}$ \\
0.54 & $\mathrm{U}_{\text {Climax }}$ & ${ }^{232} \mathrm{U},{ }^{233} \mathrm{U},{ }^{234} \mathrm{U},{ }^{235} \mathrm{U},{ }^{236} \mathrm{U},{ }^{238} \mathrm{U},{ }^{237} \mathrm{~Np}$ \\
1.14 & $\mathrm{Sr}_{\mathrm{Climax}}$ & ${ }^{90} \mathrm{Sr},{ }^{41} \mathrm{Ca}$ \\
2.15 & $(\mathrm{Ni}, \mathrm{Zr}, \mathrm{Nb})_{\text {literature }}$ & ${ }^{59} \mathrm{Ni},{ }^{63} \mathrm{Ni},{ }^{93} \mathrm{Zr},{ }^{93 \mathrm{~m}} \mathrm{Nb},{ }^{94} \mathrm{Nb}$ \\
2.96 & $\mathrm{Cs}_{\mathrm{Climax}}$ & ${ }^{135} \mathrm{Cs},{ }^{137} \mathrm{Cs},{ }^{121} \mathrm{Sn},{ }^{126} \mathrm{Sn},{ }^{107} \mathrm{Pd}$ \\
3.3 & $(\mathrm{Eu}, \mathrm{Pu}, \mathrm{Am})_{\mathrm{Climax}}$ & ${ }^{150} \mathrm{Eu},{ }^{152} \mathrm{Eu},{ }^{154} \mathrm{Eu},{ }^{151} \mathrm{Sm},{ }^{166} \mathrm{Ho},{ }^{238} \mathrm{Pu},{ }^{239} \mathrm{Pu}$, \\
& & ${ }^{242} \mathrm{Pu},{ }^{241} \mathrm{Pu},{ }^{242} \mathrm{Pu},{ }^{241} \mathrm{Am},{ }^{244} \mathrm{Cm}$ \\
\hline
\end{tabular}

*excluding Maclean et al. (1978) data from shear zone clay

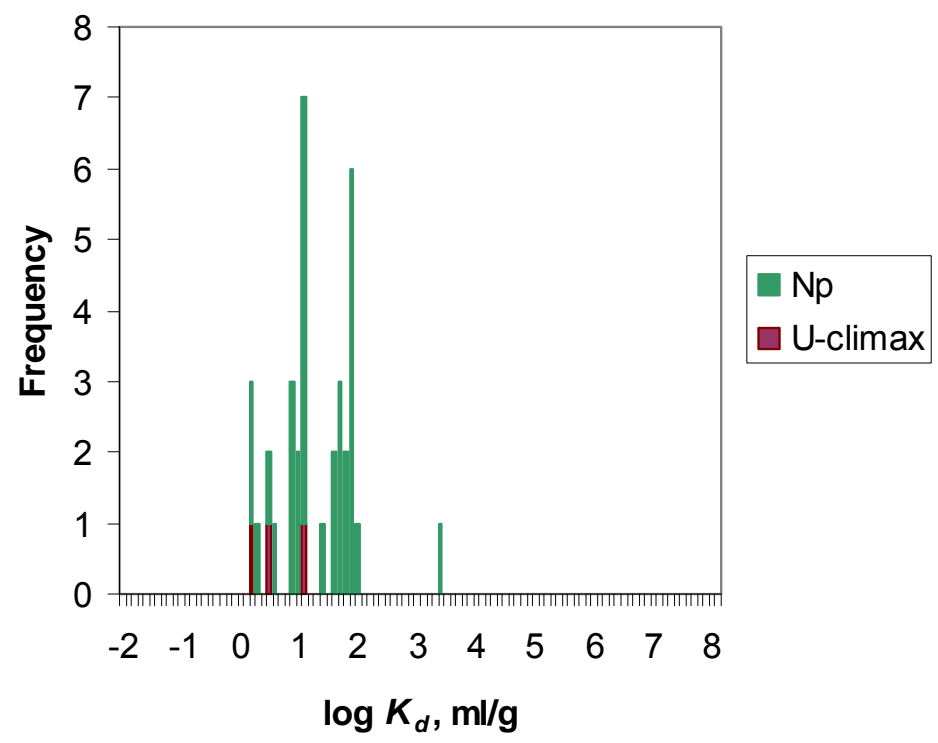

Figure 5-21. Comparison of $K_{d}$ values measured for uranium using Climax granite and values for neptunium using granites worldwide.

The next higher sorption class is defined by the Climax experimental data for strontium. A bimodal distribution is obvious in the experimental data (Figure 5-22). The higher $K_{d}$ values are from experiments conducted with material from a shear zone within Climax (Maclean et al., 1978). The upper end of the bimodal spread is neglected here under the assumption that groundwater flow through the stock will not be primarily through clayrich shear zones. No experimental data are available for ${ }^{41} \mathrm{Ca}$, though the CRUNCHcalculated $K_{d}$ values (Appendix H) reasonably coincide with the lower end of the ${ }^{90} \mathrm{Sr}$ distribution. Given this coincidence and the similar geochemical behavior of $\mathrm{Sr}$ and $\mathrm{Ca},{ }^{90} \mathrm{Sr}$ and ${ }^{41} \mathrm{Ca}$ are grouped into a single sorption class. 


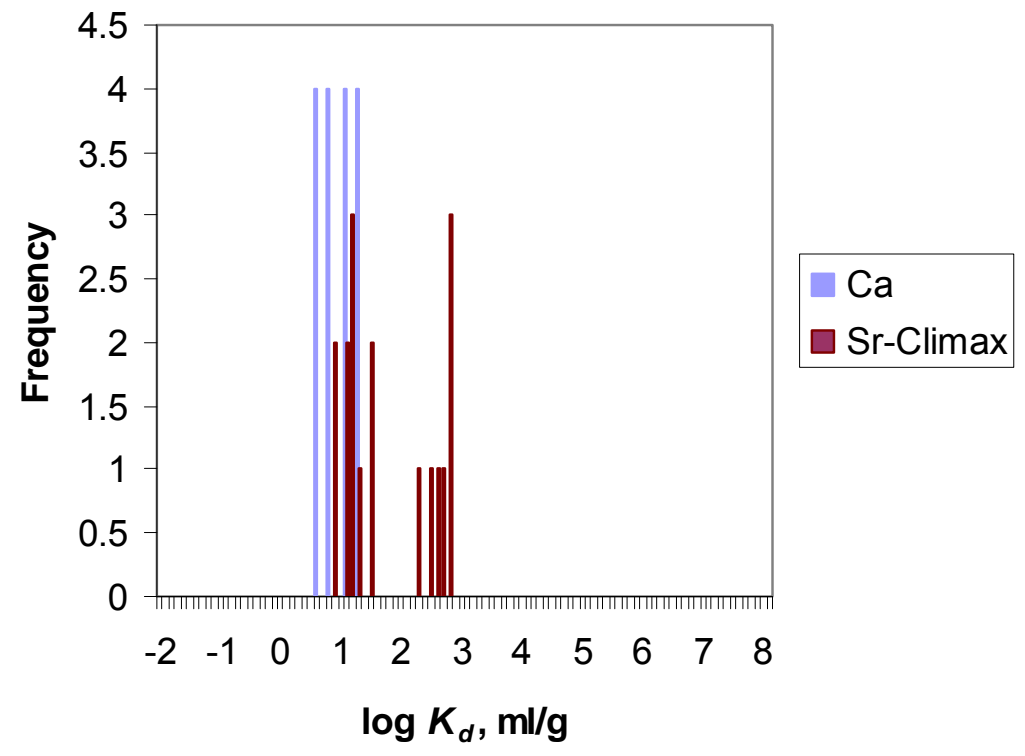

Figure 5-22. Comparison of $K_{d}$ measured for strontium using Climax granite samples and calculated for calcium using CRUNCH.

Literature values for the transition metals nickel, zirconium, and niobium overlap reasonably well (Figure 5-23). The CRUNCH calculations for nickel correspond well with the bulk of the distribution (Appendix H). For the transport calculations, ${ }^{59} \mathrm{Ni},{ }^{63} \mathrm{Ni},{ }^{93} \mathrm{Zr}$, ${ }^{93 \mathrm{~m}} \mathrm{Nb}$, and ${ }^{94} \mathrm{Nb}$ are grouped together and the lumped distribution from the literature used for the $K_{d}$.

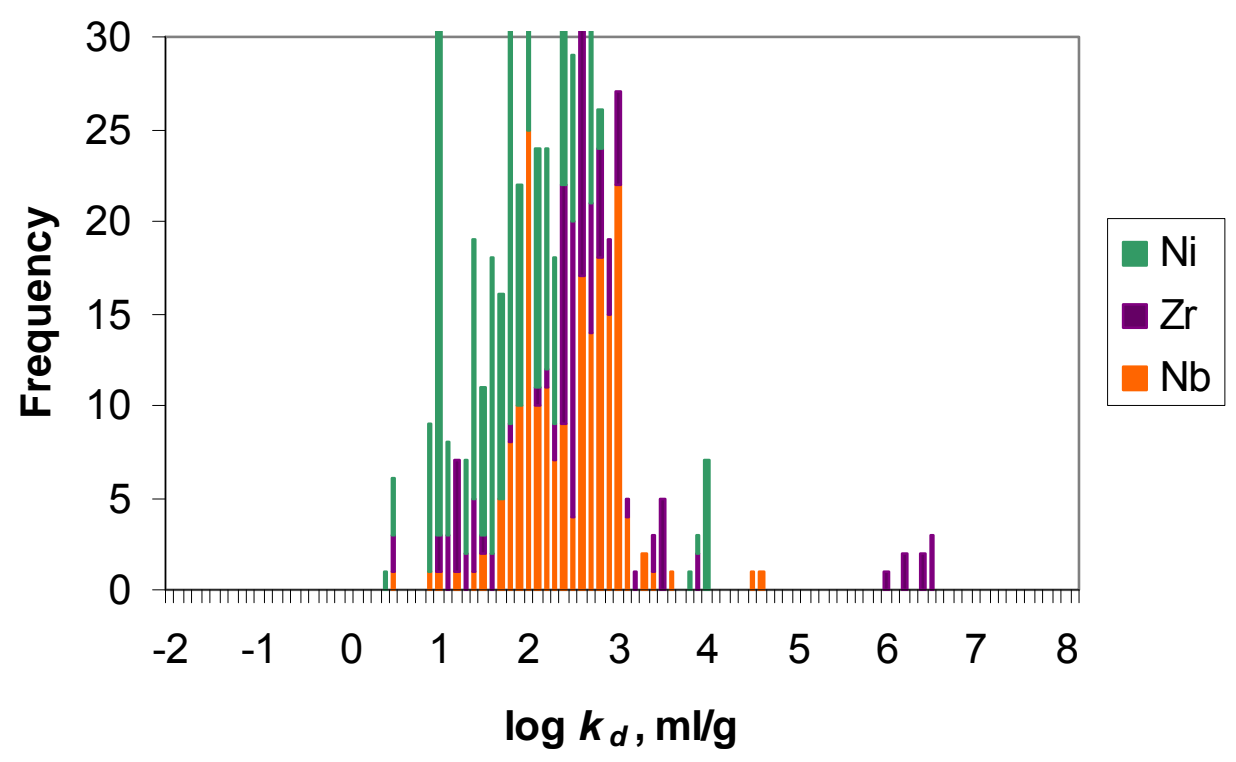

Figure 5-23. Comparison of $K_{d}$ values measured for nickel, zirconium, and niobium using granites worldwide. 
Tin and palladium have no Climax-specific laboratory $K_{d}$ values, but values reported in the literature coincide with those determined for cesium at Climax (Figure 5-24). As with strontium, a cluster of high $K_{d} \mathrm{~S}$ was measured on Climax granite and corresponds to experiments using shear zone minerals. The lower end of the cesium distribution is used here, neglecting the shear zone data, and applied to ${ }^{135} \mathrm{Cs},{ }^{137} \mathrm{Cs},{ }^{121} \mathrm{Sn},{ }^{126} \mathrm{Sn}$, and ${ }^{107} \mathrm{Pd}$.

The final, and most sorptive, group includes ${ }^{150} \mathrm{Eu},{ }^{152} \mathrm{Eu},{ }^{154} \mathrm{Eu},{ }^{151} \mathrm{Sm},{ }^{166} \mathrm{Ho},{ }^{238} \mathrm{Pu}$, ${ }^{239} \mathrm{Pu},{ }^{240} \mathrm{Pu},{ }^{241} \mathrm{Pu},{ }^{242} \mathrm{Pu},{ }^{241} \mathrm{Am}$, and ${ }^{244} \mathrm{Cm}$. Climax-specific data are available for europium, plutonium, and americium and are used for the $K_{d}$ range of this group (Figure 5-25). No data are available for holmium and curium, though $\mathrm{CRUNCH}$ calculations for samarium suggest similar retardation to europium (Appendix $\mathrm{H}$ ). All trivalent actinides and lanthanides have very high affinities for mineral surfaces and their geochemical behavior is expected to be similar.

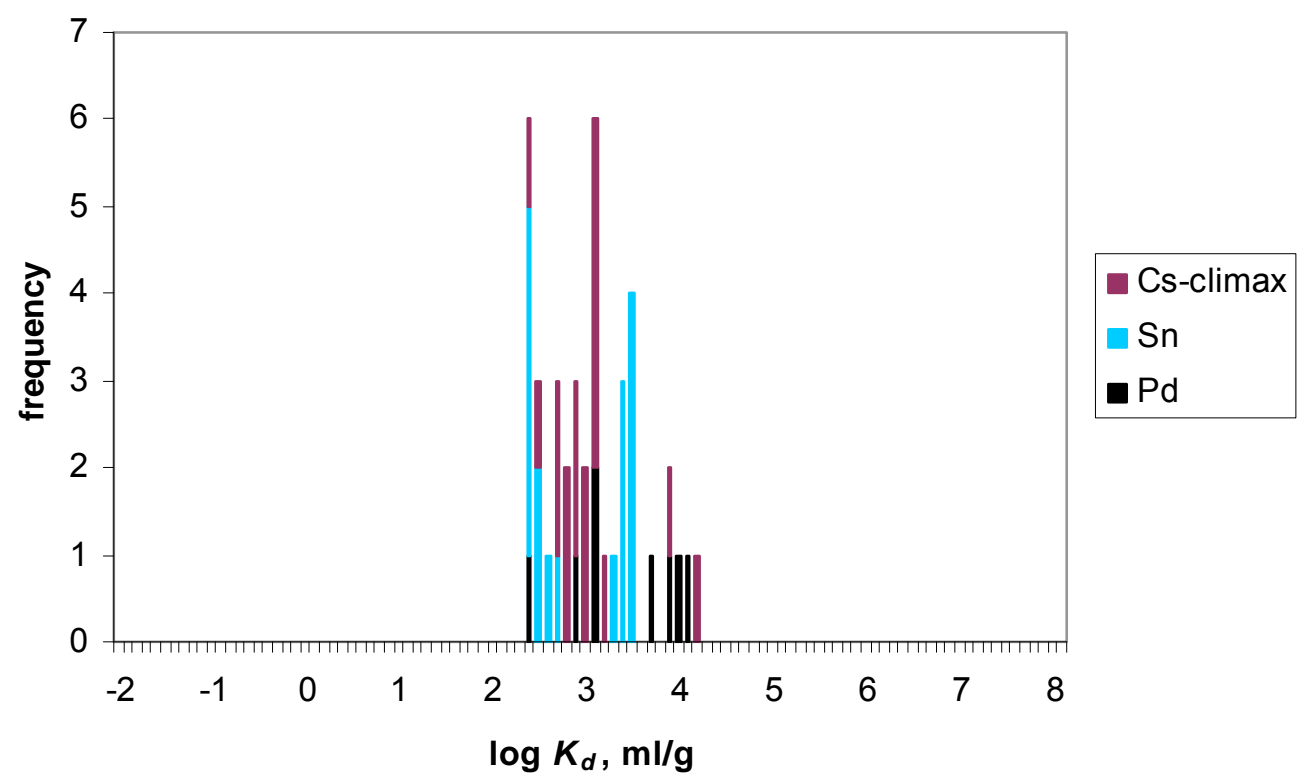

Figure 5-24. Comparison of $K_{d}$ s measured for Cs using Climax granite, and measured for Sn and Pd using other granites. 


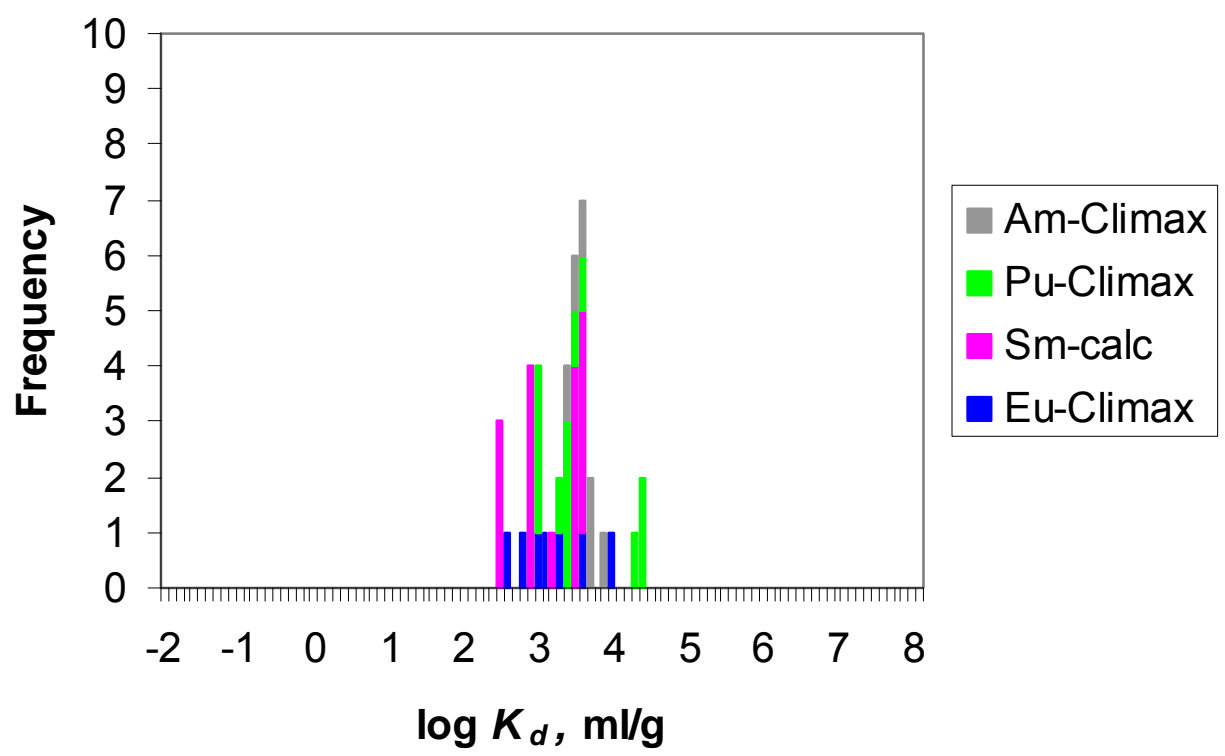

Figure 5-25. Comparison of $K_{d} \mathrm{~s}$ measured for $\mathrm{Am}, \mathrm{Pu}$, and Eu using Climax granite, and calculated for Sm using CRUNCH and Climax mineralogy.

\subsubsection{Radionuclide Diffusion Parameters for Granite}

It is generally agreed that matrix diffusion will provide a mechanism for retardation of both tracers and sorbing radionuclides. While there are no matrix diffusion data available for the Climax granite, a large number of diffusion experiments have been conducted in granite around the world (Table 5-17). These data should bound the likely diffusion coefficients for Climax granite.

Skagius and Neretnieks (1986) measured $\mathrm{I}^{-}$diffusion through a granite rock section and found effective diffusion coefficients ranging from $1 \times 10^{-14}$ to $7 \times 10^{-13} \mathrm{~m}^{2} / \mathrm{s}$. Bradbury and Green (1985) found $\mathrm{I}^{-}$effective diffusion coefficients in granite sections to be $2.3 \times 10^{-14}$ to $1.4 \times 10^{-12} \mathrm{~m}^{2} / \mathrm{s}$. Interestingly, when evaluating the role of granite weathering, Bradbury and Green (1986) found effective diffusion coefficients ranging from $5.6 \times 10^{-14}$ to $6.4 \times 10^{-12} \mathrm{~m}^{2} / \mathrm{s}$ for weathered granite surfaces and $2.3 \times 10^{-14}$ to $3.2 \times 10^{-14} \mathrm{~m}^{2} / \mathrm{s}$ for fresh granite surfaces. Furthermore, they suggested that the diffusivity decreases with distance as a result of pore connectivity. Holtta et al. (1996) measured granite gas diffusion and applied a correction factor for ions in solution. This resulted in effective diffusion coefficient of $1.4 \times 10^{-13} \mathrm{~m}^{2} / \mathrm{s}$. Sato (1999) measured diffusivity in intact granodiorite, altered granodiorite, and fracture fill material. Average porosities for these samples were 2.3, 3.2, and 5.6 percent and effective diffusion coefficients for HTO were $5.3 \times 10^{-12}, 1.8 \times 10^{-11}$, and $2.4 \times 10^{-11}$ $\mathrm{m}^{2} / \mathrm{s}$, respectively. The relatively high porosity of these rocks is likely the reason for the high diffusion coefficients. The Sr diffusion coefficients for granite, measured by Yamaguchi et al. (1993), varied with solution composition and ranged from $1 \times 10^{-13}$ to $1.7 \times 10^{-11} \mathrm{~m}^{2} / \mathrm{s}$. Skagius et al. (1982) measured diffusion coefficients for $\mathrm{Cs}$ and $\mathrm{Sr}$ on crushed granite. Effective diffusion coefficients $\left(D_{e}=D_{p} \varepsilon_{p}\right.$, where $D_{p}$ is the pore diffusivity and $\varepsilon_{p}$ is the matrix porosity) were found to range from $1 \times 10^{-12}$ to $3.7 \times 10^{-11} \mathrm{~m}^{2} / \mathrm{s}$. 
Table 5-17. Summary of diffusion parameters reported in the literature.

\begin{tabular}{|c|c|c|c|}
\hline Element & $\mathrm{De}, \mathrm{m}^{2} / \mathrm{s}$ & Method & Reference \\
\hline $\mathrm{I}^{-}$ & $1 \times 10^{-14}$ to $7 \times 10^{-13}$ & Core section & Skagius and Neretnieks (1986) \\
\hline $\mathrm{I}^{-}$ & $2.3 \times 10^{-14}$ to $1.4 \times 10^{-12}$ & Core section & Bradbury and Green (1985) \\
\hline $\mathrm{I}^{-}$ & $5.6 \times 10^{-14}$ to $6.4 \times 10^{-12}$ & $\begin{array}{l}\text { Core section } \\
\text { Weathered granite }\end{array}$ & Bradbury and Green (1986) \\
\hline $\mathrm{I}^{-}$ & $2.3 \times 10^{-14}$ to $3.2 \times 10^{-14}$ & $\begin{array}{l}\text { Core section } \\
\text { Intact granite }\end{array}$ & Bradbury and Green (1986) \\
\hline $\mathrm{He}$ & $1.4 \times 10^{-13}$ & Gas diffusion & Holtta et al. (1996) \\
\hline HTO & $5.3 \times 10^{-12}$ & $\begin{array}{l}\text { Core section } \\
\text { Intact granodiorite }\end{array}$ & Sato (1999) \\
\hline HTO & $1.8 \times 10^{-11}$ & $\begin{array}{l}\text { Core section } \\
\text { Weathered granodiorite }\end{array}$ & Sato (1999) \\
\hline HTO & $2.4 \times 10^{-11}$ & $\begin{array}{l}\text { Core section } \\
\text { Fracture fill }\end{array}$ & Sato (1999) \\
\hline $\mathrm{Sr}$ & $1 \times 10^{-13}$ to $1.7 \times 10^{-11}$ & Core section & Yamaguchi et al. (1993) \\
\hline $\mathrm{Cs}, \mathrm{Sr}$ & $1 \times 10^{-12}$ to $3.7 \times 10^{-11}$ & Crushed granite & Skagius et al (1982) \\
\hline $\mathrm{I}^{-}$ & $1.1 \times 10^{-13}$ to $1 \times 10^{-12}$ & Core section & Birgersson and Neretnieks (1990) \\
\hline $\mathrm{I}^{-}$ & $6 \times 10^{-15}$ to $>5 \times 10^{-13}$ & Field experiment & Birgersson and Neretnieks (1990) \\
\hline $\mathrm{I}^{-}, \mathrm{U}$ & $1.5 \times 10^{-13}$ to $1.5 \times 10^{-12}$ & Field experiment & Maloszewski and Zuber (1993) \\
\hline $\mathrm{Br}^{-}$ & $1.2 \times 10^{-13}$ to $4 \times 10^{-12}$ & Core section & Reimus et al. (2003) \\
\hline
\end{tabular}

Birgersson and Neretnieks (1990) compared nonsorbing tracer diffusion coefficients in laboratory and field measurements. Pore diffusivities were found to range from $5 \times 10^{-12}$ to more than $1 \times 10^{-10} \mathrm{~m}^{2} / \mathrm{s}$ in the field and from $9 \times 10^{-11}$ to $2 \times 10^{-10} \mathrm{~m}^{2} / \mathrm{s}$ in the laboratory. Measured rock porosities ranged from 0.12 to 0.52 percent, resulting in effective diffusion coefficient $\left(D_{\mathrm{p}} \varepsilon_{\mathrm{p}}\right)$ ranges of $6 \times 10^{-15}$ to more than $5 \times 10^{-13}$ and $1.1 \times 10^{-13}$ to $1 \times 10^{-12} \mathrm{~m}^{2} / \mathrm{s}$, respectively. Maloszewski and Zuber (1993) fit a single fracture dispersion model to several field tracer tests. A good fit to the granite data was achieved when pore diffusivity was set to $10^{-11} \mathrm{~m}^{2} / \mathrm{s}$ and matrix porosity to 0.015 to yield an effective diffusion coefficient of $1.5 \times 10^{-}$ ${ }^{13} \mathrm{~m}^{2} / \mathrm{s}$. For a fractured gneiss field experiment and different modeling approaches, effective diffusivities of $1.5 \times 10^{-12}$ and $9 \times 10^{-12} \mathrm{~m}^{2} / \mathrm{s}$ were estimated. However, the value of $9 \times 10^{-12}$ $\mathrm{m}^{2} / \mathrm{s}$ was calculated using an unrealistically high porosity of 0.045 . Reimus et al. (2003) reported that laboratory measured pore diffusivities for Shoal granites ( $\mathrm{Br}^{-}$experiments) ranged from $1.2 \times 10^{-11}$ to $2 \times 10^{-10} \mathrm{~m}^{2} / \mathrm{s}$. With measured porosities of 0.01 to 0.02 , the range of effective diffusivity is $1.2 \times 10^{-13}$ to $4 \times 10^{-12} \mathrm{~m}^{2} / \mathrm{s}$. Interestingly, when fitting a field tracer test, Reimus et al. (2003) reported a lumped diffusion term of $\varepsilon_{p} \sqrt{D_{p}} / b$ (where $\mathrm{b}$ is the fracture half-aperture). Based on the combination of these values, the fracture aperture ranges from 0.6 to $8 \mathrm{~mm}$. The upper range of fracture aperture is clearly unrealistic. Reimus et al. (2003) suggested that heterogeneity effects and the highly correlated $\varepsilon_{\mathrm{p}}, \mathrm{D}_{\mathrm{p}}$, and fracture aperture parameters are likely to be the source for the large apparent fracture aperture. 
However, as noted in Birgersson and Neretrnieks (1990), diffusion coefficients measured in the field tend to be lower than those measured in the laboratory. This would lead to a much lower, and more realistic, fracture aperture.

\subsubsection{Porosity}

The computation of cell velocity used in the transport model from Darcy flux values calculated in the FCM flow realizations is dependent on values of porosity. Constant values of 0.6 percent (Murray, 1981) and 20 percent are assigned for matrix-occupied cells and the three permeability disks, respectively. Equivalent porosity values for the rock fractures are best determined from a site-specific tracer test. The lack of a tracer test at the Climax stock leads us to use data from a tracer test at a similar subsurface flow system. Based on a tracer test in a fractured granite rock mass at Shoal, equivalent porosity was found to range between 0.027 and 0.054 (Pohlmann et al., 2004). Using this range, Pohlmann et al. (2004) fit the data to a lognormal distribution with a mean of 0.025 and a standard deviation of 0.023 .

A power-law relationship is derived for the Climax transport model to describe the relationship between fracture cell porosity, $n$, and fracture hydraulic conductivity, $K_{\text {frac }}$ :

$$
n=0.04 K_{\text {frac }}^{0.25}
$$

where values of fracture hydraulic conductivity, randomly selected from a lognormal distribution with a $\log _{10}$ mean of $-8.0 \mathrm{~m} / \mathrm{s}$ and a standard deviation of 1.05 , were fit to the lognormal porosity distribution used for Shoal with a mean of 0.025 and standard deviation of 0.023 (Figure 5-26).

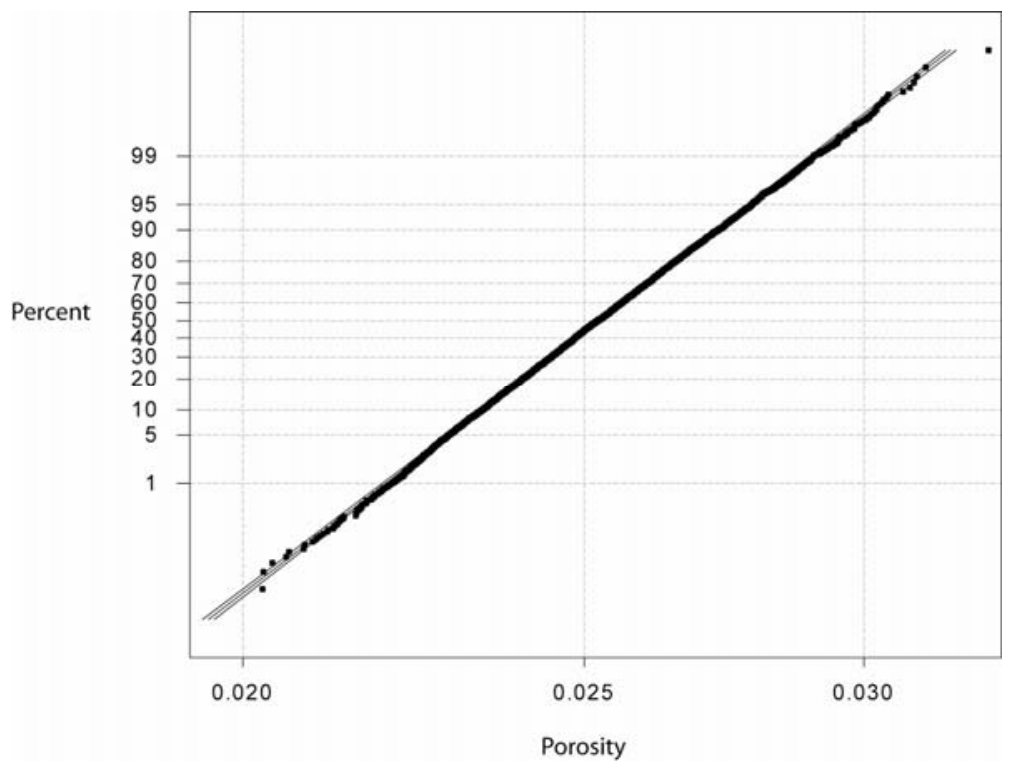

Figure 5-26. A lognormal probability plot of fracture porosity based on the conversion of 10,000 random hydraulic conductivity values to porosity according to (5.1). The mean and standard deviation of the porosity distribution are 0.025 and 0.023 , respectively. 


\subsection{Numerical Modeling Strategy}

The flow fields described in Chapter 4 preserve the degree of heterogeneity and anisotropy that fracture zone networks impart on a groundwater flow system. By simulating both conservative and nonconservative particle trajectories through these fracture zone network flow solutions, particles sample a wide variety of fracture zone lengths, orientations and velocities before reaching model boundaries. The preferential transport of particles through interconnected fracture zones of the hydraulic backbone controls radionuclide breakthrough at model boundaries. Macrodispersion arises from the geometry of the network. A local dispersion tensor is used in the random walk particle method to describe withinfracture dispersion (both longitudinal and transverse). Radionuclide retention is simulated by a transition probability approach that models the movement of radionuclides between fractures and matrix blocks via molecular diffusion. In the case of nonconservative radionuclides, retardation coefficients are used to model radionuclide sorption along fracture walls and in the matrix.

A random walk particle tracking code, Ptrack, is used to simulate radionuclide particle trajectories through each of the 5,000 velocity field realizations from the local-scale fracture continuum flow model. Ptrack simulates advective and dispersive particle motion according to the random walk particle method of LaBolle et al. (2000)

$$
\boldsymbol{X}_{t+\Delta t}=\boldsymbol{X}_{t}+\left[\boldsymbol{V}\left(\boldsymbol{X}_{t}, t\right)\right] \Delta t+\left[2 \boldsymbol{D}\left(\boldsymbol{V}\left(\boldsymbol{X}_{t}+\delta \boldsymbol{X}, t\right)\right) \Delta t\right]^{1 / 2} \cdot \boldsymbol{Z}
$$

where $\boldsymbol{X}_{t+\Delta t}$ is the updated position of a particle located at $\boldsymbol{X}_{t}$ for the previous time step, $\boldsymbol{V}\left(\boldsymbol{X}_{p}, t\right)$ is a velocity vector at the old position at time $t, \boldsymbol{D}$ is a local-scale dispersion tensor, $\Delta t$ is the time step magnitude, $\boldsymbol{Z}$ is a vector of random values generated according to a standard normal distribution (i.e., mean of 0 and variance of 1 ), and $\delta \boldsymbol{X}=\left[2 \boldsymbol{D}\left(\boldsymbol{V}\left(\boldsymbol{X}_{t}, t\right)\right) \Delta t\right]^{1 / 2} \cdot \boldsymbol{Z}$. The first and second terms on the right-hand side of Equation (5.2) represent the advective and dispersive components applied to radionuclide particles for a given $\Delta t$. The computation of $\boldsymbol{V}\left(\boldsymbol{X}_{t}, t\right)$ is based on a trilinear interpolation method, similar to the bilinear interpolation scheme introduced by LaBolle et al. (1996). The inclusion of $\delta \boldsymbol{X}$ into Equation (5.2) allows for the computation of dispersion coefficients at an intermediate location between $\boldsymbol{X}_{t}$ and $\boldsymbol{X}_{t+\Delta t}$ to avoid potential gradient effects for cells that have sharp contrasts in advective velocity and/or porosity. The particle tracking code assigns a time step based on velocities in the model domain and longitudinal dispersivity values so that particles do not overshoot fracture cells in a given jump and enter low-permeability cells of the simulated matrix. An anisotropic Gaussian dispersion tensor with values of $1.5 \mathrm{~m}$ ( $10 \%$ of the cell size) and 0.15 ( $1 \%$ of the cell size) for longitudinal and transverse dispersivity, respectively, is applied to the FCM flow fields. The trilinear interpolation scheme of the particle tracking code results in a variable velocity field within each fracture, where particle velocity is dependent on the position of each particle relative to the matrix or other low-velocity cells. The incorporation of a very small component of transverse dispersion into the motion of conservative particles allows for solute particles to randomly sample other streamlines and velocities present within a given fracture zone (i.e., transverse dispersion promotes flow path mixing within fracture zones). 
A porous media molecular diffusion algorithm is insufficient for use in the transport model since the Climax stock is conceptualized as a fractured rock groundwater flow system where high-velocity fracture zones are separated by matrix blocks with low velocity. A random walk particle transfer (RWPT) approach, originally formulated by Liu et al. (2000) and improved upon by Pohlmann et al. (2004), is used to describe the diffusion of particles from rock fractures into matrix blocks of finite size and, once in the matrix, the diffusion of particles back to the rock fractures. This algorithm is based on transfer probabilities that control the movement of particles between rock fractures and matrix blocks. The transfer probabilities are dependent on parameters such as a constant diffusion coefficient, average fracture spacing and aperture, matrix porosity, retardation coefficients for the matrix and fractures (spatially variable), and advection in the matrix and fractures (refer to Appendix D in Pohlmann et al. [2004] for more detail). A constant diffusion coefficient of $1.0 \mathrm{E}-06 \mathrm{~m}^{2} / \mathrm{d}$, representative of a generic radionuclide, is used for all transport simulations. This is at the upper end of the range in values reported in Section 5.1.3.5. The computation of retardation coefficients and fracture transport aperture will be described shortly.

Transition times for the RWPT approach are simulated according to an idealized geometry of rectangular matrix blocks separated by parallel fractures. To compute an average width for the matrix blocks, the SFT-C database was used to determine that a total of 2,495 fractures were encountered over a composite transect length of $1,578 \mathrm{~m}$. An average transect length that includes all of these fractures is $0.6 \mathrm{~m}$. However, using a value of $0.6 \mathrm{~m}$ slightly underestimates the role of the rock matrix in the retention of radionuclide particles since only a small subset of fractures in a fractured medium are conductive to flow. By assuming only 10 percent of the total fracture population contributes to flow (Dershowitz et al., 2000), a final average fracture spacing of $6.0 \mathrm{~m}$ is used for all simulations. The aperture value used in the diffusion algorithm is based on the geometric mean of the fracture aperture distribution. Particle retention in matrix blocks is greater than particle retention along fracture walls due to the contrast in both advective velocity and retardation coefficients.

The influence of radionuclide sorption in both the matrix and rock fractures is simulated using algorithms that assume fast reversible adsorption with a linear isotherm. A dimensionless retardation coefficient assigned to matrix cells, $R_{m}$, is described by (Freeze and Cherry, 1979)

$$
R_{m}=1+\frac{p_{b}}{\theta_{m}} K_{d}
$$

where $K_{d}\left(\mathrm{~L}^{3} / \mathrm{M}\right)$ is a linear sorption coefficient and $\rho_{b}\left(\mathrm{M} / \mathrm{L}^{3}\right)$ and $\theta_{m}$ are the bulk density and porosity of the matrix, respectively. A bulk density of $2.64 \mathrm{~g} / \mathrm{cm}^{3}$ was measured for the Climax granite (Patrick et al., 1982). Matrix porosity is assigned a constant value of 0.6 percent (Murray, 1982).

The simulation of adsorption of radionuclides onto fracture walls is similar to Equation (5.3) (Freeze and Cherry, 1979; Frick et al., 1991):

$$
R_{f}=1+\frac{2 K_{a}}{b}
$$

where a dimensionless fracture retardation coefficient, $R_{f}$, is dependent on a surface-based sorption coefficient, $K_{a}=K_{d} / A_{s p}$ (where $A_{s p}$ is a constant specified surface area), $K_{a}(\mathrm{~m})$, and 
the transport aperture of the fracture, $b(\mathrm{~m})$. The transport aperture is computed by the quadratic law (Dershowitz et al., 1991)

$$
b=0.25 T^{0.5}
$$

which describes an empirical relationship between transport aperture and fracture transmissivity, $T\left(\mathrm{~m}^{2} / \mathrm{s}\right)$. For the implementation of Equation (5.5) in the FCM, it is assumed that fracture transmissivity is equal to the hydraulic conductivity of a fracture cell multiplied by the cell thickness $(15 \mathrm{~m})$. Retardation values based on Equation (5.4) are spatially variable as transport aperture is computed for each fracture-occupied cell of the fracture continuum model. A constant specific surface area $\left(A_{s p}\right)$ of $0.79 \mathrm{~m}^{2} / \mathrm{g}$ is used in the computation of the surface-based sorption coefficient in Equation (5-4). This value is based on sorption experiments performed in a similar fractured granite flow medium (Pohlmann et al., 2004).

Values of the retardation coefficients according to Equation (5.4) and Equation (5.5) are used to scale advective particle velocity of radionuclides in both the simulated rock fractures and matrix. The computation of retardation coefficients for a subset of radionuclides according to a transport aperture of $1.0 \times 10^{-4} \mathrm{~m}$, a constant bulk density of $2.64 \mathrm{~g} / \mathrm{cm}^{3}$, and a surface-based sorption coefficient of $0.79 \mathrm{~m}^{2} / \mathrm{g}$ shows that $R_{m}>>R_{f}$ (Table 5-18). This is caused by the significantly lower surface area available for radionuclide adsorption onto the walls of rock fractures than that for the matrix blocks. Again, the use of these retardation coefficients in the RWPT diffusion algorithm results in a higher probability that radionuclide particles will leave a rock fracture and enter a matrix block than for particles leaving the matrix and entering a fracture.

Table 5-18. Comparison of fracture and matrix retardation coefficients used in the transport model, for $\log _{10} K_{d}$ values arbitrarily selected from modeled range.

\begin{tabular}{cccc}
\hline Radionuclide & $\log _{10} K_{d}(\mathrm{ml} / \mathrm{g})$ & $R_{m}$ & $R_{f}$ \\
\hline${ }^{90} \mathrm{Sr}$ & 1.0 & $4.4 \mathrm{E}+03$ & 1.3 \\
${ }^{135} \mathrm{Cs}$ & 3.8 & $2.8 \mathrm{E}+06$ & $1.6 \mathrm{E}+02$ \\
${ }^{93} \mathrm{Zr}$ & 6.2 & $7.0 \mathrm{E}+08$ & $4.0 \mathrm{E}+05$ \\
\hline
\end{tabular}

A total of 32 radionuclides are grouped into eight different transport classes according to both the percentage of the source in the melt glass and the range in $K_{d}$ values (refer to Section 5.1.3 for description of the sorption experiments). The range in $K_{d}$ is assumed to be uniformly distributed between lower and upper limits for each transport group (Table 5-19). Uniform distributions are used because the data do not support more complex distributions and non-conservative values at the upper end of the ranges were culled for several classes in the grouping process (see Section 5.1.3.4). Note that Tables 5-14 and 5-15 are based on the sample mean and standard deviation of $K_{d}$ values and the sample mean is not necessarily in the center of the range described in Table 5-19. For each transport realization in a given transport group, a single $K_{d}$ value is randomly selected between the lower and upper limits. This value is then used in Equation (5.3) and Equation (5.4) in the computation of both matrix and fracture retardation coefficients. 
Table 5-19. Radionuclide transport groups and associated glass mass percentage, total particles used in the transport simulations, along with minimum and maximum $\log K_{d}$ values.

\begin{tabular}{|c|c|c|c|c|c|}
\hline Class & $\begin{array}{c}\text { Glass } \\
\% \\
\end{array}$ & $\begin{array}{c}\text { Total } \\
\text { Particles }\end{array}$ & $\begin{array}{l}\text { Min Log Kd } \\
(\mathrm{ml} / \mathrm{g})\end{array}$ & $\begin{array}{l}\text { Max Log Kd } \\
(\mathrm{ml} / \mathrm{g})\end{array}$ & Radionuclides \\
\hline I & 0 & 30,000 & - & - & ${ }^{3} \mathrm{H},{ }^{14} \mathrm{C},{ }^{39} \mathrm{Ar},{ }^{85} \mathrm{Kr}$ \\
\hline II & 20 & 30,000 & 2.32 & 4.11 & ${ }^{135} \mathrm{Cs},{ }^{137} \mathrm{Cs},{ }^{121} \mathrm{Sn},{ }^{126} \mathrm{Sn},{ }^{07} \mathrm{Pd}$ \\
\hline III & 40 & 60,000 & 0.81 & 1.42 & ${ }^{90} \mathrm{Sr},{ }^{41} \mathrm{Ca}$ \\
\hline IV & 50 & 60,000 & - & - & ${ }^{36} \mathrm{Cl},{ }^{129} \mathrm{I}$ \\
\hline V & 80 & 60,000 & - & - & ${ }^{99} \mathrm{Tc}$ \\
\hline VI & 90 & 90,000 & 0.11 & 1.02 & ${ }^{232} \mathrm{U},{ }^{233} \mathrm{U},{ }^{2384} \mathrm{U},{ }^{237}{ }^{235} \mathrm{U},{ }^{236} \mathrm{U}$, \\
\hline VII & 95 & 120,000 & 0.30 & 6.50 & ${ }^{59} \mathrm{Ni},{ }^{63} \mathrm{Ni},{ }^{93} \mathrm{Zr},{ }^{93 \mathrm{~m}} \mathrm{Nb}$, \\
\hline VIII & 95 & 120,000 & 2.56 & 4.30 & $\begin{array}{l}{ }^{150} \mathrm{Eu},{ }^{152} \mathrm{Eu},{ }^{154} \mathrm{Eu},{ }^{151} \mathrm{Sm}, \\
{ }^{166} \mathrm{Ho},{ }^{238} \mathrm{Pu},{ }^{239} \mathrm{Pu},{ }^{240} \mathrm{Pu}, \\
{ }^{241} \mathrm{Pu},{ }^{242} \mathrm{Pu},{ }^{241} \mathrm{Am},{ }^{244} \mathrm{Cm}\end{array}$ \\
\hline
\end{tabular}

The total number of particles, $n p$, used in each transport class is based on the proportion of the radionuclide source in the melt glass, $p$. Four groups of total particles are used: $n p$ is equal to 30,000 for $p \leq 0.20, n p$ is equal to 60,000 for $0.20 \leq p \leq 0.50, n p$ is equal to 90,000 for $0.80<p \leq 0.90$, and $n p$ is equal to 120,000 for $p>0.90$. A total of $n p / 3$ particles for each transport realization are uniformly distributed over the area of permeability disks for the three underground nuclear tests. These particles are indexed in terms of their release (i.e., hydraulic or melt glass dissolution). The hydraulic release fraction, $n p \bullet(1-p)$, is instantaneously released at $t=0$ for all three tests; the difference in test dates is handled during post-processing. The total number of particles is randomly distributed throughout the permeability disk. The portion of particles representing the hydraulic release and glass fraction are randomly selected and are independent of location with the permeability disk. The melt glass fraction is released according to the modeling results from the melt glass dissolution described in Section 5.1.2. A porosity value of 0.20 , characteristic of rubble material, is used to limit particle velocities within the permeability disks. In cases where fractures intersect the permeability disks, lower fracture porosities and potentially greater values of permeability cause preferential transport through the fractures. The total transport simulation time is 1,000 years. Over the course of 1,000 years, the total fraction of radionuclide particles released from the melt glass for the Hard Hat, Tiny Tot, and Pile Driver tests is 3.02 percent, 4.78 percent and 3.60 percent, respectively (Figure 5-14). This indicates that radionuclide release from glass dissolution is relatively unimportant for Climax.

\subsection{Results of Transport Modeling}

Transport calculations were performed for each radionuclide class (with radionuclides from both the nuclear melt glass and from the aqueous-sorbed portion) and each Climax nuclear test. Results from the radionuclide particle tracking simulations consist of particle flux at model boundaries, physical locations where particles exit the Climax stock, velocity distributions of conservative breakthrough particles, and the final mass flux estimates for individual radionuclides leaving the Climax stock and entering the northern portion of Yucca Flat. The weighted mass flux estimates for individual radionuclides and their associated exit locations are the final results of this study. 


\subsubsection{Conservative Particle Transport and Groundwater Velocity}

Transport Class I consists of radionuclides ${ }^{3} \mathrm{H},{ }^{14} \mathrm{C},{ }^{39} \mathrm{Ar}$, and ${ }^{85} \mathrm{Kr}$ and is one of three conservative transport classes used in the Climax transport model. However, Class I is unique, as the entire source mass is assumed to be in the hydraulic release fraction (Table 5-19). Due to the combination of conservative transport and a release fraction that is entirely in the hydraulic phase, transport results from Class I provide the best data to explore the transport characteristics of the local-scale FCM realizations.

Approximately 36 percent of the radionuclide particles for Class I exited the model domain within 1,000 years. Of the particles that leave the model domain, 26 percent originate from the Hard Hat test, 41 percent originate from the Tiny Tot test, and 33 percent originate from the Pile Driver test. Tiny Tot, the closest to the southern boundary, has the highest percentage of particles that leave the model domain. Though the location of the Hard Hat test is closer to the southern boundary than the Pile Driver test (Figure 5-27), fewer particles leave the model domain from the Hard Hat test than for the Pile Driver test. The difference in the number of particles leaving the model domain for the Hard Hat and Pile Driver tests is attributed to the size of the permeability disks over which particles are introduced into each flow field realization (i.e., the greater the size of the permeability disk, the greater the probability that radionuclide particles will be located in a conductive fracture zone). Recall that the diameter of the permeability disks is proportional to the extent of shock fracturing observed for each nuclear test. The diameter of the permeability disk for Pile Driver is over two times greater than the permeability disk for the Hard Hat test (Figure 5-27).

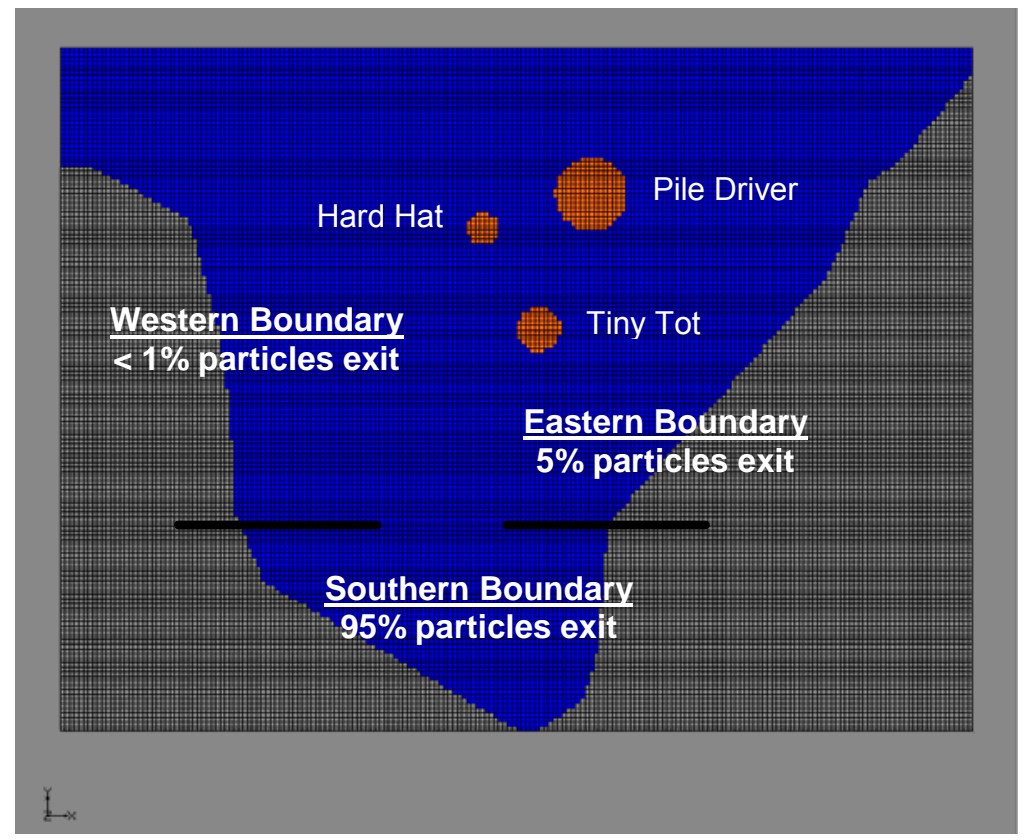

Figure 5-27. Location of eastern, western, and southern model boundaries along with percentage of radionuclide particles exiting each boundary. Blue cells represent the Climax stock, red cells represent the permeability disk assigned to each underground test, and black lines denote boundary lines between the boundaries. 
Approximately 95 percent of all particles exit through the southern model boundary (Figure 5-27). This demonstrates that the local-scale FCM model realizations honor the general flow direction of northeast to southwest flow through the Climax stock (Murray, 1981). Recall that the horizontal and vertical gradients in the FCM realizations are based on constant head boundary conditions interpolated from the alternative CRFMs. The majority of particles that leave the southern model boundary exit between layers 50 and 65 , corresponding to an elevation between 750 and $990 \mathrm{~m}$ amsl (Figure 5-28).

The flux of particles to the local-scale FCM boundaries for the Hard Hat, Tiny Tot, and Pile Driver tests peaks at 414, 276, and 263 years, respectively (Figure 5-29) (this is without consideration of radioactive decay). The peak arrival time for the ensemble of the three tests occurs at 307 years. The velocity of particles that exit the model domain ranges between $5.4 \times 10^{-4} \mathrm{~m} / \mathrm{d}$ and $0.9 \mathrm{~m} / \mathrm{d}$ and has a distribution that is remarkably similar to the distribution of maximum velocity vectors for the Shoal numerical model (compare Figure 5-30 to Pohlmann et al. [2004] Figure 5.1).

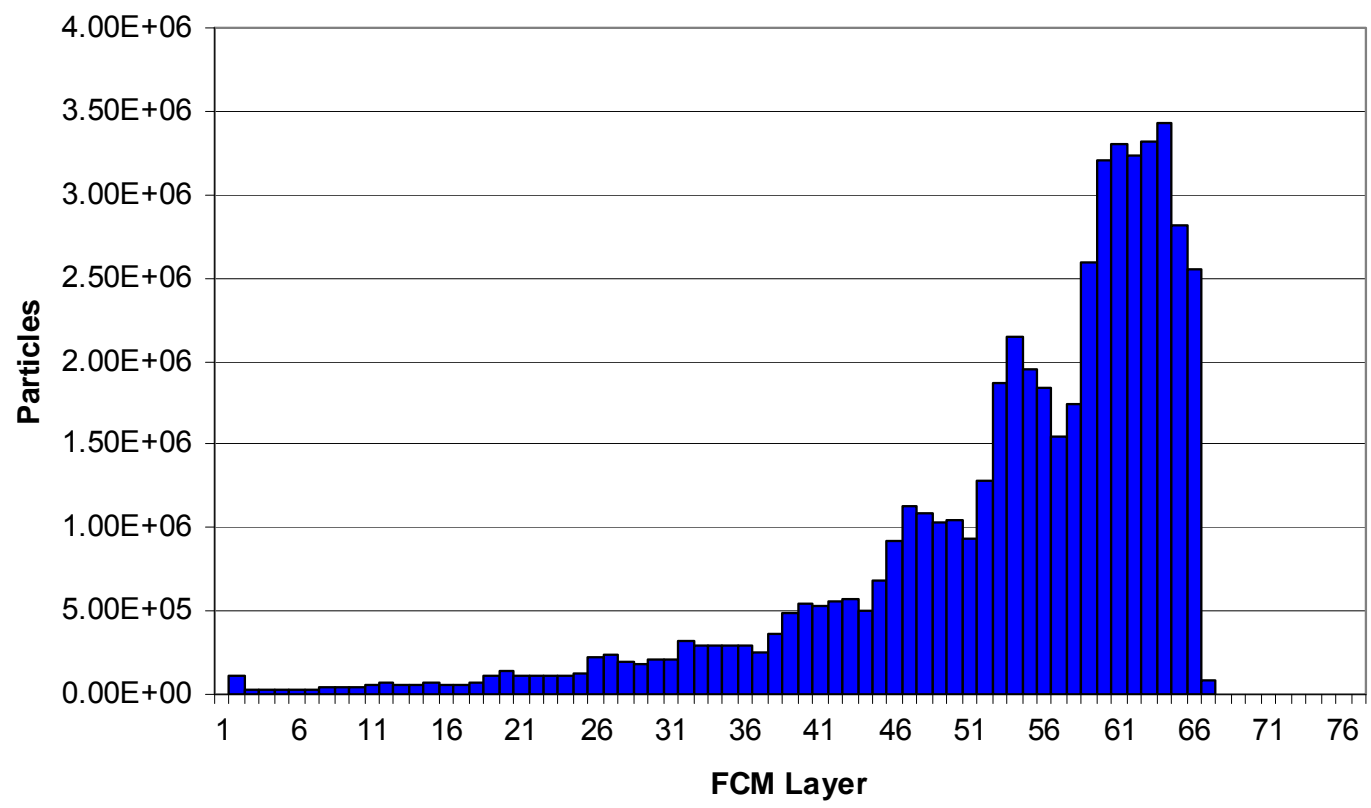

Figure 5-28. Vertical exit locations (layers) of particles leaving the Southern boundary. Layers are based on 15-m increments starting from sea level (bottom of layer 1) to 1,155 m (top of layer 77). 


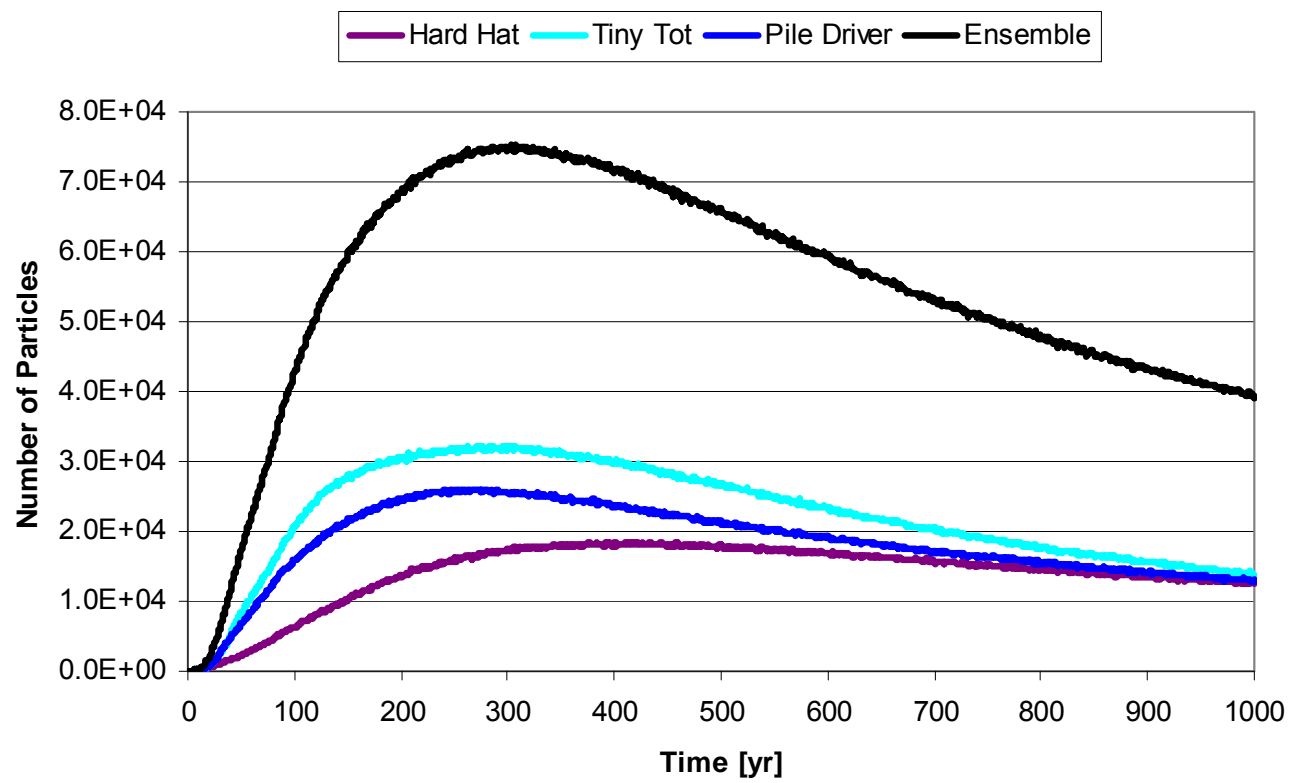

Figure 5-29. Particle flux times for transport Class I to model domain boundaries for each source origin along with the ensemble trend.

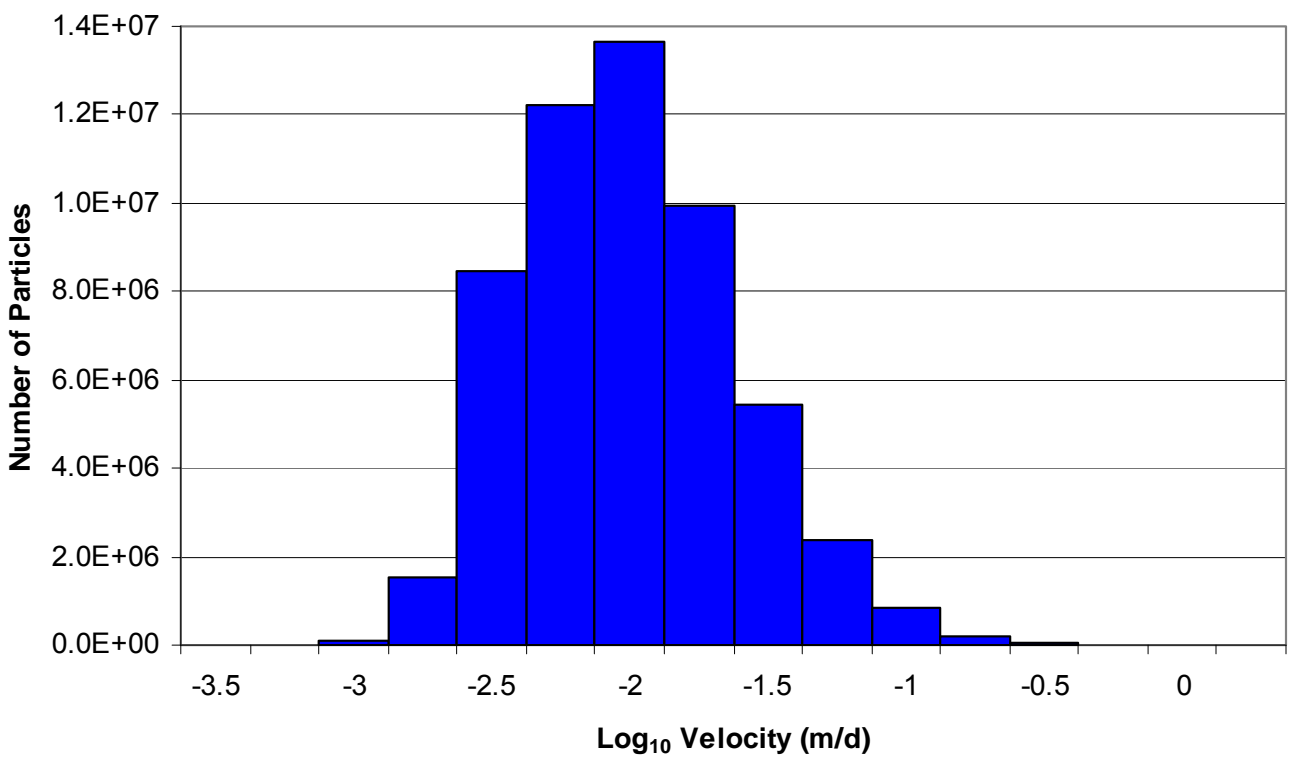

Figure 5-30. Histogram of $\log _{10}$ velocity for all particles that exit the local-scale FCM model domain. Values of bin midpoints are given.

\subsubsection{Computation of Radionuclide Flux}

The determination of radionuclide flux from the Climax stock starts with the computation of radionuclide particle flux to the boundaries of the local-scale FCM (i.e., Figure 5-29). Since Ptrack simulates particle transport for all sources starting at $t=0$ (i.e., time of the Hard Hat test), particle exit times for the Tiny Tot and Pile Driver underground tests are increased by 5.34 and 6.30 years, respectively. Exit times for each 
radionuclide particle for each of the 5,000 transport realizations are then binned into one-year intervals over a 1,000-year time span for each source origin.

Radionuclide mass flux (moles/yr) from the Climax stock is computed individually for each radionuclide within a specific transport class (Table 5-19). Each particle from a given realization and time interval is assigned a molar mass specific to the selected radionuclide, where particle mass is equal to the total radionuclide source term mass according to a particle's origin (i.e., Hard Hat, Tiny Tot, or Pile Driver) (Table 5-1) divided by the total number of particles used in the transport simulations (Table 5-19). This mass is then rescaled by an algorithm based on Faure (1977) that can compute radionuclide decay for a parent isotope with a maximum of two radioactive daughter products. After the rescaling process, values of radionuclide mass flux from each test are combined to form an ensemble mass flux.

Final weights, as described in Section 4.3.6.2, are applied to the values of ensemble mass flux for each realization at every time step. An empirical cumulative distribution function (CDF) of the ensemble radionuclide mass flux values is then computed from the final weights. Values of ensemble mass flux corresponding to the median and the upper and lower 95-percent confidence intervals (U95 and L95) are then determined from the empirical CDF for each time step (Figure 5-31). Mean radionuclide mass flux for a given time interval is the product sum of mass flux values and their corresponding weights for all 5,000 FCM realizations.

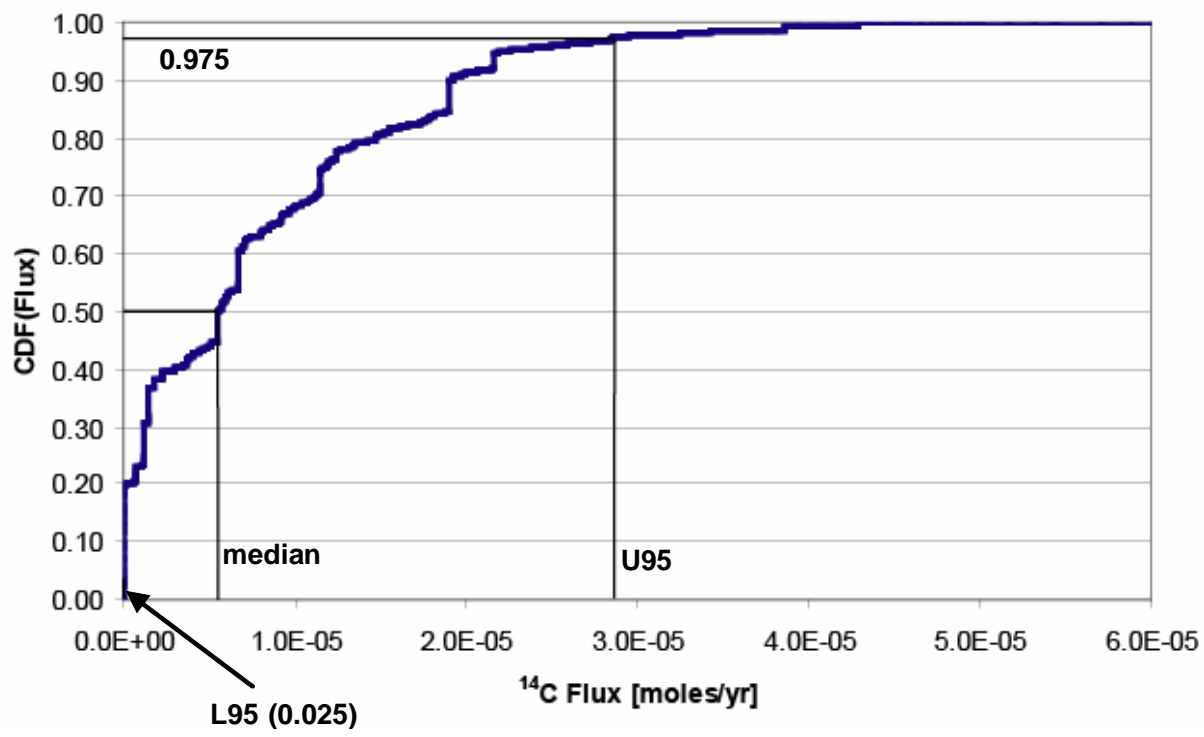

Figure 5-31. Empirical CDF of radionuclide flux for ${ }^{14} \mathrm{C}$ at a time of 307 years along with values corresponding to L95, median, and U95.

The incorporation of both conceptual and parametric uncertainty into the particle mass flux curves is illustrated in Figures 5-32 through 5-35. A single radionuclide for transport Class $1,{ }^{14} \mathrm{C}$, was selected for its long half-life (approximately 5,000 years). Radionuclide mass flux curves are then computed from particle flux times for transport Class I to model domain boundaries (Figure 5-29). The raw (i.e., unprocessed) particle flux times 


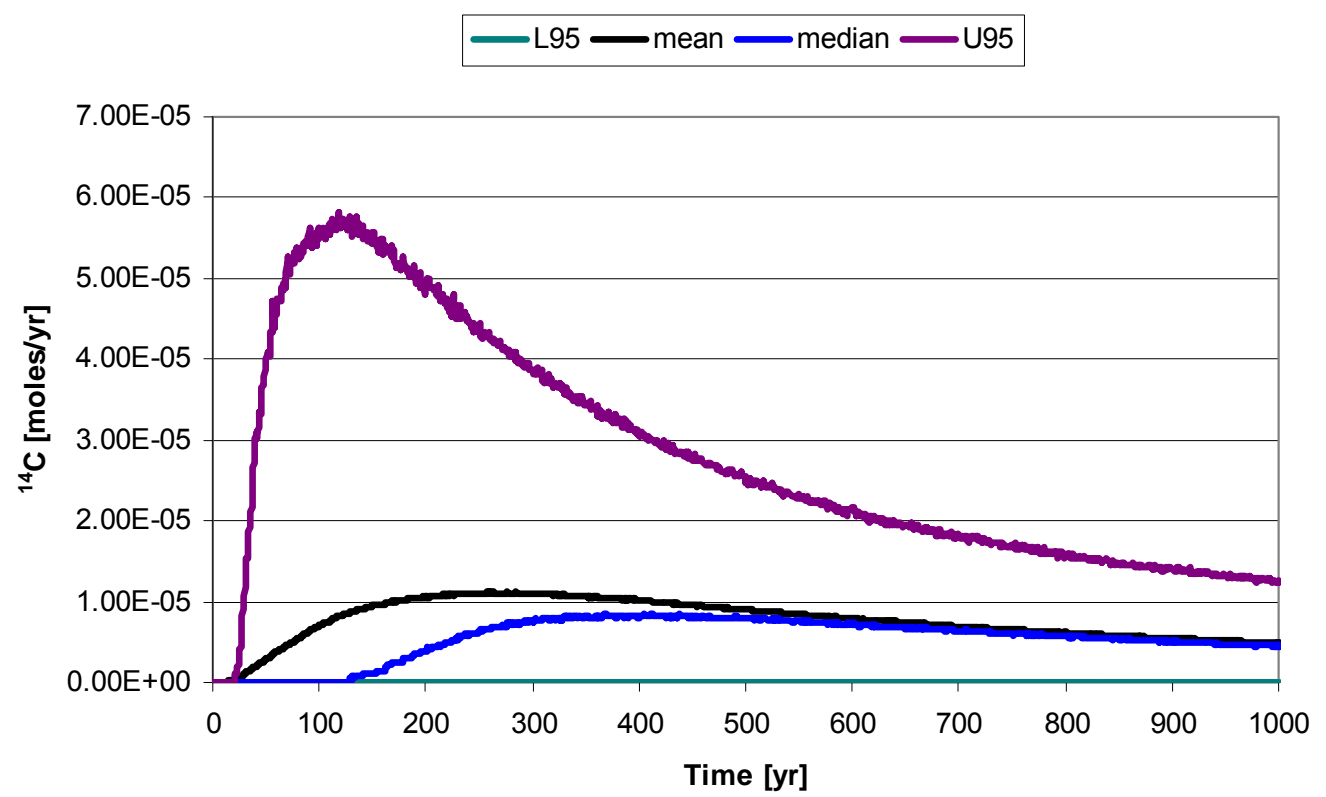

Figure 5-32. Radionuclide mass flux for ${ }^{14} \mathrm{C}$ based on a straight Monte Carlo simulation where all realizations are weighted equally.

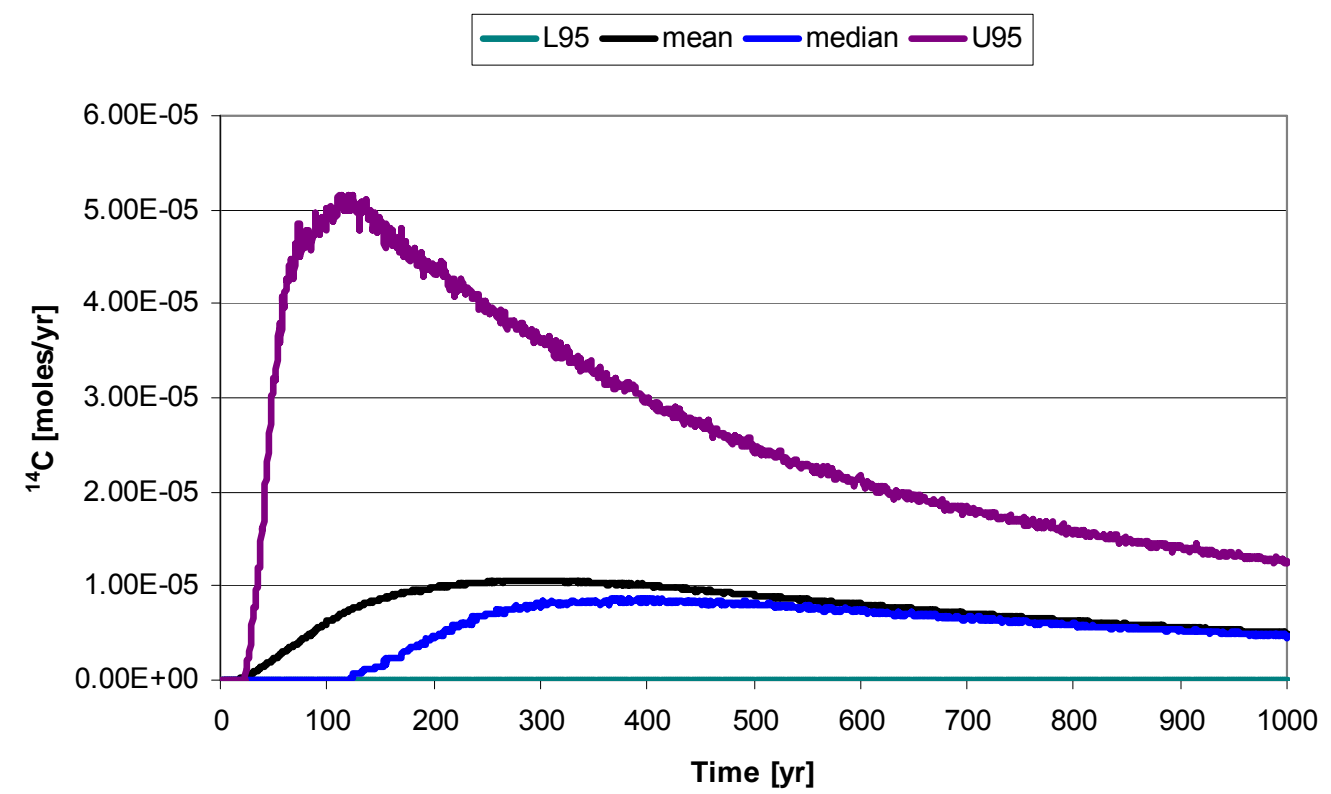

Figure 5-33. Incorporation of regional conceptual model uncertainty into radionuclide mass flux for ${ }^{14} \mathrm{C}$. Transport realizations are weighted according to their corresponding alternative model weights. 


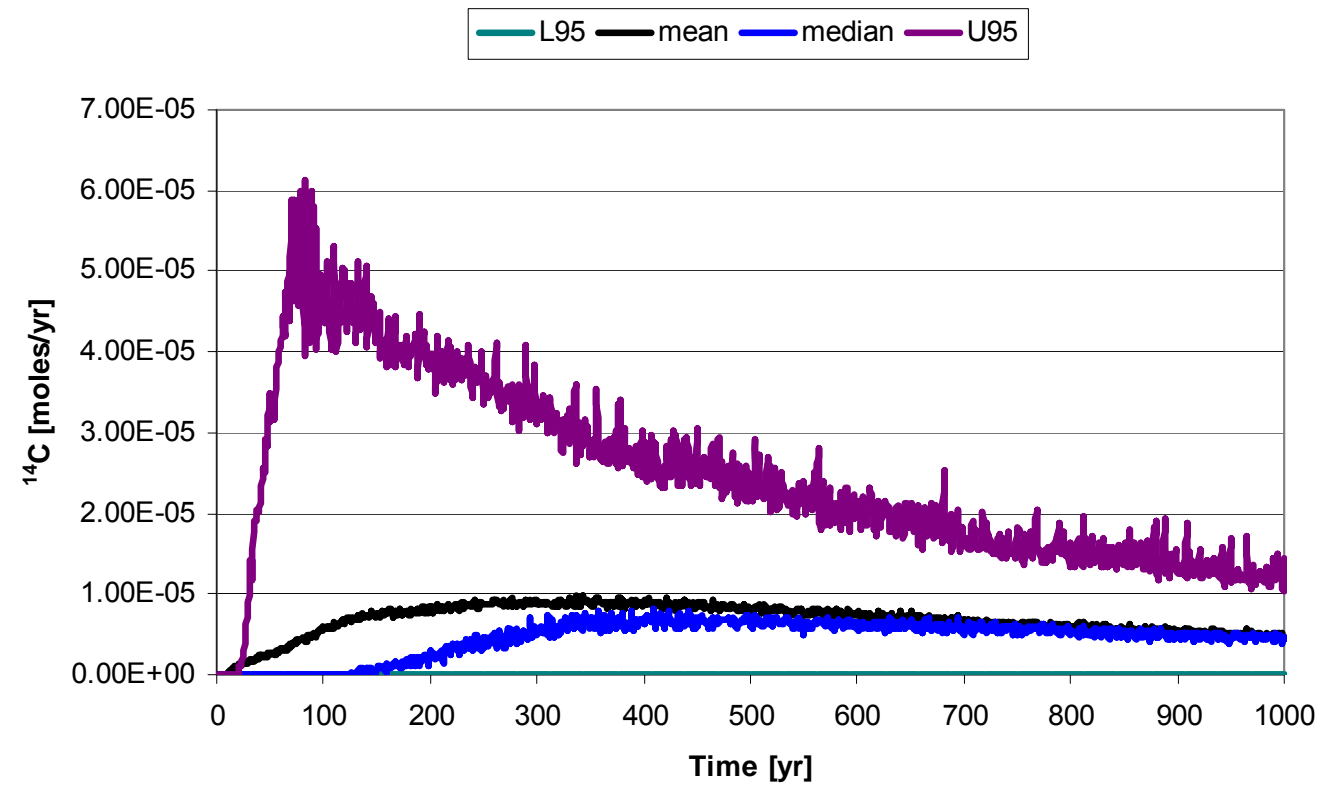

Figure 5-34. Incorporation of parametric uncertainty, expressed as values of GLUE-weighted volumetric flux, in the local-scale Climax fracture continuum model for ${ }^{14} \mathrm{C}$ mass flux.

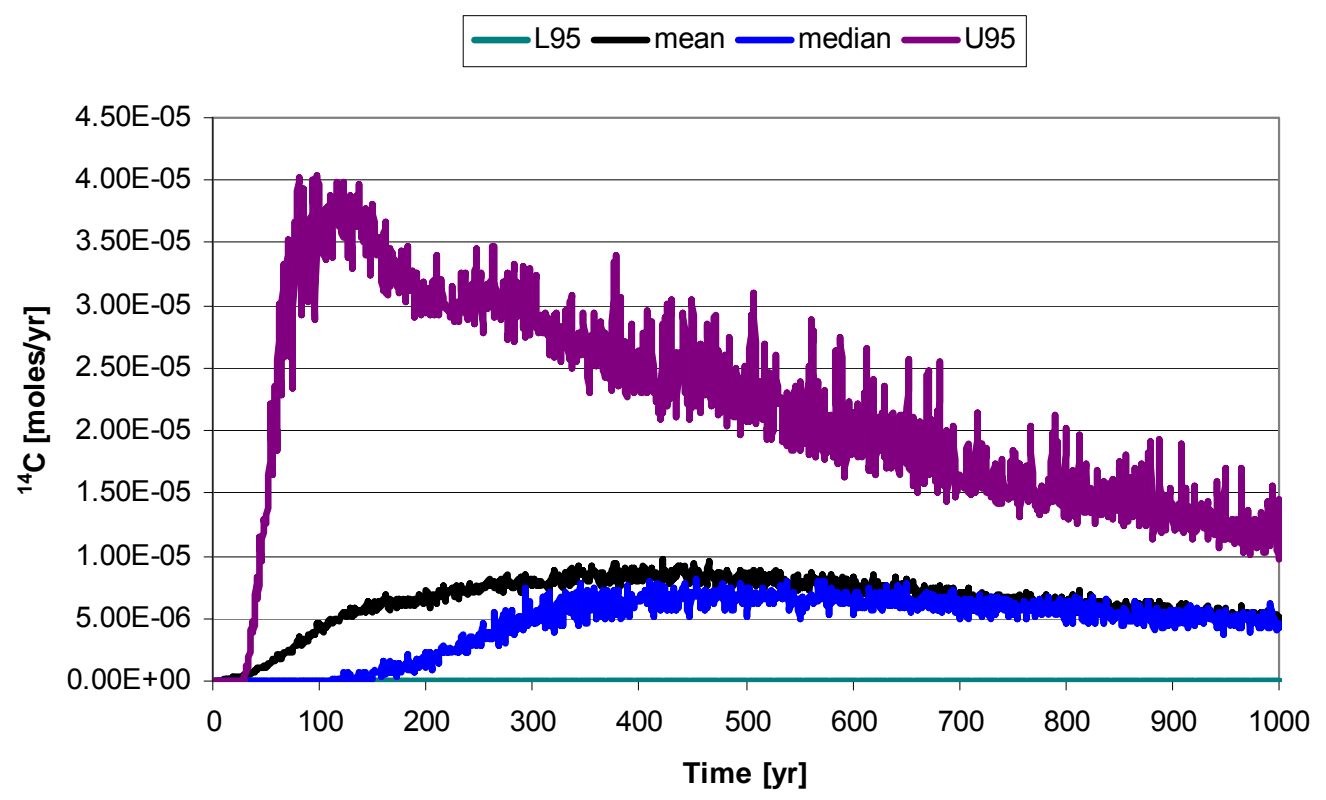

Figure 5-35. Final radionuclide mass flux values incorporate both alternative model and parametric uncertainty.

to model domain boundaries incorporate uncertainty in boundary conditions assigned to the local-scale FCM according to each alternative conceptual model and parametric uncertainty in both flow and radionuclide transport in the local-scale FCM. Specifically, parametric 
uncertainty in the local-scale flow model is addressed by fracture zone networks that consist of interconnected fractures with random fracture zone placement, orientation, length and hydraulic conductivity. In the transport model, parametric uncertainty consists of an anisotropic within-fracture dispersion tensor applied to advective particle trajectories, values of porosity and transport aperture assigned to individual fracture segments of the hydraulic backbone, retardation coefficients used to model radionuclide retention along fracture walls and in matrix blocks, and the transfer probability approach used to model the motion of radionuclide particles between fractures and the rock matrix.

Figure 5-32 consists of equally weighted realizations according to particle flux arrival times to model boundaries (i.e., a straight Monte Carlo simulation without preferential weighting). The only difference between Figure 5-32 and the ensemble curve shown in Figure 5-29 is the inclusion of the source mass for ${ }^{14} \mathrm{C}$ and subsequent mass loss with time due to radioactive decay. The influence of radioactive decay decreases the time of the peak breakthrough and overall shape of the initial particle arrival curve (Figure 5-29). The inclusion of regional conceptual model uncertainty into the radionuclide mass flux curves shown in Figure 5-32 result in a slightly more erratic profile along the mass breakthrough curve (Figure 5-33). The erratic profile in Figure 5-33 reflects the preferential weighting of radionuclide particles at model boundaries. The weights applied to the radionuclide particles are derived from each regional-scale CRFM (refer to 3.4.3.3). Note that the weighting of breakthrough particles according to model weights slightly decreases the magnitude of the breakthrough curves versus the straight Monte Carlo curve (Figure 5-32). This is most easily observed in the peak of the upper 95-percent confidence interval, which decreases from approximately $5.8 \times 10^{-5} \mathrm{~mol} / \mathrm{yr}$ to $5.8 \times 10^{-5} \mathrm{~mol} / \mathrm{yr}$ of ${ }^{14} \mathrm{C}$.

The incorporation of GLUE weights to the mass flux curves shown in Figure 5-32 results in a much more erratic profile (Figure 5-34) than caused by the model weights (Figure 5-33). The noisy quality of the GLUE-weighted curve (Figure 5-34) reflects the weights assigned to individual particles - recall that GLUE weights are based on matching volumetric flux values for individual FCM realizations to a target volumetric flux for a corresponding alternative model (refer to 4.3.3). Given that the majority of fluid flow occurs through interconnected fracture zones of the hydraulic backbone, the volumetric flux values are an indirect value of fracture zone connectivity. Thus, the GLUE weights indirectly reflect the degree of network connectivity of fracture zones with random placement, orientation, length, and hydraulic conductivity. Despite the noise, the GLUE-weighted mass flux curves (Figure 5-34) follows the same general trend as the equally weighted Monte Carlo mass flux curves (Figure 5-32).

The final weights assigned to the mass flux curves are a combination of both model and GLUE weights (refer to Equation [4.9] in Section 4.3.4, where model and GLUE weights are multiplied). The multiplication of these weights increases the amplitude of the noise as the final radionuclide mass flux curves have the most erratic profiles (Figure 5-35). The magnitude of the mass flux curves is slightly lower than the equally weighted Monte Carlo realizations (Figure 5-32).

In summary, the incorporation of model and GLUE weights (Figure 5-35) to equally weighted mass flux curves (Figure 5-32) creates noise or variability about the original mass flux curves. The variability about the general trends of the mass flux curves is attributed to the preferential weighting of breakthrough particles in time. Despite this variability, the 
general trend of the final mass flux curves (Figure 5-35) is consistent with the initial (unweighted) mass flux curve (Figure 5-32).

\subsubsection{Radionuclide Flux of Individual Radionuclides}

The mean, median, and lower (L95) and upper (U95) 95-percent confidence interval values of radionuclide flux are computed at each time interval for each radionuclide within a transport class. With the exception of Class V, which is scaled from the Class IV transport results, radionuclide transport is simulated in all 5,000 FCM flow realizations according to the unique transport characteristics specific to each transport group (Table 5-19).

Radionuclide mass flux results are presented only for transport classes with nonzero flux values (i.e., Classes I, III - VI). The primary controls on radionuclide transport within the model and breakthrough at model boundaries are the values of $\log K_{d}$ used in Equation (5.3) and Equation (5.4). Classes III and VI, where values of $\log K_{d}$ range between 0.81 and 1.42 $\mathrm{ml} / \mathrm{g}$ and 0.11 and $1.02 \mathrm{ml} / \mathrm{g}$, respectively, had little observed breakthrough. No breakthrough occurs for Classes II, VII, and VIII, which have significantly higher $K_{d}$ values.

Transport statistics for Class I have been described in detail in Section 5.3.1 and Table 5-19. By post-processing radionuclide particle flux at model boundaries (Figure 5-29), the mass flux is computed for all radionuclides in Class $\mathrm{I}:{ }^{3} \mathrm{H},{ }^{14} \mathrm{C},{ }^{39} \mathrm{Ar}$, and ${ }^{85} \mathrm{Kr}$ (Figures 5-36 through 5-39). While the source mass describes the initial magnitude of the molar mass for each radionuclide, the shape or relative decay of the mass flux curve, relative to the ensemble trend of particle flux, is controlled by the half-life of each radionuclide. For example, mass flux for ${ }^{3} \mathrm{H}$ (Figure 5-36) and ${ }^{85} \mathrm{Kr}$ (Figure 5-39) shows an initial peak followed by a dramatic decline due to half-lives of only 12.3 and 10.8 years, respectively. A less dramatic decay trend is observed for ${ }^{14} \mathrm{C}$ (Figure 5-37) and ${ }^{39} \mathrm{Ar}$ (Figure 5-38) over the 1,000-year time span due to half-lives of 5,720 and 269 years, respectively. Note that values for L95, representing the lower boundary of the 95-percent confidence interval, are zero for all times. In fact, L95 is zero for all transport classes. This is caused by the unequal distribution of particles exiting the Climax stock over all 5,000 realizations. An increase in realizations (or the total number of particles) may possibly result in nonzero values for L95; however, any nonzero value for L95 would remain extremely small. 


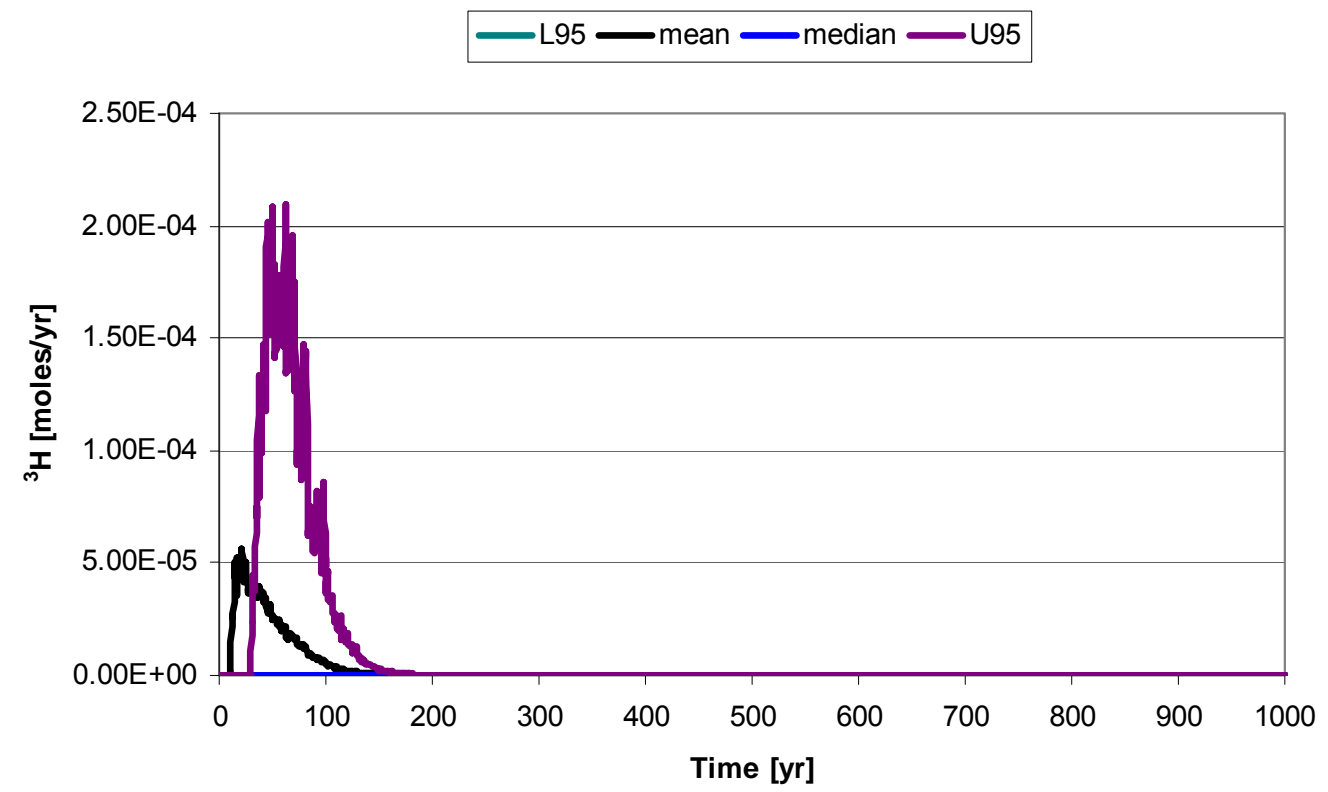

Figure 5-36. Mass flux curves for ${ }^{3} \mathrm{H}$.

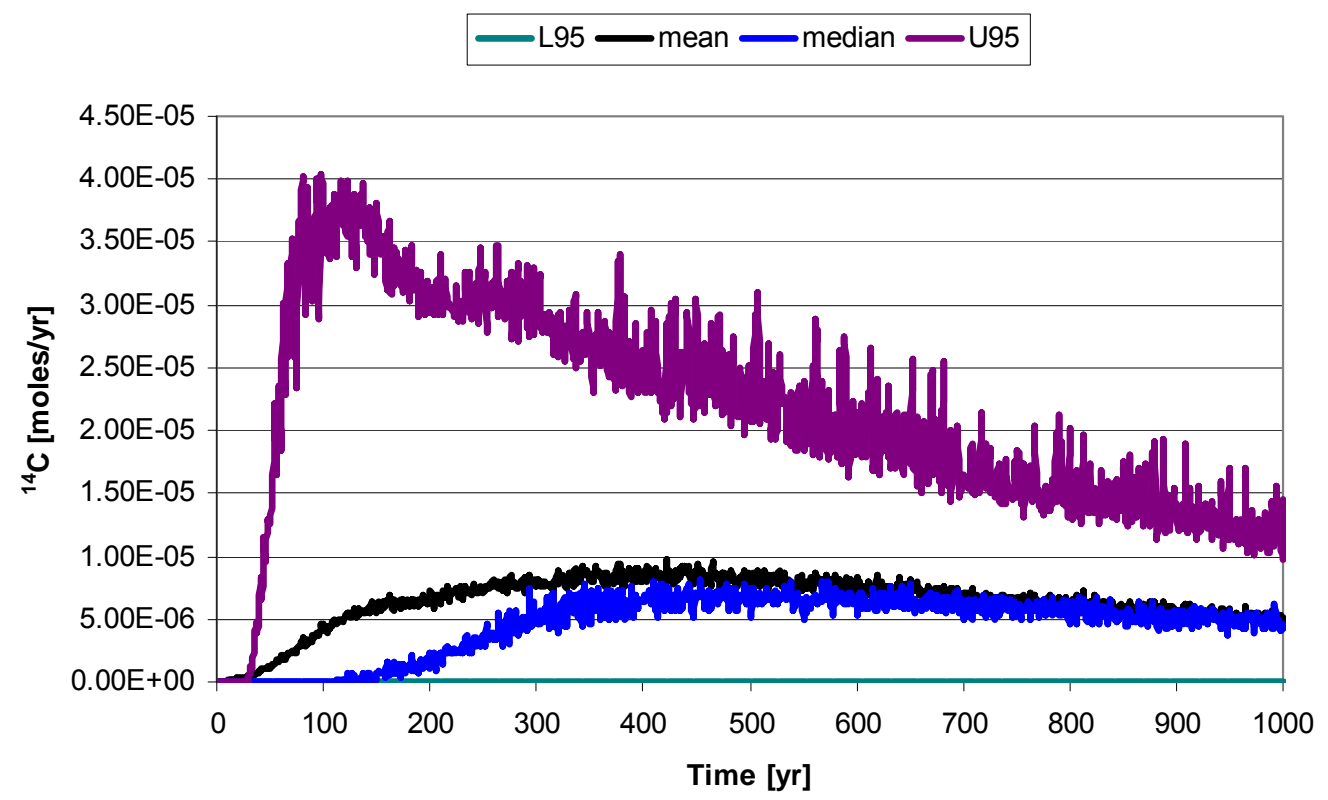

Figure 5-37. Mass flux curves for ${ }^{14} \mathrm{C}$. 


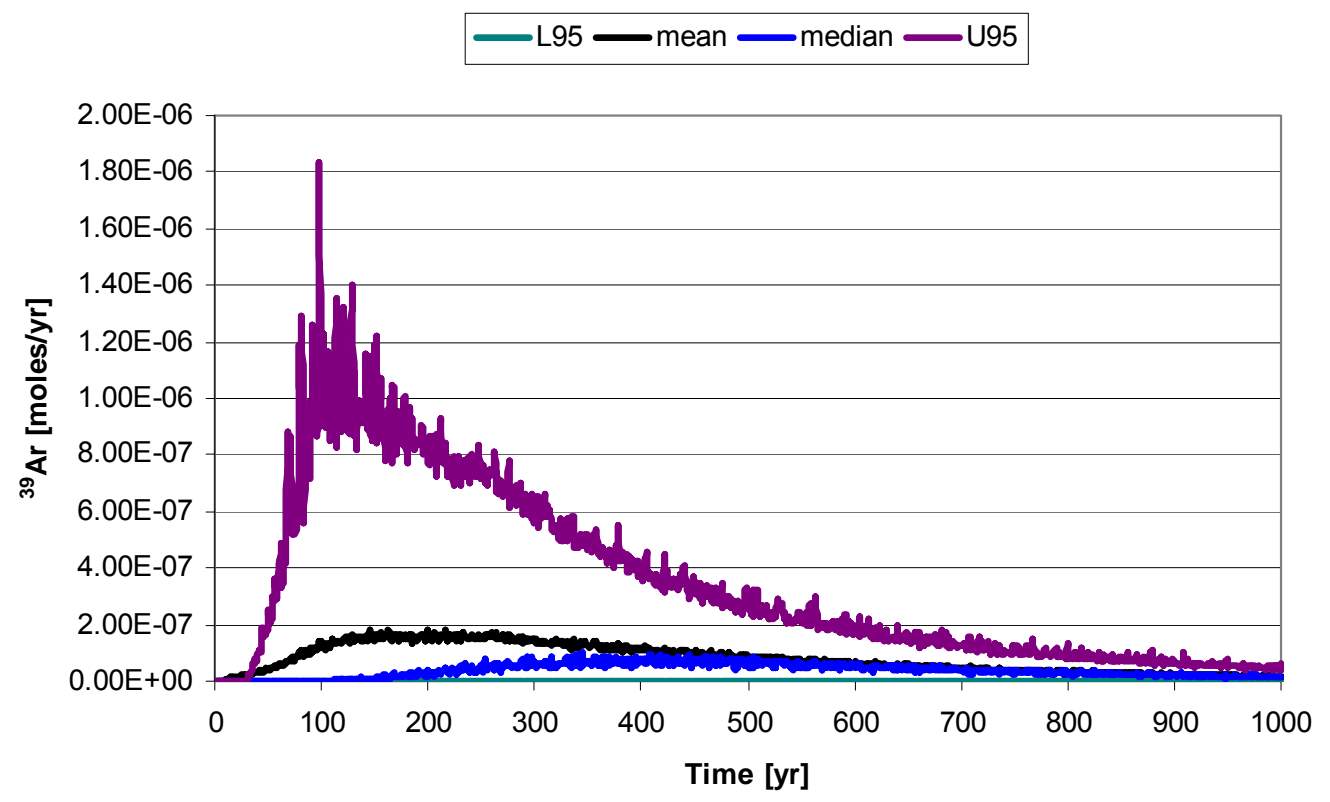

Figure 5-38. Mass flux curves for ${ }^{39} \mathrm{Ar}$.

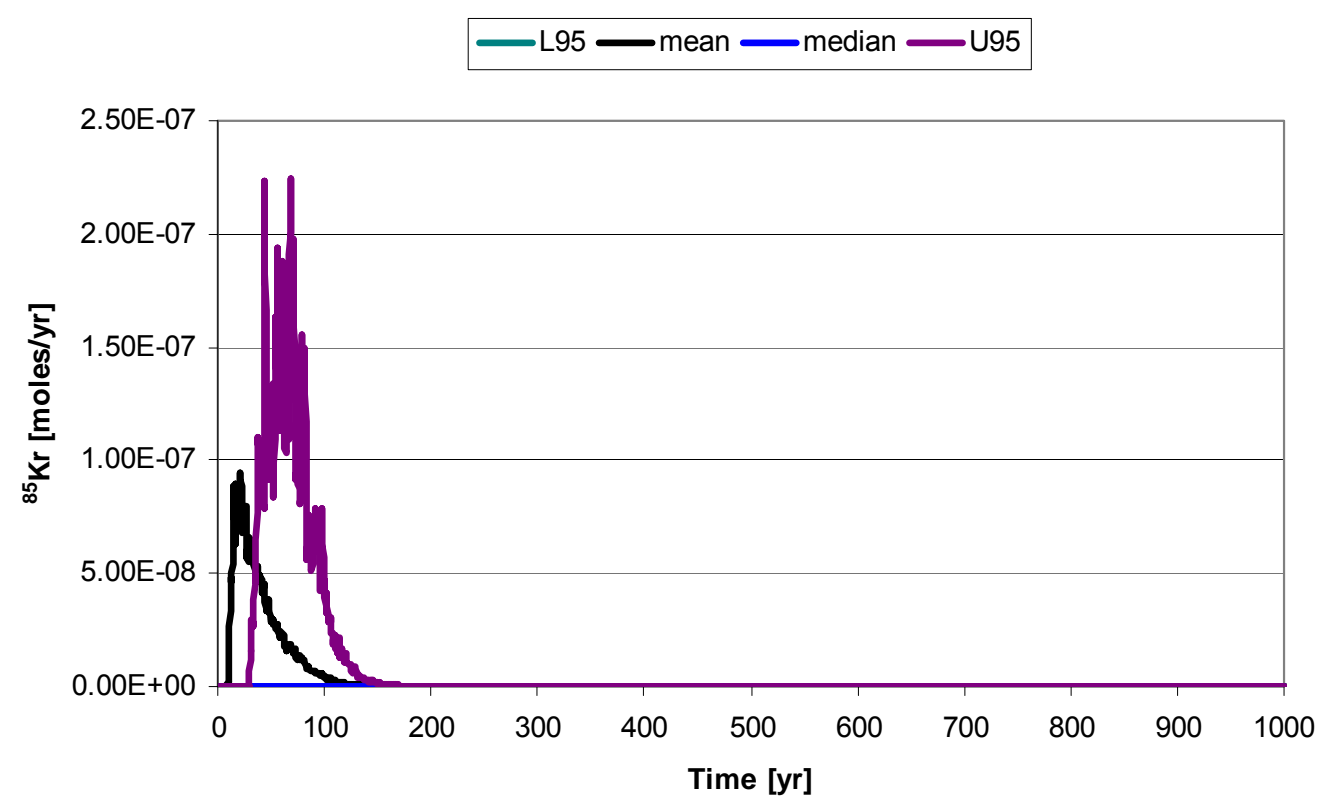

Figure 5-39. Mass flux curves for ${ }^{85} \mathrm{Kr}$.

Class III contains two sorbing radionuclides, ${ }^{41} \mathrm{Ca}$ and ${ }^{90} \mathrm{Sr}$, with a source mass consisting of 40-percent melt glass (Table 5-19). The incorporation of nonzero $K_{d}$ values for Class III results in a very low breakthrough (only 137 total particles) and an irregular particle flux trend (Figure 5-40). None of the breakthrough particles originated in the melt glass. The extremely low breakthrough $\left(\sim 4.6 \times 10^{-5} \%\right.$ of the total particles $)$ indicates that the flux of sorbing radionuclides into Yucca Flat from the three Climax tests is insignificant. Of the particles that exit the model domain, 60 percent and 40 percent of the particles originate from 
the Tiny Tot and Pile Driver tests, respectively. The difference in trends for particle flux and mean radionuclide flux for ${ }^{41} \mathrm{Ca}$ (Figure 5-41) and ${ }^{90} \mathrm{Sr}$ (Figure 5-42) is caused by the values of the final weights used in the computation of mean flux. Mean radionuclide mass flux is especially sensitive to the values of the final weights since the maximum value of particle flux is only three particles per year. At later times, the lack of mass flux for ${ }^{90} \mathrm{Sr}$ is caused by a short half-life of 29 years as opposed to a half-life of 10,300 years for ${ }^{41} \mathrm{Ca}$. The median and U95 radionuclide mass flux are undefined for Class III due to the lack of the particle breakthrough.

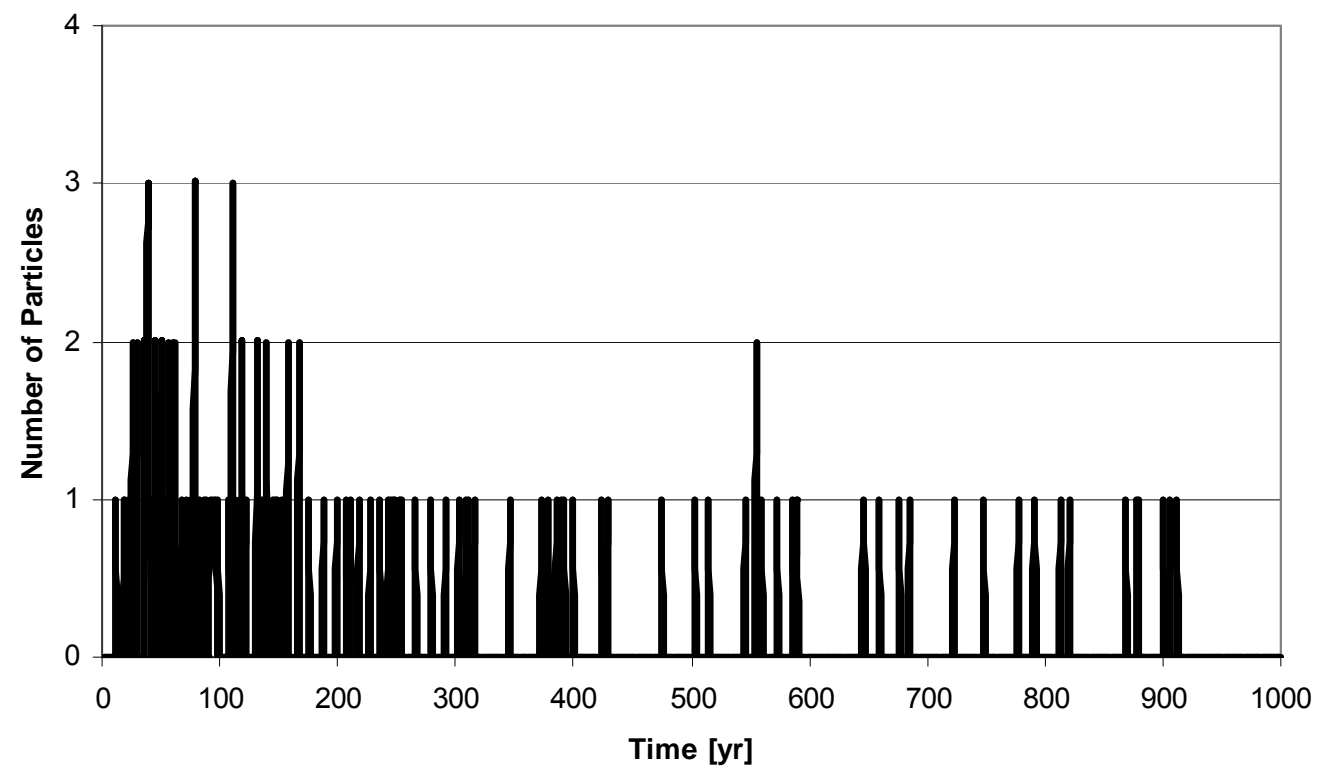

Figure 5-40. Ensemble particle flux times to model domain boundaries for Class III.

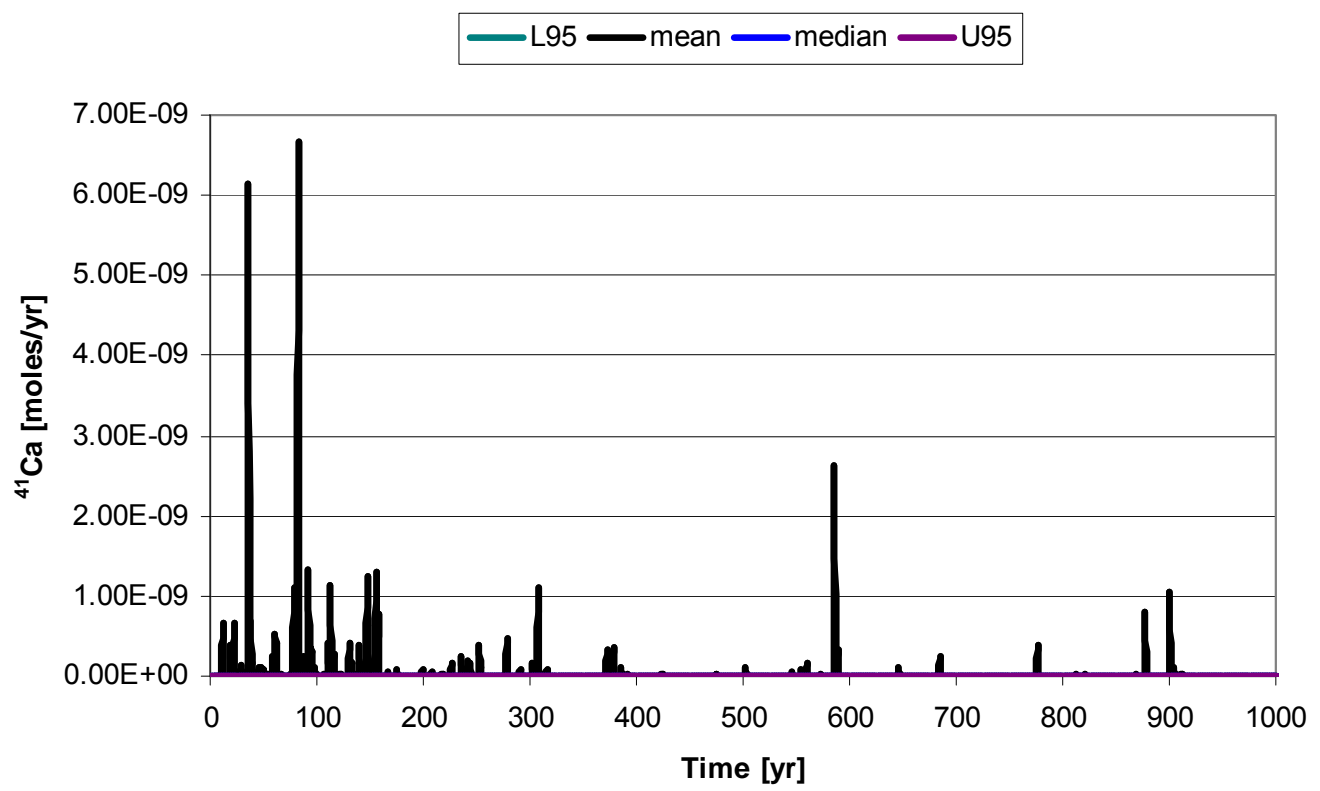

Figure 5-41. Mass flux curves for ${ }^{41} \mathrm{Ca}$. 


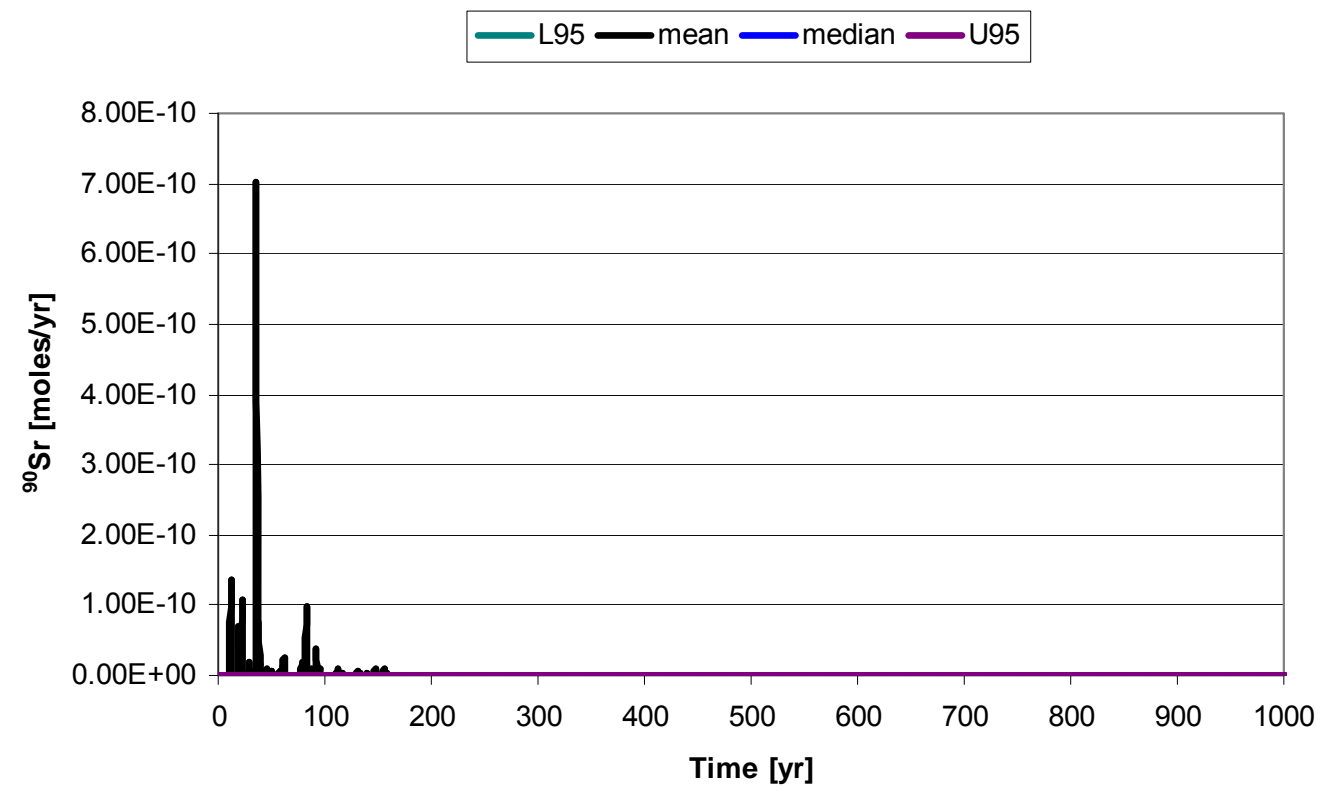

Figure 5-42. Mass flux curves for ${ }^{90} \mathrm{Sr}$.

Radionuclide particles for Classes IV and V undergo conservative transport, and the difference between the two transport classes is the amount of each radionuclide source in the melt glass (Table 5-19). Class IV represents ${ }^{36} \mathrm{Cl}$ and ${ }^{129} \mathrm{I}$, where 50 percent of the source is in the melt glass fraction, while Class $\mathrm{V}$ is reserved exclusively for ${ }^{99} \mathrm{Tc}$, which has a source that is predominately (i.e., 80\%) in the melt glass fraction. Since the transport characteristics for both classes are conservative, transport simulations were conducted for Class IV only; mass flux calculations for Class $\mathrm{V}$ are determined from the particle breakthrough curves for Class IV during post-processing.

The particle breakthrough curve for Class IV is very similar to the trend for Class I, with approximately 18 percent (versus $36 \%$ for Class I) of the total particles leaving the boundaries of the model domain (Figure 5-43). While the number of breakthrough particles is very similar for Classes I and IV, twice the number of particles were used in individual transport simulations for Class IV to allow for a sufficient number of glass particles (Table 519). The influence of a 50-percent melt glass fraction effectively reduces the number of breakthrough particles by half; only 1.6 percent of the breakthrough particles originated in the melt glass. The locations of particle breakthrough, peak arrival times, and particle origin (e.g., Hard Hat, Tiny Tot, and Pile Driver) are nearly identical to Class I. The trend of the mass flux curves for Class IV and V (Figures 5-44 through 5-46) reflect the particle flux at the model boundaries (Figure 5-43). The influence of radionuclide decay is minimal, as each of the three radionuclides for Classes IV and V have very long half-lives ( $>10^{6}$ years). 


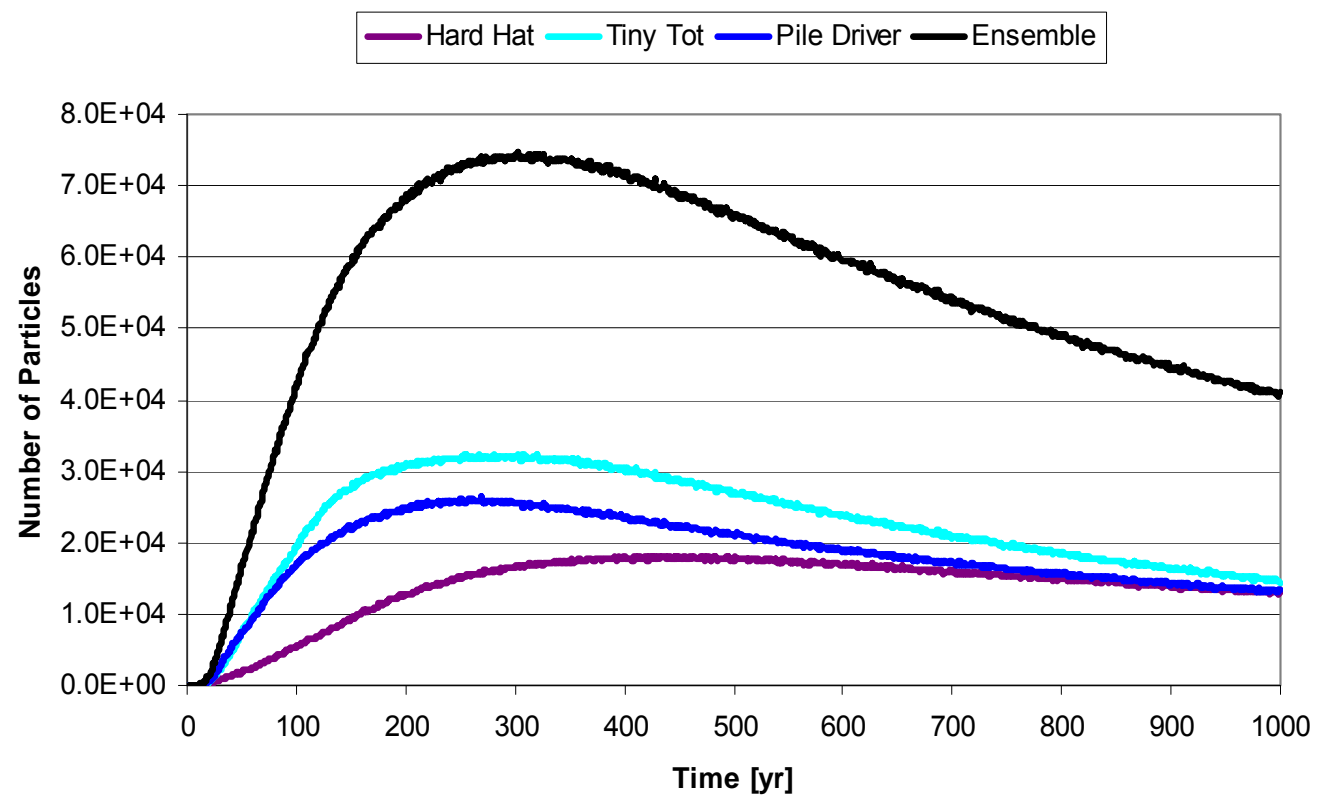

Figure 5-43. Particle flux times for transport Class IV to model domain boundaries for each source origin along with the ensemble trend.

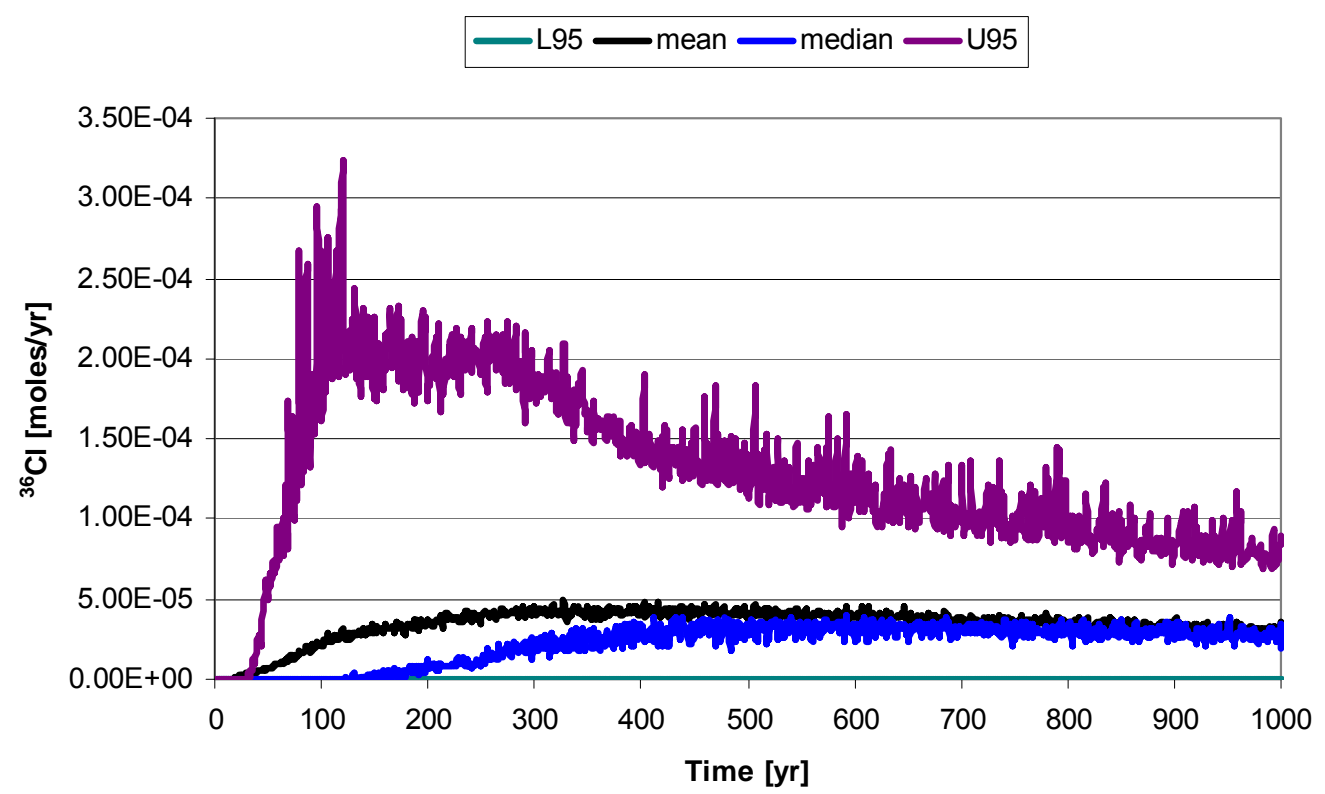

Figure 5-44. Mass flux curves for ${ }^{36} \mathrm{Cl}$. 


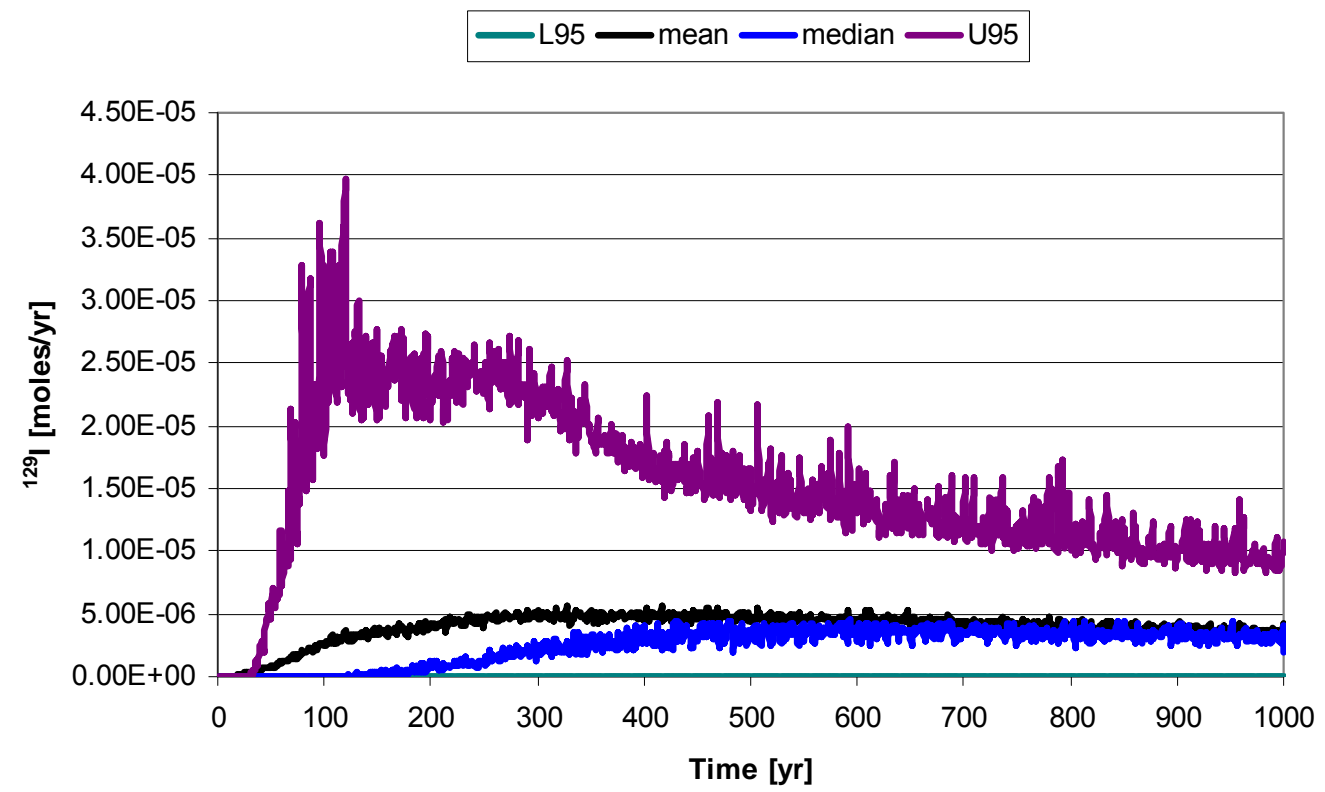

Figure 5-45. Mass flux curves for ${ }^{129} \mathrm{I}$.

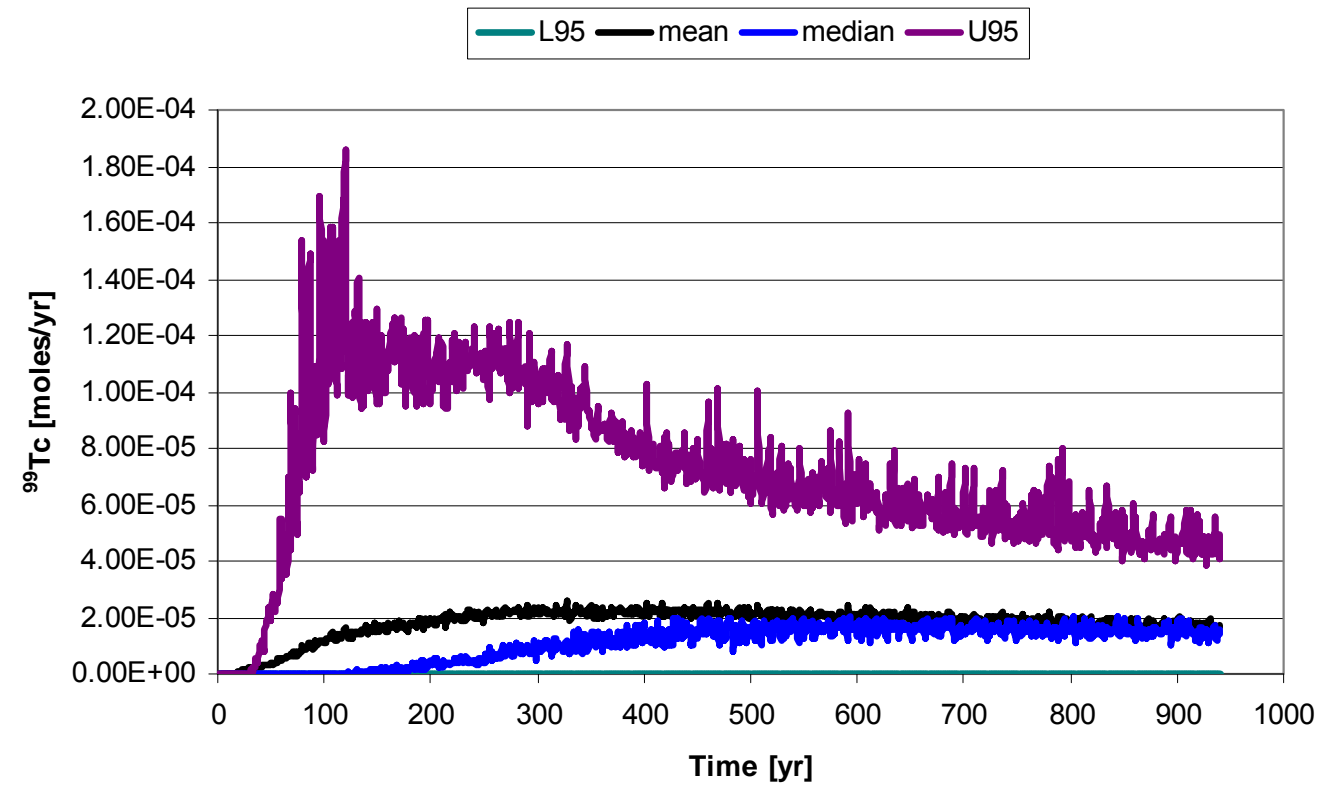

Figure 5-46. Mass flux curves for ${ }^{99} \mathrm{Tc}$.

Class VI contains seven sorbing radionuclides, ${ }^{232} \mathrm{U},{ }^{233} \mathrm{U},{ }^{234} \mathrm{U},{ }^{235} \mathrm{U},{ }^{236} \mathrm{U},{ }^{238} \mathrm{U}$, and ${ }^{237} \mathrm{~Np}$, with a source mass that consists of 90-percent melt glass (Table 5-19). The incorporation of nonzero $K_{d}$ values similar in magnitude to Class III also results in a very low breakthrough (187 particles) that is slightly higher than for Class III. Approximately 2 percent (four particles) of the breakthrough particles originated in the melt glass. Similar to 
Class III, the particle arrival curve is sparse and irregular (Figure 5-47). Of the particles that exit the model domain, 47 percent and 51 percent originate from the Tiny Tot and Pile Driver tests, respectively. Again, the difference in trends between particle flux and mean mass flux for all of the seven radionuclides in Class VI is attributed to final weight values. However, U95 is defined at 109 years for all radionuclides (e.g., Figures 5-48 through 5-54). This is caused by a single particle that has a high corresponding final weight of 0.057 . Though mean mass flux values are nonzero for other times in Figures 5-48 through 5-54, the value of U95 at 109 years dominates the scale of the mass flux curves, and flux values at other times cannot be observed. The median and U95 (except for at 109 years) radionuclide mass flux are also undefined for Class VI due to the lack of the particle breakthrough.

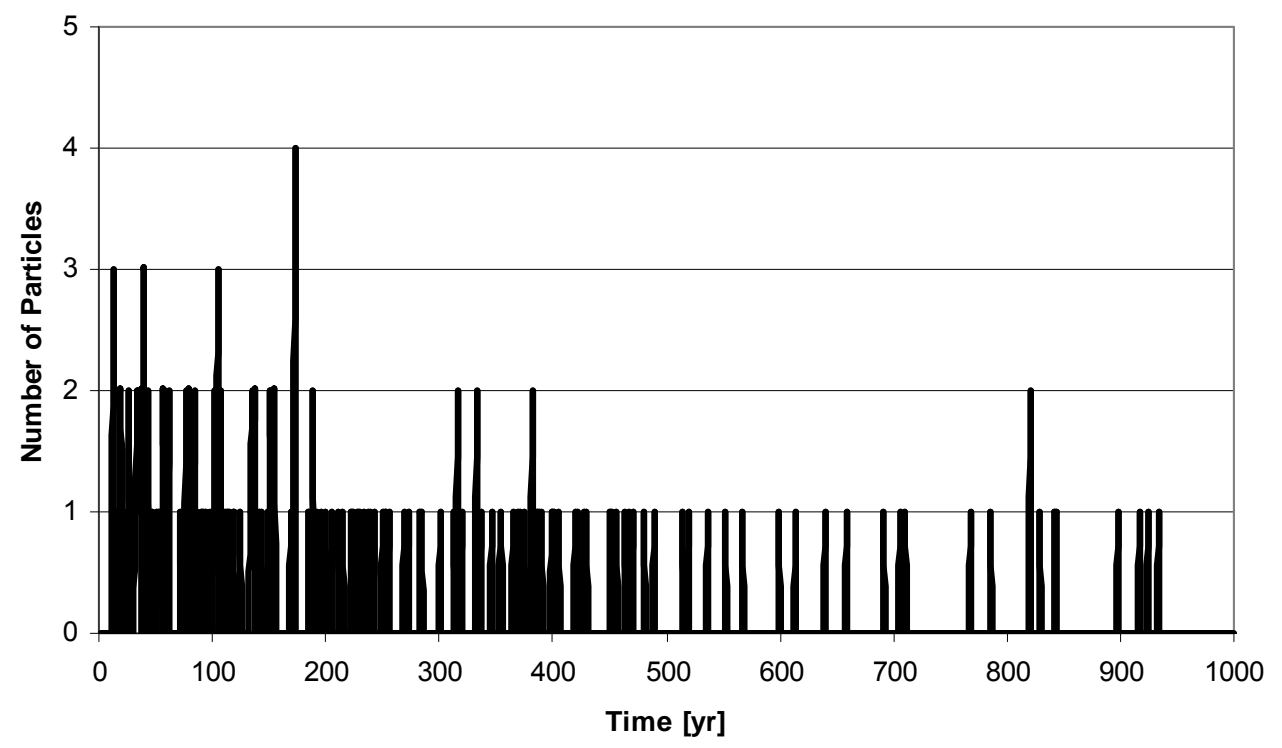

Figure 5-47. Ensemble particle flux times to model domain boundaries for Class VI.

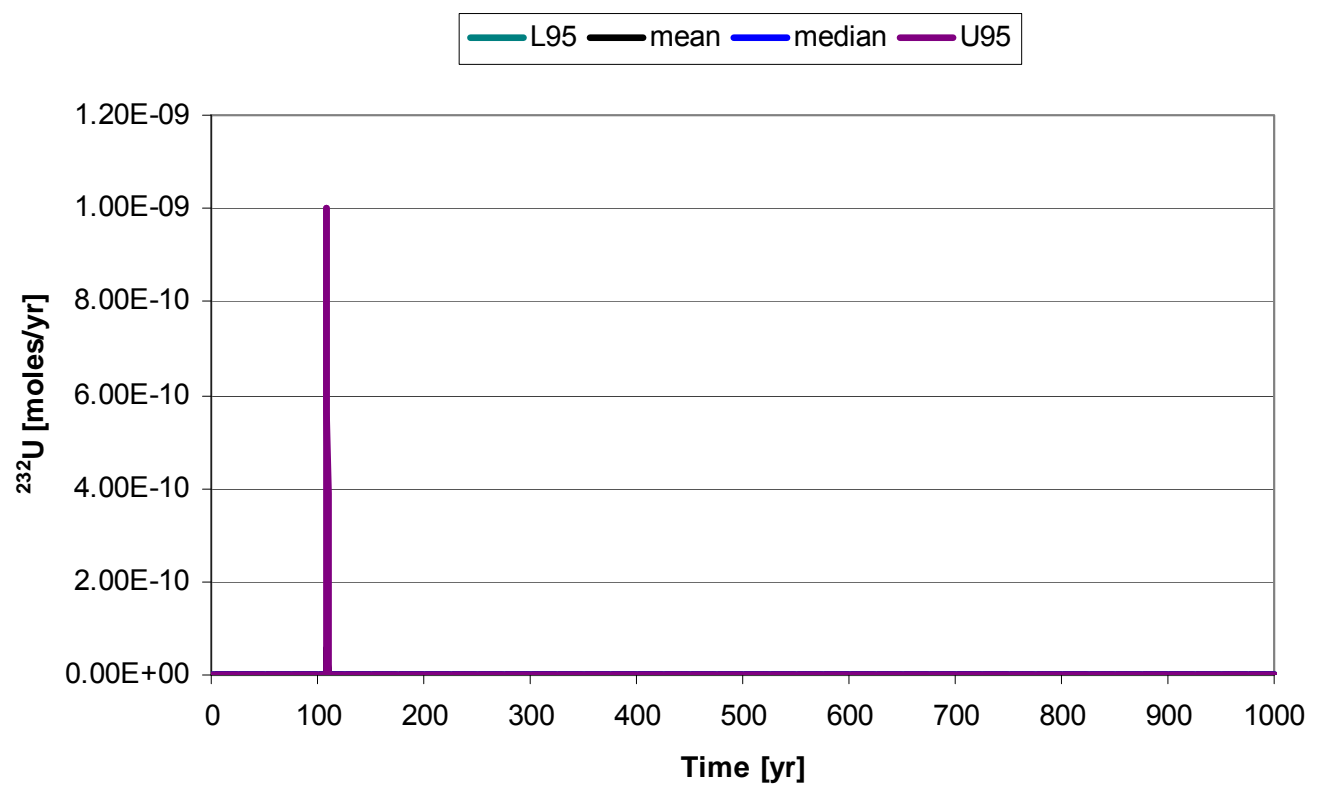

Figure 5-48. Mass flux curves for ${ }^{232} \mathrm{U}$. 


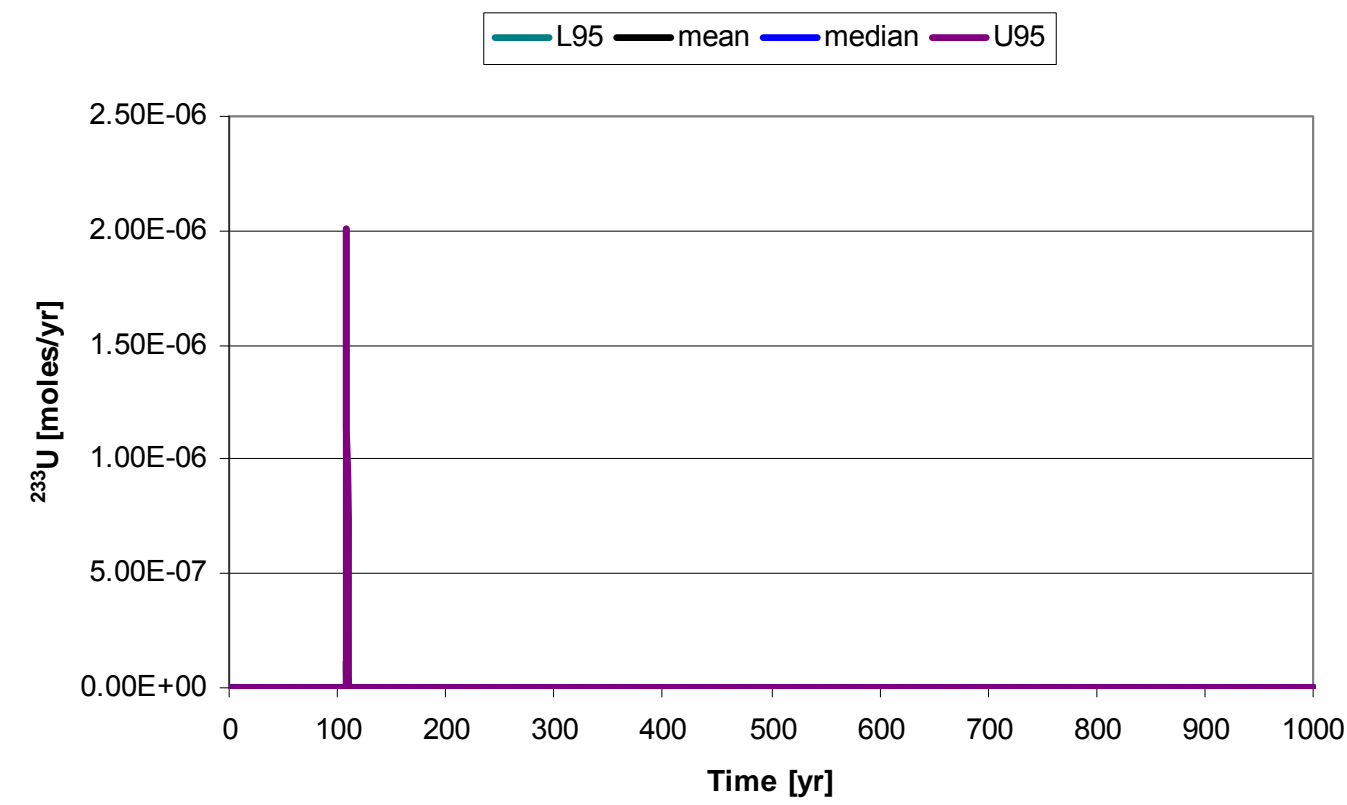

Figure 5-49. Mass flux curves for ${ }^{233} \mathrm{U}$.

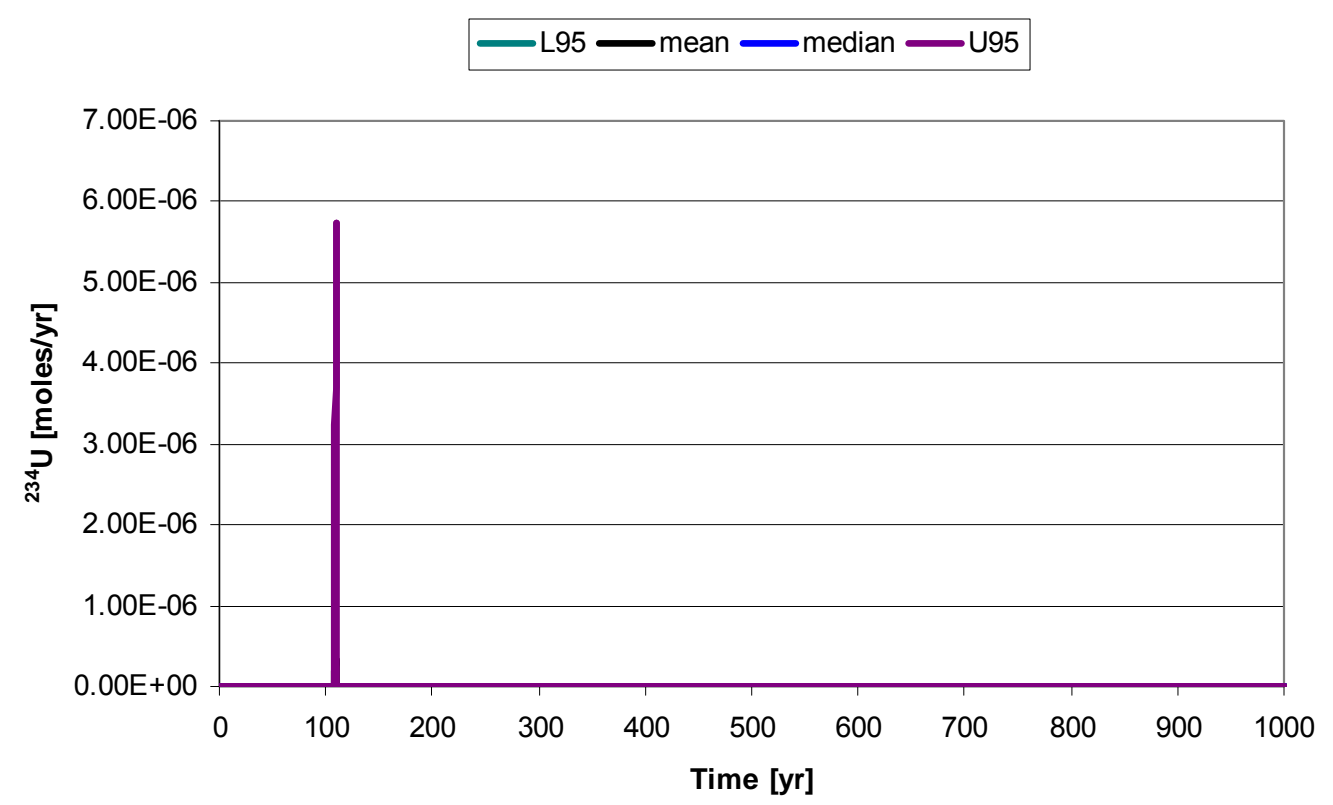

Figure 5-50. Mass flux curves for ${ }^{234} \mathrm{U}$. 


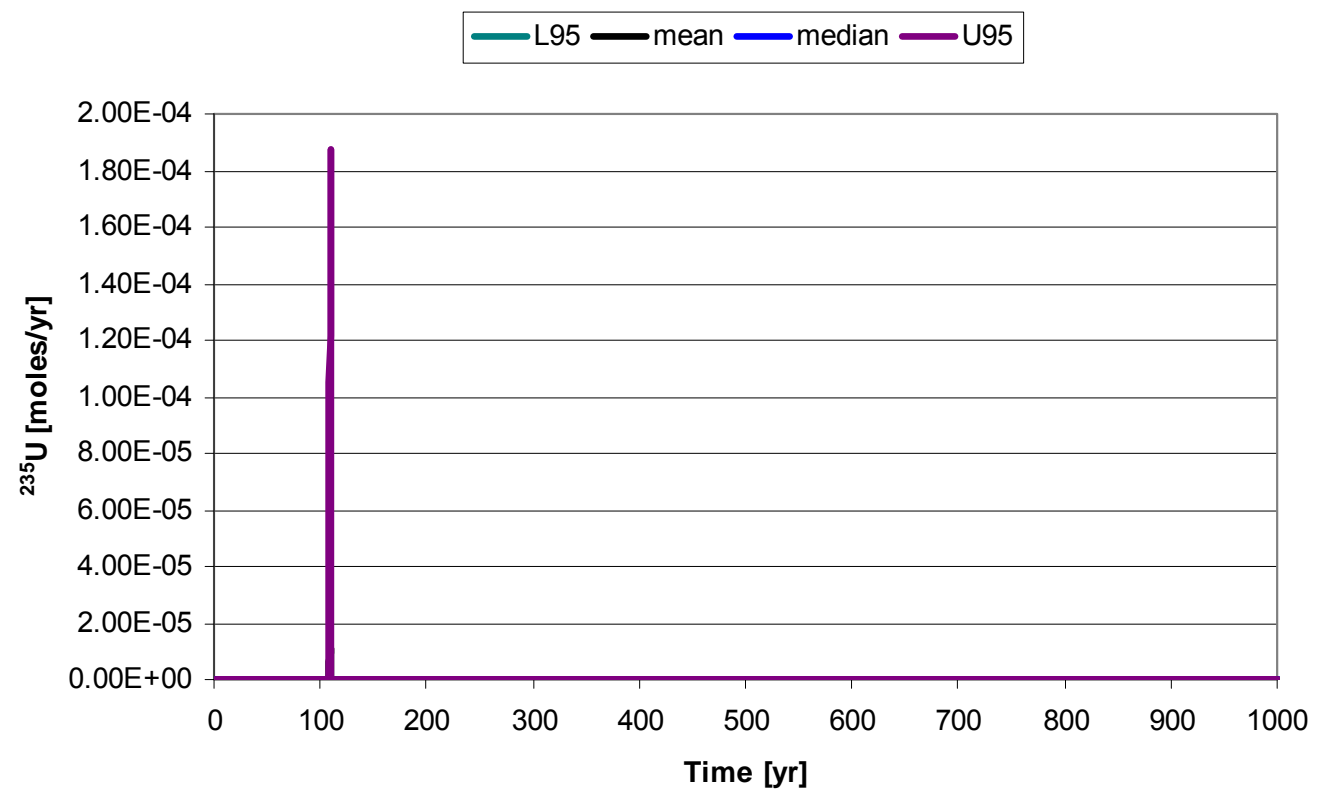

Figure 5-51. Mass flux curves for ${ }^{235} \mathrm{U}$.

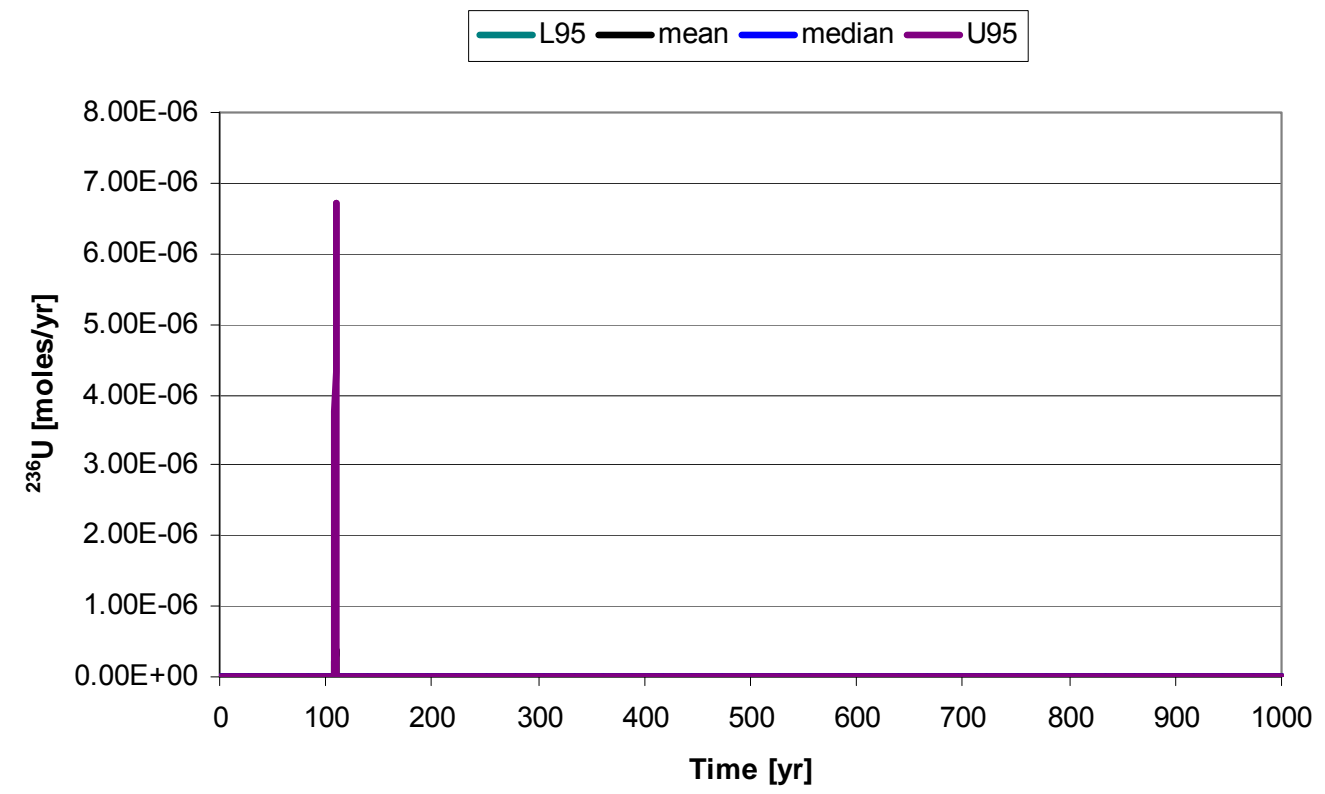

Figure 5-52. Mass flux curves for ${ }^{236} \mathrm{U}$. 


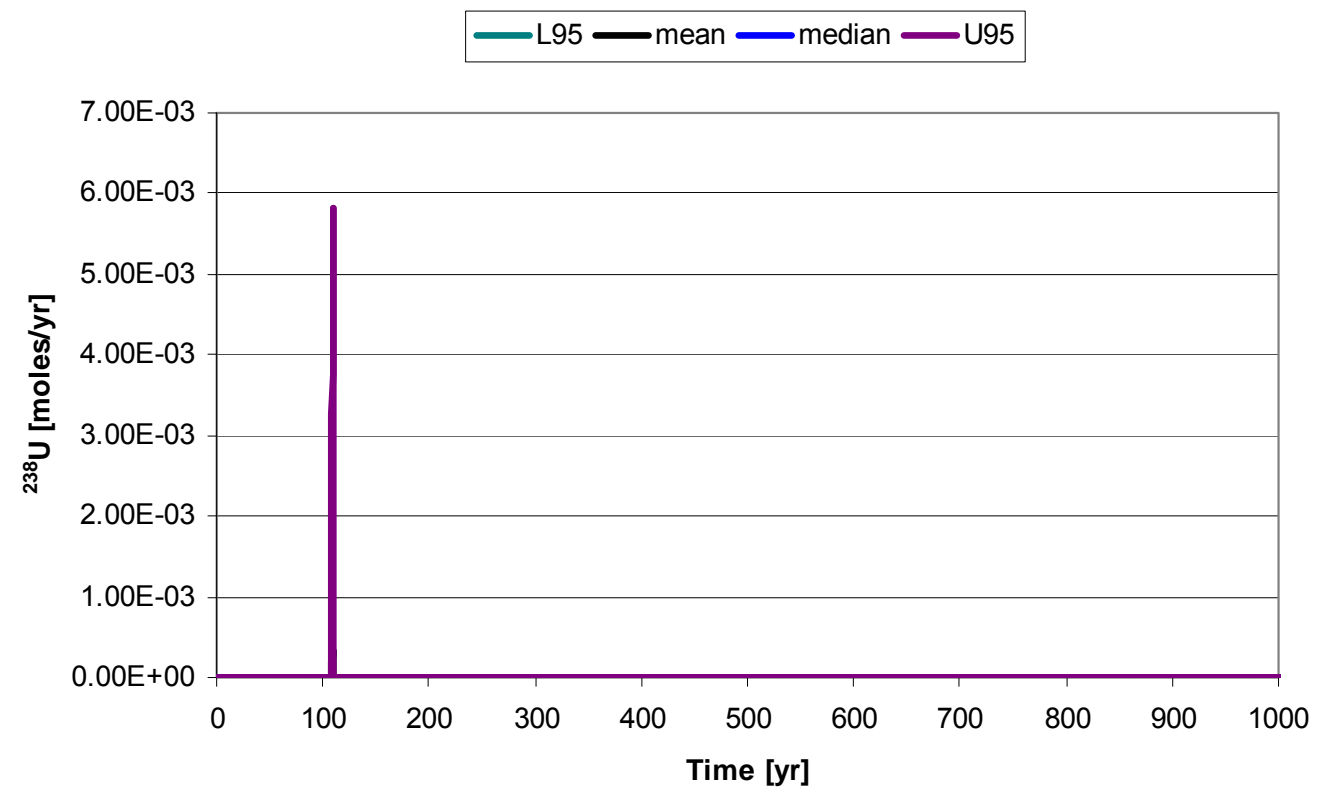

Figure 5-53. Mass flux curves for ${ }^{238} \mathrm{U}$.

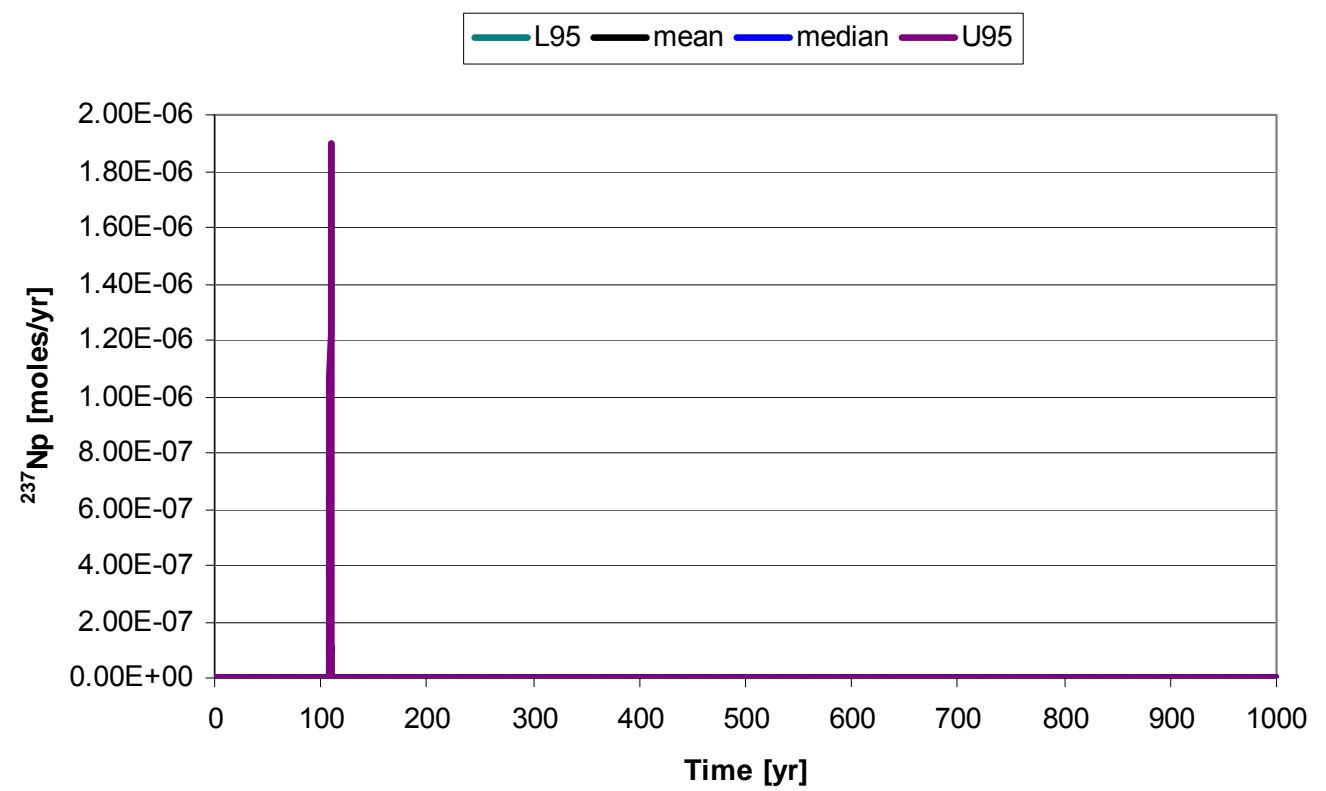

Figure 5-54. Mass flux curves for ${ }^{237} \mathrm{~Np}$. 


\subsubsection{Incorporation of Radionuclide Flux Estimates into Yucca Flat CAU Model}

The optimum transfer of radionuclide flux information from the Climax fracture continuum model (FCM) into the Yucca Flat-Climax Mine CAU transport model will depend on specifics of the CAU model domain and grid that are yet to be determined. Two basic aspects require consideration: the starting locations in the CAU model for the Climax radionuclides, and the statistical nature of the stochastic radionuclide flux transferred.

One of the prime motivations for the Climax sub-CAU model was the need to assess migration of radionuclides through the granite stock using fracture flow techniques at a scale impossible with the CAU model. Releasing radionuclide particles into the CAU model domain at the three Climax test locations would incorporate the hydrologic source term analysis performed for the Climax sub-CAU, but would neglect the transport analysis through the fracture system. Rather, the radionuclide flux from the Climax tests must be entered into the CAU model domain at a location downgradient from the granite stock. There are two basic options for these downgradient locations, corresponding to the options discussed for transfer of the regional groundwater flux information (Chapter 3). One option assumes the Climax stock is within the CAU model domain, in which case the radionuclide particles would enter the CAU model at the downgradient edge of the granite. The other option assumes the CAU model begins at the southern boundary of the northern extension region (essentially at the northern end of Yucca Flat proper), in which case the radionuclide flux from the Climax tests would enter along that northern boundary.

Breakthrough locations $(x, y, z)$ are recorded for each radionuclide particle exiting the granite FCM. The particle breakthroughs are dominated by nonsorbing radionuclides (e.g., transport classes I, IV and V). Only very minor amounts of moderately sorbing radionuclides (e.g., transport classes III and VI) reach the model boundaries. The local-scale FCM flow model honors the inferred northeast-to-southwest flow gradient through the Climax stock, as approximately 95 percent of the total particles exit the southern model boundary. Given the low percentage of particle breakthrough at the eastern and western boundaries of the Climax stock, and the lack of information on the hydraulic nature of the Boundary and Tippinip faults, it may be feasible to only include those particles that leave the southern boundary in the CAU model. These particles could be directly input into the CAU model according to their breakthrough locations $(x, y, z)$, if the CAU model encompasses the granite stock.

The majority of breakthrough particles at the southern boundary exit at an elevation between 750 and $990 \mathrm{~m}$ amsl. Both the DVRFS and Yucca Flat-Climax Mine base hydrostratigraphic models place LCA in direct contact with the southern boundary of the Climax stock over the entire vertical extent of the FCM model domain. In addition, the geometry of the HB alternative model is essentially the same as the Yucca Flat-Climax Mine base model in this location, so the boundary relationship is very similar. The CP thrust alternative differs, however, placing LCA3 in contact with the stock in the upper half of the FCM model domain, with UCCU occupying the lower half of the boundary. In this model, the LCA3 and LCA merge approximately seven kilometers south of Climax. Therefore, as a group, all of the HFM models provide the means for a direct physical connection between the Climax stock and the regional carbonate aquifer system in the northern end of Yucca Flat. If the CAU model boundary is downgradient of the granite stock, the Climax-test radionuclide particles would be transposed from their granite model breakthrough locations to equivalent 
locations in the LCA along the CAU-model northern boundary. This option would neglect transport within the carbonate between the granite edge and the northern boundary.

With either option, the scale of the CAU model cells should be considered in regard to the precision applied to the radionuclide particle locations. The $(x, y, z)$ locations from the Climax FCM will only be captured to the degree of resolution of the CAU model. As a result, particle locations may be best transferred to the CAU model in terms of the appropriate CAU model cell(s), rather $(x, y, z)$ coordinates.

The Climax FCM includes significant uncertainty in terms of the regional groundwater flux and local transport properties. This uncertainty is expressed in the calculations by the statistical measures of mean, median, and upper and lower confidence intervals. The information included in these measures of uncertainty should be carried forward into the CAU model. The lower $95^{\text {th }}$ percentile confidence interval is essentially zero for radionuclide flux and can be neglected as it does not contribute to health or environmental risk. Either the mean or median can be used in the CAU model to represent the central tendency of the calculations. The upper $95^{\text {th }}$ percentile is important to retain in the CAU transport calculations, as it carries most of the information regarding risk. In other words, for some radionuclides, breakthrough out of the granite is only observed at the $95^{\text {th }}$ percentile. 
THIS PAGE INTENTIONALLY LEFT BLANK 


\subsection{SUMMARY, CONCLUSIONS AND RECOMMENDATIONS}

\subsection{Summary}

The Yucca Flat-Climax Mine Corrective Action Unit contains one of the highest concentrations of underground nuclear tests in the world. The DOE's Environmental Restoration Program identified two issues in the northern portion of the unit, coincident with the Climax granitic stock. The work reported here restated these issues as the two specific project objectives as follows:

- Provide groundwater flow rates for the northern boundaries of the Yucca Flat-Climax Mine CAU model, incorporating alternative conceptualizations of the hydrogeologic system with their associated uncertainty, and

- Provide radionuclide flux rates from the three nuclear tests in Climax stock, using modeling techniques that account for groundwater flow in fractured granite.

Meeting these two objectives required two different model scales. The northern boundary groundwater fluxes were addressed using the Death Valley Regional Flow System model platform, with refined hydrogeology in a zone north of Yucca Flat and including Climax stock. Radionuclide transport was calculated using a model confined to the granite stock itself, but linked to the regional groundwater fluxes through boundary conditions and calibration targets.

Major portions of the work are summarized below.

\subsubsection{Alternative Conceptual Models}

A total of 25 alternative conceptual models were identified for the Climax regional flow model. These result from combinations of two groups of models: five alternative models of recharge and five alternative models of hydrostratigraphy. Alternative model identification, evaluation, and prior probabilities were generated by a process of expert elicitation. These models were then implemented within the Death Valley Regional Flow System model framework.

\subsubsection{Refinement of the DVRFS Model and Inclusion of Alternate Models}

The Death Valley model is used as the platform for evaluating the alternative models because it is the regional flow model used for DOE's Environmental Restoration Program at the Nevada Test Site, and because there are few calibration targets available in the immediate Climax area. To preserve as much detail as possible of the alternative geologic models developed by Bechtel-Nevada, the 1,500-m cell resolution of the Death Valley model is refined in the area of the northeast corner of the NTS. The refinement, to 250-m cells, creates 36 refined cells per cell in the original model. To minimize truncation error introduced by this abrupt jump in resolution, a transition zone was created that progressively increased spacing from the refined grid outward. Detailed mapping was required of many parameters, including hydrostratigraphic unit designation, from the single cells of the original model to the refined mesh. The mesh refinement led to the simulation of about five percent more groundwater moving through the flow system, but the overall mass balance of the model was actually improved and simulation of heads in the refined area improved (sum of squared weighted residuals declined almost 19 percent). 


\subsubsection{Uncertainty Assessment and Model Averaging}

Each of the 25 alternative model combinations of recharge and hydrostratigraphy were implemented within the refined Death Valley model. Calibration of the models was performed by adjusting only those parameters significant to flow in the Climax area (for example, parameters specific to discharge areas in Death Valley were not adjusted). Residuals were evaluated for each calibrated model to quantify model performance. For any of the geologic models, the modified Maxey-Eakin recharge model gave the largest residuals and thus is the least plausible, while the net infiltration model with runon-runoff performed best. The least favorable geologic models are the two that include a hydraulic barrier by raising the lower clastic confining unit up to the water table just east of Climax stock, preventing groundwater flow. The $\mathrm{CP}$ thrust alternative of the base model performed the best of the hydrostratigraphic interpretations. The calibration measures were combined with the prior model probabilities to calculate posterior probabilities. The best of the 25 models is the $\mathrm{CP}$ thrust geologic model in combination with the net infiltration runon-runoff model. These posterior probabilities are used for weighting in the model averaging process. Thus, all 25 models contribute to the resultant mean and variance of head and groundwater flow, but the best performing models carry more weight. Parametric uncertainty was included in the model simulations. Evaluation of the contribution to total variance from parametric uncertainty and from the alternative conceptual models shows that conceptual model uncertainty dominates. This indicates that uncertainty would be significantly underestimated without accounting for conceptual model uncertainty.

\subsubsection{Groundwater Flow Model for the Climax Granite}

A groundwater flow model specific to Climax stock was developed as the basis for the transport calculations. The model averaging performed for groundwater flow in the area north of Yucca Flat is carried forward into the Climax-specific model so that the radionuclide migration predictions include the effects of conceptual model and parametric uncertainty. The local-scale simulations of groundwater flow in the Climax stock are based on the conceptualization that the majority of flow occurs through rock fractures within a lowpermeability rock mass. A fracture continuum method involving MODFLOW is used to model flow through the randomly generated fracture zone networks within Climax stock. These three-dimensional networks are generated according to probability distributions based on Climax-specific data. Monte Carlo techniques are used to incorporate parametric uncertainty and spatial variability in flow and transport properties. A total of 200 Monte Carlo realizations are generated for each of the alternative models, resulting in 5,000 localscale flow field realizations. The randomness of the simulated fracture networks leads to a high degree of variability in flux values. A generalized likelihood uncertainty estimation technique is implemented to assign unique probability weights to each flow realization. Realizations that more closely match the target flux value for the given alternative model receive more weight than those with a poor match. These weights, along with model weights assigned to each of the Climax regional models, are applied to the mass flux calculations during post-processing of the transport model results.

\subsubsection{Parameterization of the Transport Model}

Radionuclides simulated in the transport model were produced by the Hard Hat, Pile Driver, and Tiny Tot tests, and the daughters created by radioactive decay. Assignments of 
radionuclide mass for each test were made using a yield-weighted approach to averaging the combined Yucca Flat source term. Projection of the source to the water table, per the UGTA approach, was implemented by creating a permeability disk at the water table beneath each test, equivalent to the cavity size. Assignments of nuclear melt-glass apportioning are similar to previous work, with the exception of a few radionuclides that were conservatively modeled with a more volatile group for numerical convenience. The surface-deposited radionuclides in the permeability disk are assumed to migrate immediately after each nuclear test, neglecting any time for vadose-zone transport. Nuclides within the melt glass are released according to glass dissolution rates, calculated based on Climax-specific conditions. Over the course of the 1,000-year simulation time frame, less than 5 percent of the particles assigned to melt glass are released into the flow field. Retardation factors, estimated from sorption experiments with Climax granite and other granites found worldwide, are used in algorithms that simulate radionuclide particle retardation along fracture walls and matrix blocks. Uncertainty in sorption coefficients is included, assuming a uniform distribution. The diffusion of radionuclides in a fractured medium is described by a transfer probability approach that controls the movement of radionuclides between rock fractures and matrix blocks.

\subsubsection{Radionuclide Transport Calculations}

The simulation of radionuclide transport in the Climax stock is based on a random walk particle code that tracks both conservative and nonconservative radionuclide particle trajectories through each of the 5,000 velocity field realizations produced from the localscale fracture continuum model. Advective velocity assigned to individual grid cells is computed from constant porosity values for rock matrix cells and variable porosity values for fracture cells. Dispersive particle motion is simulated according to a Gaussian dispersion tensor. Radionuclides are grouped according to general sorption behavior and to melt-glass proportion into eight unique transport classes. Particle tracking simulations are conducted for each transport class using specific values for sorption and the fraction of radionuclides in the melt glass state. Mass flux values for individual radionuclides leaving the Climax stock are computed by post-processing the results.

\subsection{Conclusions}

Major conclusions from the evaluation of groundwater flow and radionuclide transport through the Climax stock are as follows:

- Significant conceptual model uncertainty exists for the area north of Yucca Flat. Five alternative recharge models and five alternative hydrostratigraphic models were identified. None of these alternatives could be eliminated based on expert opinion. Overall, the effect of uncertainty in the recharge models is smaller on groundwater flow than the effect of uncertainty in the hydrostratigraphy. Of the 25 model combinations evaluated, the most probable is the CP thrust hydrostratigraphy in combination with recharge based on net infiltration with runon-runoff.

- The more probable alternative models were those that included a flowpath in the upper portion of the LCA at the northwest end of the Halfpint Range, immediately east of the Climax stock. The HSU configurations allowed substantial flow into northern Yucca Flat, as compared to other alternatives. 
- Parametric uncertainty in flow parameters, principally hydraulic conductivity, is significant, but overshadowed by the conceptual model uncertainty. Variance of head and flow is dominated by between-model variance, as compared to within-model variance from parametric uncertainty. Underestimation of predictive uncertainty is highly likely in terms of magnitude and spatial and temporal distribution if conceptual model uncertainty is neglected.

- Model averaging was successful at estimating the posterior mean and variance of head and flow, inclusive of the 25 alternative model combinations and parametric uncertainty. Model performance is included in the averaging such that model combinations that perform better relative to calibration targets are given higher weights than those that perform poorly.

- The averaged flow into northern Yucca Flat of over $88,000 \mathrm{~m}^{3} / \mathrm{d}$ is substantially higher than previous estimates. This is a consequence of both the DVRFS model, which simulates more flow than previous models, and the higher-weighted alternative models of flow in the upper LCA east of Climax.

- The groundwater flow field surrounding the Climax granite stock, in combination with fracture flow characteristics within the granite, lead to groundwater flow times from the three Climax nuclear tests to the edge of the granite that are well within the 1,000-year period of investigation for the CAU.

- The majority of breakthrough out of the granite occurs along its southern boundary where flow and contaminants are likely to enter the regional carbonate aquifer.

- Radionuclides within the nuclear melt glass play a minor role in contaminant transport, less than 5 percent of the radionuclide mass in the melt glass is released to the flow field in the 1,000-year simulation.

- Sorption is a key controlling factor on radionuclide transport. No strongly sorbing radionuclides (such as cesium, plutonium, and americium) were transported to the edge of the granite stock in 1,000 years. Only very minor amounts of moderately sorbing radionuclides (such as uranium) made it to the boundary. Significant migration was only calculated for radionuclides assumed to not react with the rock matrix.

- All three nuclear tests contribute to breakthrough at the granite boundary. Considering nonsorbing radionuclides with no percentage in the nuclear melt glass, 41 percent of the breakthrough mass originates from Tiny Tot (the closest test to the southern granite boundary), 33 percent from Pile Driver (a larger test than Hard Hat), and 26 percent from Hard Hat. These relative contributions are subject to uncertainties regarding the source term of each test. The Pile Driver and Hard Hat radionuclide sources are based on announced test yields, whereas Tiny Tot uses the maximum of an announced yield range. In addition, though the source masses are apportioned based on yield, they ultimately rely on average radionuclide production for all Yucca Flat tests. These uncertainties could be reduced, if necessary, by using classified data specific to each Climax test. 
- Radionuclides that migrate to the granite boundary tend to have peak breakthrough rates on the order of $10^{-5}$ moles/yr. The impact of uncertainty (from conceptual models and parameters) is to increase this an order of magnitude for the upper 95percent confidence interval. Time of peak breakthrough and exact magnitude and shape, are dependent on the starting mass, amount in nuclear melt glass, and radioactive half-life. The largest breakthrough mass occurs for tritium.

\subsection{Recommendations}

The investigations reported here lead to the following recommendations regarding development of the CAU model for Yucca Flat-Climax Mine. Broader recommendations applying to all UGTA CAU models are also presented.

- The Yucca Flat-Climax Mine CAU model would benefit from using the modelaveraged estimates of groundwater flow developed here for the northern boundary. The CAU model will necessarily be large and complex; applying the mean and variance for head and flux developed in this work would allow incorporation of conceptual model and parametric uncertainty into the Yucca Flat model in an efficient manner. Inclusion of this uncertainty is particularly important given the sparseness of data upgradient of Yucca Flat.

- Uncertainty in flow into northern Yucca Flat could be reduced by determining whether a flowpath exists in the upper portion of the LCA at the northwest end of the Halfpint Range, immediately east of the Climax stock. That potential flowpath is responsible for the higher flows into Yucca Flat among the alternative models.

- The contribution of radionuclides from the nuclear tests in Climax stock to the CAU transport model needs to be considered for radionuclides modeled with no sorption properties. All sorbing nuclides could be neglected, as they will not contribute to a contaminant boundary for the CAU.

- If the transport of nonsorbing radionuclides appears significant for the Yucca Flat CAU boundary, the conservative assumptions regarding projection of the Climax nuclear test sources to the water table could be reevaluated. At a minimum, travel times can be expected to be lengthened when vadose transport is included.

- Model averaging is an effective method for including conceptual model uncertainty. With the method developed here, no arbitrary decisions are required regarding which models to carry forward and which to discard. All plausible models can be included and weighted by their likelihood (based on a variety of measures), and thus contribute to a fuller assessment of uncertainty.

- In addition to dependence on the flow field, calculations of radionuclide transport are strongly dependent on the modeled retardation properties. Radionuclides modeled without sorption dominate transport predictions. An assumption of nonsorbing properties should be one of the first transport aspects reevaluated if the size of contaminant boundaries becomes a concern. 


\subsection{Integration of Climax Mine Sub-CAU Model Results in the Yucca Flat-Climax Mine CAU Model}

Specific recommendations regarding incorporation of groundwater flux and radionuclide flux from the Climax sub-CAU models into the CAU model are dependent on the configuration of boundaries and simulation mesh of the CAU model. These are not yet determined. The sub-CAU information to carry forward to the CAU are the mean and variance of hydraulic heads and groundwater flow (available for every active cell in the regional model domain, at a 250-m resolution in northern Yucca Flat), and the mean and variance of radionuclide flux along the boundary of the granite stock (available at a $15-\mathrm{m}$ mesh resolution). Note that the groundwater flows simulated by the Climax sub-CAU model into northern Yucca Flat are greater than those represented by the UGTA regional model because more flow occurs in the DVRFS model on which the sub-CAU model is based and some alternatives allow flow in the upper LCA end of Climax stock.

Two general approaches are recommended for consideration. One method is to use the Climax regional flow model to provide mean and variance of head and flow for boundary conditions on the northern end of the Yucca Flat-Climax Mine CAU model. The exact location of that northern boundary could be along any convenient transect in northern Yucca Flat because the hydrostratigraphic models of the Climax sub-CAU and Yucca Flat-Climax Mine CAU conform seamlessly. This approach allows the CAU boundary heads and flows to fully incorporate the uncertainty in conceptual models and parametric uncertainty of the subCAU model. In the event that the CAU model addresses alternative conceptual models of flow independent of each other, the mean and variance of head and flow can also be extracted from the sub-CAU model for the associated conceptual models. However, this approach will incorporate only parametric uncertainty; the quantified uncertainty arising from multiple conceptual models will not be carried forward. In this first approach, the CAU model domain would not extend northward to the granite contact. Radionuclide particles from the Climax tests predicted to breakthrough at the edge of the granite in the fracture continuum sub-CAU model would be transposed from their granite breakthrough locations to equivalent locations in the carbonate aquifer along the CAU-model northern boundary. This would neglect transport within the carbonate between the granite contact and the northern model boundary.

The second approach concerns a CAU model domain that encompasses a portion of the northern Yucca Flat region, possibly inclusive of the granite stock. In this case, mean values of head and flow from the Climax sub-CAU model would be used as observations and variations of head and flow would be used as weighting values for calibration at locations within the CAU model. However, because the sub-CAU flow model was developed prior to the CAU flow model, differences may exist in the configuration of the two models. For example, choices of model thickness, layer thickness, values of hydraulic parameters, and boundary conditions driven by the CAU-scale of the investigation may result in different patterns of simulated head and flow. If the configuration of the CAU model substantially differs from the sub-CAU model such that mean head and flow are inconsistent across the two models, then incorporation of mean values from the sub-CAU model may not be possible. In this case, variations in head and flow from the sub-CAU model would still be used as the basis for calculating weights for internal CAU-model head and flow values, thereby incorporating the uncertainty in conceptual models and parametric uncertainty of the 
sub-CAU model. With the CAU model encompassing the granite, the breakthrough curves for radionuclide flux can be assigned at the locations where they occur at the granite model boundary.

There are advantages in terms of translating the groundwater flow information from sub-CAU to CAU scale in using the sub-CAU to establish boundary conditions at the northern end of the CAU model. Conversely, it is more advantageous to have the granite stock (or at least its contact with the LCA) within the CAU model in terms of translating the radionuclide flux. Either approach can be successful provided the emphasis is on ensuring that the level of conceptual and parametric uncertainty in both groundwater flow and radionuclide transport expressed in the Climax sub-CAU models is carried forward into the Yucca Flat-Climax Mine CAU model. 
THIS PAGE INTENTIONALLY LEFT BLANK 


\subsection{REFERENCES}

Aagaard, P. and H.C. Helgeson, 1982. Thermodynamic and kinetic constraints on reaction rates among minerals and aqueous solutions, I. Theoretical considerations. American Journal of Science, 282, 237-285.

Aban, I.B., M.M. Meerschaert, and A.K. Panorska, 2005. Parameter estimation methods for the truncated Pareto distribution. J. of the Amer. Stat. Assoc.: Theory and Methods, in press.

Abrajano, T.A., Jr., J.K. Bates, and J.J. Mazer, 1989. Aqueous corrosion of natural and nuclear waste glasses II. Mechanisms of vapor hydration of nuclear waste glasses. Journal of Non-Crystalline Solids, 108: 269-288.

Akaike, H., 1974. A new look at statistical model identification, IEEE Transactions on Automatic Control, AC-19, 716-722.

Aksoyoglu, S., 1989. Sorption of U(VI) on granite. Journal of Radioanalytical and Nuclear Chemistry, Articles. 134(2) pp. 393-403.

Allard B., H. Kipatsi, and B. Torstenfelt, 1978. Sorption of long-lived radionuclides on clays and rocks, Part 2. KBS Technical Report 98, in Swedish (Abstract in English).

Allard B., J. Rydberg, H. Kipatsi, and B. Torstenfelt, 1979. Disposal of radioactive waste in granitic bedrock. American Chemical Society, 4, 47-73.

American Society of Mechanical Engineers (ASME), 2001. Strategy for Remediation of Groundwater Contamination at the Nevada Test Site, Technical Peer Review Report. ASME International, report CRTD-Vol.62, $226 \mathrm{p}$.

Anderman, E.R. and M.C. Hill, 2000. MODFLOW-2000, the U.S. Geological Survey Modular Ground-Water Model -- Documentation of the Hydrogeologic-Unit Flow (HUF) Package. U.S. Geological Survey Open-File Report 00-342.

Anderman, E.R. and M.C. Hill, 2003. MODFLOW-2000, The U.S. Geological Survey Modular Ground-water Model-Three Additions to the Hydrologic-unit Flow (HUF) Package. Open-File report 03-347, U.S. Geological Survey, Denver, Colorado.

Andersson K., B. Torstenfelt, and B. Allard, 1983. Sorption of radionuclides in geologic systems. SKBF KBS Technical Report. 83-63.

Andersson, P., B. Dershowitz, J. Hermanson, P. Meier, E.-L. Tullborg, and A. Winberg, 2002a. Final report of the True block scale project: 1) Characterization and model development. TR-02-13. Swedish Nuclear Fuel and Waste Management Co. (SKB), Stockholm, Sweden.

Andersson, J., J. Berglund, S. Follin, E. Hakami, J. Halvarson, J. Hermanson, M. Laaksoharju, I. Rhén, and C.-H. Wahlgren, 2002b. Testing the methodology for site descriptive modelling: Application for the Lexemar area, TR-02-19. Swedish Nuclear Fuel and Waste Management Co. (SKB), Stockholm, Sweden.

Ando K., A. Kostner, and S.P. Neuman, 2003. Stochastic continuum modeling of flow and transport in a crystalline rock mass: Fanas-Augres, France revisited. Hydrogeology J., 11:521-535. 
Apostolakis, G., 1990. The concept of probability in safety assessment of technological systems. Science, 250, 1359 - 1364.

Asch, T. A., B.D. Rodriguez, J.A. Sampson, E.L. Wallin,, and J.M. Williams, 2006. Deep Resistivity Structure of Yucca Flat, Nevada Test Site, Nevada. U.S. Geological Survey Open-File Report 2006-1261.

Ballou, L., 1979. Field permeability measurements. In Waste Isolation Projects: FY 1978, UCRL-50050-78,Lawrence Livermore National Laboratory, Livermore, California.

Bandis, S.C., A. Makurat, and G. Vik, 1985. Predicted and measured hydraulic conductivity of rock joints. Proceedings of the International Symposium on Fundamentals of Rock Joints, Björdkliden, Norway, September 15-20.

Barton, C.C., 1995. Fractal analysis of scaling and spatial clustering of fractures. In Fractals in the Earth Sciences. C.C. Barton and P.R. LaPointe, eds., Plenum Press, New York.

Baston G.M.N., J.A. Berry, M. Brownsword, M.M. Cowper, T.G. Heath, and C.J.Tweed, 1995. The Sorption of Uranium and Technetium on Bentonite, Tuff and Granodiorite. Materials Research Society Symposium Proceedings, 353, 989-996.

Bath, G.D., C.E. Jahren, J.G. Rosenbaum, and M.J. Baldwin, 1983. Magnetic Investigations, in Geologic and Geophysical Investigations of the Climax Stock Intrusive, Nevada. U.S. Geological Survey Open File Report 83-377.

Baxter, R.G., 1983. Description of Defense Waste Processing Facility Reference Form and Canister, Savannah River Plant, Savannah River, GA. Report no. DP-1606, rev. 1.

Bechtel Nevada, 2005. A Hydrostratigraphic Model and Alternatives for the Groundwater Flow and Contaminant Transport Model of Corrective Action Unit 98: Frenchman Flat, Clark, Lincoln, and Nye County, Nevada. DOE/NV/11718--1064.

Bechtel Nevada, 2006. A Hydrostratigraphic Model and Alternatives for the Groundwater Flow and Contaminant Transport Model of Corrective Action Unit 97: Yucca FlatClimax Mine, Lincoln and Nye Counties, Nevada. DOE/NV/11718-1119.

Belcher, W.R. (ed.), 2004. Death Valley regional ground-water flow system, Nevada and California - Hydrogeologic framework and transient ground-water flow model. U.S. Geological Survey Scientific Investigations Report 2004-5205, 408 p.

Belcher, W.R., F.A. D'Agnese, and G.M. O'Brien, 2004. Introduction. Chapter A in Belcher, W.R., ed., 2004, Death Valley Regional Groundwater Flow System, Nevada and California-Hydrogeologic Framework and Transient Ground-Water Flow Model. U.S. Geological Survey Scientific Investigations Report 2004-5205.

Berger, J.O., 1985. Statistical Decision Theory and Bayesian Analysis, 2nd edition, SpringerVerlag, New York.

Berry J.A., K.A. Bond, M. Brownsword, D.R. Ferguson, A. Green, and A.K. Littleboy, 1990. Radionuclide Sorption on Generic Rock Types. Nirex Safety Series Report NSS/R182.

Bethke C. M., 1996. Geochemical Reaction Modeling. Oxford University Press, New York. Beven, K., 2006. A manifesto for the equifinality thesis. Journal of Hydrology 320, 18-36. 
Beven, K.J. and A.M. Binley, 1992. The future of distributed models: Model calibration and uncertainty prediction. Hydrol. Processes, 6:279-298.

Bibler N.E. and C.M. Jantzen, 1987. Materials interactions relating to long-term geologic disposal of nuclear waste glass. Materials Research Society Symposium Proceedings, 84, 47-66.

Birgersson L. and I. Neretnieks, 1990. Diffusion in the matrix of granitic rock: Field test in the Stripa mine. Water Resources Research, 26(11):2833-2842.

Boardman, C.R., 1965. A Measurement of the Void Volume and Fracture Permeability Resulting from the Hardhat Event, UCID-4893, Lawrence Livermore National Laboratory, Livermore, California.

Boardman, C.R., 1966. Some Characteristics of the Hardhat Chimney and Surrounding Wall Rock, UCRL-50177, Lawrence Livermore National Laboratory, Livermore, California.

Boardman, C.R. and J. Skrove, 1966. Distribution in fracture permeability of a granitic rock mass following a contained nuclear explosion. Journal of Petroleum Technology, 619623.

Boardman, C.R., 1967. Results of an Exploration into the Top of the Piledriver Chimney, UCRL-50385, Lawrence Livermore National Laboratory, Livermore, California.

Bonano, E.J., S.C. Hora, R.L. Keeney, and D. von Winterfeldt, 1990. Elicitation and Use of Expert Judgment in Performance Assessment for High-Level Radioactive Waste Repositorie. U.S. Nuclear Regulartory Commission, NUREG/CR-5411.

Bonnet, E., O. Bour, N.E. Odling, P. Davy, I. Main, P. Cowie, and B. Berkowitz, 2001. Scaling of fracture systems in geologic media. Rev. Geophy., 39(3):347-383.

Borg L.Y., 1970. Survey of Piledriver results and preliminary interpretation of three postshot cores in and near the cavity. Lawrence Radiation Laboratory, University of California, Livermore. UCRL-50865.

Borg, I.Y., 1971. Some Shock Effects in Granodiorite to 270 kbar at the Piledriver Site, UCRL-73377 Rev. 1. Lawrence Livermore National Laboratory, Livermore, California.

Borg, I.Y., 1973. Comparison of Shock Effects in Granitic Rock Recovered From the Monique Event, Algeria, and the Piledriver Event, Nevada Test Site. UCRL-51349, Lawrence Livermore National Laboratory, Livermore, California.

Borg, I.Y., 1975. Radioactivity trapped in melt produce by a nuclear explosion. Nuclear Technology, 26:88-100.

Bour, O. and P. Davy, 1997. Connectivity of random fault networks following a power law fault length distribution. Water Resources Research, 33:1567-1583.

Bourcier, W.L., S.K. Roberts, D.K. Smith, S.Hulsey, L.Newton, A.Sawvel, C.J. Bruton, C. Papelis, W. Um, C. Russell, and J. Chapman, 2000. Determination of Reactive Surface Area of Melt Glass. UCRL-ID-145181, Lawrence Livermore National Laboratory, Livermore, California. 
Bowen, S., D.L. Finnegan, J.L. Thompson, C.M. Miller, P. L. Baca, L.F. Olivas, C.G. Geoffrion, D.K. Smith, W. Goishi, B.K. Esser, J.W. Meadows, N. Namboodiri, J.F. Wild, 2001. Nevada Test Site Radionuclide Inventory 1951-1992, LA-13859-MS. Los Alamos National Laboratory, Los Alamos, New Mexico.

Bower, K.M., C.W. Gable, and G.A. Zyvoloski, 2005. Grid resolution study of groundwater flow and transport. Ground Water, 43(1): 122-132.

Bradbury, M.H., and A. Green, 1985. Measurements of important parameters determining aqueous phase diffusion rates through crystalline rock matrices. Journal of Hydrology, $82: 39-55$.

Bradbury, M.H., and A. Green, 1986. Investigation into factors influencing long range matrix diffusion rates and ppore space accessibility at depth in granite. Journal of Hydrology, 89:123-139.

Brooks, B.A., R.W. Allmendinger, and G.I. de la Barra, 1996. Fault spacing in the El Teniente Mine, central Chile: Evidence of nonfractal fault geometry. J. Geophys. Res., 101:13,633-13,653.

Burchfiel, B.C., R. Fleck, D.T. Secor, R.R. Vincelette, and G.A. Davis, 1974. Geology of the Spring Mountains. Geological Society of America Bulletin, 85(7):1013-1022.

Burnham, K.P. and A.R. Anderson, 2002. Model Selection and Multiple Model Inference: A Practical Information-theoretical Approach, 2nd edition, New York, Springer.

Butkovich, T.R., 1974. Rock Melt from an Underground Nuclear Explosion. UCRL-51554, Lawrence Livermore National Laboratory, Livermore, California.

Byegard J., H. Johansson, M. Skaalberg, and E.L. Tullborg, 1998. The interaction of sorbing and non-sorbing tracers with different Aespoe rock types. Sorption and diffusion experiments in the laboratory scale. Swedish Nuclear Fuel and Waste Management Company, SKB-TR-98-18.

California Department of Conservation, Division of Mines and Geology, 2000. GIS Data for the Geologic Map of California. DMG CD 2000-07.

Carle, S.F., R.M. Maxwell, and G.A. Pawloski, 2003. Impact of Test Heat on Groundwater Flow at Pahute Mesa, Nevada Test Site, UCRL-152599, Lawrence Livermore National Laboratory, Livermore, California.

Carle, S.F., R.M. Maxwell, G.A. Pawloski, D.E. Shumkaer, A.F.B. Thompson, and M. Zavarin, 2007. Evaluation of the Transient Hydrologic Source Term for the Cambric Underground Nuclear Test at Frenchman Flat, Nevada Test Site. UCRL-TR-226916, Lawrence Livermore National Laboratory, Livermore, California.

Carlson, R.C., W.C. Patrick, D.G. Wilder, W.G. Brough, D.N. Montan, P.E. Harben, L.B. Ballou, and H.C. Heard, 1980. Spent Fuel Test - Climax: Technical measurements interim report. UCRL-53064, Lawrence Livermore National Laboratory, Livermore, California.

Carslaw, H.S. and J.C. Jaeger, 1986. Conduction of Heat in Solids. Oxford University Press, USA. 
Chen, Z., S.P. Narayan, Z. Yang, and S.S. Rahman, 2000. An experimental investigation of hydraulic behavior of fractures and joints in granitic rock. Int. J. of Rock Mechanics .Min. Sci., 37: 267-273.

Christakos, G., 2003. Critical conceptualism in environmental modeling and prediction. Envir. Sci. Tech., 37 (20), 4685-4693.

Cole, J.C., 1997. Major Structural Controls on the Distribution of pre-Tertiary Rocks, Nevada Test Site Vicinity, Southern Nevada. U.S. Geological Survey Open-File Report 97-533.

Coles D.G., H.C. Weed, and J.D. Tewhey, 1980. Geochemical studies of sorption and transport of radionuclides in rock media. UCRL-52929, Lawrence Livermore National Laboratory, Livermore, California.

Cook, A.M., L.R. Myer, N.G.W. Cook, and F.M. Doyle, 1990. The effect of tortuosity on flow through a natural fracture. In Rock Mechanics Contributions and Challenges, Proceedings of the $31^{\text {st }}$ U.S. Symposium on Rock Mechanics, W.A. Hustrulid and G.A. Johnson, eds., A.A. Balkema, Rotterdam.

Cooke, R.M., 1991. Expert in Uncertainty: Expert Opinion and Subjective Probability in Science. Oxford Univ. Press, New York.

Connolly J.A., 1981. Hydrothermal alteration in the Climax Granite Stock at the Nevada Test Site. Master's Thesis, Arizona State University, December 1981.

Cui, D. and E.E. Trygve, 1997. On the sorption of Co and Cs on Stripa granite fracture-filling material. Radiochimica Acta, 79, 29-35.

Cui D. and T. Eriksen, 1998. Reactive transport of Sr, Cs and Tc through a column packed with fracture-filling material. Radiochimica Acta 82, 287-292.

Cvetkovic, V., S. Painter, N. Outters, and J.O. Selroos, 2004. Stochastic simulation of radionuclide migration in discretely fractured rock near the Äspö Hard Rock Laboratory. Water Resources Research, 40, W02404, doi:10.1029/2003WR002655.

D'Agnese, F.A., C.C. Belcher, A.K. Turner, and M.C. Hill, 1997. Hydrogeologic Evaluation and Numerical Simulation of the Death Valley Regional Ground-Water Flow System, Nevada and California. U.S. Geological Survey Water-Resources Investigations Report 96-4300.

Daly, C., R.P. Neilson, and D.L. Phillips, 1994. A statistical-topographic model for mapping climatological precipitation over mountainous terrain. Journal of Applied Meteorology, 33, 140-158.

Daniels W.R., 1981. Laboratory Studies of Radionuclide Distributions between selected groundwaters and geologic media. October 1979 - September, 1980. Los Alamos National Laboratory Report LA-8586-PR.

De Groot, M., 1974. Reaching a consensus. J. Amer. Statist. Assoc., 69, 118-121.

Denton, V., 1962. Water Level at Hardhat, Memorandum to Gary Higgins, June 21, 1962, VFD 62-277. 
Dershowitz, W., P. Wallmann, and S. Kindred, 1991. Discrete fracture network modeling of tracer migration experiments at the SCV site. R-91-23, Swedish Nuclear Fuel and Waste Management Co. (SKB), Stockholm, Sweden.

Dershowitz, B., T. Eiben, S. Follin, and J. Anderson, 1999. SR97-Alternative models project, Discrete fracture network modeling for performance assessment of Aberg, Rep. R 99-43, Swedish Nuclear Fuel and Waste Management Co. (SKB), Stockholm, Sweden.

Dershowitz, W.J. Hermanson, S. Follin, and M. Mauldon, 2000. Fracture intensity measures in 1-D, 2-D, and 3-D at Äspö, Sweden. Proceedings of the Fourth North American Rock Mechanics Symposium, Seattle, WA, Pacific Rocks 2000, 4, 849-853.

Dettinger, M.D., 1989. Reconnaissance estimates of natural recharge to desert basins in Nevada, U.S.A., by using chloride-balance calculations. Journal of Hydrology, 106(1-2), 55-78.

Doherty, J., 2000. PEST - Model-Independent Parameter Estimation - User's Manual, $4^{\text {th }}$ Ed., Watermark Numerical Computing.

Draper, D., 1995. Assessment and propagation of model uncertainty. J. R. Statist. Soc. B, 57(1), 45-97.

Efron, B. and R.J. Tibshirani, 1993. An Introduction to the Bootstrap. Monographs on Statistics and Applied Probability, Chapman and Hall/CRC, New York.

Ehlen, J., 2000. Fractal analysis of joint patterns in granite. International Journal of Rock Mechanics and Mining Sciences, 37, 909-922.

Epstein, B., 2004. Development and Uncertainty Analysis of Empirical Recharge Prediction Models for Nevada's Desert Basins. University of Nevada, Masters Thesis, 202p.

Erdal B.R., R.D. Aguilar, B.P. Bayhurst, W.R. Daniels, C.J. Duffy, F.O. Lawrence, S. Maestas, P.Q. Oliver, and K. Wolfsberg, 1979. Sorption-desorption studies on granite. LA-7456-MS Los Alamos Scientific Laboratory.

Eriksen T.E. and B. Locklund, 1989. Radionuclide Sorption on Crushed and Intact Granitic Rock Volume and Surface Effects. SKB Technical Report, 89-25.

Failor R., D. Isherwood, E. Raber, and T. Vandergraaf, 1982. Laboratory studies of radionuclide transport in fractured Climax granite. UCRL-53308, Lawrence Livermore National Laboratory, Livermore, California.

Farnham, I.M., T. Rose, E. Kwicklis, R. Hershey, J. Paces, and W. Fryer, 2006. Geochemical and isotopic evaluation of groundwater movement in Corrective Action Unit 97: Yucca Flat/Climax Mine, Nevada Test Site, Nevada. Stoller-Navarro Joint Venture report for the U.S. Department of Energy, S-N/99205--070.

Faure, G., 1977. Principles of Isotope Geology. John Wiley and Sons, New York, 464p.

Feeney, T.A., M.E. Campana, and R.J. Jacobson, 1987. A Deuterium-calibrated Groundwater Flow Model of the West Nevada Test Site and Vicinity. DOE/NV/10384-16, Desert Research Institute, NV. 
Feth, J.H., C.E. Roberson, and W.L. Polzer, 1964. Sources of mineral constituents in water from Granitic Rocks, Sierra Nevada, California and Nevada. U.S. Geological Survey Water-Supply Paper 1535-I.

Fisher, R., 1953. Dispersion on a sphere. Proceedings of the Royal Society of London, 295305.

Francis, C.W. and E.A. Bondietti, 1979. Sorption-Desorption of Long-Lived Radionuclide Species on Geologic Media. Annual Report PNL-SA-857.

Freer, J., K.J. Beven, and B. Ambroise, 1996. Bayesian estimation of uncertainty in runoff prediction and the value of data: An application of the GLUE approach. Water Resources Research, 32, 2161-21.

Freeze, R.A. and J.A. Cherry, 1979. Groundwater. Prentice-Hall, Inc., Englewood Cliffs, New Jersey.

Frick, U., W. Alexander, B. Baeyens, P. Bossart, M.H. Bradbury, C. Buhler, Jh. Eikenberg, Th. Fierz, W. Heer, E. Hoehn, I.G. McKinley, and P.A. Smith, 1991. Grimsel Test Site The radionuclide migration experiment-overview of investigations 1985-1990. National cooperative for the disposal of radioactive waste technical report 91-94.

Fujikawa Y. and M. Fukui, 1997. Radionuclide sorption to rocks and minerals: effects of $\mathrm{pH}$ and inorganic anions. Part 1. Sorption of cesium, cobalt, strontium and manganese. Radiochimica Acta 76, 153-162.

Gaganis P. and L. Smith, 2001. A Bayesian approach to the quantification of the effect of model error on the predictions of groundwater models. Water Resources Research, 37(9), 2309-2322.

Gauch, H.G., Jr., 1993. Prediction, parsimony and noise. American Scientist, 81, 468-478.

Gillespie, P.A., C.B. Howard, J.J. Walsh, and J. Watterson, 1993. Measurement and characterization of spatial distributions of fractures. Tectonophysics, 226, 113-141.

Grambow, B., 1987. Nuclear Waste Glass Dissolution: Mechanism, Model and Application, JSS Project, Swedish Nuclear Fuel and Waste Management Co. Report Number 87-02, $114 \mathrm{p}$.

Guimerà, J. and J. Carrera, 2000. A comparison of hydraulic and transport parameters measured in low-permeability fractured media. Journal of Contaminant Hydrology, 41, 261-281.

Gustafson, G. and A. Fransson, 2005. The use of the Pareto distribution for fracture transmissivity assessment. Hydrogeology Journal, doi:10.1007/s10040-005-0440-y.

Guth, P.L., 1986. Bedrock Geologic Map of the Black Hills 1:24,000 Quadrangle, Nevada. U.S. Geological Survey Open-File Map 86-438.

Gutierrez, M.G., G. Bidoglio, A. Avogadro, E. Mingarro, and M. D'Alessandro, 1991. Experimental investigations of radionuclide transport through cored granite samples. Radiochimica Acta, 52/53, 213-217. 
Harbaugh, A.W., E.R. Banta, M.C. Hill, and M.G. McDonald, 2000. MODFLOW-2000, the U.S. Geological Survey Modular Ground-Water Model -- User Guide to Modularization Concepts and the Ground-Water Flow Process. U.S. Geological Survey Open-File Report $00-92$

Hardman, G., 1936. Nevada Precipitation and Acreages of Land by Rainfall Zones. Reno, University of Nevada Agricultural Experiments Station, 10 pgs. and map.

Hardman, G., 1965. Nevada precipitation map, adapted from map prepared by George Hardman and others, 1936. Nevada University Agricultural Experiment Station Bulletin 183.

Harrill, J.R., 1976. Pumping and Groundwater Storage Depletion in Las Vegas Valley, Nevada, 1955-74. Nevada Division of Water Resources Bulletin 44, 70 p.

Hatipoglu S., H. Gokturk, and H. Erten, 1994. Migration behavior of barium and strontium in granite. Radiochimica Acta, 66/67, 369-372.

Hevesi, J.A., A.L. Flint, and L.E. Flint, 2003. Simulation of Net Infiltration and Potential Recharge Using a Distributed Parameter Watershed Model for the Death Valley Region, Nevada and California. Water-Resources, Investigations Report 03-4090. Sacramento, CA: U.S. Geological Survey.

Hill, M.C., 1998. Methods and Guidelines for Effective Model Calibration, U.S. Geologic Survey, Water-Resources Investigator Report, 98-4005, Denver, Colorado.

Hoeting, J.A., D. Madigan, A.E. Raftery, and C.T. Volinsky, 1999. Bayesian model averaging: A tutorial. Statistical Science, 14(4), 382-417.

Holmén, J.G. and N. Outters, 2002. Theoretical study of rock mass investigation efficiency. TR-02-21, Swedish Nuclear Fuel and Waste Management Co. (SKB), Stockholm, Sweden.

Holtta, P., M. Hakanen, A. Hautojarvi, J. Timonen, and K. Vaatainen, 1996. The effects of matrix diffusion on radionuclide migration in rock column experiments. Journal of Contaminant Hydrology, 21, 165-173.

Holtta P., M. Siitari-Kauppi, P. Huihuri, A. Lindberg, and A. Hautojarvi, 1997. The effect of specific surface area on radionuclide sorption on crushed crystalline rock. Material Resources Society Symposium Proceedings, 465, 789-796.

Hora, S.C. and R.L. Iman, 1989. Expert opinion in risk analysis: The NUREG-1150 methodology. Nuclear Science and Engineering, 102, 323 - 331.

Hsu, C.N., Y.Y. Wei, T. Chuang, C.L. Tsent, J.Y. Yang, C.H. Ke, H.P. Cheng, and S.P. Teng, 2002. Sorption of several safety relevant radionuclides on granite and diorite - a potential repository host rock in the Taiwan area. Radiochimica Acta 90, 659-664.

Huitti T., M. Hakanen, and A. Lindberg, 1998a. Sorption of Cesium on Olkiluoto Mica Gneiss, Granodiorite and Granite. Posiva Oy, 98-11.

Huitti T., M. Hakanen, and A. Lindberg, 1998b. Sorption characteristics of Rapakivi Granite. Sorption of Cs and U. Radiochemistry, 40(6), 511-515. 
Hurvich, C.M. and C-L. Tsai, 1989. Regression and time series model selection in small sample. Biometrika, 76(2), 99-104.

IAEA (International Atomic Energy Agency), 1998. The Radiological Situation at the Atolls of Mururoa and Fangataufa, Technical Report, Volume 3: Inventory of radionuclides underground at the atolls, Vienna, Austria, IAEA-MFTR-3.

Ikeda T. and T. Amaya, 1998. Model Development of Chemical Evolution in Repository. Vol.II Acquisition of Nuclide Migration Data in Near-Field. PNC ZJ 1281 98-003.

Isherwood D., J. Harrar, and E. Raber, 1982. Characterization of Climax Granite Ground Water. UCRL-53309, Lawrence Livermore National Laboratory, Livermore, California.

IT Corporation, 1996a. Regional Geologic Model Data Documentation Package, Volume I in Underground Test Area Subproject, Phase I, Data Analysis Task, ITLV/10972-181.

IT Corporation, 1996b. Potentiometric Data Documentation Package, Volume II in Underground Test Area Subproject, Phase I, Data Analysis Task, ITLV/10972-181.

IT Corporation, 1996c. Hydrogeologic Parameter Data Documentation Package, Volume IV in Underground Test Area Subproject, Phase I, Data Analysis Task, ITLV/10972-181.

IT Corporation, 1996d. Groundwater Flow Model Data Documentation Package, Volume VI in Underground Test Area Subproject, Phase I, Data Analysis Task, ITLV/10972-181.

IT Corporation, 1999. Value of Information Analysis for Corrective Action Unit 97: Yucca Flat, Nevada Test Site, Nevada, ITLV/13052-079.

Izett, G.A., 1960. Granite exploration hole, Area 15, NTS, Nye County, Nevada. Interim Report, Part C, Physical Properties. U.S. Geological Survey TEM-836-C.

JGC Corporation, 1991. Analytical Code Development and Data Set Preparation for Near Field Analysis (Vol. 3). PNC Technical Report PNC PJ1281 91-005(3).

Johansson H., J. Byegard, G. Skarnemark, and M. Skalberg, 1997. Matrix diffusion of some alkali- and alkaline-earth metals in granitic rock. Material Research Society 465, 871878.

Johansson, H., M. Siitari-Kauppi, M. Skalberg, and E.L. Tullborg, 1998. Diffusion pathways in crystalline rock - examples from Aspo-diorite and fine-grained granite. Journal of Contaminant Hydrology, 35 41-53.

Johnson, J.W. and S.R. Lundeen, 1997. GEMBOCHS thermodynamic datafiles for use with the EQ3/6 modeling package, Internal Report, Lawrence Livermore National Laboratory, Livermore, California.

Kamineni, D.C., K.V. Ticknor, and T.T. Vandergraaf, 1986. Occurrence, composition and radionuclide sorption characteristics of illite from a fractured granite pluton, southeastern Manitoba, Canada. Clay Minerals, 21, 909-924.

Kashyap, R.L., 1982. Optimal choice of AR and MA parts in autoregressive moving average models. IEEE Transactions on Pattern Analysis and Machine Intellegience, 4(2), 99-104.

Kaukonen V., M. Hakanen, and A. Lindberg, 1993. Sorption of Cs, U, Np, and Pu and Diffusion of water, $\mathrm{Cs}$ and $\mathrm{Np}$ in basic plutonic rocks and vulcanite. YJT Report YJT-9313. 
Kaukonen, V., and M. Hakanen, 1996. Diffusion and sorption of neptunium in crystalline rock. Radiochemistry, 38(4), 322-324.

Keeney R.L. and D. von Winterfeldt, 1991. Eliciting probabilities from experts in complex technical problems, IEEE Transactions on Engineering Management, 38 (3):191-201.

Kirk, S.T. and M.E. Campana, 1990. A deuterium-calibrated groundwater flow model of a regional carbonate-alluvial system. Journal of Hydrology, 119, 357-3888.

Kitamura A., T. Yamamoto, H. Moriyama, and S. Nishikawa, 1997. Selective adsorption behavior of cesium ions onto granite. Journal of Nuclear Fuel Cycle and Environment, $4(1), 39-45$.

Kitamura A., T. Yamamoto, S. Nishikawa, and H. Moriyama, 1999a. Sorption behavior of Am(III) on granite. Journal of Radioanalytical and Nuclear Chemistry, 239(3) 449-453.

Kitamura A., K. Fujiwara, T. Yamamoto, S. Nishikawa, and H. Moriyama, 1999b. Mechanism of adsorption of cations onto rocks. JAREI-Conf 99-004, 671-626.

Knauss, K.G., W.L. Bourcier, K.D. McKeegan, C.I. Marzbacher, S.N. Nguyen, F.J. Ryerson, D.K. Smith, H.C. Weed, and L. Newton. 1990. Dissolution kinetics of a simple analogue nuclear waste glass as a function of $\mathrm{pH}$, time, and temperature. Material Resources Society Symposium Proceedings, 176, 371-381.

Koskinen A., M. Alaluusa, S. Pinnioja, T. Jaakola, and A. Lindberg, 1985. Sorption of Iodine, Neptunium, Technetium, Thorium and Uranium on Rocks and Minerals. YJT Report YJT-85-36.

Kulmala S. and M. Hakanen, 1993. The Solubility of Zr, Nb and Ni in Groundwater and Concrete Water, and Sorption on Crushed Rock and Cement. Report YJT-93-21.

Kulmala S., M. Hakanen, and A. Lindberg, 1998. Sorption of Plutonium on Rocks in Groundwaters from Posiva Investigation Sites. PCIVA 98-12.

Kumata, M. and T.T. Vandergraaf, 1998. Experimental study on neptunium migration under in situ geochemical conditions. Journal of Contaminant Hydrology, 35, 31-40.

LaBolle, E., G. Fogg, and A.F.B. Thompson, 1996. Random-walk simulation of solute transport in heterogeneous porous media: Local mas-conservation and implementation methods. Water Resources Research, 32:583-593.

LaBolle, E., J. Quastel, G. Fogg, and J. Gravner, 2000. Diffusion processes in composite porous media with their integration by numerical walks: Generalized stochastic differential equations with discontinuous coefficients. Water Resources Research, 36, 651-662.

Laczniak, R.J., J.C. Cole, D.A. Sawyer, and D.G. Trudeau, 1996. Summary of the Hydrogeologic Controls on Groundwater Flow at the Nevada Test Site, Nye County, Nevada. U.S. Geological Survey Water Resources Investigations Report 96-4109.

Liu, H.H., G.S. Bodvarsson, and L. Pan, 2000. Determination of particle transfer in random walk particle methods for fractured porous media. Water Resources Research, 36, 707713. 
Loeltz, O.J., D.A. Phoenix, and T.W. Robinson, 1949. Groundwater in Paradise Valley, Humboldt County, Nevada. No. 10, State of Nevada, Office of the State Engineer in cooperation with the United States Geological Survey, Carson City, Nevada.

Maclean S.C., D.G. Coles, and H.C. Weed, 1978. The measurement of sorption ratios for selected radionuclides on various geologic media. UCID-17928, Lawrence Livermore National Laboratory, Livermore, California.

Maldonado, F., 1977. Summary of the geology and physical properties of the Climax stock, Nevada Test Site. U.S. Geological Survey Open-file Report 77-356.

Maloszewski, P., and A. Zuber, 1993. Tracer experiments in fractured rocks: Matrix diffusion and the validity of models. Water Resources Research, 29(8), 2723-2735.

Mandelbrot, B.B., 1982. The Fractal Geometry of Nature, W.H. Freeman, New York.

Mardia, K.V. and P.E. Jupp, 2000. Directional Statistics, Wiley, New York.

Marrett, R., O.J. Ortega, and C.M. Kelsey, 1999. Extent of power-law scaling for natural fractures in rock. Geology, 27, 799-802.

Maurer, D.K., D.L. Berger, and D.E. Prudic, 1996. Subsurface Flow to Eagle Valley from Vicee, Ash, and Kings Canyons, Carson City, Nevada, Estimated from Darcy's Law and the Chloride-Balance Method. U.S. Geological Survey Water-Resources Investigation Report 96-4088, 38 p.

Maxey, G.B., and C.H. Jameson, 1945. Progress report on the ground-water resources of the Las Vegas Artesian Basin, Nevada. State of Nevada, Office of the State Engineer, Carson City, Nevada.

Maxey, G.B., and T.E. Eakin, 1949. Groundwater in White River Valley, White Pine, Nye, and Lincoln Counties, Nevada. No. 8, State of Nevada Office of the State Engineer prepared in cooperation with the United State Department of the Interior Geological Survey, Carson City, Nevada.

Maxey, G.B. and T.W. Robinson, 1947. Groundwater in Las Vegas, Pahrump, and Indian Spring Valleys, Nevada (a summary). No. 6, State of Nevada, Office of the State Engineer in cooperation with the United States Geological Survey, Carson City, Nevada.

Mazer, J.J., 1987. Kinetics of glass dissolution as a function of temperature, glass composition, and solution pHs. Ph.D. thesis, Northwestern University.

McArthur, R.D., 1962. Preliminary Geologic Data From Drill Hole U15a 28S, Hardhat Event, NTS. GN 4-62, Lawrence Livermore National Laboratory, Livermore, California.

McArthur, R.D., 1963. Geologic and Engineering Effects the Hardhat Event, (Preliminary). UCID-4580, Lawrence Livermore National Laboratory, Livermore, California.

Mehta, M.M., V.S. Gupta, and W.H. Somerton, 1964. Changes in Physical Properties of Rocks in the Vicinity of an Underground Nuclear Explosion. UCRL-13105, Lawrence Livermore National Laboratory, Livermore, California.

Morse, B., G. Pohll, J. Huntington, and R.R. Castillo, 2003. Stochastic capture zone analysis of an arsenic-contaminated well using the generalized likelihood uncertainty estimator (GLUE) methodology. Water Resources Research, 39(6), doi:10.1029/20002WR001470. 
Munier, R., 2004. Statistical analysis of fracture data adapted for modeling discrete fracture networks - Version 2. Rep. R. 04-66, Swedish Nuclear Fuel and Waste Management, Co. (SKB), Stockholm, Sweden.

Murali, M.S. and J.N. Mathur, 2002. Sorption characteristics of Am(III), Sr(II) and Cs(I) on bentonite and granite. Journal of Radioanalytical and Nuclear Chemistry, 254(1), 129136.

Murray, W.A., 1980. Permeability testing of fractures in Climax stock granite, NTS. Repository Sealing Field Testing Workshop, Santa Fe, New Mexico, September 18-19.

Murray, W.A. 1981. Geohydrology of the Climax stock Granite and Surrounding Rock Formations, NTS. UCRL-53138, Lawrence Livermore National Laboratory, Livermore, California.

Nakayama S., H. Moriyama, H. Arimoto, K. and Higashi, 1986. Distribution Coefficients of Americium, Neptunium and Protactinium for Selected Rocks. The Memoirs of the Faculty of Engineering, Kyoto University, 48(3), 275-283.

National Research Council, 1996. Rock Fractures and Fluid Flow: Comtemporary Understanding and Applications, National Academy Press, Washington, D.C.

Neuman, S.P., 2003. Maximum likelihood Bayesian averaging of alternative conceptualmathematical models. Stochastic Environmental Research and Risk Assessment, 17(5), 291-305, doi: 10.1007/s00477-003-0151-7.

Neuman, S.P. and P.J. Wierenga, 2003. A comprehensive strategy of hydrogeologic modeling and uncertainty analysis for nuclear facilities and sites. NUREG/CR-6805, U.S. Nuclear Regulatory Commission, Washington, D.C.

Neuman, S.P., 2005. Trends, prospects and challenges in quantifying flow and transport through fractured rocks. Hydrologeology Journal, 13, 124-147.

Paillet, F.L., 1998. Flow modeling and permeability estimation using borehole flow logs in heterogeneous fractured formations. Water Resources Research, 34(5), 997-1010.

Patrick, W.C., L.B. Ballou, T.R. Butkovich, R.C. Carlson, W.B. Durham, G.L. Hage, E.L. Majer, D.N. Montan, R.A. Nyholm, N.L. Rector, D.G. Wilder, and J.L. Yow, Jr., 1982. Spent Fuel Test - Climax: Technical Measurements Interim Report. UCRL-53294, Lawrence Livermore National Laboratory, Livermore, California.

Patrick, W.C., 1986. Spent Fuel Test-Climax: An Evaluation of the Technical Feasibility of Geologic Storage of Spent Nuclear Fuel in Granite. UCRL-53702, Lawrence Livermore National Laboratory, Livermore, California.

Pawloski, G.A., 1999. Development of Phenomenological Models at Underground Nuclear Tests on Pahute Mesa, Nevada Test Site - BENHAM and TYBO. UCRL-ID-136003, Lawrence Livermore National Laboratory, Livermore, California.

Pawloski, G.A., A.F.B. Tompson, and S.F. Carle, eds., 2001. Evaluation of the Hydrologic Source Term from Underground Nuclear Tests on Pahute Mesa at the Nevada Test Site: The CHESHIRE Test. UCRL-ID-147023, Lawrence Livermore National Laboratory, Livermore, California. 
Peterson, E., K. Lie, N. Rimer, R. Nilson, and G. Higgins, 1991. Thermodynamic Evolution of Nuclear Cavities, In $6^{\text {th }}$ Symposium on Containment of Underground Nuclear Explosions, Volume 1. CONF-9109114, September 24-27, 1991, University of Nevada, Reno, Nevada, pp. 257-274.

Phelps, G.A., R.C. Jachens, B.C. Moring, and C.W. Roberts, 2004. Modeling of the Climax Stock and related plutons based on the inversion of magnetic data, Southwest Nevada. U.S. Geological Survey, Open-File Report 2004-1345.

Phoenix, D.A., G. Hardman, and M.R. Miller. 1948. Geology and groundwater in the Meadow Valley Wash Drainage Area, Nevada, above the vicinity of Caliente - with statements on classification of irrigable lands in the Panaca Area of Meadow Valley and quality of spring and well waters of the Meadow Valley Wash Drainage Area above the vicinity of Caliente. No. 7, State of Nevada, Office of the State Engineer in cooperation with the United States Geological Survey, Carson City, Nevada.

Pickus, J., 1997. Shaft and Tunnel Nuclear Detonations at the Nevada Test Site:

Development of A Primary Database for the Estimation of Potential Interactions with the Regional Groundwater System. DOE/NV--464, UC-700, U.S. Department of Energy Nevada Operations Office, Las Vegas, Nevada.

Pinnioja T., T. Jaakkola, and J.K. Miettinen, 1984. Comparison of batch and autoradiographic methods in sorption studies of radionuclides in rock and mineral samples. Material Research Society, 26, 979-984.

Poeter, E.P. and D.A. Anderson (2005), Multimodel ranking and inference in groundwater modeling. Ground Water, 43(4), 597-605.

Pohlmann, K., G. Pohll, J. Chapman, A.E. Hassan, R. Carroll, and C. Shirley, 2004. Modeling to support groundwater contaminant boundaries for the Shoal underground nuclear test. Desert Research Institute, Division of Hydrologic Sciences Publication No. 45184.

Price, C.E., 1959. "Granite” exploration hole, Area 15, Nevada Test Site, Nye County, Nevada - Interim Report, Part B, Hydrological Data. U.S. Geological Survey TEM-836-B.

Quong, R., 1969. Permeability Increases in Hardhat Ganodiorite Samples Fractured by Exploding Foils. UCRL-50783, Lawrence Livermore National Laboratory, Livermore, California.

Raab, D.D., 1968. Size-Distribution Study of Piledriver Particles. UCRL-50489, Lawrence Livermore National Laboratory, Livermore, California.

Raab, D.D., 1969. Particle-size Distribution Study: Piledriver Event. UCRL-72078, Lawrence Livermore National Laboratory, Livermore, California.

Reeves, D.M., 2006. Ensemble transport of conservative solutes and the correspondence to operator-stable limit distributions. Ph.D. Thesis, University of Nevada, Reno.

Refsgaard, J.C., J.P. van der Sluijs, J. Brown, and P. van der Keur, 2006. A framework for dealing with uncertainty due to model structure error. Advances in Water Resources, 29, 1586-1597. 
Reimus, P., G. Pohll, R. Mihevc, J. Chapman, M. Haga, B. Lyles, S. Kosinski, R. Niswonger, and P. Sanders, 2003. Testing and paramerizing a conceptual model for solute transport in a fractured granite using multiple tracers in a forced-gradient test. Water Resources Research, 39(12), 1356.

Relyea J. F., L.L. Ames, R.J. Serne, R.W. Fulton, and C.D. Washburne, 1978. Batch Kd Determinations with Common Minerals and Representative Groundwaters. PNL-SA7352. Vol. 2 pp 259-330.

Renshaw, C.E., 1995. On the relationship between mechanical and hydraulic apertures in rough walled fractures. Journal of Geophysical Research, 100(B12).

Renshaw, C.E., 1999. Connectivity of joint networks with power law length distributions. Water Resources Research, 35(9), 2661-2670.

Rives, T., M. Razack, J.-P. Petit, and K.D. Rawnsley, 1992. Joint spacing: Analogue and numerical simulations. Journal of Structural Geology, 14, 925-937.

Robinson, T.W., G.B. Maxey, J.C. Fredericks, and C.H. Jameson, 1947. Water level and artesian pressure in wells in Las Vegas Valley and in other valleys in Nevada, 1913-1945. No. 3, State of Nevada, Office of the State Engineer in cooperation with the United States Geological Survey, Carson City, Nevada.

Ross, S.M., 1985. Introduction to Probability Models, $3^{\text {rd }}$ Ed., Academic Press, Orlando, Florida.

Rush, F.E., 1970. Regional Ground-Water Systems in the Nevada Test Site Area, Nye, Lincoln, and Clark Counties, Nevada. Nevada Department of Conservation and Water Resources Reconnaissance Series Report 54, 21 p.

Russell, C.E. and T. Minor, 2002. Reconnaissance Estimates of Recharge Based on an Elevation-dependent Chloride Mass-balance Approach. Desert Research Institute, Division of Hydrologic Sciences Publication No. 45164.

Russell, C.E., 2004. Documentation of Data and Method for EDCMB Extended Analysis. Desert Research Institute, Division of Hydrologic Sciences Letter Report.

Ryerson F.J. and B.J. Qualheim, 1983. Mineralogic and petrologic investigation of pre-test core samples from the spent fuel test - Climax. UCID 19976 Lawrence Livermore Laboratory.

Sadler, W.R., M.E. Campana, R.J. Jacobson, and N.L. Ingraham, 1991. A deuteriumcalibrated, discrete-state compartment model of regional groundwater flow, Nevada Test Site and vicinity. Desert Research Institute Publication No. 45088.

Saito, Y., et al., 2007. An update of the sorption database: correction and addition of published literature data. JAEA Technical Report (in Japanese with English abstract) JAEA-Data/Code 2007-014.

Sato H., T. Shibutani, Y. Tachi, K. Ota, K. Amano, and M. Yui, 1997. Diffusion Behavior of Nuclides Considering Pathways in Fractured Crystalline Rocks. PNC Technical Report. PNC TN8410 97-127. 
Sato, H., 1999. Matrix diffusion of simple cations, anions, and neutral species in fractured crystalline rocks. Nuclear Technology, 127, 199-211.

Scanlon, B.R., 2004. Evaluation of methods of estimating recharge in semiarid and arid regions in the southwestern U.S. In Groundwater Recharge in a Desert Environmental: the Southwestern United States, .F. Hogan, F.M. Phillips, and B.R. Scanlon (eds.), 235254.

Schwarz, G., 1978. Estimating the dimension of a model. Annual Statistics, 6 (2), 461-464.

Shibutani, T., T. Suyama, and M. Shibata, 1999. Sorption database for radionuclides on bentonite and rocks. JNC Technical Report (in Japanese with English abstract) TN8410 99-050.

Short, N.M., 1964. Memorandum: Variations in Physical Properties of the HARDHAT Medium. UCID-4775, Lawrence Livermore National Laboratory, Livermore, California.

Skagius, K., G. Svedberg, and I. Neretnieks, 1982. A study of strontium and cesium sorption on granite. Nuclear Technology, 59, 302-313.

Skagius, K. and I. Neretnieks. 1986. Porosities and diffusivities of some nonsorbing species in crystalline rocks. Water Resources Research, 22, 389.

Snow, D.T., 1965. A parallel plate model of fractured permeable media. Ph.D. Thesis, University of California, Berkeley.

Steefel, C.I. and S.B. Yabusaki, 1995. OS3D/GIMRT, Software for modeling multicomponent-multidimensional reactive transport, User manual and programmer's guide. Richland, Washington, Pacific Northwest National Laboratory.

Sterrett, T.S., 1969. Drilling Investigation of the Lower Part of the Piledriver Cavity. UCRL50765, Lawrence Livermore National Laboratory, Livermore, California.

Stewart, J.H. and J.E. Carlson, 1978. Geologic Map of Nevada. U.S. Geological Survey Map MF-930.

Stigsson, M., N. Outters, and J. Hermanson, 2001. Aspo Hard Rock Laboratory, Prototype Repository Hydraulic DFN Model no: 2. IPR-01-39, Swedish Nuclear Fuel and Waste Management Co. (SKB), Stockholm, Sweden.

Stoller-Navarro Joint Venture (SNJV), 2004. Unclassified Source Term and Radionuclide Data for the Groundwater Flow and Contaminant Transport Model of Corrective Action Units 101 and 102: Central and Western Pahute Mesa, Nye County, Nevada, Revision No.: 0, S-N/99205-022, August 2004, Las Vegas, Nevada.

Stoller-Navarro Joint Venture (SNJV), 2005a. Unclassified Source Term and Radionuclide Data for Corrective Action Unit 98: Frenchman Flat, Nevada Test Site, Nevada, Revision No.: 0, S-N/99205-058, September 2005, Las Vegas, Nevada.

Stoller-Navarro Joint Venture (SNJV), 2005b. Geochem05.mdb and a user's guide to the comprehensive water quality database for the groundwater in the vicinity of the Nevada Test Site. Rev. 0, September 2005. 
Stoller-Navarro Joint Venture (SNJV), 2006a. Phase II Groundwater Flow Model of Corrective Action Unit 98: Frenchman Flat, Nevada Test Site, Nye County, Nevada, S-N/99205-074, Rev. 0.

Stoller-Navarro Joint Venture (SNJV), 2006b. Groundwater Flow Model of Corrective Action Units 101 and 102: Central and Western Pahute Mesa, Nevada Test Site, Nye County, Nevada, S-N/99205-076, Rev. 0.

Stoller-Navarro Joint Venture (SNJV), 2006c. Phase I Hydrologic Data for the Groundwater Flow and Contaminant Transport Model of Corrective Action Unit 97: Yucca Flat/Climax Mine, Nevada Test Site, Nye County, Nevada, S-N/99205-077, Rev. 0.

Suksi S., E.L. Kaemaeraenen, M. Siitari-Kauppi, and A. Lindberg, 1987. Sorption and diffusion of cobalt, nickel, strontium, iodine, cesium and americium in natural fissure surfaces and drill core cups studied by autoradiography, III. YJT - 87-17.

Suksi S., M. Siitari-Kauppi, P. Hollta, T. Jaakola, and A. Lindberg, 1989. Sorption and diffusion of radionuclides $(\mathrm{C}, \mathrm{Tc}, \mathrm{U}, \mathrm{Pu}, \mathrm{Np})$ in rock samples under oxic and anoxic conditions. YJT Report YJT-89-13.

Suyama, T. and H. Sasamoto, 2004. A renewal of the JNC-Sorption Database (JNC-SDB) addition of literature data published from 1998 to 2003. JNC Technical Report (in Japanese with English abstract) TN8410 2003-018.

Svensson, U., 2001a. A continuum representation of fracture networks, Part I: Method and basic test cases. Journal of Hydrology, 250, 170-186.

Svensson, U. 2001b. A continuum representation of fracture networks, Part II: Application to the Äspö Hard Rock Laboratory. Journal of Hydrology, 250, 187-205.

Tachi Y., T. Shibutani, H. Sato, and M. Shibata, 1999. Sorption and Diffusion Behavior of Palladium in Bentonite, Granodiorite and Tuff. JNC Technical Report, JNC TN8400 99088.

Taki H. and K. Hata, 1991. Measurement Study on Distribution Coefficient and Effective Diffusion Coefficient for Some Rocks and Bentonite. JNC Technical Report PNC ZJ $121491-010$.

Thordarson, W., R.A. Young, and I.J. Winograd, 1967. Records of Wells and Test Holds in the Nevada Test Site and Vicinity (through December 1966). U.S. Geological Survey Open-file Report TEI-872.

Ticknor, K.V., 1994. Uranium sorption on geologic materials. Radiochimica Acta 64, 229236.

Ticknor, K.V. and J. McMurry, 1996. A study of selenium and tin sorption on granite and goethite. Radiochimica Acta 73, 149-156.

Timmons, D.M., and L.E. Thompson, 1996. Geochemical and petrographic studies and the relationships to durability and leach resistance of vitrified products from the in situ vitrification process, International Topical Meeting on Nuclear and Hazardous Waste Management. 
Tompson, A.F.B., C.J. Bruton, and G.A. Pawloski, 1999. Evaluation of the Hydrologic Source Term from Underground Nuclear Tests in Frenchman Flat at the Nevada Test Site: The Cambric Test. UCRL-ID-132300, Lawrence Livermore National Laboratory, Livermore, California.

Tompson, A.F.B, M. Zavarin, C. J. Bruton, and G. A. Pawloski, 2004. Methods for Calculating a Simplified Hydrologic Source Term for Frenchman Flat Sensitivity Studies of Radionuclide Transport Away from Underground Nuclear Tests. UCRL-TR-201817, Lawrence Livermore National Laboratory, Livermore, California.

Tompson, A.F.B., R.M. Maxwell, S.R. Carle, M. Zavarin, G.A. Pawloski, and D.E. Shumaker, 2005. Evaluation of the Non-Transient Hydrologic Source Term for the CAMBRIC Underground Nuclear Test in Frenchman Flat, Nevada Test Site. UCRL-TR217191, Lawrence Livermore National Laboratory, Livermore, California.

Torstenfelt B., R.S. Rundberg, and J.A. Mitchell, 1988. Actinide Sorption on Granites and Minerals as a Function of $\mathrm{pH}$ and Colloids/ Pseudocolloids. Radiochimica Acta, 44/45, 111-117.

Treyer, E.N and N.A. Raybold, 1982. The elution of radionuclides through columns of crushed rock from the NTS. Los Alamos National Laboratory, LA-9329-MS.

U.S. Department of Energy (DOE), 1997. Regional Groundwater Flow and Tritium Transport Modeling and Risk Assessment of the Underground Test Area, Nevada Test Site, Nevada, DOE/NV-477, UC-700.

U.S. Department of Energy (DOE), 2000a. United States Nuclear Tests, July 1945 through September 1992, DOE/NV-209 (Rev. 15), Nevada Operations Office.

U.S. Department of Energy, Nevada Operations Office, 2000b. Corrective Action Investigation Plan for Corrective Action Unit 97: Yucca Flat/Climax Mine, Nevada Test Site, Nevada. DOE/NV - 659, Nevada Operations Office.

Velde, B., J. Dubois, G. Touchard, and A. Badri, 1990: Fractal analysis of fractures in rock: the Cantor's Dust method. Tectonophysics. 179:345-352.

Wahl, R.R., D.A. Sawyer, S.A. Minor, M.D. Carr, J.C. Cole, W.C. Swadley, R.J. Laczniak, R.G. Warren, K.S. Green, and C.M. Engle, 1997. Digital Geologic Maps Database of the Nevada Test Site Area, Nevada. U.S. Geological Survey Open-File Report 97-140.

Watson, P., P. Sinclair, and R. Waggoner, 1976. Quantitative evaluation of a method for estimating recharge to the desert basins of Nevada. Journal of Hydrology, 31:335-357.

Widestrand, H., P. Andersson, J. Byegard, G. Skarnemark, M. Skalberg, and E. Wass, 2001. In situ migration experiments at Aspo Hard Rock Laboratory, Sweden. Results of radioactive tracer migration studies in a single fracture. Journal of Radioanalytical and Nuclear Chemistry, 250(3), 501-517.

Wilder, D.G. and J.L. Yow Jr., 1981. Fracture Mapping at the Spent Fuel Test-Climax, UCRL-53201. Lawrence Livermore Laboratory, Livermore.

Wilder, D.G. and J.L. Yow Jr., 1984. Structural Geology Report Spent Fuel Test-Climax Nevada Test Site. UCRL-53381, Lawrence Livermore Laboratory, Livermore. 
Wilder, D.G., 1987. Influence of Stress-Induced Deformations on Observed Water Flow in Fractures at the Climax Granitic Stock, UCRL-95539 Rev.1, Lawrence Livermore National Laboratory, Livermore, California.

Wines, D.R. and P.A. Lilly, 2002. Measurement and analysis of rock mass discontinuity spacing and frequency in part of th Fimiston Open Pit operation in Kalgoorlie, West Australia: A case study. Int. J. Rock Mech. Min. Sci., 39, 589-602.

Winograd, I.J. and W. Thordarson, 1975. Hydrogeologic and Hydrochemical Framework, South-Central Great Basin, Nevada-California, with Special Reference to the Nevada Test Site. U.S. Geological Survey Professional Paper 712-C.

Witherspoon, P.A., J.S.Y. Wang, K. Iwai, and J.E. Gale, 1980. Validity of the Cubic law for fluid flow in a deformable rock fracture. Water Resources Research, 16(6).

Wood, A.T.A., 1994. Simulation of the Von Mises Distribution. Commun. Stat.-Simula., 23(1), 157-164.

Yamagata S., K. Shimooka, M. Senoo, K. Araki, and H. Amano, 1981. Study on Distribution Coefficient for Cesium between Granite and Water. JAERI-M-9432.

Yamaguchi, R., Y. Sakamoto, and M. Senoo, 1993. Consideration of effective diffusivity of strontium in granite. Journal of Nuclear Science and Technology, 30(8), 796-803.

Ye, M. S.P. Neuman, and P.D. Meyer, 2004. Maximum likelihood Bayesian averaging of spatial variability models in unsaturated fractured tuff. Water Resources Research, 40, doi:10.1029/2003WR002557.

Ye, M., S.P. Neuman, P.D. Meyer, and K.F. Pohlmann. 2005. Sensitivity analysis and assessment of prior model probabilities in MLBMA with application to unsaturated fractured tuff. Water Resources Research, 41, W12429, doi:10.1029/2005WR004260.

Yow, J.L. Jr., 1984. Geologic Structure Mapping Database, Spent Fuel Test - Climax, Nevada Test Site. DE85006267.

Zavarin M., S.K. Roberts, T.P. Rose, and D.L. Phinney, 2002. Validating Mechanistic Sorption Model Parameters and Processes for Reactive Transport in Alluvium. UCRLID-149728, Lawrence Livermore National Laboratory, Livermore, California.

Zavarin M. and C.J. Bruton, 2004a. A Non-Electrostatic Surface Complexation Approach to Modeling Radionuclide Migration at the Nevada Test Site. Aluminosilicates. Lawrence Livermore National Laboratory, Livermore, California, UCRL-TR-208672.

Zavarin M. and C.J. Bruton, 2004b. A Non-Electrostatic Surface Complexation Approach to Modeling Radionuclide Migration at the Nevada Test Site. Iron Oxides and Calcite. Lawrence Livermore National Laboratory, Livermore, California, UCRL-TR-208673.

Zavarin, M., S. Roberts, B. Viani, G. A. Pawloski and T. Rose, 2004a. Nuclear Melt Glass Dissolution and Secondary Mineral Precipitation at 40 to 200C, UCRL-TR-204870, Lawrence Livermore National Laboratory, Livermore, California.

Zavarin, M., S. Roberts, P. Zhao, R. Williams, T. Rose, A. Rainier and G. A. Pawloski, 2004b. High Temperature Studies of Glass Dissolution Rates Close to Saturation. UCRLTR-204874, Lawrence Livermore National Laboratory, Livermore, California. 
Zavarin, M., S.F. Carle and R.M. Maxwell, 2004. Upscaling Radionuclide Retardation Linking the Surface Complexation and Ion Exchange Mechanistic Approach to a Linear Kd Approach. UCRL-TR-204713, Lawrence Livermore National Laboratory, Livermore, California.

Zio, E. and G.E. Apostolakis, 1996. Two methods for the structured assessment of model uncertainty by experts in performance assessments of radioactive waste repositories. Reliability Engineering and System Safety, 54, 225-241.

Zimmerman, R.W. and G.S. Bodvarsson, 1996. Hydraulic conductivity of rock fractures. Transport in Porous Media, 23, 1-30. 
THIS PAGE INTENTIONALLY LEFT BLANK 


\section{Appendix A. Recharge Model Elicitation}

\section{Part I}

Taking into consideration the Climax modeling project, answer questions below for each recharge model by filling in Table B1.

1. To what degree is the model based on solid physical principles? (high, intermediate, or low)

2. To what degree are the model assumptions solid and reasonable? (high, intermediate, or low)

3. Are the model parameters measurable outside the context of the model? (yes, no)

4. What is the degree of sensitivity of the model outputs to model parameters? (high, intermediate, or low)

5. To what degree is the model amenable to confirmation/validation on the basis of available measurements? (high, intermediate, or low)

6. To what degree does model calibration demonstrate model plausibility? (high, intermediate, or low)

7. To what degree may the model capture plausible future phenomena and events against which it cannot be presently assessed or calibrated? (high, intermediate, or low)

8. To what degree does the model (concept, assumptions, implementation, and results) agree with your knowledge and experience? (high, intermediate, or low)

9. Is the model contrary to any of your knowledge and experience? (yes, no) If your answer is "yes," please specify the reason.

10. Is the model qualitatively comparable with others in terms of their plausibility? (yes, no) If your answer is “no," please specify the reason.

Part II

Taking into consideration the Climax modeling project, answer the questions below with your best estimates expressed as a point value and fill in Table B2.

1. Is the model set complete? (yes, no) If not, specify the additional plausible recharge model(s)?

2. Which model do you believe gives the best predictions of recharge?

3. What probability range (e.g., 40 to 60 percent) reflects your degree of belief that the model is the best?

4. Which model do you believe gives the worst predictions of recharge?

5. What probability range reflects your degree of belief that the model is the worst?

\section{Part III}

Taking into consideration the Climax modeling project, answer the questions below with your best estimates expressed as a point value.

1. What are the model ranks in terms of model plausibility? Answer this question in Table B3. Models are ranked from 1 (the most plausible) to 5 (the most implausible). Different models may have the same rank, indicating that the expert has the same degree of belief as to the plausibility of the models.

2. What are the relationships between model plausibility? Answer this question in Table B4. The relationships can be expressed in the form of probability odds. Given models $M_{i}$ and $M_{j}$ and their probabilities are $\mathrm{P}\left(M_{i}\right)$ and $\mathrm{P}\left(M_{j}\right)$, the probability odds are 
$O_{i j}=\mathrm{P}\left(M_{i}\right) / \mathrm{P}\left(M_{j}\right)$, which can be any real value. If two models in a model pair are incomparable, you do not need to specify $O_{i j}$.

3. What is the probability value that best represents the confidence you would place on each recharge model, given the objective of the analysis? Answer this question in Table B5. Different models may have the same probability, indicating that the expert has the same degree of belief as to the plausibility of the models.

\section{Questionnaire of geological model elicitation}

Part I

1. Taking into consideration the project of analysis, is it reasonable to exclude alternative models: Fault Juxtaposition Alternative and Partial Zeolitization Alternative? (yes, no) If not, specify the model(s) that will be excluded and the reason why you believe it should be included?

2. Taking into consideration the project of Climax Mine modeling, is the model set complete? (yes, no) If not, specify the plausible model(s) and the reason why you believe it should be included?

Part II

Taking into consideration the project of analysis, answer questions below for each geological model. The number of models is not limited by 6 and detailed introduction of the models will be provided to the experts later on.

1. To what degree the model is based on solid physical principles? (high, intermediate, or low) A model could be viewed more plausible if it is based on more solid physical principles.

2. To what degree the model assumptions are reasonable? (high, intermediate, or low) A model could be viewed more plausible if it is based on more reasonable assumptions.

3. To what degree the data used to propose the model are reliable? (high, intermediate, or low) A model could be viewed more plausible if it is based on reliable data.

4. To what degree the data used to propose the model are interpreted properly? (high, intermediate, or low) A model could be viewed more plausible if the data based on which it is proposed are properly interpreted.

5. To what degree the model agrees with your knowledge and experience? (high, intermediate, or low) A model could be more plausible if it agrees with your knowledge or experience at higher degree.

6. Is the model against any of your knowledge and experience? (yes, no) While a model against your experience or knowledge may not be implausible, you may view the model as less plausible one.

7. To what degree the model is amenable to confirmation on the basis of available measurements? (high, intermediate, or low) A model could be more plausible if it is more amenable to be confirmed by the measurements.

8. To what degree flow simulation results at the Climax Mine are sensitive to the model? (high, intermediate, or low) A model to which flow simulations are sensitive is more likely to be retained in the model set. 
9. To what degree the model may capture plausible future flow phenomena and events against which it cannot be presently assessed or calibrated? (high, intermediate, or low) A model could be more plausible if it can capture plausible future flow events.

Part III

Taking into consideration the project of analysis, answer the questions below.

1. Which model you would like to select as the best one based on your reasonable belief that it represents best the reality? Specify your reasons.

2. Which model you would like to select as the worst one based on your reasonable belief that it represents worst the reality? Specify your reasons.

Part IV

1. What are the plausibility ranks of these models? Models are ranked from 1 (the most implausible) to 7 (the most plausible). Specify your reasons.

2. Which models you think can be compared with others in terms of their plausibility? For example, Model $\mathrm{i}$ is comparable with Model $\mathrm{j}$, but it may not be comparable with Model k. Specify your reasons.

3. What is the plausibility relationship between the comparable models? For example Model i is 1.5 times more plausible than Model j. Specify your reasons.

4. What is the probability value that best represents the confidence you would place on each geologic model? Specify your reasons.

B. Quality Assurance Statement 
THIS PAGE INTENTIONALLY LEFT BLANK 


\section{Appendix B. Expert Eliciting Process}

This appendix describes details of implementing the expert elicitation procedure suggested by Keeney and von Winterfeldt (1991):

(1) Identification and selection of issues;

(2) Identification and selection of experts;

(3) Discussion and refinement of the issues;

(4) Training for the elicitation;

(5) Elicitation;

(6) Analysis, aggregation, and resolution of disagreements; and

(7) Documentation and communication.

Implementation of each step in the elicitations is described in detail below.

\section{Step 1: Identification and Selection of Issues}

Issues selected for elicitation should be comprehensive, and comments from experts and stakeholders should be incorporated so that important issues will not be neglected. On the other hand, due to the time and budget restrictions, the selected issues should be the most relevant to the purpose of expert elicitation, and all of them should be elicited in the proposed time frame of expert elicitation. For this project, three issues were selected for the assessment of conceptual model uncertainty in recharge and geological models, and the elicitation was conducted in one day. The issues and the rationale for selecting them are as follows:

(1) Is the model set complete? If not, specify plausible recharge model(s).

Bayesian Model Averaging (BMA) requires that alternative models are mutually exclusive and comprehensively exhaustive. The exclusiveness can be satisfied in standard hydrologic practice, where one typically selects a single model at the exclusion of all other models. However, the exhaustiveness cannot be satisfied in absolute sense, since a true model representing reality is unknown. We thus require that a model set is complete if, for given objectives of an analysis, it includes all models consistent with prior knowledge and data. In other words, a complete model set is expected to provide a satisfactory representation of the system of interest and enclose all uncertain conceptual models.

(2) What are the plausibility ranks of these models?

While ranking of model plausibility is qualitative and the ranks are not used in BMA, evaluating the ranks helps experts evaluate relative plausibility of alternative models before they estimate prior model probability.

(3) What is the probability value that best represents the confidence you would place on each recharge model, given the objective of the analysis?

Model probabilities are the final goal of expert elicitation, and will be used directly in the Bayesian Model Averaging. Summation of the model probabilities is one. Setting prior probability of one more to 1 requires setting the prior probabilities of all other models equal to zero. This means that the joint probabilities of any two models in the model set is zero, i.e., they are mutually exclusive.

Since recharge and geological models are independent, the three issues above were elicited separately for the recharge and geological models in two elicitations. Prior 
probabilities of a combination of any recharge and geological models can be easily estimated due to their independent nature.

\section{Step 2: Identification and Selection of Experts}

Expert elicitation requires three types of experts: generalists, specialists, and normative experts (Bonano et al., 1990). The generalists should be knowledgable about various overall aspects of the recharge and geological models and the project. They typically have substantive knowledge in one discipline (e.g., geology, hydrology, transport phenomena) and a general understanding of the technical aspects of the problem. However, they are not necessarily at the forefront of any specialty within their main discipline. The specialists, on the other hand, are at the forefront of one specialty relevant to the recharge models, but they often do not have the generalists' knowledge about how their expertise contributes to the project with respect to recharge model uncertainty analysis. Normative experts typically have training in probability theory, psychology, and decision analysis. They assist generalists and specialists with substantive knowledge in articulating their professional judgments and thoughts so that they can be meaningful used in the conceptual model uncertainty assessment. A high-quality elicitation requires the teamwork of all three types of experts.

Selecting experts is a time-consuming process, and may take more than a year for a full-scale elicitation (e.g., soliciting expert candidates internationally and forming an expert panel of international scientists). Based on the project needs and limit of time and budget, the project team (Ming Ye, Karl Pohlmann, Jenny Chapman, Chuck Russell, and Greg Pohll) at the Desert Research Institute (DRI) was in charge of selecting national experts who are familiar with hydrogeologic conditions of Nevada.

For the elicitation of recharge models, five specialists, two generalists, and one normative expert were selected. The number of experts is considered sufficient for the elicitation (Kenney and von Winterfeldt, 1991). The experts and their affiliation are listed below:

Specialists: Greg Pohll (DRI), Joe Hevesi (USGS), Chuck Russell (DRI), Glendon Gee (PNNL), and Randy Laczniak (USGS)

Generalists: Karl Pohlmann (DRI) and Jenny Chapman (DRI)

Normative expert: Ming Ye (DRI).

Among the specialists, Joe Hevesi and Chuck Russell have developed the net infiltration models and chloride mass-balance models, respectively. Including them in the expert panel is considered as a strength, not a weakness, as explained later on. The normative expert does not estimate plausibility of the recharge models.

For the elicitation of geological models, six specialists, three generalists, and three normative experts were selected. The number of experts is considered sufficient for the elicitation (Kenney and von Winterfeldt, 1991). The experts and their affiliation are listed below:

Specialist: Sig Drellack (Bechtel-Nevada), Gayle Pawloski (LLNL), Goeff Phelps (USGSMenlo Park), Maggie Townsend (Bechtel-Nevada), Pat Cashman (UNR), Donald Sweetkind (USGS-Denver),

Generalists: Greg Ruskauff (SNJV), Chuck Russell (DRI), Steve Mizell (DRI) 
Normative Experts: Ming Ye (DRI), Jenny Chapman (DRI), Karl Pohlmann (DRI)

Among the specialists, Sig Drellack and Donal Sweetkind are involved in the USGS and UGTA geological models, respectively. Again, including the model developers in the expert panel is considered as a strength, not a weakness, as explained later on.

\section{Step 3: Discussion and Refinement of Elicited Issues}

The purpose of this step is to discuss and refine, if necessary, the issues and quantities that will be elicited. While Kenney and von Winterfeldt (1991) suggested completing this step by a one-day meeting of all experts, such a meeting is considered unnecessary for this project, since the project team (Ming Ye, Karl Pohlmann, Jenny Chapman, Chuck Russell, and Greg Pohll) consists of all three kinds of experts needed for the elicitation. The project (not elicitation) team reviewed and refined the issues and quantities to avoid any ambiguity. Material (e.g., examples and questionnaires) used for training experts and conducting elicitation were also reviewed. After the discussion and refinement, the qualities and issues to be elicited and background knowledge needed for the elicitation were sent to the experts via email. The background knowledge includes:

(1) Rigorously and clearly defined elicitation issues and quantities.

(2) Reading material about conceptual model uncertainty, Bayesian Model Averaging method, prior model probability, and expert judgment.

(3) Descriptions of the recharge and geological models.

The experts studied the material before elicitation, and some experts discussed details of the models with the project team, and required more reading materials.

\section{Step 4: Training for the Elicitation}

Led by normative experts, the training is to (1) further familiarize the experts with the concepts and techniques used in the elicitation, (2) give experts some practice with probabilistic assessments, (3) inform the experts about potential biases in judgment, and (4) motivate them for the elicitation to be performed later on. It is very critical to make clear to the experts that the probability is expressed, in a Bayesian point of view, as a subjective degree of belief.

The training was conducted through two meetings in the first half day of the elicitation. In the first meeting, the normative experts introduced the following information to the experts:

(1) The purpose of the elicitation and the issues and quantities to be elicited.

(2) The concept of prior and posterior model probabilities and their relationships and applications in BMA. Examples of assessing geostatistical model uncertainty at the Apache Leap Research Site (ALRS) was introduced to the experts, since the example has the complete procedure of BMA and thus can give the experts the whole picture of the methodology.

(3) One example (Zio and Apostolakis, 1996) of using expert elicitation for prior model probability was introduced. The example compares six groundwater models based on a set of common assumptions and simplifications, but they differ by some fundamental hypotheses on the flow and transport mechanism in the system of 
interest. The example was selected since it has the complete procedure of expert elicitation and the application of elicitation results.

Three types of biases that may occur during elicitation were introduced:

overconfidence, anchoring, and availability (Kenney and von Winterfeldt, 1991).

Overconfidence is to express more certainty than what is appropriate and assign a

large prior probability to certain models. Anchoring is to hesitate to adjust the prior

model probability but to focus on its initial value. For example, assigning an equally

likely prior probability to all models. Availability is to overemphasize the events that are easily imagined or recalled. Bias can also occur if experts focus on concrete

evidence and data as a main source of probability judgments and ignore more abstract information.

The second training meeting was to further familiarize the experts with the recharge and geological models. For the elicitation of recharge models, Joe Hevesi, Chuck Russell, and Greg Pohll made presentations for the models of net infiltration, chloride mass-balance, and Maxey-Eakin methods, respectively. For the elicitation of geological models, Karl Pohlmann and Sig Drellack made presentations for the USGS and UGTA models, respectively. During the presentations, experts asked questions about advantages, disadvantages, assumptions, and most appropriate application areas of these models.

\section{Step 5: Elicitation}

Since most of the elicitation can be completed within one to three hours (Kenney and von Winterfeldt, 1991), the elicitation was conducted in the second half day of elicitation. All experts were asked to answer a questionnaire prepared by the project team. Eighteen and seventeen questions were designed for the elicitation of recharge and geological models. The questionnaires of elicitation of recharge and geological models are listed in Appendix A of the report. The questions were designed in the order that progressively quantitative questions follow qualitative ones. Assigning prior model probabilities was the last question for the experts to answer. Experts were also required to provide justifications of their answers. The experts were elicited in a group meeting, not individually. Communications between experts were only encouraged before they answered the questionnaire. Normative experts assisted the experts during the session, but they did participate in the elicitation.

\section{Step 6: Analysis, Aggregation, and Resolution of Disagreement}

Right after the elicitation, when the meeting is still vivid in memory, experts' answers were analyzed and aggregated to yield the final estimation of the elicited quantity. Kenney and von Winterfeldt (1991) suggest resolving the disagreements between the answers by having a meeting after the elicitation. This seems unnecessary in our case, since different distributions of model plausibility reflect experts' different degree of belief on model uncertainty. In addition, because the aggregation of model probability elicited from experts is based on mathematical formulas, not behavioral approaches, there is no need to arrive at a consensus distribution. The aggregation can be implemented by simply averaging (Hora and Iman, 1989), but comprehensive analysis and aggregation rules may be needed, for example, to examine sensitivity of the final result to individual answers. Therefore, in addition to the simple average, we also applied the two-step aggregation method of De Groot (1974) for each elicitation, and the two aggregation results will be discussed later on. 
The two-step aggregation method requires each expert to assign averaging weights to his and other experts' judgments. In the first step, given five experts, each expert assigns weights to his and other experts' judgments. This gives a matrix of weight $\mathbf{W}$ in the form of $\left[\begin{array}{lllll}W_{11} & W_{12} & W_{13} & W_{14} & W_{15} \\ W_{21} & W_{22} & W_{23} & W_{24} & W_{25} \\ W_{31} & W_{32} & W_{33} & W_{33} & W_{34} \\ W_{41} & W_{42} & W_{43} & W_{44} & W_{45} \\ W_{51} & W_{52} & W_{53} & W_{54} & W_{55}\end{array}\right]$

where $W_{i j}$ is the weight that expert $i$ assigns to expert $j$ and $\sum_{j} W_{i j}=1$. Assuming that the probabilities of five models are elicited, the model probability matrix $\mathrm{P}$ is

$\left[\begin{array}{lllll}P_{11} & P_{12} & P_{13} & P_{14} & P_{15} \\ P_{21} & P_{22} & P_{23} & P_{24} & P_{25} \\ P_{31} & P_{32} & P_{33} & P_{34} & P_{35} \\ P_{41} & P_{42} & P_{43} & P_{44} & P_{45} \\ P_{51} & P_{52} & P_{53} & P_{54} & P_{55}\end{array}\right]$

where $P_{i j}$ is the probability that expert $i$ assigns to model $j$ and $\sum_{j} P_{i j}=1$. Multiplying weight matrix $\mathbf{W}$ by probability matrix $\mathbf{P}$ gives a new probability matrix $\mathbf{P}^{\prime}=\mathbf{W P}$, where $P^{\prime}{ }_{i j}$ is the averaged probability of model $j$ given by expert $i$. In this step, the within-expert uncertainty is considered. In the second step, each column of the matrix $\mathbf{P}^{\prime}$

$$
\left[\begin{array}{lllll}
P_{11}^{\prime} & P_{12}^{\prime} & P_{13}^{\prime} & P_{14}^{\prime} & P_{15}^{\prime} \\
P_{21}^{\prime} & P_{22}^{\prime} & P_{23}^{\prime} & P_{24}^{\prime} & P_{25}^{\prime} \\
P_{31}^{\prime} & P_{32}^{\prime} & P_{33}^{\prime} & P_{34}^{\prime} & P_{35}^{\prime} \\
P_{41}^{\prime} & P_{42}^{\prime} & P_{43}^{\prime} & P_{44}^{\prime} & P_{45}^{\prime} \\
P_{51}^{\prime} & P_{52}^{\prime} & P_{53}^{\prime} & P_{54}^{\prime} & P_{55}^{\prime}
\end{array}\right]
$$

is averaged by assigning the same weight to $P^{\prime}{ }_{i j}$ and $P_{j}=\sum_{i} P_{i j}$ is the probability of model $j$.

This is another way to consider within-expert uncertainty, but averaged of model probability by each expert is weighted equally likely.

\section{Step 7: Documentation and Communication}

The following material related to the elicitation process should be well documented for public scrutiny:

(1) Elicitation issues and quantities;

(2) Expert identification and selection;

(3) Training material;

(4) Training and elicitation process and the results from each expert;

(5) Aggregation of the elicited quantities; and

(6) Final model probabilities. 
THIS PAGE INTENTIONALLY LEFT BLANK 


\section{Appendix C. Selection of Calibrated Parameters}

This appendix lists the calibrated parameters and rationale of selecting these parameters. The tables below list all 100 parameters in the DVRFS modeling, the 55 calibrated parameters in the DVRFS, the 32 calibrated parameters in this project, and rational of selecting them. The 100 parameters are organized into 11 groups: hydraulic conductivity of basement and confining units, hydraulic conductivity of carbonate rocks, hydraulic conductivity of volcanic rocks, hydraulic conductivity of basin fill units, flow barriers, drains, depth decay, recharge multiplier, specific storage, specific yield, and anisotropic ratio. These groups correspond to those of Belcher et al. (2004) presented in their Figures F-37 and F-38 and discussed in detail in their report.

Table C-1. Selected hydraulic conductivity parameters of basement and confining units to be calibrated for the Climax project.

\begin{tabular}{|c|c|c|c|c|}
\hline $\begin{array}{l}\text { Parameter } \\
\text { Group }\end{array}$ & Parameter Name & $\begin{array}{l}\text { Calibrated } \\
\text { (DVRFS) }\end{array}$ & $\begin{array}{l}\text { Calibrated } \\
\text { (Climax) }\end{array}$ & Rationale \\
\hline \multirow{8}{*}{$\begin{array}{l}\text { Hydraulic } \\
\text { conductivity } \\
\text { of basement } \\
\text { and } \\
\text { confining } \\
\text { units (K1) }\end{array}$} & K11_ICU & $\mathrm{Y}$ & $\mathrm{Y}$ & $\begin{array}{l}\text { Close and upgradient to the } \\
\text { Climax mine }\end{array}$ \\
\hline & K11C_XILCU & Y & Y & $\begin{array}{l}\text { Close and upgradient to the } \\
\text { Climax mine }\end{array}$ \\
\hline & K1LCCU_XCU & Y & Y & $\begin{array}{l}\text { Close and upgradient to the } \\
\text { Climax mine }\end{array}$ \\
\hline & K11DV_XCU & $\mathrm{Y}$ & $\mathrm{N}$ & Located at Death Valley \\
\hline & K12223프CU & Y & Y & $\begin{array}{l}\text { Close and upgradient to the } \\
\text { Climax mine }\end{array}$ \\
\hline & K122fgLCCU & $\mathrm{N}$ & $\mathrm{N}$ & Not calibrated in DVRFS \\
\hline & K122esLCCU & $\mathrm{Y}$ & $\mathrm{N}$ & Located at Death Valley \\
\hline & K1221UCCU & $\mathrm{Y}$ & $\mathrm{N}$ & Numerical instability \\
\hline
\end{tabular}


Table C-2. Selected hydraulic conductivity parameters of carbonate rocks to be calibrated for the Climax project.

\begin{tabular}{|c|c|c|c|c|}
\hline $\begin{array}{l}\text { Parameter } \\
\text { Group }\end{array}$ & Parameter Name & $\begin{array}{l}\text { Calibrated } \\
\text { (DVRFS) }\end{array}$ & $\begin{array}{c}\text { Calibrated } \\
\text { (Climax) }\end{array}$ & Rationale \\
\hline \multirow{20}{*}{$\begin{array}{l}\text { Hydraulic } \\
\text { conductivity } \\
\text { of carbonate } \\
\text { rocks (K2) }\end{array}$} & K221_LCA & $\mathrm{N}$ & $\mathrm{N}$ & Not calibrated in DVRFS \\
\hline & K232_LCA & $\mathrm{N}$ & $\mathrm{N}$ & Not calibrated in DVRFS \\
\hline & K241SM_LCA & $\mathrm{Y}$ & $\mathrm{N}$ & $\begin{array}{l}\text { Beyond NTS and downgradient } \\
\text { to the Climax mine }\end{array}$ \\
\hline & K241LCA_T1 & Y & Y & Located in the Climax mine \\
\hline & K241SMWLCA & $\mathrm{Y}$ & $\mathrm{N}$ & $\begin{array}{l}\text { Beyond NTS and downgradient } \\
\text { to the Climax mine }\end{array}$ \\
\hline & K2_DV_LCA & $\mathrm{N}$ & $\mathrm{N}$ & Not calibrated in DVRFS \\
\hline & $\mathrm{K} 2 \overline{4} 12 \_\overline{\mathrm{L} C A}$ & Y & $\mathrm{N}$ & $\begin{array}{l}\text { Beyond NTS and west of the } \\
\text { Climax mine (a small unit) }\end{array}$ \\
\hline & K2412fLCA & Y & $\mathrm{N}$ & $\begin{array}{l}\text { Beyond NTS and downgradient } \\
\text { to the Climax mine }\end{array}$ \\
\hline & K242G_LCA & Y & $\mathrm{Y}$ & $\begin{array}{l}\text { Close to and upgradient of the } \\
\text { Climax mine }\end{array}$ \\
\hline & K242YN_LCA & $\mathrm{N}$ & $\mathrm{N}$ & Not calibrated in DVRFS \\
\hline & K242A_LCA & Y & $\mathrm{Y}$ & Close to the Climax mine \\
\hline & K2SHPLCA & $\mathrm{N}$ & $\mathrm{N}$ & Not calibrated in DVRFS \\
\hline & K2YMLCA & $\mathrm{Y}$ & $\mathrm{N}$ & $\begin{array}{l}\text { Located at YM and downgradient } \\
\text { to the Climax mine }\end{array}$ \\
\hline & K2421_LCA & Y & $\mathrm{N}$ & $\begin{array}{l}\text { East of the Climax mine and } \\
\text { somehow downgradient }\end{array}$ \\
\hline & K2422b_LCA & Y & $\mathrm{Y}$ & $\begin{array}{l}\text { Upgradient of the Climax mine } \\
\text { (far though) }\end{array}$ \\
\hline & K243_LCA & Y & $\mathrm{Y}$ & $\begin{array}{l}\text { Close to the Climax mine } \\
\text { (downgradient though) }\end{array}$ \\
\hline & K243_UCA & $\mathrm{N}$ & $\mathrm{N}$ & Not calibrated in DVRFS \\
\hline & K243PיP_LCA & $\mathrm{Y}$ & $\mathrm{N}$ & $\begin{array}{l}\text { Beyond NTS and downgradient } \\
\text { of the Climax mine }\end{array}$ \\
\hline & K243GV_LCA & $\mathrm{N}$ & $\mathrm{N}$ & Not calibrated in DVRFS \\
\hline & K244_LCA & $\mathrm{N}$ & $\mathrm{N}$ & Not calibrated in DVRFS \\
\hline
\end{tabular}


Table C-3. Selected hydraulic conductivity parameters of volcanic rocks to be calibrated for the Climax project.

\begin{tabular}{|c|c|c|c|c|}
\hline $\begin{array}{l}\text { Parameter } \\
\text { Group }\end{array}$ & Parameter Name & $\begin{array}{l}\text { Calibrated } \\
\text { (DVRFS) }\end{array}$ & $\begin{array}{l}\text { Calibrated } \\
(\text { Climax })\end{array}$ & Rationale \\
\hline \multirow{14}{*}{$\begin{array}{l}\text { Hydraulic } \\
\text { conductivity } \\
\text { of volcanic } \\
\text { rocks (K3) }\end{array}$} & K3C_PVA & $\mathrm{N}$ & $\mathrm{N}$ & Not calibrated in DVRFS \\
\hline & $\mathrm{K} 3 \mathrm{C}_{-}^{-} \mathrm{TM}$ & Y & $\mathrm{Y}$ & $\begin{array}{l}\text { Close to and upgradient of the } \\
\text { Climax mine }\end{array}$ \\
\hline & K3211TMVA & Y & $\mathrm{Y}$ & Close to the Climax mine \\
\hline & K3PVA & Y & $\mathrm{N}$ & Numerical instability \\
\hline & K3BRU123 & Y & $\mathrm{Y}$ & Significant to flow \\
\hline & K3LFU_am & $\mathrm{N}$ & $\mathrm{N}$ & Not calibrated in DVRFS \\
\hline & $\mathrm{K} 32 \mathrm{BR} \overline{4} \mathrm{CH} 13$ & Y & $\mathrm{Y}$ & $\begin{array}{l}\text { Close to and upgradient of the } \\
\text { Climax mine }\end{array}$ \\
\hline & $\mathrm{K} 32 \mathrm{CH} 24 \mathrm{LF}$ & Y & Y & $\begin{array}{l}\text { The HGU covers a large portion } \\
\text { of the simulation domain }\end{array}$ \\
\hline & K321521_PP & Y & Y & $\begin{array}{l}\text { Close to and upgradient of the } \\
\text { Climax mine }\end{array}$ \\
\hline & K3215BCU1 & $\mathrm{N}$ & $\mathrm{N}$ & Not calibrated in DVRFS \\
\hline & K3215BCU34 & Y & Y & $\begin{array}{l}\text { Close to and upgradient of the } \\
\text { Climax mine }\end{array}$ \\
\hline & K3215TR & $\mathrm{N}$ & $\mathrm{N}$ & Not calibrated in DVRFS \\
\hline & K33_OVU & $\mathrm{N}$ & $\mathrm{N}$ & Not calibrated in DVRFS \\
\hline & K33_OVUsw & $\mathrm{N}$ & $\mathrm{N}$ & Not calibrated in DVRFS \\
\hline
\end{tabular}

Table C-4. Selected hydraulic conductivity parameters of basin fill units to be calibrated for the Climax project.

\begin{tabular}{|c|c|c|c|c|}
\hline $\begin{array}{l}\text { Parameter } \\
\text { Group }\end{array}$ & Parameter Name & $\begin{array}{l}\text { Calibrated } \\
\text { (DVRFS) }\end{array}$ & $\begin{array}{l}\text { Calibrated } \\
(\text { Climax })\end{array}$ & Rationale \\
\hline \multirow{14}{*}{$\begin{array}{l}\text { Hydraulic } \\
\text { conductivity } \\
\text { of basin fill } \\
\text { units (K4) }\end{array}$} & K4_VF_AQ & $\mathrm{Y}$ & $\mathrm{Y}$ & $\begin{array}{l}\text { This HGU covers a large portion } \\
\text { of the simulation domain }\end{array}$ \\
\hline & K4_VF_CU & Y & $\mathrm{Y}$ & $\begin{array}{l}\text { This HGU covers a large portion } \\
\text { of the simulation domain }\end{array}$ \\
\hline & K4_VF_OAA & $\mathrm{N}$ & $\mathrm{N}$ & Not calibrated in DVRFS \\
\hline & K4UP_VSUC & $\mathrm{N}$ & $\mathrm{N}$ & Not calibrated in DVRFS \\
\hline & K4UP_VSUP & Y & $\mathrm{N}$ & $\begin{array}{l}\text { Located at Pahrump Valley and } \\
\text { far from the Climax mine }\end{array}$ \\
\hline & K42UP_VSU & Y & Y & $\begin{array}{l}\text { Close to and upgradient of the } \\
\text { climax mine }\end{array}$ \\
\hline & K4222P_VSU & $\mathrm{N}$ & $\mathrm{N}$ & Not calibrated in DVRFS \\
\hline & K42222_VSU & $\mathrm{N}$ & $\mathrm{N}$ & Not calibrated in DVRFS \\
\hline & K422GV_VSU & Y & $\mathrm{N}$ & $\begin{array}{l}\text { Beyond NTS and west of the } \\
\text { Climax mine }\end{array}$ \\
\hline & K422DV_VSU & $\mathrm{Y}$ & $\mathrm{N}$ & Located in the Death Valley \\
\hline & K422GW_VSU & Y & $\mathrm{N}$ & Located in the Death Valley \\
\hline & K4222S_VSU & Y & Y & Covers the Climax mine \\
\hline & K422LNEVSU & Y & Y & $\begin{array}{l}\text { Close to and upgradient of the } \\
\text { climax mine }\end{array}$ \\
\hline & K422LNWVSU & Y & Y & $\begin{array}{l}\text { Close to and upgradient of the } \\
\text { climax mine }\end{array}$ \\
\hline
\end{tabular}


Table C-5. Selected barrier conductance parameters of flow barriers to be calibrated for the Climax project.

\begin{tabular}{|c|c|c|c|c|}
\hline $\begin{array}{l}\text { Parameter } \\
\text { Group }\end{array}$ & Parameter Name & $\begin{array}{l}\text { Calibrated } \\
\text { (DVRFS) }\end{array}$ & $\begin{array}{l}\text { Calibrated } \\
\text { (Climax) }\end{array}$ & Rationale \\
\hline \multirow{9}{*}{ Flow barriers } & B LVVSZ 1 & $\mathrm{~N}$ & $\mathrm{~N}$ & Not calibrated in DVRFS \\
\hline & B_HWY95 & $\mathrm{N}$ & $\mathrm{N}$ & Not calibrated in DVRFS \\
\hline & B_DVFC_FCR & $\mathrm{N}$ & $\mathrm{N}$ & Not calibrated in DVRFS \\
\hline & B_LVVSZ̄IS & $\mathrm{N}$ & $\mathrm{N}$ & Not calibrated in DVRFS \\
\hline & $\mathrm{B}^{-} \mathrm{LVVSZ}^{-} \mathrm{I} 2$ & $\mathrm{~N}$ & $\mathrm{~N}$ & Not calibrated in DVRFS \\
\hline & B_PAHRUMP & Y & $\mathrm{N}$ & $\begin{array}{l}\text { Located at Pahrump Valley and } \\
\text { far from the Climax mine }\end{array}$ \\
\hline & B_DV_N & Y & $\mathrm{N}$ & $\begin{array}{l}\text { Located at Death Valley and far } \\
\text { from the Climax mine }\end{array}$ \\
\hline & B_SOLTARIO & $\mathrm{Y}$ & Y & $\begin{array}{l}\text { Close to and downgradient of the } \\
\text { Climax mine }\end{array}$ \\
\hline & B TC LINE & $\mathrm{N}$ & $\mathrm{N}$ & Not calibrated in DVRFS \\
\hline
\end{tabular}

Table C-6. Selected drain conductance parameters of drains to be calibrated for the Climax project.

\begin{tabular}{|c|c|c|c|c|}
\hline $\begin{array}{l}\text { Parameter } \\
\text { Group }\end{array}$ & Parameter Name & $\begin{array}{l}\text { Calibrated } \\
\text { (DVRFS) }\end{array}$ & $\begin{array}{l}\text { Calibrated } \\
\text { (Climax) }\end{array}$ & Rationale \\
\hline \multirow[t]{7}{*}{ Drains } & UPPER_DRN & $\mathrm{Y}$ & $\mathrm{N}$ & $\begin{array}{l}\text { Located far from and } \\
\text { downgradient of the Climax mine }\end{array}$ \\
\hline & DEEP_DRN & $\mathrm{Y}$ & $\mathrm{N}$ & $\begin{array}{l}\text { Located far from and } \\
\text { downgradient of the Climax mine }\end{array}$ \\
\hline & UP_PLY_DRN & Y & $\mathrm{N}$ & $\begin{array}{l}\text { Located far from and } \\
\text { downgradient of the Climax mine }\end{array}$ \\
\hline & UP_PAH_DRN & Y & $\mathrm{N}$ & $\begin{array}{l}\text { Located far from and } \\
\text { downgradient of the Climax mine }\end{array}$ \\
\hline & UP_DV_DRN & $\mathrm{N}$ & $\mathrm{N}$ & $\begin{array}{l}\text { Located far from and } \\
\text { downgradient of the Climax mine }\end{array}$ \\
\hline & UP_DVN_DRN & Y & $\mathrm{N}$ & $\begin{array}{l}\text { Located far from and } \\
\text { downgradient of the Climax mine }\end{array}$ \\
\hline & FRNCR_DRN & $\mathrm{N}$ & $\mathrm{N}$ & $\begin{array}{l}\text { Located far from and } \\
\text { downgradient of the Climax mine }\end{array}$ \\
\hline
\end{tabular}


Table C-7. Selected depth decay factor parameters to be calibrated for the Climax project.

\begin{tabular}{clccl}
\hline $\begin{array}{c}\text { Parameter } \\
\text { Group }\end{array}$ & Parameter Name & $\begin{array}{c}\text { Calibrated } \\
\text { (DVRFS) }\end{array}$ & $\begin{array}{c}\text { Calibrated } \\
\text { (Climax) }\end{array}$ & \multicolumn{1}{c}{ Rationale } \\
\hline Depth decay & KDP_VOL & Y & Y & Significant to flow simulation \\
& KDEP_LCA & Y & Y & Significant to flow simulation \\
& KDEP_VFVL & N & N & Not calibrated in DVRFS \\
& KDEP_VSUU & N & N & Not calibrated in DVRFS \\
& KDEP_NO & N & N & Not calibrated in DVRFS \\
& KDP_LCANO & Y & Y & Significant to flow simulation \\
& KDP_LCAT1 & Y & Y & Significant to flow simulation \\
& KDEP_VSUL & N & N & Not calibrated in DVRFS \\
& KDEP_UCCU & Y & Y & Significant to flow simulation \\
& KDEP_XL & Y & Y & Significant to flow simulation \\
\hline
\end{tabular}

Table C-8. Selected recharge multipliers to be calibrated for the Climax project.

\begin{tabular}{llccl}
\hline $\begin{array}{c}\text { Parameter } \\
\text { Group }\end{array}$ & Parameter Name & $\begin{array}{c}\text { Calibrated } \\
\text { (DVRFS) }\end{array}$ & $\begin{array}{c}\text { Calibrated } \\
\text { (Climax) }\end{array}$ & Rationale \\
\hline Recharge & RCH_2 & Y & Y & Significant to flow simulation \\
multiplier & RCH_35 & Y & Y & Significant to flow simulation \\
& RCH_467 & N & N & Not calibrated in DVRFS \\
& RCH_8 & N & N & Not calibrated in DVRFS \\
\hline
\end{tabular}

Table C-9. Selected specific storage and specific yield parameters to be calibrated for the Climax project.

\begin{tabular}{llccl}
\hline $\begin{array}{c}\text { Parameter } \\
\text { Group }\end{array}$ & Parameter Name & $\begin{array}{c}\text { Calibrated } \\
\text { (DVRFS) }\end{array}$ & $\begin{array}{c}\text { Calibrated } \\
\text { (Climax) }\end{array}$ & Rationale \\
\hline Specific & STOR_12 & $\mathrm{N}$ & $\mathrm{N}$ & Not calibrated in DVRFS \\
storage & STOR_34 & $\mathrm{N}$ & $\mathrm{N}$ & Not calibrated in DVRFS \\
& STOR_4VUP & $\mathrm{N}$ & $\mathrm{N}$ & Not calibrated in DVRFS \\
& STOR_4C & $\mathrm{N}$ & $\mathrm{N}$ & Not calibrated in DVRFS \\
Specific & SY_OTHER & $\mathrm{N}$ & $\mathrm{N}$ & Not calibrated in DVRFS \\
yield & SY_PAH & $\mathrm{N}$ & $\mathrm{N}$ & Not calibrated in DVRFS \\
& SY_PUMP & $\mathrm{N}$ & $\mathrm{N}$ & Not calibrated in DVRFS \\
\hline
\end{tabular}

Table C-10. Selected anisotropic ratios to be calibrated for the Climax project.

\begin{tabular}{llccl}
\hline $\begin{array}{c}\text { Parameter } \\
\text { Group }\end{array}$ & Parameter Name & $\begin{array}{c}\text { Calibrated } \\
\text { (DVRFS) }\end{array}$ & $\begin{array}{c}\text { Calibrate } \\
\text { (Climax) }\end{array}$ & \multicolumn{1}{c}{ Rationale } \\
\hline Anisotropy & K1_VANI & $\mathrm{N}$ & $\mathrm{N}$ & Not calibrated in DVRFS \\
ratio & K2CARBVANI & $\mathrm{N}$ & $\mathrm{N}$ & Not calibrated in DVRFS \\
& K3_VOLVANI & $\mathrm{Y}$ & $\mathrm{Y}$ & Significant to flow simulation \\
& K4_VFVANIA & $\mathrm{N}$ & $\mathrm{N}$ & Not calibrated in DVRFS \\
& K4_VFVANIC & $\mathrm{N}$ & $\mathrm{N}$ & Not calibrated in DVRFS \\
& K4_VFVANVL & $\mathrm{Y}$ & $\mathrm{N}$ & Numerical instability \\
\hline
\end{tabular}


THIS PAGE INTENTIONALLY LEFT BLANK 


\section{Appendix D. Calibrated Parameters and Simulated Results of Individual Models}

Tables D-1 through D-5 list values of the calibrated parameters of the 25 models. Parameter ranges and values for the DVRFS model are adopted from Belcher et al. (2004). Tables D-6 through D-10 list mass balance of the 25 models of the last stress period (87). Figures D-1 through D-15 plot contours of hydraulic head simulated in the northern extension area of the 25 models; Figures D-16 through D-20 plot the contour of cell-by-cell flow crossing the front face of MODFLOW cells $\left(\mathrm{Q}_{\mathrm{y}}, \mathrm{m}^{3} /\right.$ day) predicted at the southern boundary (x-z cross section) of northern Yucca Flat in the 25 models. Figures D-21 through D-25 are scatterplots of residuals of heads and head-changes and contours of hydraulic head simulated by the calibrated models. Each of the figures contains contours of the five recharge models associated with a specific HFM model.

Table D-1. Calibrated parameters for the five recharge models under geological model G1 (USGS model).

\begin{tabular}{|c|c|c|c|c|c|c|c|}
\hline \multirow[b]{2}{*}{ Parameters } & \multirow[b]{2}{*}{ Ranges } & \multirow[b]{2}{*}{ DVRFS } & \multicolumn{5}{|c|}{ Geological Model 1 (USGS model) } \\
\hline & & & MME & NIM1 & NIM2 & CMB1 & CMB2 \\
\hline KDP_LCANO & & $2.89 \mathrm{E}-05$ & $1.00 \mathrm{E}-14$ & $1.68 \mathrm{E}-04$ & 2.61E-04 & $1.00 \mathrm{E}-14$ & $1.00 \mathrm{E}-14$ \\
\hline B_SOLTARIO & & $4.45 \mathrm{E}-05$ & $3.66 \mathrm{E}-07$ & $8.12 \mathrm{E}-05$ & $1.11 \mathrm{E}-04$ & $9.03 \mathrm{E}-05$ & $3.37 \mathrm{E}-05$ \\
\hline KDEP_LCA & & $1.00 \mathrm{E}-04$ & $5.65 \mathrm{E}-05$ & $2.10 \mathrm{E}-04$ & $3.18 \mathrm{E}-04$ & $8.58 \mathrm{E}-05$ & $1.04 \mathrm{E}-04$ \\
\hline KDEP_XL & & $6.20 \mathrm{E}-04$ & $3.29 \mathrm{E}-04$ & $1.38 \mathrm{E}-03$ & $1.31 \mathrm{E}-03$ & $6.58 \mathrm{E}-04$ & $5.89 \mathrm{E}-04$ \\
\hline KDP_LCAT1 & & $1.50 \mathrm{E}-03$ & $1.30 \mathrm{E}-03$ & $1.63 \mathrm{E}-03$ & $1.68 \mathrm{E}-03$ & $1.42 \mathrm{E}-03$ & $1.45 \mathrm{E}-03$ \\
\hline KDEP_UCCU & & $1.50 \mathrm{E}-03$ & $2.25 \mathrm{E}-03$ & $2.78 \mathrm{E}-03$ & $2.68 \mathrm{E}-03$ & $3.55 \mathrm{E}-03$ & $3.51 \mathrm{E}-03$ \\
\hline K12223LCCU & $3 \mathrm{E}-8 \sim 5$ & $1.57 \mathrm{E}-03$ & $3.89 \mathrm{E}-03$ & $2.12 \mathrm{E}-04$ & $8.84 \mathrm{E}-05$ & $9.11 \mathrm{E}-04$ & $3.17 \mathrm{E}-03$ \\
\hline K11C_XILCU & $3 \mathrm{E}-8 \sim 5$ & $1.94 \mathrm{E}-03$ & 7.97E-03 & $2.78 \mathrm{E}-03$ & $2.36 \mathrm{E}-03$ & $6.55 \mathrm{E}-03$ & $1.88 \mathrm{E}-04$ \\
\hline K11_ICU & $6 \mathrm{E}-4 \sim 1.4$ & $2.46 \mathrm{E}-03$ & $1.61 \mathrm{E}-02$ & $3.33 \mathrm{E}-03$ & $2.68 \mathrm{E}-03$ & $5.21 \mathrm{E}-03$ & $1.12 \mathrm{E}-02$ \\
\hline KDP_VOL & & $2.48 \mathrm{E}-03$ & $2.62 \mathrm{E}-03$ & $2.90 \mathrm{E}-03$ & $2.93 \mathrm{E}-03$ & $1.91 \mathrm{E}-03$ & $2.10 \mathrm{E}-03$ \\
\hline K1LCCU_XCU & $3 \mathrm{E}-8 \sim 5$ & $4.08 \mathrm{E}-03$ & $2.30 \mathrm{E}-03$ & 8.51E-03 & $5.86 \mathrm{E}-03$ & $1.13 \mathrm{E}-02$ & $8.41 \mathrm{E}-03$ \\
\hline K2422b_LCA & & $6.45 \mathrm{E}-02$ & 7.27E-02 & $6.77 \mathrm{E}-02$ & $8.02 \mathrm{E}-02$ & $5.80 \mathrm{E}-02$ & $6.00 \mathrm{E}-02$ \\
\hline K242G_LCA & & $6.46 \mathrm{E}-02$ & $5.72 \mathrm{E}-03$ & $1.37 \mathrm{E}-01$ & $2.20 \mathrm{E}-01$ & $5.42 \mathrm{E}-02$ & 4.37E-02 \\
\hline K4222S_VSU & $4 \mathrm{E}-5 \sim 6$ & $1.26 \mathrm{E}-01$ & $5.62 \mathrm{E}-03$ & $1.60 \mathrm{E}-01$ & $2.15 \mathrm{E}-01$ & $2.87 \mathrm{E}-02$ & 3.39E-02 \\
\hline $\mathrm{K} 32 \mathrm{CH} 24 \mathrm{LF}$ & $2 \mathrm{E}-3 \sim 4$ & $1.33 \mathrm{E}-01$ & $3.20 \mathrm{E}+00$ & 7.91E-01 & $8.40 \mathrm{E}-01$ & 7.90E-01 & $1.68 \mathrm{E}+00$ \\
\hline K32BR4CH13 & $8 \mathrm{E}-3 \sim 4$ & $1.60 \mathrm{E}-01$ & $1.53 \mathrm{E}-01$ & $1.32 \mathrm{E}-01$ & $1.25 \mathrm{E}-01$ & $4.26 \mathrm{E}-01$ & $6.49 \mathrm{E}-01$ \\
\hline K422LNEVSU & $4 \mathrm{E}-5 \sim 6$ & $1.85 \mathrm{E}-01$ & 3.96E-01 & $3.12 \mathrm{E}-01$ & $3.24 \mathrm{E}-01$ & $2.88 \mathrm{E}-01$ & $2.90 \mathrm{E}-01$ \\
\hline K422LNWVSU & $4 \mathrm{E}-5 \sim 6$ & $1.92 \mathrm{E}-01$ & $2.74 \mathrm{E}-01$ & $7.50 \mathrm{E}-01$ & $8.05 \mathrm{E}-01$ & $4.88 \mathrm{E}-01$ & $5.47 \mathrm{E}-01$ \\
\hline K3211TMVA & 2E-4 20 & $5.66 \mathrm{E}-01$ & $4.10 \mathrm{E}+00$ & $1.01 \mathrm{E}+01$ & $1.27 \mathrm{E}+01$ & $1.09 \mathrm{E}+01$ & $1.62 \mathrm{E}+01$ \\
\hline K4_VF_AQ & $6 \mathrm{E}-5 \sim 130$ & $5.97 \mathrm{E}-01$ & $1.86 \mathrm{E}+00$ & $9.50 \mathrm{E}-01$ & $3.42 \mathrm{E}-01$ & $1.13 \mathrm{E}+00$ & $7.28 \mathrm{E}-01$ \\
\hline RCH_2 & & $7.60 \mathrm{E}-01$ & $1.00 \mathrm{E}+00$ & $5.30 \mathrm{E}-01$ & $3.86 \mathrm{E}-01$ & $1.00 \mathrm{E}+00$ & $1.00 \mathrm{E}+00$ \\
\hline K241LCA_T1 & & $9.87 \mathrm{E}-01$ & $1.06 \mathrm{E}+01$ & $4.67 \mathrm{E}+00$ & $5.61 \mathrm{E}+00$ & $7.42 \mathrm{E}+00$ & $8.80 \mathrm{E}+00$ \\
\hline K3_VOLVANI & & $1.00 \mathrm{E}+00$ & $7.15 \mathrm{E}-02$ & $2.68 \mathrm{E}-01$ & $1.96 \mathrm{E}-01$ & $1.87 \mathrm{E}+01$ & $1.84 \mathrm{E}+01$ \\
\hline RCH_35 & & $1.12 \mathrm{E}+00$ & $1.00 \mathrm{E}+00$ & $5.71 \mathrm{E}-01$ & $6.64 \mathrm{E}-01$ & $1.00 \mathrm{E}+00$ & $1.00 \mathrm{E}+00$ \\
\hline K3215BCU34 & $3 \mathrm{E}-4 \sim 55$ & $1.24 \mathrm{E}+00$ & $1.15 \mathrm{E}+00$ & $5.20 \mathrm{E}-01$ & $8.00 \mathrm{E}-01$ & 8.03E-01 & $1.06 \mathrm{E}+00$ \\
\hline K4_VF_CU & $3 \mathrm{E}-3 \sim 34$ & $1.58 \mathrm{E}+00$ & $2.04 \mathrm{E}+00$ & $9.81 \mathrm{E}-01$ & $1.05 \mathrm{E}+00$ & $1.49 \mathrm{E}+00$ & $1.43 \mathrm{E}+00$ \\
\hline K3BRU123 & $1 \mathrm{E}-2 \sim 4$ & $1.89 \mathrm{E}+00$ & $4.76 \mathrm{E}+01$ & $1.08 \mathrm{E}+01$ & $5.66 \mathrm{E}+00$ & $7.74 \mathrm{E}+00$ & $1.82 \mathrm{E}+01$ \\
\hline K243_LCA & & $2.19 \mathrm{E}+00$ & $2.45 \mathrm{E}+00$ & $4.36 \mathrm{E}+00$ & $5.91 \mathrm{E}+00$ & $1.97 \mathrm{E}+00$ & $2.25 \mathrm{E}+00$ \\
\hline K242A_LCA & & $3.39 \mathrm{E}+00$ & $2.90 \mathrm{E}+00$ & $5.39 \mathrm{E}+00$ & $9.42 \mathrm{E}+00$ & $3.24 \mathrm{E}+00$ & $4.08 \mathrm{E}+00$ \\
\hline K42UP_VSU & $4 \mathrm{E}-5 \sim 6$ & $7.06 \mathrm{E}+00$ & $2.36 \mathrm{E}+01$ & $9.08 \mathrm{E}+00$ & $9.14 \mathrm{E}+00$ & $1.29 \mathrm{E}+01$ & $1.14 \mathrm{E}+01$ \\
\hline K3C_TM & 2E-4 4 & $8.44 \mathrm{E}+00$ & $1.14 \mathrm{E}+01$ & $2.19 \mathrm{E}+00$ & $8.98 \mathrm{E}-01$ & $2.58 \mathrm{E}-01$ & $1.51 \mathrm{E}-01$ \\
\hline K321521_PP & $1 \mathrm{E}-3 \sim 180$ & $1.66 \mathrm{E}+02$ & $5.85 \mathrm{E}+02$ & $1.79 \mathrm{E}+02$ & $1.47 \mathrm{E}+02$ & $1.69 \mathrm{E}+02$ & $2.22 \mathrm{E}+02$ \\
\hline
\end{tabular}


Table D-2. Calibrated parameters for the five recharge models under geological model G2 (UGTA base model).

\begin{tabular}{|c|c|c|c|c|c|c|c|}
\hline \multirow[b]{2}{*}{ Parameters } & \multirow[b]{2}{*}{ Ranges } & \multirow[b]{2}{*}{ DVRFS } & \multicolumn{5}{|c|}{ Geological Model 2 (UGTA base model) } \\
\hline & & & MME & NIM1 & NIM2 & CMB1 & CMB2 \\
\hline KDP_LCANO & & $2.89 \mathrm{E}-05$ & $1.00 \mathrm{E}-14$ & $3.08 \mathrm{E}-04$ & $4.15 \mathrm{E}-04$ & $1.00 \mathrm{E}-14$ & $1.00 \mathrm{E}-14$ \\
\hline B_SOLTARIO & & $4.45 \mathrm{E}-05$ & $1.00 \mathrm{E}-14$ & $8.70 \mathrm{E}-06$ & $2.51 \mathrm{E}-05$ & $1.00 \mathrm{E}-14$ & $1.00 \mathrm{E}-14$ \\
\hline KDEP_LCA & & $1.00 \mathrm{E}-04$ & 4.44E-04 & $3.12 \mathrm{E}-04$ & $3.77 \mathrm{E}-04$ & $3.22 \mathrm{E}-04$ & $3.59 \mathrm{E}-04$ \\
\hline KDEP_XL & & $6.20 \mathrm{E}-04$ & $1.11 \mathrm{E}-04$ & 4.94E-04 & $9.30 \mathrm{E}-04$ & $3.40 \mathrm{E}-04$ & 4.31E-04 \\
\hline KDP_LCAT1 & & $1.50 \mathrm{E}-03$ & $1.13 \mathrm{E}-03$ & $1.45 \mathrm{E}-03$ & $1.66 \mathrm{E}-03$ & $1.23 \mathrm{E}-03$ & $1.30 \mathrm{E}-03$ \\
\hline KDEP_UCCU & & $1.50 \mathrm{E}-03$ & $1.62 \mathrm{E}-03$ & $1.35 \mathrm{E}-03$ & 2.91E-03 & $2.53 \mathrm{E}-03$ & $2.54 \mathrm{E}-03$ \\
\hline K12223LCCU & $3 \mathrm{E}-8 \sim 5$ & $1.57 \mathrm{E}-03$ & $9.45 \mathrm{E}-03$ & $2.69 \mathrm{E}-04$ & $1.73 \mathrm{E}-04$ & $2.74 \mathrm{E}-03$ & $3.43 \mathrm{E}-03$ \\
\hline K11C_XILCU & $3 \mathrm{E}-8 \sim 5$ & $1.94 \mathrm{E}-03$ & $1.92 \mathrm{E}-03$ & $1.30 \mathrm{E}-04$ & $1.81 \mathrm{E}-04$ & $8.14 \mathrm{E}-04$ & $1.47 \mathrm{E}-04$ \\
\hline K11_ICU & $6 \mathrm{E}-4 \sim 1.4$ & $2.46 \mathrm{E}-03$ & $2.48 \mathrm{E}-02$ & 4.70E-03 & $4.23 \mathrm{E}-03$ & $1.26 \mathrm{E}-02$ & $1.29 \mathrm{E}-02$ \\
\hline KDP_VOL & & $2.48 \mathrm{E}-03$ & $2.51 \mathrm{E}-03$ & $2.98 \mathrm{E}-03$ & $3.05 \mathrm{E}-03$ & $2.83 \mathrm{E}-03$ & $2.70 \mathrm{E}-03$ \\
\hline K1LCCU_XCU & $3 \mathrm{E}-8 \sim 5$ & $4.08 \mathrm{E}-03$ & $2.63 \mathrm{E}-04$ & $5.23 \mathrm{E}-04$ & $1.54 \mathrm{E}-03$ & $5.10 \mathrm{E}-04$ & 5.99E-04 \\
\hline K2422b_LCA & & $6.45 \mathrm{E}-02$ & $1.47 \mathrm{E}-01$ & $3.88 \mathrm{E}-02$ & $5.37 \mathrm{E}-02$ & $6.06 \mathrm{E}-02$ & 7.33E-02 \\
\hline K242G_LCA & & $6.46 \mathrm{E}-02$ & $1.37 \mathrm{E}-03$ & 4.42E-04 & $9.87 \mathrm{E}-05$ & $4.76 \mathrm{E}-04$ & $5.22 \mathrm{E}-04$ \\
\hline K4222S_VSU & $4 \mathrm{E}-5 \sim 6$ & $1.26 \mathrm{E}-01$ & $3.56 \mathrm{E}-03$ & $7.30 \mathrm{E}-02$ & $8.36 \mathrm{E}-02$ & $1.23 \mathrm{E}-02$ & $1.35 \mathrm{E}-02$ \\
\hline $\mathrm{K} 32 \mathrm{CH} 24 \mathrm{LF}$ & $2 \mathrm{E}-3 \sim 4$ & $1.33 \mathrm{E}-01$ & $2.12 \mathrm{E}+00$ & $8.74 \mathrm{E}-01$ & $1.25 \mathrm{E}+00$ & $2.46 \mathrm{E}+00$ & $2.18 \mathrm{E}+00$ \\
\hline K32BR4CH13 & $8 \mathrm{E}-3 \sim 4$ & $1.60 \mathrm{E}-01$ & $7.00 \mathrm{E}-02$ & $1.06 \mathrm{E}-01$ & $1.29 \mathrm{E}-01$ & $2.87 \mathrm{E}-01$ & $2.05 \mathrm{E}-01$ \\
\hline K422LNEVSU & $4 \mathrm{E}-5 \sim 6$ & $1.85 \mathrm{E}-01$ & $3.14 \mathrm{E}-01$ & $4.51 \mathrm{E}-01$ & $4.98 \mathrm{E}-01$ & $3.88 \mathrm{E}-01$ & $3.73 \mathrm{E}-01$ \\
\hline K422LNWVSU & $4 \mathrm{E}-5 \sim 6$ & $1.92 \mathrm{E}-01$ & $2.07 \mathrm{E}-01$ & $5.76 \mathrm{E}-01$ & $5.98 \mathrm{E}-01$ & $2.74 \mathrm{E}-01$ & $2.83 \mathrm{E}-01$ \\
\hline K3211TMVA & 2E-4 20 & $5.66 \mathrm{E}-01$ & $6.25 \mathrm{E}+00$ & $8.22 \mathrm{E}+00$ & $8.28 \mathrm{E}+00$ & $7.46 \mathrm{E}+00$ & $7.75 \mathrm{E}+00$ \\
\hline K4_VF_AQ & $6 \mathrm{E}-5 \sim 130$ & $5.97 \mathrm{E}-01$ & $3.32 \mathrm{E}+00$ & $1.46 \mathrm{E}+00$ & $8.31 \mathrm{E}-01$ & $1.61 \mathrm{E}+00$ & $1.60 \mathrm{E}+00$ \\
\hline RCH_2 & & 7.60E-01 & $1.00 \mathrm{E}+00$ & $2.56 \mathrm{E}-01$ & $2.36 \mathrm{E}-01$ & $1.00 \mathrm{E}+00$ & $1.00 \mathrm{E}+00$ \\
\hline K241LCA_T1 & & 9.87E-01 & $1.14 \mathrm{E}+01$ & $2.32 \mathrm{E}-01$ & $2.72 \mathrm{E}+00$ & $8.34 \mathrm{E}+00$ & $1.04 \mathrm{E}+01$ \\
\hline K3_VOLVANI & & $1.00 \mathrm{E}+00$ & $3.21 \mathrm{E}-02$ & $1.90 \mathrm{E}-01$ & $2.23 \mathrm{E}-01$ & 7.09E-02 & $1.08 \mathrm{E}-01$ \\
\hline $\mathrm{RCH} \_35$ & & $1.12 \mathrm{E}+00$ & $1.00 \mathrm{E}+00$ & $7.00 \mathrm{E}-01$ & $6.04 \mathrm{E}-01$ & $1.00 \mathrm{E}+00$ & $1.00 \mathrm{E}+00$ \\
\hline K3215BCU34 & $3 \mathrm{E}-4 \sim 55$ & $1.24 \mathrm{E}+00$ & $1.11 \mathrm{E}+00$ & 7.74E-01 & $6.54 \mathrm{E}-01$ & $8.68 \mathrm{E}-01$ & $9.39 \mathrm{E}-01$ \\
\hline K4_VF_CU & $3 E-3 \sim 34$ & $1.58 \mathrm{E}+00$ & $1.04 \mathrm{E}+00$ & $3.86 \mathrm{E}-01$ & $5.53 \mathrm{E}-01$ & $1.43 \mathrm{E}+00$ & $1.43 \mathrm{E}+00$ \\
\hline K3BRU123 & $1 \mathrm{E}-2 \sim 4$ & $1.89 \mathrm{E}+00$ & $3.98 \mathrm{E}+01$ & $9.42 \mathrm{E}+01$ & $6.42 \mathrm{E}+01$ & $1.13 \mathrm{E}+02$ & $9.48 \mathrm{E}+01$ \\
\hline K243_LCA & & $2.19 \mathrm{E}+00$ & $4.61 \mathrm{E}+00$ & $2.04 \mathrm{E}+01$ & $2.44 \mathrm{E}+01$ & $3.98 \mathrm{E}+00$ & $3.73 \mathrm{E}+00$ \\
\hline K242A_LCA & & $3.39 \mathrm{E}+00$ & $2.07 \mathrm{E}+01$ & $9.08 \mathrm{E}+00$ & $1.47 \mathrm{E}+01$ & $1.26 \mathrm{E}+01$ & $1.54 \mathrm{E}+01$ \\
\hline K42UP_VSU & $4 \mathrm{E}-5 \sim 6$ & $7.06 \mathrm{E}+00$ & $1.72 \mathrm{E}+01$ & $8.09 \mathrm{E}+00$ & $8.90 \mathrm{E}+00$ & $9.56 \mathrm{E}+00$ & $9.13 \mathrm{E}+00$ \\
\hline K3C_TM & 2E-4 4 & $8.44 \mathrm{E}+00$ & $1.16 \mathrm{E}+01$ & $1.88 \mathrm{E}+00$ & $9.73 \mathrm{E}-01$ & $9.74 \mathrm{E}+00$ & $8.17 \mathrm{E}+00$ \\
\hline K321521_PP & $1 \mathrm{E}-3 \sim 180$ & $1.66 \mathrm{E}+02$ & $4.94 \mathrm{E}+02$ & $5.19 \mathrm{E}+02$ & $3.74 \mathrm{E}+02$ & $1.01 \mathrm{E}+03$ & $8.34 \mathrm{E}+02$ \\
\hline
\end{tabular}


Table D-3. Calibrated parameters for the five recharge models under geological model G3 (CP thrust alternative model).

\begin{tabular}{|c|c|c|c|c|c|c|c|}
\hline \multirow[b]{2}{*}{ Parameters } & \multirow[b]{2}{*}{ Ranges } & \multirow[b]{2}{*}{ DVRFS } & \multicolumn{5}{|c|}{ Geological Model 3 (CP thrust alternative model) } \\
\hline & & & MME & NIM1 & NIM2 & CMB1 & CMB2 \\
\hline KDP_LCANO & & $2.89 \mathrm{E}-05$ & $1.00 \mathrm{E}-14$ & $3.54 \mathrm{E}-04$ & $4.31 \mathrm{E}-04$ & $1.00 \mathrm{E}-14$ & $1.00 \mathrm{E}-14$ \\
\hline B_SOLTARIO & & $4.45 \mathrm{E}-05$ & $1.00 \mathrm{E}-14$ & 2.04E-05 & $3.35 \mathrm{E}-05$ & $1.06 \mathrm{E}-06$ & $1.00 \mathrm{E}-14$ \\
\hline KDEP_LCA & & $1.00 \mathrm{E}-04$ & 4.69E-04 & $2.97 \mathrm{E}-04$ & $4.18 \mathrm{E}-04$ & 2.89E-04 & $3.23 \mathrm{E}-04$ \\
\hline KDEP_XL & & $6.20 \mathrm{E}-04$ & $1.47 \mathrm{E}-04$ & $9.15 \mathrm{E}-04$ & $1.67 \mathrm{E}-03$ & $3.53 \mathrm{E}-04$ & $3.95 \mathrm{E}-04$ \\
\hline KDP_LCAT1 & & $1.50 \mathrm{E}-03$ & $1.17 \mathrm{E}-03$ & $1.60 \mathrm{E}-03$ & $1.74 \mathrm{E}-03$ & $1.25 \mathrm{E}-03$ & $1.23 \mathrm{E}-03$ \\
\hline KDEP_UCCU & & $1.50 \mathrm{E}-03$ & $1.65 \mathrm{E}-03$ & $2.06 \mathrm{E}-03$ & $2.97 \mathrm{E}-03$ & $2.76 \mathrm{E}-03$ & $2.72 \mathrm{E}-03$ \\
\hline K12223LCCU & $3 \mathrm{E}-8 \sim 5$ & $1.57 \mathrm{E}-03$ & $1.12 \mathrm{E}-02$ & $1.98 \mathrm{E}-04$ & $9.41 \mathrm{E}-05$ & $2.38 \mathrm{E}-03$ & $3.02 \mathrm{E}-03$ \\
\hline K11C_XILCU & $3 \mathrm{E}-8 \sim 5$ & $1.94 \mathrm{E}-03$ & $2.13 \mathrm{E}-03$ & $1.54 \mathrm{E}-04$ & $2.45 \mathrm{E}-04$ & $1.36 \mathrm{E}-03$ & $1.39 \mathrm{E}-04$ \\
\hline K11_ICU & $6 \mathrm{E}-4 \sim 1.4$ & $2.46 \mathrm{E}-03$ & $2.25 \mathrm{E}-02$ & $4.48 \mathrm{E}-03$ & $4.20 \mathrm{E}-03$ & $1.03 \mathrm{E}-02$ & $1.36 \mathrm{E}-02$ \\
\hline KDP_VOL & & $2.48 \mathrm{E}-03$ & $2.50 \mathrm{E}-03$ & $3.00 \mathrm{E}-03$ & $3.39 \mathrm{E}-03$ & $2.30 \mathrm{E}-03$ & $2.68 \mathrm{E}-03$ \\
\hline K1LCCU_XCU & $3 \mathrm{E}-8 \sim 5$ & 4.08E-03 & $3.05 \mathrm{E}-04$ & $1.38 \mathrm{E}-03$ & $2.23 \mathrm{E}-02$ & $1.16 \mathrm{E}-03$ & $5.23 \mathrm{E}-04$ \\
\hline K2422b_LCA & & $6.45 \mathrm{E}-02$ & $1.91 \mathrm{E}-01$ & 4.69E-02 & 7.60E-02 & $6.10 \mathrm{E}-02$ & $7.38 \mathrm{E}-02$ \\
\hline K242G_LCA & & $6.46 \mathrm{E}-02$ & $4.06 \mathrm{E}-02$ & $1.99 \mathrm{E}-04$ & $7.49 \mathrm{E}-03$ & $9.98 \mathrm{E}-02$ & $3.17 \mathrm{E}-02$ \\
\hline K4222S_VSU & $4 \mathrm{E}-5 \sim 6$ & $1.26 \mathrm{E}-01$ & $3.49 \mathrm{E}-03$ & $7.95 \mathrm{E}-02$ & $1.19 \mathrm{E}-01$ & $1.99 \mathrm{E}-02$ & $2.68 \mathrm{E}-02$ \\
\hline $\mathrm{K} 32 \mathrm{CH} 24 \mathrm{LF}$ & $2 \mathrm{E}-3 \sim 4$ & $1.33 \mathrm{E}-01$ & $2.12 \mathrm{E}+00$ & $1.26 \mathrm{E}+00$ & $5.74 \mathrm{E}+00$ & $2.62 \mathrm{E}+00$ & $2.12 \mathrm{E}+00$ \\
\hline K32BR4CH13 & $8 \mathrm{E}-3 \sim 4$ & $1.60 \mathrm{E}-01$ & $1.27 \mathrm{E}-01$ & $1.15 \mathrm{E}-01$ & $6.18 \mathrm{E}-01$ & $6.80 \mathrm{E}-01$ & $4.75 \mathrm{E}-01$ \\
\hline K422LNEVSU & $4 \mathrm{E}-5 \sim 6$ & $1.85 \mathrm{E}-01$ & $3.12 \mathrm{E}-01$ & 4.06E-01 & 4.33E-01 & $3.52 \mathrm{E}-01$ & 3.64E-01 \\
\hline K422LNWVSU & $4 \mathrm{E}-5 \sim 6$ & $1.92 \mathrm{E}-01$ & $3.20 \mathrm{E}-01$ & $5.99 \mathrm{E}-01$ & $6.97 \mathrm{E}-01$ & $5.34 \mathrm{E}-01$ & $4.45 \mathrm{E}-01$ \\
\hline K3211TMVA & 2E-4 20 & $5.66 \mathrm{E}-01$ & $8.19 \mathrm{E}+00$ & $8.39 \mathrm{E}+00$ & $1.48 \mathrm{E}+01$ & $1.67 \mathrm{E}+01$ & $1.19 \mathrm{E}+01$ \\
\hline K4_VF_AQ & $6 \mathrm{E}-5 \sim 130$ & 5.97E-01 & $3.17 \mathrm{E}+00$ & $9.47 \mathrm{E}-01$ & $1.52 \mathrm{E}-01$ & $1.57 \mathrm{E}+00$ & $1.75 \mathrm{E}+00$ \\
\hline RCH_2 & & 7.60E-01 & $1.00 \mathrm{E}+00$ & $2.75 \mathrm{E}-01$ & $2.27 \mathrm{E}-01$ & $1.00 \mathrm{E}+00$ & $1.00 \mathrm{E}+00$ \\
\hline K241LCA_T1 & & $9.87 \mathrm{E}-01$ & $1.14 \mathrm{E}+01$ & $1.69 \mathrm{E}+00$ & $3.22 \mathrm{E}+00$ & $8.23 \mathrm{E}+00$ & $6.66 \mathrm{E}+00$ \\
\hline K3_VOLVANI & & $1.00 \mathrm{E}+00$ & $6.57 \mathrm{E}-02$ & 2.39E-01 & $9.42 \mathrm{E}-02$ & $6.26 \mathrm{E}+00$ & $3.83 \mathrm{E}-01$ \\
\hline $\mathrm{RCH} \_35$ & & $1.12 \mathrm{E}+00$ & $1.00 \mathrm{E}+00$ & $5.04 \mathrm{E}-01$ & $3.72 \mathrm{E}-01$ & $1.00 \mathrm{E}+00$ & $1.00 \mathrm{E}+00$ \\
\hline K3215BCU34 & $3 \mathrm{E}-4 \sim 55$ & $1.24 \mathrm{E}+00$ & $8.49 \mathrm{E}-01$ & 7.77E-01 & $7.53 \mathrm{E}-01$ & $8.46 \mathrm{E}-01$ & $9.84 \mathrm{E}-01$ \\
\hline K4_VF_CU & $3 E-3 \sim 34$ & $1.58 \mathrm{E}+00$ & $7.66 \mathrm{E}-01$ & 5.91E-01 & $7.16 \mathrm{E}-01$ & $1.27 \mathrm{E}+00$ & $1.59 \mathrm{E}+00$ \\
\hline K3BRU123 & $1 \mathrm{E}-2 \sim 4$ & $1.89 \mathrm{E}+00$ & $3.70 \mathrm{E}+01$ & $9.30 \mathrm{E}+01$ & $1.09 \mathrm{E}+02$ & $2.14 \mathrm{E}+01$ & $6.69 \mathrm{E}+01$ \\
\hline K243_LCA & & $2.19 \mathrm{E}+00$ & $4.50 \mathrm{E}+00$ & $1.65 \mathrm{E}+01$ & $1.53 \mathrm{E}+01$ & $4.06 \mathrm{E}+00$ & $3.55 \mathrm{E}+00$ \\
\hline K242A_LCA & & $3.39 \mathrm{E}+00$ & $1.58 \mathrm{E}+01$ & $9.04 \mathrm{E}+00$ & $1.73 \mathrm{E}+01$ & $8.22 \mathrm{E}+00$ & $1.05 \mathrm{E}+01$ \\
\hline K42UP_VSU & $4 \mathrm{E}-5 \sim 6$ & $7.06 \mathrm{E}+00$ & $1.80 \mathrm{E}+01$ & $8.27 \mathrm{E}+00$ & $9.46 \mathrm{E}+00$ & $1.16 \mathrm{E}+01$ & $1.02 \mathrm{E}+01$ \\
\hline K3C_TM & 2E-4 4 & $8.44 \mathrm{E}+00$ & $8.41 \mathrm{E}+00$ & $1.61 \mathrm{E}+00$ & $9.37 \mathrm{E}-02$ & $9.64 \mathrm{E}-02$ & $5.96 \mathrm{E}+00$ \\
\hline K321521_PP & $1 \mathrm{E}-3 \sim 180$ & $1.66 \mathrm{E}+02$ & $4.46 \mathrm{E}+02$ & $5.07 \mathrm{E}+02$ & $3.07 \mathrm{E}+02$ & $3.19 \mathrm{E}+02$ & $6.83 \mathrm{E}+02$ \\
\hline
\end{tabular}


Table D-4. Calibrated parameters for the five recharge models under geological model G4 (hydrologic barrier alternative model).

\begin{tabular}{|c|c|c|c|c|c|c|c|}
\hline \multirow[b]{2}{*}{ Parameters } & \multirow[b]{2}{*}{ Ranges } & \multirow[b]{2}{*}{ DVRFS } & \multicolumn{5}{|c|}{ Geological Model 4 (hydrologic barrier alternative model) } \\
\hline & & & MME & NIM1 & NIM2 & CMB1 & CMB2 \\
\hline KDP_LCANO & & $2.89 \mathrm{E}-05$ & $1.00 \mathrm{E}-14$ & $1.14 \mathrm{E}-04$ & $1.88 \mathrm{E}-04$ & $1.00 \mathrm{E}-14$ & $1.00 \mathrm{E}-14$ \\
\hline B_SOLTARIO & & 4.45E-05 & $1.00 \mathrm{E}-14$ & $9.57 \mathrm{E}-05$ & $9.28 \mathrm{E}-05$ & $8.67 \mathrm{E}-05$ & $1.95 \mathrm{E}-05$ \\
\hline KDEP_LCA & & $1.00 \mathrm{E}-04$ & 5.67E-05 & $1.90 \mathrm{E}-04$ & $2.78 \mathrm{E}-04$ & $1.34 \mathrm{E}-04$ & $1.62 \mathrm{E}-04$ \\
\hline KDEP_XL & & $6.20 \mathrm{E}-04$ & $3.12 \mathrm{E}-04$ & $1.77 \mathrm{E}-03$ & $1.28 \mathrm{E}-03$ & 5.92E-04 & 4.74E-04 \\
\hline KDP_LCAT1 & & $1.50 \mathrm{E}-03$ & $1.22 \mathrm{E}-03$ & $1.68 \mathrm{E}-03$ & $1.58 \mathrm{E}-03$ & $1.36 \mathrm{E}-03$ & $1.36 \mathrm{E}-03$ \\
\hline KDEP_UCCU & & $1.50 \mathrm{E}-03$ & $2.10 \mathrm{E}-03$ & $2.91 \mathrm{E}-03$ & $3.19 \mathrm{E}-03$ & $3.03 \mathrm{E}-03$ & $3.07 \mathrm{E}-03$ \\
\hline K12223LCCU & $3 \mathrm{E}-8 \sim 5$ & $1.57 \mathrm{E}-03$ & 4.13E-03 & $3.05 \mathrm{E}-04$ & $2.00 \mathrm{E}-04$ & 8.84E-04 & $3.27 \mathrm{E}-03$ \\
\hline K11C_XILCU & $3 \mathrm{E}-8 \sim 5$ & $1.94 \mathrm{E}-03$ & $6.80 \mathrm{E}-03$ & $3.30 \mathrm{E}-03$ & $2.36 \mathrm{E}-03$ & 7.39E-03 & $1.61 \mathrm{E}-04$ \\
\hline K11_ICU & $6 \mathrm{E}-4 \sim 1.4$ & $2.46 \mathrm{E}-03$ & $1.93 \mathrm{E}-02$ & $3.73 \mathrm{E}-03$ & $3.93 \mathrm{E}-03$ & $5.18 \mathrm{E}-03$ & $1.13 \mathrm{E}-02$ \\
\hline KDP_VOL & & $2.48 \mathrm{E}-03$ & $2.62 \mathrm{E}-03$ & $2.95 \mathrm{E}-03$ & $2.83 \mathrm{E}-03$ & 2.04E-03 & $2.70 \mathrm{E}-03$ \\
\hline K1LCCU_XCU & $3 \mathrm{E}-8 \sim 5$ & 4.08E-03 & $1.30 \mathrm{E}-03$ & $2.00 \mathrm{E}-02$ & $5.28 \mathrm{E}-03$ & $1.45 \mathrm{E}-02$ & $9.04 \mathrm{E}-03$ \\
\hline K2422b_LCA & & $6.45 \mathrm{E}-02$ & $6.07 \mathrm{E}-02$ & $6.61 \mathrm{E}-02$ & 7.87E-02 & $6.47 \mathrm{E}-02$ & $6.43 \mathrm{E}-02$ \\
\hline K242G_LCA & & $6.46 \mathrm{E}-02$ & $1.07 \mathrm{E}-02$ & $2.21 \mathrm{E}-01$ & $5.45 \mathrm{E}-01$ & $1.44 \mathrm{E}-01$ & $1.80 \mathrm{E}-01$ \\
\hline K4222S_VSU & $4 \mathrm{E}-5 \sim 6$ & $1.26 \mathrm{E}-01$ & $8.59 \mathrm{E}-03$ & 2.23E-01 & $1.90 \mathrm{E}-01$ & $3.20 \mathrm{E}-02$ & $3.36 \mathrm{E}-02$ \\
\hline $\mathrm{K} 32 \mathrm{CH} 24 \mathrm{LF}$ & $2 \mathrm{E}-3 \sim 4$ & $1.33 \mathrm{E}-01$ & $3.34 \mathrm{E}+00$ & 8.57E-01 & $1.05 \mathrm{E}+00$ & $1.01 \mathrm{E}+00$ & $4.26 \mathrm{E}+00$ \\
\hline K32BR4CH13 & $8 \mathrm{E}-3 \sim 4$ & $1.60 \mathrm{E}-01$ & $1.59 \mathrm{E}-01$ & $1.64 \mathrm{E}-01$ & $1.09 \mathrm{E}-01$ & 5.09E-01 & $1.25 \mathrm{E}+00$ \\
\hline K422LNEVSU & $4 \mathrm{E}-5 \sim 6$ & $1.85 \mathrm{E}-01$ & 2.91E-01 & $3.00 \mathrm{E}-01$ & 2.91E-01 & $2.86 \mathrm{E}-01$ & $2.76 \mathrm{E}-01$ \\
\hline K422LNWVSU & $4 \mathrm{E}-5 \sim 6$ & $1.92 \mathrm{E}-01$ & $2.95 \mathrm{E}-01$ & $8.26 \mathrm{E}-01$ & 8.27E-01 & 5.32E-01 & $6.45 \mathrm{E}-01$ \\
\hline K3211TMVA & 2E-4 20 & $5.66 \mathrm{E}-01$ & $4.40 \mathrm{E}+00$ & $9.45 \mathrm{E}+00$ & $1.24 \mathrm{E}+01$ & $1.33 \mathrm{E}+01$ & $2.92 \mathrm{E}+01$ \\
\hline K4_VF_AQ & $6 \mathrm{E}-5 \sim 130$ & $5.97 \mathrm{E}-01$ & $4.22 \mathrm{E}+00$ & $7.04 \mathrm{E}-01$ & $3.44 \mathrm{E}-01$ & $1.36 \mathrm{E}+00$ & $8.50 \mathrm{E}-01$ \\
\hline RCH_2 & & $7.60 \mathrm{E}-01$ & $1.00 \mathrm{E}+00$ & $6.44 \mathrm{E}-01$ & $4.80 \mathrm{E}-01$ & $1.00 \mathrm{E}+00$ & $1.00 \mathrm{E}+00$ \\
\hline K241LCA_T1 & & 9.87E-01 & $7.63 \mathrm{E}+00$ & $7.45 \mathrm{E}+00$ & $4.47 \mathrm{E}+00$ & $1.03 \mathrm{E}+01$ & $8.22 \mathrm{E}+00$ \\
\hline K3_VOLVANI & & $1.00 \mathrm{E}+00$ & 7.14E-02 & 3.33E-01 & $2.87 \mathrm{E}-01$ & $1.32 \mathrm{E}+01$ & $2.10 \mathrm{E}+00$ \\
\hline RCH_35 & & $1.12 \mathrm{E}+00$ & $1.00 \mathrm{E}+00$ & 4.42E-01 & 7.46E-01 & $1.00 \mathrm{E}+00$ & $1.00 \mathrm{E}+00$ \\
\hline K3215BCU34 & $3 \mathrm{E}-4 \sim 55$ & $1.24 \mathrm{E}+00$ & $1.30 \mathrm{E}+00$ & $7.16 \mathrm{E}-01$ & $7.56 \mathrm{E}-01$ & $8.34 \mathrm{E}-01$ & $1.13 \mathrm{E}+00$ \\
\hline K4_VF_CU & $3 E-3 \sim 34$ & $1.58 \mathrm{E}+00$ & $2.38 \mathrm{E}+00$ & $1.25 \mathrm{E}+00$ & $1.39 \mathrm{E}+00$ & $1.71 \mathrm{E}+00$ & $1.39 \mathrm{E}+00$ \\
\hline K3BRU123 & $1 \mathrm{E}-2 \sim 4$ & $1.89 \mathrm{E}+00$ & $5.27 \mathrm{E}+01$ & $9.06 \mathrm{E}+00$ & $1.93 \mathrm{E}+01$ & $1.06 \mathrm{E}+01$ & $7.79 \mathrm{E}+01$ \\
\hline K243_LCA & & $2.19 \mathrm{E}+00$ & $2.81 \mathrm{E}+00$ & $2.74 \mathrm{E}+00$ & $4.07 \mathrm{E}+00$ & $2.15 \mathrm{E}+00$ & $2.88 \mathrm{E}+00$ \\
\hline K242A_LCA & & $3.39 \mathrm{E}+00$ & $3.06 \mathrm{E}+00$ & $3.36 \mathrm{E}+00$ & $4.83 \mathrm{E}+00$ & $8.47 \mathrm{E}+00$ & $7.23 \mathrm{E}+00$ \\
\hline K42UP_VSU & $4 \mathrm{E}-5 \sim 6$ & $7.06 \mathrm{E}+00$ & $2.18 \mathrm{E}+01$ & $9.63 \mathrm{E}+00$ & $8.51 \mathrm{E}+00$ & $1.14 \mathrm{E}+01$ & $9.53 \mathrm{E}+00$ \\
\hline K3C_TM & 2E-4 4 & $8.44 \mathrm{E}+00$ & $1.31 \mathrm{E}+01$ & $4.51 \mathrm{E}+00$ & $2.47 \mathrm{E}+00$ & $1.81 \mathrm{E}-01$ & $4.21 \mathrm{E}-02$ \\
\hline K321521_PP & $1 \mathrm{E}-3 \sim 180$ & $1.66 \mathrm{E}+02$ & $6.38 \mathrm{E}+02$ & $2.29 \mathrm{E}+02$ & $2.32 \mathrm{E}+02$ & $2.02 \mathrm{E}+02$ & $5.39 \mathrm{E}+02$ \\
\hline
\end{tabular}


Table D-5. Calibrated parameters for the five recharge models under geological model G5 (combination of $\mathrm{CP}$ thrust and hydrologic barrier alternative models).

\begin{tabular}{|c|c|c|c|c|c|c|c|}
\hline \multirow[b]{2}{*}{ Parameters } & \multirow[b]{2}{*}{ Ranges } & \multirow[b]{2}{*}{ DVRFS } & \multicolumn{5}{|c|}{$\begin{array}{c}\text { Geological Model } 5 \text { (CP thrust and hydrologic barrier } \\
\text { alternative models) }\end{array}$} \\
\hline & & & MME & NIM1 & NIM2 & CMB1 & CMB2 \\
\hline KDP_LCANO & & $2.89 \mathrm{E}-05$ & $1.00 \mathrm{E}-14$ & $7.86 \mathrm{E}-05$ & $3.38 \mathrm{E}-04$ & $1.00 \mathrm{E}-14$ & $1.00 \mathrm{E}-14$ \\
\hline B_SOLTARIO & & $4.45 \mathrm{E}-05$ & $6.07 \mathrm{E}-08$ & 8.70E-05 & 8.89E-05 & $6.10 \mathrm{E}-05$ & $2.40 \mathrm{E}-05$ \\
\hline KDEP_LCA & & $1.00 \mathrm{E}-04$ & $9.29 \mathrm{E}-05$ & $1.45 \mathrm{E}-04$ & 2.94E-04 & $9.48 \mathrm{E}-05$ & $1.40 \mathrm{E}-04$ \\
\hline KDEP_XL & & $6.20 \mathrm{E}-04$ & $2.96 \mathrm{E}-04$ & $1.31 \mathrm{E}-03$ & $8.65 \mathrm{E}-04$ & $6.14 \mathrm{E}-04$ & $5.29 \mathrm{E}-04$ \\
\hline KDP_LCAT1 & & $1.50 \mathrm{E}-03$ & $1.24 \mathrm{E}-03$ & $1.70 \mathrm{E}-03$ & $1.50 \mathrm{E}-03$ & $1.44 \mathrm{E}-03$ & $1.41 \mathrm{E}-03$ \\
\hline KDEP_UCCU & & $1.50 \mathrm{E}-03$ & $1.98 \mathrm{E}-03$ & $2.30 \mathrm{E}-03$ & $2.44 \mathrm{E}-03$ & $3.21 \mathrm{E}-03$ & $3.04 \mathrm{E}-03$ \\
\hline K12223LCCU & $3 \mathrm{E}-8 \sim 5$ & $1.57 \mathrm{E}-03$ & 4.38E-03 & $6.11 \mathrm{E}-04$ & $3.45 \mathrm{E}-04$ & $1.39 \mathrm{E}-03$ & $3.33 \mathrm{E}-03$ \\
\hline K11C_XILCU & $3 \mathrm{E}-8 \sim 5$ & $1.94 \mathrm{E}-03$ & $7.42 \mathrm{E}-03$ & $2.72 \mathrm{E}-03$ & 8.39E-05 & $5.72 \mathrm{E}-03$ & $1.76 \mathrm{E}-04$ \\
\hline K11_ICU & $6 \mathrm{E}-4 \sim 1.4$ & $2.46 \mathrm{E}-03$ & $1.66 \mathrm{E}-02$ & $3.94 \mathrm{E}-03$ & $7.08 \mathrm{E}-03$ & 4.99E-03 & $1.09 \mathrm{E}-02$ \\
\hline KDP_VOL & & $2.48 \mathrm{E}-03$ & $2.51 \mathrm{E}-03$ & $2.91 \mathrm{E}-03$ & $2.72 \mathrm{E}-03$ & $2.37 \mathrm{E}-03$ & $2.62 \mathrm{E}-03$ \\
\hline K1LCCU_XCU & $3 \mathrm{E}-8 \sim 5$ & $4.08 \mathrm{E}-03$ & $1.16 \mathrm{E}-03$ & $1.62 \mathrm{E}-02$ & $1.52 \mathrm{E}-02$ & $4.88 \mathrm{E}-03$ & $8.43 \mathrm{E}-03$ \\
\hline K2422b_LCA & & $6.45 \mathrm{E}-02$ & $6.55 \mathrm{E}-02$ & $6.04 \mathrm{E}-02$ & $6.68 \mathrm{E}-02$ & $5.06 \mathrm{E}-02$ & $5.95 \mathrm{E}-02$ \\
\hline K242G_LCA & & $6.46 \mathrm{E}-02$ & $1.30 \mathrm{E}-02$ & $1.18 \mathrm{E}-01$ & 4.14E-01 & $1.36 \mathrm{E}-01$ & $9.74 \mathrm{E}-02$ \\
\hline K4222S_VSU & $4 \mathrm{E}-5 \sim 6$ & $1.26 \mathrm{E}-01$ & $4.83 \mathrm{E}-03$ & $1.95 \mathrm{E}-01$ & $2.41 \mathrm{E}-01$ & $2.82 \mathrm{E}-02$ & $3.35 \mathrm{E}-02$ \\
\hline $\mathrm{K} 32 \mathrm{CH} 24 \mathrm{LF}$ & $2 \mathrm{E}-3 \sim 4$ & $1.33 \mathrm{E}-01$ & $2.48 \mathrm{E}+00$ & $6.59 \mathrm{E}-01$ & $1.21 \mathrm{E}+00$ & $1.35 \mathrm{E}+00$ & $4.17 \mathrm{E}+00$ \\
\hline K32BR4CH13 & $8 \mathrm{E}-3 \sim 4$ & $1.60 \mathrm{E}-01$ & $9.84 \mathrm{E}-02$ & $1.75 \mathrm{E}-01$ & $5.46 \mathrm{E}-02$ & $6.36 \mathrm{E}-01$ & $1.21 \mathrm{E}+00$ \\
\hline K422LNEVSU & $4 \mathrm{E}-5 \sim 6$ & $1.85 \mathrm{E}-01$ & 2.84E-01 & $3.09 \mathrm{E}-01$ & $3.36 \mathrm{E}-01$ & $2.43 \mathrm{E}-01$ & $2.56 \mathrm{E}-01$ \\
\hline K422LNWVSU & $4 \mathrm{E}-5 \sim 6$ & $1.92 \mathrm{E}-01$ & $3.05 \mathrm{E}-01$ & $6.91 \mathrm{E}-01$ & $9.59 \mathrm{E}-01$ & $5.54 \mathrm{E}-01$ & $6.19 \mathrm{E}-01$ \\
\hline K3211TMVA & 2E-4 20 & $5.66 \mathrm{E}-01$ & $4.92 \mathrm{E}+00$ & $4.73 E+00$ & $1.96 \mathrm{E}+01$ & $1.73 \mathrm{E}+01$ & $2.74 \mathrm{E}+01$ \\
\hline K4_VF_AQ & $6 \mathrm{E}-5 \sim 130$ & $5.97 \mathrm{E}-01$ & $4.59 \mathrm{E}+00$ & $1.44 \mathrm{E}+00$ & $1.23 \mathrm{E}-01$ & $1.72 \mathrm{E}+00$ & $8.63 \mathrm{E}-01$ \\
\hline RCH_2 & & 7.60E-01 & $1.00 \mathrm{E}+00$ & $7.25 \mathrm{E}-01$ & $2.76 \mathrm{E}-01$ & $1.00 \mathrm{E}+00$ & $1.00 \mathrm{E}+00$ \\
\hline K241LCA_T1 & & $9.87 \mathrm{E}-01$ & $9.71 \mathrm{E}+00$ & $2.69 \mathrm{E}+00$ & $1.12 \mathrm{E}+00$ & $6.98 \mathrm{E}+00$ & $1.05 \mathrm{E}+01$ \\
\hline K3_VOLVANI & & $1.00 \mathrm{E}+00$ & $6.60 \mathrm{E}-02$ & $4.75 \mathrm{E}-01$ & $2.12 \mathrm{E}-01$ & $3.27 \mathrm{E}+00$ & $3.05 \mathrm{E}+00$ \\
\hline RCH_35 & & $1.12 \mathrm{E}+00$ & $1.00 \mathrm{E}+00$ & $6.60 \mathrm{E}-01$ & $5.31 \mathrm{E}-01$ & $1.00 \mathrm{E}+00$ & $1.00 \mathrm{E}+00$ \\
\hline K3215BCU34 & $3 \mathrm{E}-4 \sim 55$ & $1.24 \mathrm{E}+00$ & $1.16 \mathrm{E}+00$ & $7.05 \mathrm{E}-01$ & $1.67 \mathrm{E}+00$ & $9.64 \mathrm{E}-01$ & $1.23 \mathrm{E}+00$ \\
\hline K4_VF_CU & $3 \mathrm{E}-3 \sim 34$ & $1.58 \mathrm{E}+00$ & $1.95 \mathrm{E}+00$ & $1.39 \mathrm{E}+00$ & $1.32 \mathrm{E}+00$ & $1.31 \mathrm{E}+00$ & $1.24 \mathrm{E}+00$ \\
\hline K3BRU123 & $1 \mathrm{E}-2 \sim 4$ & $1.89 \mathrm{E}+00$ & $3.66 \mathrm{E}+01$ & $4.63 \mathrm{E}+00$ & $1.11 \mathrm{E}+01$ & $2.07 \mathrm{E}+01$ & $6.39 \mathrm{E}+01$ \\
\hline K243_LCA & & $2.19 \mathrm{E}+00$ & $3.62 \mathrm{E}+00$ & $2.74 \mathrm{E}+00$ & $9.32 \mathrm{E}+00$ & $2.70 \mathrm{E}+00$ & $2.89 \mathrm{E}+00$ \\
\hline K242A_LCA & & $3.39 \mathrm{E}+00$ & $3.76 \mathrm{E}+00$ & $2.85 \mathrm{E}+00$ & $5.37 \mathrm{E}+00$ & $5.42 \mathrm{E}+00$ & $3.51 \mathrm{E}+00$ \\
\hline K42UP_VSU & $4 \mathrm{E}-5 \sim 6$ & $7.06 \mathrm{E}+00$ & $1.99 \mathrm{E}+01$ & $1.01 \mathrm{E}+01$ & $1.03 \mathrm{E}+01$ & $9.60 \mathrm{E}+00$ & $1.00 \mathrm{E}+01$ \\
\hline K3C_TM & $2 \mathrm{E}-4 \sim 4$ & $8.44 \mathrm{E}+00$ & $9.81 \mathrm{E}+00$ & $6.45 \mathrm{E}+00$ & $2.87 \mathrm{E}-01$ & $1.25 \mathrm{E}-01$ & $5.05 \mathrm{E}-02$ \\
\hline K321521_PP & $1 \mathrm{E}-3 \sim 180$ & $1.66 \mathrm{E}+02$ & $4.94 \mathrm{E}+02$ & $1.91 \mathrm{E}+02$ & $1.49 \mathrm{E}+02$ & $3.38 \mathrm{E}+02$ & $5.09 \mathrm{E}+02$ \\
\hline
\end{tabular}


Table D-6. Mass balance (flow rate, $\mathrm{m}^{3} / \mathrm{d}$ ) for the five recharge models associated with geological model G1 (the USGS model).

\begin{tabular}{lccrrrc}
\hline & DVRFS & MME & NIM1 & NIM2 & CMB1 & CMB2 \\
\hline IN $\left(\mathrm{m}^{3} / \mathrm{d}\right)$ & & & & & & \\
Storage & 221,487 & 214,195 & 222,254 & 224,155 & 217,593 & 220,015 \\
Constant Head & 386,393 & 721,125 & 455,100 & 433,779 & 552,949 & 599,812 \\
Recharge & 303,537 & 585,275 & 180,223 & 143,011 & 380,361 & 361,075 \\
Wells & 45,567 & 45,504 & 47,067 & 47,282 & 46,493 & 46,643 \\
Total & 956,984 & $1,566,099$ & 904,644 & 848,227 & $1,197,396$ & $1,227,546$ \\
OUT $\left(\mathrm{m}^{3} / \mathrm{d}\right)$ & & & & & & \\
Storage & 8,971 & 8,195 & 10,344 & 10,157 & 8,454 & 9,082 \\
Constant Head & 321,298 & 692,976 & 307,449 & 276,777 & 495,099 & 508,675 \\
Drain & 351,389 & 588,560 & 311,456 & 285,689 & 418,357 & 433,914 \\
Wells & 275,395 & 275,332 & 276,895 & 277,110 & 276,321 & 276,471 \\
Total & 957,053 & $1,565,063$ & 906,144 & 849,733 & $1,198,231$ & $1,228,142$ \\
IN - OUT $\left(\mathrm{m}^{3} / \mathrm{d}\right)$ & -69 & 1,036 & $-1,501$ & $-1,505$ & -835 & -597 \\
Percent Difference & -0.01 & 0.07 & -0.17 & -0.18 & -0.07 & -0.05 \\
\hline
\end{tabular}

Table D-7. Mass balance (flow rate, $\mathrm{m}^{3} / \mathrm{d}$ ) for the five recharge models associated with geological model G2 (the UGTA base model).

\begin{tabular}{lccrrrc}
\hline & DVRFS & MME & NIM1 & NIM2 & CMB1 & CMB2 \\
\hline IN $\left(\mathrm{m}^{3} / \mathrm{d}\right)$ & & & & & & \\
Storage & 221,487 & 216,931 & 230,556 & 231,023 & 220,090 & 219,700 \\
Constant Head & 386,393 & 709,272 & 391,103 & 402,343 & 549,615 & 555,782 \\
Recharge & 303,537 & 585,275 & 156,420 & 112,850 & 380,361 & 361,075 \\
Wells & 45,567 & 46,621 & 49,340 & 49,412 & 464,53 & 46,539 \\
Total & 956,984 & $1,558,099$ & 827,418 & 795,628 & $1,196,518$ & $1,183,096$ \\
OUT $\left(\mathrm{m}^{3} / \mathrm{d}\right)$ & & & & & & \\
Storage & 8,971 & 9,381 & 10,544 & 10,309 & 9,479 & 9,598 \\
Constant Head & 321,298 & 613,565 & 196,704 & 216,643 & 447,316 & 461,293 \\
Drain & 351,389 & 658,677 & 340,085 & 289,152 & 464,551 & 436,930 \\
Wells & 275,395 & 276,449 & 279,168 & 279,240 & 276,281 & 276,367 \\
Total & 957,053 & $1,558,072$ & 826,502 & 795,344 & $1,197,627$ & $1,184,189$ \\
IN - OUT $\left(\mathrm{m}^{3} / \mathrm{d}\right)$ & -69 & 26 & 917 & 284 & $-1,109$ & $-1,093$ \\
Percent Difference & -0.01 & 0.07 & -0.17 & 0.04 & -0.09 & -0.09 \\
\hline
\end{tabular}


Table D-8. Mass balance (flow rate, $\mathrm{m}^{3} / \mathrm{d}$ ) for the five recharge models associated with geological model G3 (the CP Thrust alternative model).

\begin{tabular}{lccrrrc}
\hline & DVRFS & MME & NIM1 & NIM2 & CMB1 & CMB2 \\
\hline IN $\left(\mathrm{m}^{3} / \mathrm{d}\right)$ & & & & & & \\
Storage & 221,487 & 217,024 & 230,088 & 231,303 & 221,177 & 219,186 \\
Constant Head & 386,393 & 674,894 & 398,390 & 407,789 & 565,370 & 539,574 \\
Recharge & 303,537 & 585,275 & 128,624 & 83,859 & 380,361 & 361,075 \\
Wells & 45,567 & 46,924 & 48,901 & 48,837 & 46,952 & 46,149 \\
Total & 956,984 & $1,524,117$ & 806,002 & 771,787 & $1,213,860$ & $1,165,984$ \\
OUT $\left(\mathrm{m}^{3} / \mathrm{d}\right)$ & & & & & & \\
Storage & 8,971 & 9,562 & 10,215 & 9,985 & 8,930 & 9,145 \\
Constant Head & 321,298 & 594,675 & 219,330 & 217,747 & 452,937 & 421,567 \\
Drain & 351,389 & 642,658 & 297,589 & 265,361 & 474,919 & 460,351 \\
Wells & 275,395 & 276,752 & 278,729 & 278,665 & 276,780 & 275,977 \\
Total & 957,053 & $1,523,647$ & 805,862 & 771,757 & $1,213,567$ & $1,167,041$ \\
IN - OUT $\left(\mathrm{m}^{3} / \mathrm{d}\right)$ & -69 & 470 & 140 & 29 & 294 & $-1,057$ \\
Percent Difference & -0.01 & 0.03 & 0.02 & 0.00 & 0.02 & -0.09 \\
\hline
\end{tabular}

Table D-9. Mass balance (flow rate, $\mathrm{m}^{3} / \mathrm{d}$ ) for the five recharge models associated with geological model G4 (the hydrologic barrier alternative model).

\begin{tabular}{lccrrrc}
\hline & DVRFS & MME & NIM1 & NIM2 & CMB1 & CMB2 \\
\hline IN $\left(\mathrm{m}^{3} / \mathrm{d}\right)$ & & & & & & \\
Storage & 221,487 & 215,779 & 221,243 & 223,013 & 219,260 & 221,935 \\
Constant Head & 386,393 & 699,322 & 502,562 & 445,140 & 584,577 & 590,854 \\
Recharge & 303,537 & 585,275 & 178,465 & 167,189 & 380,361 & 361,075 \\
Wells & 45,567 & 44,158 & 46,225 & 46,652 & 46,224 & \multicolumn{1}{c}{46,570} \\
Total & 956,984 & $1,544,534$ & 948,495 & 881,994 & $1,230,421$ & $1,220,434$ \\
OUT $\left(\mathrm{m}^{3} / \mathrm{d}\right)$ & & & & & & \\
Storage & 8,971 & 8,140 & 9,813 & 9,255 & 8,275 & 8,788 \\
Constant Head & 321,298 & 646,766 & 348,578 & 290,336 & 522,535 & 480,275 \\
Drain & 351,389 & 615,025 & 314,977 & 305,614 & 423,361 & 455,054 \\
Wells & 275,395 & 273,986 & 276,053 & 276,480 & 276,052 & 276,398 \\
Total & 957,053 & $1,543,916$ & 949,421 & 881,686 & $1,230,223$ & $1,220,514$ \\
IN - OUT $\left(\mathrm{m}^{3} / \mathrm{d}\right)$ & -69 & 617 & -927 & 308 & 199 & -80 \\
Percent Difference & -0.01 & 0.04 & -0.10 & 0.03 & 0.02 & -0.01 \\
\hline
\end{tabular}


Table D-10. Mass balance (flow rate, $\mathrm{m}^{3} / \mathrm{d}$ ) for the five recharge models associated with geological model G5 (the CP Thrust and hydrologic barrier alternative model).

\begin{tabular}{lccrrrc}
\hline & DVRFS & MME & NIM1 & NIM2 & CMB1 & CMB2 \\
\hline IN $\left(\mathrm{m}^{3} / \mathrm{d}\right)$ & & & & & & \\
Storage & 221,487 & 216,205 & 218,357 & 228,735 & 220,938 & 222,658 \\
Constant Head & 386,393 & 685,630 & 452,097 & 463,314 & 537,137 & 615,979 \\
Recharge & 303,537 & 585,275 & 225,795 & 110,279 & 380,361 & 361,075 \\
Wells & 45,567 & 45,780 & 45,770 & 47,510 & 46,493 & \multicolumn{1}{c}{46,697} \\
Total & 956,984 & 1,532890 & 942,020 & 849,837 & $1,184,928$ & $1,246,409$ \\
OUT $\left(\mathrm{m}^{3} / \mathrm{d}\right)$ & & & & & & \\
Storage & 8,971 & 8,495 & 9,911 & 9,385 & 8,954 & 8,838 \\
Constant Head & 321,298 & 639,566 & 320,734 & 242,843 & 469,049 & 514,852 \\
Drain & 351,389 & 609,060 & 337,011 & 320,062 & 430,853 & 445,818 \\
Wells & 275,395 & 275,608 & 275,598 & 277,338 & 276,321 & 276,525 \\
Total & 957,053 & $1,532,728$ & 943,253 & 849,628 & $1,185,176$ & $1,246,033$ \\
IN - OUT $\left(\mathrm{m}^{3} / \mathrm{d}\right)$ & -69 & 162 & $-1,233$ & 209 & -249 & 376 \\
Percent Difference & -0.01 & 0.01 & -0.13 & 0.02 & -0.02 & 0.03 \\
\hline
\end{tabular}

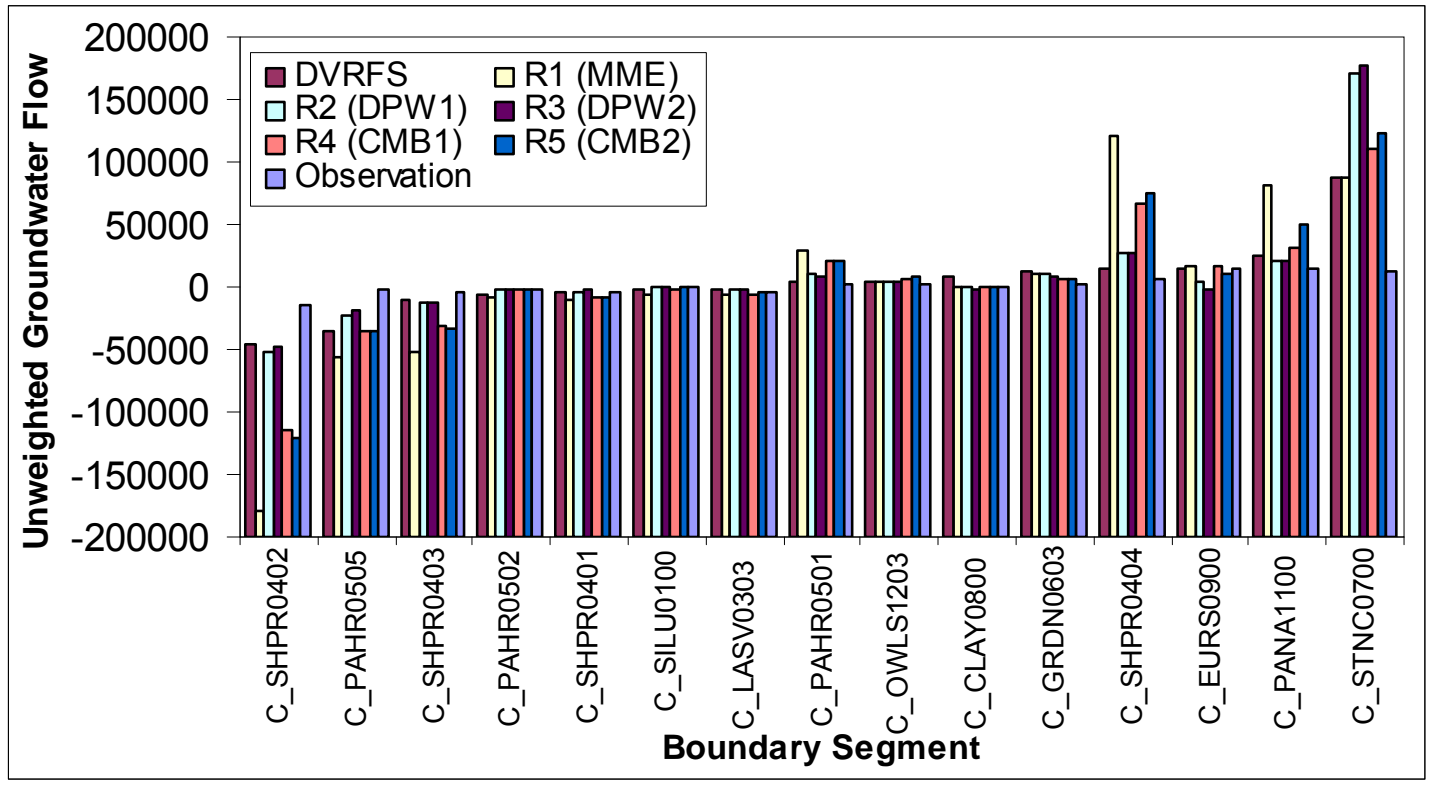

Figure D-1. Unweighted boundary-flow rate along constant-head boundary segments of the DVRFS. The simulated flow rate is for the USGS geological model. 


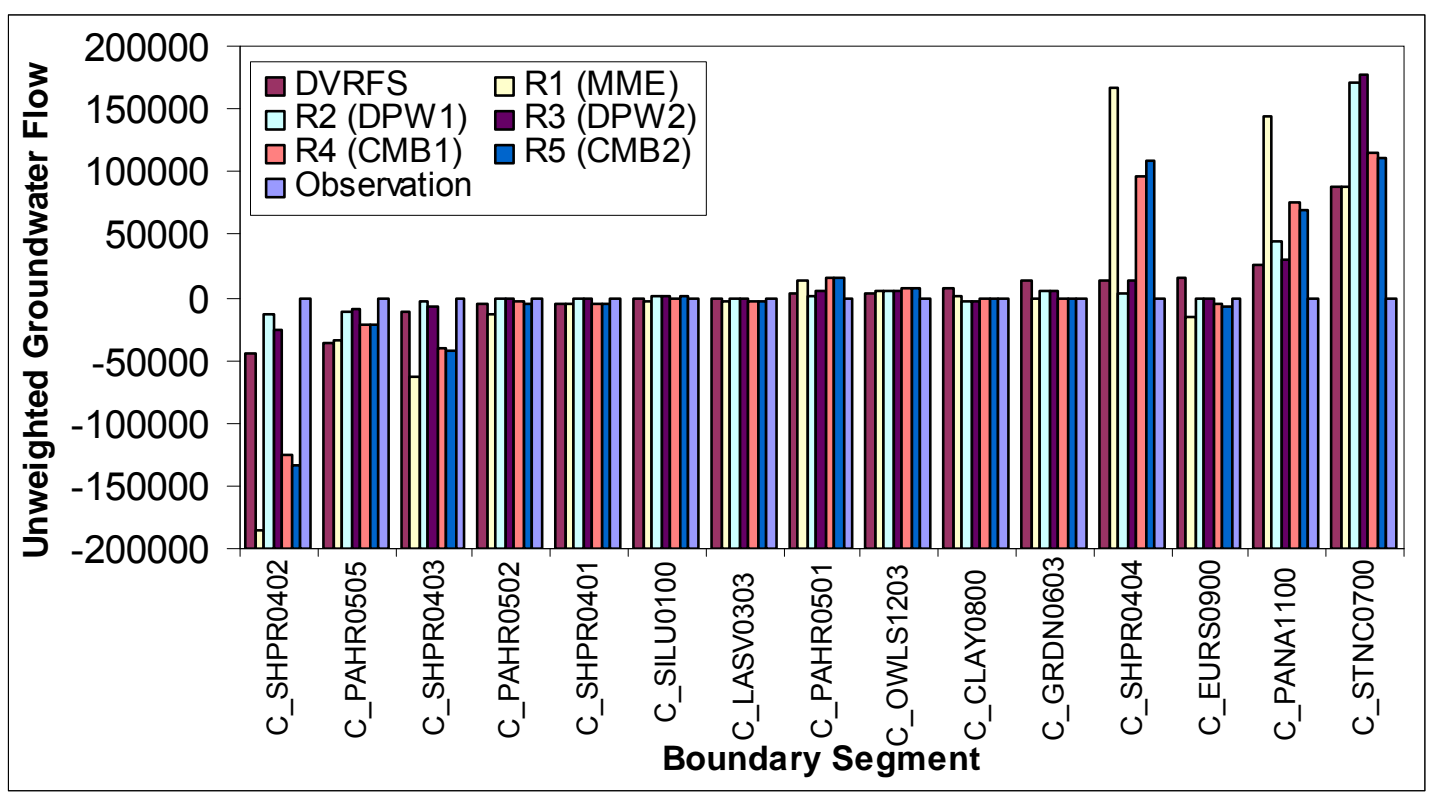

Figure D-2. Unweighted boundary-flow rate along constant-head boundary segments of the DVRFS. The simulated flow rate is for the UGTA base model.

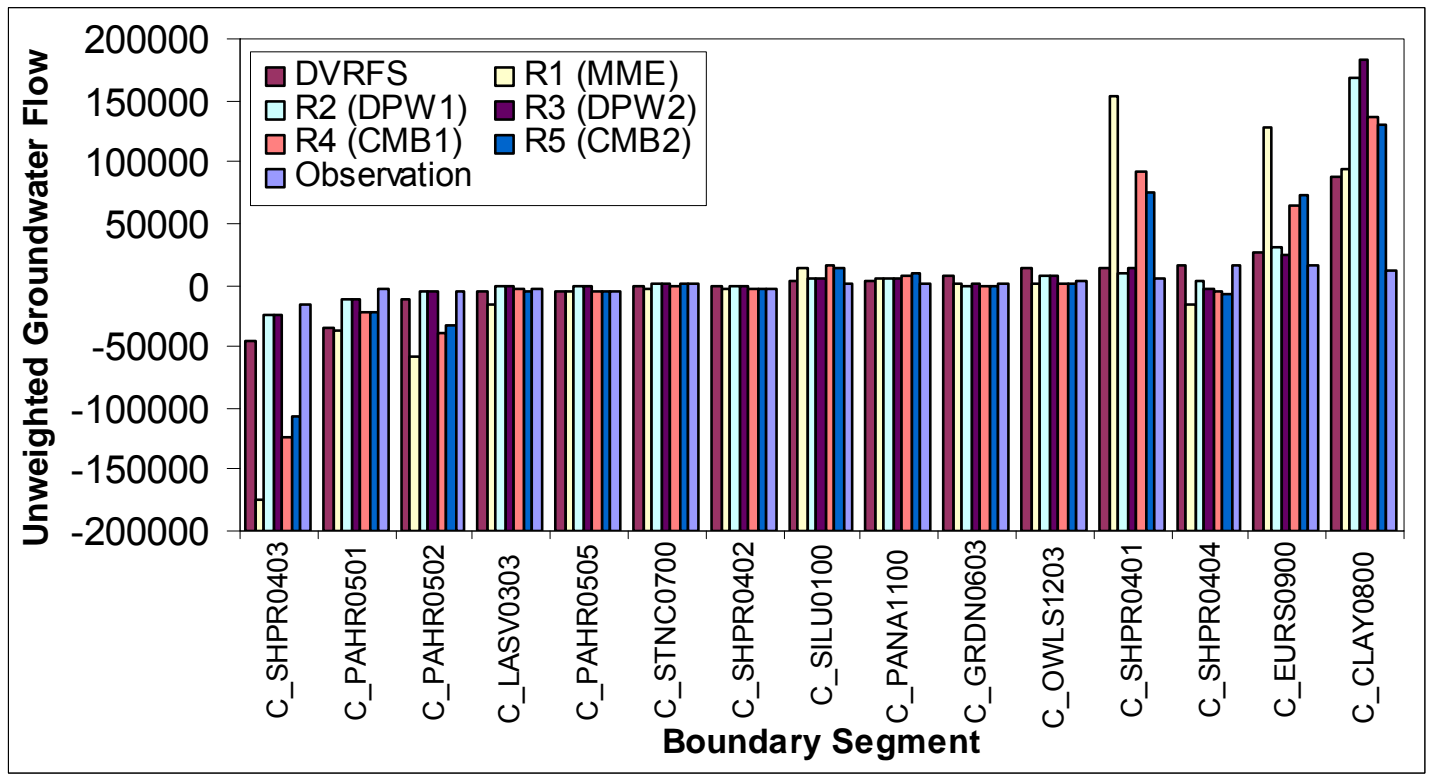

Figure D-3. Unweighted boundary-flow rate along constant-head boundary segments of the DVRFS. The simulated flow rate is for the CP Thrust alternative model. 


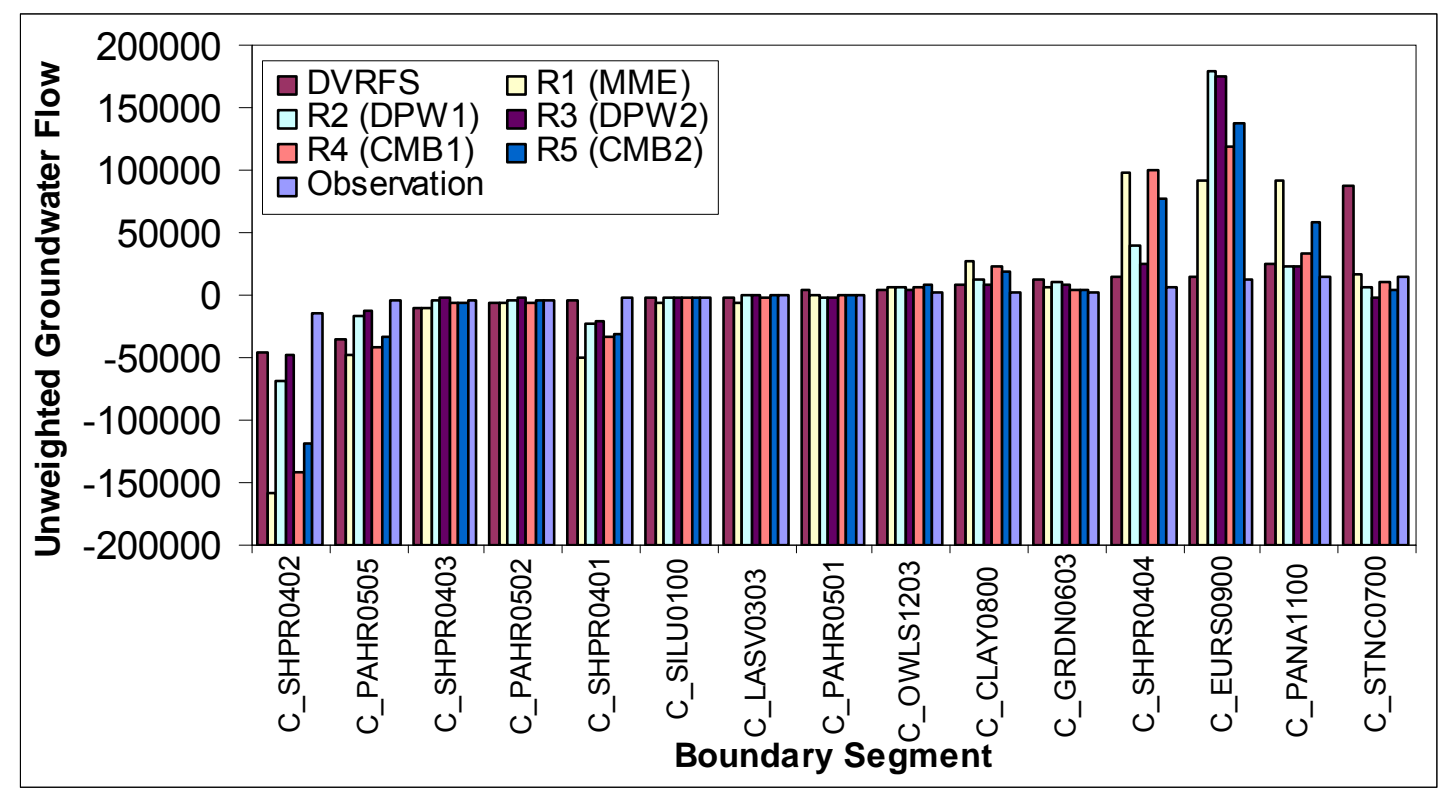

Figure D-4. Unweighted boundary-flow rate along constant-head boundary segments of the DVRFS. The simulated flow rate is for the hydrologic barrier alternative model.

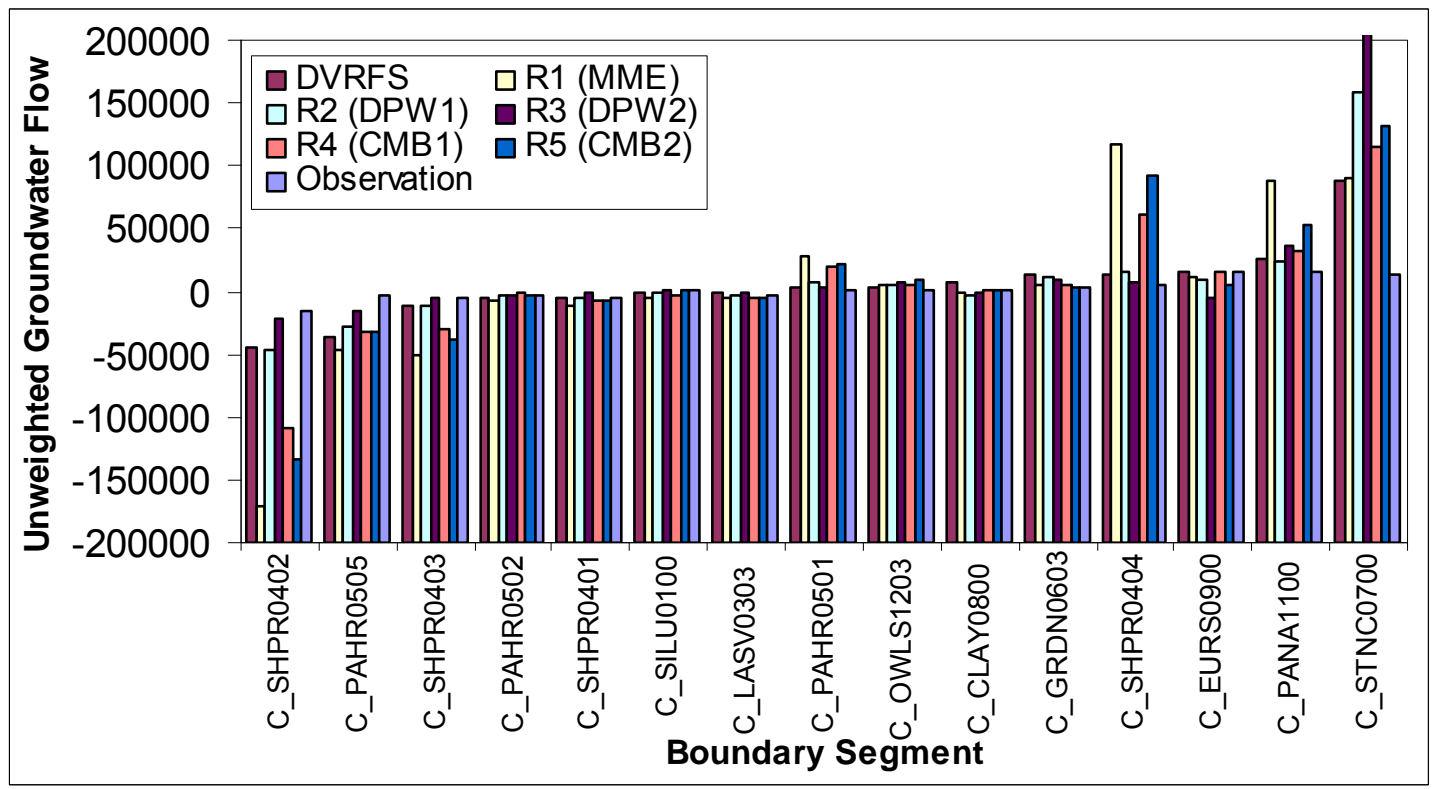

Figure D-5. Unweighted boundary-flow rate along constant-head boundary segments of the DVRFS. The simulated flow rate is for the CP Thrust and hydrologic barrier alternative model. 


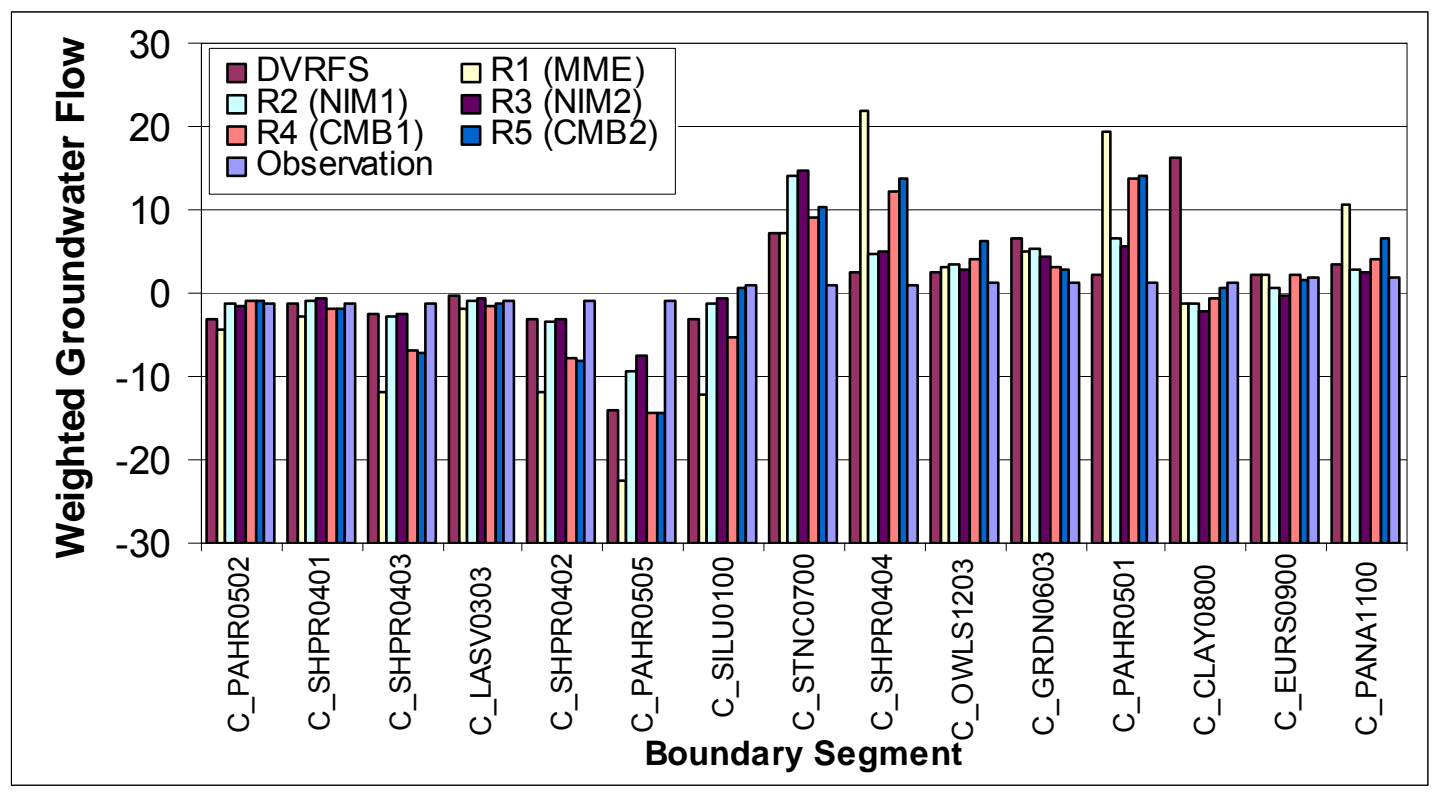

Figure D-6. Weighted boundary-flow rate along constant-head boundary segments of the DVRFS. The simulated flow rate is for the USGS geological model.

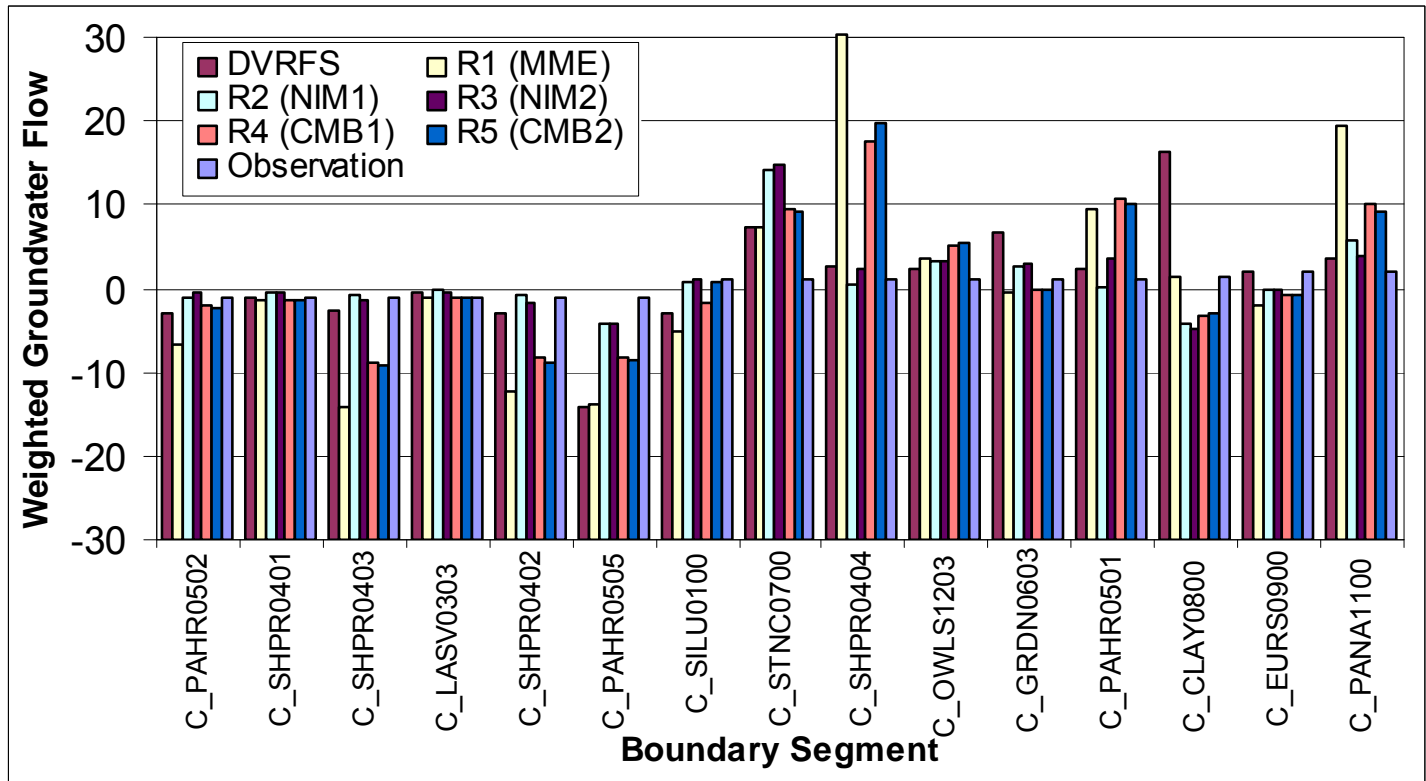

Figure D-7. Weighted boundary-flow rate along constant-head boundary segments of the DVRFS. The simulated flow rate is for the UGTA base model. 


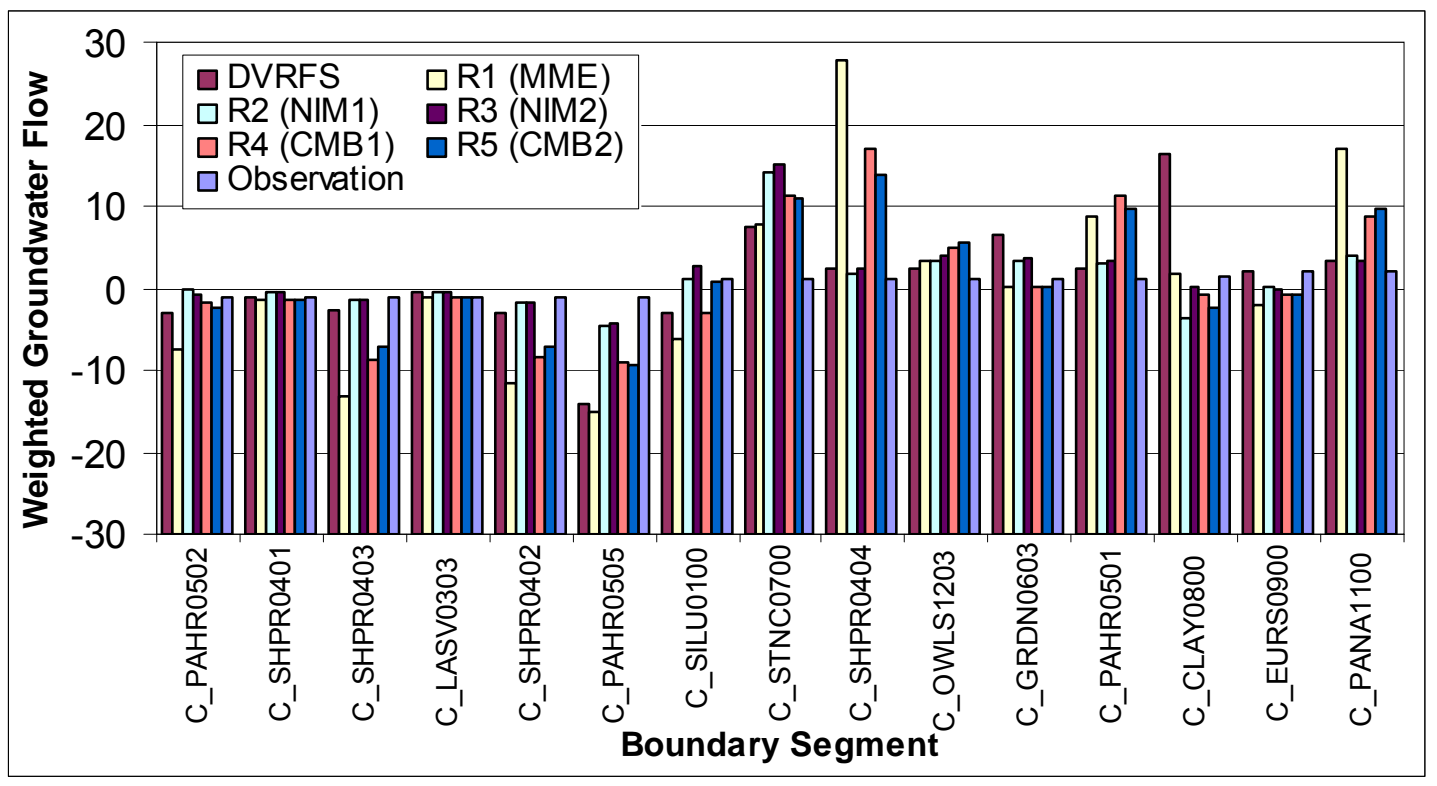

Figure D-8. Weighted boundary-flow rate along constant-head boundary segments of the DVRFS. The simulated flow rate is for the CP Thrust alternative model.

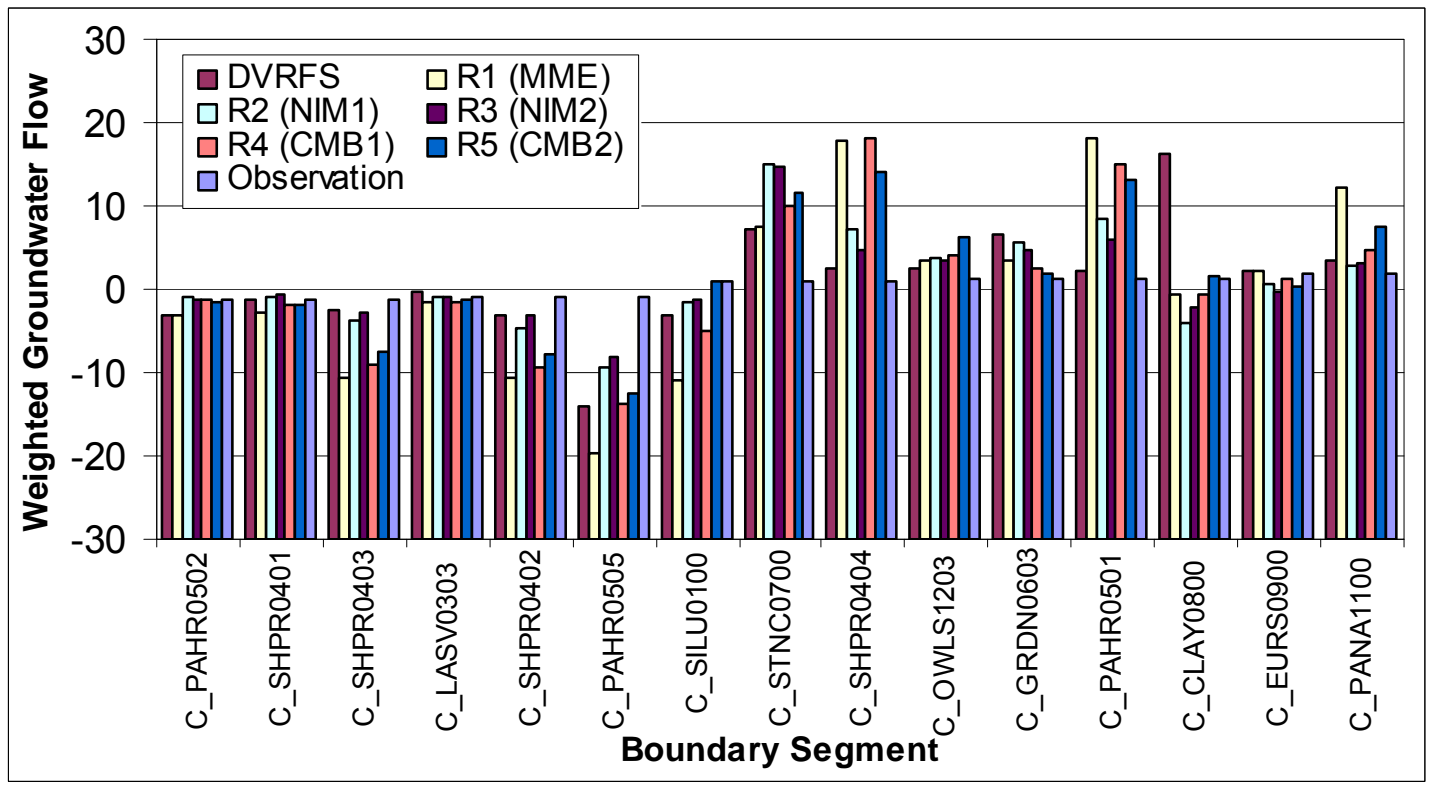

Figure D-9. Weighted boundary-flow rate along constant-head boundary segments of the DVRFS. The simulated flow rate is for the hydrologic barrier alternative model. 


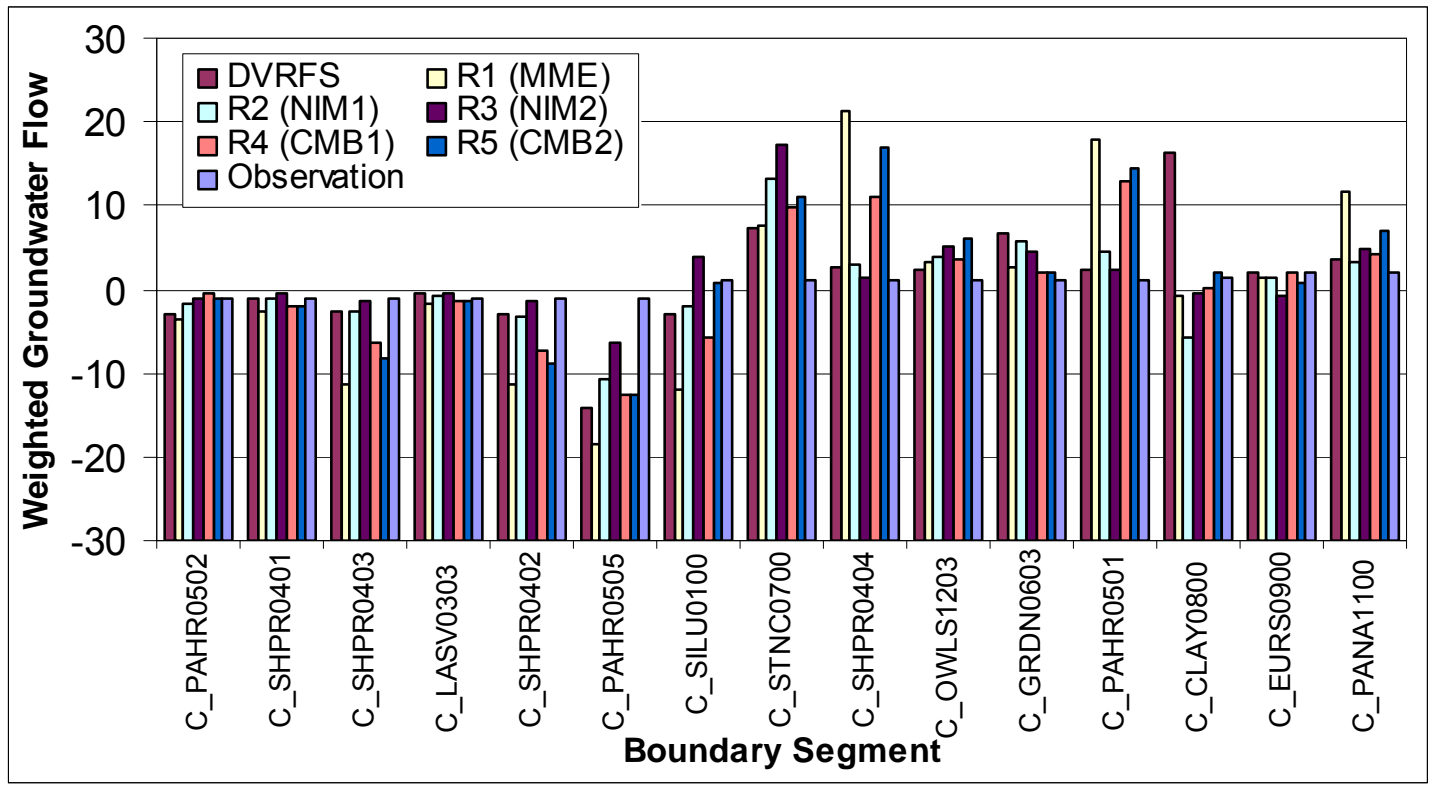

Figure D-10. Weighted boundary-flow rate along constant-head boundary segments of the DVRFS. The simulated flow rate is for the CP Thrust and hydrologic barrier alternative model. 
(a) G1R1

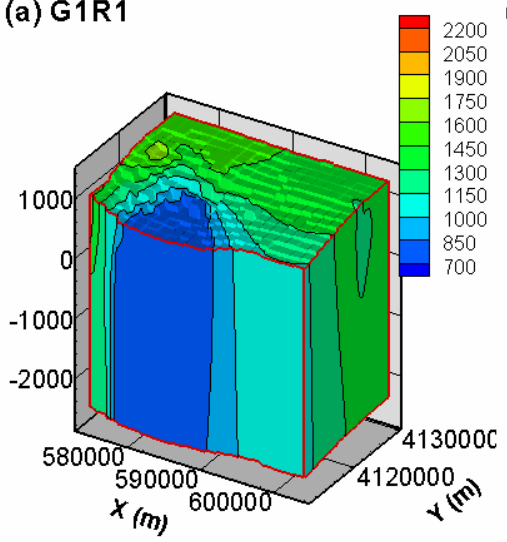

(c) G1R3

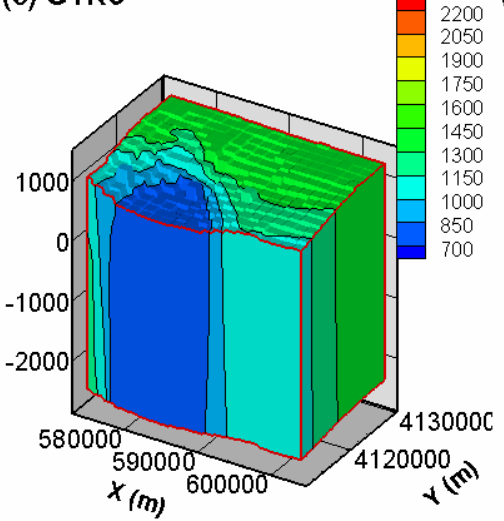

(b) G1R2

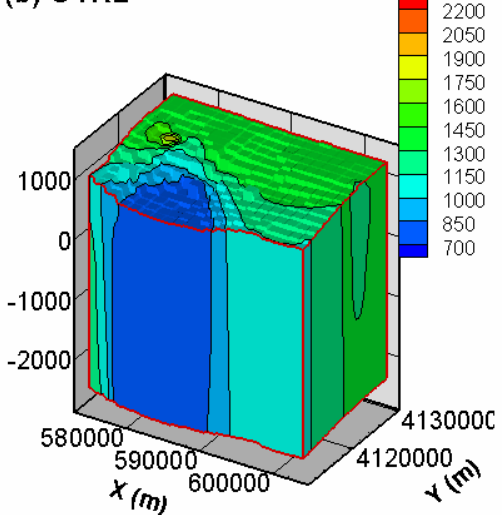

(d) G1R4

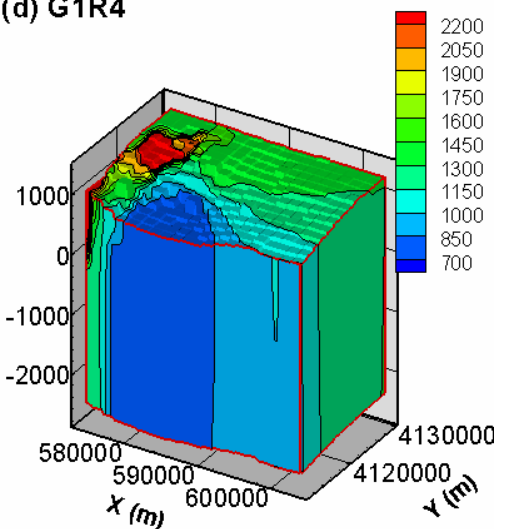

(e) G1R5

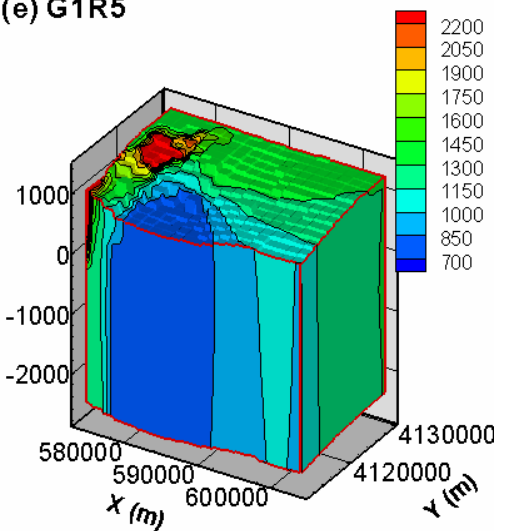

Figure D-11. Three-dimensional contours of hydraulic head in the northern Yucca Flat area. Z coordinates are exaggerated 8 times for better presentation. G1 is the DVRFS HFM model, and R1 through R5 stands for the MME, NIM1, NIM2, CMB1, and CMB2 recharge models. 


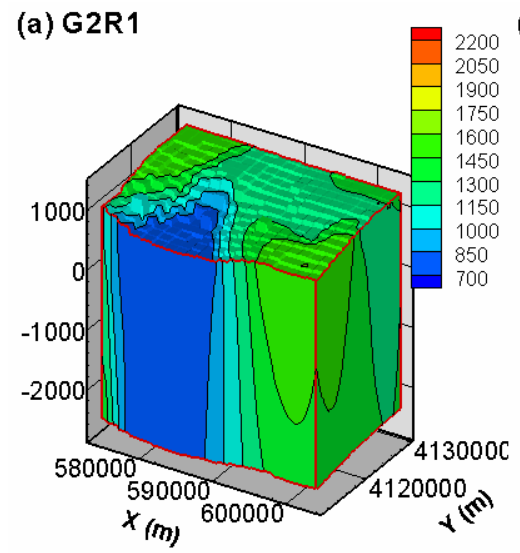

(b) G2R2

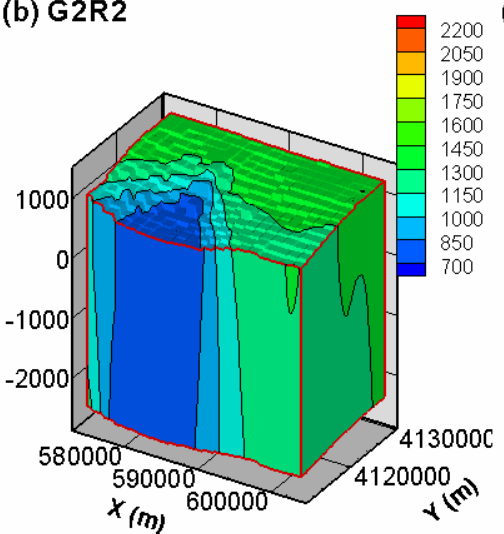

(c) G2R3

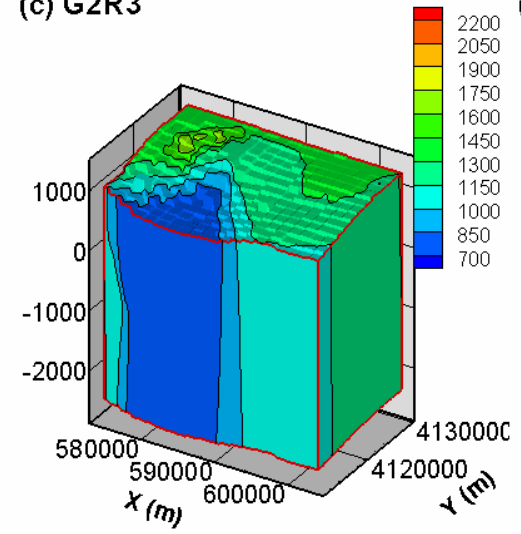

(d) G2R4

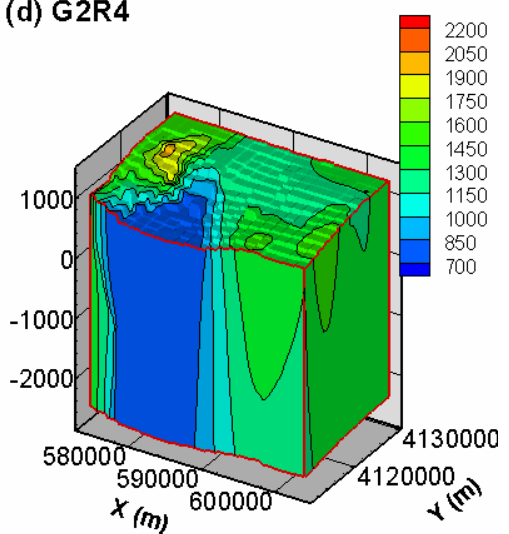

(e) G2R5

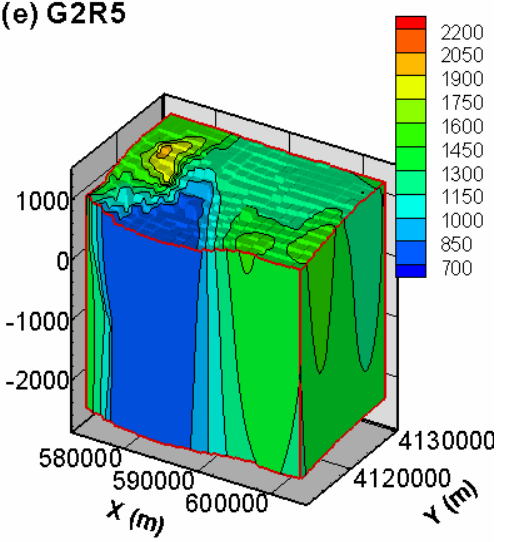

Figure D-12. Three-dimensional contours of hydraulic head in the northern Yucca Flat area. Z coordinates are exaggerated 8 times for better presentation. G2 is the UGTA base HFM model, and R1 through R5 stands for the MME, NIM1, NIM2, CMB1, and CMB2 recharge models. 


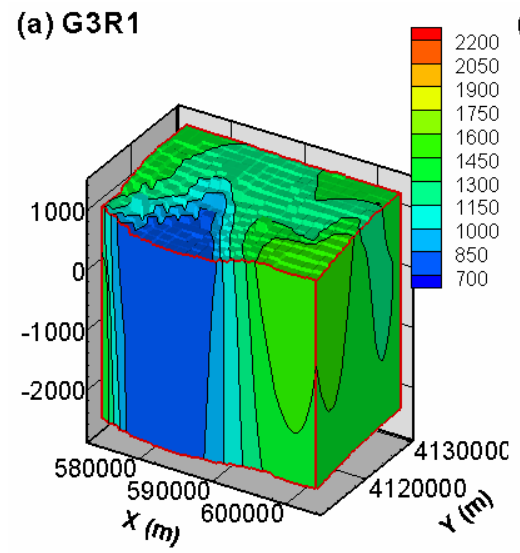

(b) G3R2

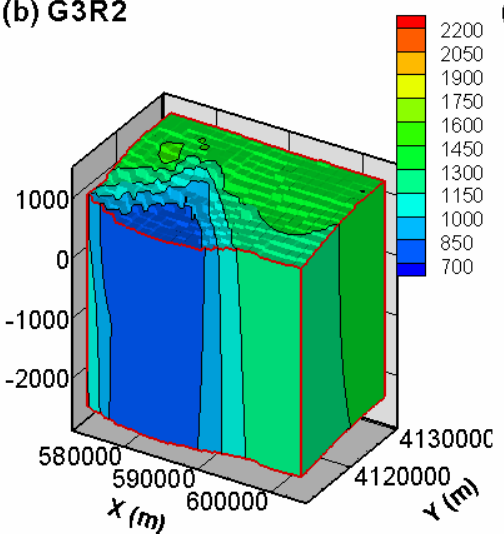

(c) G3R3

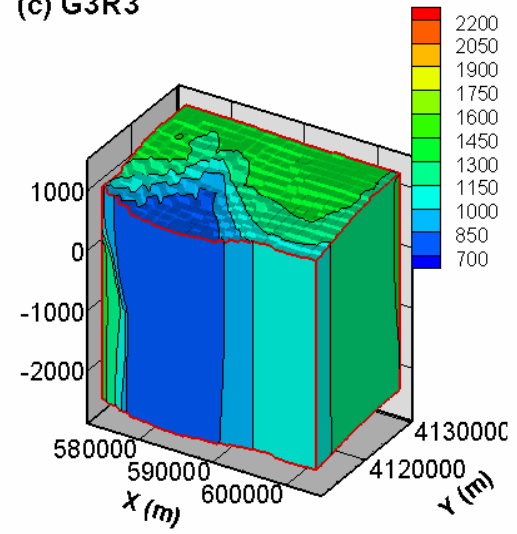

(d) G3R4

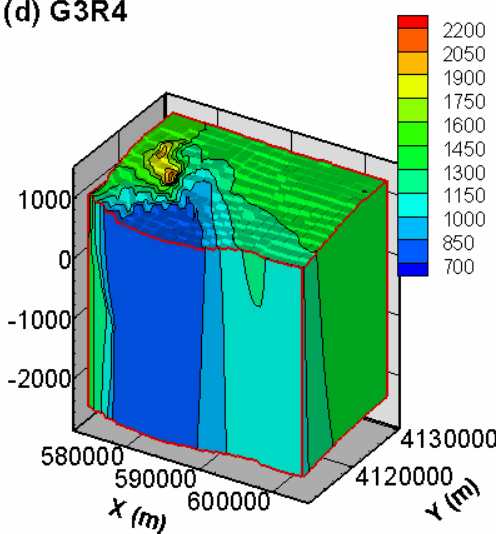

(e) G3R5

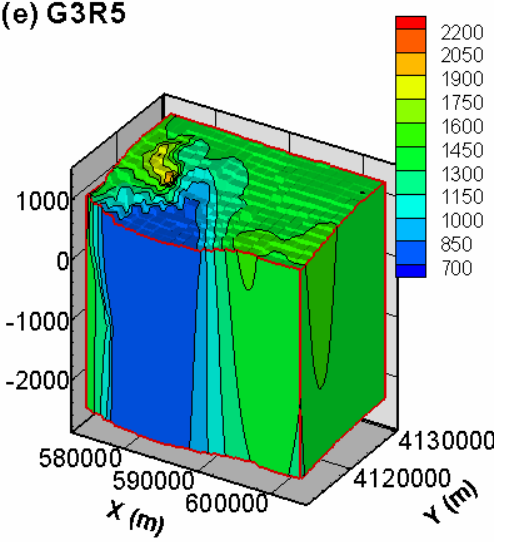

Figure D-13. Three-dimensional contours of hydraulic head in the northern Yucca Flat area. Z coordinates are exaggerated 8 times for better presentation. G3 is the CP Thrust alternative model, and R1 through R5 stands for the MME, NIM1, NIM2, CMB1, and CMB2 recharge models. 


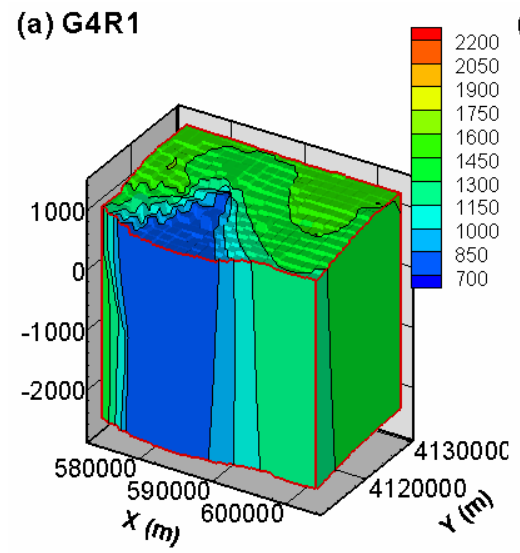

(b) G4R2

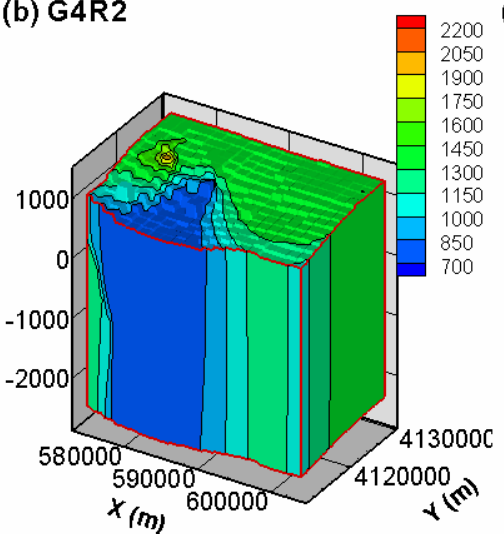

(c) G4R3

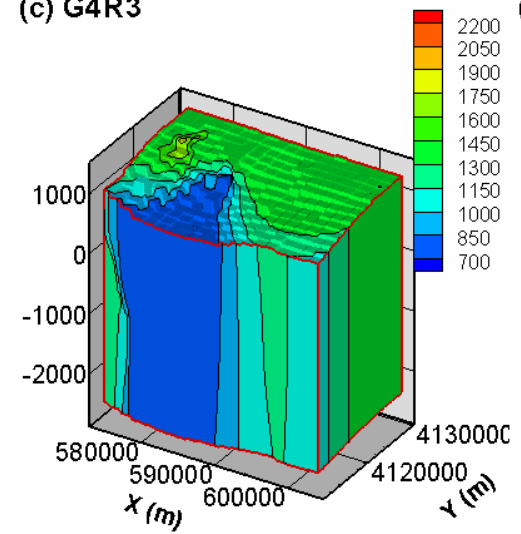

(d) G4R4

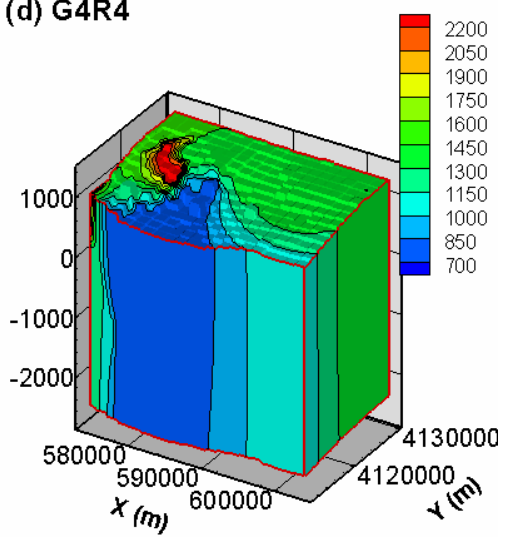

(e) G4R5

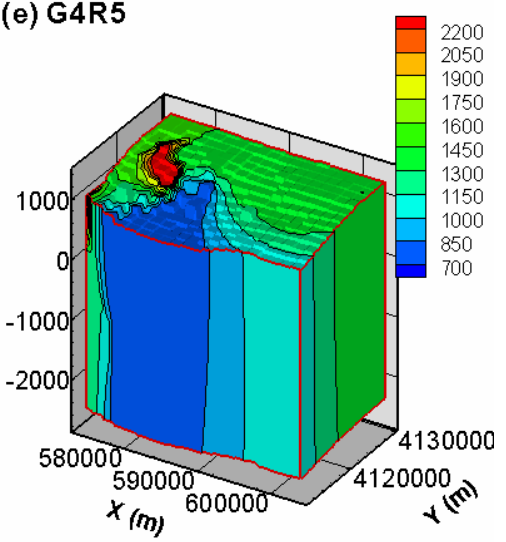

Figure D-14. Three-dimensional contours of hydraulic head in the northern Yucca Flat area. Z coordinates are exaggerated 8 times for better presentation. G4 is the hydrologic barrier alternative model, and R1 through R5 stands for the MME, NIM1, NIM2, CMB1, and CMB2 recharge models. 


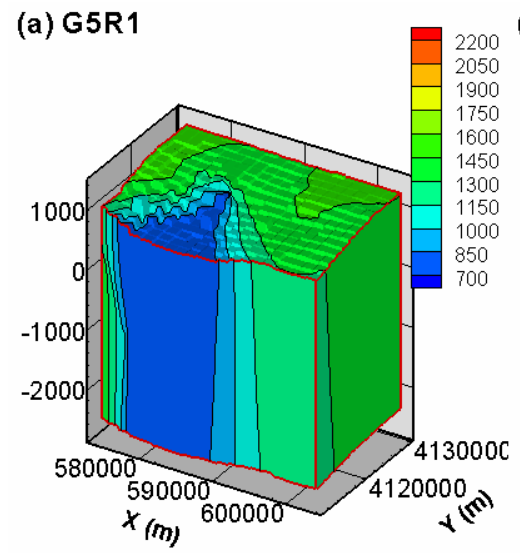

(b) G5R2

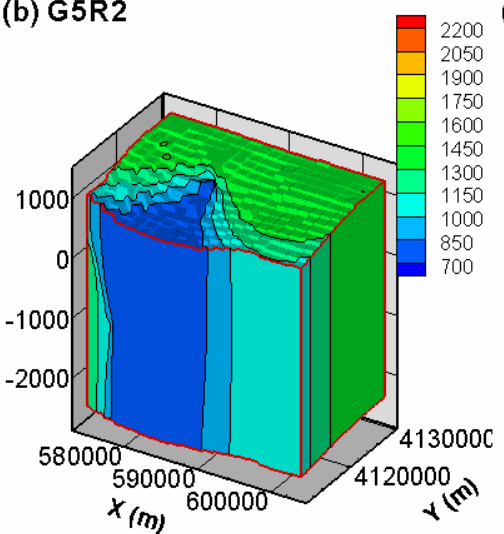

(c) G5R3

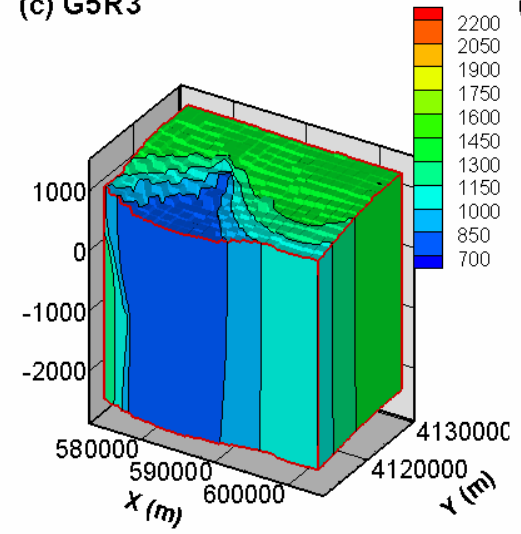

(d) G5R4

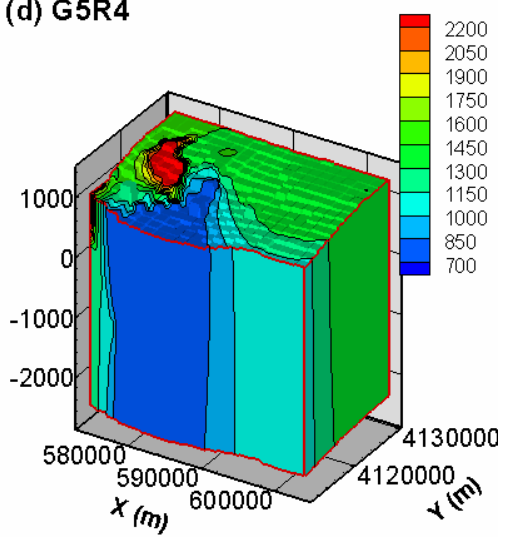

(e) G5R5

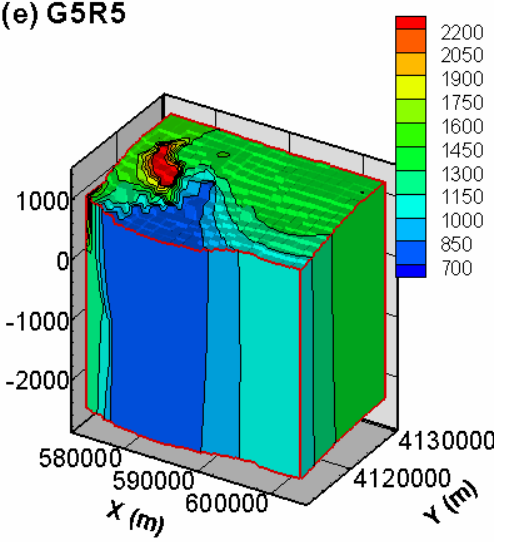

Figure D-15. Three-dimensional contours of hydraulic head in the northern Yucca Flat area. Z coordinates are exaggerated 8 times for better presentation. G5 is the CP Thrust and hydrologic barrier alternative model, and R1 through R5 stands for the MME, NIM1, NIM2, CMB1, and CMB2 recharge models. 
(a) G1R1

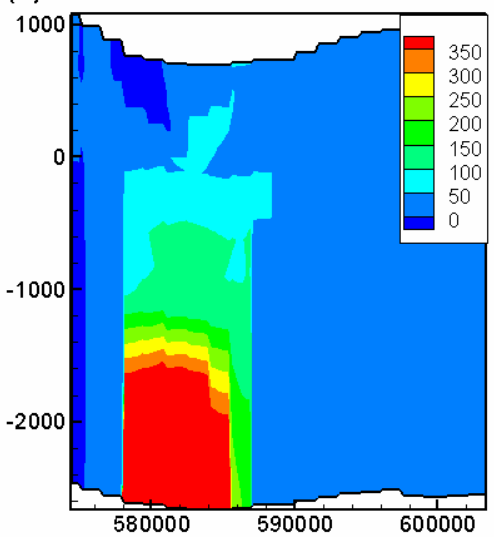

(c) G1R2

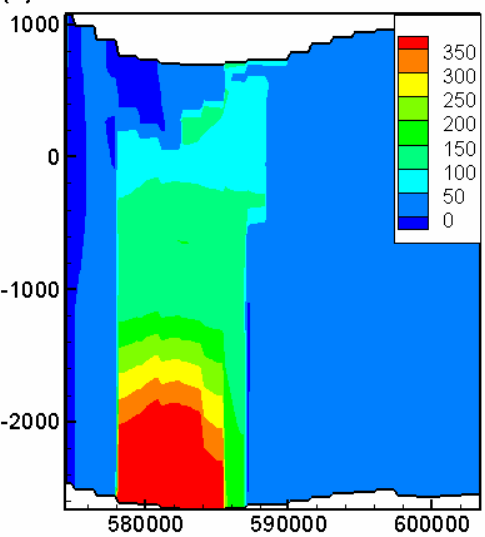

(d) G1R3

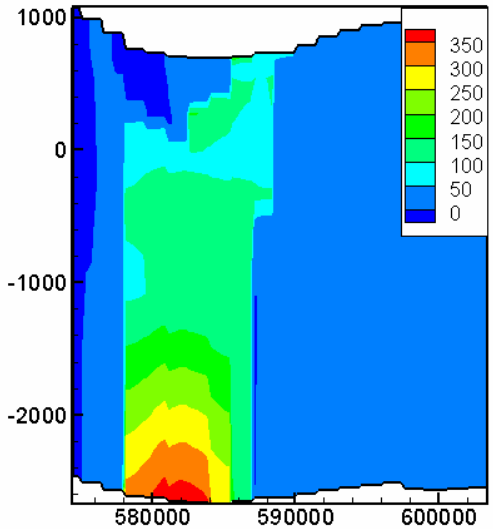

(e) G1R4

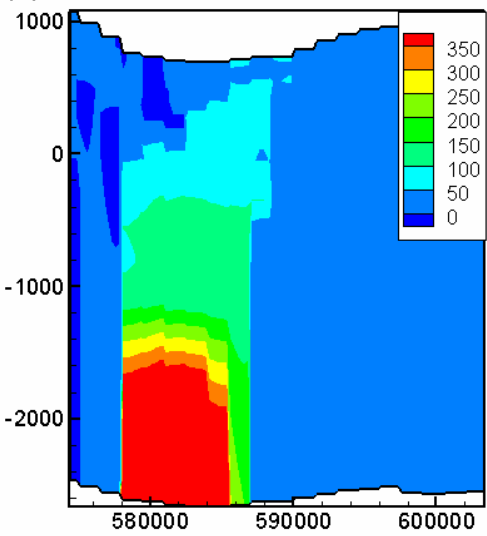

(e) G1R5

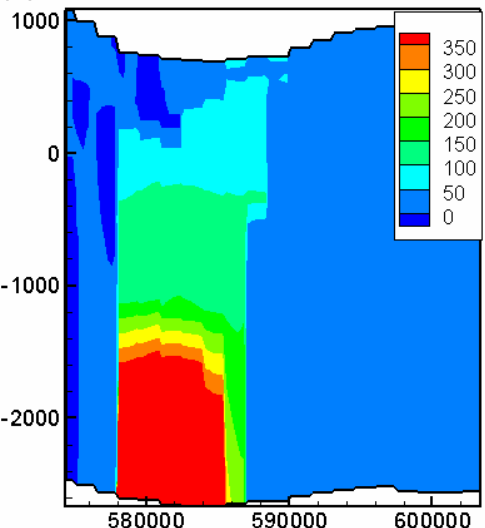

Figure D-16. Contours of cell-by-cell flow crossing the front face of MODFLOW cells $\left(\mathrm{Q}_{\mathrm{y}}, \mathrm{m}^{3} / \mathrm{day}\right)$ predicted at the southern boundary (x-z cross section) of the northern Yucca Flat by models. G1 is the DVRFS HFM model, and R1 through R5 stands for the MME, NIM1, NIM2, CMB1, and CMB2 recharge models. 
(a) G2R1

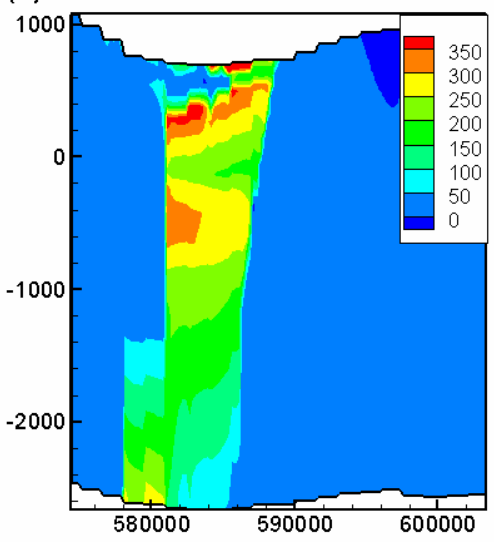

580000 (c) G2R2

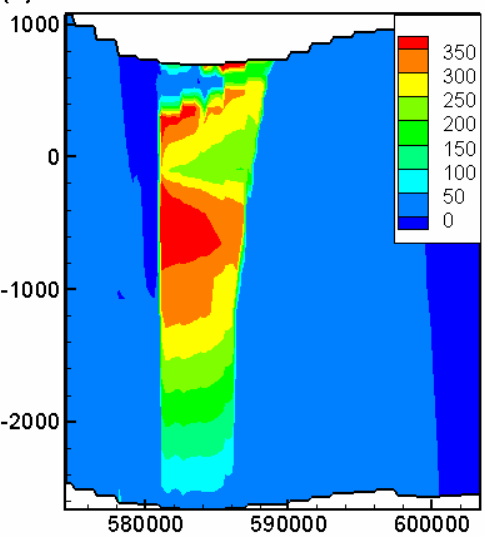

(d) G2R3

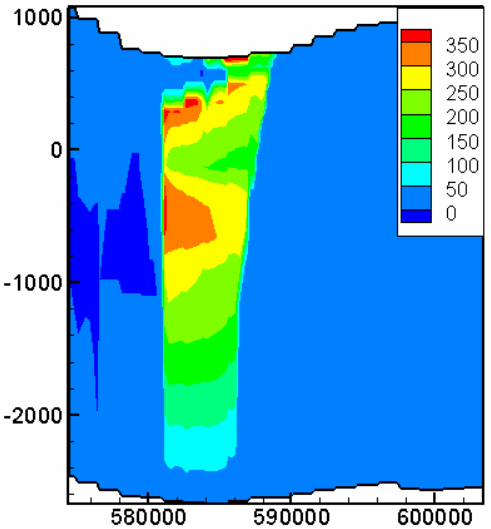

(e) G2R4

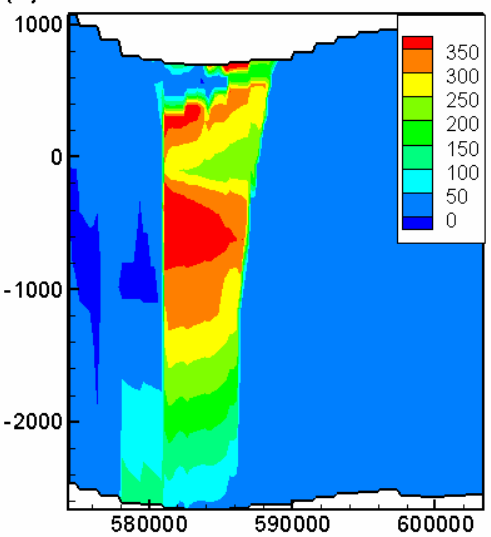

(e) G2R5

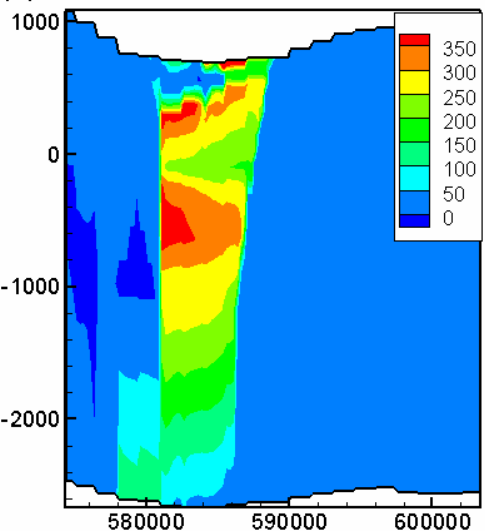

Figure D-17. Contours of cell-by-cell flow crossing the front face of MODFLOW cells $\left(\mathrm{Q}_{\mathrm{y}}, \mathrm{m}^{3} / \mathrm{day}\right)$ predicted at the southern boundary (x-z cross section) of the northern Yucca Flat by models. G1 is the UGTA base HFM model, and R1 through R5 stands for the MME, NIM1, NIM2, CMB1, and CMB2 recharge models. 
(a) G3R1

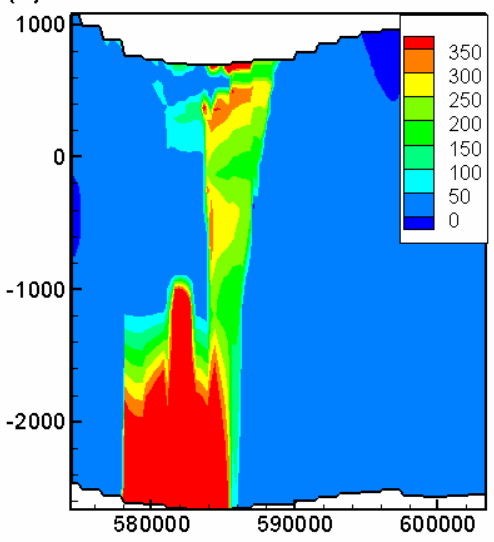

580000 (c) G3R2

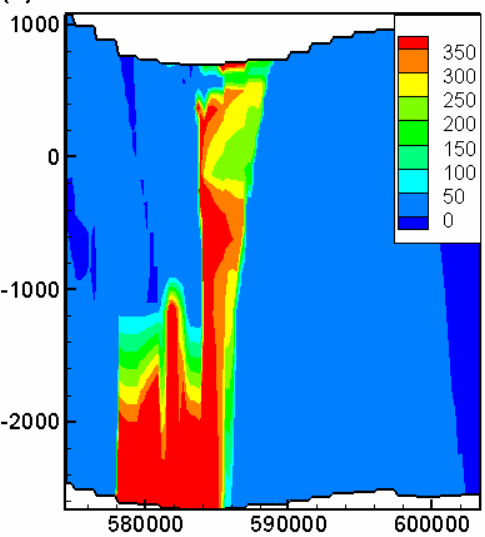

(d) G3R3

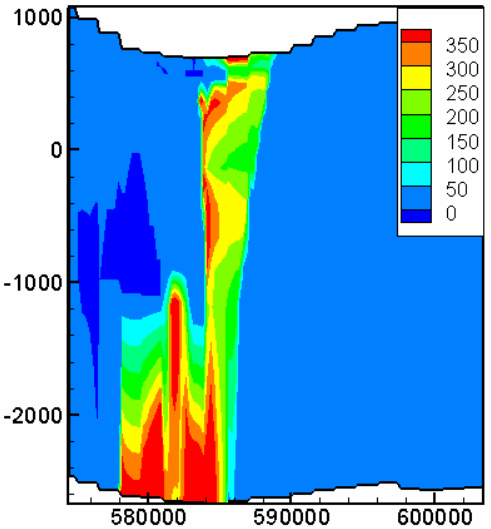

(e) G3R4

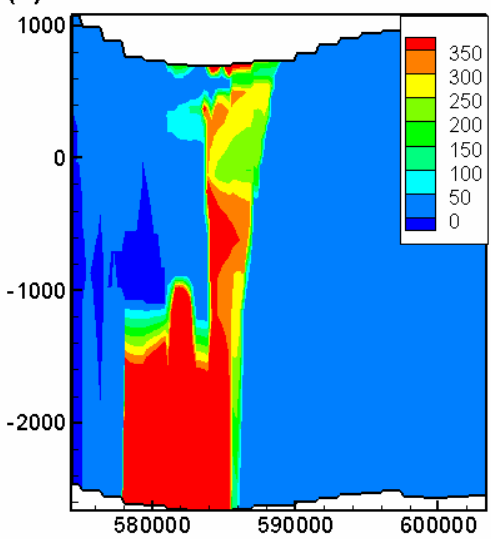

(e) G3R5

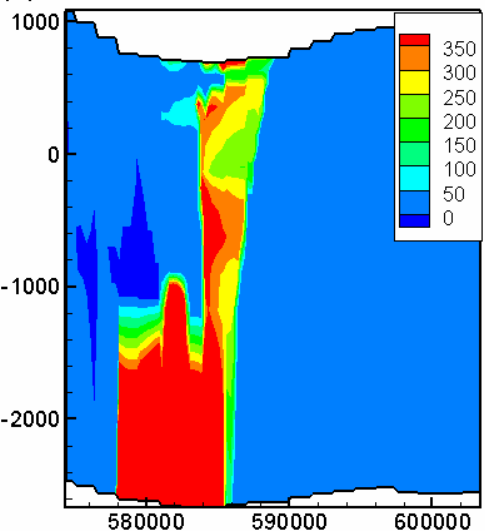

Figure D-18. Contours of cell-by-cell flow crossing the front face of MODFLOW cells $\left(\mathrm{Q}_{\mathrm{y}}, \mathrm{m}^{3} / \mathrm{day}\right)$ predicted at the southern boundary (x-z cross section) of the northern Yucca Flat by models. G1 is the CP Thrust alternative HFM model, and R1 through R5 stands for the MME, NIM1, NIM2, CMB1, and CMB2 recharge models. 
(a) G4R1

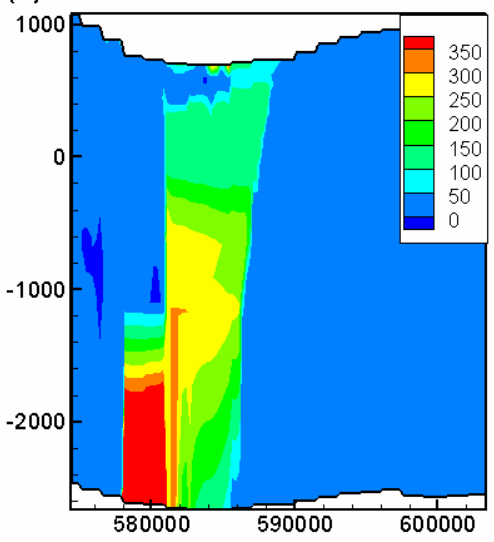

580000 (c) G4R2

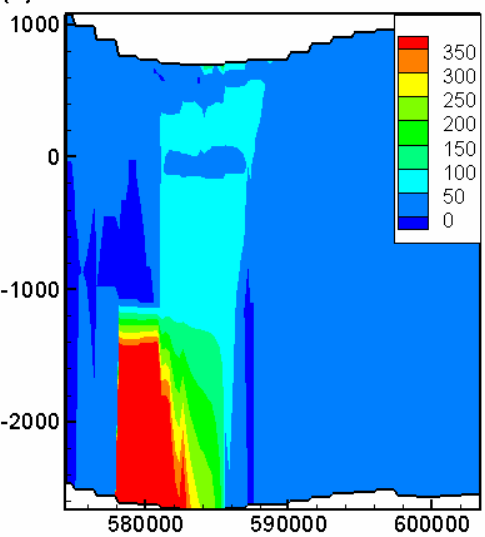

(d) G4R3

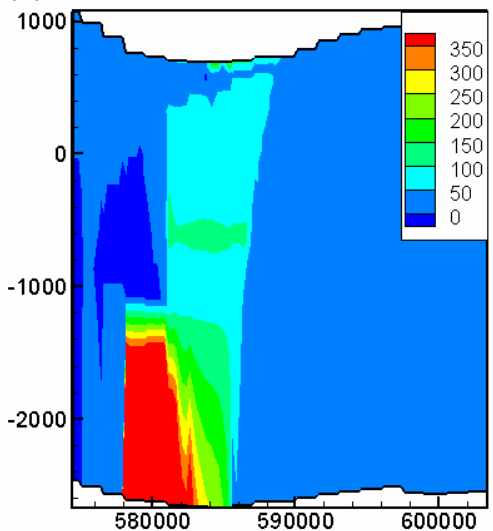

(e) G4R4

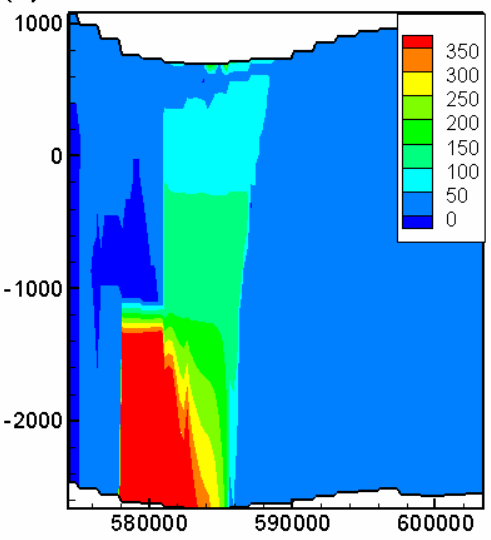

(e) G4R5

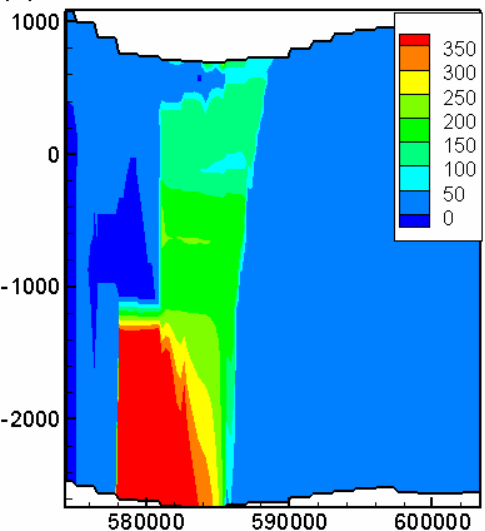

Figure D-19. Contours of cell-by-cell flow crossing the front face of MODFLOW cells $\left(\mathrm{Q}_{\mathrm{y}}, \mathrm{m}^{3} / \mathrm{day}\right)$ predicted at the southern boundary (x-z cross section) of the northern Yucca Flat by models. G1 is the hydrologic barrier HFM model, and R1 through R5 stands for the MME, NIM1, NIM2, CMB1, and CMB2 recharge models. 
(a) G5R1

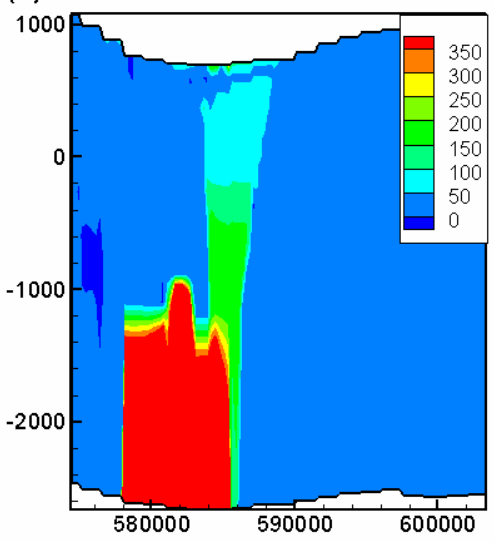

580000 (c) G5R2

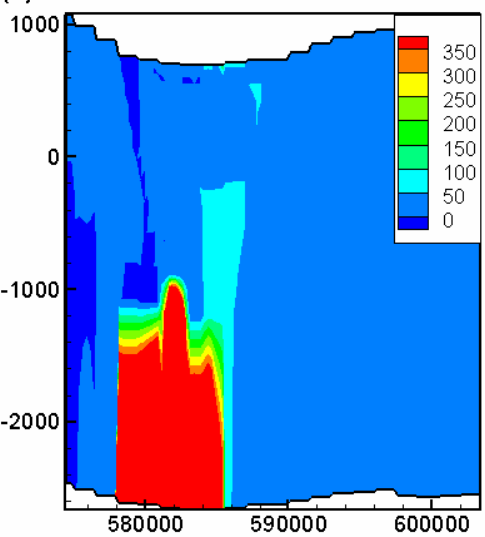

(d) G5R3

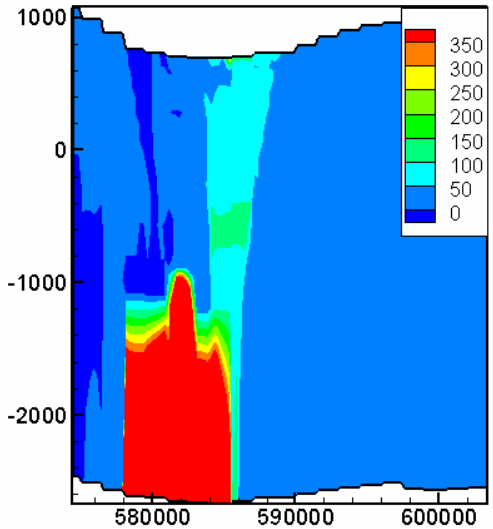

(e) G5R4

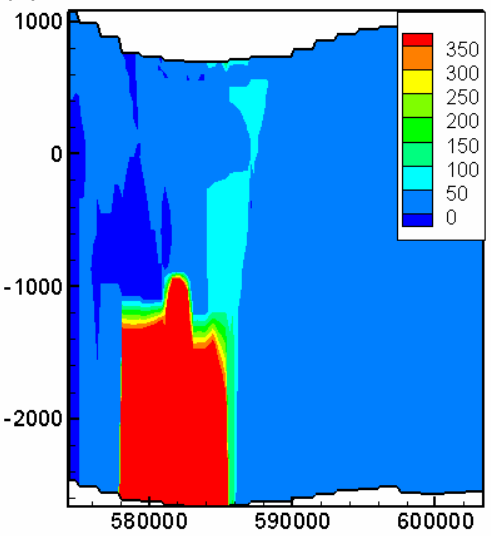

(e) G5R5

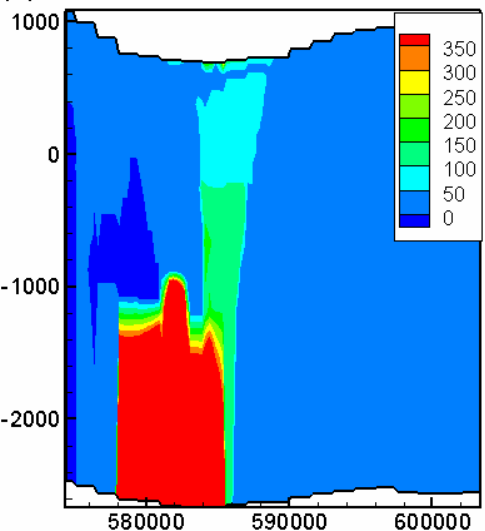

Figure D-20. Contours of cell-by-cell flow crossing the front face of MODFLOW cells $\left(\mathrm{Q}_{\mathrm{y}}, \mathrm{m}^{3} / \mathrm{day}\right)$ predicted at the southern boundary (x-z cross section) of the northern Yucca Flat by models. G1 is the CP Thrust alternative HFM model, and R1 through R5 stands for the MME, NIM1, NIM2, CMB1, and CMB2 recharge models. 

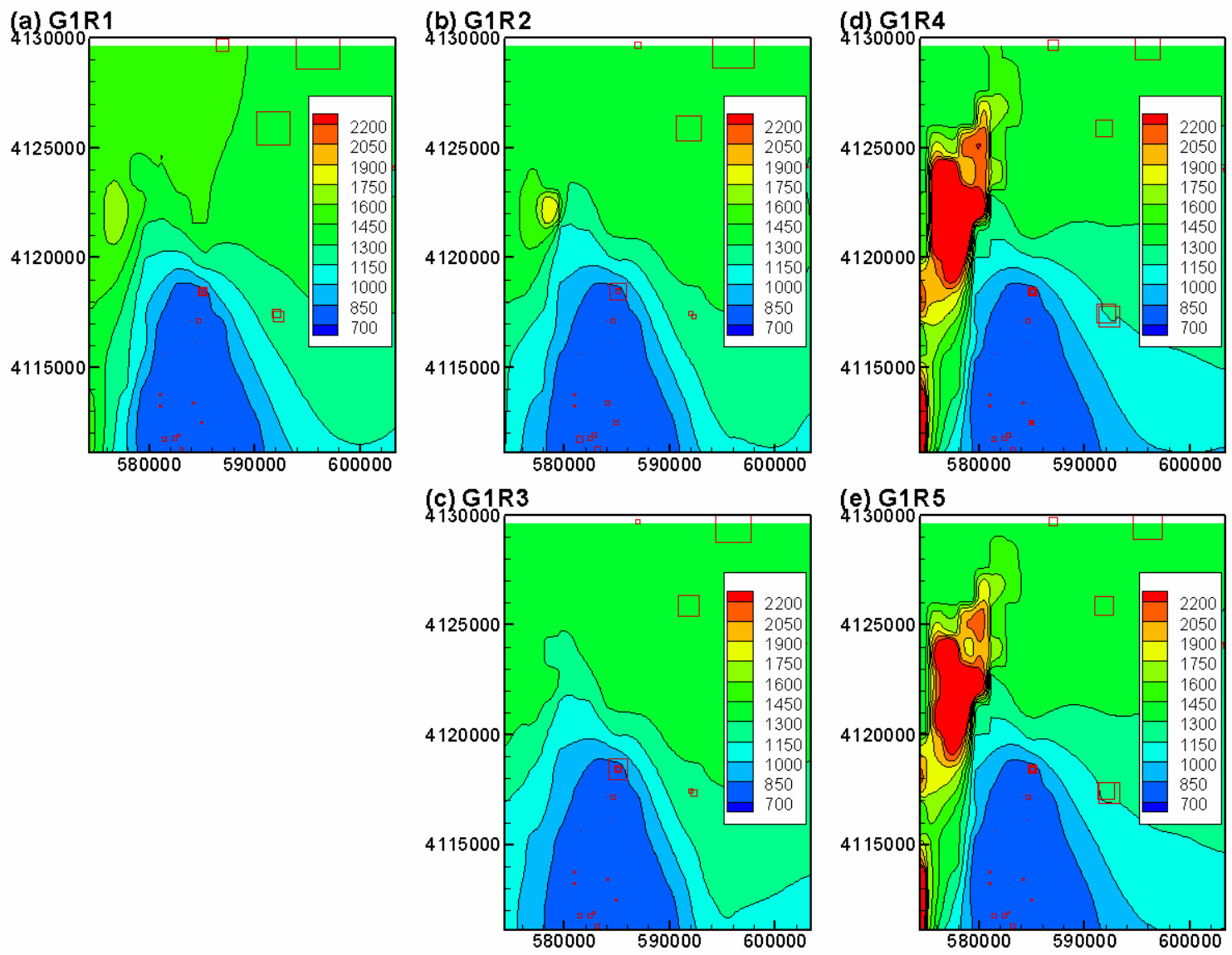

Figure D-21. Scatterplot of residuals of heads and head-changes and contours of hydraulic head at the top layer of the northern Yucca Flat area. Scatter size is proportional to magnitude of the residuals. G1 is the DVRFS HFM model, and R1 through R5 stands for the MME, NIM1, NIM2, CMB1, and CMB2 recharge models. 

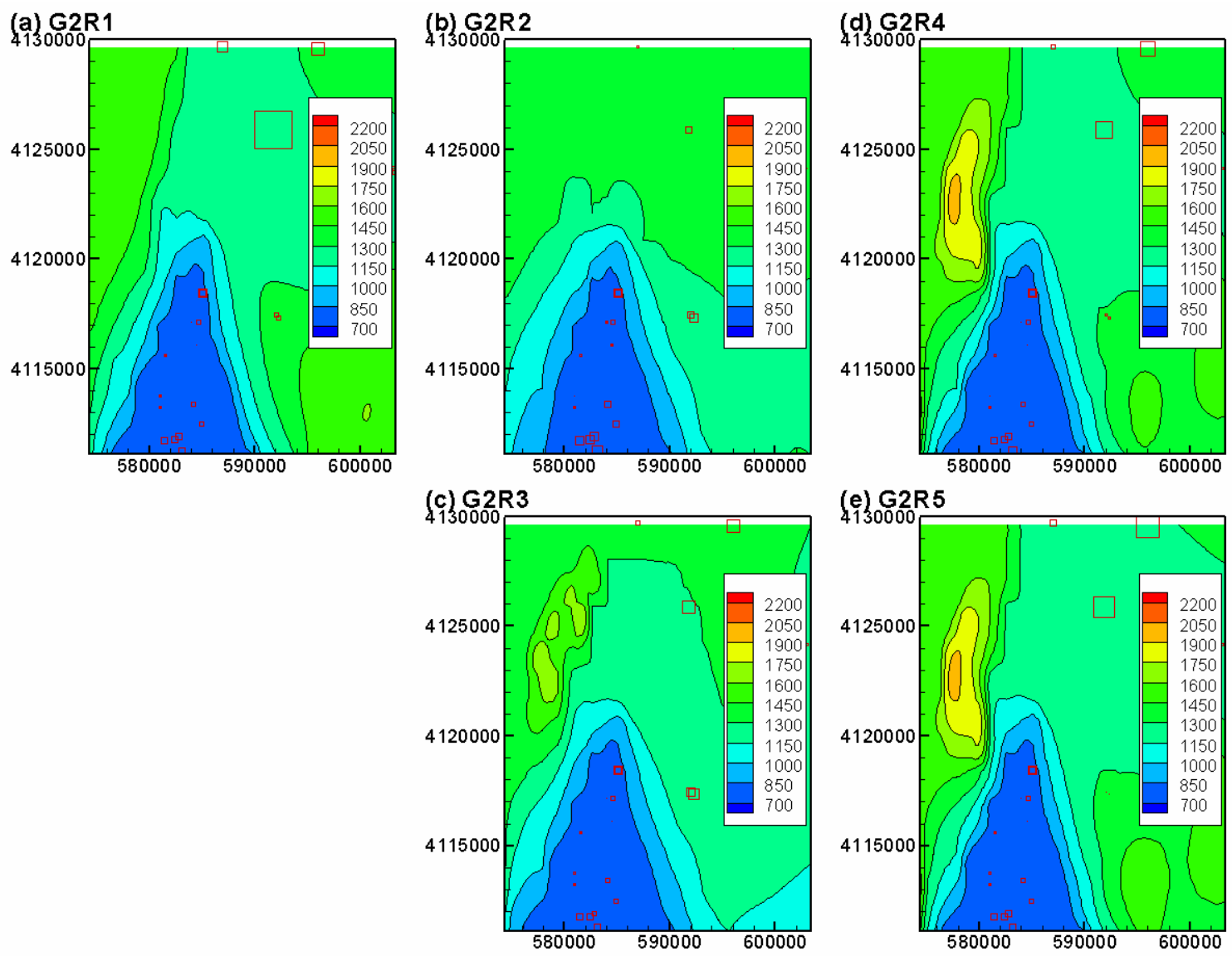

Figure D-22. Scatterplot of residuals of heads and head-changes and contours of hydraulic head at the top layer of the northern Yucca Flat area. Scatter size is proportional to magnitude of the residuals. G2 is the UGTA base model, and R1 through R5 stands for the MME, NIM1, NIM2, CMB1, and CMB2 recharge models. 

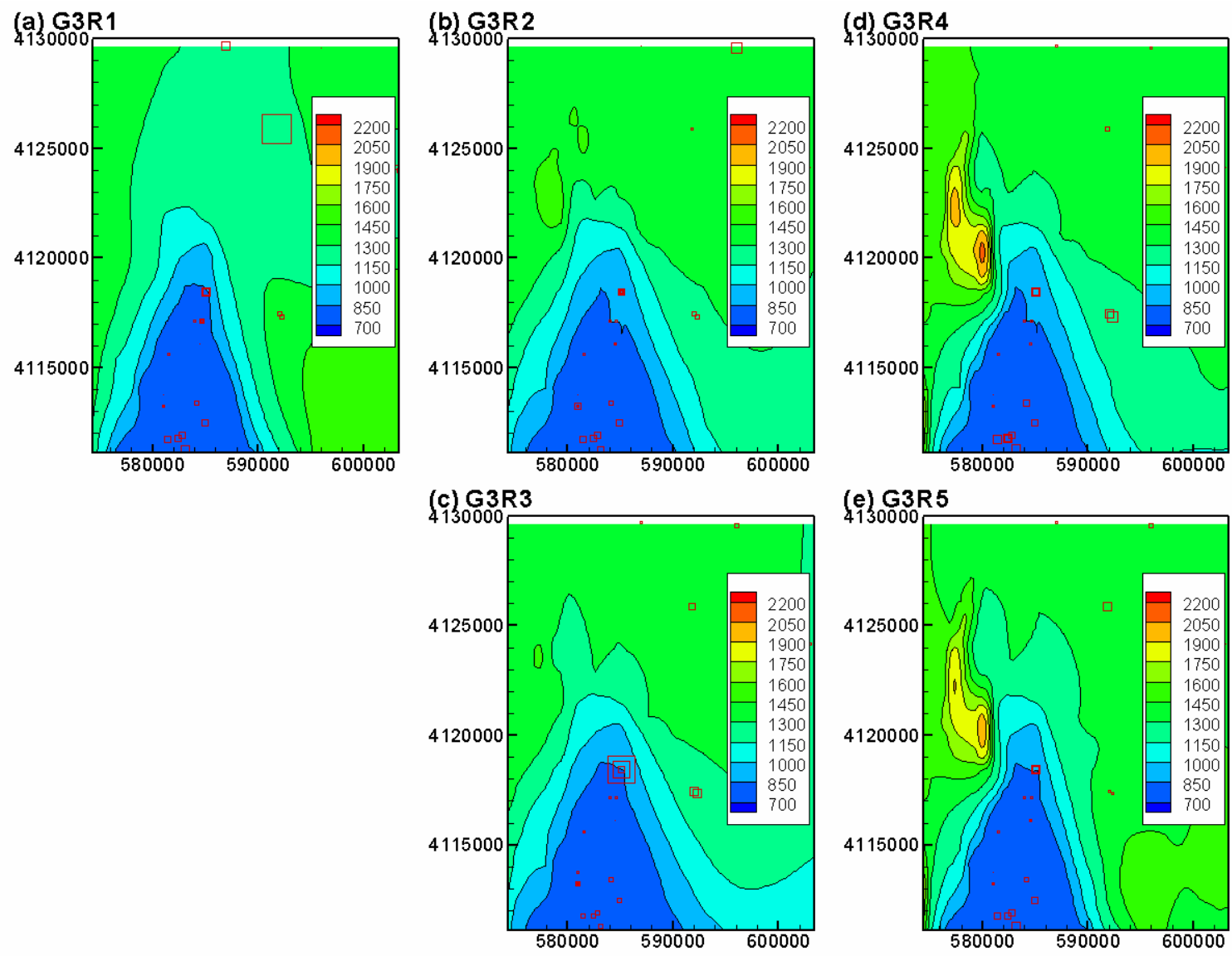

Figure D-23. Scatterplot of residuals of heads and head-changes and contours of hydraulic head at the top layer of the northern Yucca Flat area. Scatter size is proportional to magnitude of the residuals. G3 is the CP Thrust alternative model, and R1 through R5 stands for the MME, NIM1, NIM2, CMB1, and CMB2 recharge models. 

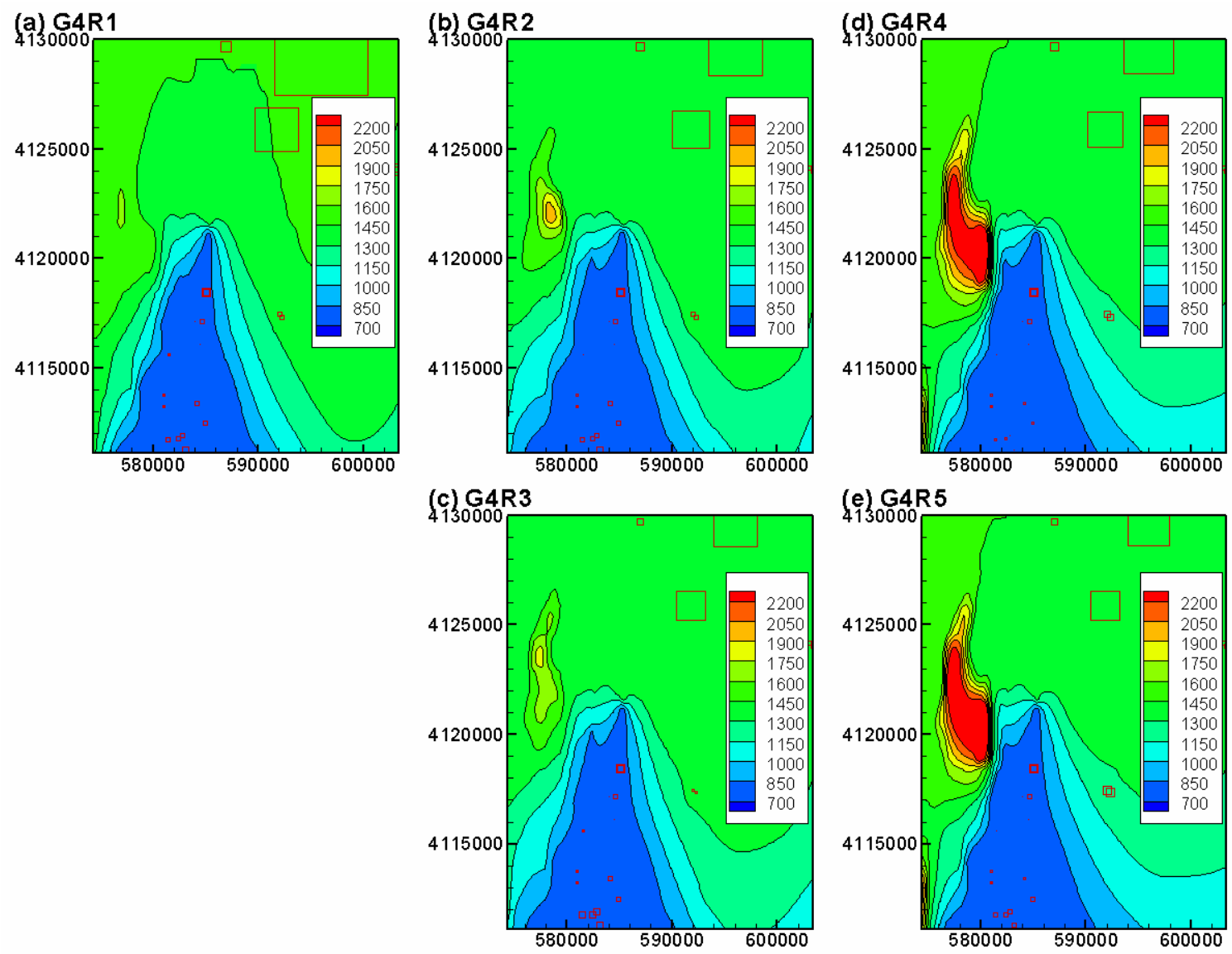

Figure D-24. Scatterplot of residuals of heads and head-changes and contours of hydraulic head at the top layer of the northern Yucca Flat area. Scatter size is proportional to magnitude of the residuals. G4 is the hydrologic barrier alternative model, and R1 through R5 stands for the MME, NIM1, NIM2, CMB1, and CMB2 recharge models. 

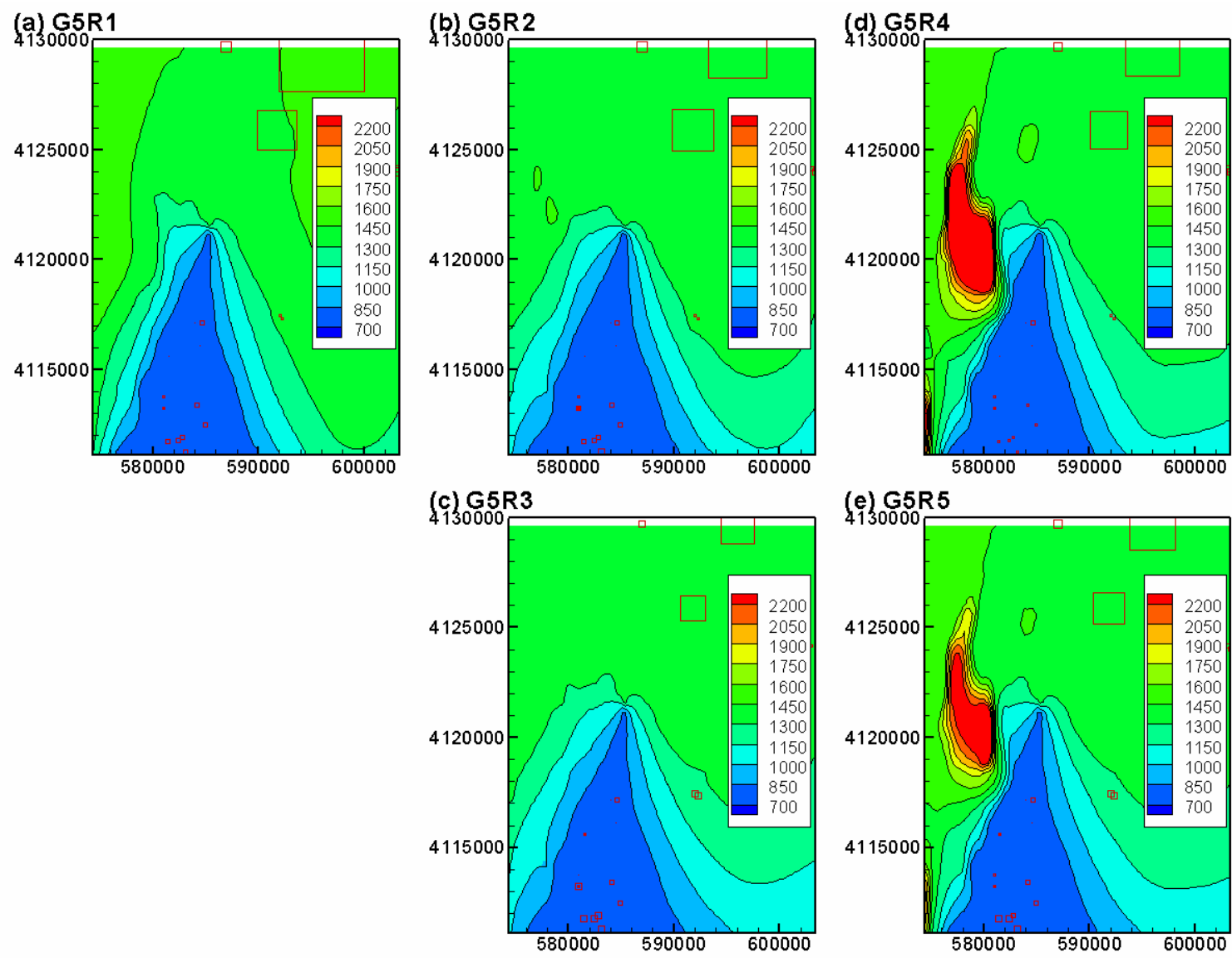

Figure D-25. Scatterplot of residuals of heads and head-changes and contours of hydraulic head at the top layer of the northern Yucca Flat area. Scatter size is proportional to magnitude of the residuals. G5 is the CP Thrust and hydrologic barrier alternative model, and R1 through R5 stands for the MME, NIM1, NIM2, CMB1, and CMB2 recharge models. 


\title{
Appendix E. Refinement of the DVRFS Model Horizontal Mesh
}

\author{
Greg Pohll \\ Division of Hydrologic Sciences \\ Desert Research Institute
}

This appendix describes the methodology used to refine the horizontal simulation mesh of the Death Valley Regional Flow System (DVRFS) model in the area of the northern Yucca Flat of the Yucca Flat-Climax Mine CAU.

\section{Methodology}

The refinement procedure scans the MODFLOW name file and processes all of the files listed, including the name file itself.

Name File The name file is essentially copied to the new directory.

Discretization File This file is processed first as it contains the model geometry. The first step is to build the original grid from the geometry information contained in this file. Next, the program calculates the number of columns and rows required in the refined grid and then calculates the $\mathrm{x}$ - and $\mathrm{y}$-coordinate positions of the entire grid. The vertical discretization remains exactly as specified in the original model.

The program can create a transition zone between the refinement zone and the original discretization. A transition zone is used to gradually adjust the column and row sizes between these zones. The transition zone is created in an iterative fashion by first calculating the number of cells required to transition assuming that adjacent cells change by a factor of 1.5 . The adjustment factor is then changed through an optimization process such that the end of the transition zone directly intersects an existing cell. The optimization routine allows the adjustment factor to vary between 1.1 and 1.6 to abut the transition zone to the original cell locations exactly. If a transition zone is not requested, then the refinement zone abuts directly to the original cells. The model also adjusts the refinement rectangle such that it directly overlays existing cell coordinates.

The top and bottom elevations are mapped directly to the new grid without interpolation. Direct mapping is done by locating the center of each new cell and then determining which original cell it is located within. The original cell elevations are then mapped to the new cell. If a transition zone is used, then the cell-refined cell elevations will not be exactly the same as the original grid, as the refined cell edges do not directly coincide with the original grid locations within this zone.

The time-stepping information for the refined model is taken directly from the original model so the temporal discretization for both models is identical. 
Once the refined grid geometry is calculated, the program constructs the refine discretization file. If requested, the program will also output a two-dimensional GMS grid file for the original and new grids.

BAS6 File The basic package file, which contains IBOUND and INITIAL HEAD arrays, is processed similar to the cell elevations. These arrays are directly mapped to the refined grid.

CHD File The CHD file contains information on the specified head boundary conditions. Each specified head cell location is transferred to the refined model by direct mapping. An additional step is required to ensure that the original specified head cell area is mapped to the refined model. If, for example, at a given specified head cell in the original model there are five refined cells, then all five cells in the refined model are represented as a specified head cell.

CHOB File The CHD file contains information on the segments in which specified head boundary flows are to be calculated and compared against observed values. This file is processed in a manner similar to the CHD file such that each specified head flow observation segment is directly mapped to the refined model. As with the CHD file, each observation cell taken from the original model may be represented my multiple cells in the refined model.

DRN File This file contains information on the locations of all model drains. The program provides two options to map the drains to the refined model. One option maps a single original model drain cell to a single refined model drain cell. The second option allows multiple drains in the refined model to represent a single drain cell in the original model. The latter option is done to provide consistency in the total drain cell area between models.

DROB File This file contains information on the locations of drain observations. The options chosen for single or multiple drain representation are transferred to this file as well. For example, if the multiple drain option is chosen, then the all drains mapped to the refined model are included within the appropriate drain observation group.

HFB6 File This file contains information on the locations of horizontal flow barriers. Each flow barrier segment in the original model is mapped to the refined model while ensuring that there are no gaps within segments.

HOB File This file contains information on the location of head observations. Head observations are mapped to the refined model by first locating the position of the observation as defined by the original model cell indices and the offset coefficients. The offset coefficients ( $C O F F$ and $R O F F$ ) indicate the position relative to the center of the cell. The coordinate position of the head observation is used to calculate the row and column indices within the new model and the revised offset coefficients.

HUF File This file contains information on the geologic model. Each geologic unit is represented by a top elevation and thickness. These arrays are processed in a manner similar to the cell elevation arrays. As was the case with the starting heads, the geologic unit 
elevations and thicknesses may not directly coincide with the original model if the transition zone option is used.

HYD File This file contains information on the location data types in which time-series data will be recorded. The HYDMOD package uses model coordinates rather than cell indices to specify locations, so this file did not need to be modified to reflect the new grid information.

KDEP File This file contains information in the depth dependence of hydraulic conductivity. This file contains an array of the land surface elevation that had to be mapped to the revised grid.

MULT File This file contains an array of recharge multipliers that had to be mapped to the revised grid.

OBS File No changes are made to the OBS file.

PCG File No changes are made to the PCG file.

PES File No changes are made to the PES file.

$\underline{\mathrm{RCH}}$ File No changes are made to the $\mathrm{RCH}$ file as the recharge rates and recharge zones are input in the MULT and ZONE files.

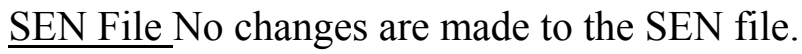

ZONE File The ZONE file contains various integer arrays specifying the location of geologic, recharge, and specific yield locations. Each of these arrays is mapped directly to the revised grid.

MNW1 File This file contains information on the multi-node wells. A one-to-one mapping is used such that each well in the original model is represented by a single well in the revised model.

\section{Results}

Revised Grid The original and refined grids are shown in Figure E-1. The original and refined grids are shown in black and yellow, respectively. Since the refined grid overlaps the original grid outside of the refinement zone, the refined cells are not visible in this region.

Simulated Water Budget Tables E-1 and E-2 show the results of the simulated water budget for the original and refined models for stress periods 1 and 87, respectively. Stress period 1 is the steady-state period, and 87 is the final transient stress period. The refined model is predicting approximately 13 percent larger fluid across the specified head boundaries. The overall fluid rate within the refined model is seven and five percent larger for the steady-state and final transient stress periods, respectively. 
A hypothetical simulation was constructed to evaluate the potential fluid rate differences between a high-resolution and low-resolution model. The test simulations showed that global fluid rates could be as much as 20 percent different between the low- and high-resolution models if the underlying hydraulic conductivity field is heterogeneous. The spatial distribution of hydraulic conductivity was mapped from the low-resolution model to the high-resolution model in a manner similar to the methodology described above.

Simulated Hydraulic Heads Figure E-2 shows the potentiometric surface from the original and refined models for the steady-state stress period. Figure E-3 shows the difference in hydraulic heads between the original and refined models (original - refined). The largest differences are found in the refined and transition zones. The maximum difference between the two models is $96 \mathrm{~m}$ (refined model simulates a hydraulic head of $96 \mathrm{~m}$ less than the original model). The original model also simulates higher heads in the west central portion of the model adjacent to a horizontal flow barrier. The mapping of the horizontal flow barriers was checked in this region and all barrier cells are being mapping properly. 


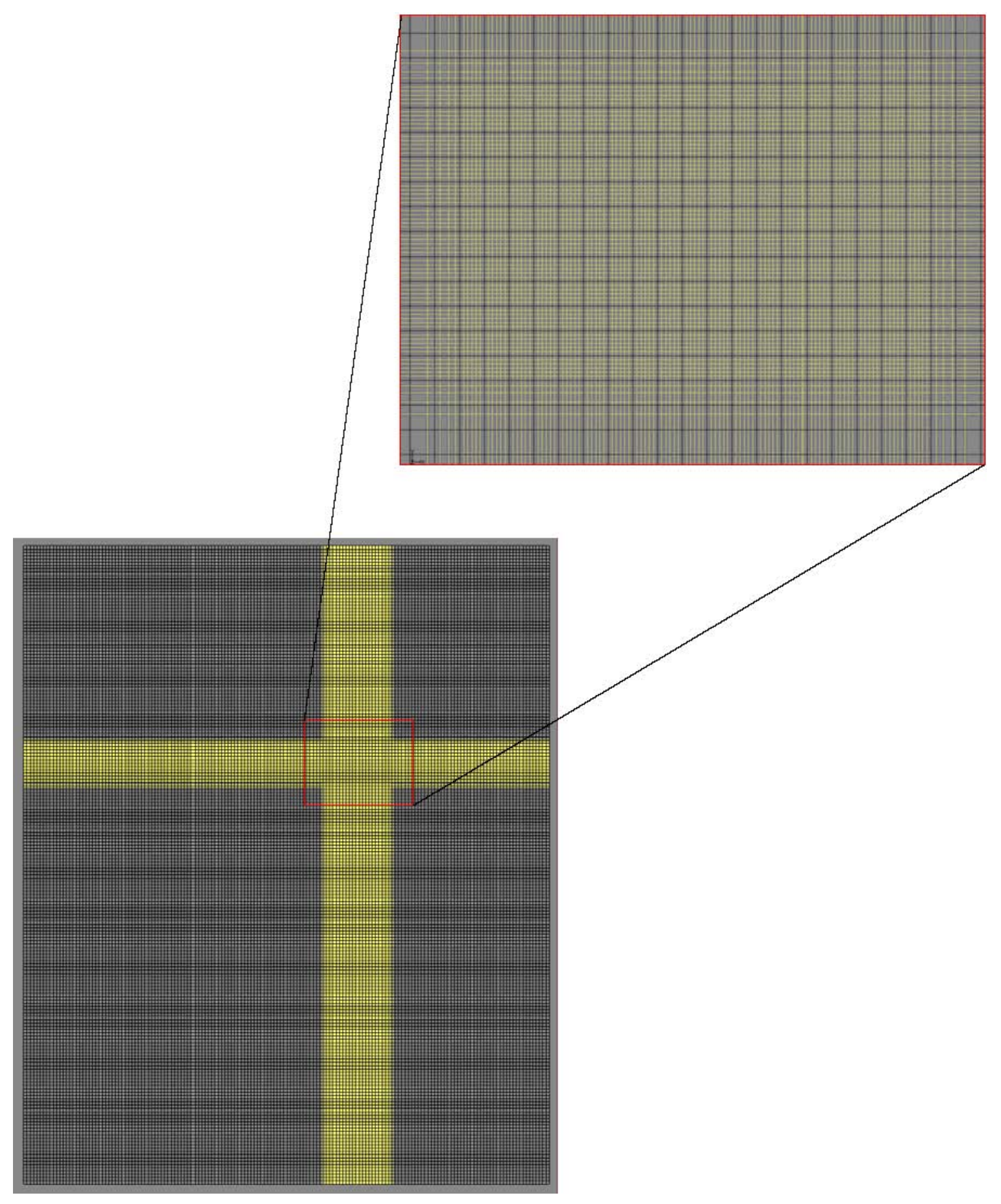

Figure E-1. The DVRFS model grid (black) and 250-m refined grid (yellow). 


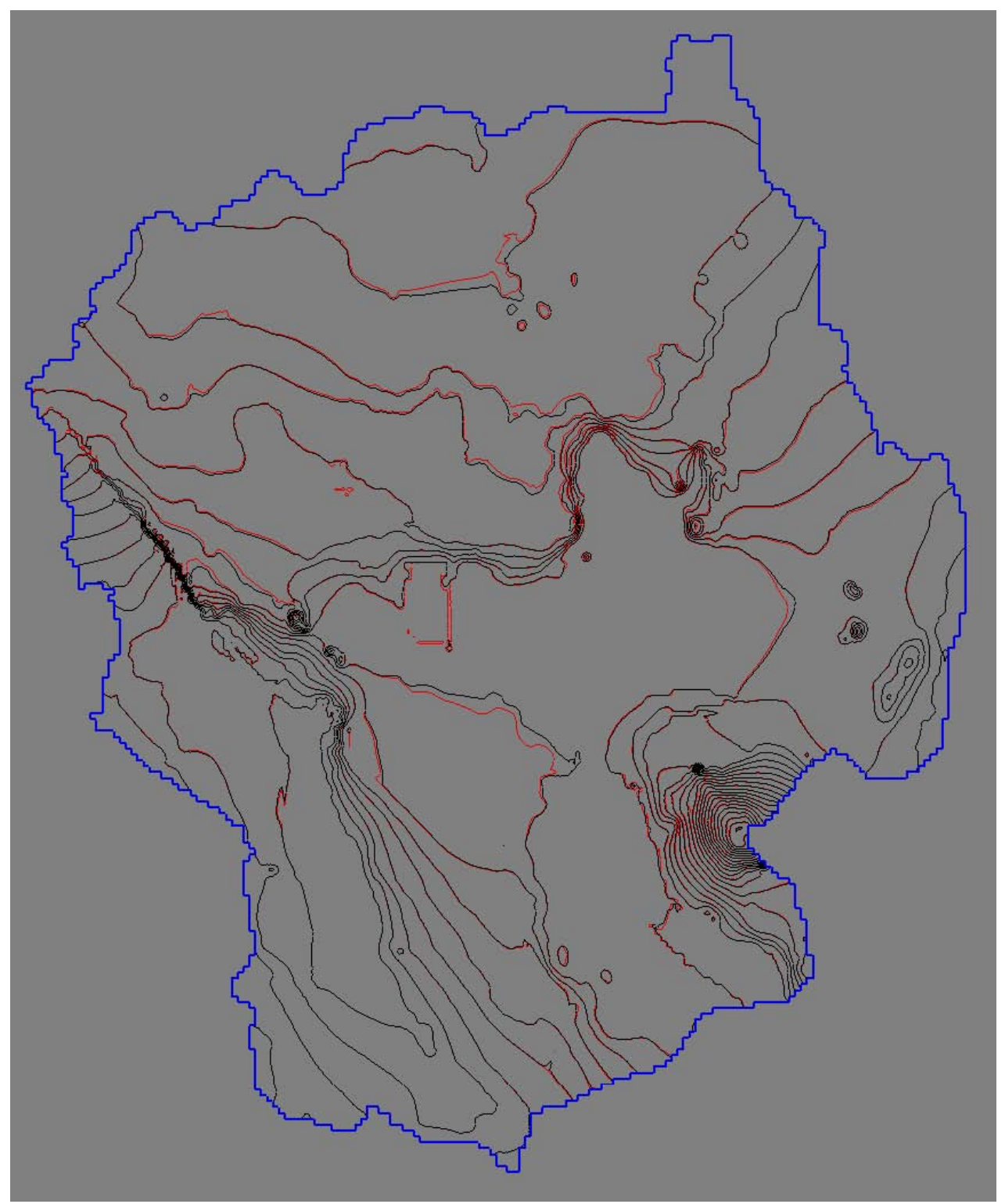

Figure E-2. Potentiometric map from original (black) and refined (red) models. Both models are shown with a $100-\mathrm{m}$ contour interval. 


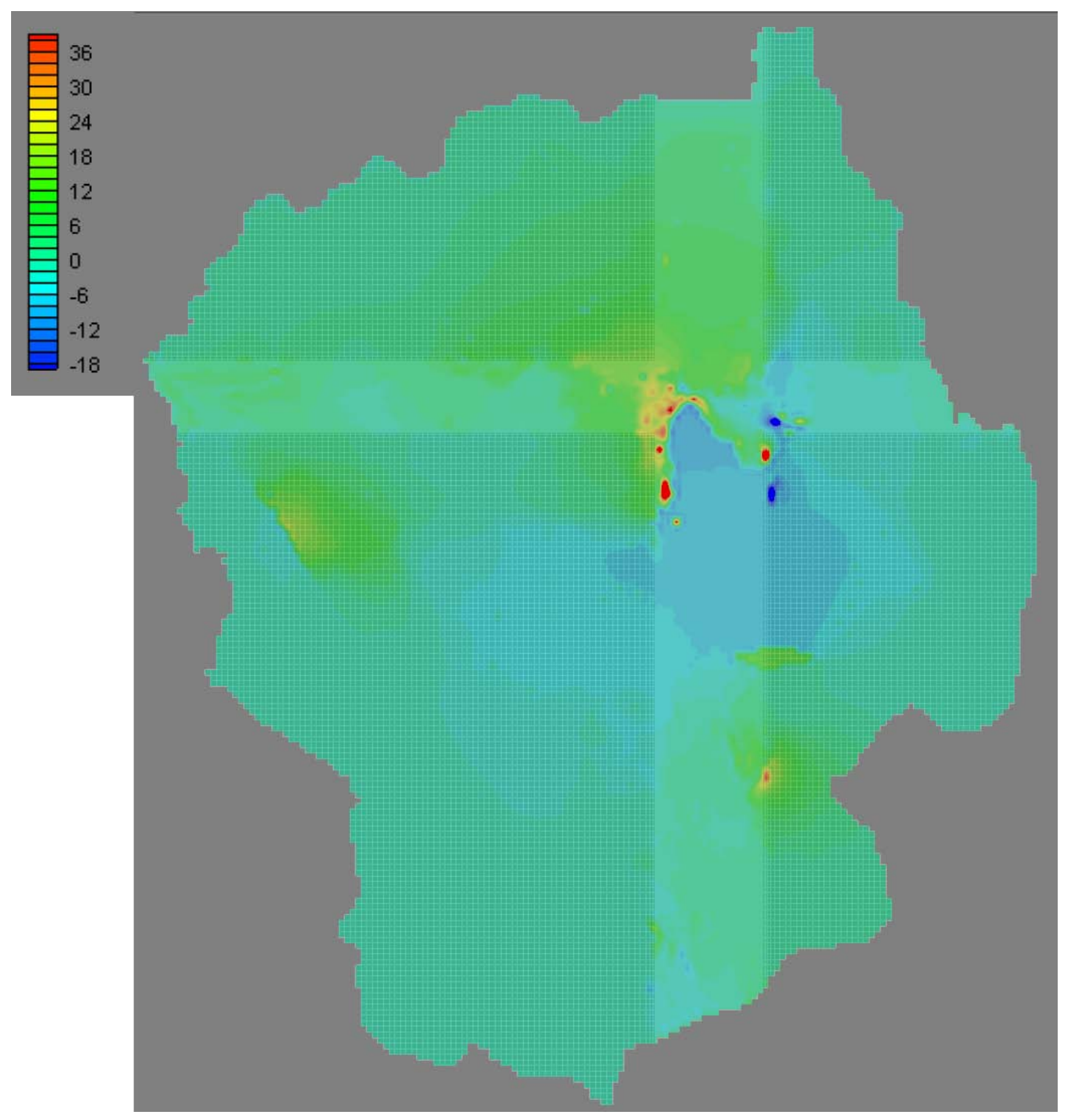

Figure E-3. Difference in hydraulic heads between original and refined model (original - refined). 
Table E-1. Fluid mass balance for stress period 1.

\begin{tabular}{|c|c|c|c|}
\hline \multicolumn{4}{|c|}{ Fluid Rates IN ( $\mathrm{m}^{3} /$ day) } \\
\hline Item & USGS & Refined & $\%$ Difference \\
\hline Storage & 0 & 0 & \\
\hline Constand Head & 341,263 & 384,927 & $-12.79 \%$ \\
\hline Drains & 0 & 0 & \\
\hline Recharge & 303,415 & 303,505 & $-0.03 \%$ \\
\hline Wells & 0 & 0 & \\
\hline & 644,678 & 688,432 & $-6.79 \%$ \\
\hline
\end{tabular}

\begin{tabular}{|c|c|c|c|}
\hline \multicolumn{4}{|c|}{ Fluid Rates OUT ( $\mathrm{m}^{3} /$ day) } \\
\hline Item & USGS & Refined & $\%$ Difference \\
\hline Storage & 0 & 0 & \\
\hline Constant Head & 282,305 & 320,071 & $-13.38 \%$ \\
\hline Drains & 362,280 & 368,176 & $-1.63 \%$ \\
\hline Recharge & 0 & 0 & \\
\hline Wells & 0 & 0 & \\
\hline Total: & 644,584 & 688,247 & $-6.77 \%$ \\
\hline Difference: & 93 & 185 & \\
\hline \% Difference: & $0.01 \%$ & $0.03 \%$ & \\
\hline
\end{tabular}

Table E-2. Fluid mass balance for stress period 87.

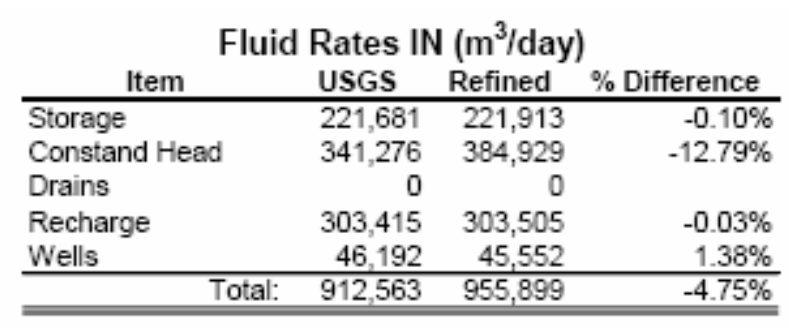

\begin{tabular}{|c|c|c|c|}
\hline \multicolumn{4}{|c|}{ Fluid Rates OUT ( $\mathrm{m}^{3} /$ day) } \\
\hline Item & USGS & Refined & $\%$ Difference \\
\hline Storage & 9,114 & 9,172 & \\
\hline Constant Head & 282,300 & 320,070 & $-13.38 \%$ \\
\hline Drains & 344,591 & 351,260 & $-1.94 \%$ \\
\hline Recharge & 0 & 0 & \\
\hline Wells & 276,020 & 275,380 & $0.23 \%$ \\
\hline Total: & 912,024 & 955,882 & $-4.81 \%$ \\
\hline Difference: & 539 & 18 & \\
\hline \% Difference: & $0.06 \%$ & $0.00 \%$ & \\
\hline
\end{tabular}


Appendix F. Data Analysis of Fracture, Fault, and Joint Distribution and Orientation in Climax Stock (located on CD at back of report) 
THIS PAGE INTENTIONALLY LEFT BLANK 


\section{Appendix G. Examples of Matching Temperature History of Nuclear Test Glass Zones Using an Analytical Solution}

\section{Example 1: Transient Cambric HST Model}

As a first example of the effectiveness of the analytical solution, the temperature history of the glass zone at the Cambric site is examined. Hydrologic source term simulations being conducted in fiscal year (FY) 2005 (Tompson et al., 2005) have examined the temperature history of the Cambric site at great detail. Although little direct information is available on the cooling history of the glass at the Cambric site, it is known that the glass zone temperature decreased to near ambient within 10 years of the test. This result was predicted based on nonisothermal flow and transport calculations conducted at Lawrence Livermore National Laboratory (Tompson, 2005). In these simulations, the initial glass zone temperature was set to the boiling temperature of water under hydrostatic conditions $\left(170^{\circ} \mathrm{C}\right)$ and both conductive and convective heat loss were simulated. The simulation results were in good agreement with the drillback information suggesting ambient temperatures in the glass zone by 10 years (Figure G-1).

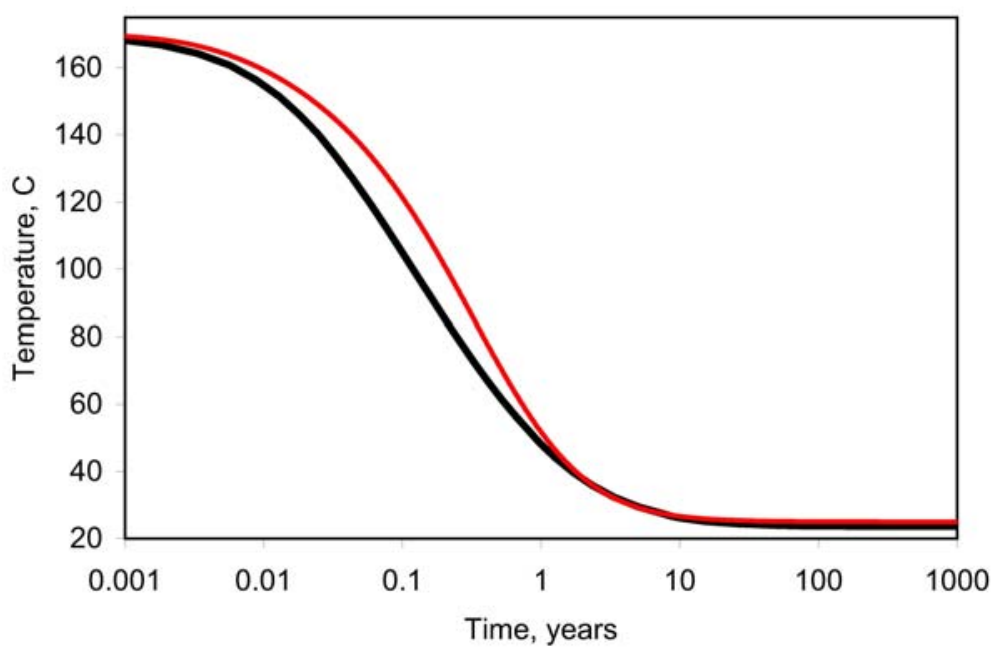

Figure G-1. Comparison of nonisothermal flow model calculation of Cambric glass mean temperature history (black) with the analytical solution mean temperature history (red).

The analytical solution was based on a bulk density of $2,200 \mathrm{~kg} / \mathrm{m}^{3}$, porosity of 0.32 , $1 \mathrm{cal} / \mathrm{g} /{ }^{\circ} \mathrm{C}$ heat capacity of water, $0.20 \mathrm{cal} / \mathrm{g} /{ }^{\circ} \mathrm{C}$ heat capacity of rock, and $2 \mathrm{~W} / \mathrm{m} /{ }^{\circ} \mathrm{C}$ conductivity of rock, which results in a thermal diffusivity of $7.24 \times 10^{-7} \mathrm{~m}^{2} / \mathrm{s}$. The height of the glass puddle, based on gamma log data, was estimated to be $7.4 \mathrm{~m}$, resulting in a glass zone volume of $1,881 \mathrm{~m}^{3}$. To preserve a volume balance for the glass zone, the effective width of the parallelepiped shown in Figure 5-11 (2a, 2b) was calculated to be $15.94 \mathrm{~m}$. Except for the glass zone porosity (which varied in the flow model) and the shape of the glass zone, all the parameters used in the analytical solution were identical to those in the flow model. It appears from this comparison that: 1) the analytical solution compares very well with the nonisothermal flow model and 2) heat loss from Cambric occurred principally 
through conduction and not convection. The slightly lower temperatures in the flow model, particularly at 0.1 years, appear to be the only indication of convective heat loss.

The choice of initial glass zone temperature is, in some respects, one of convenience rather than realism. However, there are also good reasons for choosing the hydrostatic boiling temperature, particularly for saturated tests. A temperature of $170{ }^{\circ} \mathrm{C}$ was chosen because it is the highest temperature, under ambient hydrostatic conditions, that the glass zone water may experience without boiling. At early time, temperatures in the cavity are thousands of degrees. However, at these high temperatures, boiling will quickly drive heat out of the glass zone and reduce the glass zone temperature. Butkovich (1974) used Hugoniot equations of state to estimate the temperature distribution after a nuclear detonation but before any displacement occurs. Butkovich used the heat capacity for granite in these calculations $\left(0.2\right.$ to $\left.0.26 \mathrm{cal} / \mathrm{g} /{ }^{\circ} \mathrm{C}\right)$. While the heat capacity of alluvium may be slightly different, it is not sufficiently different to alter the conclusions of this analysis. The equation that defines the relationship between yield, rock density, distance, and temperature is

$$
\Delta T=\frac{8.9 \times 10^{5}}{\rho^{3.156}}\left(\frac{R}{W^{1 / 3}}\right)^{\frac{-4.576}{\rho^{0.411}}}
$$

where $\rho$ is the rock density (calculations assume dry rock), $R$ is the radial distance from the working point, $W$ is the yield in kilotons, and $\Delta T$ is the change in temperature. Figure G-2 is a plot of the predicted initial temperature distribution in a nuclear test cavity. Clearly, the rock in the vicinity of the working point initially experiences temperatures much higher than the hydrostatic boiling temperature. However, mixing between melt glass and infallen chimney material and boiling of infiltrated water will quickly and drastically decrease the temperature of the melt glass zone. Importantly, the temperature profile in Figure G-2 extends radially from the working point and far beyond the cavity. Peterson et al. (1991) estimated that only 30 to 50 percent of the total energy associated with a test is deposited within the melt glass in the first milliseconds after a test. Using the earlier estimates of heat capacity, a glass zone volume of $1,881 \mathrm{~m}^{3}$ (with a large quantity of infallen rubble material), and the assumption that 30 percent of the test yield energy is deposited in the melt glass zone, the initial Cambric glass zone temperature was estimated to be $215^{\circ} \mathrm{C}$ above ambient. This is in approximate agreement with the maximum mixing model reported by Petersen et al. (1991) (Figure G-3). Thus, while the initial temperatures predicted milliseconds after a test may be as high as several thousand degrees or more, melt glass mixing with adjacent alluvium and mixing with infallen rubble should quickly reduce the temperatures in the glass zone. Once chimney collapse has occurred, it is likely that cavity temperatures are on the order of hundreds of degrees $\mathrm{C}$ but certainly not thousands. Boiling of infiltrating water will reduce glass zone temperatures even further.

Interestingly, glass may begin to dissolve prior to the cessation of boiling. Abrajano et al. (1989) measured glass dissolution rates at various relative humidities and found that glass dissolution proceeds above 70 percent relative humidity but is absent or very slow below this value. If it is assumed that the pressures in the cavity are primarily hydrostatic in nature, and that the maximum hydrostatic pressure is observed under ambient groundwater conditions, a calculation can be made of the relative humidity in the glass zone above the boiling temperature of water under hydrostatic conditions. These data are presented for Cambric in Figure G-4. Importantly, this analysis indicates that glass dissolution will not 
occur at temperatures significantly higher that the boiling temperature. However, glass may begin to dissolve at temperatures as high as $185^{\circ} \mathrm{C}$.

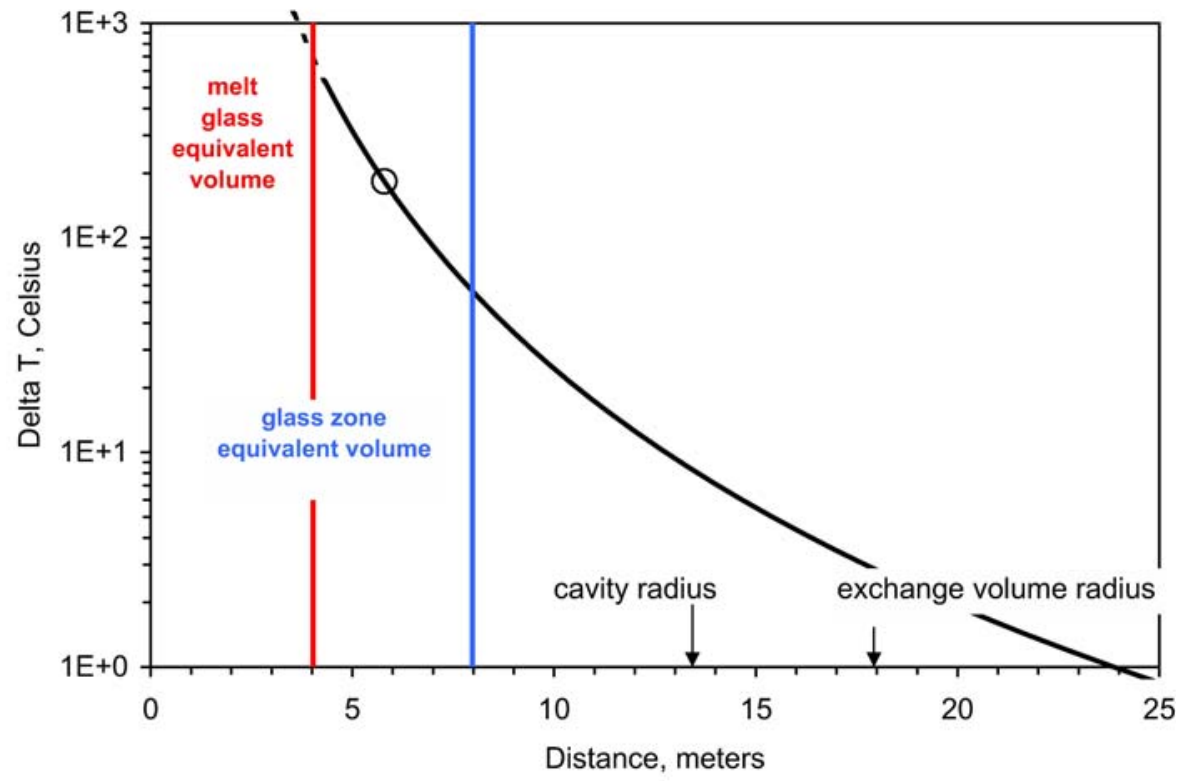

Figure G-2. Initial temperature distribution in the vicinity of the Cambric cavity based on the Hugoniot equations of state reported in Butkovich (1974). Circle indicates this initial temperature used in glass zone temperature history calculations presented in Figure G-1.

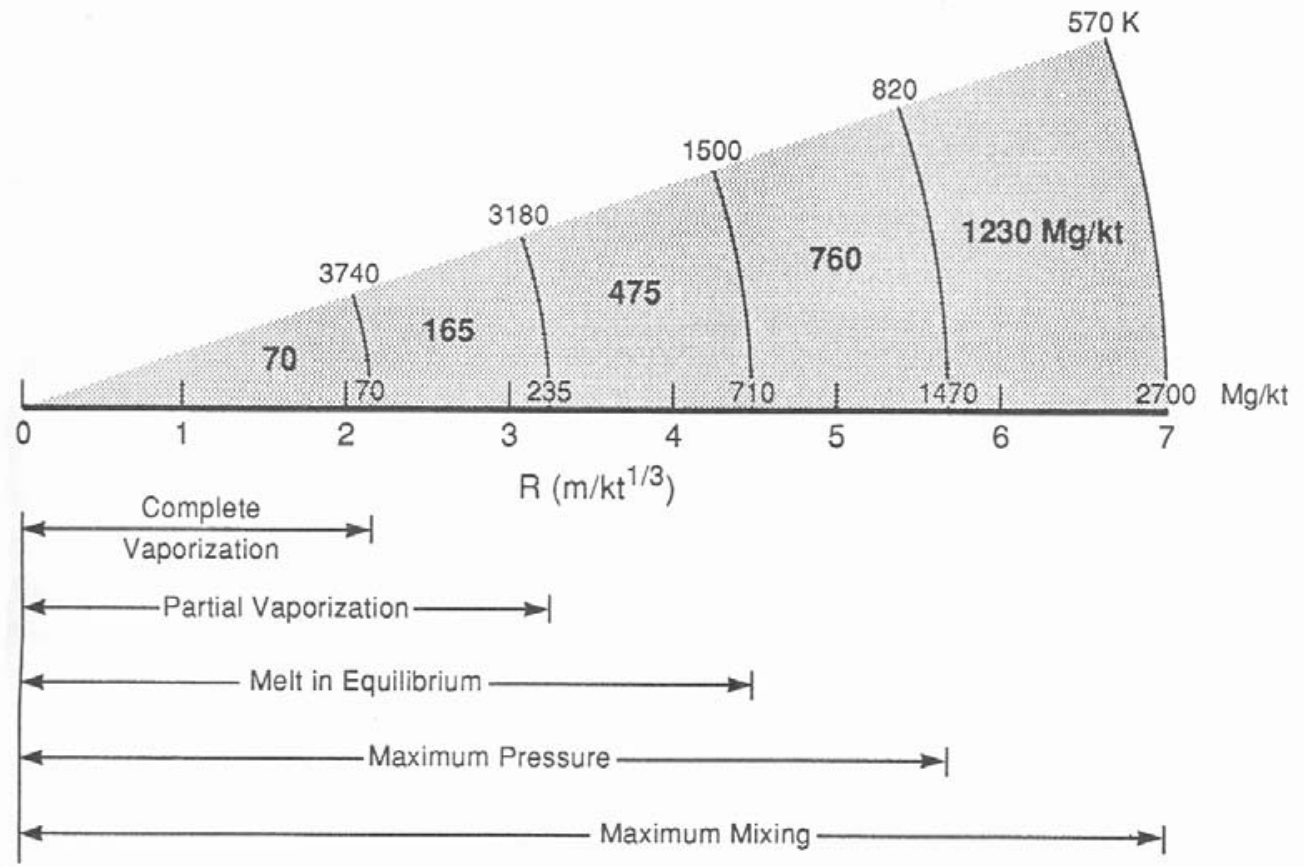

Figure G-3. Evolution of cavity state during mixing and equilibration of wall material. From Petersen et al. (1991). 


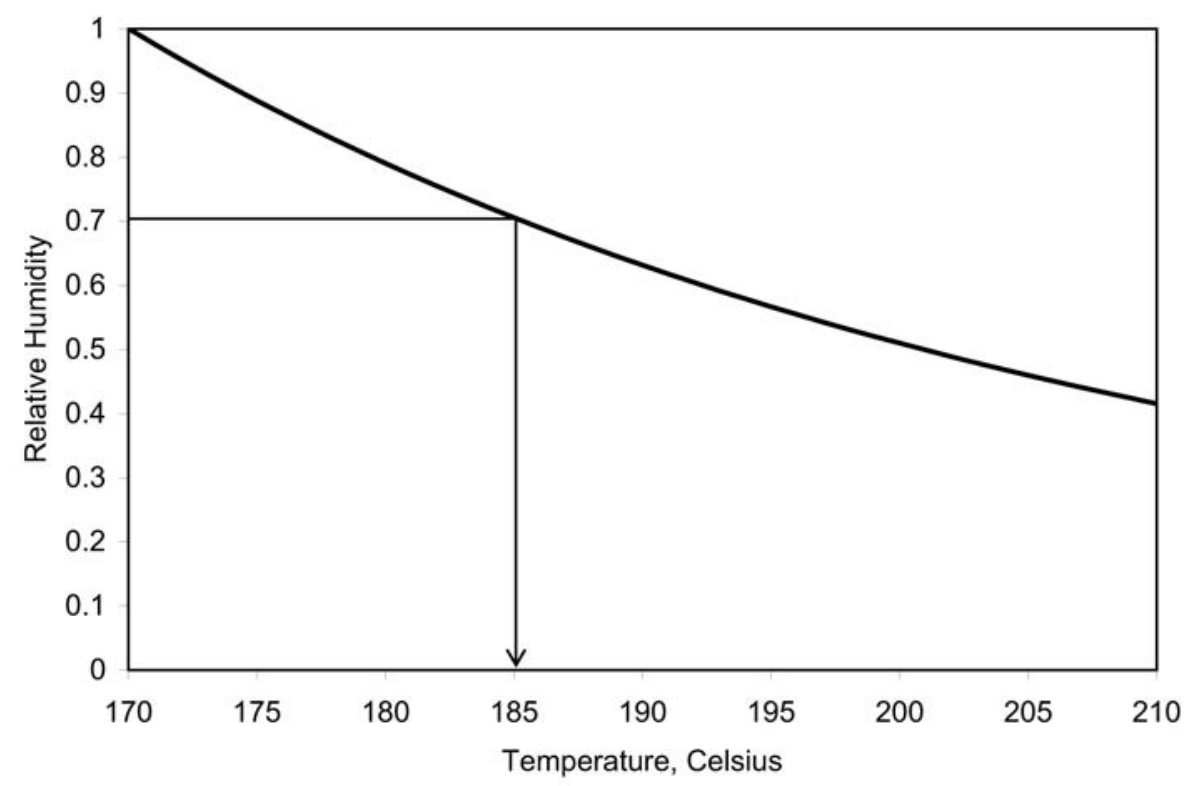

Figure G-4. Relative humidity in the vicinity of the Cambric glass zone as a function of temperature. Note that the boiling point of water near the Cambric glass zone is $170{ }^{\circ} \mathrm{C}$. Based on the measurements of Abrajano et al. (1996), glass dissolution is expected to slow dramatically or cease below 0.7 relative humidity $\left(185^{\circ} \mathrm{C}\right.$ in the case of Cambric).

In summary, initial temperatures in the glass zone may be on the order of thousands of degrees $\mathrm{C}$ in the first milliseconds after a test. However, in the mixing of cavity wall rock and chimney material, melt glass temperatures will quickly decrease to hundreds of degrees C. Boiling of infiltrating water will reduce the glass zone temperatures even further. While the glass zone temperature is likely to be initially well above the hydrostatic boiling temperature, the relative humidity will be too low to allow significant glass dissolution. Glass dissolution will begin only as the glass zone temperature approaches saturation. The ambient hydrostatic pressure at the glass zone provides the maximum initial temperature at which boiling will cease; glass dissolution under unsaturated conditions (above boiling) may occur but only at temperatures slightly above the boiling temperature.

\section{Example 2: Temperature history of three Pahute Mesa tests}

In the report by Carle et al. (2003), heat loss from Cheshire, Greeley, and Almendro was investigated. The focus of these simulations was to investigate heat loss and resaturation of the test cavities and how these affect groundwater transport away from the test cavities at early times. All rocks were assumed to have a dry thermal conductivity of $1.0 \mathrm{~W} / \mathrm{m}^{\circ} \mathrm{K}$, wet thermal conductivity of $2.0 \mathrm{~W} / \mathrm{m}^{\circ} \mathrm{K}$, specific heat of $840 \mathrm{~J} / \mathrm{kg}^{\circ} \mathrm{K}$, and a bulk density of $2,160 \mathrm{~kg} / \mathrm{m}^{3}$. Spatial variation of thermal properties of rocks is typically small and was not considered in the simulations. These same properties were used in the analytical solution for conduction-only heat loss. 
The results for the Cheshire case of Carle et al. (2003) are presented in Figure G-5 along with the analytic solution conducted in the present study based on a hydrostatic boiling temperature initial condition. Carle et al. (2003) varied the initial temperature of the glass zone to examine the sensitivity of temperature history to the choice of initial temperature. The initial temperature used in the analytical solution was set by the maximum temperature of water at the hydrostatic pressure of the bottom of the glass zone. Our hydrostatic temperature is slightly different from the hydrostatic temperature used by Carle. Carle used a hydrostatic pressure at the working point while we used a hydrostatic pressure at the bottom of the cavity. Importantly, Carle's calculations show that boiling ceases and the cavity resaturates quickly (at around 20 days). Furthermore, the mean glass zone temperature decreased rapidly irrespective of the initial temperature of the glass zone. The simulation based on hydrostatic initial conditions resulted in the slowest temperature decrease. Pressures in the cavity were significantly lower in the other simulations which allowed for greater boiling and faster heat redistribution.

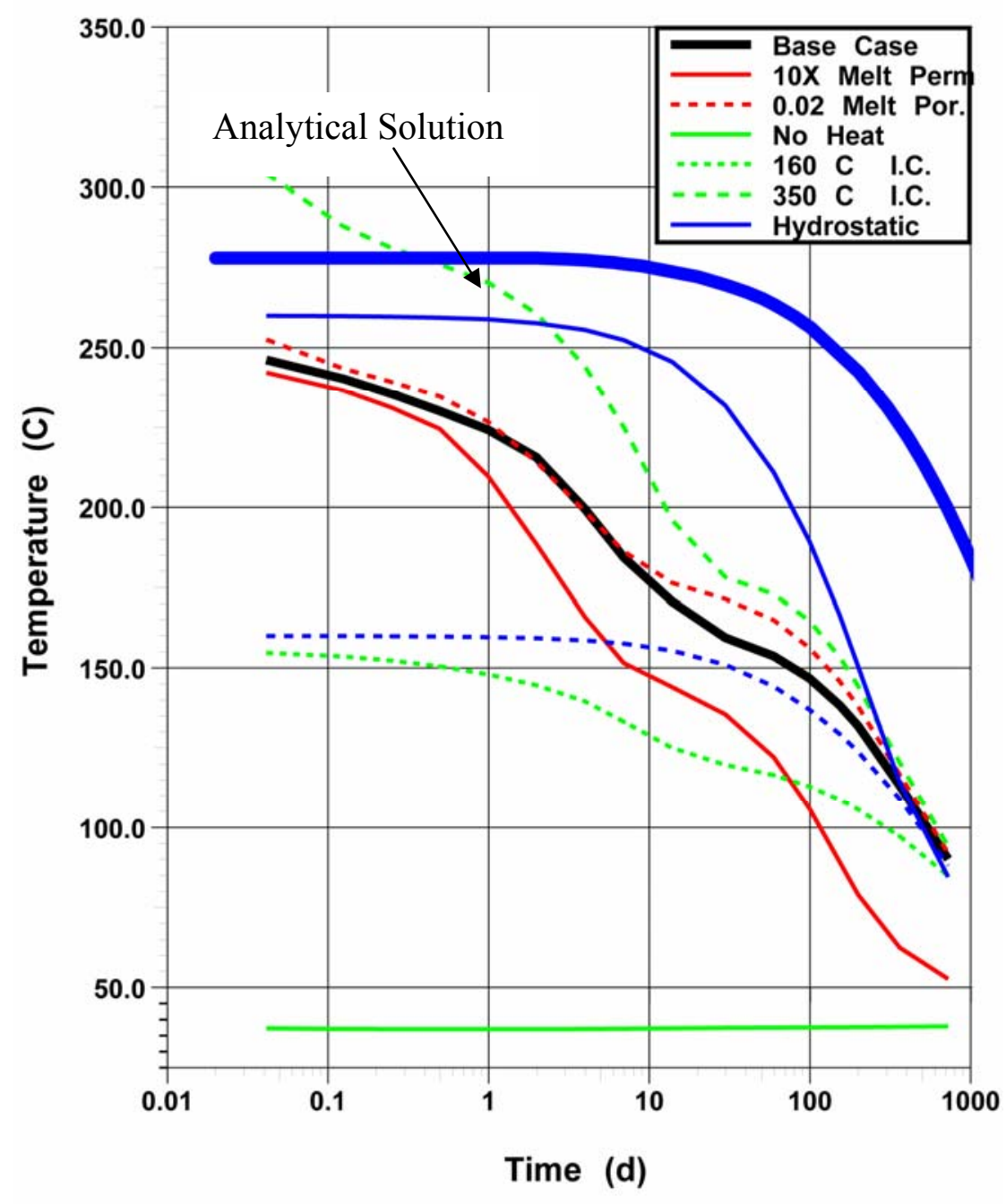

Figure G-5. Simulated mean melt glass zone temperature as a function of time for the Cheshire base case and sensitivity cases of Carle et al. (2003), compared to the conduction-only analytical solution. 
As expected, this study's conduction-only analytical solution resulted in a significantly slower temperature decrease from the glass zone when compared to the simulations of Carle et al. (2003). At the end of boiling and re-saturation of the cavity, the mean glass zone temperature in the analytical solution is approximately $100^{\circ} \mathrm{C}$ higher than the base case of Carle et al. (2003) and about $30^{\circ} \mathrm{C}$ higher than the hydrostatic model. This is attributed to the large convective heat loss from the Cheshire site, especially when compared to the Cambric site. The Cheshire glass zone initially provides a much larger heat source and is hydrologically connected to a high-permeability chimney and highpermeability fractured lavas. As a result, convective heat loss is much greater than conductive heat loss.

A comparison of the analytical solution to the simulations of Carle et al. (2003) for the Greeley test (Figure G-6) leads to similar conclusions. Rates of cooling are qualitatively similar for all the Greeley sensitivity studies, while the hydrostatic simulation consistently shows the slowest cooling rates, an observation attributed by Carle et al. (2003) to the higher boiling point under hydrostatic pressure. It should be noted that the hydrostatic sensitivity simulation initial conditions used by Carle et al. (2003) for the Greeley test are different from those used in the analytical solution. Carle et al. (2003) set the initial conditions at hydrostatic but allowed the glass zone temperature to initially be much higher than the boiling point at that pressure. The rapid cooling of the glass zone can be attributed to heat redistribution as a result of boiling. Similar to Cheshire, the mean glass temperature in the Greeley analytic solution based on hydrostatic initial glass temperature is higher than any of the flow simulations once boiling has ceased and the cavity resaturates (approximately 60 days at Greeley). Comparison of the temperature histories of the analytical and numerical solutions indicates that convective cooling contributes significantly to the rapid decrease in mean glass temperatures in Carle et al.'s simulations. Ignoring convection and using the analytical conduction-only solution provides a conservative estimate of glass zone cooling rates.

Comparing the base-case simulations of Cheshire and Greeley to the simulation of Almendro provides additional insight into the cooling behavior of these Pahute Mesa tests (Figure G-7). In the Almendro case, the conduction-only analytical solution is quite similar to the flow model of Carle et al. (2003), particularly once the cavity has resaturated. The Almendro cavity is believed to be hydrologically isolated from the surrounding rock due to its location in a very low permeability rock and sealing of any high permeable fractures. Thus, it should not be surprising that the cooling rates are much slower than for Cheshire or Greeley. It should also not be surprising that the cooling rates calculated based on the conduction-only analytical solution are comparable to the flow model developed by Carle et al. (2003). 


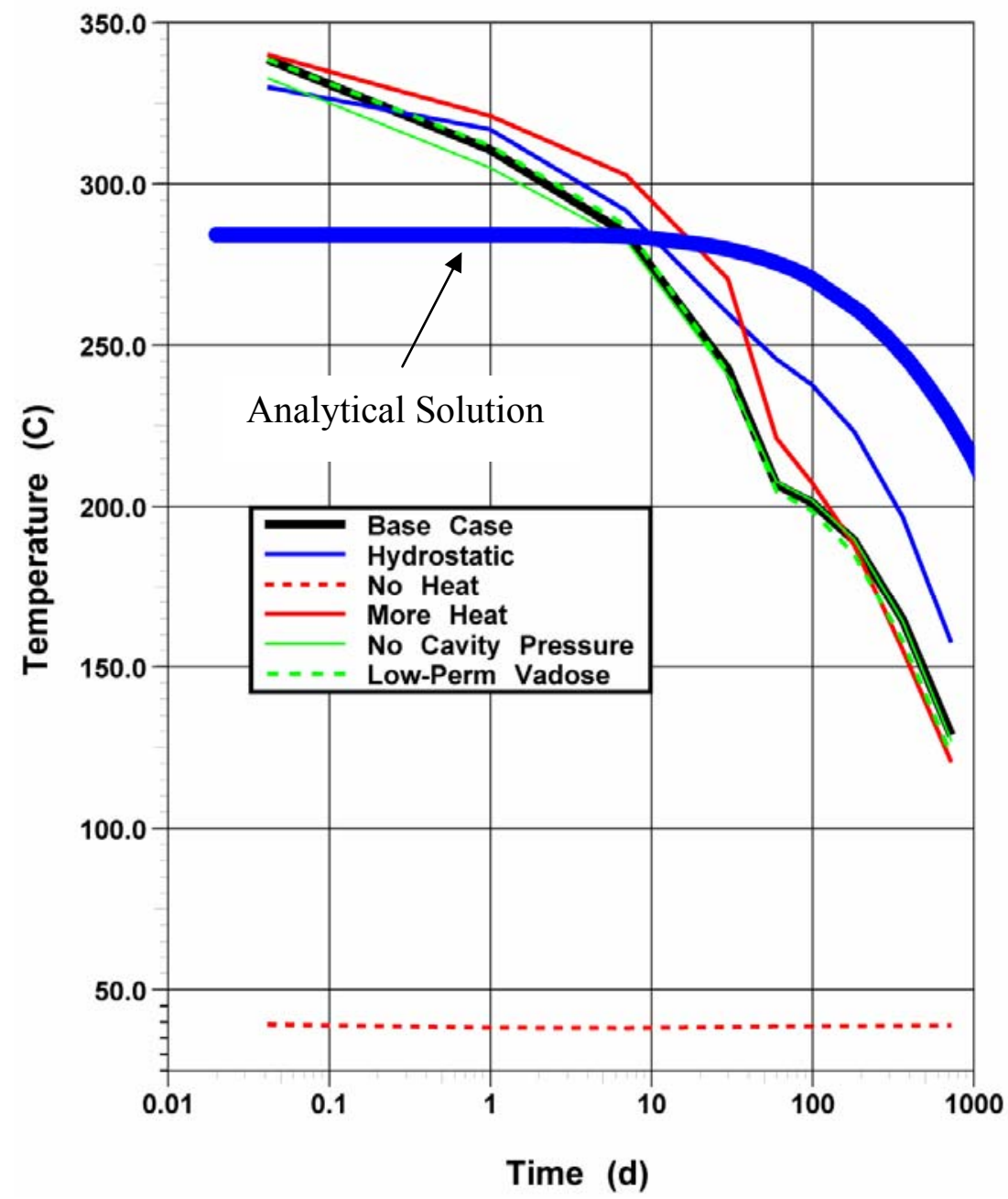

Figure G-6. Simulated mean melt glass zone temperature as a function of time for the Greeley base-case and sensitivity cases of Carle et al. (2003) compared with the conduction-only analytical solution. 

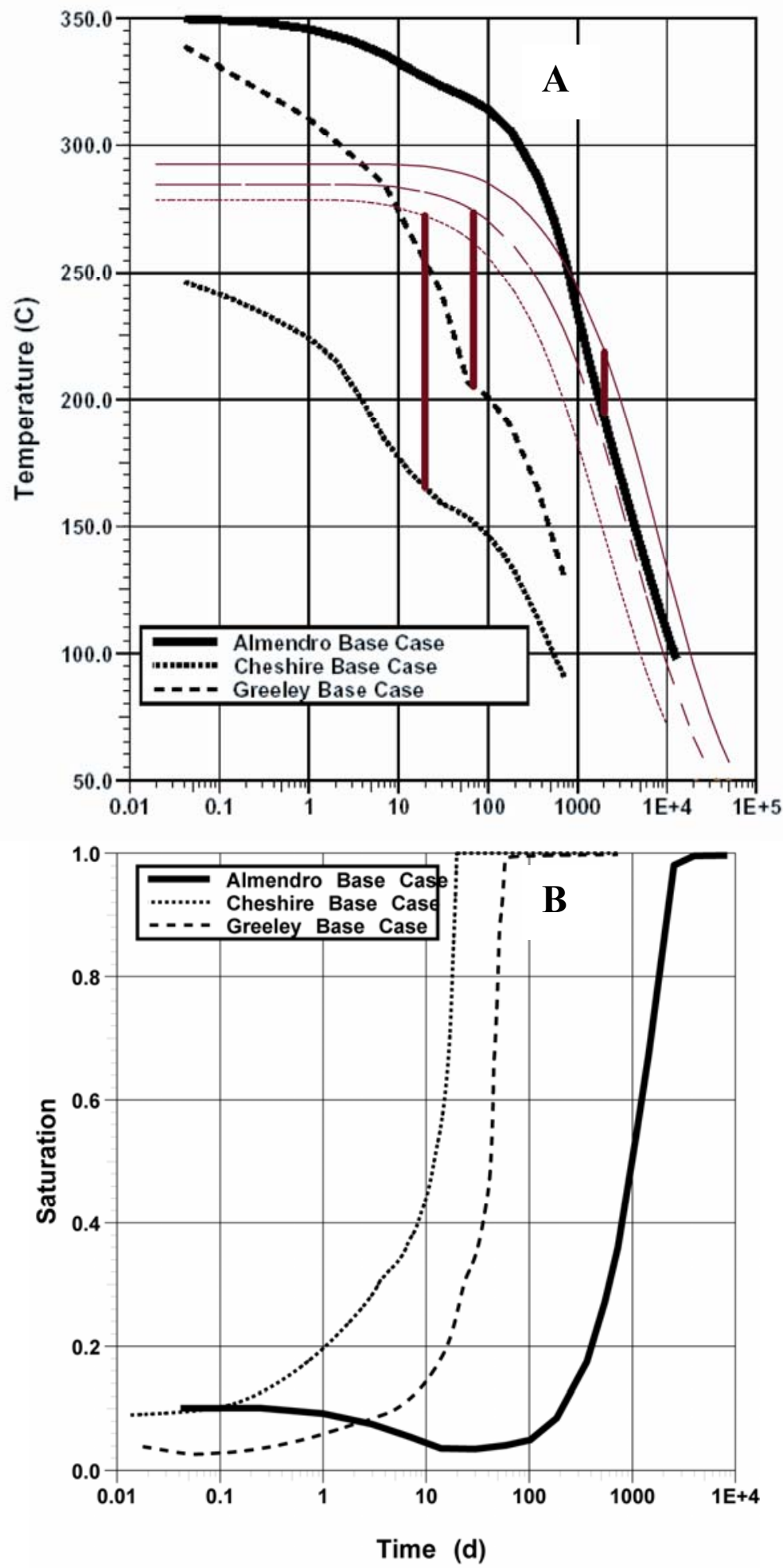

Figure G-7. Modeled temperature (A) and saturation (B) histories of Cheshire, Greeley, and Almendro melt glass zones. Simulations of Carle et al. (2003) (thick lines) are compared with the conduction-only analytical solution (thin lines). Red lines identify difference between the two models at the point of cavity resaturation. 
By comparing the simulated cooling history of all three tests examined by Carle et al. (2003) to the conduction-only analytical solution for these tests, the following conclusions can be made:

- The rate of convective cooling increases as a function of the permeability of the cavity and surrounding rock and follows the order Almendro $<$ Greeley $<$ Cheshire.

- As the role of convective cooling decreases, the similarity between the conductiononly analytical solution and flow models increases.

- In all cases, the conduction-only analytical solution results in slower glass cooling compared to the flow model predictions once cavity resaturation has been reached.

- The use of conduction-only analytical solutions coupled with a starting glass zone temperature equal to hydrostatic pressures at the bottom of the glass zone should always provide a reasonable yet conservative estimate of glass cooling rates for saturated tests.

- The glass zone temperature history based on the conduction-only analytical solution will result in a reasonable yet conservative estimate of glass dissolution rates for saturated tests. 
THIS PAGE INTENTIONALLY LEFT BLANK 


\section{Appendix H. Predicting Radionuclide Sorption for the Climax Stock with Mechanistic Geochemical Models}

The apparent differences in reported sorption behavior between the Climax stock and other granites are significant when considered in the context of calculating a representative $K_{d}$ and associated statistics for ${ }^{41} \mathrm{Ca}$ and ${ }^{151} \mathrm{Sm}$. To successfully predict radionuclide sorption onto the Climax granite with a mechanistic sorption model, a representative mineralogy for the Climax stock must be determined rather than using a 'generic' granite mineralogy for this purpose. Two-column transport studies were completed with rock collected from the Climax stock (Failor et al. 1982; Treyer and Raybold, 1982). However, the Failor et al. (1982) project report did not provide enough information to develop a numerical model representation of their dataset. The Treyer and Raybold (1982) study did contain enough hydraulic and geochemical information, and a reactive transport model was developed to simulate their experiments, thereby validating the use of a mechanistic sorption model to calculate radionuclide $K_{d}$ parameters for the Climax stock.

Calculations of representative $K_{d}$ parameters were accomplished with the CRUNCH code (an updated version of the OS3D/GIMRT code) (Steefel and Yabusaki, 1995). Sorption to matrix minerals and aqueous speciation was accomplished directly in the CRUNCH code based on surface complexation, ion exchange, and aqueous speciation thermodynamic parameters and mineral characteristics reported in Zavarin and Bruton $(2004 \mathrm{a}, \mathrm{b})$ and Zavarin et al. (2004). Details regarding the surface complexation and ion exchange modeling approach and the relevant surface complexation, ion exchange, and speciation constants can be found in those and other recent model validation efforts (Zavarin et al., 2002). Minerals addressed in the surface complexation/ion exchange model included iron oxide, smectite, clinoptilolite, illite/mica, and calcite. Radionuclides evaluated in the model included ${ }^{41} \mathrm{Ca}$, ${ }^{59,63} \mathrm{Ni},{ }^{90} \mathrm{Sr},{ }^{135,137} \mathrm{Cs},{ }^{151} \mathrm{Sm},{ }^{150,152,154} \mathrm{Eu},{ }^{232,233,234,235,236,238} \mathrm{U},{ }^{237} \mathrm{~Np},{ }^{238,239,240,241,242} \mathrm{Pu}$, and ${ }^{241} \mathrm{Am}$. The surface complexation of $\mathrm{Ni}$ was added only recently to the database of sorption reactions (see Tompson et al., 2005). The water chemistry and rock mineralogy used in the model are presented in detail below. Mineral characteristics (surface area, ion exchange capacity, etc.) were taken directly from Zavarin et al. (2002).

Two approaches were used to estimate ${ }^{41} \mathrm{Ca}$ and ${ }^{151} \mathrm{Sm} K_{d}$ values for Climax granite. In one, a water-rock reactor is simulated using mineralogic analyses and the experimentally derived $K_{d}$ values for other elements are compared to predicted values. In the other, the column experiments of Treyer and Raybold (1982) are simulated, fitting the calculations to observed breakthrough curves. Results from these two approaches are described below.

\section{Comparative $K_{d}$ Analysis with Available Mineralogical Analyses}

The first approach introduced above was to incorporate the available mineralogy from Connolly (1981) and Ryerson and Qualheim (1983) and the groundwater chemistry reported in Table 5-6 and then calculate a $K_{d}$ for each radionuclide in a simulated water-rock reactor. The calculation results for mineralogy reported by Connolly are presented in Table H-1 and Figure H-1. Each alteration type reported in Connolly (1981), Table 5-11, as well as an average of the five alteration types, was used as a basis for the CRUNCH calculations. The $K_{d}$ values for Cs are comparable to those determined experimentally on Climax granite (Table 5-14). The remaining radionuclide $K_{d}$ values are generally lower than observed 
experimentally on the Climax granite, but are comparable to $K_{d}$ values reported for other granites. The CRUNCH calculations using the mineralogy reported in Ryerson and Qualheim (1983) are presented in Table $\mathrm{H}-2$ and Figure $\mathrm{H}-2$ showing similarity to the results using the Connolly (1981) mineralogy.

Table H-1. CRUNCH calculated $K_{d}$ parameters using mineralogy reported in Connolly (1981).

\begin{tabular}{ccccccccccc}
\hline & \multicolumn{1}{c}{$\log K_{d}, \mathrm{~mL} / \mathrm{g}$} \\
\cline { 2 - 10 } Alteration Type & ${ }^{41} \mathrm{Ca}$ & $\mathrm{Cs}$ & $\mathrm{Sr}$ & $\mathrm{Ni}$ & $\mathrm{Sm}$ & $\mathrm{Eu}$ & $\mathrm{Am}$ & $\mathrm{Np}$ & $\mathrm{Pu}$ & $\mathrm{U}$ \\
\hline Argillic & -0.13 & 3.12 & -0.33 & 1.63 & 3.12 & 2.66 & 2.76 & 0.04 & 1.73 & 0.24 \\
Deuteric & 0.02 & 2.98 & -0.27 & 1.94 & 2.25 & 2.05 & 2.54 & -0.81 & 1.18 & -0.53 \\
Potassic & -0.30 & 3.25 & -0.35 & 0.52 & 2.90 & 2.40 & 2.44 & -0.21 & 1.32 & -1.90 \\
Propylitic & 0.20 & 3.03 & -0.12 & 2.16 & 2.63 & 2.36 & 2.78 & -0.42 & 1.51 & -0.01 \\
Rhyllic & 0.02 & 3.53 & -0.05 & 1.26 & 2.88 & 2.40 & 2.49 & -0.23 & 1.34 & -1.20 \\
Averaged mineralogy all types & -0.01 & 3.23 & -0.21 & 1.77 & 2.84 & 2.42 & 2.63 & -0.25 & 1.46 & -0.21 \\
Average (not including averaged min) & -0.03 & 3.19 & -0.22 & 1.55 & 2.77 & 2.38 & 2.61 & -0.31 & 1.42 & -0.60 \\
Standard Deviation & 0.17 & 0.20 & 0.12 & 0.59 & 0.30 & 0.20 & 0.14 & 0.29 & 0.19 & 0.81 \\
\hline
\end{tabular}

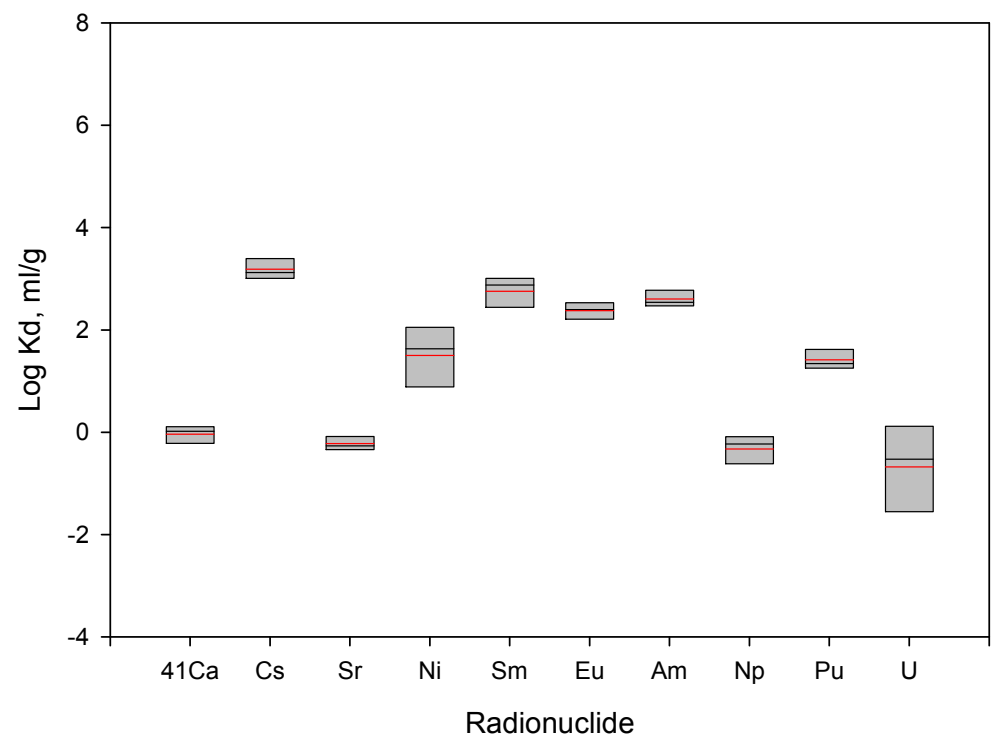

Figure H-1. Box plot of computed Log $K_{d}$ values from mineralogy reported in Connolly (1981) using the representative groundwater chemistry given in Table 5-6. 
Table H-2. CRUNCH-calculated $K_{d}$ parameters using mineralogy reported in Ryerson and Qualheim (1983).

\begin{tabular}{|c|c|c|c|c|c|c|c|c|c|c|}
\hline \multirow{2}{*}{ Sample } & \multicolumn{10}{|c|}{$\log K_{d}, \mathrm{~mL} / \mathrm{g}$} \\
\hline & ${ }^{41} \mathrm{Ca}$ & $\mathrm{Cs}$ & $\mathrm{Sr}$ & $\mathrm{Ni}$ & $\mathrm{Sm}$ & $\mathrm{Eu}$ & $\mathrm{Am}$ & $\mathrm{Np}$ & $\mathrm{Pu}$ & $\mathrm{U}$ \\
\hline 1 & -0.15 & 3.11 & -0.34 & 1.62 & 2.50 & 2.10 & 2.38 & -0.59 & 1.12 & -0.85 \\
\hline 2 & -0.25 & 3.13 & -0.39 & 1.39 & 2.16 & 1.79 & 2.11 & -0.94 & 0.83 & -1.07 \\
\hline 3 & -0.33 & 3.08 & -0.45 & 1.22 & 2.59 & 2.12 & 2.26 & -0.52 & 1.08 & -1.25 \\
\hline 4 & -0.44 & 2.92 & -0.58 & 1.22 & 2.06 & 1.67 & 1.97 & -1.03 & 0.70 & -1.25 \\
\hline 5 & -0.25 & 2.86 & -0.49 & 1.62 & 2.18 & 1.87 & 2.27 & -0.90 & 0.95 & -0.85 \\
\hline 6 & 0.02 & 2.92 & -0.29 & 1.96 & 2.29 & 2.08 & 2.56 & -0.77 & 1.20 & -0.51 \\
\hline 7 & -0.21 & 2.98 & -0.43 & 1.62 & 2.09 & 1.81 & 2.24 & -0.99 & 0.91 & -0.85 \\
\hline 8 & -0.58 & 2.87 & -0.68 & 0.92 & 1.76 & 1.37 & 1.66 & -1.33 & 0.40 & -1.55 \\
\hline 9 & -0.33 & 2.80 & -0.57 & 1.52 & 2.04 & 1.75 & 2.16 & -1.04 & 0.83 & -0.95 \\
\hline 10 & -0.15 & 3.00 & -0.38 & 1.70 & 2.18 & 1.90 & 2.32 & -0.90 & 0.99 & -0.77 \\
\hline 11 & -0.44 & 2.92 & -0.58 & 1.22 & 2.06 & 1.67 & 1.97 & -1.03 & 0.70 & -1.25 \\
\hline 12 & -0.25 & 3.00 & -0.44 & 1.52 & 2.15 & 1.82 & 2.19 & -0.94 & 0.88 & -0.95 \\
\hline 13 & -0.11 & 2.85 & -0.40 & 1.82 & 2.28 & 2.01 & 2.44 & -0.80 & 1.11 & -0.65 \\
\hline 14 & -0.44 & 2.73 & -0.67 & 1.39 & 2.11 & 1.75 & 2.09 & -0.98 & 0.80 & -1.07 \\
\hline 15 & -0.43 & 2.94 & -0.57 & 1.22 & 1.85 & 1.52 & 1.89 & -1.24 & 0.58 & -1.25 \\
\hline 16 & 0.05 & 3.07 & -0.22 & 1.96 & 2.46 & 2.17 & 2.59 & -0.62 & 1.26 & -0.51 \\
\hline 17 & -0.45 & 2.90 & -0.60 & 1.22 & 1.60 & 1.37 & 1.83 & -1.47 & 0.48 & -1.25 \\
\hline averaged mineralogy & -0.24 & 2.96 & -0.46 & 1.57 & 2.21 & 1.87 & 2.24 & -0.88 & 0.93 & -0.90 \\
\hline Average (not including averaged min) & -0.28 & 2.95 & -0.48 & 1.48 & 2.14 & 1.81 & 2.17 & -0.95 & 0.87 & -0.99 \\
\hline Standard Deviation & 0.18 & 0.11 & 0.13 & 0.29 & 0.25 & 0.25 & 0.26 & 0.25 & 0.25 & 0.29 \\
\hline
\end{tabular}

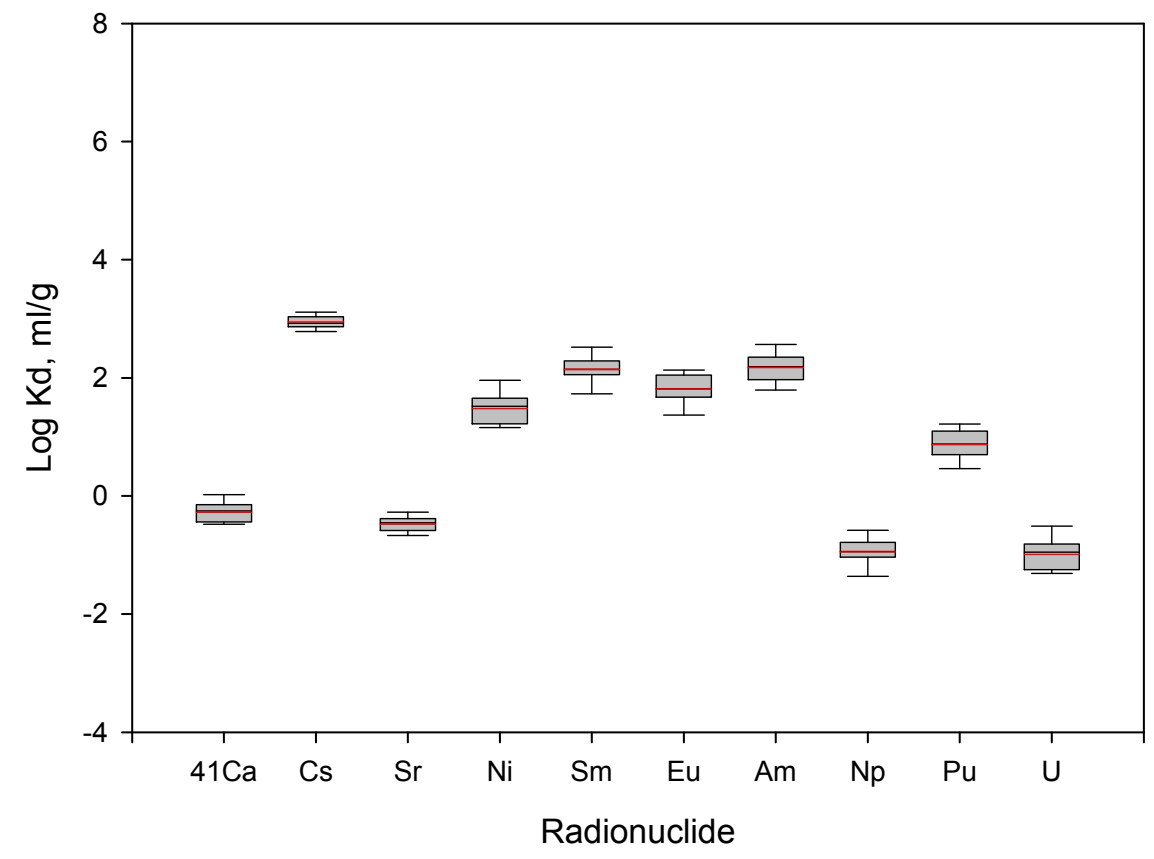

Figure H-2. Box plot of computed Log $K_{d}$ values from mineralogy reported in Ryerson and Qualheim, 1983 using the representative groundwater chemistry given in Table 5-11. 


\section{Modeling of Laboratory-scale Radionuclide Column Experiments with Climax Granite}

The second approach taken to calculate representative $K_{d}$ parameters was to model the column transport experiments reported in Treyer and Raybold (1982). Treyer and Raybold performed four separate experiments with Climax stock granite obtained from the Pile Driver drift tailings dump. This material was crushed and sieved prior to packing into columns. A synthetic groundwater solution was prepared following the recipe given in Erdal et al. (1979) after Feth et al. (1964) (H-3). The radionuclide tracers used in the experiments were $\mathrm{Cs}, \mathrm{Sr}, \mathrm{Tc}$, and Ba.

Table H-3. Geochemical analysis for the synthetic groundwater used by Treyer and Raybold (1982) (1982) in their column transport experiments.

\begin{tabular}{cccc}
\hline Cations & $\mathrm{mg} / \mathrm{L}$ & Anions & $\mathrm{mg} / \mathrm{L}$ \\
\hline $\mathrm{Na}$ & 7.6 & $\mathrm{Cl}$ & 2.3 \\
$\mathrm{Ca}$ & 13.71 & $\mathrm{SO}_{4}$ & 4.5 \\
$\mathrm{~K}$ & 3.85 & Alkalinity & 64.5 \\
$\mathrm{Mg}$ & 2.26 & $\mathrm{~F}$ & 0.2 \\
$\mathrm{Fe}$ & 0.09 & & \\
$\mathrm{Li}$ & 0.025 & $\mathrm{pH}$ & 8.38 \\
& & $\mathrm{SiO}_{2}, \mathrm{mg} / \mathrm{L}$ & 8.95 \\
\hline
\end{tabular}

Four different mineralogy combinations were used in conjunction with the water chemistry reported in Table H-3 to represent the breakthrough results presented in the Treyer and Raybold (1982) report. The mineralogy reported by Connolly (1981) and Ryerson and Qualheim (1983) was used as a basis for these simulations. Because CRUNCH does not explicitly model the sorption contributions of biotite and muscovite, the mineral mass fractions of these ion exchange minerals were summed together. This sum was then divided by a factor of 10 and served as a proxy for illite. Similarly, CRUNCH does not explicitly account for the contributions from chlorite, and therefore chlorite was added together with smectite. The volume fractions reported by both references were converted to mass fractions by assuming that in both cases the volume percent values reported did not account for porosity following standard petrographic reporting procedures. As a caveat, if this is not correct, the highest porosity reported for the samples in these references is three percent, and therefore the error in mineral mass fraction estimates is negligible. Following this methodology, the average mineralogy of the alteration types reported in Connolly (1981) produced approximate model breakthrough curves for $\mathrm{Sr}$ and Cs compared to the Treyer and Raybold (1982) experimental results, Figure H-3. Similarly, the CRUNCH-calculated breakthrough results using the Ryerson and Qualheim (1983) mineralogy (Figure H-4) and the XRD gross mineralogy in Treyer and Raybold (1982) (Figure H-5) approximate the experimental results. An additional set of CRUNCH simulations were run to attempt to provide an improved fit between the modeled and observed breakthrough results using a mineralogy chosen on the basis of the reported mineralogy and the model results given in Figure H-3 through Figure H-5 and Table H-4. These model results are presented in Figure H-6 and provide generally improved overall representations of the observed breakthrough 
behavior for all four column experiments over the use of the Connolly (1981), Ryerson and Qualheim (1983), and Treyer and Raybold (1982) mineralogy.

In spite of not providing perfect representations of the experimental results, the CRUNCH simulations presented are successful in providing useful approximations to the retardation behavior of the radionuclides under consideration. The very large range in $K_{d}$ for any of the radionuclides reported in the literature is accommodated by the largest differences in breakthrough behavior between modeled and observed in Figures H-3 through H-6. A tabulation of the calculated $K_{d}$ values for each of these numerical experiments is given in Table H-5. Suggested variances on these calculated $K_{d}$ values are those from the combined Climax stock and worldwide granite literature search presented in Table 5-13. 
(a)

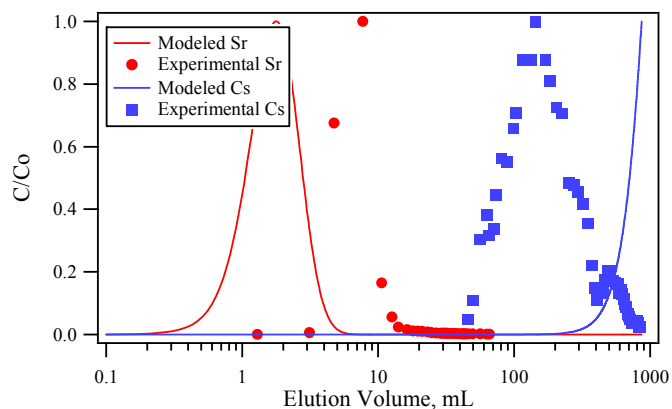

(c)

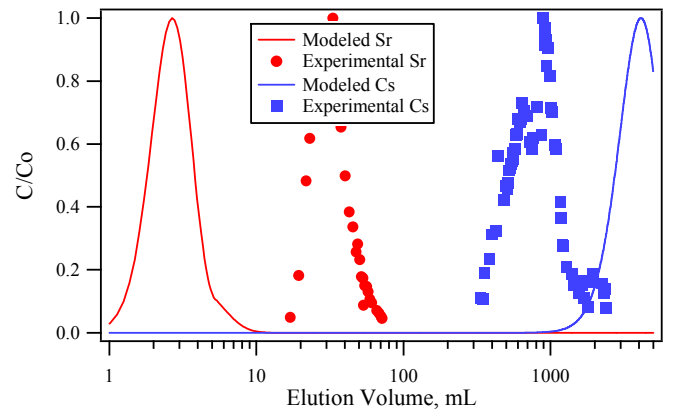

(b)

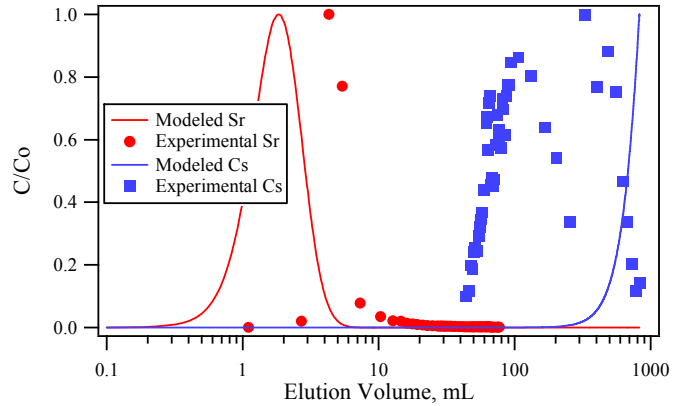

(d)

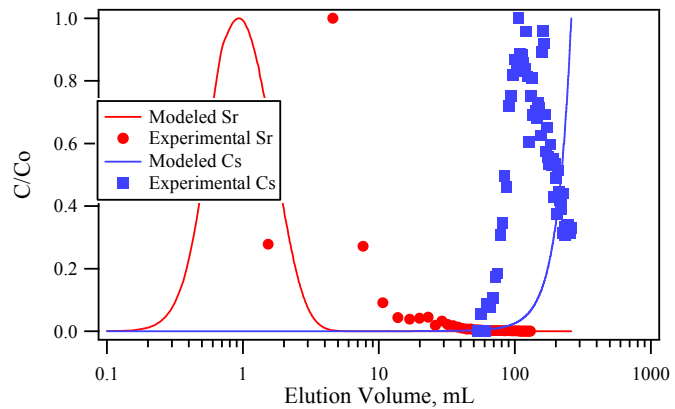

Figure H-3. Cs and Sr modeled breakthrough for the Treyer and Raybold (1982) experiments using the averaged Connolly (1981) mineralogy: (a) CS7, (b) CS5-1, (c) CS5-2, and (d) CS5-3.

(a)

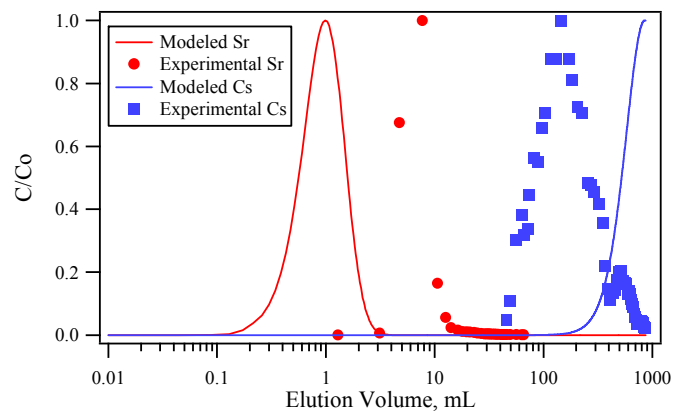

(c)

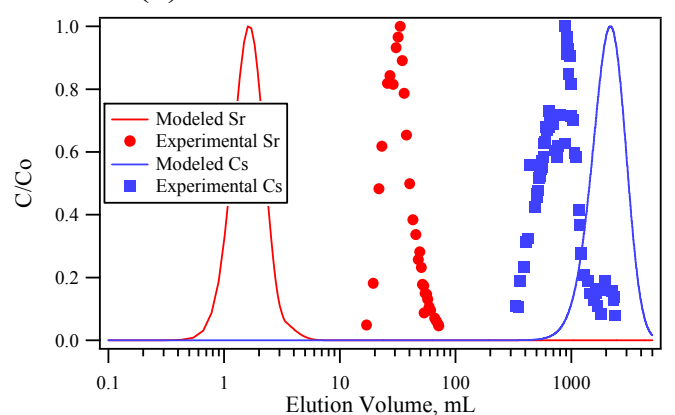

(b)

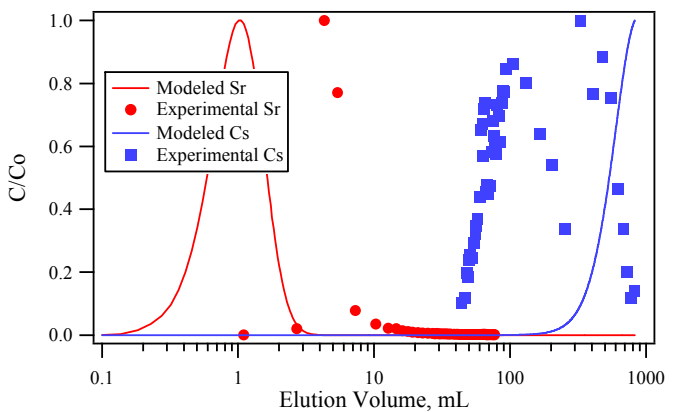

(d)

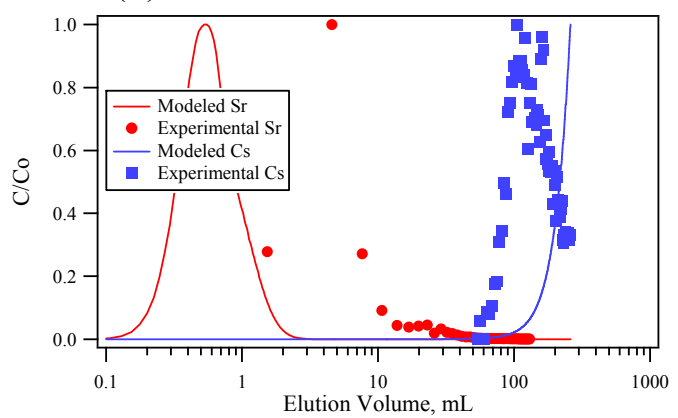

Figure H-4. Cs and Sr modeled breakthrough for the Treyer and Raybold (1982) experiments using the averaged Ryerson and Qualheim (1983) mineralogy: (a) CS7, (b) CS5-1, (c) CS5-2, and (d) CS5-3. 
(a)

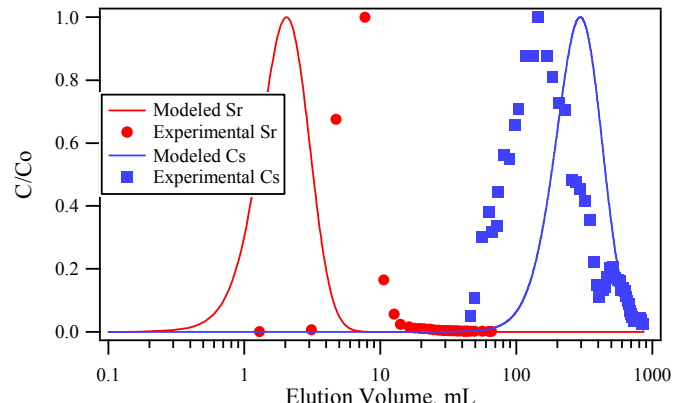

(c)

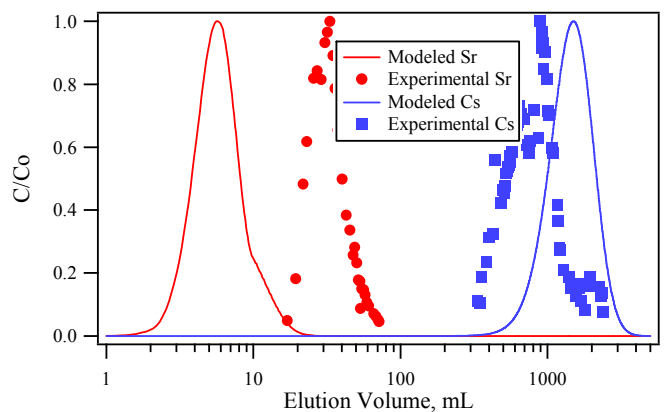

(b)

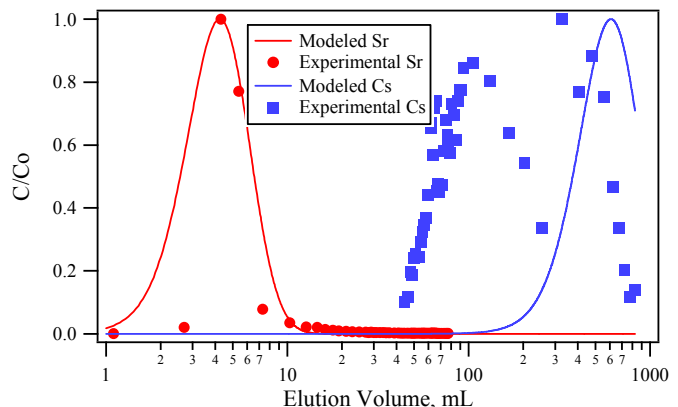

(d)

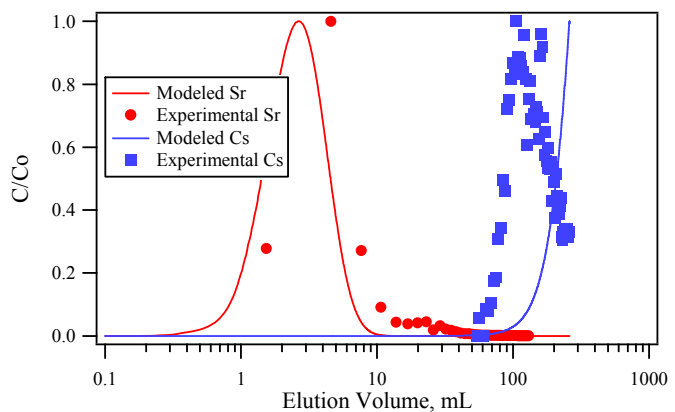

Figure H-5. Cs and Sr modeled breakthrough for the Treyer and Raybold (1982) experiments using the XRD mineralogy reported therein for CS7 and CS5: (a) CS7, (b) CS5-1, (c) CS5-2, and (d) CS5-3.

(a)

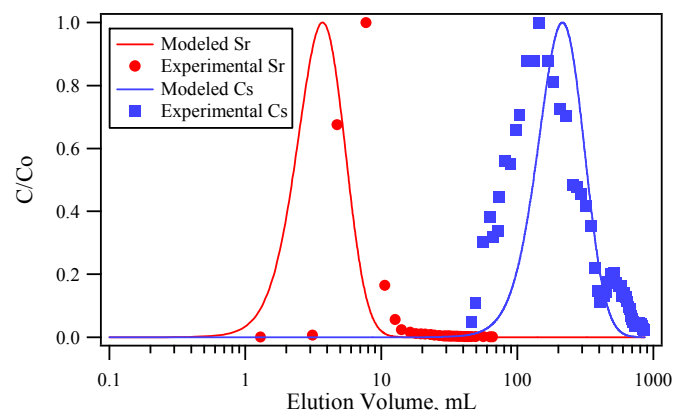

(c)

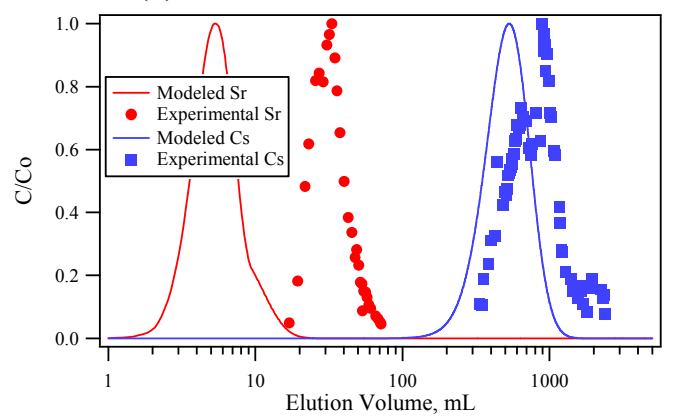

(b)

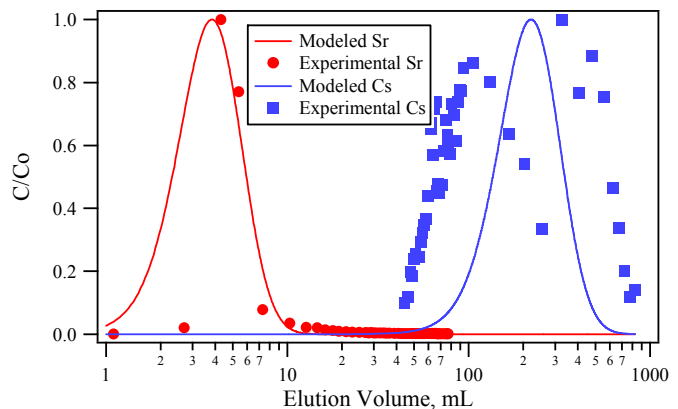

(d)

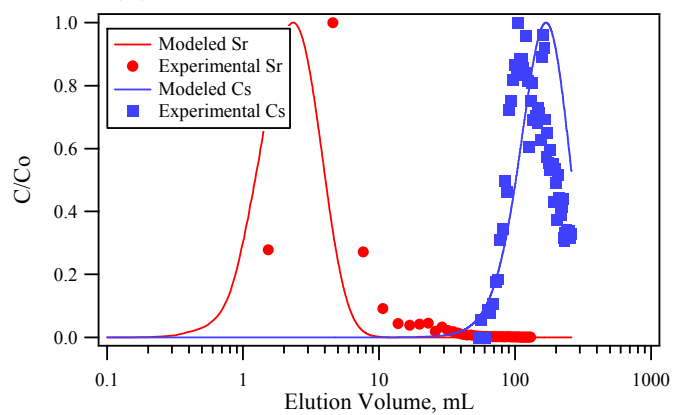

Figure H-6. Cs and Sr modeled breakthrough for the Treyer and Raybold (1982) CS7 experiment using the mineralogy reported in Table 5-24: (a) CS7, (b) CS5-1, (c) CS5-2, and (d) CS5-3. 
Table H-4. Mineral volume and mass percentages for CRUNCH transport simulations of the Treyer and Raybold (1982) column experiments.

\begin{tabular}{|c|c|c|c|c|c|c|c|c|c|c|}
\hline \multirow[b]{2}{*}{ Mineralogy Origin } & \multirow[b]{2}{*}{ Test ID } & \multirow{2}{*}{$\begin{array}{l}\text { Column } \\
\text { Porosity }\end{array}$} & \multicolumn{4}{|c|}{ Mineral Volume \% } & \multicolumn{4}{|c|}{ Calculated Mineral Mass \% from Vol \% } \\
\hline & & & Calcite & Hematite & Mica & Smectite & Calcite & Hematite & Mica & Smectite \\
\hline \multicolumn{11}{|l|}{ Connolly (1981) } \\
\hline & CS7 & 0.556 & $1.76 \mathrm{E}-02$ & 4.97E-04 & $5.46 \mathrm{E}-03$ & $3.18 \mathrm{E}-03$ & 4.26 & 0.23 & 1.38 & 0.81 \\
\hline & CS5_1 & 0.566 & $1.72 \mathrm{E}-02$ & $4.86 \mathrm{E}-04$ & 5.34E-03 & $3.11 \mathrm{E}-03$ & 4.26 & 0.23 & 1.38 & 0.81 \\
\hline & CS5_2 & 0.586 & $1.64 \mathrm{E}-02$ & 4.64E-04 & $5.09 \mathrm{E}-03$ & $2.97 \mathrm{E}-03$ & 4.26 & 0.23 & 1.38 & 0.81 \\
\hline & CS5 3 & 0.630 & $1.47 \mathrm{E}-02$ & 4.14E-04 & $4.55 \mathrm{E}-03$ & $2.65 \mathrm{E}-03$ & 4.26 & 0.23 & 1.38 & 0.80 \\
\hline \multicolumn{11}{|c|}{ Ryerson and Qualheim (1983) } \\
\hline & CS7 & 0.556 & $3.08 \mathrm{E}-03$ & 0 & $2.89 \mathrm{E}-03$ & $1.98 \mathrm{E}-03$ & 0.75 & 0 & 0.74 & 0.50 \\
\hline & CS5_1 & 0.566 & $3.01 \mathrm{E}-03$ & 0 & $2.83 \mathrm{E}-03$ & $1.94 \mathrm{E}-03$ & 0.75 & 0 & 0.74 & 0.50 \\
\hline & CS5 2 & 0.586 & $2.87 \mathrm{E}-03$ & 0 & $2.70 \mathrm{E}-03$ & $1.85 \mathrm{E}-03$ & 0.75 & 0 & 0.74 & 0.50 \\
\hline & CS5_3 & 0.630 & $2.57 \mathrm{E}-03$ & 0 & $2.41 \mathrm{E}-03$ & $1.65 \mathrm{E}-03$ & 0.75 & 0 & 0.74 & 0.50 \\
\hline \multicolumn{11}{|c|}{ Treyer and Raybold (1982) } \\
\hline & CS7 & 0.556 & 0 & 0 & $9.84 \mathrm{E}-04$ & $9.84 \mathrm{E}-03$ & 0 & 0 & 0.25 & 2.50 \\
\hline & CS5_1 & 0.566 & 0 & 0 & $1.93 \mathrm{E}-03$ & $1.93 \mathrm{E}-02$ & 0 & 0 & 0.50 & 5.00 \\
\hline & CS5_2 & 0.586 & 0 & 0 & $1.84 \mathrm{E}-03$ & $1.84 \mathrm{E}-02$ & 0 & 0 & 0.50 & 5.00 \\
\hline & CS5_3 & 0.630 & 0 & 0 & $1.64 \mathrm{E}-03$ & $1.64 \mathrm{E}-02$ & 0 & 0 & 0.50 & 5.00 \\
\hline \multicolumn{11}{|c|}{ Selected mineral assemblage } \\
\hline & CS7 & 0.556 & 0 & 0 & $6.92 \mathrm{E}-04$ & $1.91 \mathrm{E}-02$ & 2.00 & 0.10 & 0.18 & 4.82 \\
\hline & CS5_1 & 0.566 & 0 & 0 & $6.76 \mathrm{E}-04$ & $1.86 \mathrm{E}-02$ & 2.00 & 0.10 & 0.18 & 4.82 \\
\hline & CS5_2 & 0.586 & 0 & 0 & $6.45 \mathrm{E}-04$ & $1.78 \mathrm{E}-02$ & 2.00 & 0.10 & 0.18 & 4.82 \\
\hline & CS5_3 & 0.630 & 0 & 0 & $5.77 \mathrm{E}-04$ & $1.59 \mathrm{E}-02$ & 2.00 & 0.10 & 0.18 & 4.82 \\
\hline
\end{tabular}


Table H-5. Calculated $K_{d}$ s for the CRUNCH-simulated BTCs for the Treyer and Raybold (1982) column experiments.

\begin{tabular}{|c|c|c|c|c|c|c|c|c|c|c|c|}
\hline \multirow[b]{2}{*}{ Mineralogy } & \multirow[b]{2}{*}{ Test } & \multicolumn{10}{|c|}{$\log K_{d} \mathrm{~mL} / \mathrm{g}$} \\
\hline & & ${ }^{41} \mathrm{Ca}$ & Cs & $\mathrm{Sr}$ & $\mathrm{Ni}$ & $\mathrm{Sm}$ & $\mathrm{Eu}$ & $\mathrm{Am}$ & $\mathrm{Np}$ & $\mathrm{Pu}$ & $\mathrm{U}$ \\
\hline \multicolumn{12}{|c|}{ Connolly (1981) } \\
\hline & CS7 & 0.86 & 3.63 & 0.67 & 2.07 & 3.43 & 2.98 & 3.28 & 0.38 & 1.93 & 0.45 \\
\hline & CS5_1 & 0.86 & 3.63 & 0.67 & 2.07 & 3.43 & 2.98 & 3.28 & 0.38 & 1.93 & 0.45 \\
\hline & CS5_2 & 0.86 & 3.63 & 0.67 & 2.07 & 3.43 & 2.98 & 3.28 & 0.38 & 1.93 & 0.45 \\
\hline & CS5_3 & 0.86 & 3.63 & 0.67 & 2.07 & 3.43 & 2.98 & 3.28 & 0.38 & 1.93 & 0.45 \\
\hline \multicolumn{12}{|c|}{ Ryerson and Qualheim (1983) } \\
\hline & CS7 & 0.62 & 3.35 & 0.42 & 1.87 & 2.83 & 2.47 & 2.92 & -0.34 & 1.32 & -0.38 \\
\hline & CS5_1 & 0.62 & 3.35 & 0.42 & 1.87 & 2.83 & 2.47 & 2.92 & -0.34 & 1.32 & -0.38 \\
\hline & CS5_2 & 0.62 & 3.35 & 0.42 & 1.87 & 2.83 & 2.47 & 2.92 & -0.34 & 1.32 & -0.38 \\
\hline & CS5_3 & 0.62 & 3.35 & 0.42 & 1.87 & 2.83 & 2.47 & 2.92 & -0.34 & 1.32 & -0.38 \\
\hline \multicolumn{12}{|c|}{ Treyer and Raybold XRD (1982) } \\
\hline & $\mathrm{CS} 7^{1}$ & 1.11 & 2.89 & 0.73 & 2.56 & 3.12 & 2.95 & 3.54 & -0.22 & 1.80 & 0.32 \\
\hline & CS5_1 & 1.14 & 4.19 & 1.09 & 1.86 & 2.42 & 2.26 & 2.84 & -0.92 & 1.10 & -0.38 \\
\hline & CS5_2 & 1.14 & 4.19 & 1.09 & 1.86 & 2.42 & 2.26 & 2.84 & -0.92 & 1.10 & -0.38 \\
\hline & CS5_3 & 1.14 & 4.19 & 1.09 & 1.86 & 2.42 & 2.26 & 2.84 & -0.92 & 1.10 & -0.38 \\
\hline \multicolumn{12}{|c|}{ Selected mineral assemblage } \\
\hline & CS7 & 1.38 & 2.75 & 0.99 & 2.85 & 3.56 & 3.31 & 3.85 & 0.34 & 2.18 & 0.69 \\
\hline & CS5_1 & 1.38 & 2.75 & 0.99 & 2.85 & 3.56 & 3.31 & 3.85 & 0.34 & 2.18 & 0.69 \\
\hline & CS5_2 & 1.38 & 2.75 & 0.99 & 2.85 & 3.56 & 3.31 & 3.85 & 0.34 & 2.18 & 0.69 \\
\hline & CS5_3 & 1.38 & 2.75 & 0.99 & 2.85 & 3.56 & 3.31 & 3.85 & 0.34 & 2.18 & 0.69 \\
\hline
\end{tabular}

${ }^{1}$ The $K_{d}$ results for the Treyer and Raybold (1982) CS7 simulation are different from those for the CS5-1, -2 and -3 simulations because the reported mineralogy for CS7 and CS5 is significantly different (Table H-4). In the other three mineralogy experiments, the same mineral assemblage was used to represent all four Treyer and Raybold (1982) experiments, and therefore the calculated $K_{d}$ values are the same for each experiment for each respective mineral assemblage reference. 


\section{DISTRIBUTION}

Naomi Becker

Los Alamos National Laboratory

P.O. 1663, EES-6, MSF-665

Los Alamos, NM 87545

Jeff Daniels

Lawrence Livermore National Laboratory

P.O. Box 808 M/S J514 CST-7

Livermore, CA 94551

Richard Hopper

Deputy Laboratory Directory

U.S. Environmental Protection Agency

Radiation \& Indoor Environments National

Laboratory

4220 S. Maryland Parkway, Bldg. C

Las Vegas, NV 89119

Bruce Hurley

Hydrology Program Manager

Environment, Safety \& Health Division

Nevada Site Office

National Nuclear Security Administration

U.S. Department of Energy

P.O. Box 98518

Las Vegas, NV 89193-8518

Marjory Jones

Division of Hydrologic Sciences

Desert Research Institute

2215 Raggio Parkway

Reno, NV 89512-1095

John McCord

Stoller-Navarro Joint Venture

7710 W. Cheyenne Avenue

Las Vegas, NV 89129

Ken Ortego

Bechtel Nevada

P.O. Box 98521

Las Vegas, NV 89193-8521

Gayle Pawloski

Lawrence Livermore National Laboratory

P.O. Box 808 L-221

Livermore, CA 94551
Greg Ruskauff

Stoller-Navarro Joint Venture

7710 W. Cheyenne Avenue

Las Vegas, NV 89129

Chuck Russell

Division of Hydrologic Sciences

Desert Research Institute

755 E. Flamingo Road

Las Vegas, NV 89119-7363

Peter Sanders

Environmental Restoration Division

Nevada Site Office

National Nuclear Security Administration

U.S. Department of Energy

P.O. Box 98518

Las Vegas, NV 89193-8518

Reina Serino, Contracting Specialist

Office of Business Services

NNSA Service Center

Pennsylvania and H Street, Bldg. 20388

P.O. Box 5400

Albuquerque, NM 87185-5400

David Shafer

Division of Hydrologic Sciences

Desert Research Institute

755 E. Flamingo Road

Las Vegas, NV 89119-7363

Bonnie Thompson

Water Resources, Nevada District

U.S. Geological Survey

160 N. Stephanie Street

Henderson, NV 89074

K.C. Thompson

Environmental Restoration Division

Nevada Site Office

National Nuclear Security Administration

U.S. Department of Energy

P.O. Box 98518

Las Vegas, NV 89193-8518 
Bill Wilborn

Environmental Restoration Division

Nevada Site Office

National Nuclear Security Administration

U.S. Department of Energy

P.O. Box 98518

Las Vegas, NV 89193-8518

Janet Appenzeller-Wing, Director

Environmental Restoration Division

Nevada Site Office

National Nuclear Security Administration

U.S. Department of Energy

P.O. Box 98518

Las Vegas, NV 89193-8518

Mavrik Zavarin

Lawrence Livermore National Laboratory

P.O. Box 808, M/S L-231

Livermore, CA 94551

Nevada State Library and Archives

State Publications

100 North Stewart Street

Carson City, NV 89701-4285

Archives

Getchell Library

University of Nevada, Reno

DeLaMare Library/262

University of Nevada, Reno

Document Section, Library

University of Nevada, Las Vegas

4505 Maryland Parkway

Las Vegas, NV 89154
Library

Stoller-Navarro Joint Venture

7710 W. Cheyenne, Bldg. 3

Las Vegas, NV 89128

Library

Southern Nevada Science Center

Desert Research Institute

755 E. Flaming Road

Las Vegas, NV 89119-7363

Public Reading Facility

c/o Nuclear Testing Archive

Nevada Site Office

National Nuclear Security Administration

U.S. Department of Energy

P.O. Box 98521, M/S 400

Las Vegas, NV 89193-8521

Technical Library

Nevada Site Office

National Nuclear Security Administration

U.S. Department of Energy

P.O. Box 98518

Las Vegas, NV 89193-8518

Office of Scientific and Technical Information

U.S. Department of Energy

P.O. Box 62

Oak Ridge, TN 37831-9939

(electronic copy) 